Woods Hole Oceanographic Institution

Technical Report

August 1996

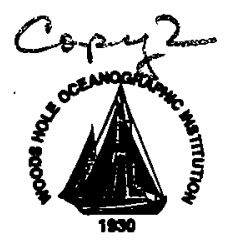

Mata

Meteorological and Oceanographic Bata
during the ASREX III Field Experiment:

Cruise and Data Report

by

Nancy R. Galbraith

Anand Gnanadesikan

William M. Ostrom

Eugene A. Terray

Bryan S. Way

Upper Ocean Processes Group

Woods Hole Oceanographic Institution

Neil J. Williams

Rosenstiel School of Marine and Atmospheric Sciences

University of Miami

Steven H. Hill

Ocean Acoustics Group

Institute for Ocean Sciences

Eric Terrill

Scripps Institution of Oceanography

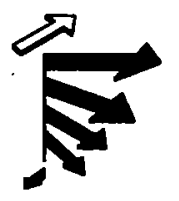




\title{
WHOI-96-10
}

UOP 96-01

\section{Meteorological and Oceanographic Measurements during the ASREX III Field Experiment: Cruise and Data Report}

\author{
by \\ Nancy R. Galbraith \\ Anand Gnanadesikan \\ William M. Ostrom \\ Eugene A. Terray \\ Bryan S. Way \\ Upper Ocean Processes Group \\ Woods Hole Oceanographic Institution \\ Neil J. Williams \\ Rosenstiel School of Marine and Atmospheric Sciences \\ University of Miami \\ Steven H. Hill \\ Ocean Acoustics Group \\ Institute for Ocean Sciences \\ Eric Terrill \\ Scripps Institution of Oceanography
}

\section{Technical Report}

Woods Hole Oceanographic Institution

Woods Hole, Massachusetts 02543

September 1996

Funding was provided by the Office of Naval Research through

Grant No. N00014-91-J-1891.

Reproduction in whole or in part is permitted for any purpose of the United States Government. This report should be cited as Woods Hole Oceanog. Inst. Tech. Rept., WHOI-96-10.

Approved for public release; distribution unlimited.

Approved for Distribution:

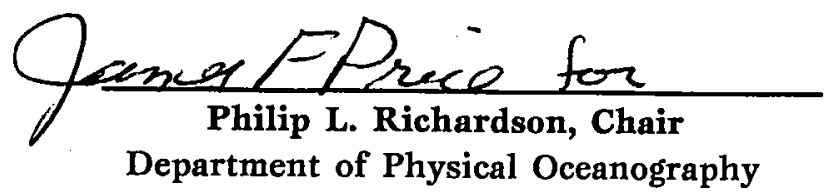




\begin{abstract}
The Third Acoustic Surface Reverberation Experiment (ASREX III) took place from December 1993 to March 1994 at Site L (34N, 70 W) in the mid-Atlantic. As part of this experiment, two moorings were deployed to measure the environmental background. A meteorological and oceanographic mooring was deployed to characterize the surface wind stress, buoyancy flux, and the current and temperature structure over the top 500 meters. A Seatex Wavescan ${ }^{\mathrm{TM}}$ buoy was deployed to characterize the directional wave spectrum. This report presents results from these moorings. Wind speeds up to $25 \mathrm{~m} / \mathrm{s}$ were seen, with significant heat losses (up to $1050 \mathrm{~W} / \mathrm{m}^{2}$ ) when cold continental air moved out over the warm Atlantic. The wave heights ranged up to $8 \mathrm{~m}$, with significant wave heights of several meters persisting for relatively long periods. Wave height and period, nondirectional spectra, directional spectra and a typology of wave events are presented and related to surface forcing.
\end{abstract}




\section{Table of Contents}

Page No.

Abstract

List of Figures $\mathrm{v}$

List of Tables vi

1. Introduction 1

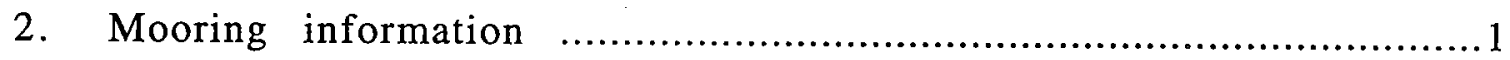

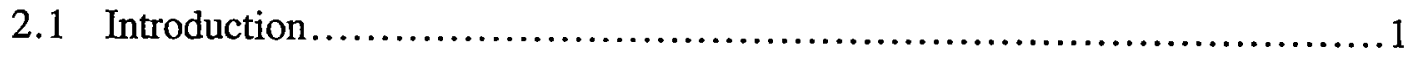

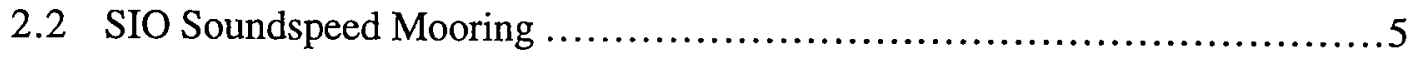

2.3 The Seatex Mooring .................................................6

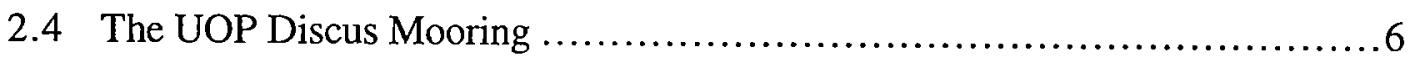

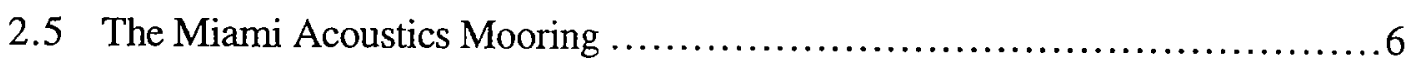

2.6 The ELSI B Mooring ............................................... 12

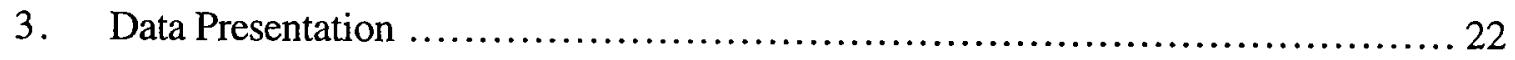

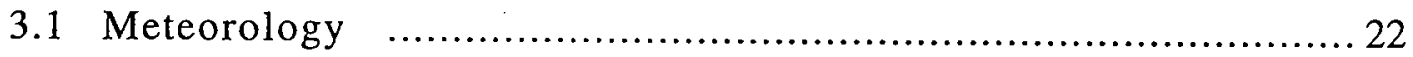

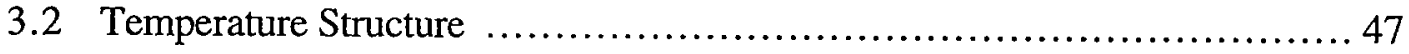

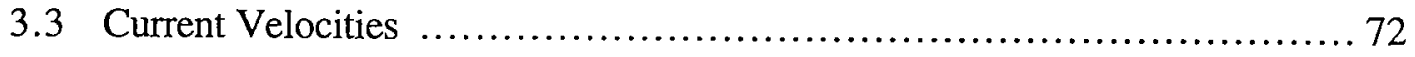

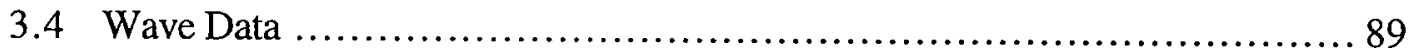

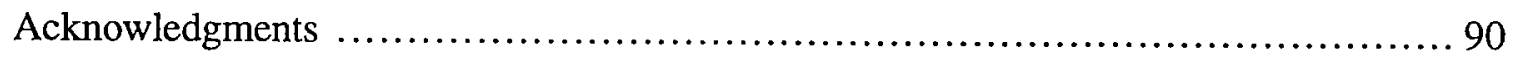

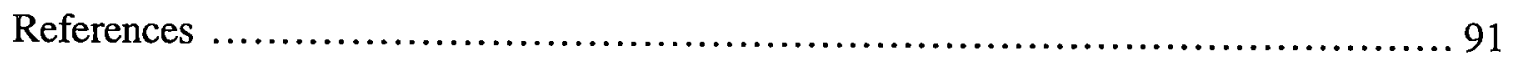

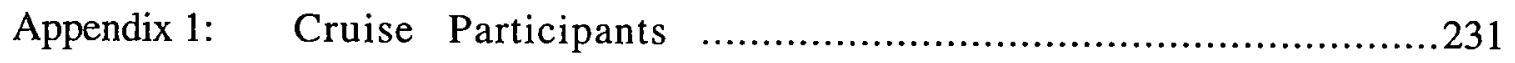

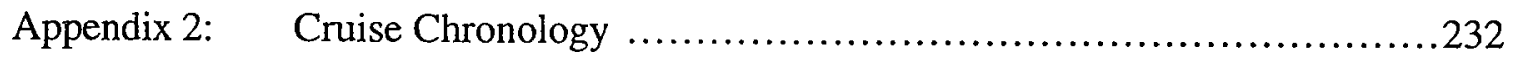

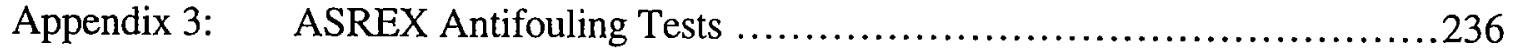

Appendix 4: $\quad$ Matlab code for calculating wave directional spectra ..................242 


\section{List of Figures}

Page No.

2.1

2.2

2.3

2.4

2.5

2.6

2.7

2.8

2.9

3.1.1-7

3.1.8-14

$3.1 .15-21$

3.1 .22

3.2 .1

$3.2 .2-23$

3.2 .24

3.3.1-6

3.3.7-8

3.3.9-16

3.4.1-3

3.4.4-6

3.4.7-9

3.4.10-139

A.3.1

A.3.2

A.3.3
Map of ASREX Site

Map of the moorings deployed during ASREX

Diagram of SIO Soundspeed mooring

Diagram of Seatex mooring

Diagram of Discus mooring

Diagram of Miami Acoustics mooring

Diagram of ELSI B mooring

Argos positions of the Discus mooring

Argos positions of the Seatex mooring

Meteorology Time Series

Heat Flux Time Series

Wind Stress Time Series

Autospectra of Meteorological Variables

Contour Plot of Temperature

Temperature Time Series and Spectra

Seacat Temperature Profiles

Subsurface Velocity Vectors (Low-Frequency)

Progressive Vector Diagrams

Velocity Time Series and Spectra

Nondirectional wave parameters

Evolution of wave field vs. Frequency

Evolution of wave direction and wind direction

Directional wave spectra

Discus hull and bridle profile

Discus hull antifouling diagram

Instrument antifouling diagram 


\section{List of Tables}

Page No.

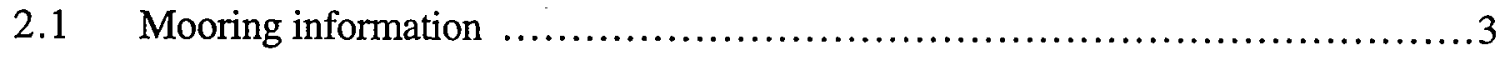

2.2 SIO Soundspeed mooring instrumentation information ........................

2.3 Seatex instrumentation information ..........................................

2.4 Discus instrumentation information f...........................................

2.5 Miami Acoustics Mooring instrumentation information ........................9

2.6 Miami acoustics package specifications .................................. 10

2.7 ELSI B instrumentation information ……...................................... 14

3.1.1 Schematic of VAWR sensor averaging periods ............................. 30

3.1.2 Meteorological sensor specifications, VAWR .............................. 30 


\section{Introduction}

The Third Acoustic Surface Reverberation Experiment, (ASREX III) was designed to study processes causing degraded acoustic transmission in high sea states (see McDaniel, 1993, for a review of the state of the scientific understanding before this experiment). The experiment took place in late 1993 and early 1994 at Site L ( 34 N 70W) over the Hatteras Abyssal Plain. In support of this experiment, a total of five moorings were deployed. Section 2 of this report describes the mooring array in order to provide the overall context for the experiment. Section 3 then describes the environmental background during the experiment, including the temperature, salinity, and current structure in the upper $500 \mathrm{~m}$, surface meteorology, and wave conditions. The bulk of this data is taken from two moorings, a meteorological/oceanographic mooring and a wave mooring deployed by the Upper Ocean Processes (UOP) group at the Woods Hole Oceanographic Institution.

\section{Mooring Information}

\subsection{Introduction}

The moorings were deployed from the R/V Knorr of Woods Hole Oceanographic Institution, sailing from Woods Hole on 8 December 1993. The moorings were recovered by the R/V Edwin Link of Harbor Branch Oceanographic Institution, sailing from Jacksonville on 18 March 1994. Figure 2.1 shows a bathymetric map of the area surrounding the experiment site. Recovery and deployment were directed by John Kemp of WHOI's Ocean Acoustics Laboratory (OAL). A list of cruise participants appears in Appendix 1 and the chronology of the cruises is described in Appendix 2.

A total of five moorings were deployed during ASREX III. These were:

1. A near-surface soundspeed mooring, instrumented by Dr. W. K. Melville's group at Scripps Institution of Oceanography (SIO).

2. A Seatex wave mooring instrumented by the UOP and OAL groups at WHOI.

3. A meteorological/oceanographic discus mooring instrumented by the UOP group at WHOI.

4. An acoustics mooring instrumented by Dr. H. DeFerrari's group at the University of Miami and Dr. D. M. Farmer's group at the Institute for Ocean Sciences (IOS), Sidney, BC, Canada.

5. An ELSI B sonar mooring instrumented by D. Farmer's group at IOS. 


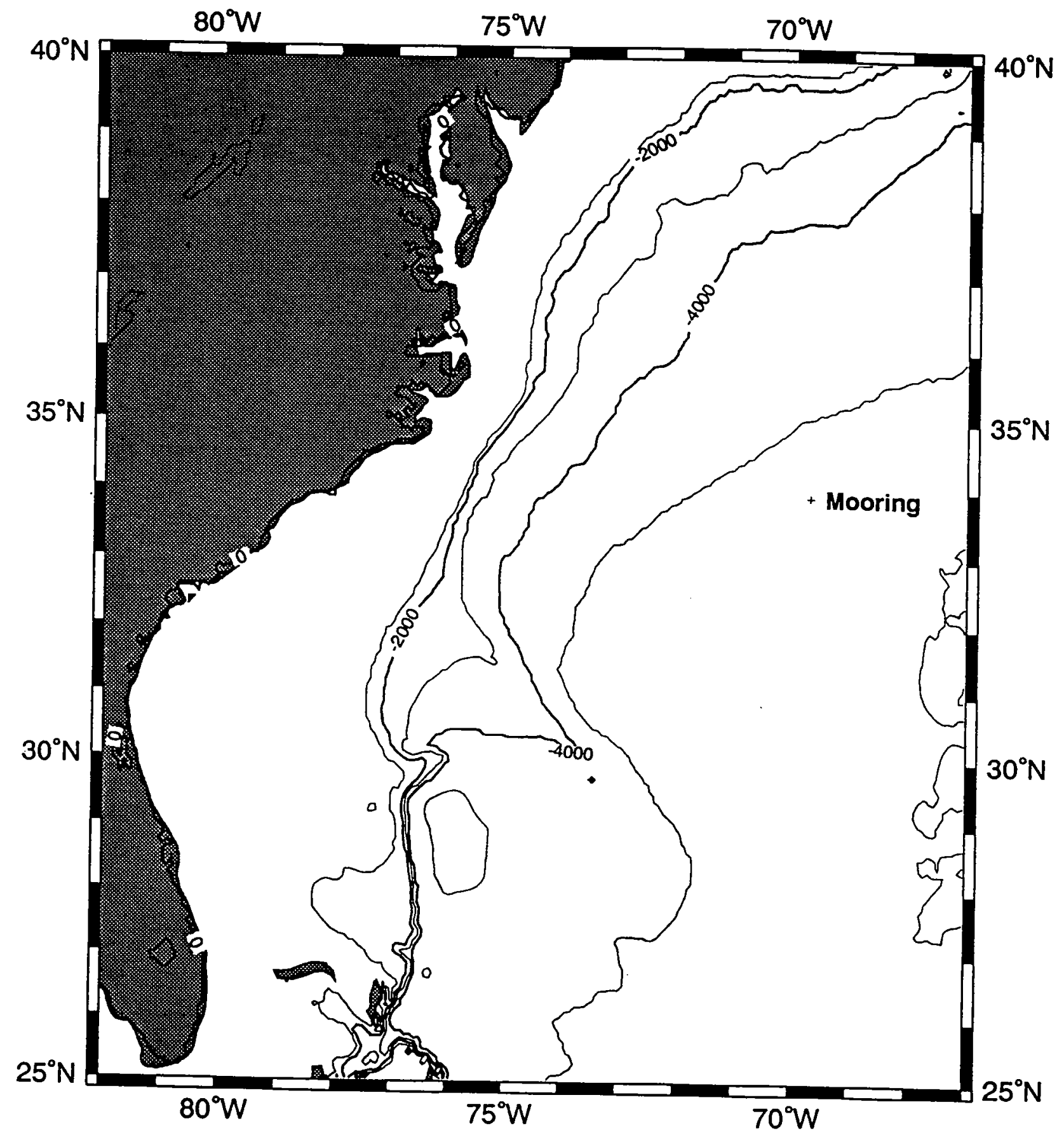

Figure 2.1: Bathymetric map of experiment site. 
Table 2.1 lists the locations and durations of the five moorings and Figure 2.2 shows their locations and watch circles. The planned duration for the array was 12 weeks. The actual deployment was longer than this because the ship scheduled for the pickup cruise, the R/V Endeavor, was unable to get clearance to sail as planned.

$\begin{array}{lllll}\text { Buoy } & \text { Deployed } & \text { Recovered } & \text { Latitude } & \text { Longitude } \\ \begin{array}{l}\text { SIO Spar } \\ \text { (WHOI 957) }\end{array} & 204110 \mathrm{Dec} 93 & 221324 \mathrm{Mar} 94 & 33^{\circ} 56.62 \mathrm{~N} & 70^{\circ} 06.34 \mathrm{~W} \\ \begin{array}{l}\text { WHOI Seatex } \\ \text { (WHOI 958) }\end{array} & 221613 \mathrm{Dec} 93 & 132423 \mathrm{Mar} 94 & 34^{\circ} 03.89 \mathrm{~N} & 70^{\circ} 05.10 \mathrm{~W} \\ \begin{array}{l}\text { WHOI Discus } \\ \text { (WHOI 959) }\end{array} & 061315 \mathrm{Dec} 93 & 114324 \mathrm{Mar} 94 & 33^{\circ} 52.70 \mathrm{~N} & 69^{\circ} 44.83 \mathrm{~W} \\ \begin{array}{l}\text { Miami } \\ \text { Acoustics }\end{array} & 214018 \mathrm{Dec} 93 & 141621 \mathrm{Mar} 94 & 33^{\circ} 49.05 \mathrm{~N} & 70^{\circ} 00.25 \mathrm{~W} \\ \text { (WHOI 960) } & & & & \\ & & & & \\ \text { ISO ELSI B } & 063119 \mathrm{Dec} 93 & 123422 \mathrm{Mar} 94 & 33^{\circ} 54.52 \mathrm{~N} & 69^{\circ} 56.20 \mathrm{~W} \\ \text { (WHOI 961) } & & & & \end{array}$

Table 2.1: Locations and durations of the five moorings. Deployment time is anchor splash, recovery time is when release is fired. Position is for the anchor. 


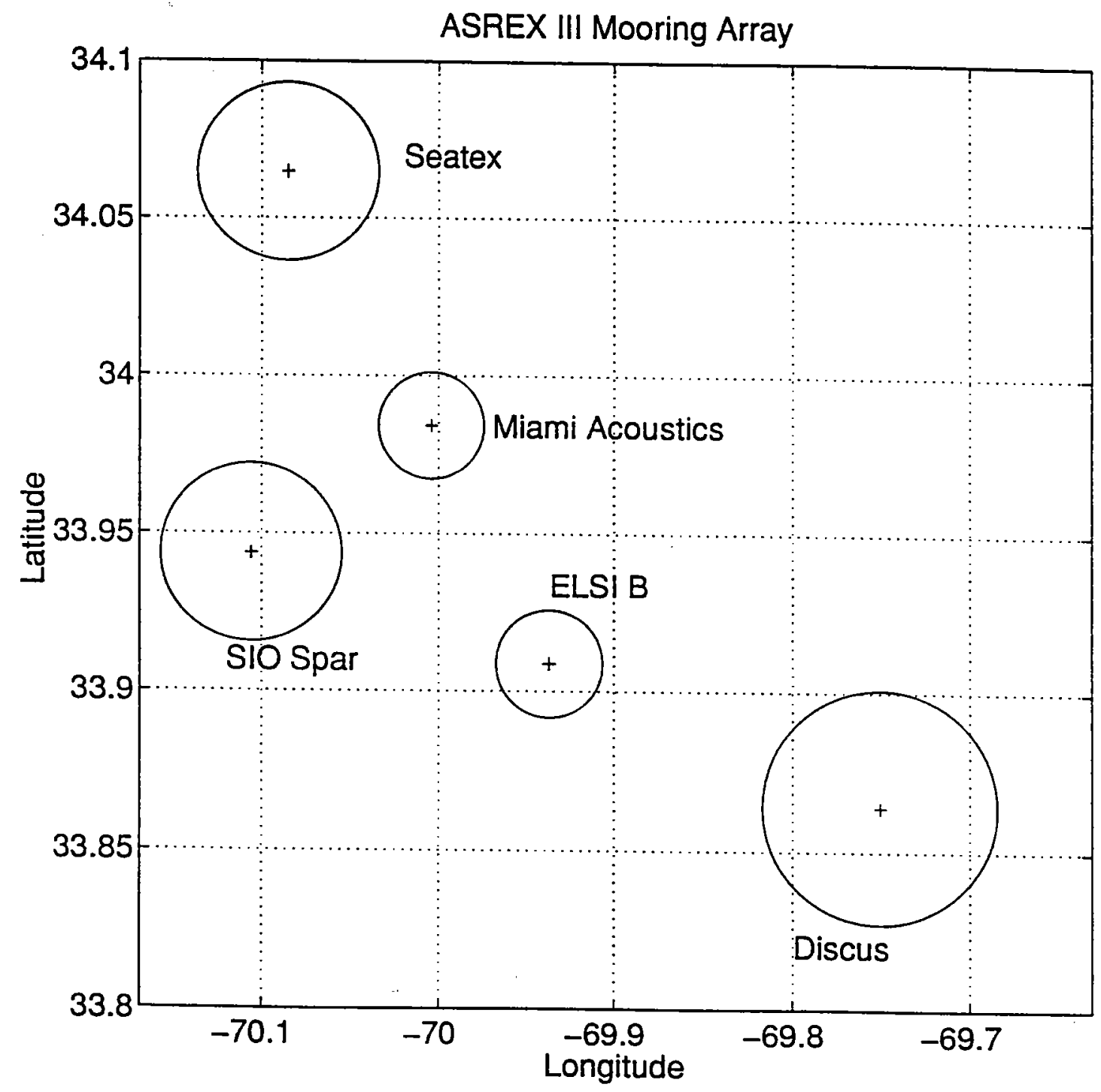

Figure 2.2: Locations and watch circles of the moorings in the array. 


\subsection{SIO Soundspeed Mooring}

A spar buoy was deployed by SIO to measure acoustic properties of bubble clouds in the upper 7 meters. The buoy had an overall length of $10.66 \mathrm{~m}$ and a maximum diameter of $2.43 \mathrm{~m}$. It was composed of three pieces:

a. A stainless steel tower above the surface holding solar panels, Argos PTTs, the data acquisition system and associated electronics.

b. A Seward International donut-shaped float with $6400 \mathrm{lb}$ total buoyancy. The central well of this float was filled with a battery pack which was recharged by the solar panels.

c. A $7 \mathrm{~m}$ spar made of $20.31 \mathrm{~cm}$ (8 in) outer diameter Aluminum 6061 tubing, extending below the float. All environmental sensors were connected to this spar.

The buoy made measurements of four environmental parameters. Soundspeed was measured by recording the travel times of acoustic pulses between hydrophone pairs at approximately $1 \mathrm{~m}$ spacing. The duty cycle was 40 minutes on, $2 \mathrm{~Hz}$ pulse rate/pair and 50 minutes off. The frequency of the pulses transmitted during each acquisition period cycled though 3,5 and $10 \mathrm{kHz}$, so that 40 minute time series for individual frequencies occur at 4.5 hour intervals. Measurements were made at $0.69,1.02,1.58,1.96,2.964 .44$, and $6.94 \mathrm{~m}$ depth. The acoustic data was logged to hard disk on a Compaq 486 notebook computer.

Temperature was measured using a sensor manufactured by Falmouth Scientific Inc. (F.S.I.) at depths of $0.71,1.33,1.97,3.03,4.49$ and $7.00 \mathrm{~m}$. Conductivity was measured using a sensor manufactured by F.S.I. at depths of 0.713 .03 and $7.00 \mathrm{~m}$. Dissolved oxygen was measured using a sensor by Royce at $0.65,3.18$, and $7.19 \mathrm{~m}$. The environmental data was logged to disk on an Onset Tattletale 6.

Data was successfully sampled from 10 December 1993 until 22 January 1994. On 22 January, the system unexpectedly shut down due to low power. It is suspected that a seawater ground/short developed and quickly drained the batteries faster than the solar panels could recharge them. Evidence of this has been seen in the time series of battery voltage saved on the Tattletale.

In order to allow the buoy to be attached to the mooring at one side, it was important to limit the tension on the mooring line. This presented a difficulty given the high currents known to be associated with cold-core rings seen at the site during previous deployments. The problem was solved by linking the surface and subsurface floats with an S-tether with a scope of 2.5 consisting of a negatively buoyant upper section and a positively buoyant lower section. This design allowed the mooring to tilt over in high current regimes without greatly increasing the surface tension. A surface tether made of 3/8" trawler chain covered with Tygon tubing was connected to the center of gravity of the buoy. Buoyancy for the surface tether was 
provided via 45 Panther-Plast Type 629 floats equally spaced on the top 21 meters. It was presumed that the Tygon tubing would provide sufficient stiffness to prevent the tether from fouling on the spar. This appears to have been the case. The mooring diagram for this instrument is shown in Figure 2.3, and a summary of the instrumentation is presented in Table 2.2.

\subsection{The Seatex Mooring}

This mooring was instrumented with a Seatex Wavescan ${ }^{\mathrm{TM}}$ buoy manufactured by Seatex A/S of Trondheim, Norway. Like the SIO Spar, the Wavescan buoy was tethered to a subsurface float via an S-tether which was designed to decouple the dynamics of the mooring from the motion of the surface float. Like the SIO Spar mooring, the Seatex mooring tether also lost most of the surface floats on the tether due to working in rough seas. The data collected from the buoy is summarized in Table 2.3 and the mooring diagram is shown in Figure 2.4.

\subsection{The UOP Discus Mooring}

The surface float on this mooring was a $3 \mathrm{~m}$ discus buoy outfitted with two meteorological packages, a Vector Averaging Wind Recorder (VAWR) with a full sensor suite, and an Improved Meteorological (IMET) package with a reduced sensor suite. The mooring line was instrumented with 8 Vector Measuring Current Meters (VMCMs), 12 temperature pods (T-POD) made by Brancker Inc. of Toronto, Ontario, Canada, 2 Seacat conductivity/ temperature packages, and an inverted Echo-sounder. Details of the instrumentation and sampling are given in Table 2.4. The mooring diagram is shown in Figure 2.5.

\subsection{The Miami Acoustics Mooring}

The Miami Acoustic Mooring for ASREX III was designed to produce high level acoustic transmissions at frequencies ranging from $100 \mathrm{~Hz}$ to $800 \mathrm{~Hz}$ and record the acoustic energy backscattered from the ocean surface via a 64 element hydrophone array and a pair of electronic receivers over the course of the 3 month long experiment. The mooring diagram is shown in Figure 2.6, and specifications of the instrumentation and acoustics packages are given in Tables 2.5 and 2.6. From top to bottom the mooring consisted of the following major components: 


\begin{tabular}{|c|c|c|c|c|}
\hline Instrument & $\begin{array}{l}\text { Parameters } \\
\text { Measured }\end{array}$ & Sample Rate & Duty Cycle & Depth \\
\hline $\begin{array}{l}\text { Dissolved Oxygen } \\
\text { sensor }\end{array}$ & Dissolved oxygen & $0.5 \mathrm{~Hz}$ & Continuous & $0.65 \mathrm{~m}$ \\
\hline $\begin{array}{l}\text { Acoustic } \\
\text { transducer }\end{array}$ & $\begin{array}{l}\text { Soundspeed } \\
@ 3,5 \text { and } 10 \mathrm{kHz}\end{array}$ & $2 \mathrm{~Hz}$ pulse rate & $\begin{array}{l}40 \mathrm{~min} \text {. on, } 50 \mathrm{~min} \\
\text { off cycling through } \\
\text { all } 3 \text { frequencies }\end{array}$ & $0.69 \mathrm{~m}$ \\
\hline $\begin{array}{l}\text { Conductivity/ } \\
\text { Temperature } \\
\text { sensor }\end{array}$ & $\begin{array}{l}\text { Conductivity, } \\
\text { temperature }\end{array}$ & $\begin{array}{l}0.5 \mathrm{~Hz} \text { (Cond) } \\
2 \mathrm{~Hz} \text { (Temp) }\end{array}$ & Continuous & $0.71 \mathrm{~m}$ \\
\hline $\begin{array}{l}\text { Acoustic } \\
\text { transducer }\end{array}$ & $\begin{array}{l}\text { Soundspeed } \\
@ 3,5 \text { and } 10 \mathrm{kHz} \text {. }\end{array}$ & $2 \mathrm{~Hz}$ pulse rate & $\begin{array}{l}40 \mathrm{~min} \text {. on, } 50 \mathrm{~min} \\
\text { off cycling through } \\
\text { all } 3 \text { frequencies }\end{array}$ & $1.02 \mathrm{~m}$ \\
\hline $\begin{array}{l}\text { Temperature } \\
\text { sensor }\end{array}$ & Temperature & $2 \mathrm{~Hz}$ & Continuous & $1.33 \mathrm{~m}$ \\
\hline $\begin{array}{l}\text { Acoustic } \\
\text { transducer }\end{array}$ & $\begin{array}{l}\text { Soundspeed } \\
@ 3,5 \text { and } 10 \mathrm{kHz} \text {. }\end{array}$ & $2 \mathrm{~Hz}$ pulse rate & $\begin{array}{l}40 \mathrm{~min} \text {. on, } 50 \mathrm{~min} \\
\text { occ cycling through } \\
\text { all } 3 \text { frequencies }\end{array}$ & $1.69 \mathrm{~m}$ \\
\hline $\begin{array}{l}\text { Temperature } \\
\text { sensor }\end{array}$ & Temperature & $2 \mathrm{~Hz}$ & Continuous & $1.97 \mathrm{~m}$ \\
\hline $\begin{array}{l}\text { Acoustic } \\
\text { transducer }\end{array}$ & $\begin{array}{l}\text { Soundspeed } \\
@ 3,5 \text { and } 10 \mathrm{kHz}\end{array}$ & $2 \mathrm{~Hz}$ pulse rate & $\begin{array}{l}40 \mathrm{~min} \text { on, } 50 \mathrm{~min} \\
\text { off cycling through } \\
\text { all } 3 \text { frequencies }\end{array}$ & $2.96 \mathrm{~m}$ \\
\hline $\begin{array}{l}\text { Conductivity/ } \\
\text { Temperature } \\
\text { sensor }\end{array}$ & $\begin{array}{l}\text { Conductivity, } \\
\text { temperature }\end{array}$ & $\begin{array}{l}0.5 \mathrm{~Hz} \text { (Cond) } \\
2 \mathrm{~Hz} \text { (Temp) }\end{array}$ & Continuous & $3.03 \mathrm{~m}$ \\
\hline $\begin{array}{l}\text { Dissolved Oxygen } \\
\text { sensor }\end{array}$ & Dissolved oxygen & $0.5 \mathrm{~Hz}$ & Continuous & $3.18 \mathrm{~m}$ \\
\hline $\begin{array}{l}\text { Acoustic } \\
\text { transducer }\end{array}$ & $\begin{array}{l}\text { Soundspeed } \\
@ 3,5 \text { and } 10 \mathrm{kHz} \text {. }\end{array}$ & $2 \mathrm{~Hz}$ pulse rate & $\begin{array}{l}40 \mathrm{~min} \text {. on, } 50 \mathrm{~min} \\
\text { off cycling through } \\
\text { all } 3 \text { frequencies }\end{array}$ & $4.44 \mathrm{~m}$ \\
\hline $\begin{array}{l}\text { Temperature } \\
\text { sensor }\end{array}$ & Temperature & $2 \mathrm{~Hz}$ & Continuous & $4.49 \mathrm{~m}$ \\
\hline $\begin{array}{l}\text { Acoustic } \\
\text { transducer }\end{array}$ & $\begin{array}{l}\text { Soundspeed } \\
@ 3,5 \text { and } 10 \mathrm{kHz} \text {. }\end{array}$ & $2 \mathrm{~Hz}$ pulse rate & $\begin{array}{l}40 \mathrm{~min} \text {. on, } 50 \mathrm{~min} \\
\text { off cycling through } \\
\text { all } 3 \text { frequencies }\end{array}$ & $6.94 \mathrm{~m}$ \\
\hline $\begin{array}{l}\text { Conductivity/ } \\
\text { Temperature } \\
\text { sensor }\end{array}$ & $\begin{array}{l}\text { Conductivity, } \\
\text { temperature }\end{array}$ & $\begin{array}{l}0.5 \mathrm{~Hz} \text { (Cond) } \\
2 \mathrm{~Hz} \text { (Temp) }\end{array}$ & Continuous & $7.00 \mathrm{~m}$ \\
\hline $\begin{array}{l}\text { Dissolved Oxygen } \\
\text { sensor }\end{array}$ & Dissolved oxygen & $0.5 \mathrm{~Hz}$ & Continuous & $7.18 \mathrm{~m}$ \\
\hline
\end{tabular}

Table 2.2: Instrumentation, sampling strategy, and days good data for the SIO soundspeed mooring. 


$\begin{array}{llllc}\text { Instrument } & \begin{array}{l}\text { Fields } \\ \text { Measured }\end{array} & \begin{array}{l}\text { Sample } \\ \text { Interval }\end{array} & \begin{array}{l}\text { Sample } \\ \text { Rate }\end{array} & \begin{array}{c}\text { Days Good } \\ \text { Data }\end{array} \\ \text { Motion Package } & \begin{array}{l}\text { Heave } \\ \text { Tilts }\end{array} & 1 \mathrm{sec} & \begin{array}{l}\text { 2048 samples } \\ \text { every 3 hours }\end{array} & 98 \\ & \text { Wave Spectrum } & 2048 \mathrm{sec} & \text { Every 3 hours } & \end{array}$

Table 2.3: Seatex Wave Mooring. All instrumentation is at surface.

\begin{tabular}{|c|c|c|c|c|c|}
\hline $\begin{array}{l}\text { Istrument } \\
\text { Type }\end{array}$ & $\begin{array}{l}\text { Fields } \\
\text { Measured }\end{array}$ & $\begin{array}{l}\text { Sample } \\
\text { Interval }\end{array}$ & $\begin{array}{l}\text { Sample } \\
\text { Rate (sec) }\end{array}$ & $\begin{array}{l}\text { Days of } \\
\text { Good Data }\end{array}$ & $\begin{array}{l}\text { Depth } \\
\text { (meters) }\end{array}$ \\
\hline VAWR & $\begin{array}{l}\text { WS, WD, AT, } \\
\text { SST, RH, BP, } \\
\text { SW, LW }\end{array}$ & 450 & 450 & $\begin{array}{l}99 \\
\text { except } \\
\text { WD }\end{array}$ & Surface \\
\hline IMET & $\begin{array}{l}\text { WS,WD, AT, } \\
\text { RH, SW }\end{array}$ & 450 & 450 & 99 & Surface \\
\hline T-POD & $\mathrm{T}$ & 450 & 450 & 99 & 1 \\
\hline T-POD & $\mathrm{T}$ & 450 & 450 & 99 & 1 \\
\hline Seacat & $\bar{S}, \mathrm{~T}$ & 225 & 225 & 99 & 1 \\
\hline VMCM & $\mathrm{U}, \mathrm{V}, \mathrm{T}$ & 120 & 120 & 90 & 5 \\
\hline $\mathrm{VMCM}$ & $\mathrm{U}, \mathrm{V}, \mathrm{T}$ & 120 & 120 & 89 & 10 \\
\hline $\mathrm{VMCM}$ & $\mathrm{U}, \mathrm{V}, \mathrm{T}$ & 120 & 120 & 90 & 15 \\
\hline $\mathrm{VMCM}$ & $\mathrm{U}, \mathrm{V}, \mathrm{T}$ & 120 & 120 & 90 & 20 \\
\hline T-POD & $\mathbf{T}$ & 450 & 450 & 99 & 37.5 \\
\hline $\mathrm{VMCM}$ & $\mathrm{U}, \mathrm{V}, \mathrm{T}$ & 120 & 120 & 89 & 50 \\
\hline T-POD & $\mathrm{T}$ & 450 & 450 & 99 & 75 \\
\hline T-POD & $\mathrm{T}$ & 450 & 450 & 99 & 100 \\
\hline T-POD & $\mathrm{T}$ & 450 & 450 & 99 & 125 \\
\hline VMCM & $\mathrm{U}, \mathrm{V}, \mathrm{T}$ & 120 & 120 & 90 & 150 \\
\hline T-POD & $\mathrm{T}$ & 450 & 450 & 99 & 175 \\
\hline T-POD & $\mathrm{T}$ & 450 & 450 & 99 & 200 \\
\hline T-POD & $\mathrm{T}$ & 450 & 450 & 99 & 230 \\
\hline T-POD & $\mathrm{T}$ & 450 & 450 & 99 & 260 \\
\hline VMCM & $\mathrm{U}, \mathrm{V}, \mathrm{T}$ & 120 & 120 & 89 & 300 \\
\hline T-POD & $\mathrm{T}$ & 450 & 450 & 99 & 350 \\
\hline T-POD & $\mathrm{T}$ & 450 & 450 & 99 & 400 \\
\hline Seacat & $\mathrm{T}, \mathrm{C}$ & 225 & 225 & 87 & 450 \\
\hline VMCM & $\mathrm{U}, \mathrm{V}, \mathrm{T}$ & 120 & 120 & 89 & 500 \\
\hline \multicolumn{2}{|c|}{$\begin{array}{l}\text { WS: Wind speed } \\
\text { BP: Barometric Pressure } \\
\text { SW: Short wave Radiation } \\
\text { T: Temperature }\end{array}$} & $\begin{array}{l}\text { WD: Wind D } \\
\text { AT: Air Tem } \\
\text { LW: Long w: } \\
\text { C: Conduc }\end{array}$ & $\begin{array}{l}\text { n } \\
\text { re } \\
\text { diation }\end{array}$ & \multicolumn{2}{|c|}{$\begin{array}{l}\text { RH: Relative Humidity } \\
\text { SST: Sea Surface Temp. } \\
\text { U,V: East, North Velocity }\end{array}$} \\
\hline
\end{tabular}

Table 2.4: Instrumentation and data return from the UOP meteorological/oceanographic mooring. Total deployment time for this mooring was 99 days. An inverted Echo-sounder package was also deployed at 30 meters, but did not record any data. 


\begin{tabular}{|c|c|c|c|c|c|}
\hline Instrument & $\begin{array}{l}\text { Fields } \\
\text { Measured }\end{array}$ & $\begin{array}{l}\text { Sample } \\
\text { Rate }\end{array}$ & $\begin{array}{l}\text { Sample } \\
\text { Interval }\end{array}$ & $\begin{array}{l}\text { Depths } \\
\text { relative to } \\
\text { top plate }\end{array}$ & $\begin{array}{l}\text { Days } \\
\text { Good } \\
\text { Data }\end{array}$ \\
\hline $\begin{array}{l}\text { Conical Beam } \\
\text { Sonars (4) }\end{array}$ & $\begin{array}{l}\text { Backscatter } \\
@ 55,110,200 \\
\text { and } 300 \mathrm{Khz}\end{array}$ & $2 \mathrm{~Hz}$ & $\begin{array}{l}27 \text { minutes } \\
\text { every } \\
12 \text { hours }\end{array}$ & Surface & 10 \\
\hline $\begin{array}{l}\text { Water Structure } \\
\text { Profiler (WASP) }\end{array}$ & $\begin{array}{l}\text { Backscatter } \\
@ 200 \mathrm{kHz}\end{array}$ & $1 / 6 \mathrm{sec}$ & Continuous & $\begin{array}{l}0.25 \mathrm{~m} \text { bins, } \\
10-50 \mathrm{~m} \text { above } \\
\text { instrument }\end{array}$ & 10 \\
\hline $\begin{array}{l}\text { Sidescan sonars } \\
\text { (4) }\end{array}$ & $\begin{array}{l}\text { Backscatter, } \\
\text { doppler velocity } \\
\text { @ } 100 \mathrm{kHz}\end{array}$ & $2 \mathrm{~Hz}$ & $\begin{array}{l}27 \text { minutes } \\
\text { every } \\
12 \text { hours }\end{array}$ & Surface & 10 \\
\hline $\begin{array}{l}\text { Wide-band, } \\
\text { omnidirectional } \\
\text { hydrophone }\end{array}$ & $\begin{array}{l}\text { Ambient noise } \\
\text { spectrum }\end{array}$ & & Every 1 hour & At instrument & 10 \\
\hline $\begin{array}{l}\text { Temperature } \\
\text { sensor }\end{array}$ & Temp, & & Every 1 hour & At instrument & 10 \\
\hline $\begin{array}{l}\text { Conductivity } \\
\text { sensor }\end{array}$ & Cond. & & Every 1 hour & At instrument & 10 \\
\hline Pressure sensor & Pressure & & Every 1 hour & At instrument & 10 \\
\hline Motion Package & Tilt, Orientation & & Every 1 hour & At instrument & 10 \\
\hline SeaData TDR & Temp, Pressure & $1 / 450 \mathrm{sec}$ & & & 84 \\
\hline $\begin{array}{l}\text { Hydrophone array } \\
\text { (see Table } 2.6 \\
\text { for details) }\end{array}$ & $\begin{array}{l}\text { Sound level at } \\
100,200,400 \\
\text { and } 800 \mathrm{~Hz}\end{array}$ & & & & 84 \\
\hline
\end{tabular}

Table 2.5: Miami Acoustics Mooring, Instrumentation and Data Return. One TDR, located on the disk buoy, was inadvertently turned off when the endcap was placed on the instrument. This instrument functioned normally during post-cruise calibrations and the data loss, while unfortunate, was apparently due to human error and/or a design flaw (twisting of the end cap to line up the securing latches apparently caught the switch and turned it off). 


\section{Extended Life Sonar Instrument (ELSI) - IOS/Canada}

This instrument used high frequency acoustics to measure the content and nature of bubble plumes that were generated by breaking surface gravity waves at high sea states. Parameters of the ELSI deployed from this mooring are described in Table 2.5.

\section{Disk Buoy}

A disk shaped syntactic foam buoy package provided most of the buoyancy required to maintain high tension in the subsurface taut mooring. It provided approximately $3100 \mathrm{lbs}$ of positive buoyancy at depths up to $2000 \mathrm{~m}$. A pair of Argos satellite Platform Terminal Transmitters (PTTs), one oriented up and the other down, were mounted on the side of the buoy to provide location information to a shore station should the mooring have surfaced prematurely. A Sea Data/Pacer/WHIS temperature-depth recorder (TDR) was mounted on the top of the disk buoy and recorded the temperature and pressure every 7.5 minutes over the course of the experiment.

\section{Acoustic Transmitter ("Miami Sound Machine")}

A 5.3 meter long, $6100 \mathrm{lb}$ (in air) package contained an electronic signal generating system powered by alkaline batteries, a syntactic foam flotation module that reduced its weight in water to under $750 \mathrm{lbs}$, and an array of acoustic transducers mounted in an aluminum framework that could broadcast acoustic signals at levels on the order of $200 \mathrm{~dB} / / 1 \mu \mathrm{Pa} @ 1 \mathrm{~m}$ at four frequencies $(100 \mathrm{~Hz}, 200 \mathrm{~Hz}, 400 \mathrm{~Hz}$, and $800 \mathrm{~Hz})$. This instrument transmits a series of acoustic pulses and coded signals that are listened for by the receiver packages/acoustic array described below. The transmitter also provided a clock signal that was transmitted down a 20 meter long electro-mechanical cable to the uppermost receiver system. This technique assured that the source and receivers were always "in synch" with one another.

\section{Acoustic Receivers/Hydrophone Array}

There were two receiving packages on the Miami mooring each of which recorded signals received by 32 of the 64 total hydrophones distributed between them. The receiver packages contain electronics and tape recording systems capable of recording 25 gigabytes of data each. The electronics are powered by a series of alkaline battery packs mounted in cylindrical aluminum pressure housings. The pressure housings are recess mounted in custom built syntactic foam buoyancy modules, and bolted to an aluminum framework. Each receiver package weighs about $4000 \mathrm{lbs}$ in air and is 3.1 meters long. In seawater, however, the packages provide over $650 \mathrm{lbs}$ of positive buoyancy. In addition to recording acoustic signals, the receivers also monitor and record tilt and ambient pressure. TDR's were mounted on each 
end of each receiver to provide additional records of pressure and ambient temperature. A Benthos XT-6000 acoustic beacon, modified to include a pressure sensor, was mounted on the uppermost receiver and was used to telemeter its pressure (depth) back to a DS7000 deck unit when interrogated at the proper frequency. This was useful during the deployment operation as it gave a real time indication that the instrument was moored at its proper depth.

The hydrophone array consisted of $64 \mathrm{HT} 1$ hydrophones spaced to provide beam-forming capabilities at all of the frequencies output by the transmitter. The hydrophones were mounted in aluminum pipes that were whipped to a Kevlar-based electromechanical cable that has a breaking strength in excess of $12,000 \mathrm{lb}$. In addition, a 3/8" diameter $3 \times 19$ jacketed wire rope ran in parallel to provide backup protection, should the Kevlar strength member be severed (i.e., by fish bite). The array also featured a 3-strand fairing to reduce cable strumming. Just below the lower receiver system was a 200 meter length of SAIC Quiet Cable $\circledast$ which was also used to reduce cable strumming which can interfere with acoustic measurements.

The remainder of the mooring consisted of $3 / 8$ " wire rope, $1 / 2$ " chain, glass buoyant spheres, and a pair of Benthos 865A acoustic releases mounted in parallel, all of which were chained to a $7000 \mathrm{lb}$ cast iron anchor (Figure 2.6).

\subsection{The ELSI B Mooring}

This mooring included an ELSI $B$ instrument platform which included a number of sonar instruments as shown on Figure 2.7. These were:

a. 6 upward looking conical beam sonars operating at frequencies of $28,50,88,100,200$, and $400 \mathrm{kHz}$.

b. A fixed $100 \mathrm{kHz}$ sidescan sonar identical to that deployed on the Miami acoustics mooring.

c. A $100 \mathrm{kHz}$ sidescan sonar mounted on a rotating base allowing it to scan 360 degrees in azimuth every 77 seconds. Because of the extra time required to move the sonar, the overall ping rate was reduced to $1.67 \mathrm{~Hz}$.

d. Instruments to measure ambient sound and environmental parameters. The sonars collected data for 27 minutes every 6 hours.

Additional instrumentation on the mooring included an Anderaa temperature chain with thermistors every 5 meters below the top plate of ELSI B, an S4 current meter at $7.5 \mathrm{~m}$ below the top plate of ELSI B and a 12 channel WOTAN (wind observation through ambient noise) instrument $70 \mathrm{~m}$ below the top plate of ELSI B. Table 2.7 lists the ELSI B mooring instrumentation. 
Figures 2.8 and 2.9 show the positions of the Discus and Seatex buoys from System Argos. Both buoys show a consistent pattern, lying to the northeast of the moorings during December, shifting around to the east during January, and then more to the southeast during February, and finally to the south during March. These positions reflect the prevailing currents over the course of the deployment. 


\begin{tabular}{|c|c|c|c|c|c|}
\hline Instrument & $\begin{array}{l}\text { Parameters } \\
\text { Measured }\end{array}$ & $\begin{array}{l}\text { Sample } \\
\text { Rate }\end{array}$ & $\begin{array}{l}\text { Sample } \\
\text { Frequency }\end{array}$ & $\begin{array}{l}\text { Depths } \\
\text { relative } \\
\text { to top plate }\end{array}$ & $\begin{array}{l}\text { Days } \\
\text { Good } \\
\text { Data }\end{array}$ \\
\hline $\begin{array}{l}\text { Conical beam } \\
\text { sonars }\end{array}$ & $\begin{array}{l}\text { Backscatter at } \\
28,50,88 \text {, } \\
100,200 \text {, and } \\
400 \mathrm{kHz}\end{array}$ & $\begin{array}{l}1557 \mathrm{sec} \\
(2600 \text { pings } \\
@ 1.67 \mathrm{~Hz})\end{array}$ & 12 hours & Ocean Surface & 90 \\
\hline $\begin{array}{l}\text { Fixed } 100 \mathrm{kHz} \\
\text { Sidescan }\end{array}$ & $\begin{array}{l}\text { Backscatter, } \\
\text { Doppler veloci- } \\
\text { ties out to } \\
\sim 300 \mathrm{~m}\end{array}$ & $\begin{array}{l}1557 \text { sec. } \\
\text { (2600 pings } \\
\text { @ } 1.67 \mathrm{~Hz} \text { ) }\end{array}$ & 12 hours & Ocean Surface & 90 \\
\hline $\begin{array}{l}\text { Rotating } 100 \mathrm{kHz} \\
\text { Sidescan }\end{array}$ & $\begin{array}{l}\text { Backscatter, } \\
\text { Doppler veloci- } \\
\text { ties out to } \\
-300 \mathrm{~m}\end{array}$ & $\begin{array}{l}1557 \mathrm{sec} . \\
\text { (2600 pings } \\
\text { @ } 1.67 \mathrm{~Hz}\end{array}$ & 12 hours & Ocean Surface & 90 \\
\hline $\begin{array}{l}\text { Environmental } \\
\text { Sensor Pack }\end{array}$ & $\begin{array}{l}\text { Temperature, } \\
\text { conducitivity, } \\
\text { depth }\end{array}$ & & & 1 & 90 \\
\hline $\begin{array}{l}\text { Thermistor } \\
\text { String }\end{array}$ & Temperature & $1200 \mathrm{sec}$ & $1200 \mathrm{sec}$ & $\begin{array}{l}10,15,20,25, \\
30,35,40,45, \\
50,55,60\end{array}$ & 82 \\
\hline WOTAN & $\begin{array}{l}\text { Ambient noise in } \\
12 \text { channels }\end{array}$ & $15 \mathrm{sec}$ & $180 \mathrm{sec}$ & 70 & 90 \\
\hline
\end{tabular}

Table 2.7: IOS ELSI B Mooring, Instrumentation and Data Return. This mooring was deployed for a total of 90 days. An S4 current meter was also deployed on this mooring but was severely damaged on recovery with consequent loss of data. 


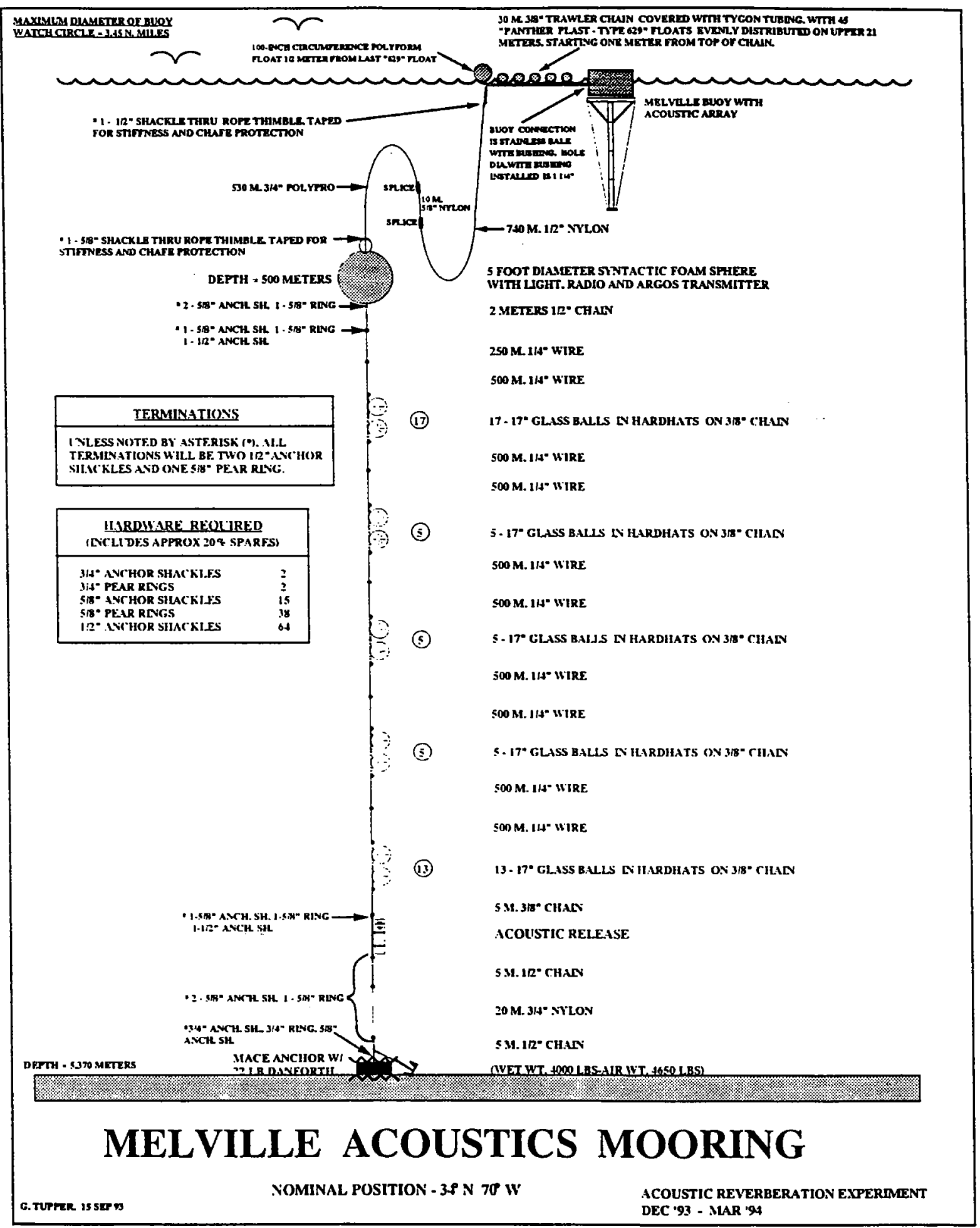

Figure 2.3: Diagram of SIO Soundspeed Mooring. 


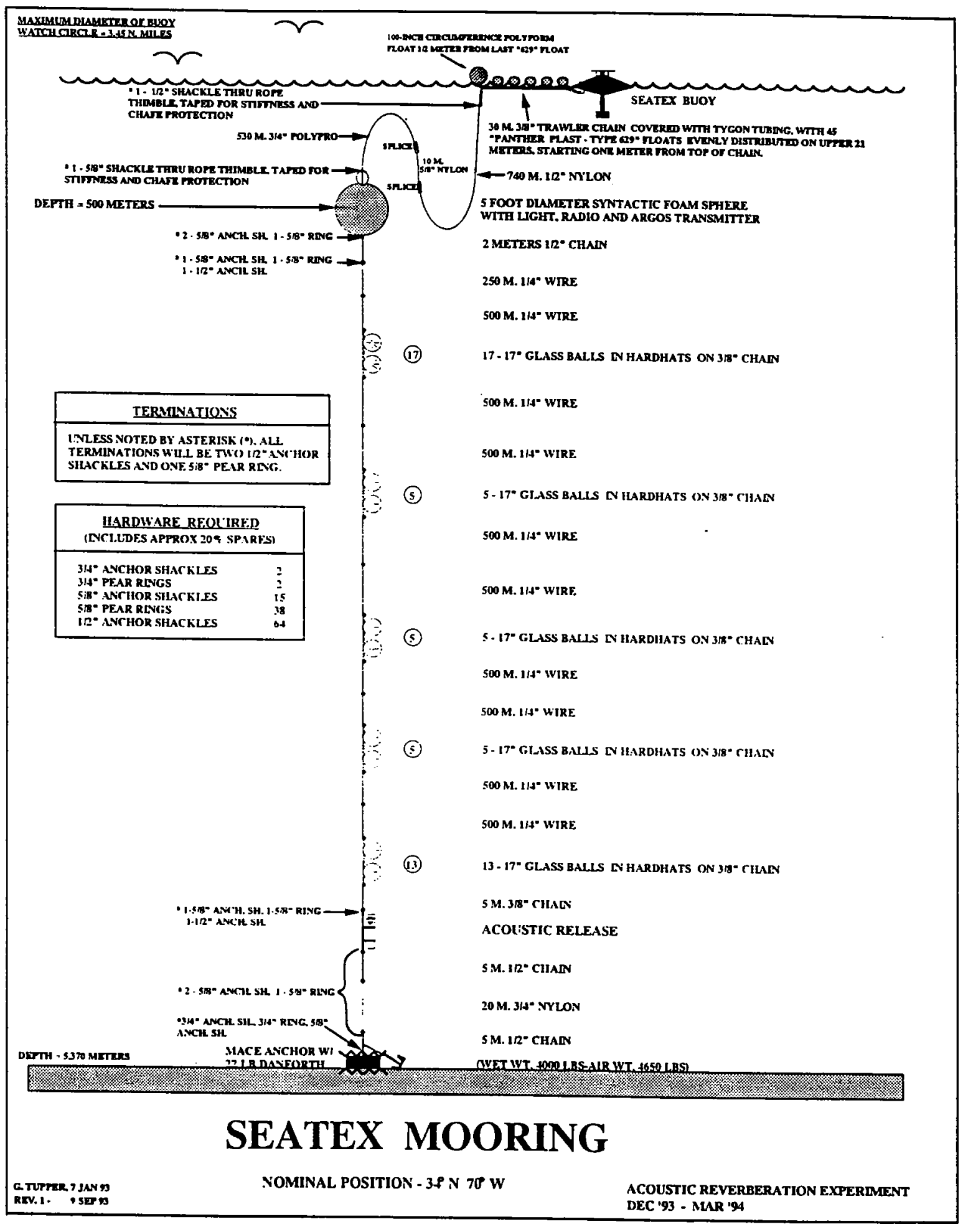

Figure 2.4: Diagram of WHOI Seatex Mooring. 


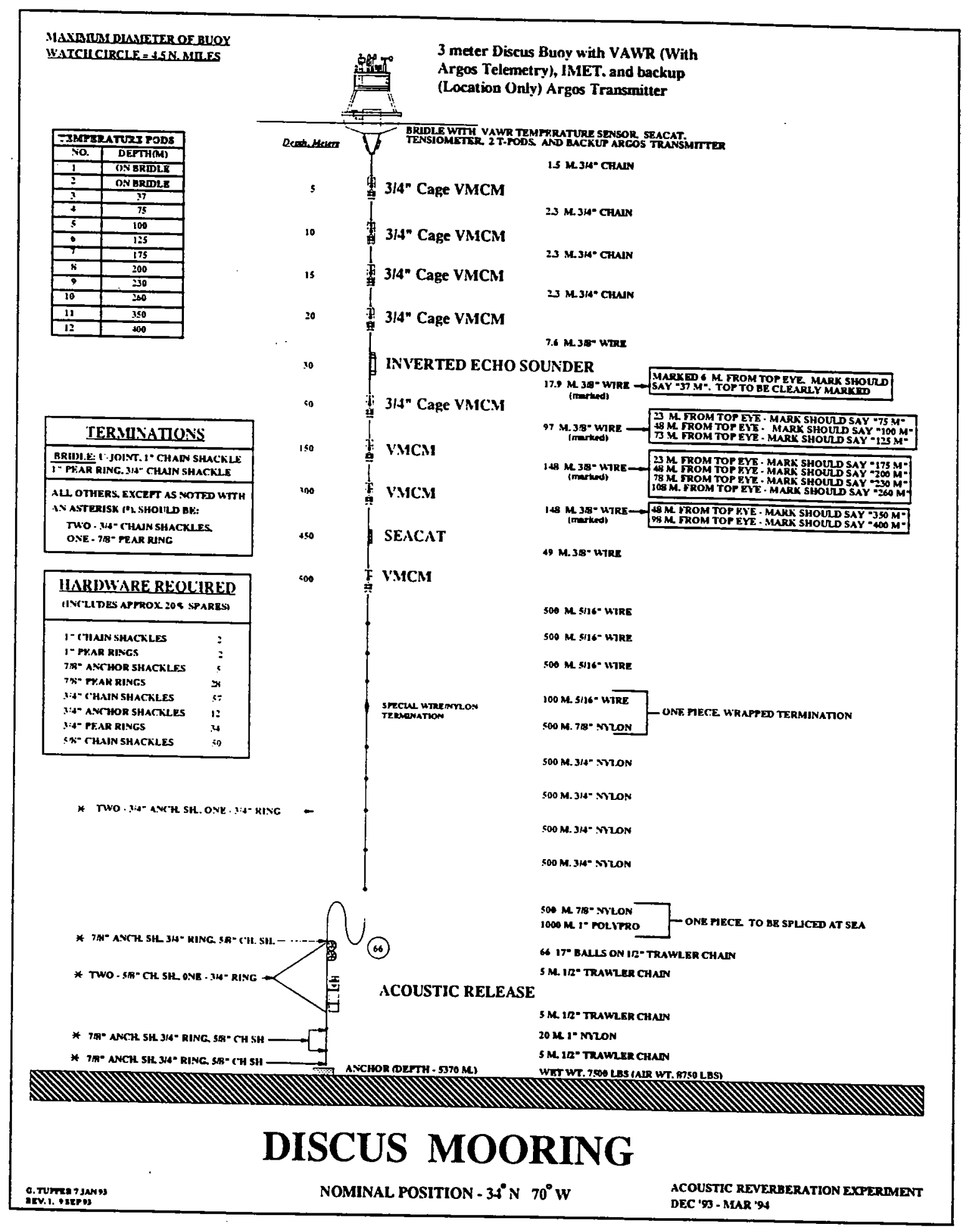

Figure 2.5: Diagram of WHOI Discus Mooring. 


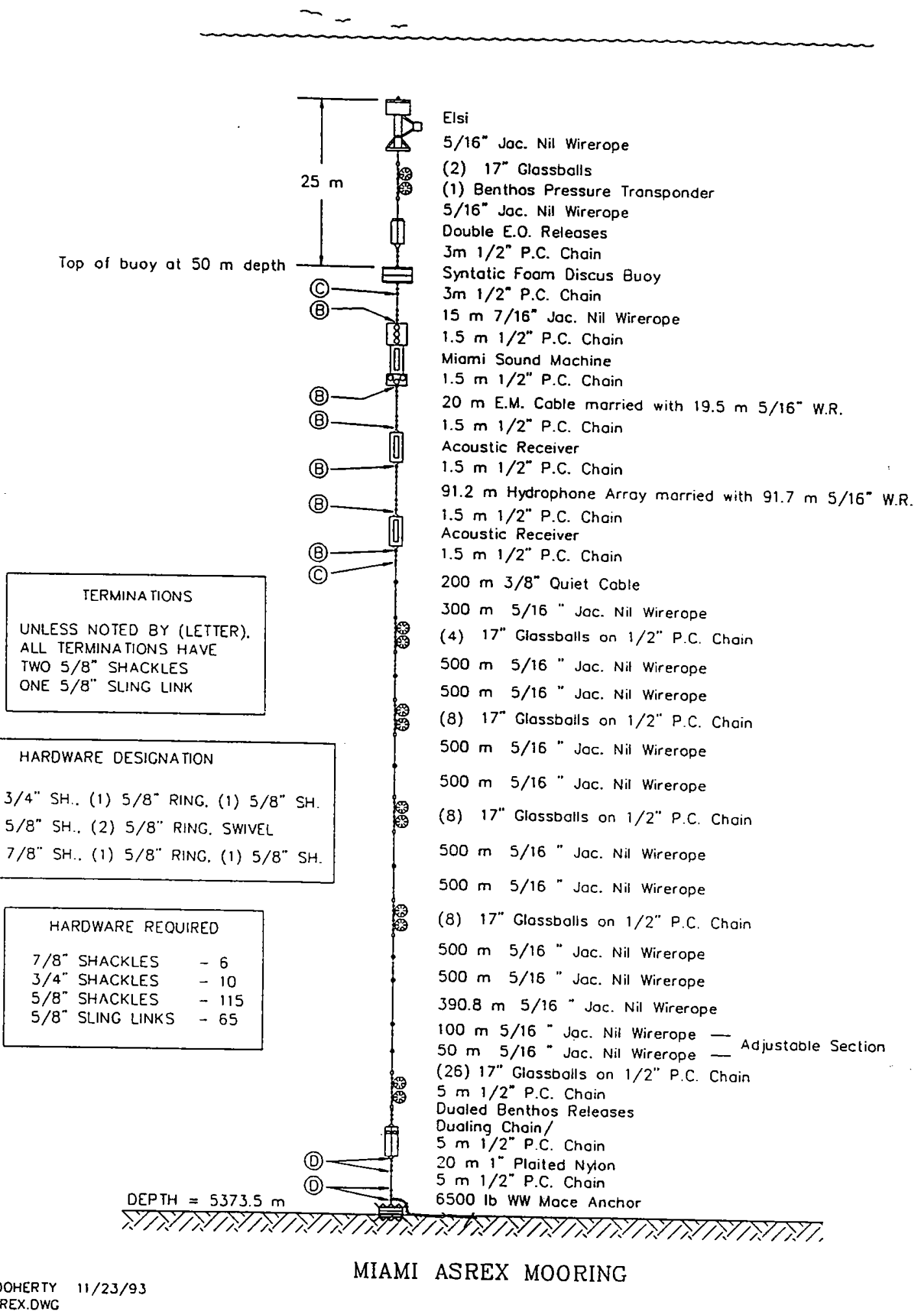

BETSEY DOHERTY
KEMP / ASREX.OWG

(B) (1) $3 / 4^{\prime \prime} \mathrm{SH}$. (1) $5 / 8^{*}$ RING. (1) $5 / 8^{\prime \prime} \mathrm{SH}$

(C) (4) $5 / 8^{\prime \prime}$ SH.. (2) $5 / 8^{\prime \prime ~ R I N G . ~ S W I V E L ~}$

(D) 91) $7 / 8^{\prime \prime} \mathrm{SH}$. (1) $5 / 8^{\prime \prime}$ RING. (1) $5 / 8^{\prime \prime} \mathrm{SH}$.

(1) Benthos Pressure Transponder

Nil Wirerope

Syntatic Foom Discus Buoy

1/2 P.C. Chain

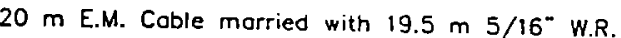

$1.5 \mathrm{~m} \mathrm{1/2}$ P.C. Chain

$91.2 \mathrm{~m}$ Hydrophone Arroy morried with $91.7 \mathrm{~m} \mathrm{5/16^{ \circ }}$ W.R.

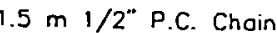

200 m 3/8" Quiet Cable

$300 \mathrm{~m} \mathrm{5/16}$ " Jac. Nil Wirerope

(4) 17" Glassballs on 1/2" P.C. Chain

$500 \mathrm{~m} \mathrm{5/16"} \mathrm{Jac.} \mathrm{Nil} \mathrm{Wirerope}$

$500 \mathrm{~m} \mathrm{5/16} \mathrm{"} \mathrm{Jac.} \mathrm{Nil} \mathrm{Wirerope}$

(8) $17^{*}$ Glassballs on $1 / 2^{\prime \prime}$ P.C. Chain

$500 \mathrm{~m} \mathrm{5/16}$ " Joc. Nii Wirerope

$5 / 16$ Joc. Nil Wirerope

Chain

$500 \mathrm{~m} \mathrm{5/16}$ " Jac. Nil Wirerope

$500 \mathrm{~m} \mathrm{5/16} \mathrm{"} \mathrm{Jac.} \mathrm{Nil} \mathrm{Wirerape}$

$390.8 \mathrm{~m} \mathrm{5/16}$ " Joc. Nil Wirerope

$100 \mathrm{~m} \mathrm{5/16}$. Jac. Nil Wirerope - Adjustable Section

(26) 17" Giossbolls on 1/2" P.C. Chain

uoling Chain/

DEPTH $=5373.5 \mathrm{~m}$

$5 \mathrm{~m} 1 / 2^{\text {"Pl P.C. Chain }}$

6500 lo WW Moce Anchor

Figure 2.6: Diagram of Miami Acoustics Mooring. 


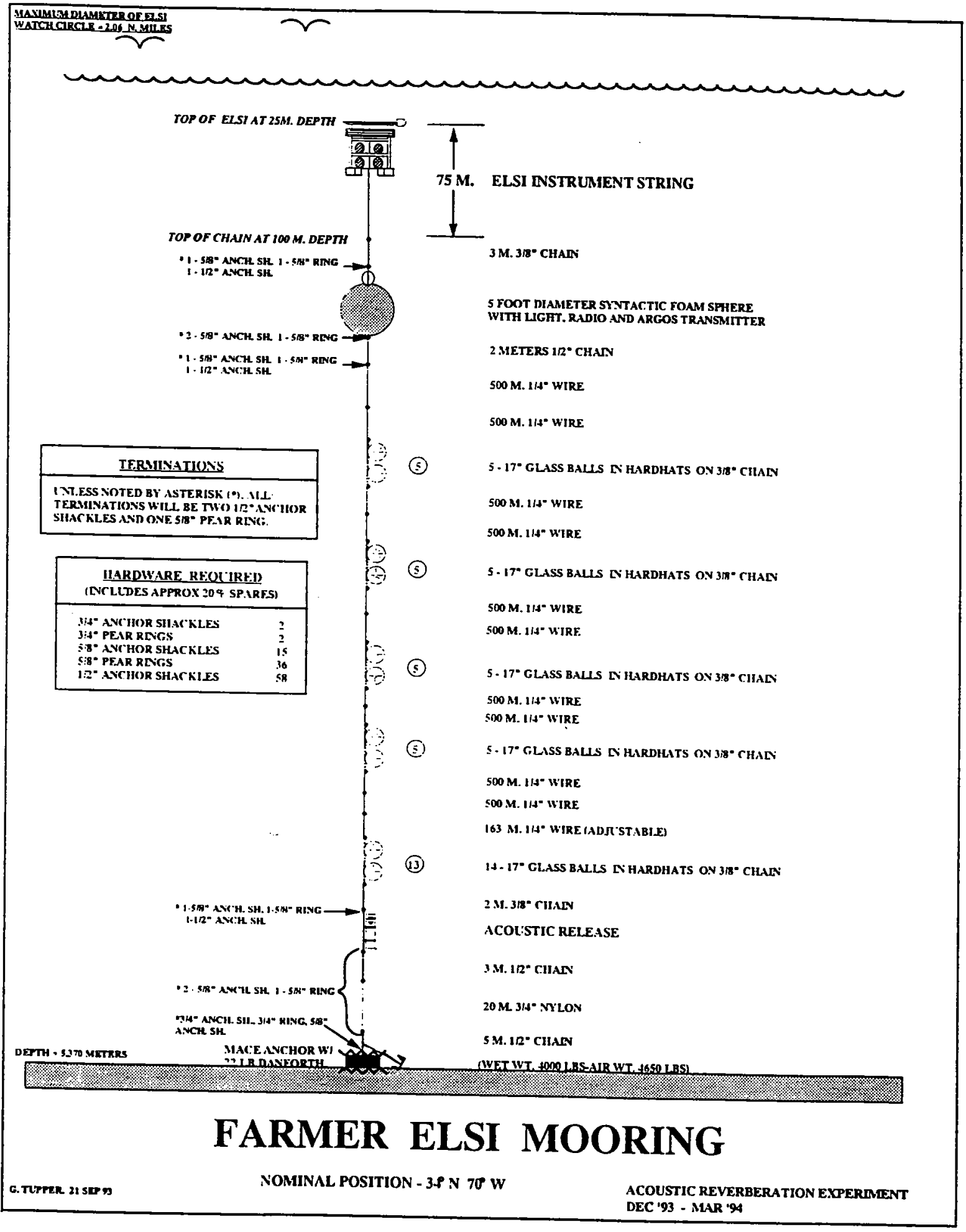

Figure 2.7: Diagram of IOS ELSI B Mooring. 
Discus Positions: December 1993

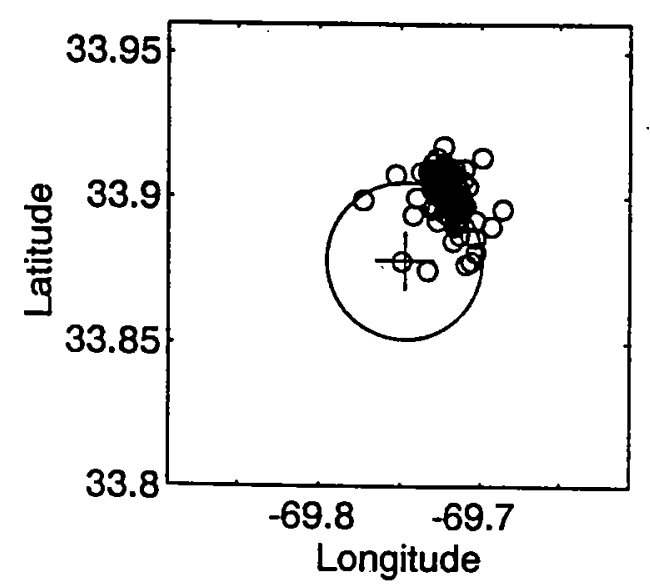

Discus Positions: February 1994

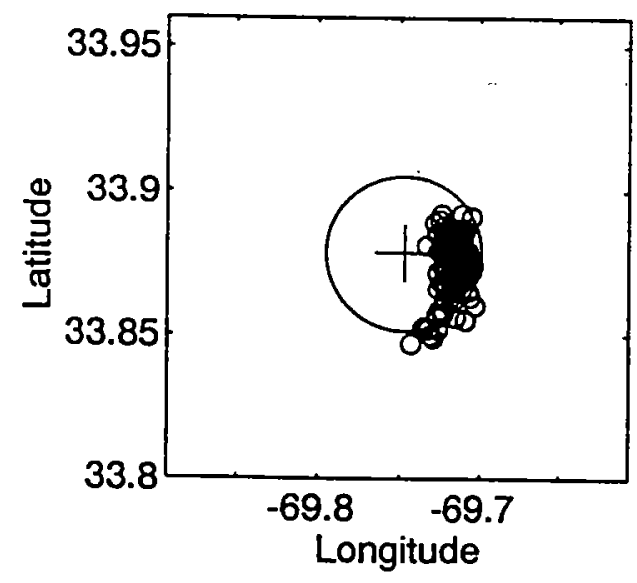

Discus Positions: January 1994

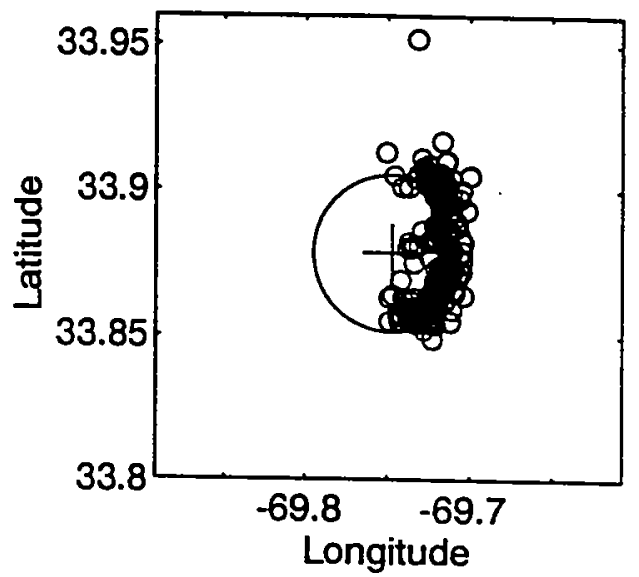

Discus Positions: March 1994

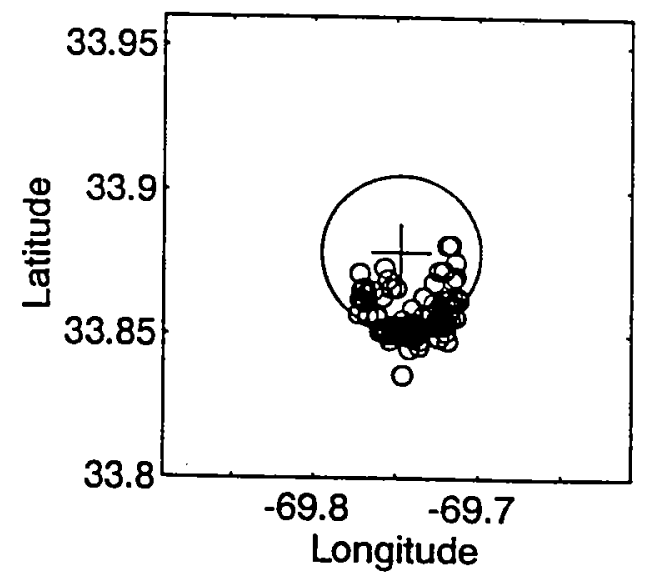

Figure 2.8: Argos positions of Discus buoy. 
Seatex Positions: December 1993

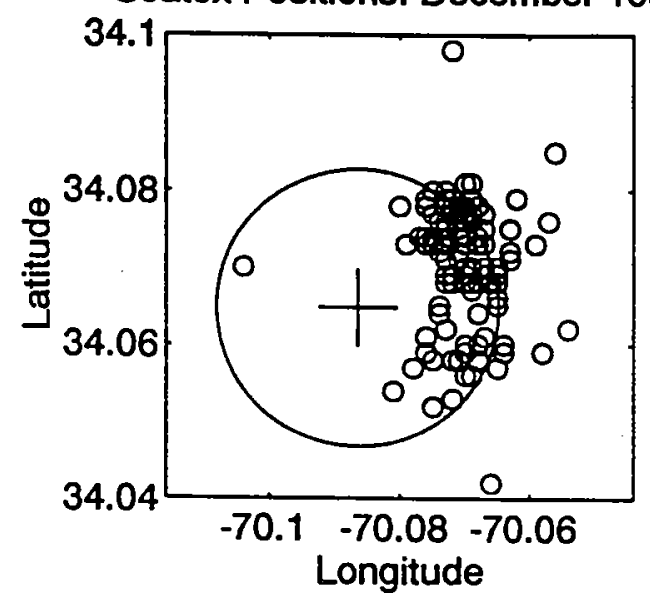

Seatex Positions: February 1994

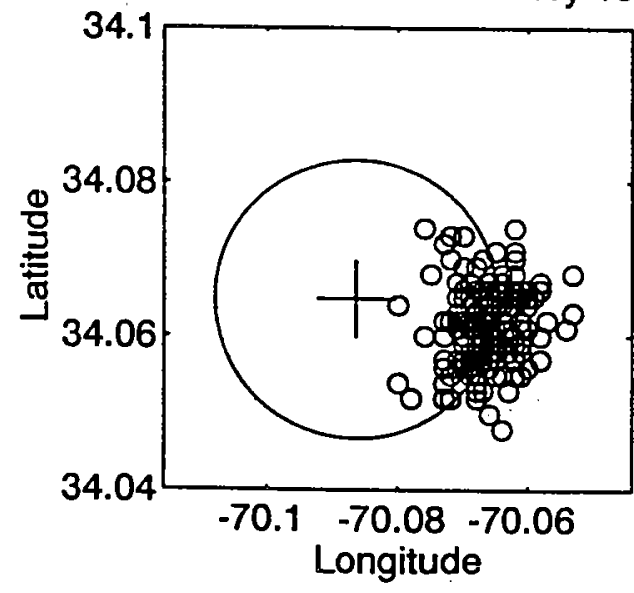

Seatex Positions: January 1994

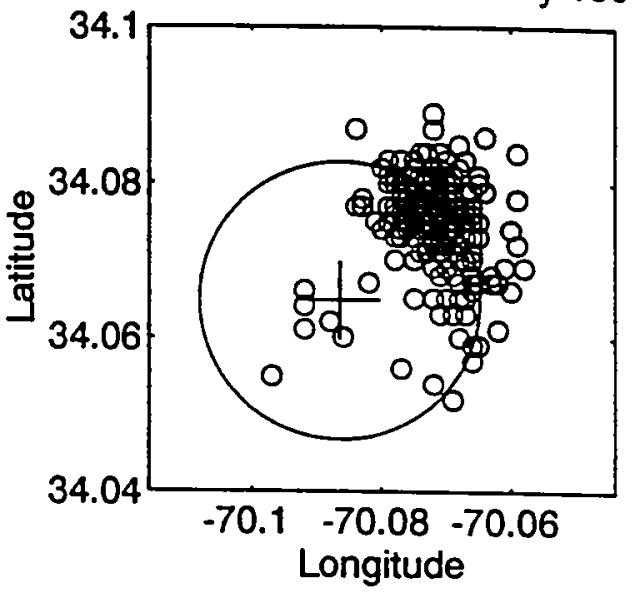

Seatex Positions: March 1994

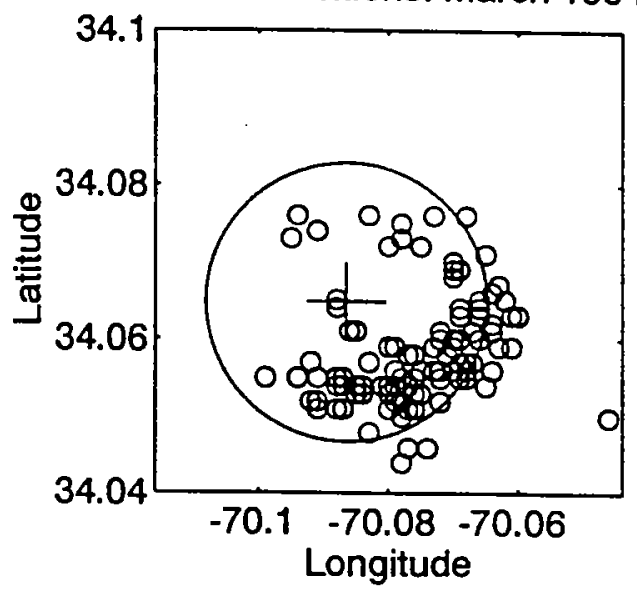

Figure 2.9: Argos positions of Seatex buoy. 


\section{Data Presentation}

\subsection{Meteorology during ASREX III \\ Meteorological Observations}

Meteorological data was recorded using a VAWR with a 7.5 minute record rate. A second meteorological instrument package, an IMET system, also recorded a reduced set of data (short wave radiation, wind speed and direction, relative humidity and air temperature).

Tables 3.1.1-3.1.2 summarize the sensors, their accuracy, and the sampling strategy for each of the packages. Table 3.1.1 shows a schematic of how the VAWR sampled each sensor during the 7.5 minute recording interval. Note that while the wind and radiation sensors recorded over the entire interval, the relative humidity and barometric pressure are sampled for a very short period of time in the middle of the recording interval.

Figures 3.1.1-3.1.7 show time series of meteorological variables from the composite data set. From top to bottom, the wind east and north, sea surface and air temperature, barometric pressure, relative humidity, and short wave and long wave radiation are shown.

A check of the time base for the VAWR found 99 missing or incorrect clock counts. The data was interpolated over these gaps. The final processed data file had a total of 19099 records at 7.5 minute intervals between 15 December 1993 00:18 and 24 March 1994 11:33. A magnetic variation of $15.9^{\circ}$ was applied to the data from both instruments.

The IMET data were found to agree very well with the VAWR data in general, although several small, systematic differences were found. The VAWR recorded wind speeds about $9 \%$ higher than the IMET. The IMET and VAWR air temperatures exhibited a systematic difference with the IMET showing lower air temperatures than the VAWR when the surface air temperatures were low. Both sensors showed a consistent diurnal cycle, with the VAWR exhibiting a mean diurnal cycle of about $0.5^{\circ} \mathrm{C}$, while the IMET showed a mean diurnal cycle of about half that amplitude. Because this is most likely due to radiative heating of the sensor, the IMET temperature was used in the composite meteorological file.

Like the air temperature, the long wave radiation exhibited a diurnal cycle which had an averaged amplitude of about $13 \mathrm{~W} / \mathrm{m}^{2}$. Alados-Arboledas et al. (1988) showed that such an effect could arise from solar heating of the pyrgeometer dome. They suggested that the long wave radiation be reduced by $3.6 \%$ of the incoming short wave radiation. When this correction was applied to the data, the diurnal cycle of long wave radiation disappeared. The corrected long wave radiation was used in the composite meteorological file.

On 15 January 1994, the wind vane on the VAWR broke at the height of a strong storm. Thereafter wind direction was not available from the VAWR. This would not have been serious had not the IMET wind sensor experienced significant interference, which contaminated 


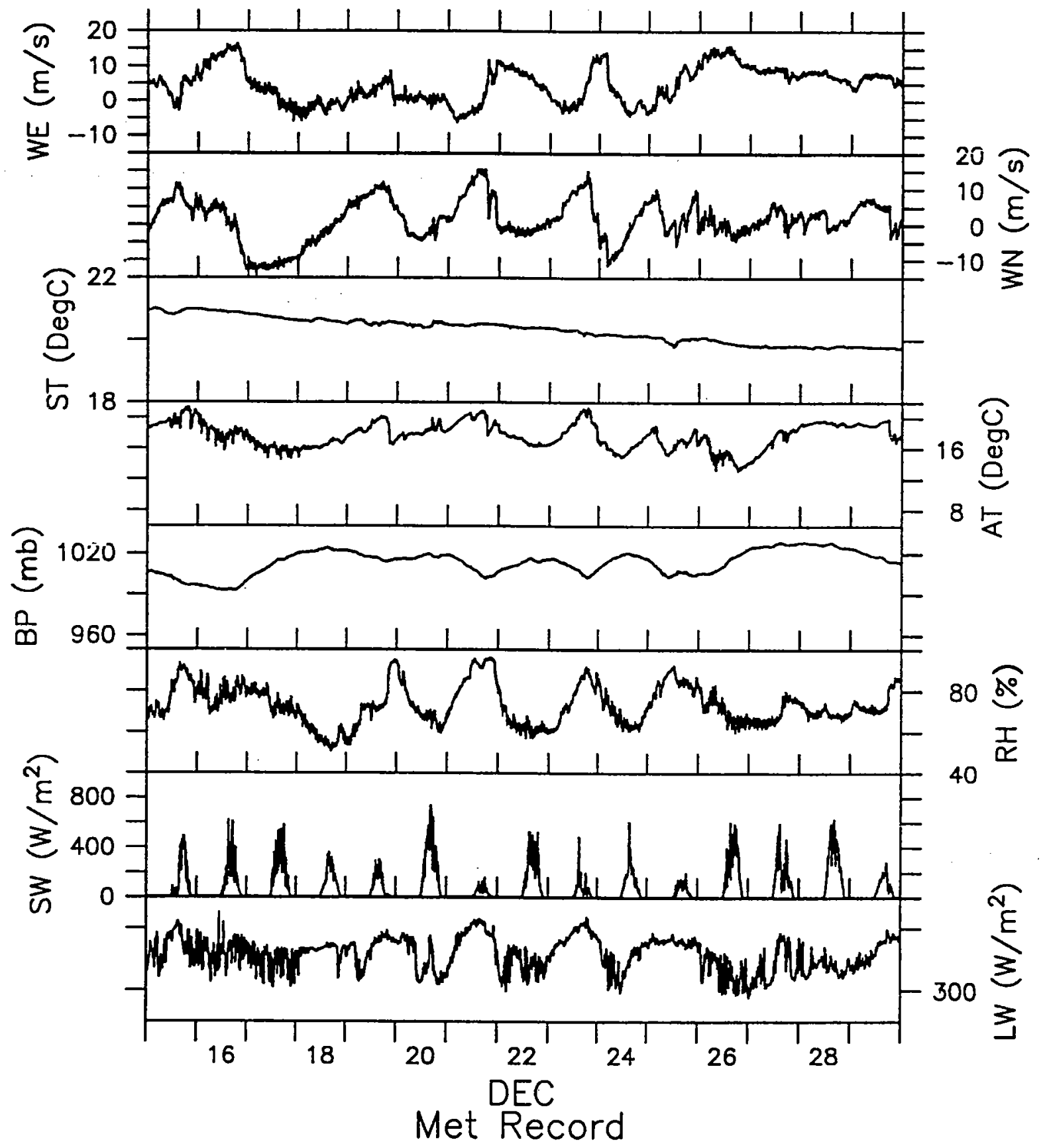

Figure 3.1.1: Meteorological Variables from the Composite Data Set. 


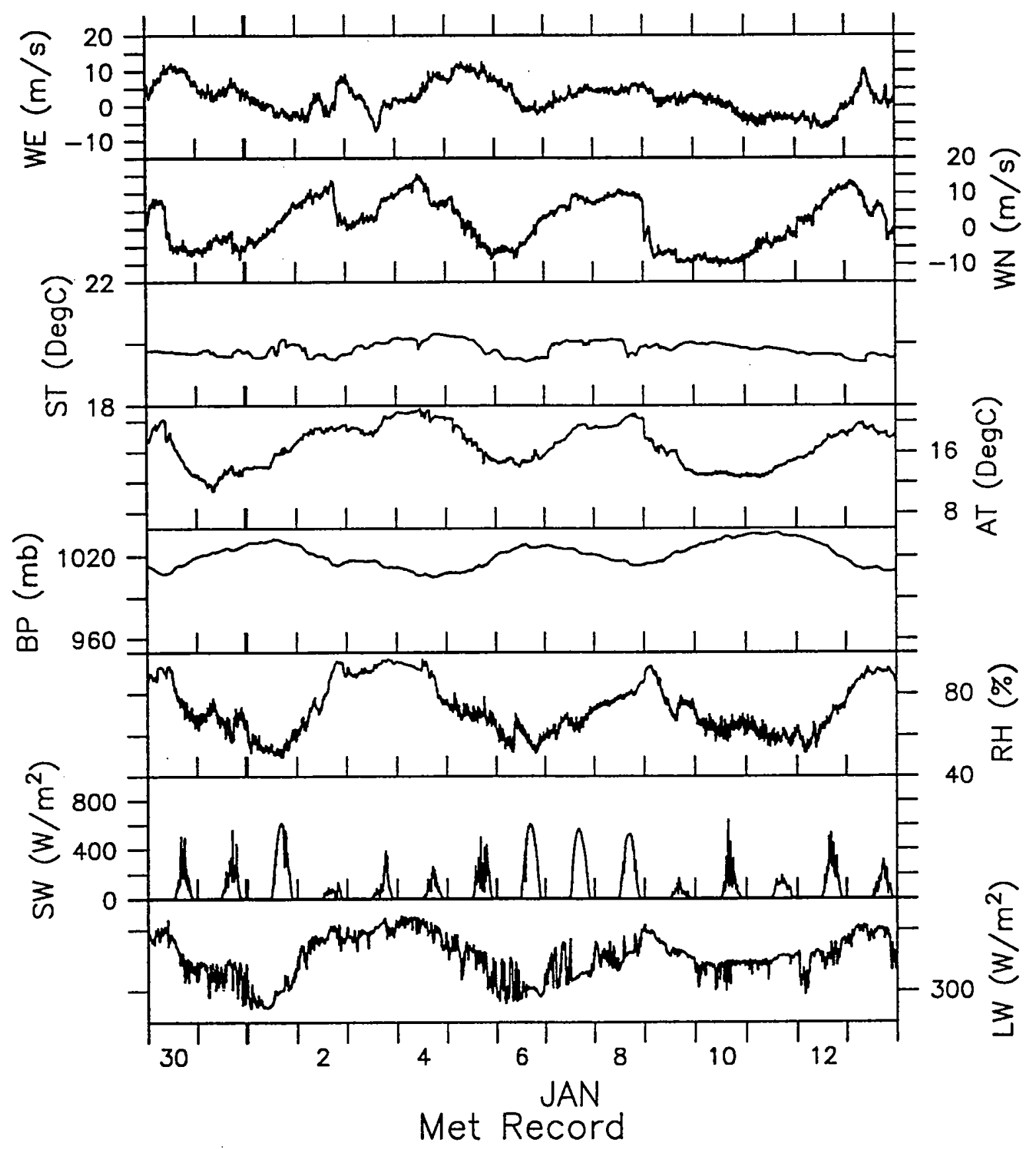

Figure 3.1.2: Meteorological Variables from the Composite Data Set. 


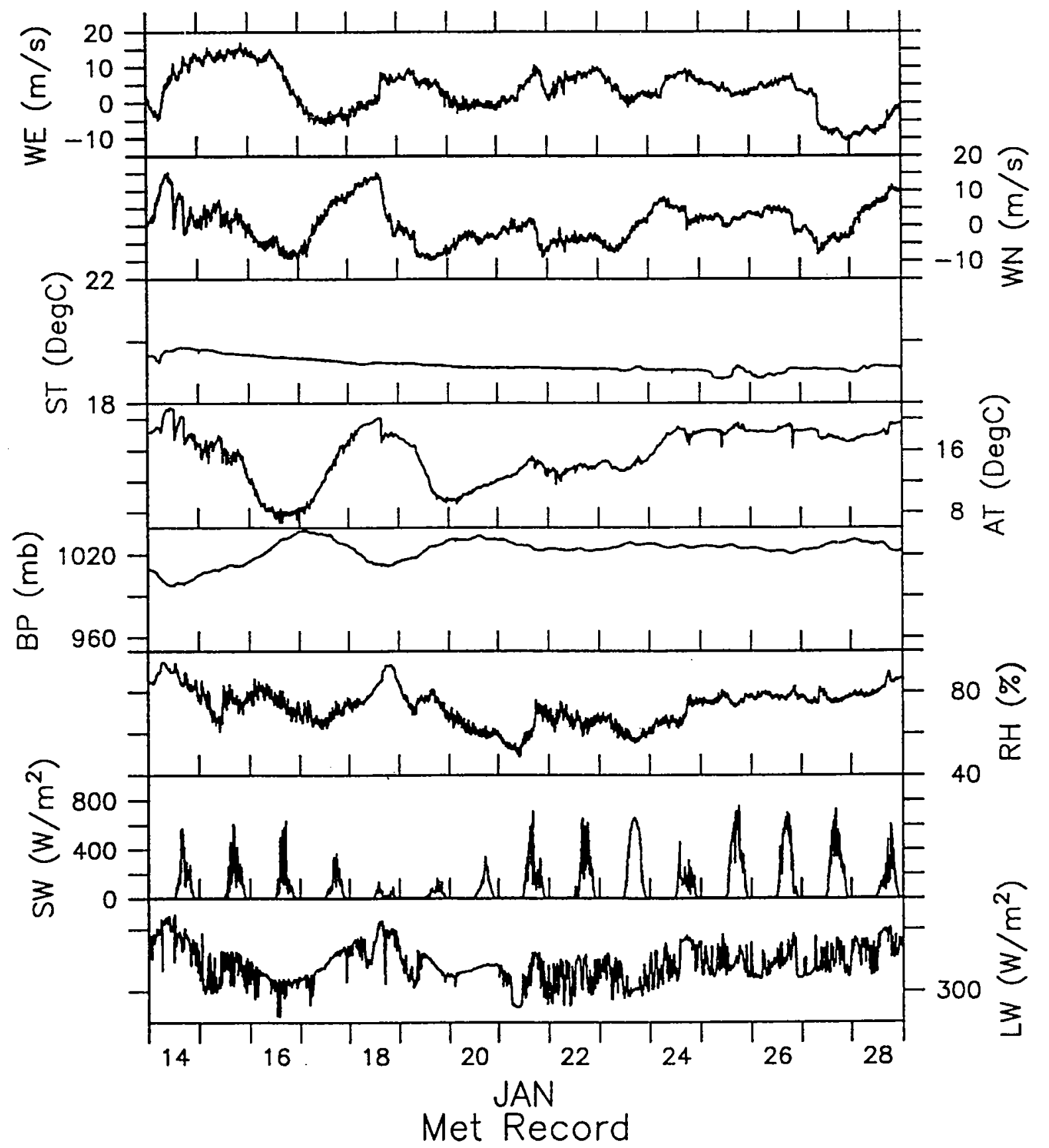

Figure 3.1.3: Meteorological Variables from the Composite Data Set. 


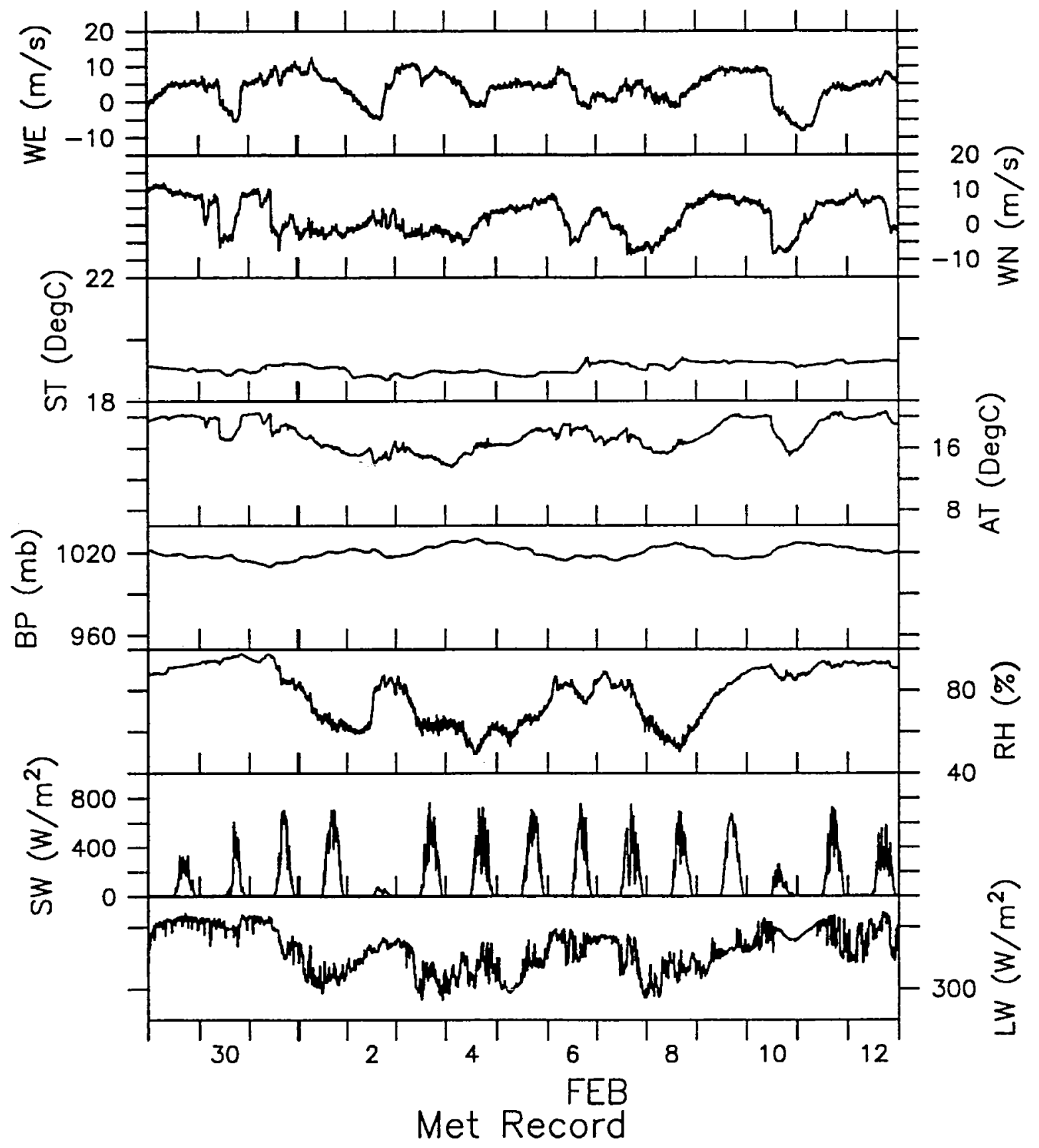

Figure 3.1.4: Meteorological Variables from the Composite Data Set. 


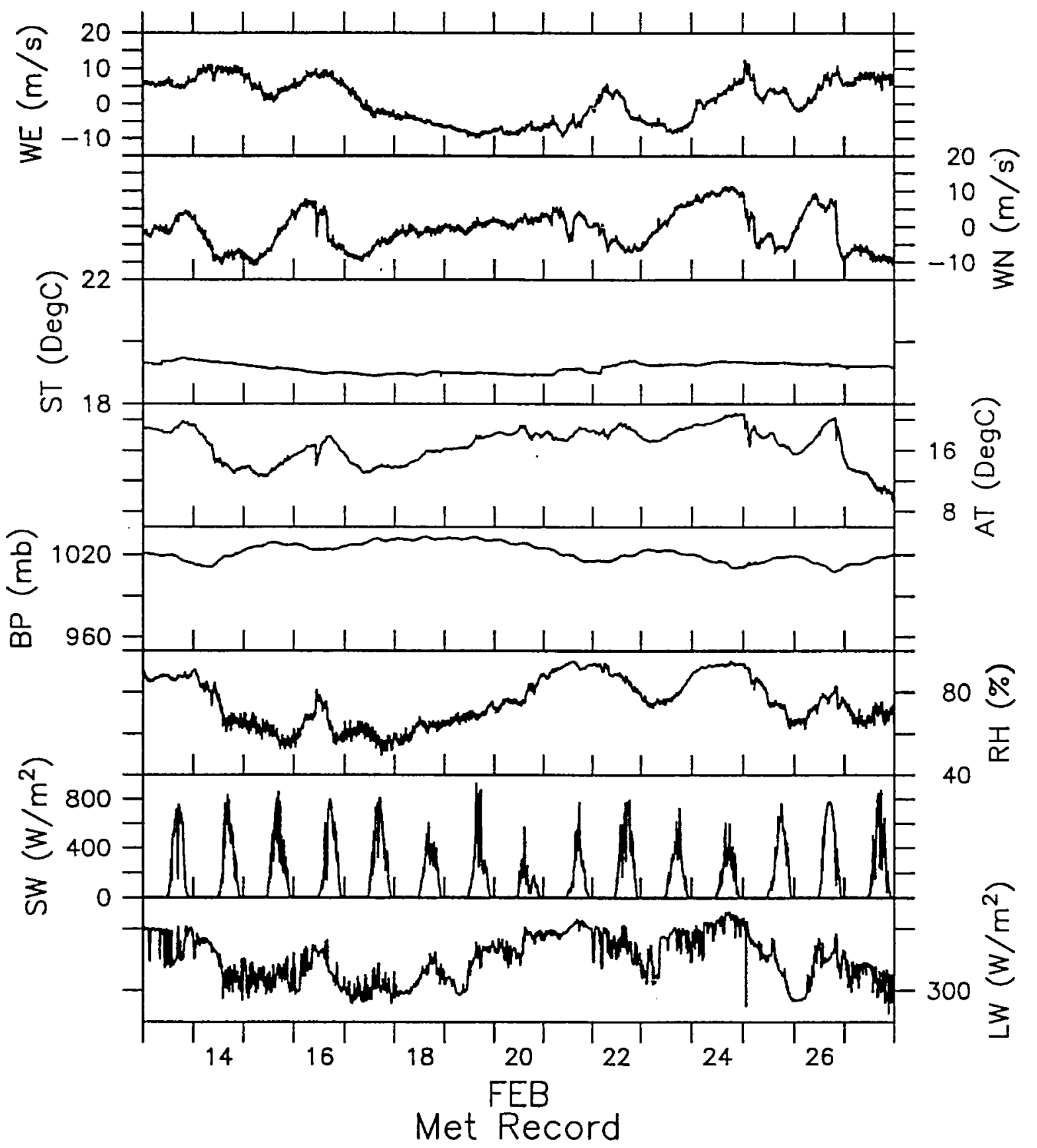

Figure 3.1.5: Meteorological Variables from the Composite Data Set. 


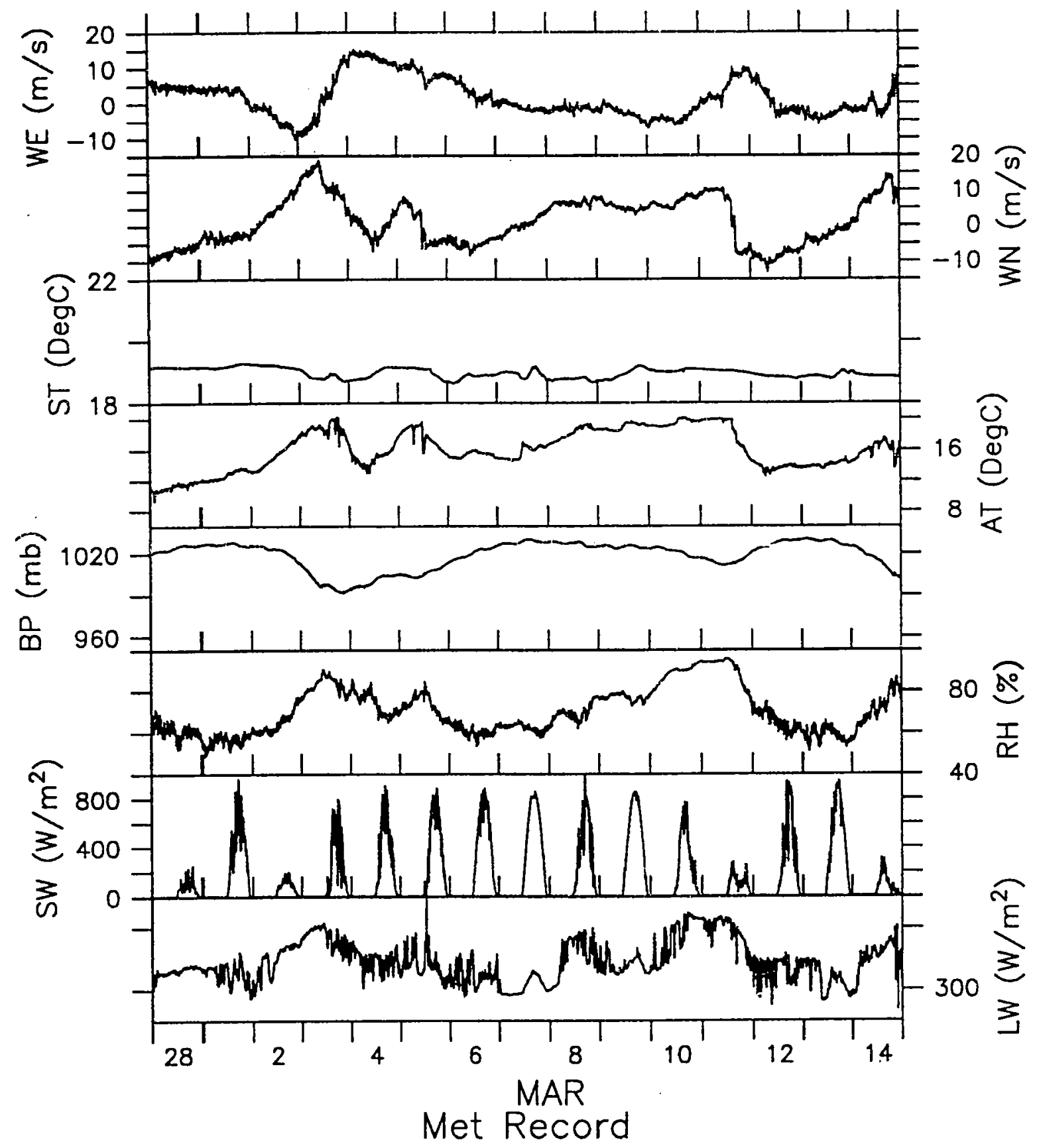

Figure 3.1.6: Meteorological Variables from the Composite Data Set. 


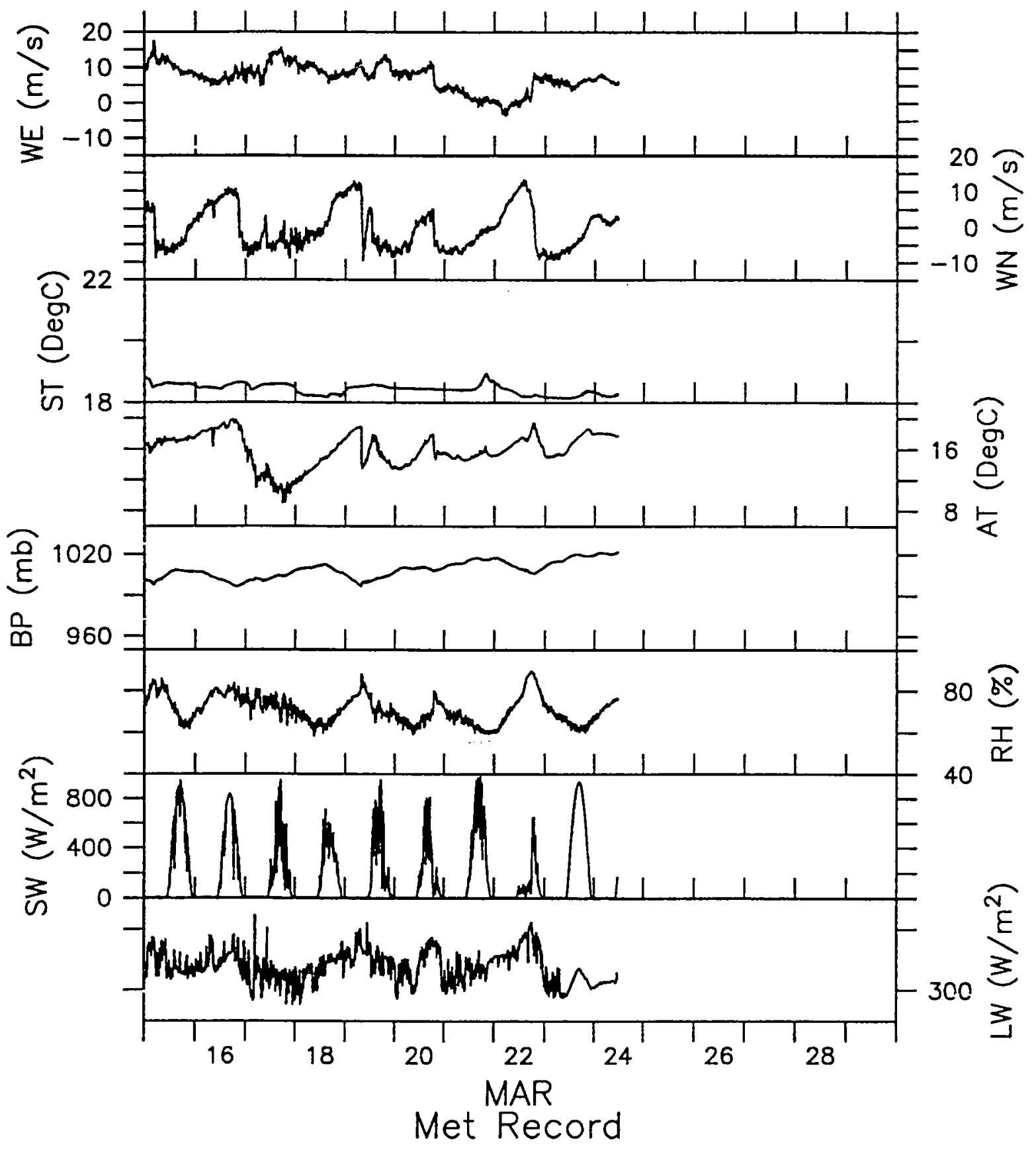

Figure 3.1.7: Meteorological Variables from the Composite Data Set. 


\section{WHOI VAWR Sensor Averaging Periods}

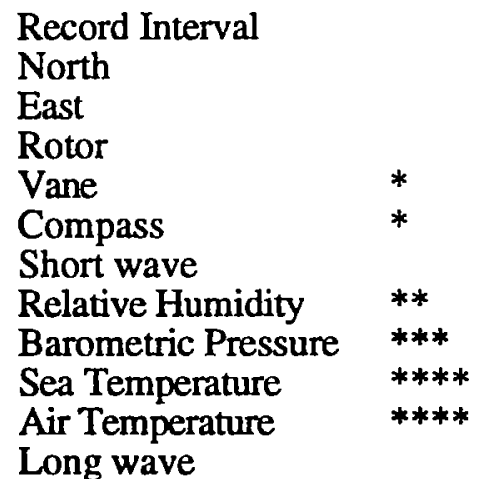

* Vane and Compass data recorded is the last sample taken in the record interval.

** Relative Humidity sensor is on for 7 seconds and counted for 3.515 seconds

*** Barometric Pressure sensor is on for 4.39 seconds and counted for 2.636 seconds

**** Air and Sea Temperature sensors are counted for $1 / 2$ the record interval. Actual averaging interval is half the record rate minus 1.7578125 seconds (delay and settle time between sensors)

Table 3.1.1: Schematic of VAWR sensor averaging periods.

\begin{tabular}{|c|c|c|c|}
\hline Parameter & Sensor Type & Accuracy & Record Time \\
\hline Wind Speed & $\begin{array}{l}\text { R.M.Young } 3 \text { cup } \\
\text { anemometer }\end{array}$ & $\begin{array}{l}+/-2 \% \\
\text { above } 0.7 \mathrm{~m} / \mathrm{s}\end{array}$ & Vector Averaged \\
\hline Wind Direction & Integral vane WHOI/EG\&G & $+/-1$ bit 5.6 degrees & Vector Averaged \\
\hline $\begin{array}{l}\text { Short Wave } \\
\text { Radiation }\end{array}$ & Pyranometer Eppley 8-48 & $+1-3 \%$ & $\begin{array}{l}\text { Averaged over } \\
\text { record interval }\end{array}$ \\
\hline $\begin{array}{l}\text { Long Wave } \\
\text { Radiation }\end{array}$ & $\begin{array}{l}\text { Pyrgeometer } \\
\text { Eppley PIR }\end{array}$ & $+/-10 \%$ & $\begin{array}{l}\text { Averaged over } \\
\text { record interval }\end{array}$ \\
\hline $\begin{array}{l}\text { Relative } \\
\text { Humidity }\end{array}$ & Vaisala umicap 0062HMP & $+1-2 \%$ & $\begin{array}{l}3.515 \text { Seconds } \\
\text { Average } \\
\text { Note 1 }\end{array}$ \\
\hline $\begin{array}{l}\text { Barometric } \\
\text { Pressure }\end{array}$ & $\begin{array}{l}\text { Paroscientific } \\
216-\mathrm{B}-101\end{array}$ & $\begin{array}{l}+/-0.2 \mathrm{mbar} \\
\text { wind }<2 . \mathrm{m} / \mathrm{s}\end{array}$ & $\begin{array}{l}2.636 \text { Seconds } \\
\text { Average } \\
\text { Note } 1\end{array}$ \\
\hline Sea Temperature & $\begin{array}{l}\text { Thermistor } \\
\text { Thermometrics }\end{array}$ & $\begin{array}{l}+/-0.005 \\
\text { degrees } C\end{array}$ & $\begin{array}{l}\text { Averaged over } \\
\text { record time } \\
\text { Note } 2\end{array}$ \\
\hline Air Temperature & $\begin{array}{l}\text { Thermistor } \\
\text { Yellow Springs \#44034 }\end{array}$ & $\begin{array}{l}+/-0.2 \\
\text { degrees C } \\
\text { wind }>5 \mathrm{~m} / \mathrm{s}\end{array}$ & $\begin{array}{l}\text { Averaged over } \\
1 / 2 \text { record time } \\
\text { Note } 3\end{array}$ \\
\hline
\end{tabular}

Table 3.1.2: Meteorological Sensor Specifications, VAWR 
approximately $20 \%$ of the records. In order to reconstruct the wind direction during the remainder of the experiment, the following procedure was applied:

1. A "first guess" based on the VAWR wind speed and the orientation of the buoy was calculated.

2. Points where the IMET wind direction deviated from the first guess by more than 90 degrees, or the IMET wind speed differed from 0.91 of the VAWR wind speed by more than $2 \mathrm{~m} / \mathrm{s}$, were interpolated.

3. Any remaining "spikes" (defined as a 1-point deviation in the east or north IMET wind by more than $2 \mathrm{~m} / \mathrm{s}$ ) were interpolated over.

The resulting time series of wind direction was found to agree extremely well with the observed wind direction from the VAWR (rms difference of $\sim 2$ degrees) during the time period when this parameter was available. Additionally, the synthetic wind direction agreed very well with the high frequency $(3-4 \mathrm{sec})$ wave direction over the course of the experiment. This gives us strong confidence that the synthetic time series accurately represents the real wind.

\section{Air-Sea Fluxes}

Fluxes of momentum, sensible heat, and latent heat for the site were computed from the meteorological variables using the stability-dependent bulk aerodynamic formulae of Large and Pond $(1981 ; 1982)$. The net short wave radiation is computed using an albedo of 0.06 . The net long wave radiation is estimated using sea surface temperature assuming a sea-surface which radiates with an emissivity of 0.98 .

Time series of the heat fluxes computed from the composite meteorological data set are shown in Figures 3.1.8-3.1.14. From top to bottom, the sensible, latent, net short wave, net long wave and total heat flux in $\mathrm{W} / \mathrm{m}^{2}$ are shown. Figures 3.1.15-3.1.21 show the wind stress time series computed from the composite meteorological data set. Shown from top to bottom are the eastward wind stress, northward wind stress, wind stress magnitude, wind stress direction (towards), and the nondimensional stability parameter $z / L$. ( $L$ is the Monin-Obhukhov length $-c_{p} T u^{3} * k g Q$, where $c_{p}$ is the specific heat, $T$ is the temperature, $u^{*}$ the friction velocity, $g$ is gravity, $k$ is the Von Karman constant, and $Q$ is the heat gained by the atmosphere from the ocean). Large negative values of $L$ mean that the atmospheric boundary layer is convectively unstable, so that the shear of the velocity is reduced from a logarithmic profile.

Figure 3.1.22 shows the rotary spectrum of the wind stress (solid represents clockwise rotation, dashed counterclockwise rotation), and the spectrum of the sea-surface temperature, air temperature, short wave radiation, barometric pressure and relative humidity. Other than the short wave radiation, which shows a distinct set of peaks at the first, second, and third harmonics of the diurnal frequency, there are no significant peaks. 


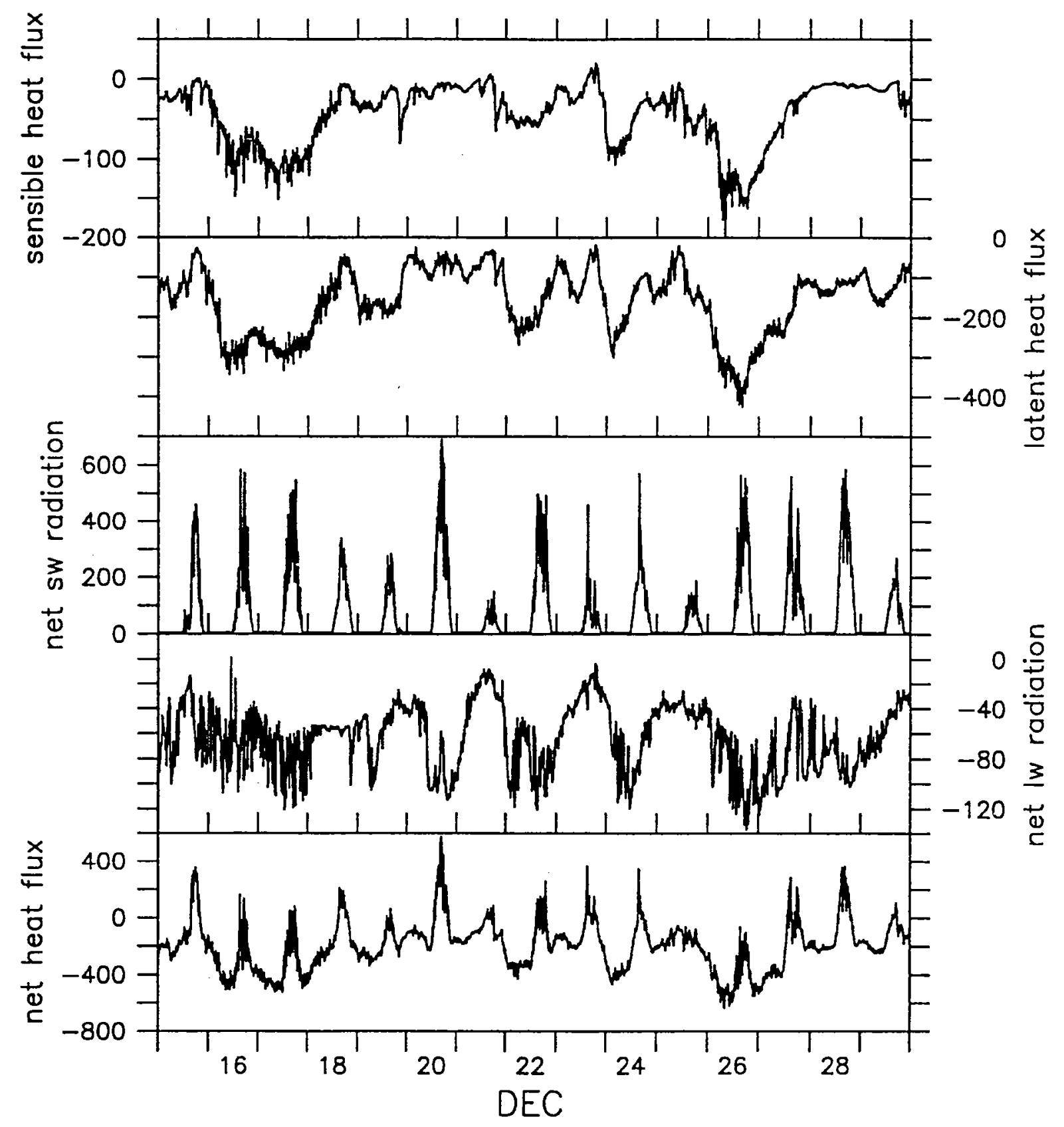

Heat Flux

Figure 3.1.8: Heat Flux Time Series from the Composite Data Set. 


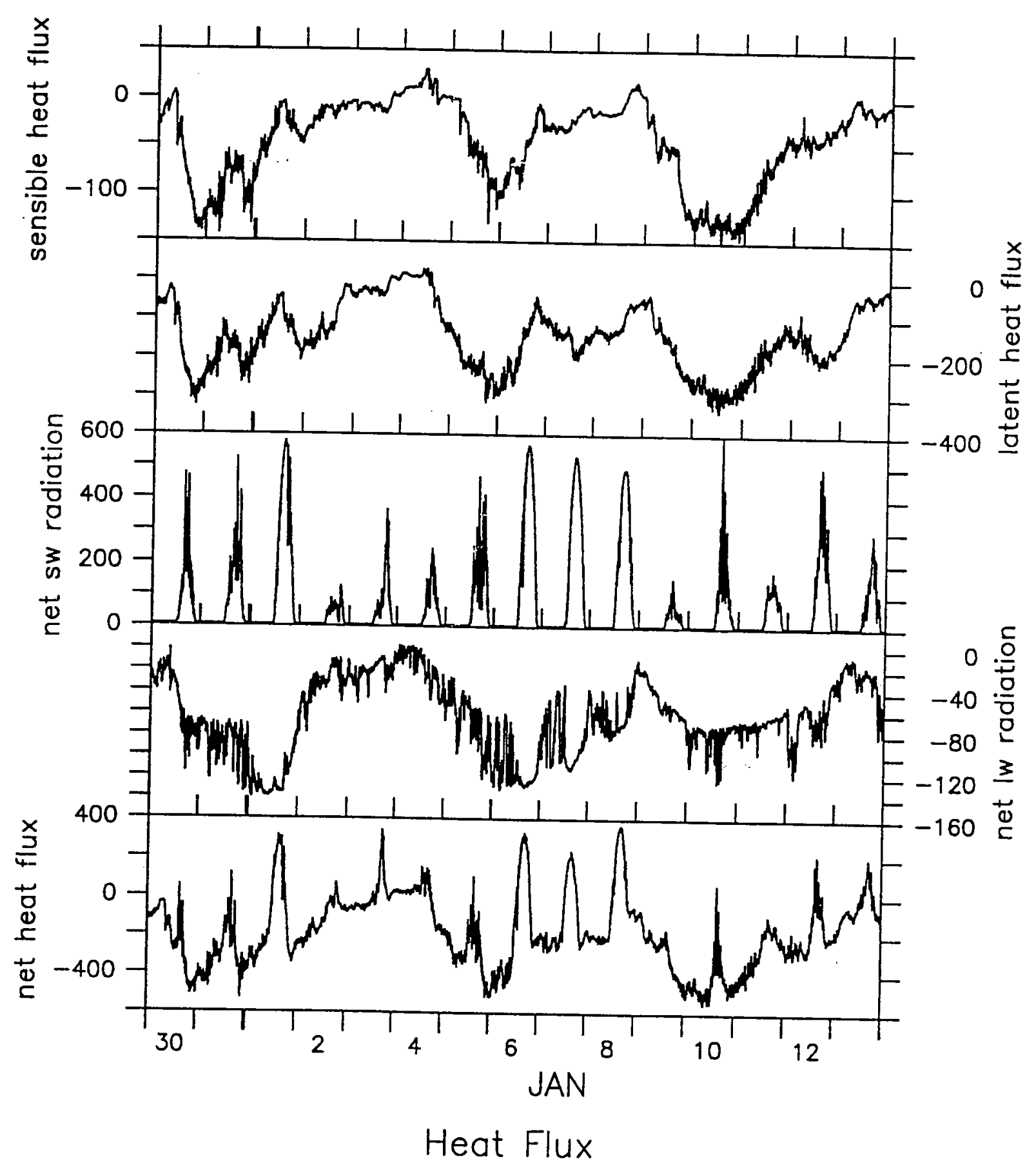

Figure 3.1.9: Heat Flux Time Series from the Composite Data Set. 


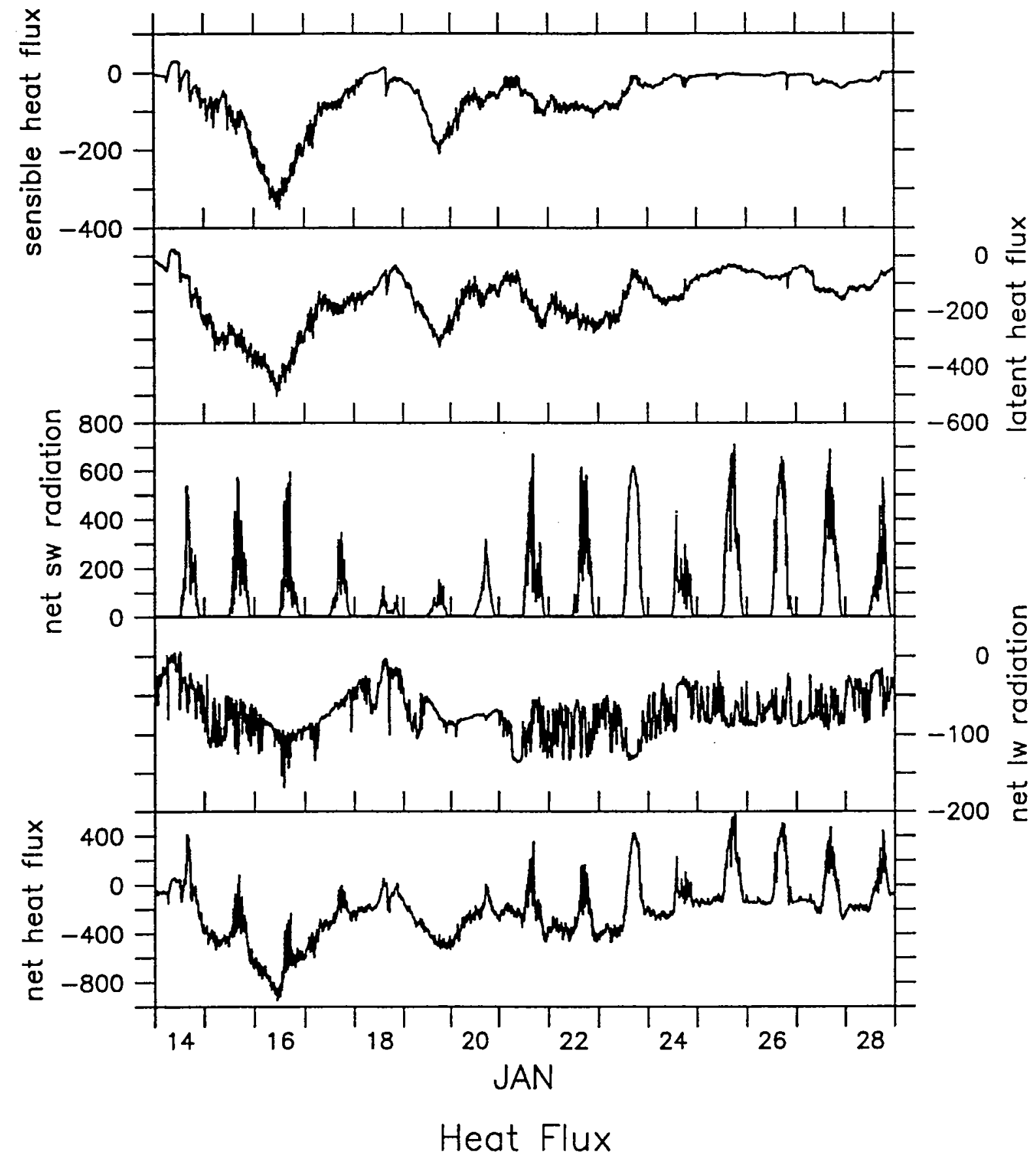

Figure 3.1.10: Heat Flux Time Series from the Composite Data Set. 


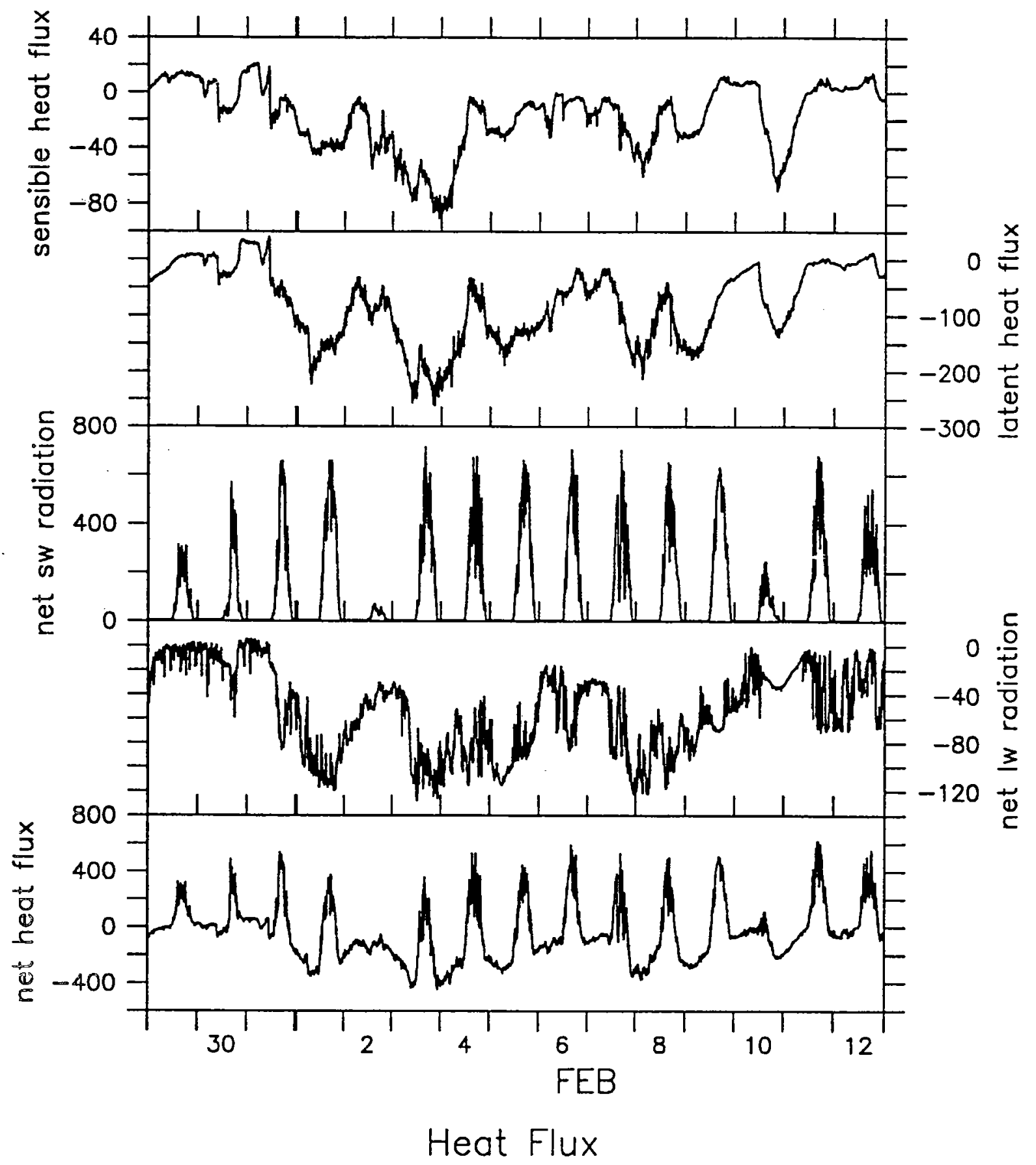

Figure 3.1.11: Heat Flux Time Series from the Composite Data Set. 


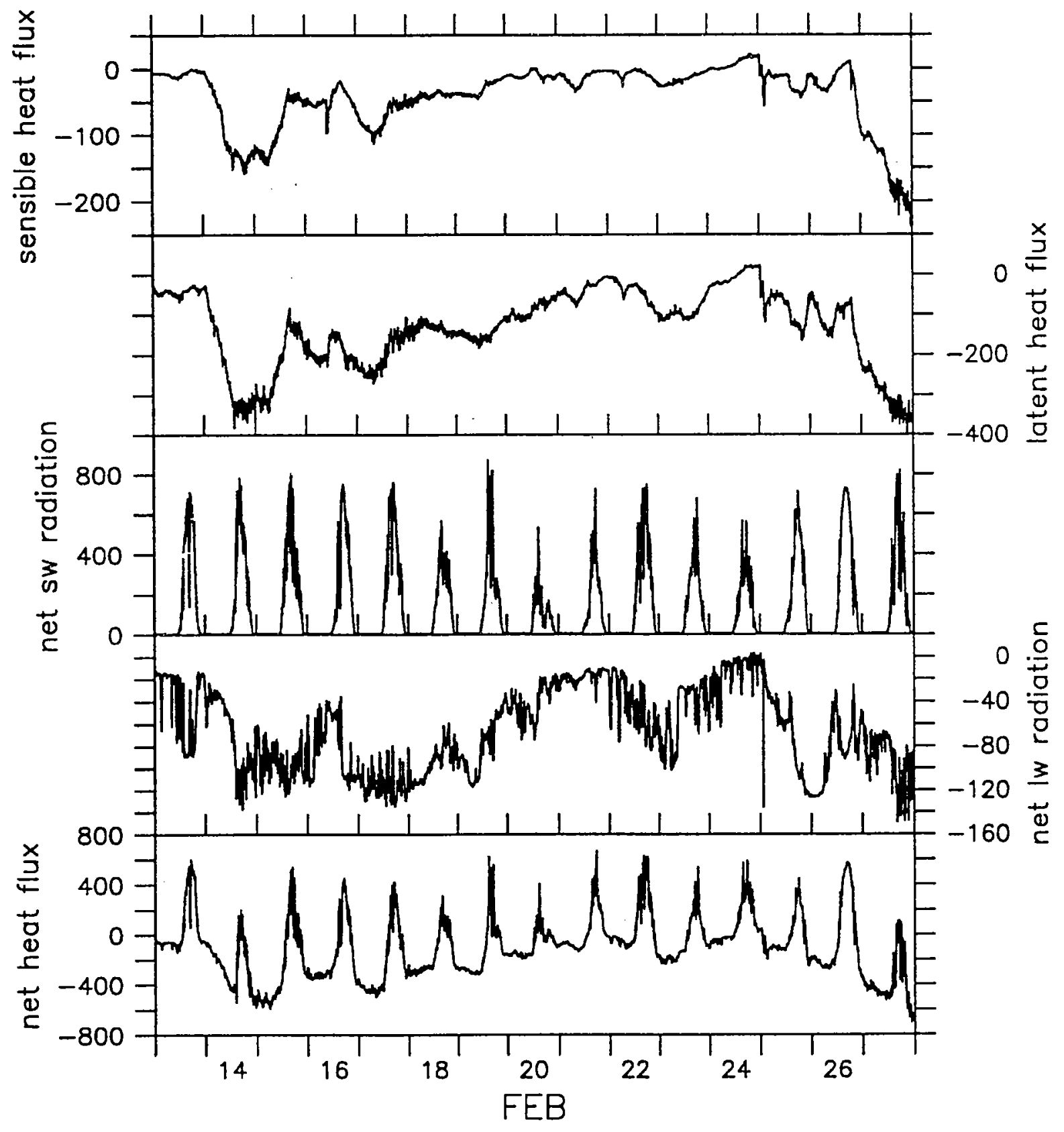

Heat Flux

Figure 3.1.12: Heat Flux Time Series from the Composite Data Set. 


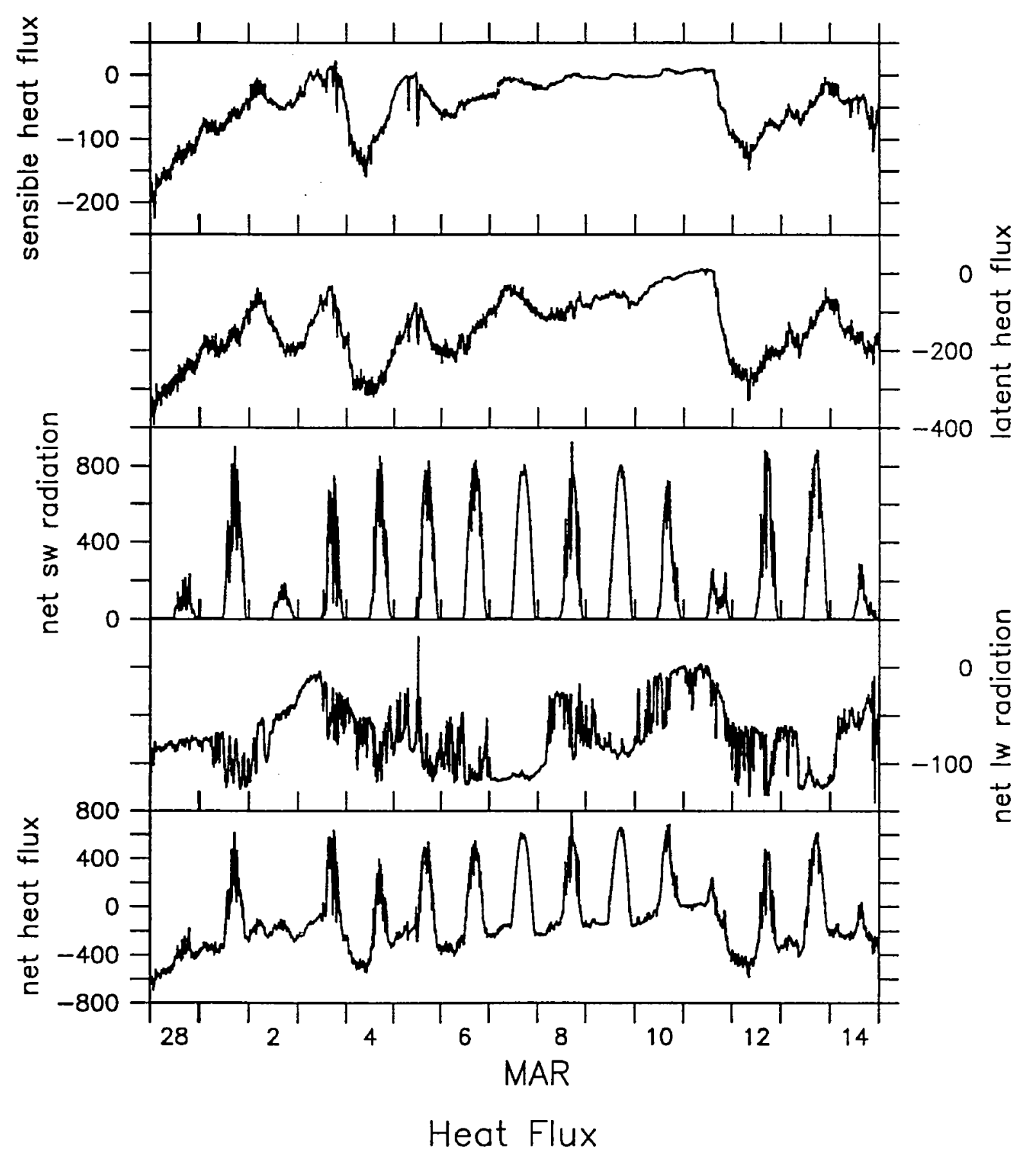

Figure 3.1.13: Heat Flux Time Series from the Composite Data Set. 


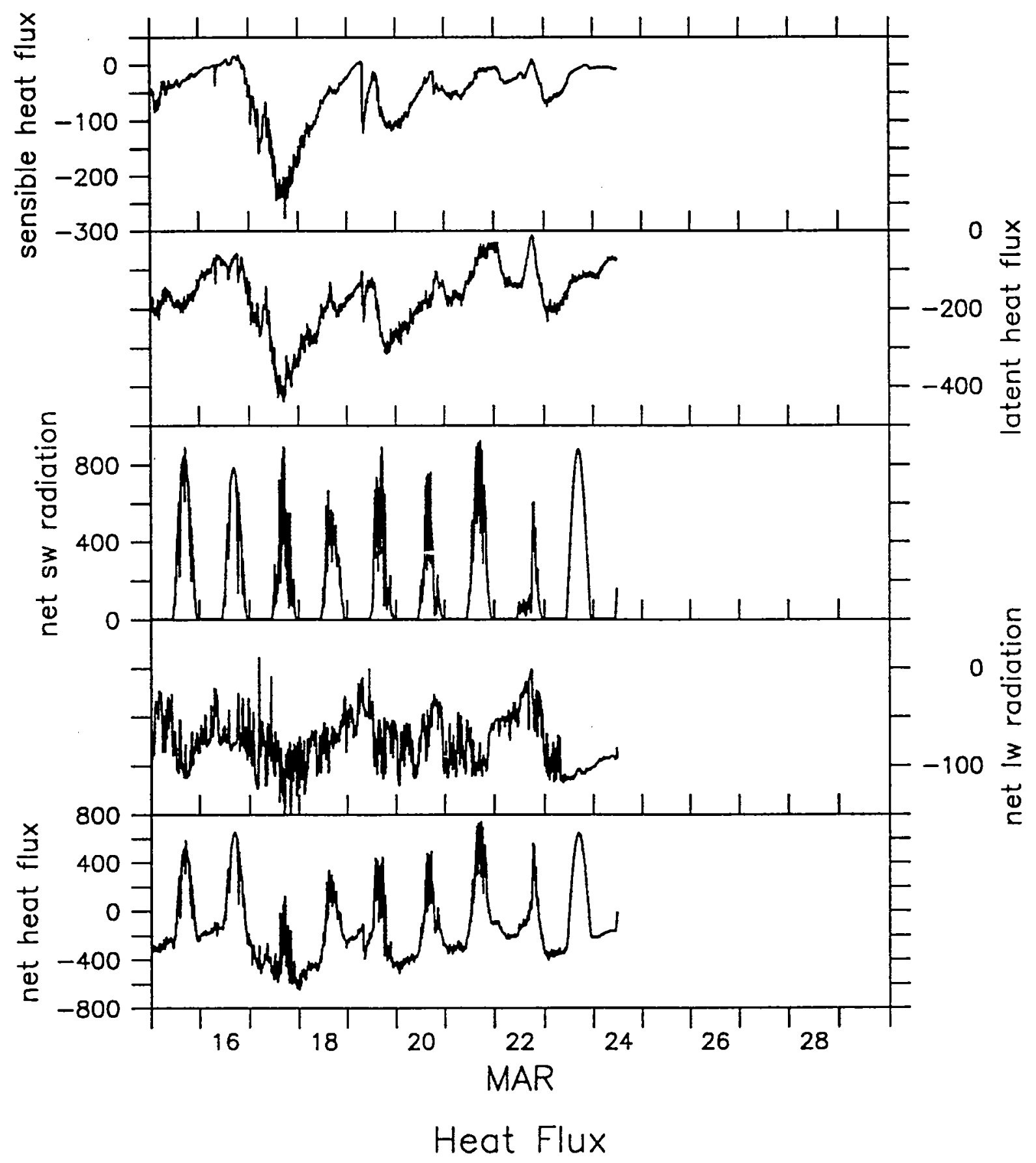

Figure 3.1.14: Heat Flux Time Series from the Composite Data Set. 


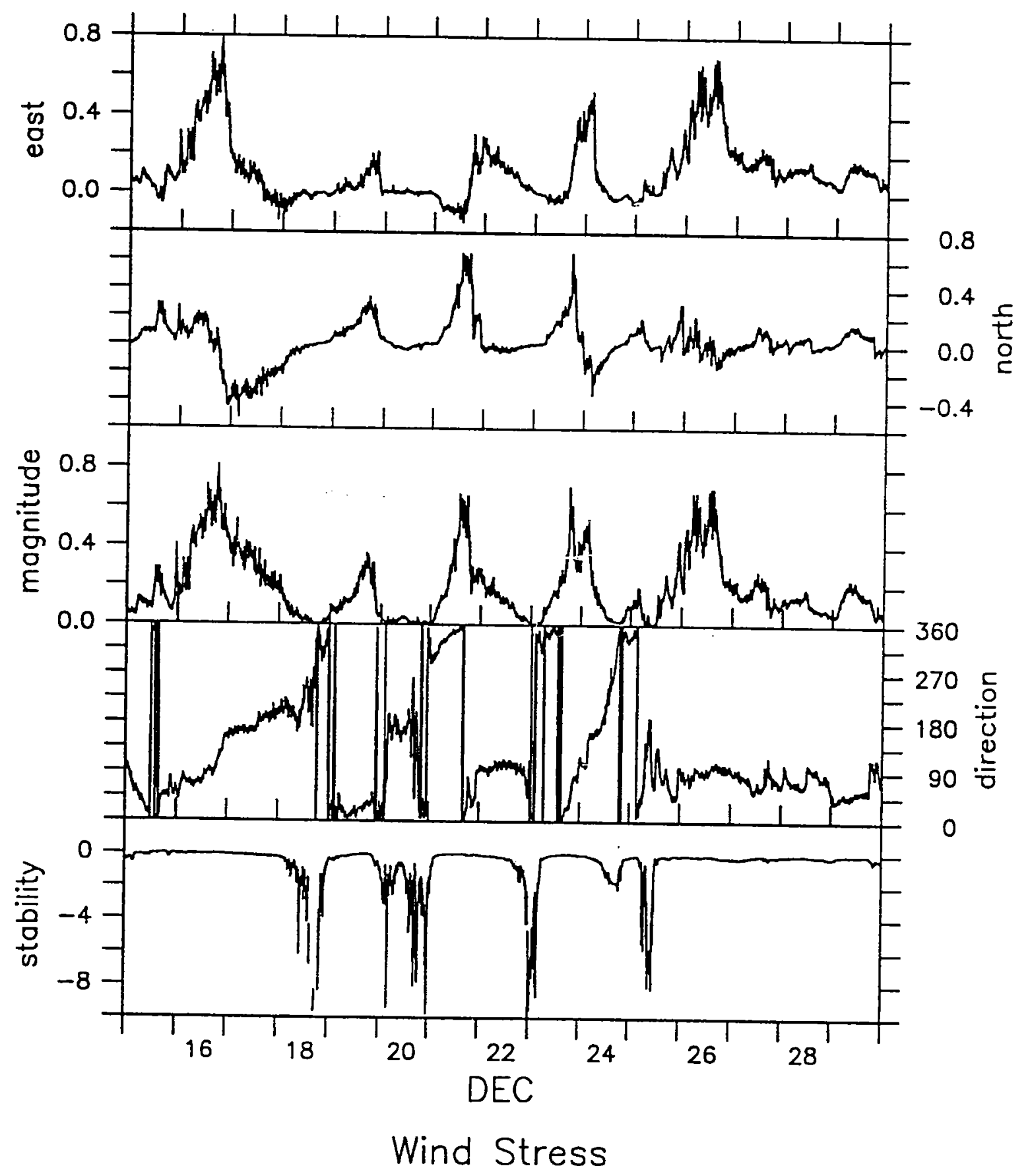

Figure 3.1.15: Wind Stress Time Series from the Composite Data Set. 


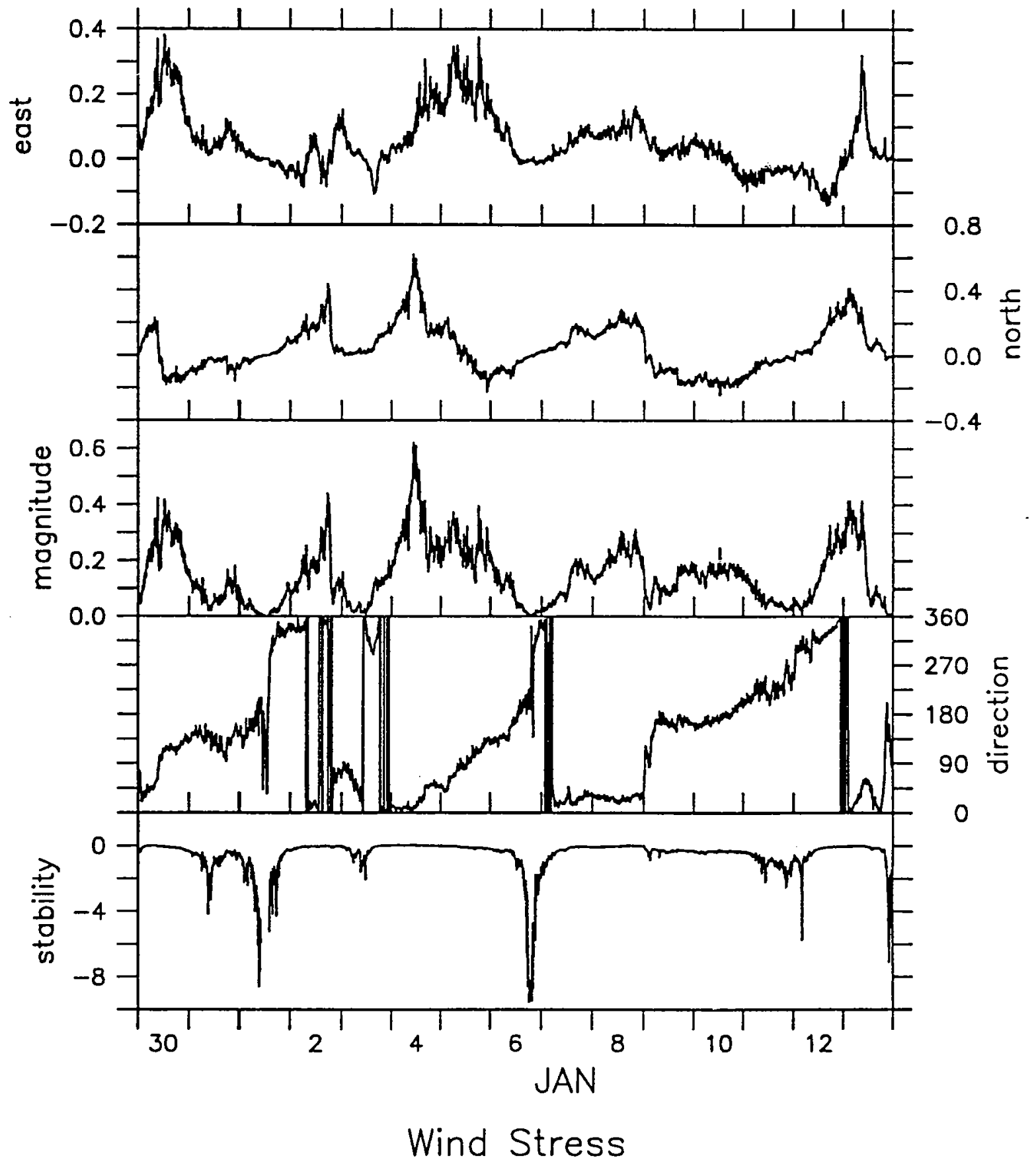

Figure 3.1.16: Wind Stress Time Series from the Composite Data Set. 


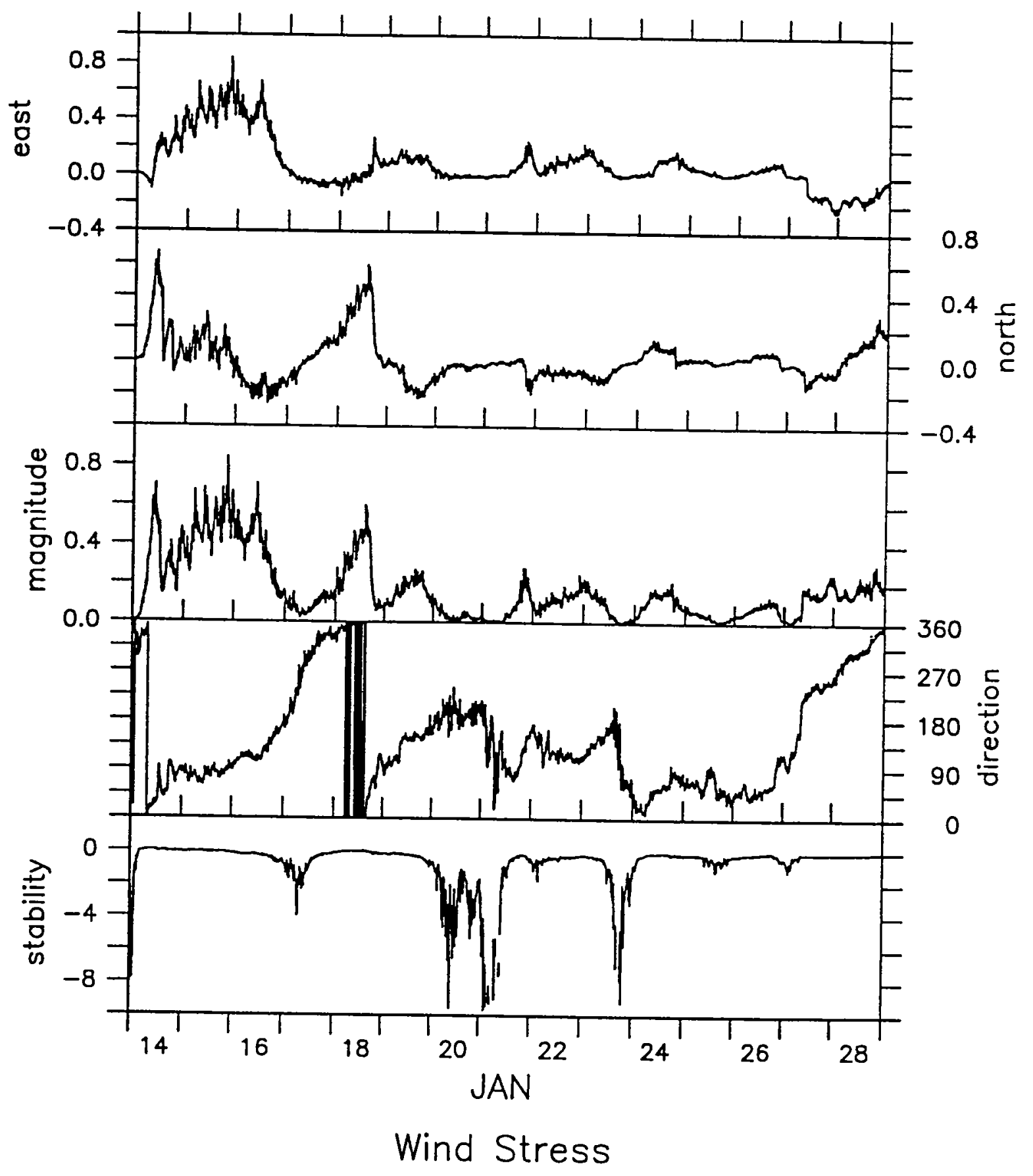

Figure 3.1.17 Wind Stress Time Series from the Composite Data Set. 


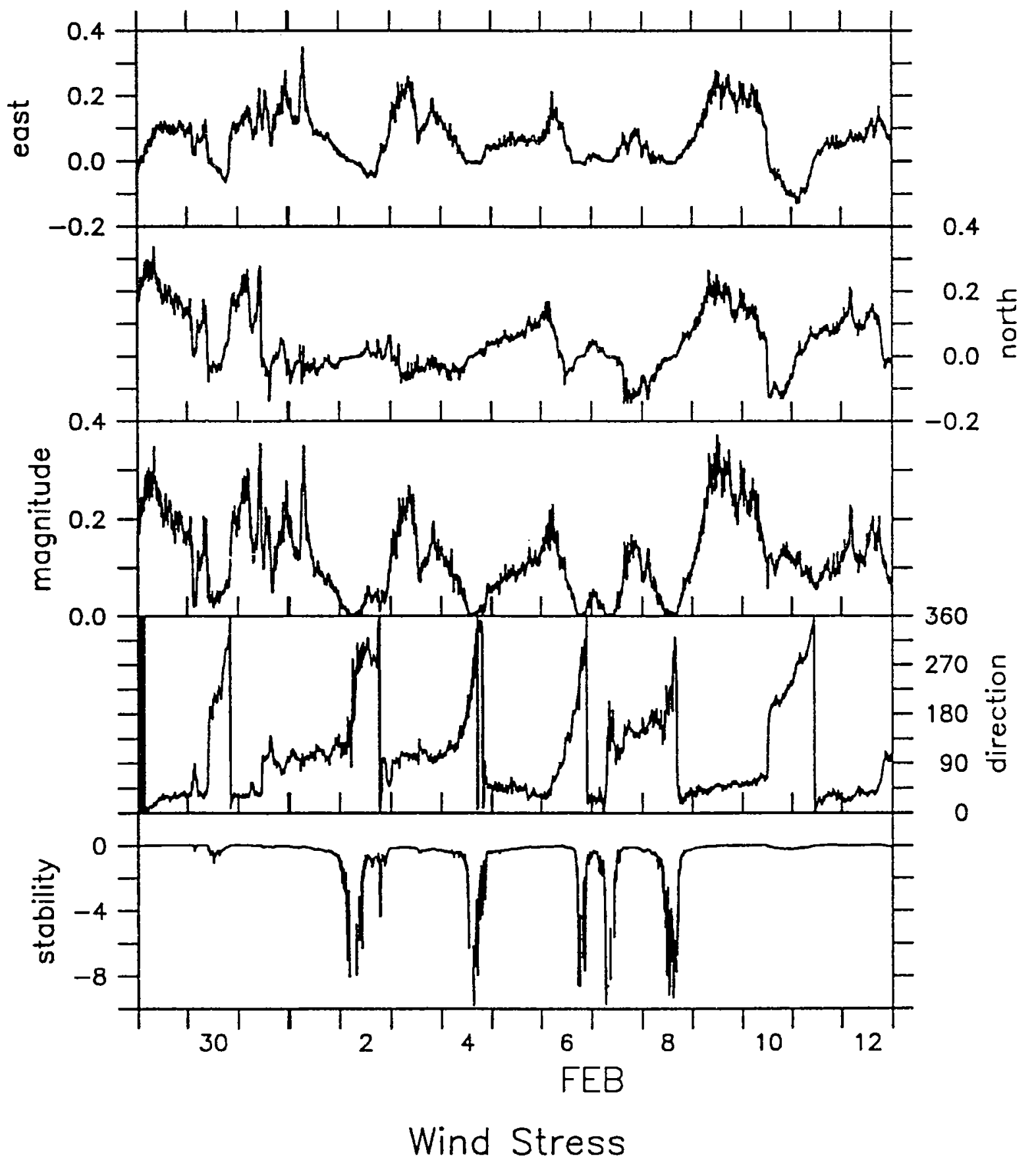

Figure 3.1.18 Wind Stress Time Series from the Composite Data Set. 


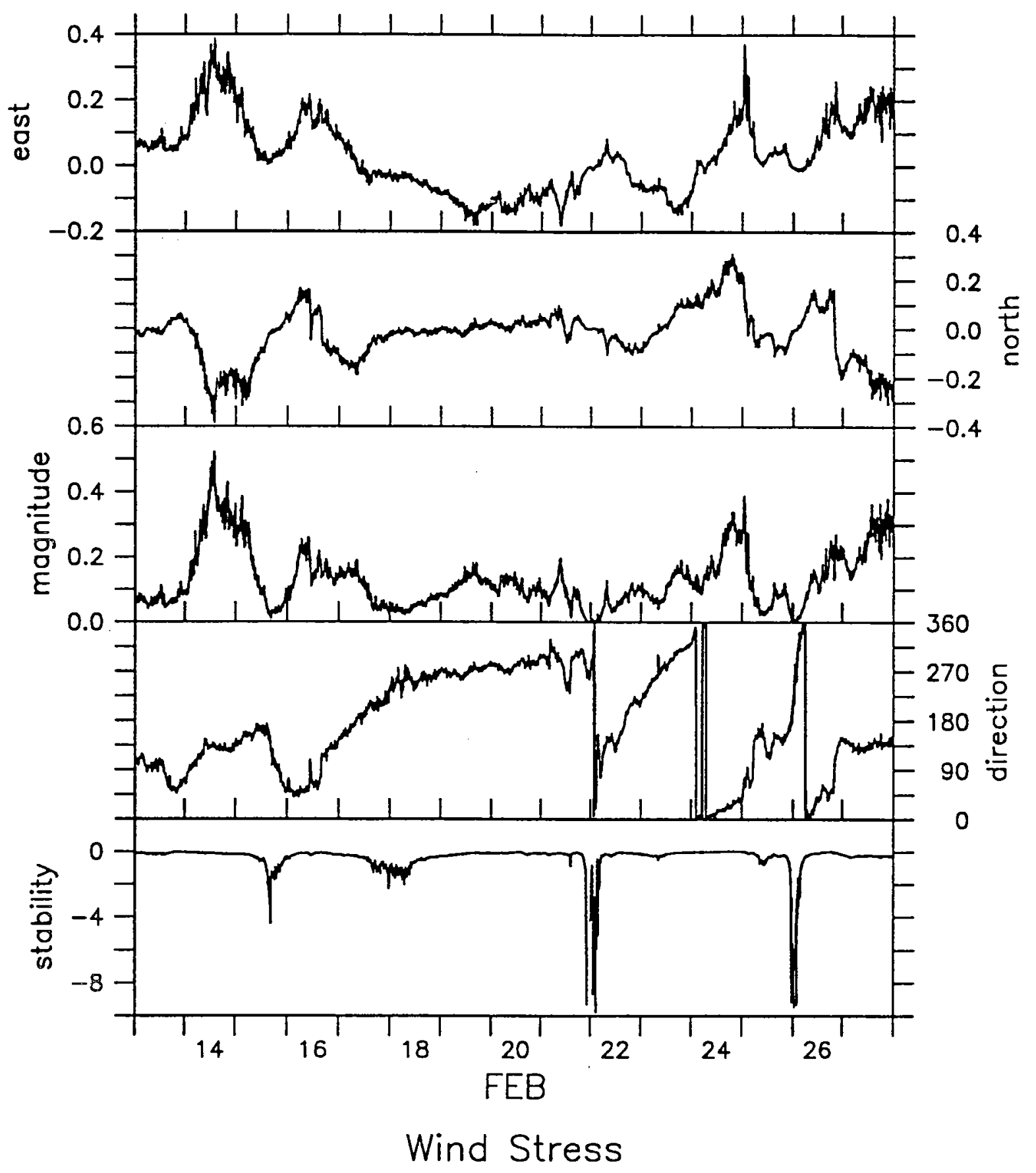

Figure 3.1.19 Wind Stress Time Series from the Composite Data Set. 


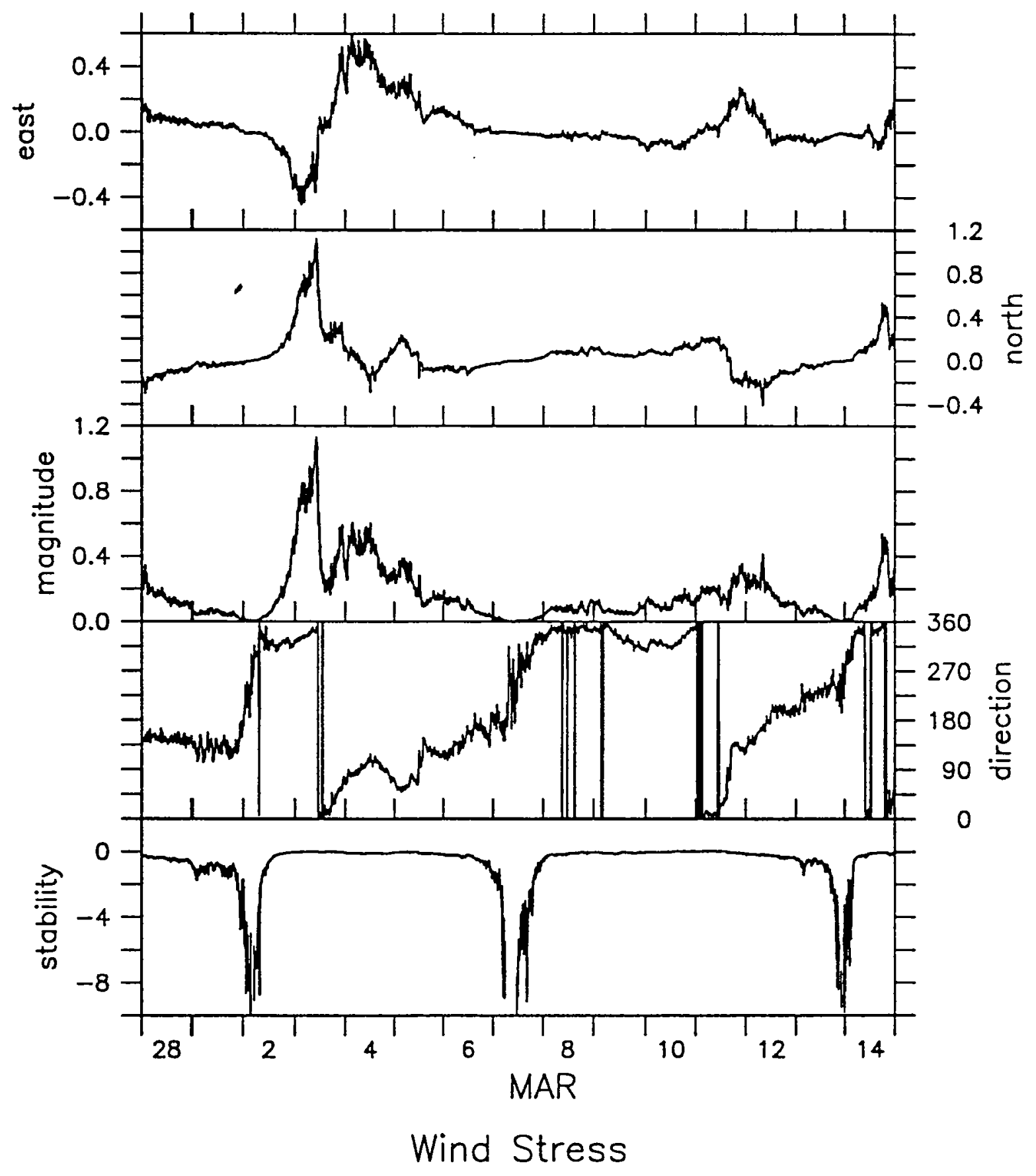

Figure 3.1.20 Wind Stress Time Series from the Composite Data Set. 


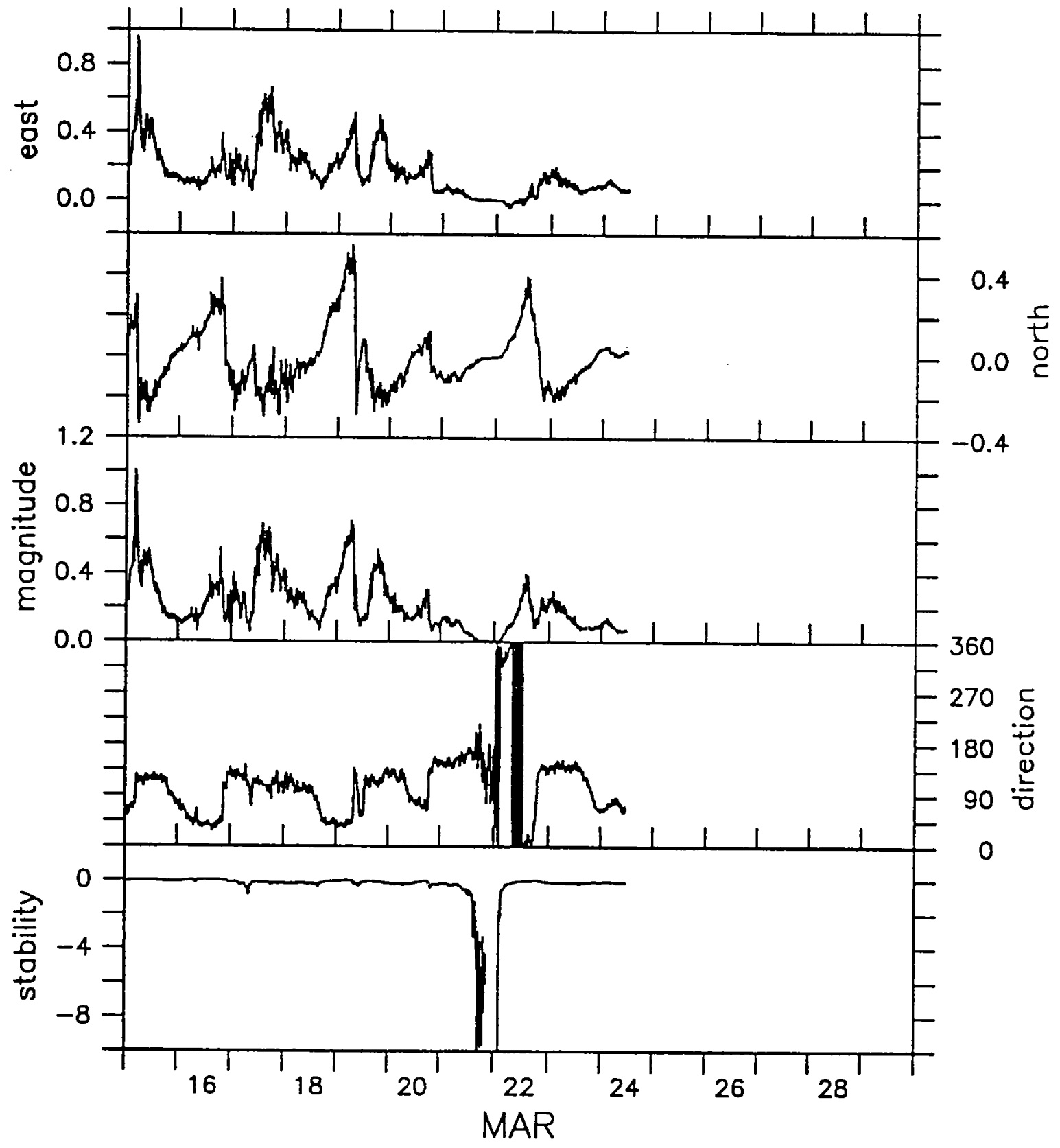

Wind Stress

Figure 3.1.21 Wind Stress Time Series from the Composite Data Set. 

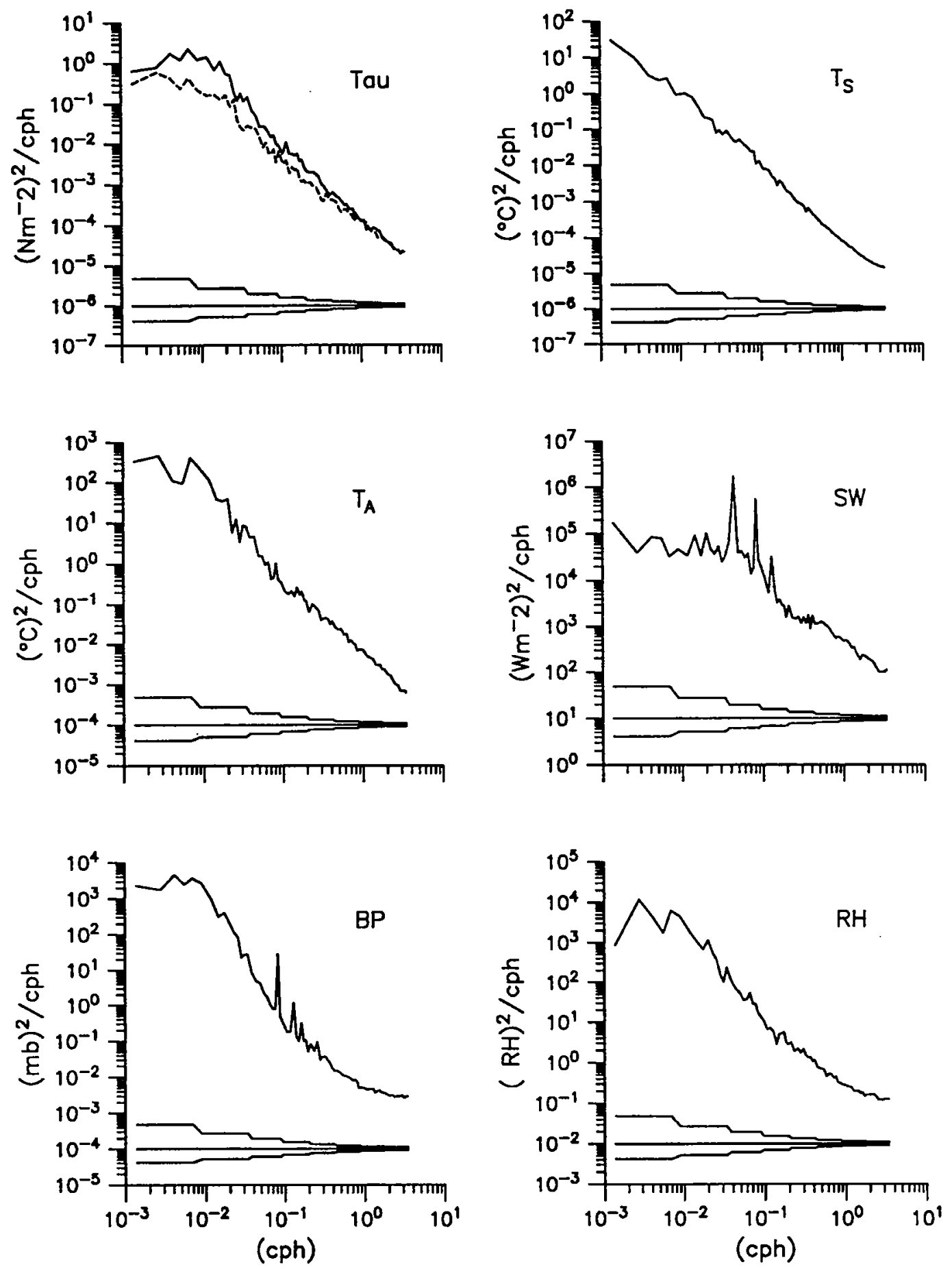

Figure 3.1.22: Autospectra of wind stress, air temperature, barometric pressure, sea surface temperature, insolation, and relative humidity from the composite data set. Rotary autospectra are shown for wind stress; solid curves show the clockwise component, and dashed curves show the counter-clockwise 


\subsection{Temperature and Density Structure during ASREX III}

Sea temperatures were measured by the VAWR, by twelve Brancker temperature recorders (TPODs) two of which were on the bridle at a depth of $1 \mathrm{~m}$, the remainder on the mooring line at depths of $37,75,125,175,200,230,260,300,350$, and $400 \mathrm{~m}$, by two Seabird Seacats at depths of 1 and $450 \mathrm{~m}$, and by eight Vector Measuring Current Meters (VMCMs) at 5,10,15,20,50,150,300 and $500 \mathrm{~m}$. VMCMs recorded data every 120 seconds, Seacats every 225 seconds, and TPODs recorded every 7.5 minutes.

Each temperature was calibrated in the lab before and after the experiment. There was an improvement made to the calibration procedure for the TPODs during this experiment, and therefore the post-cruise calibrations for those instruments was used in the final processing. Both VMCM and Seacat temperatures calculated with pre-deployment calibrations matched surrounding instrument data, so pre-deployment calibrations were used for those instruments.

Figure 3.2.1 is a contour plot of all the temperature data from the moored array instruments. Data was filtered using a 24-hour running mean to remove the semidiurnal tide signal, and subsampled at 2-hour intervals to produce a uniform time-series for the contour plot.

Time-series and spectra of temperature at each depth are presented in Figures 3.2.2 through 3.2.23. In the upper frame of each of these plots, temperature is represented along the $y$ axis and time (UTC) along the $x$ axis. The lower frame contains the spectra. The long arrows on the lower frames indicate the frequency of the semidiurnal tidal peak and the short arrows show the frequency of the Coriolis peak. Confidence limits are displayed at the bottom of the frame. Captions indicate instrument type and depth. Unlike the previous plot, the data here is not smoothed, so that the strong signals associated with the semidiurnal tides are readily visible.

A Seacat with a pressure sensor was used to collect profile data shortly before deployment and shortly after recovery of the moored array. There were 4 pre-deployment casts, one to 400 $\mathrm{m}$ and 3 to about $150 \mathrm{~m}$. The post-recovery cast was to a depth of $475 \mathrm{~m}$. Although the Seacat recorded temperature, salinity, and density, the salinity and density records were too noisy to be of use. Temperature profiles from these casts are shown in Figure 3.2.24. Salinity and density values recorded by the instrument are not included because the data quality was poor due to different sensors' time-constants.

The moored instrument temperature records in the upper 75 meters of the water column show relatively little short-time variability. The temperature records between depths of 100 and 260 meters exhibit rapid changes as the instruments move in and out of the mixed layer as the result of tidal and inertial motions. 


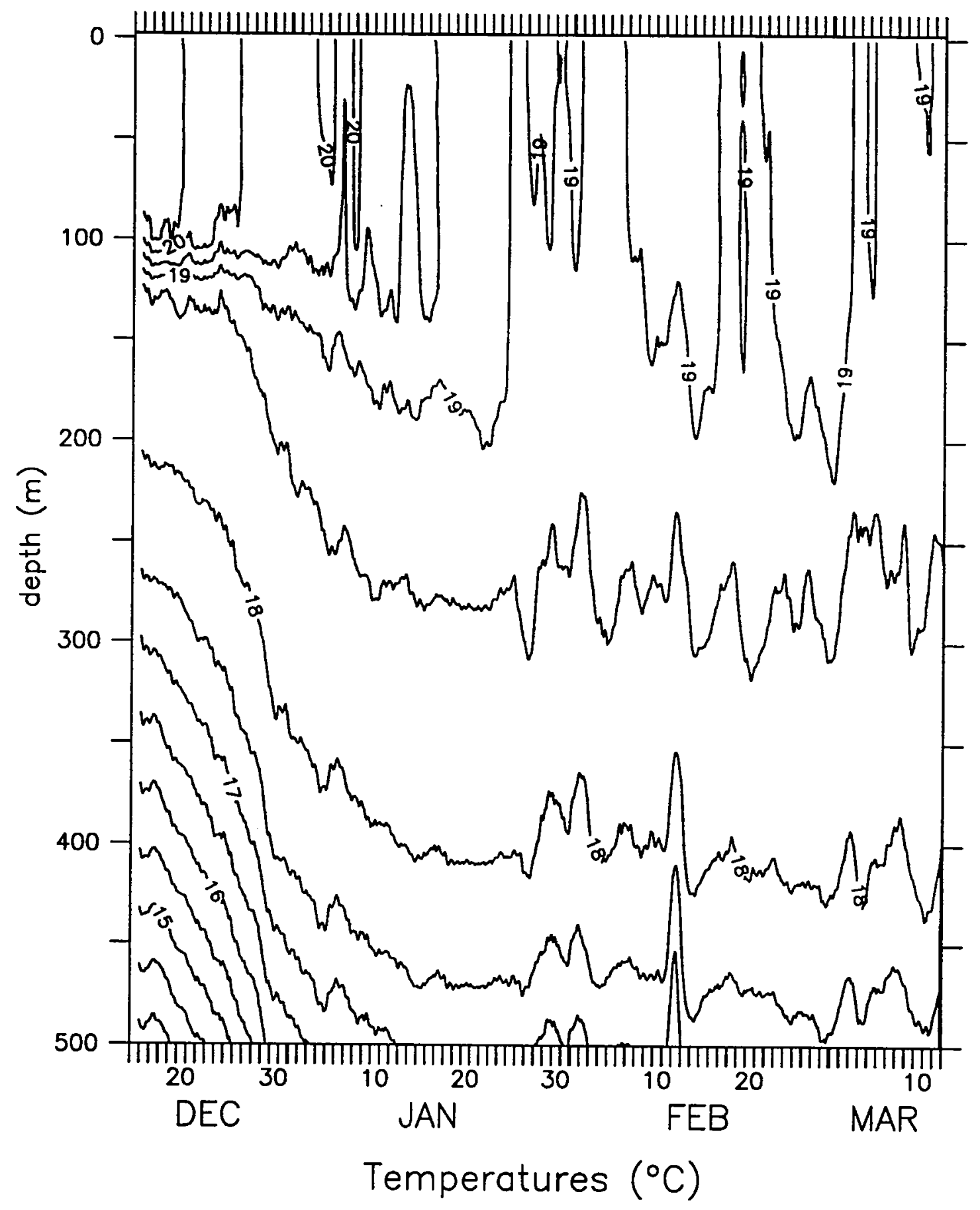

Figure 3.2.1: Temperature Contours from instruments at 1, 5, 10, 15, $20,37,50,75,100,125,150,175,200,230,260,300,350,400$, 450 , and $500 \mathrm{~m}$. 


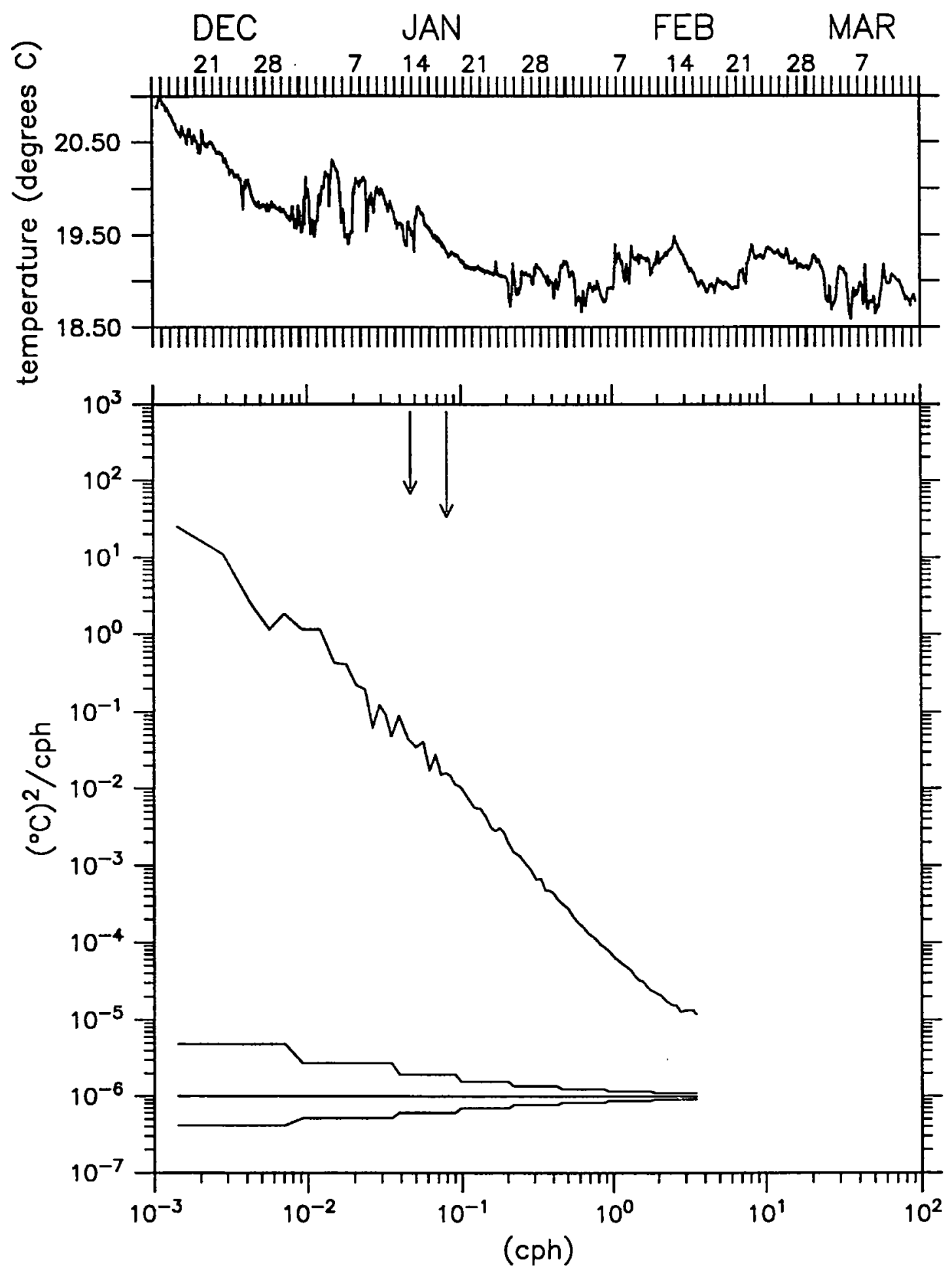

tpod 4481 ot $1.0 \mathrm{~m}$

Figure 3.2.2: Temperature Time Series and Spectra at $1 \mathrm{~m}$. Long arrow indicates semi-diurnal tidal frequency, short arrow indicates Coriolis frequency. 


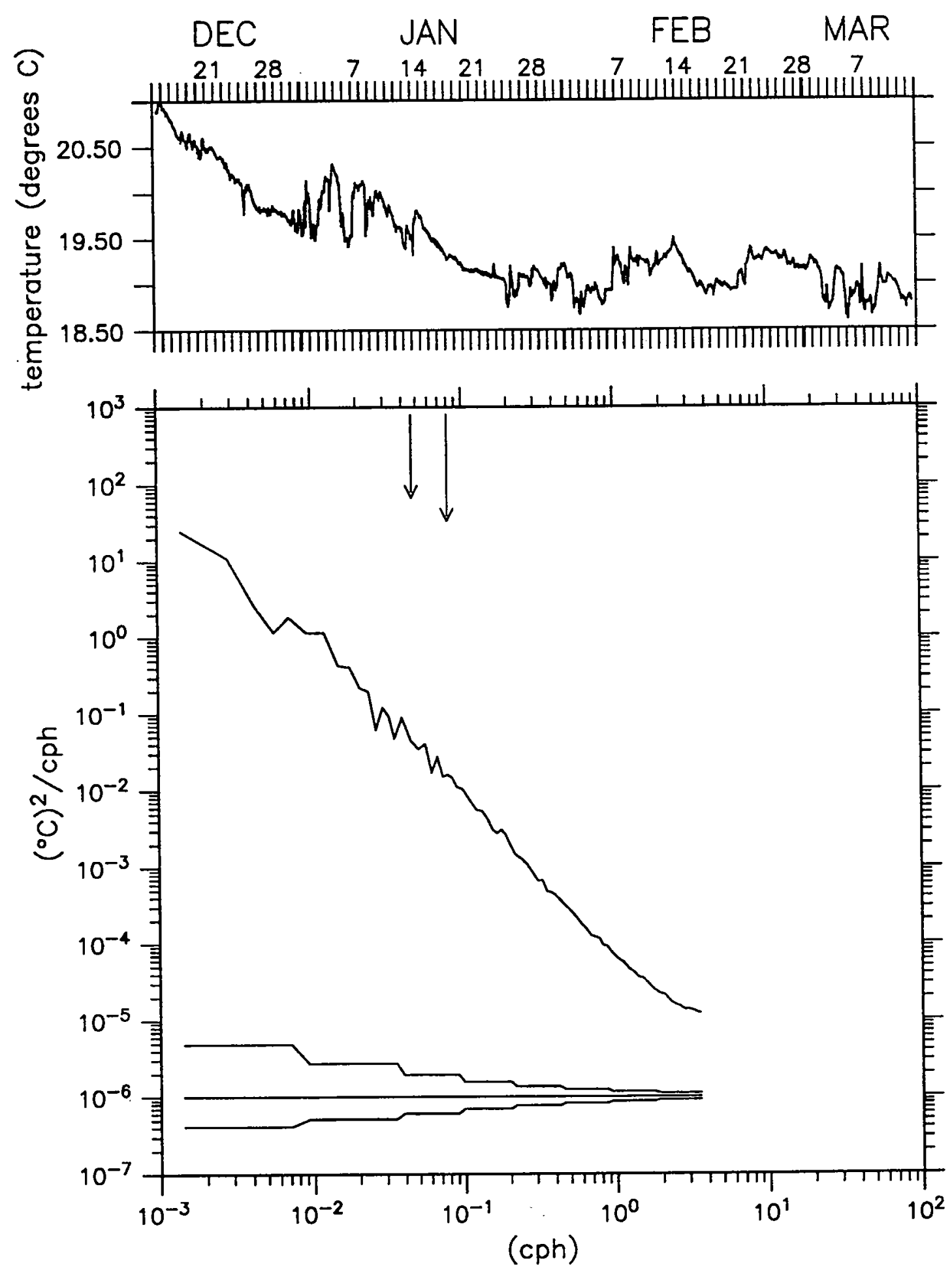

tpod 3761 at $1.0 \mathrm{~m}$

Figure 3.2.3: Temperature Time Series and Spectra at $1 \mathrm{~m}$. Long arrow indicates semi-diurnal tidal frequency, short arrow indicates Coriolis frequency. 

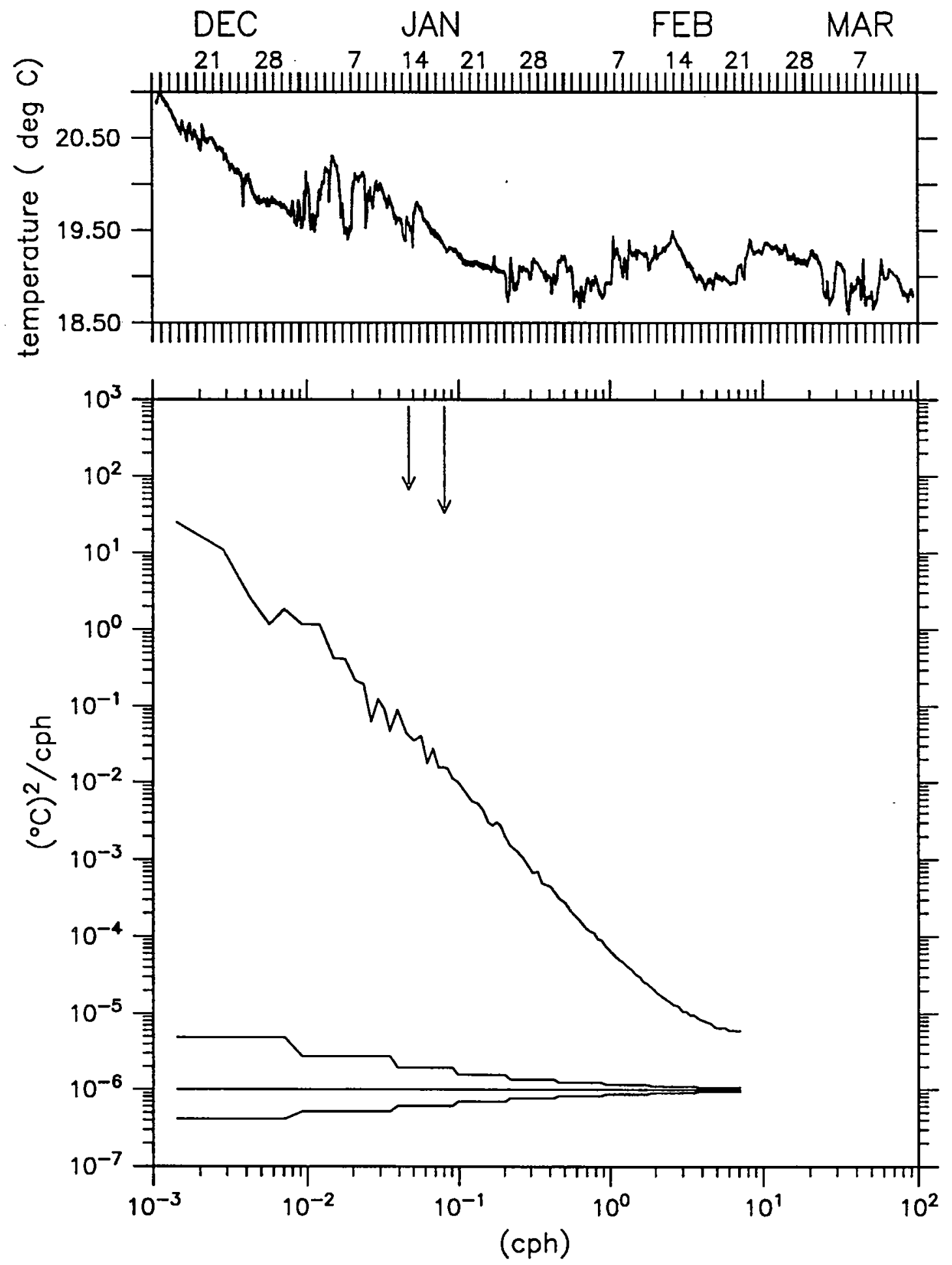

Seacat 0927 at 1.0 meters

Figure 3.2.4: Temperature Time Series and Spectra at $1 \mathrm{~m}$. Long arrow indicates semi-diurnal tidal frequency, short arrow indicates Coriolis frequency. 


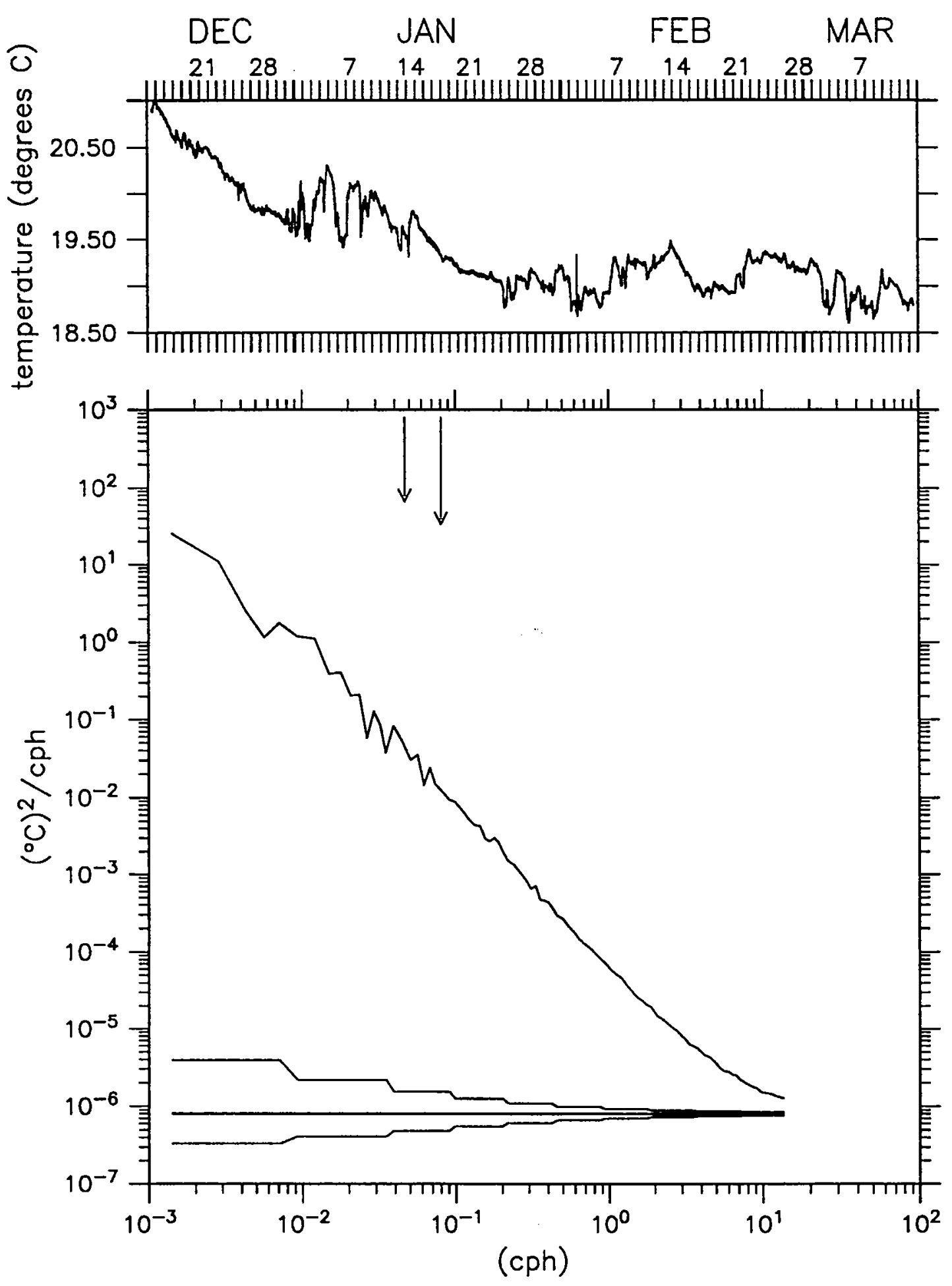

vmem 23 at $5.0 \mathrm{~m}$

Figure 3.2.5: Temperature Time Series and Spectra at $5 \mathrm{~m}$. Long arrow indicates semi-diurnal tidal frequency, short arrow indicates Coriolis frequency. 


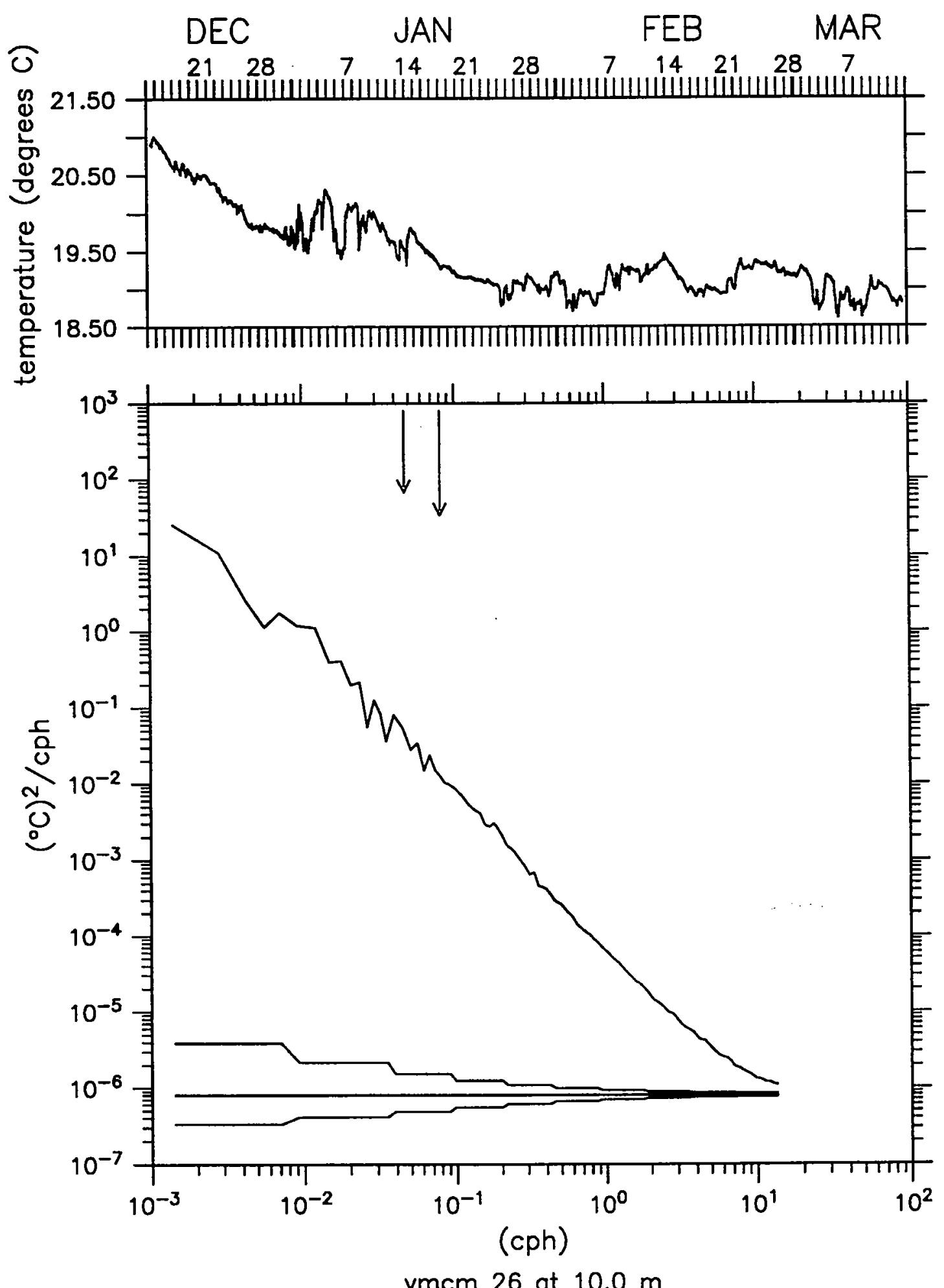

Figure 3.2.6: Temperature Time Series and Spectra at $10 \mathrm{~m}$. Long arrow indicates semi-diurnal tidal frequency, short arrow indicates Coriolis frequency. 


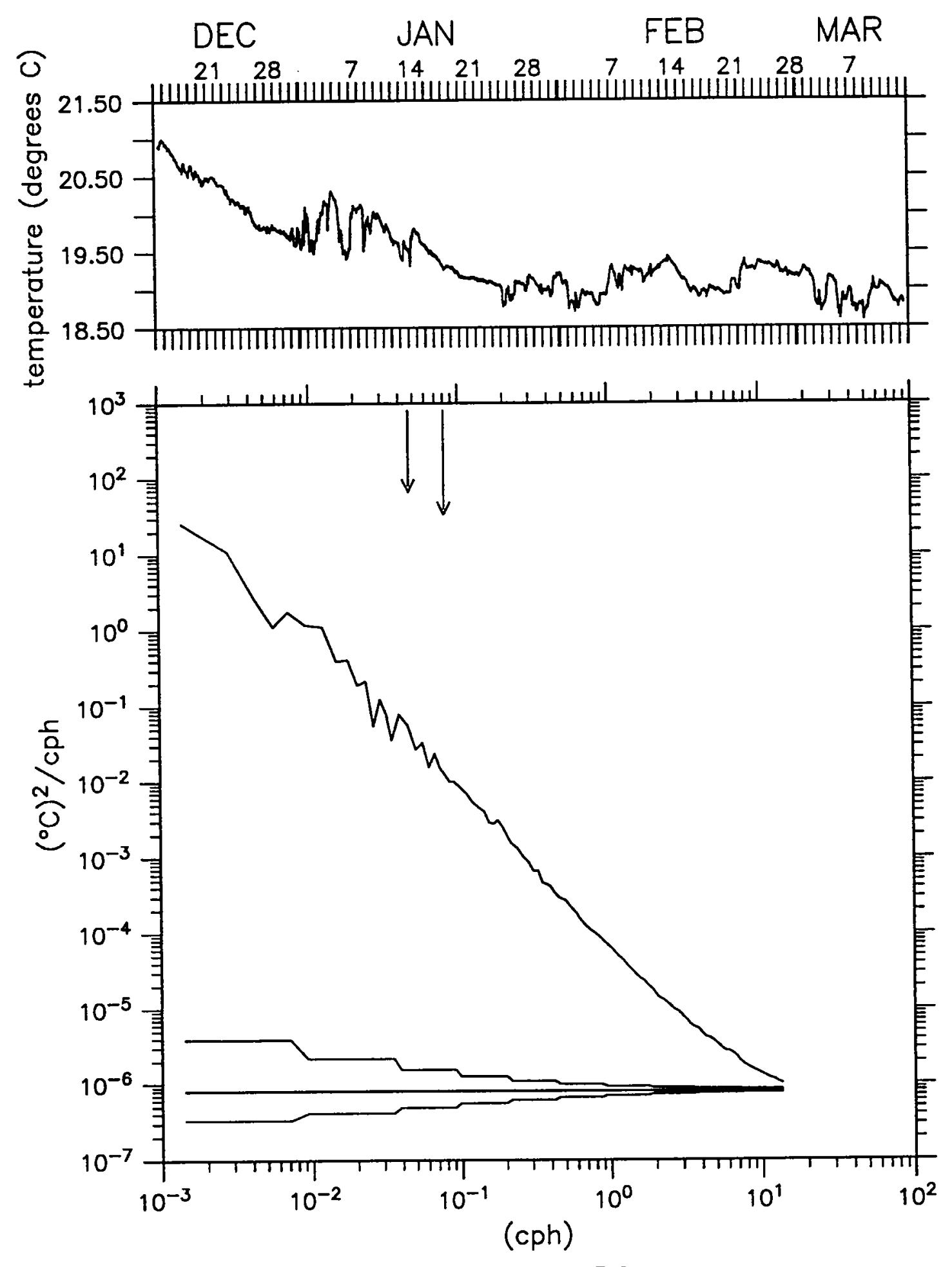

vmcm 10 ot $15.0 \mathrm{~m}$

Figure 3.2.7: Temperature Time Series and Spectra at $15 \mathrm{~m}$. Long arrow indicates semi-diurnal tidal frequency, short arrow indicates Coriolis frequency. 


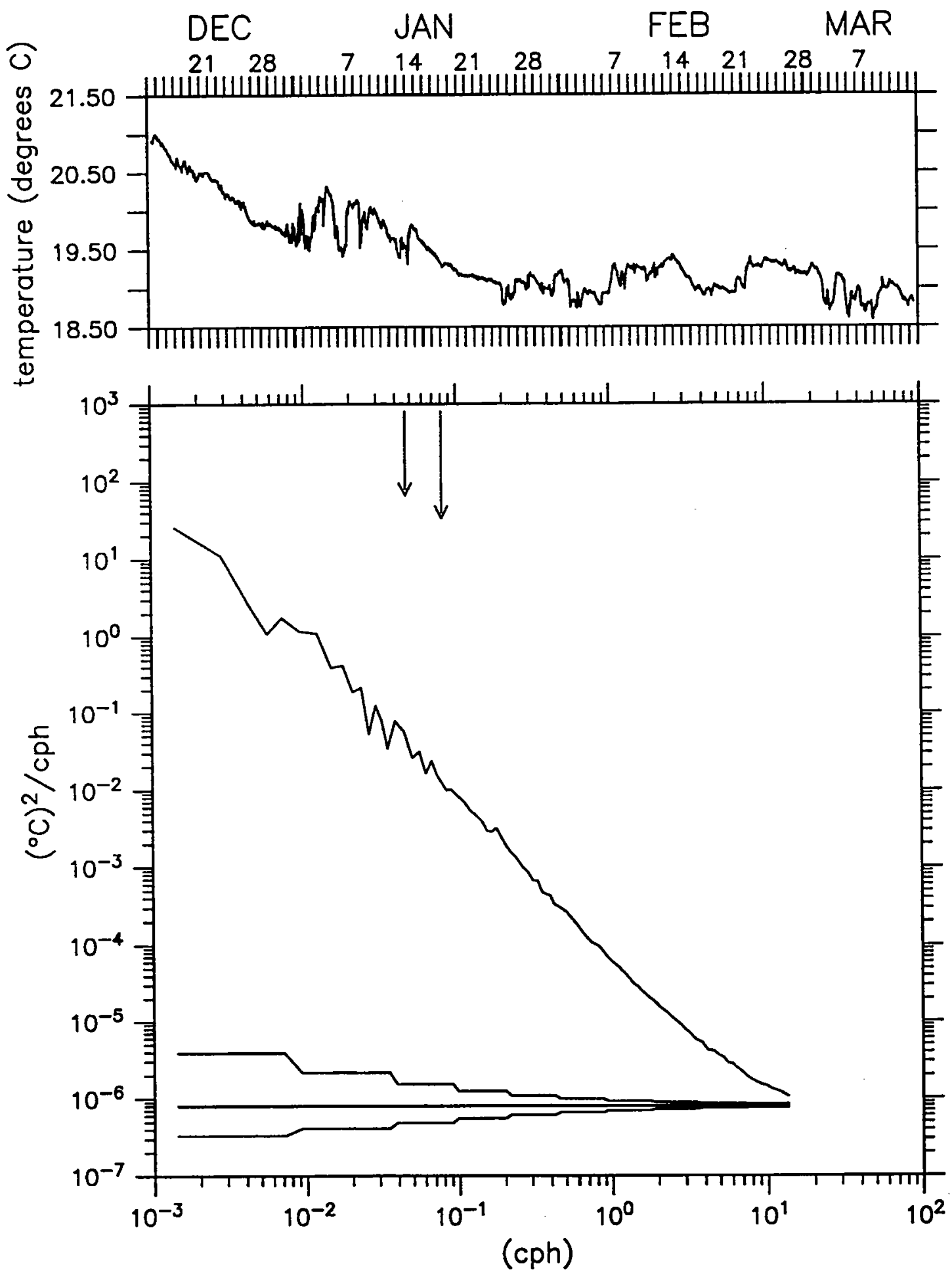

vmem 31 at $20.0 \mathrm{~m}$

Figure 3.2.8: Temperature Time Series and Spectra at $20 \mathrm{~m}$. Long arrow indicates semi-diurnal tidal frequency, short arrow indicates Coriolis frequency. 


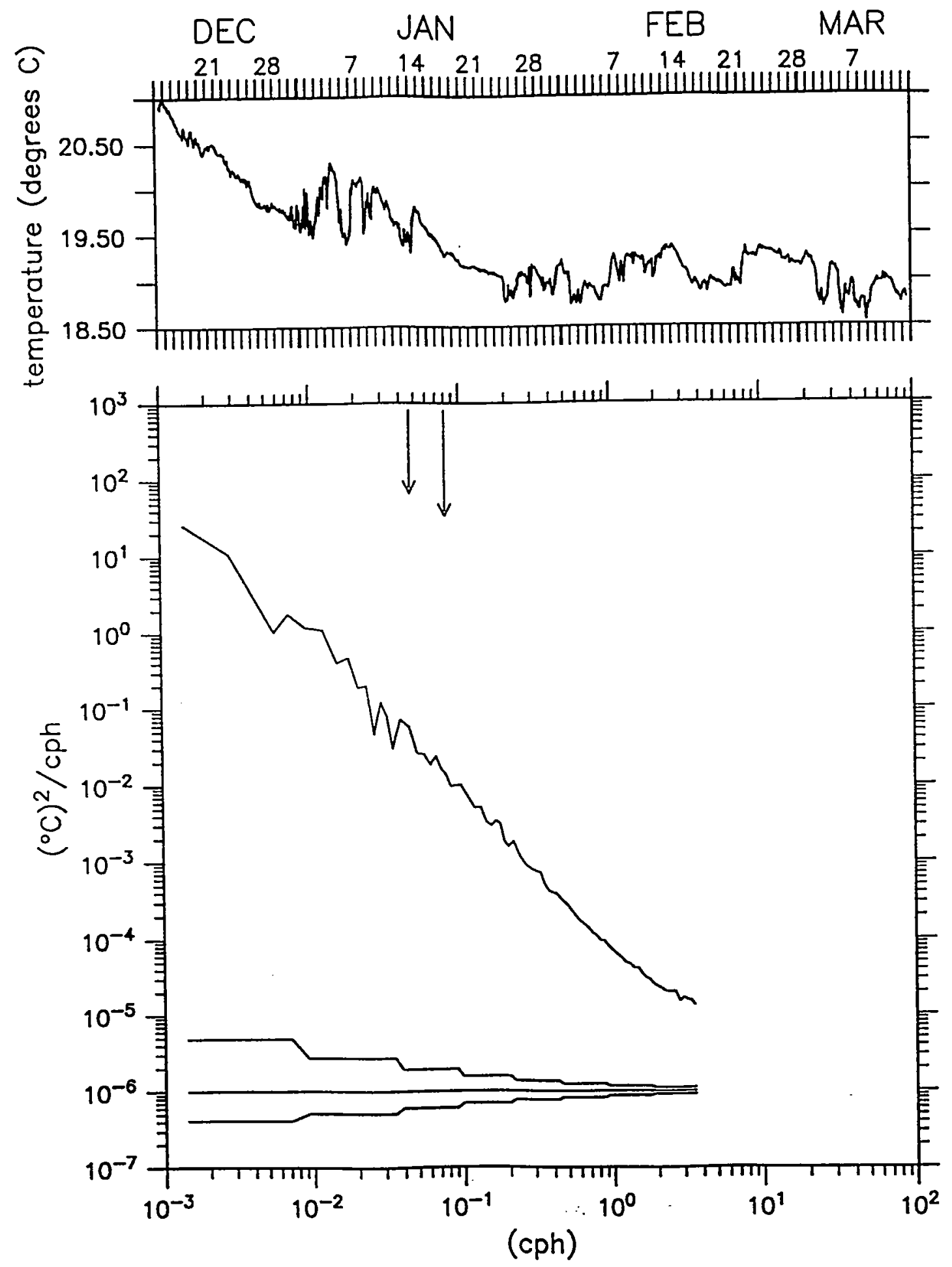

tpod 3271 at $37.0 \mathrm{~m}$

Figure 3.2.9: Temperature Time Series and Spectra at $37 \mathrm{~m}$. Long arrow indicates semi-diurnal tidal frequency, short arrow indicates Coriolis frequency. 


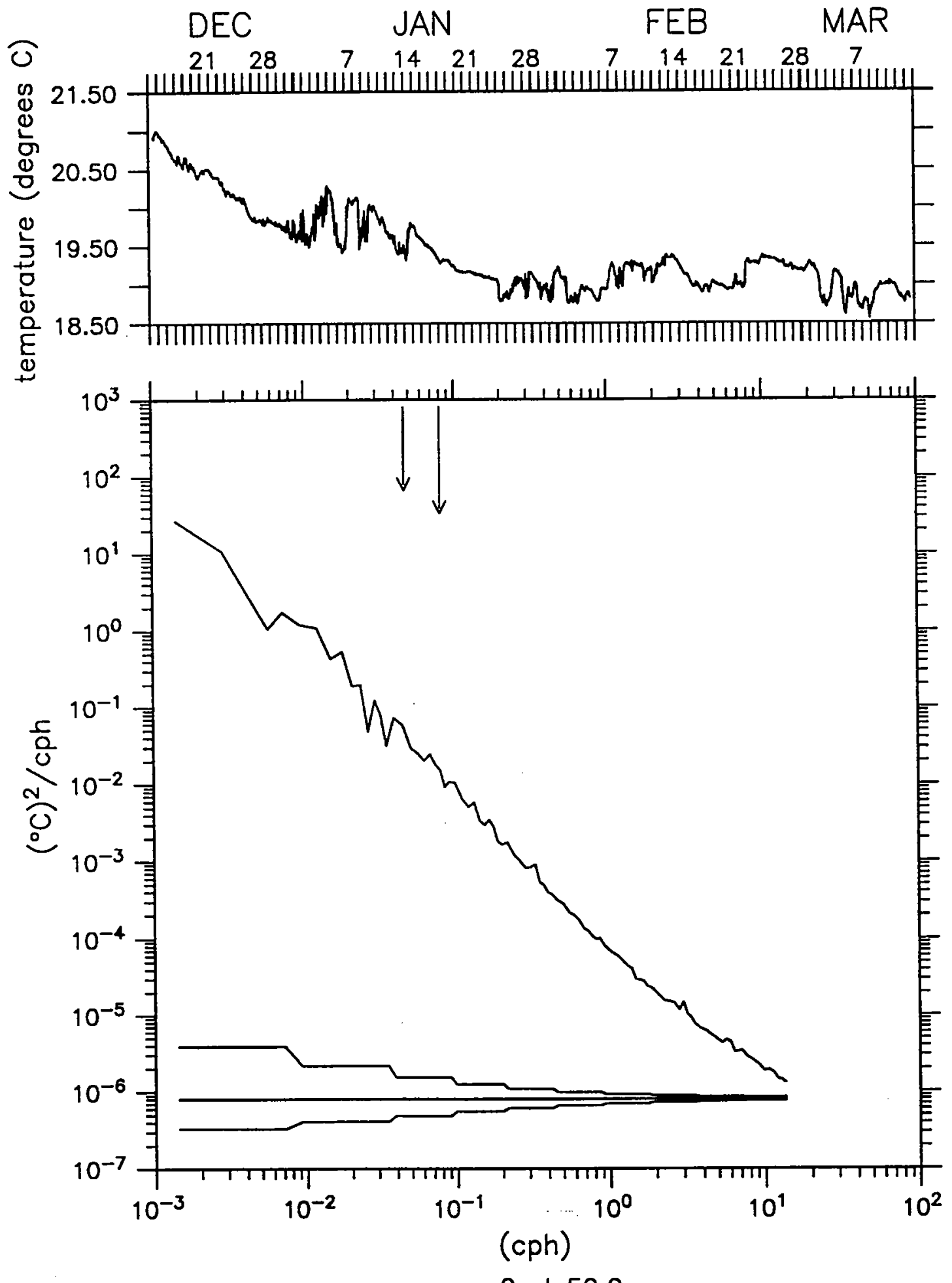

vmcm 2 at $50.0 \mathrm{~m}$

Figure 3.2.10: Temperature Time Series and Spectra at $50 \mathrm{~m}$. Long arrow indicates semi-diurnal tidal frequency, short arrow indicates Coriolis frequency. 


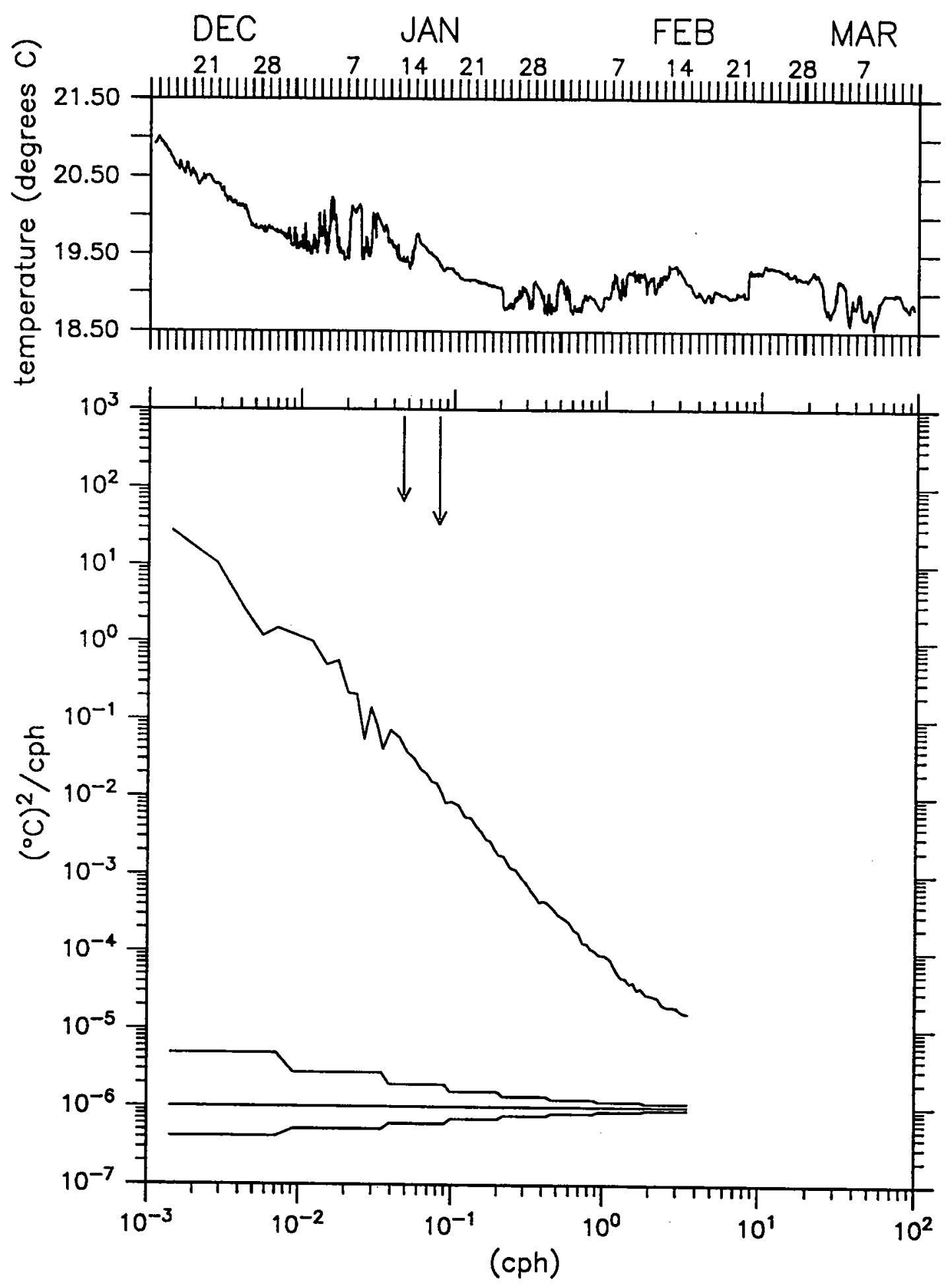

tpod 3259 at $75.0 \mathrm{~m}$

Figure 3.2.11: Temperature Time Series and Spectra at $75 \mathrm{~m}$. Long arrow indicates semi-diurnal tidal frequency, short arrow indicates Coriolis frequency. 


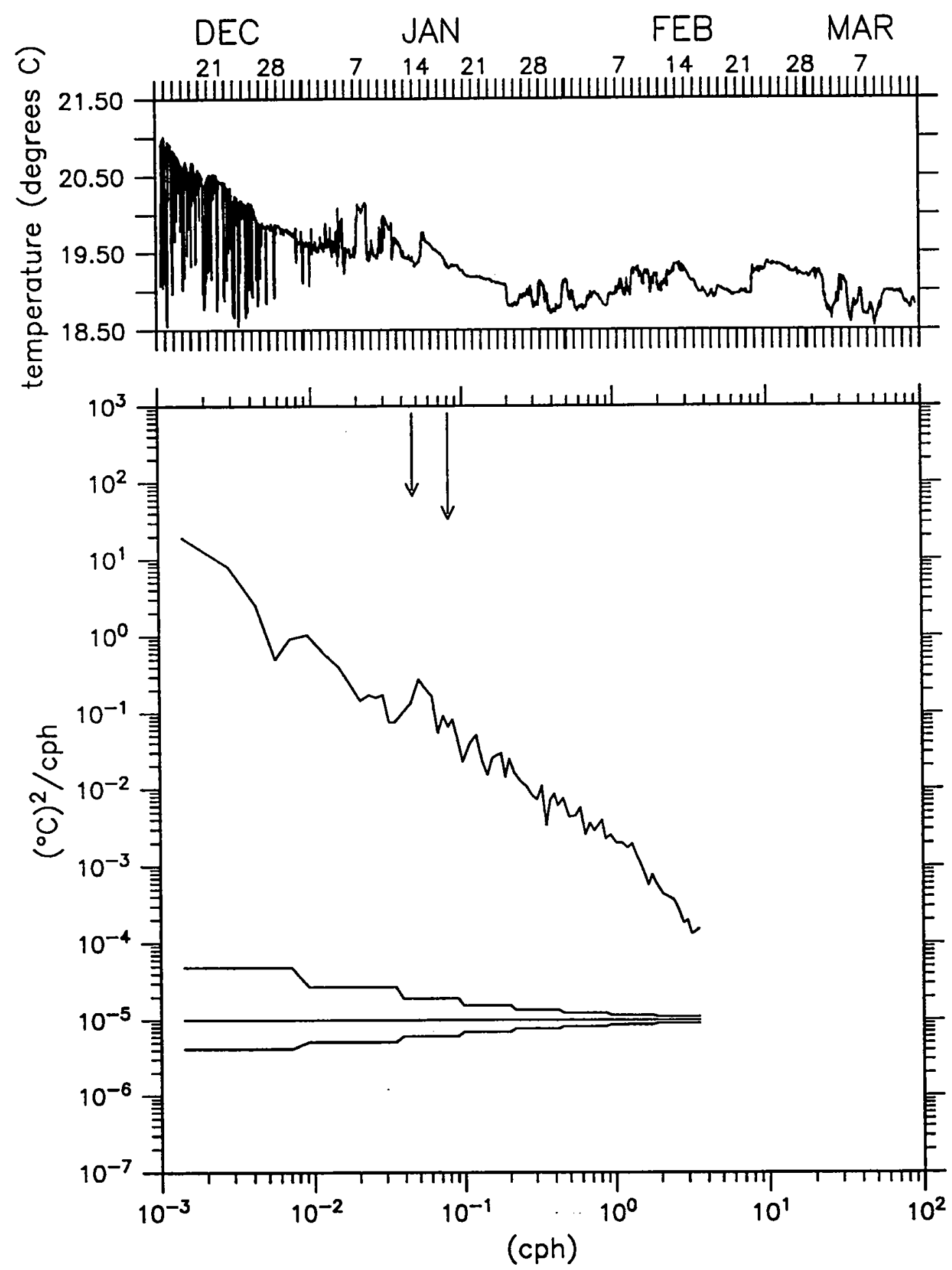

tpod 4488 at $100.0 \mathrm{~m}$

Figure 3.2.12: Temperature Time Series and Spectra at $100 \mathrm{~m}$. Long arrow indicates semi-diurnal tidal frequency, short arrow indicates Coriolis frequency. 


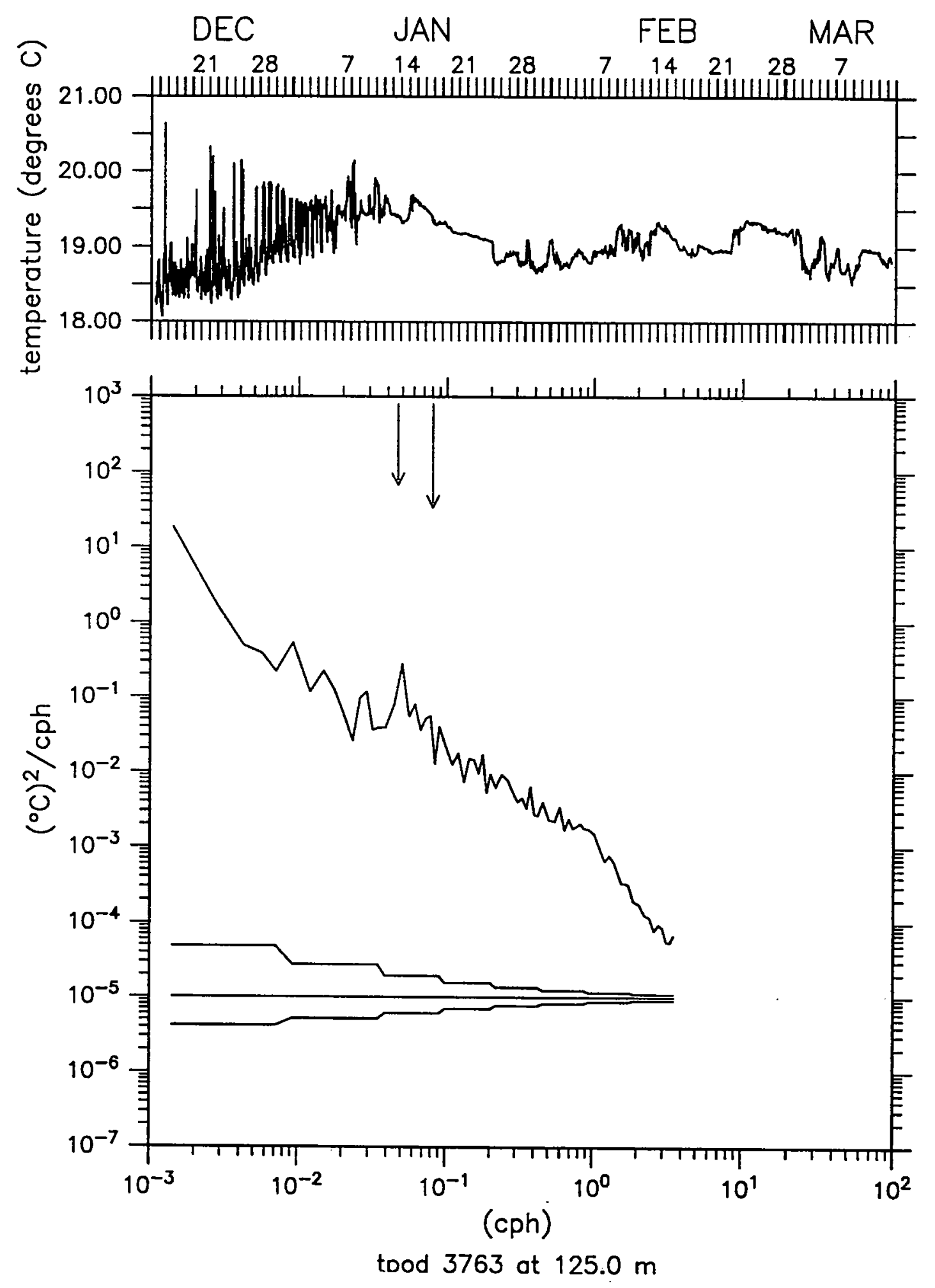

Figure 3.2.13: Temperature Time Series and Spectra at $125 \mathrm{~m}$. Long arrow indicates semi-diurnal tidal frequency, short arrow indicates
Coriolis frequency. 


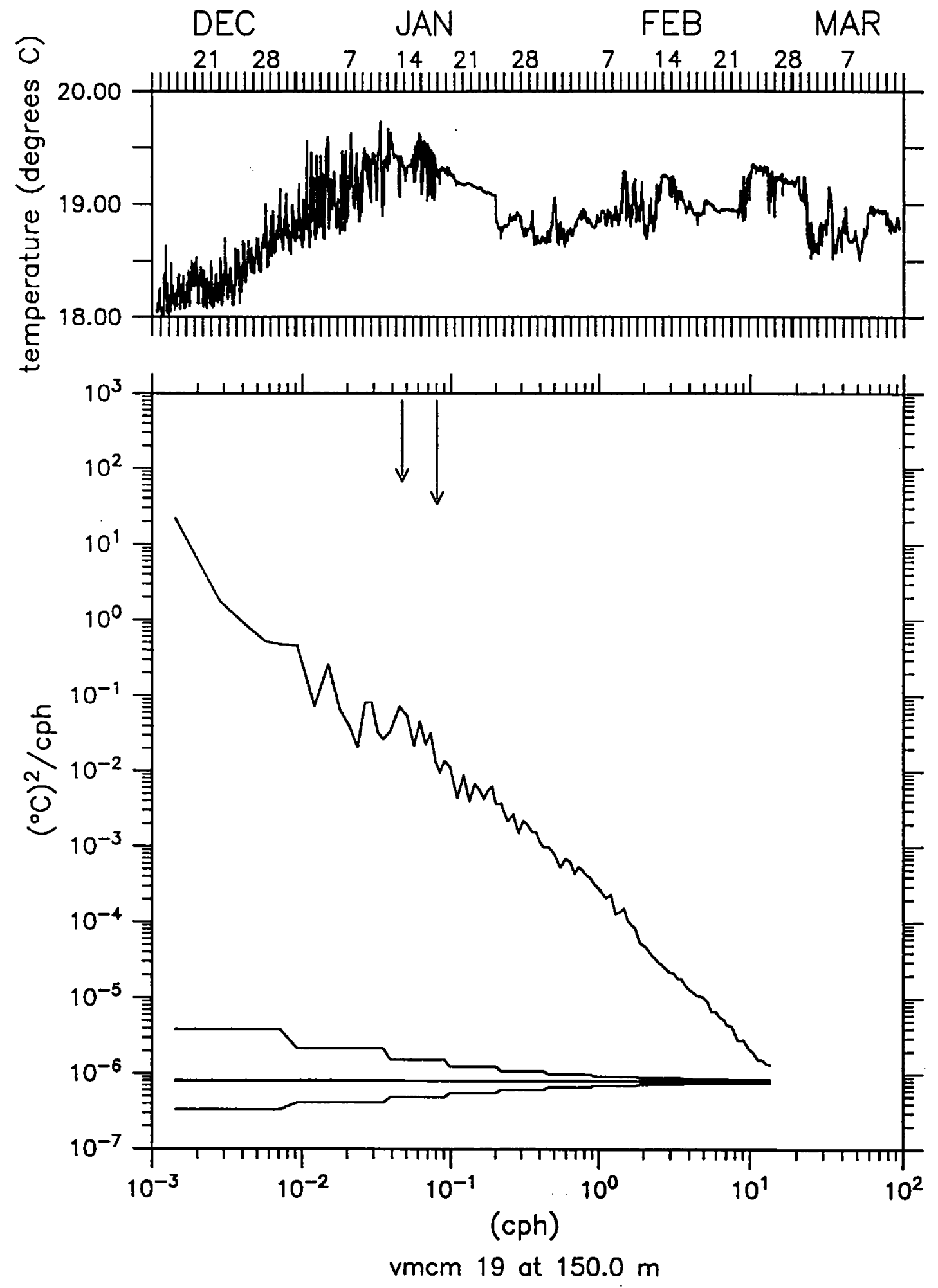

Figure 3.2.14: Temperature Time Series and Spectra at $150 \mathrm{~m}$. Long arrow indicates semi-diurnal tidal frequency, short arrow indicates Coriolis frequency. 


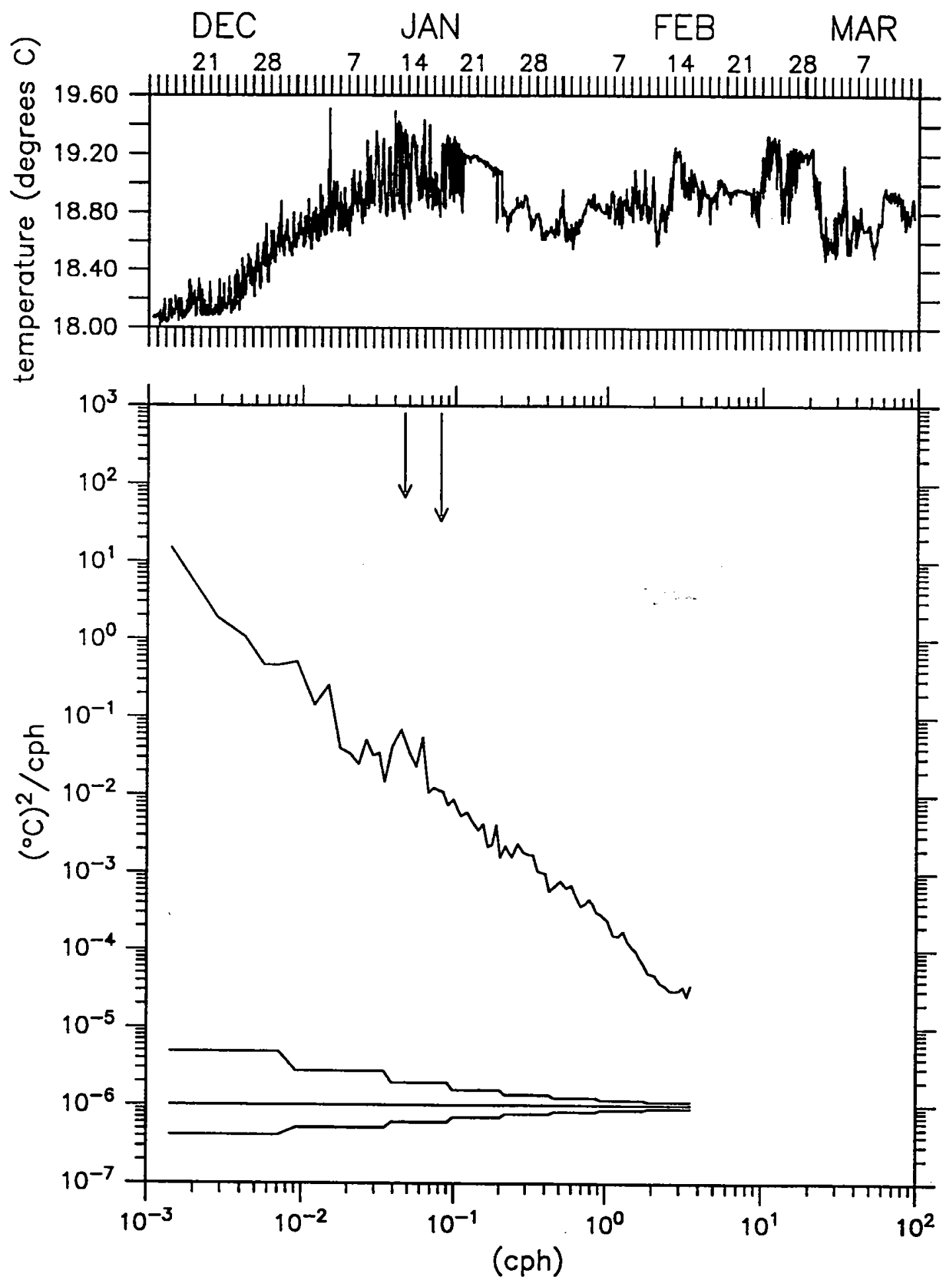

tpod 3762 at $175.0 \mathrm{~m}$

Figure 3.2.15: Temperature Time Series and Spectra at $175 \mathrm{~m}$. Long arrow indicates semi-diurnal tidal frequency, short arrow indicates Coriolis frequency. 

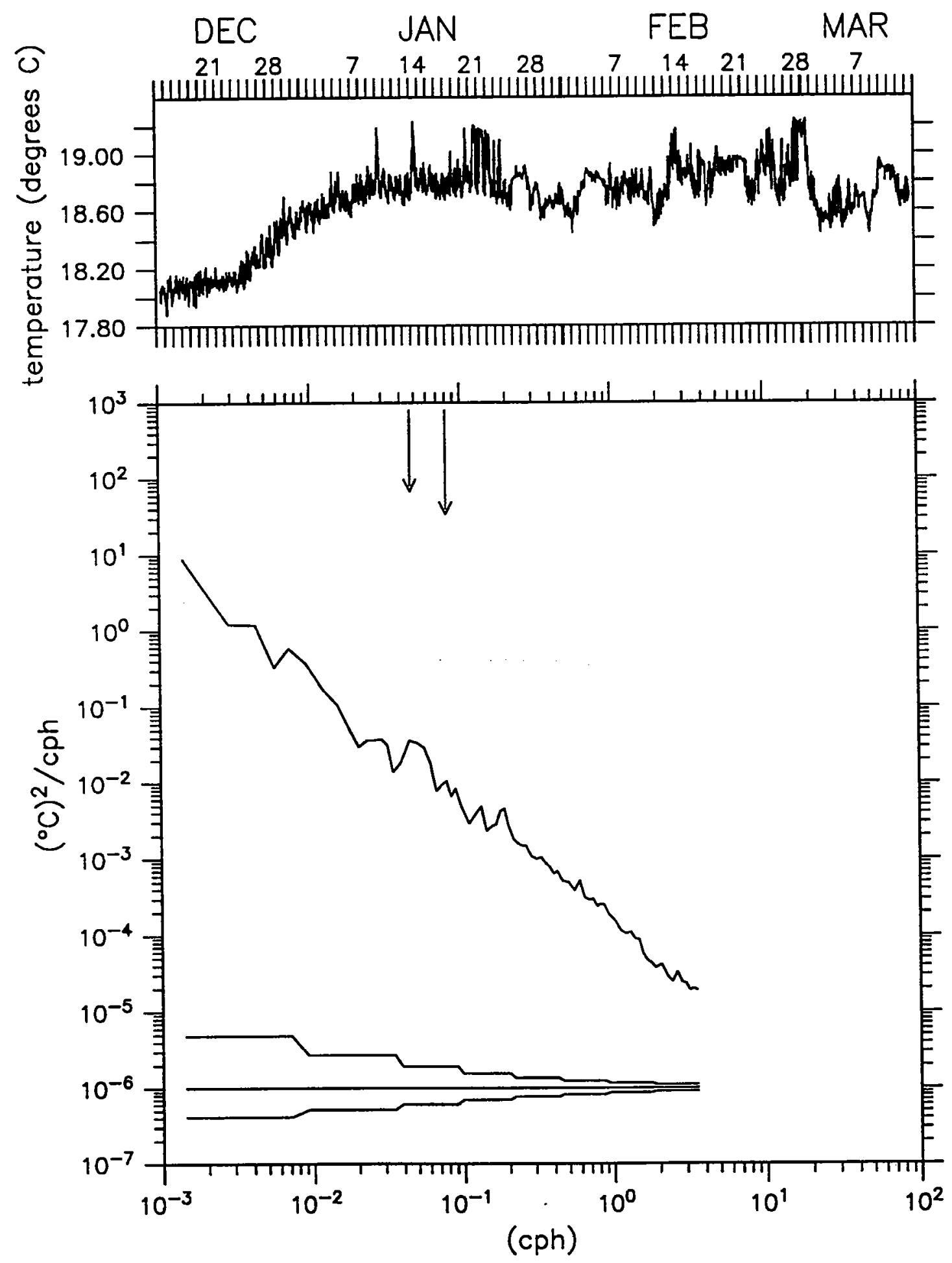

tpod 3662 at $200.0 \mathrm{~m}$

Figure 3.2.16: Temperature Time Series and Spectra at $200 \mathrm{~m}$. Long arrow indicates semi-diurnal tidal frequency, short arrow indicates Coriolis frequency. 


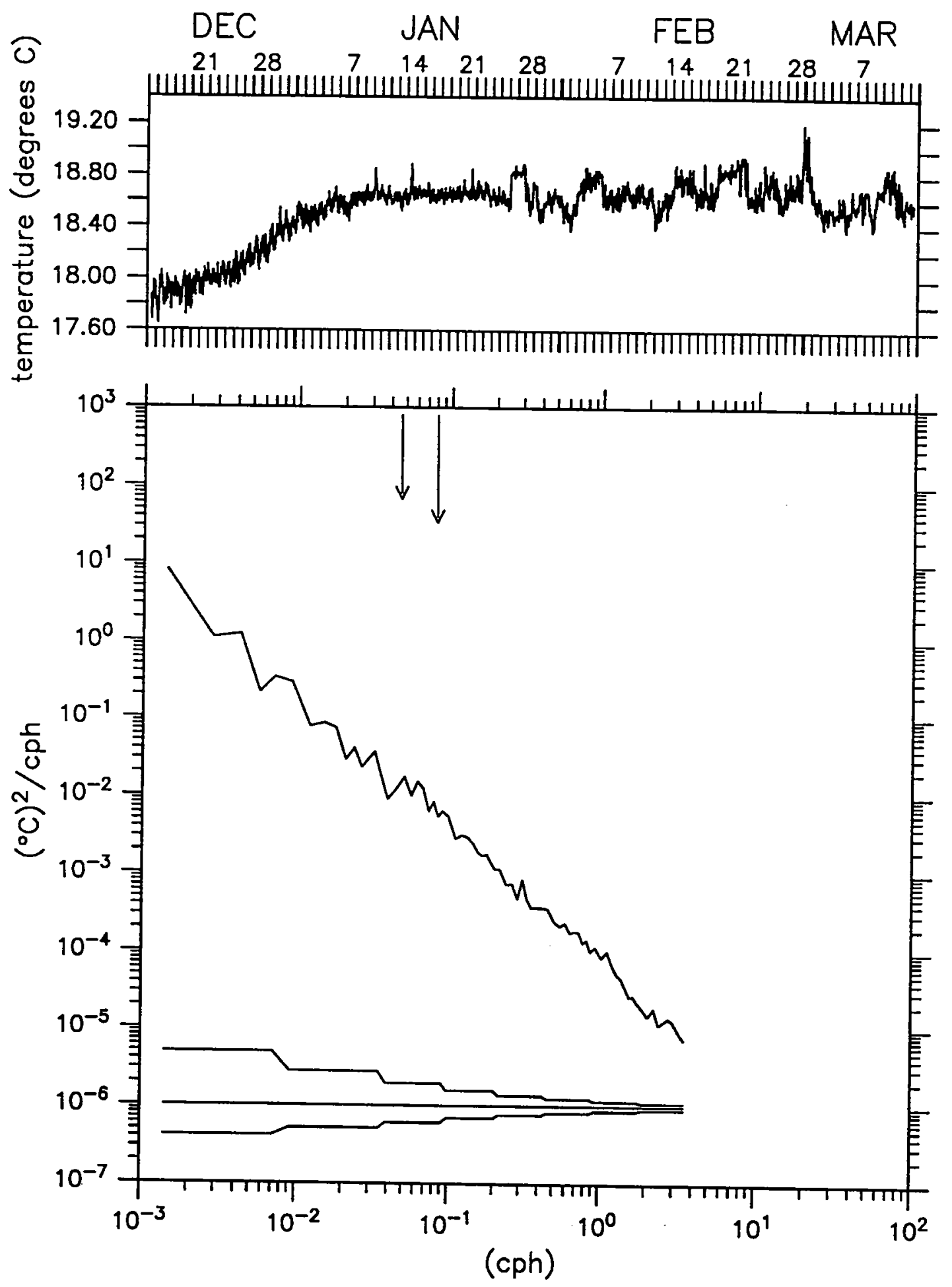

tpod 3265 at $230.0 \mathrm{~m}$

Figure 3.2.17: Temperature Time Series and Spectra at $230 \mathrm{~m}$. Long arrow indicates semi-diurnal tidal frequency, short arrow indicates Coriolis frequency. 


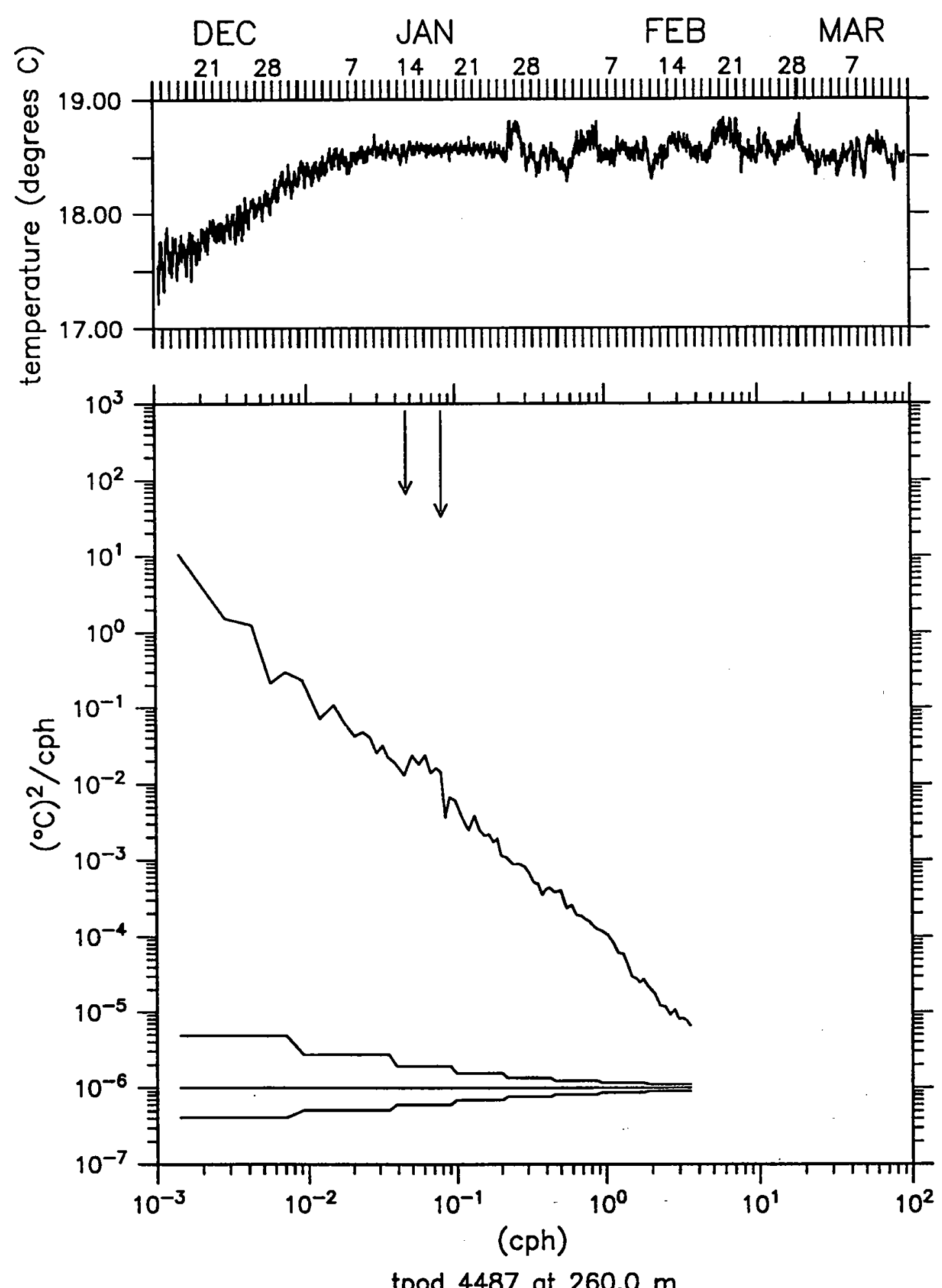

tpod 4487 at $260.0 \mathrm{~m}$

Figure 3.2.18: Temperature Time Series and Spectra at $260 \mathrm{~m}$. Long arrow indicates semi-diurnal tidal frequency, short arrow indicates Coriolis frequency. 


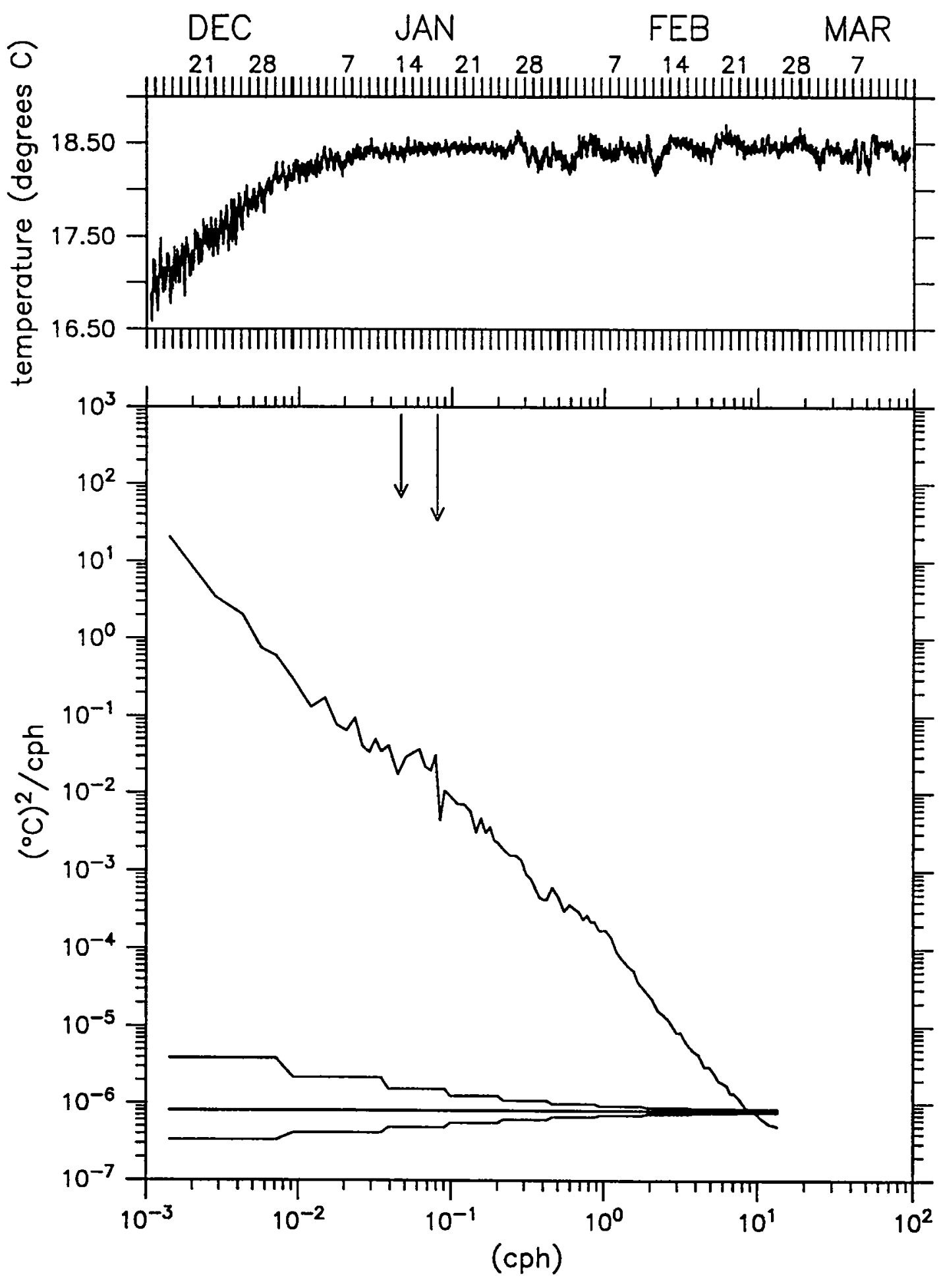

vmcm 13 at $300.0 \mathrm{~m}$

Figure 3.2.19: Temperature Time Series and Spectra at 300m. Long arrow indicates semi-diurnal tidal frequency, short arrow indicates Coriolis frequency. 


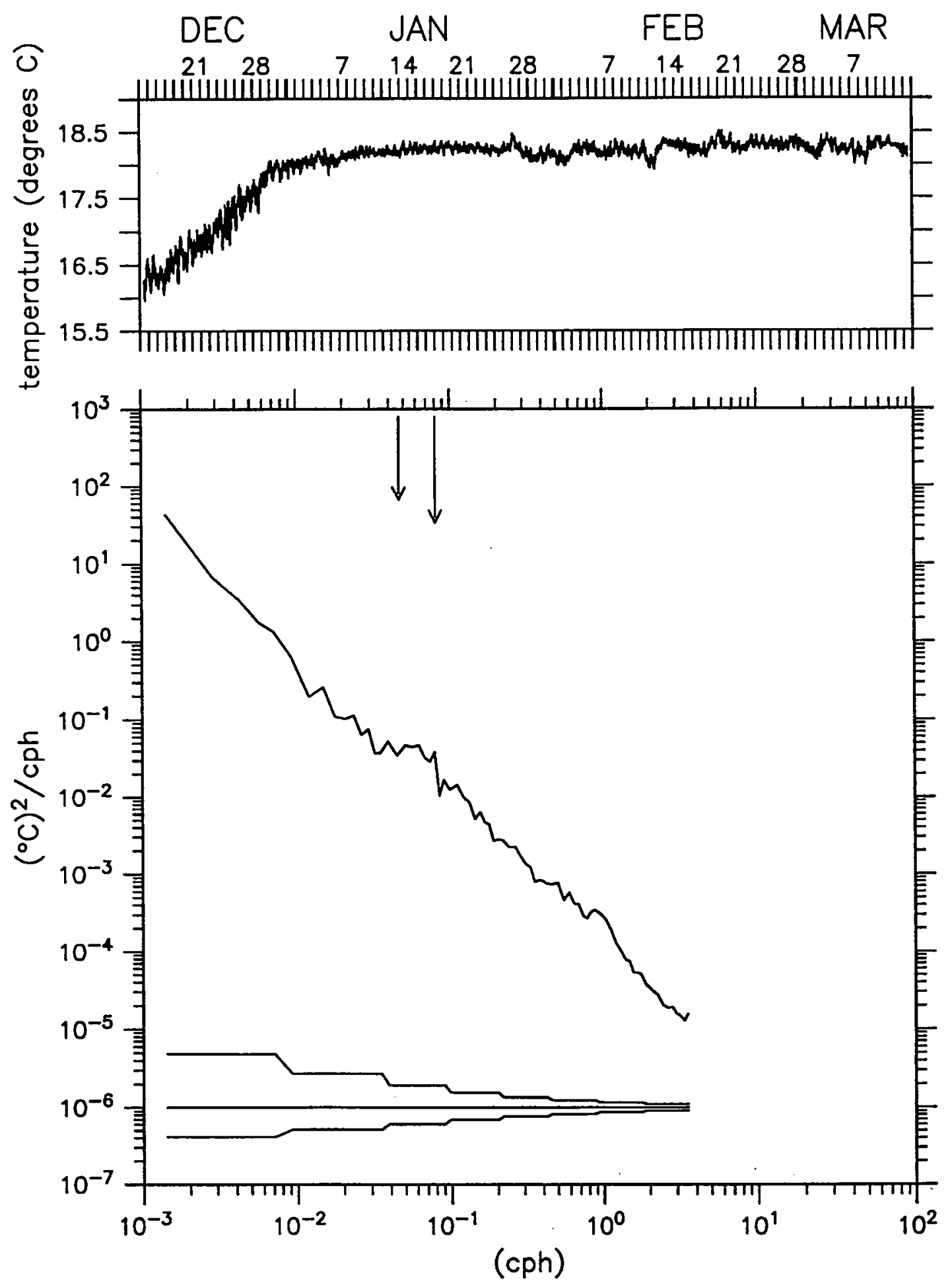

tpod 3703 at $350.0 \mathrm{~m}$

Figure 3.2.20: Temperature Time Series and Spectra at $350 \mathrm{~m}$. Long arrow indicates semi-diurnal tidal frequency, short arrow indicates Coriolis frequency. 


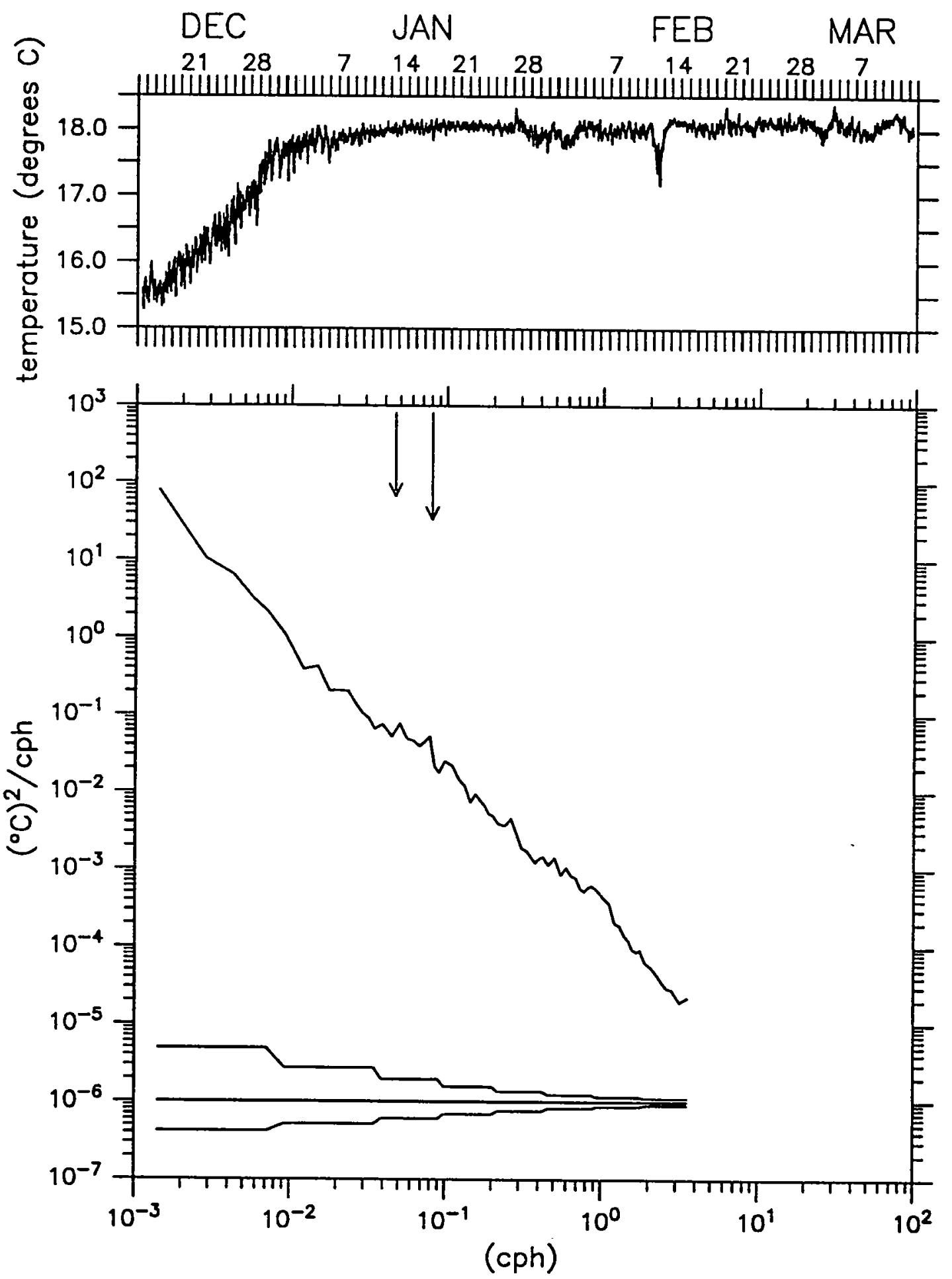

tpod 3291 at $400.0 \mathrm{~m}$

Figure 3.2.21: Temperature Time Series and Spectra at $400 \mathrm{~m}$. Long arrow indicates semi-diurnal tidal frequency, short arrow indicates Coriolis frequency. 


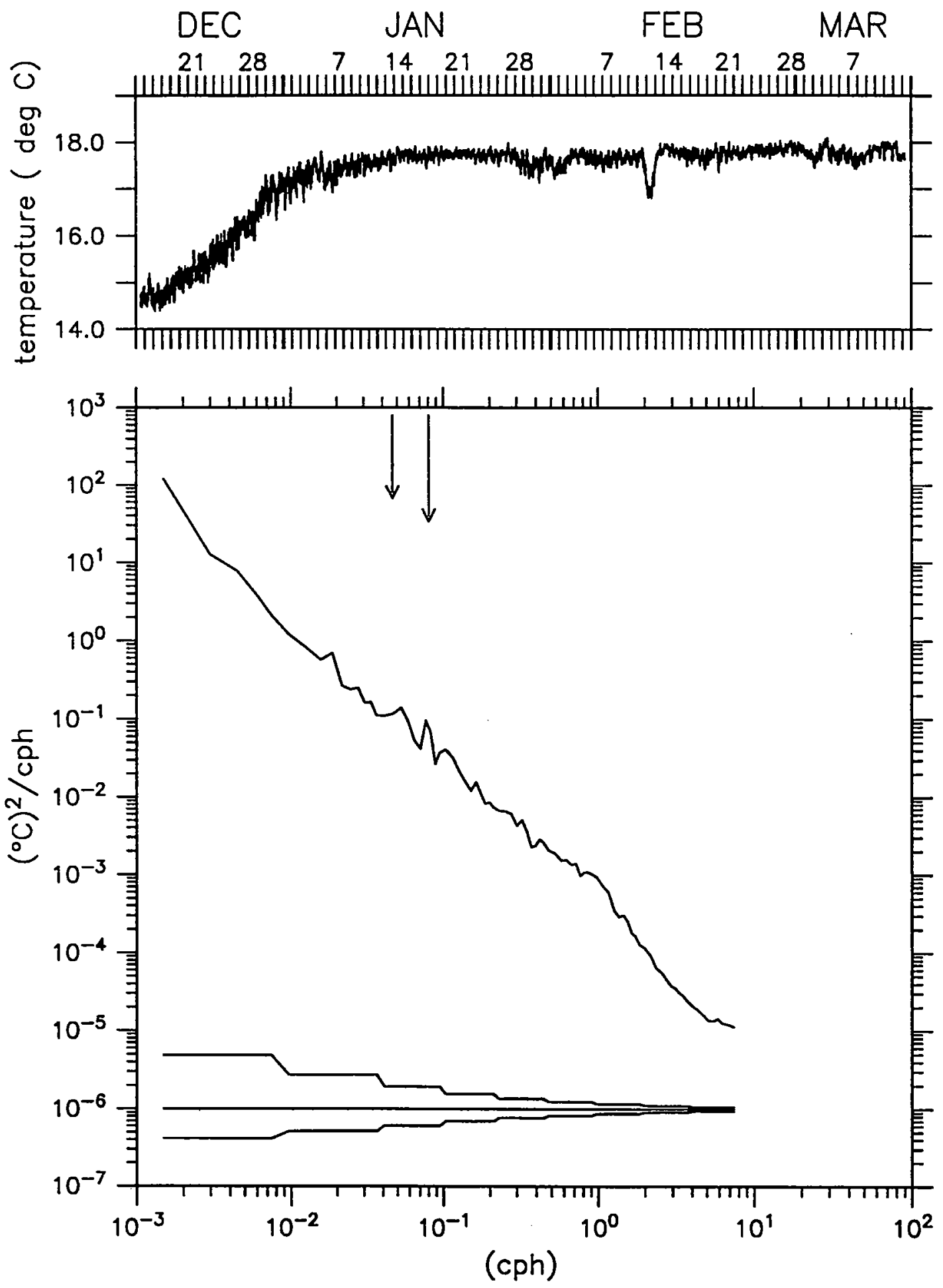

Seacat 0929 at 450.0 meters

Figure 3.2.22: Temperature Time Series and Spectra at 450m. Long arrow indicates semi-diurnal tidal frequency, short arrow indicates Coriolis frequency. 


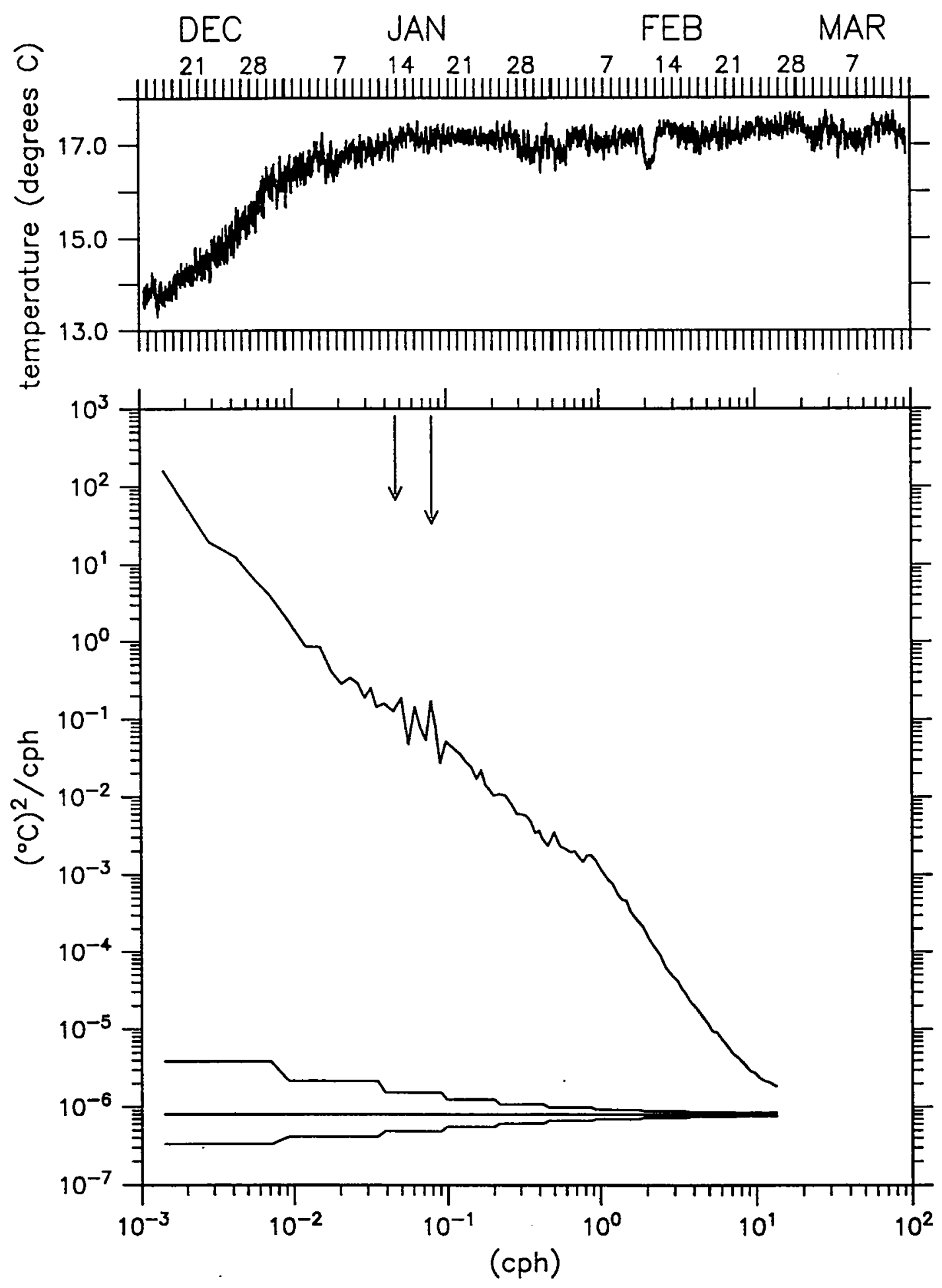

vmcm 1 at $500.0 \mathrm{~m}$

Figure 3.2.23: Temperature Time Series and Spectra at 500m. Long arrow indicates semi-diurnal tidal frequency, short arrow indicates Coriolis frequency. 


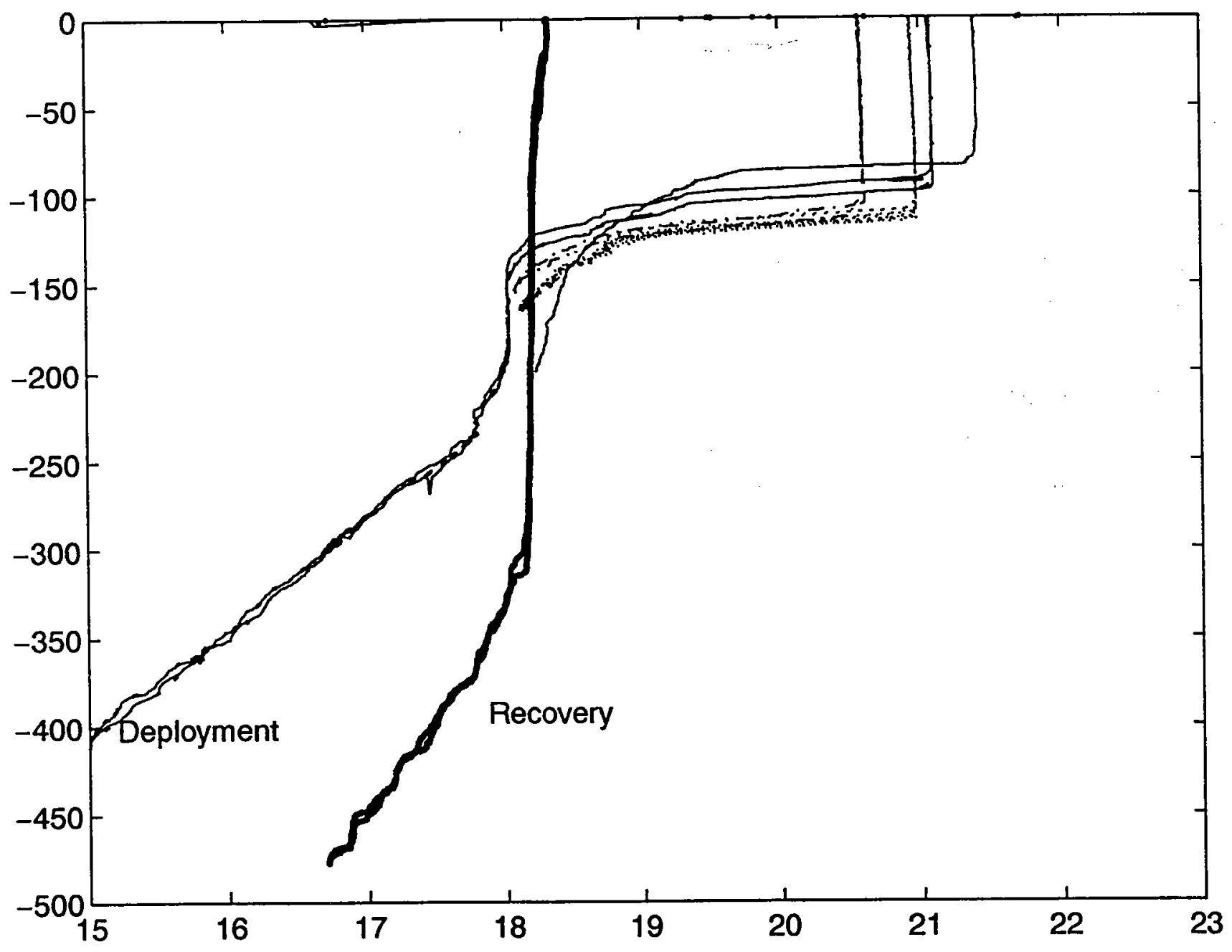

Figure 3.2.24: Temperature profiles from Seacat casts. 


\subsection{Current Velocities During ASREX III}

Currents were measured by VMCMs at 5, 10,15, 20, 50, 150, 300 and $500 \mathrm{~m}$. The current meters recorded at a rate of once every 120 seconds. A time-base checking program was used to correct missing data and data with invalid time-words before any further processing was carried out.

Time series stick-plots of the water vectors at each depth are in Figures 3.3.1 through 3.3.6. Data was filtered over a 48-hour period and decimated to 2 hours for the vector plots. Northerly velocities are represented by vectors pointing toward the top of the page.

Progressive vector plots for the eight VMCMs are shown in Figures 3.3.7 and 3.3.8. Velocity data was filtered and decimated to 4 hour values before plotting. Relative speed is indicated by the square symbols, which mark months.

Figures 3.3.9 through 3.3.16 are combined time-series and spectra for currents at each depth. These plots show unfiltered data. The upper frame for each plot represents the north and east velocities along the vertical axes and time (UTC) along the horizontal axis. The lower frame contains the spectra, with a solid line indicating the clockwise component and a dashed line indicating the counterclockwise component. As for temperature plots, the frequency of the Coriolis parameter and the semidiurnal tide are shown on the plots, and confidence limits are displayed. There are significant peaks associated with both the tide and Coriolis frequency. 


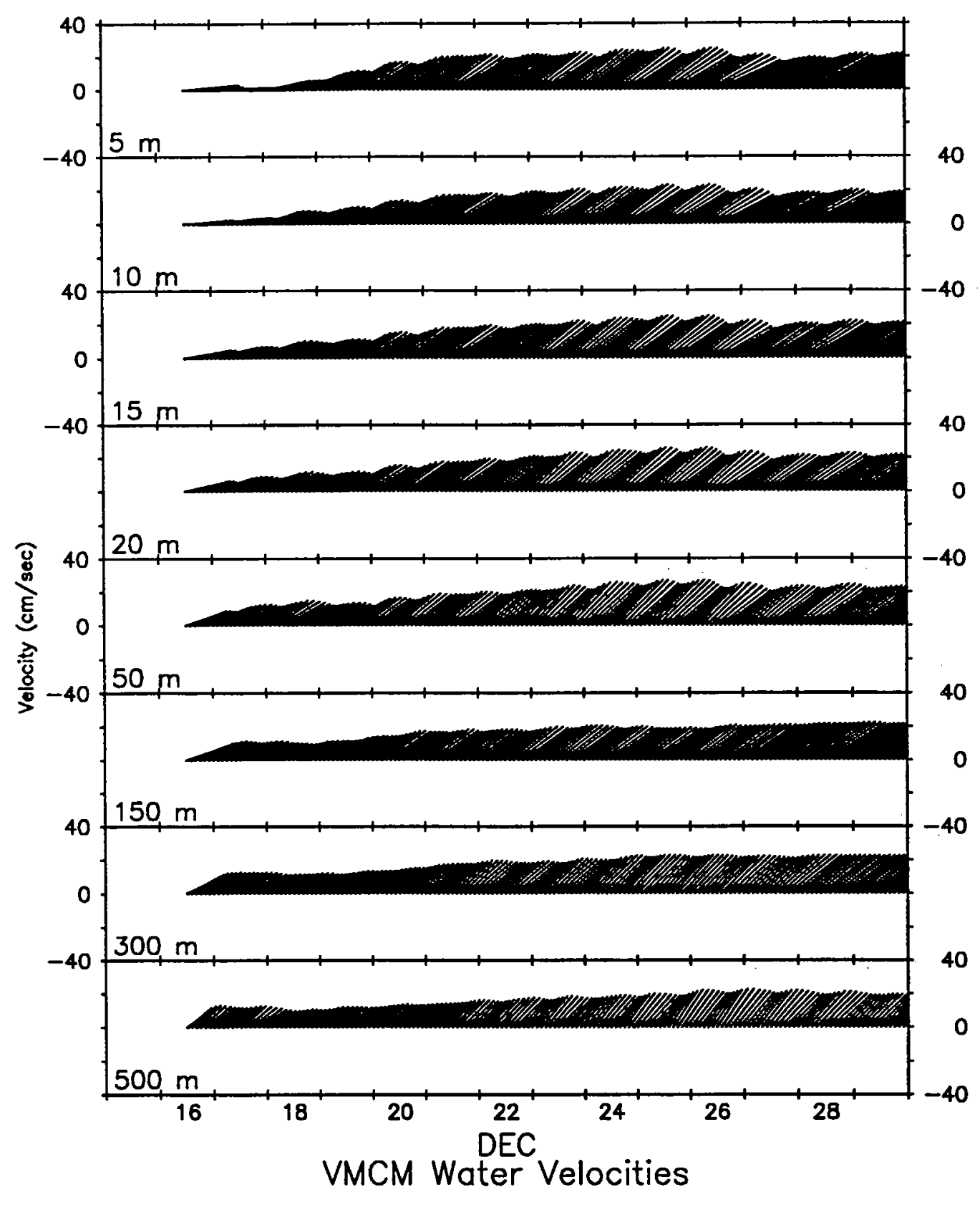

Figure 3.3.1: Sub-surface velocity vectors at 8 depths. Northerly component is towards top of page. Data is filtered over 48 hours and subsampled at 2 hours before plotting. 


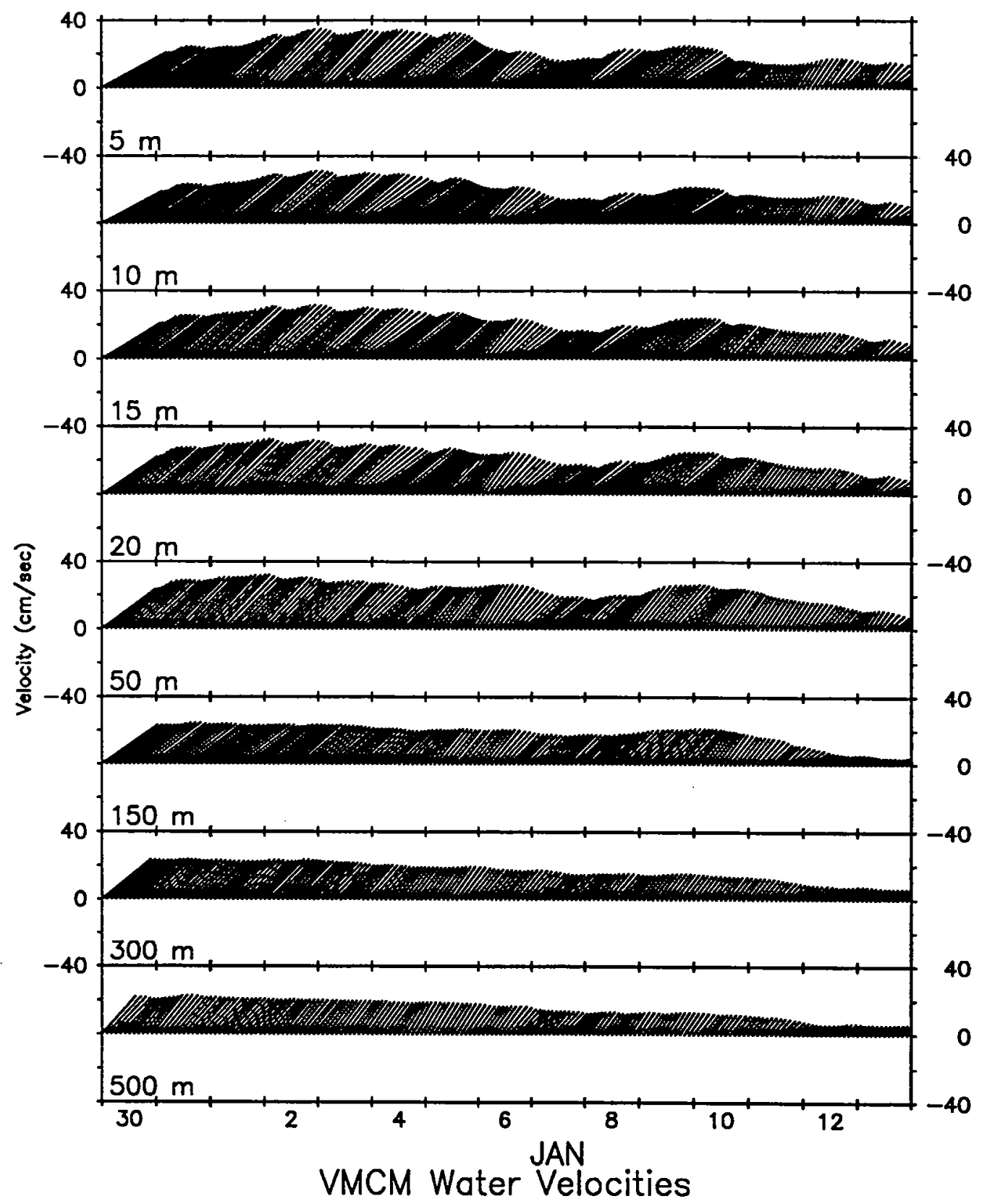

Figure 3.3.2: Sub-surface velocity vectors at 8 depths. Northerly component is towards top of page. Data is filtered over 48 hours and subsampled at 2 hours before plotting. 


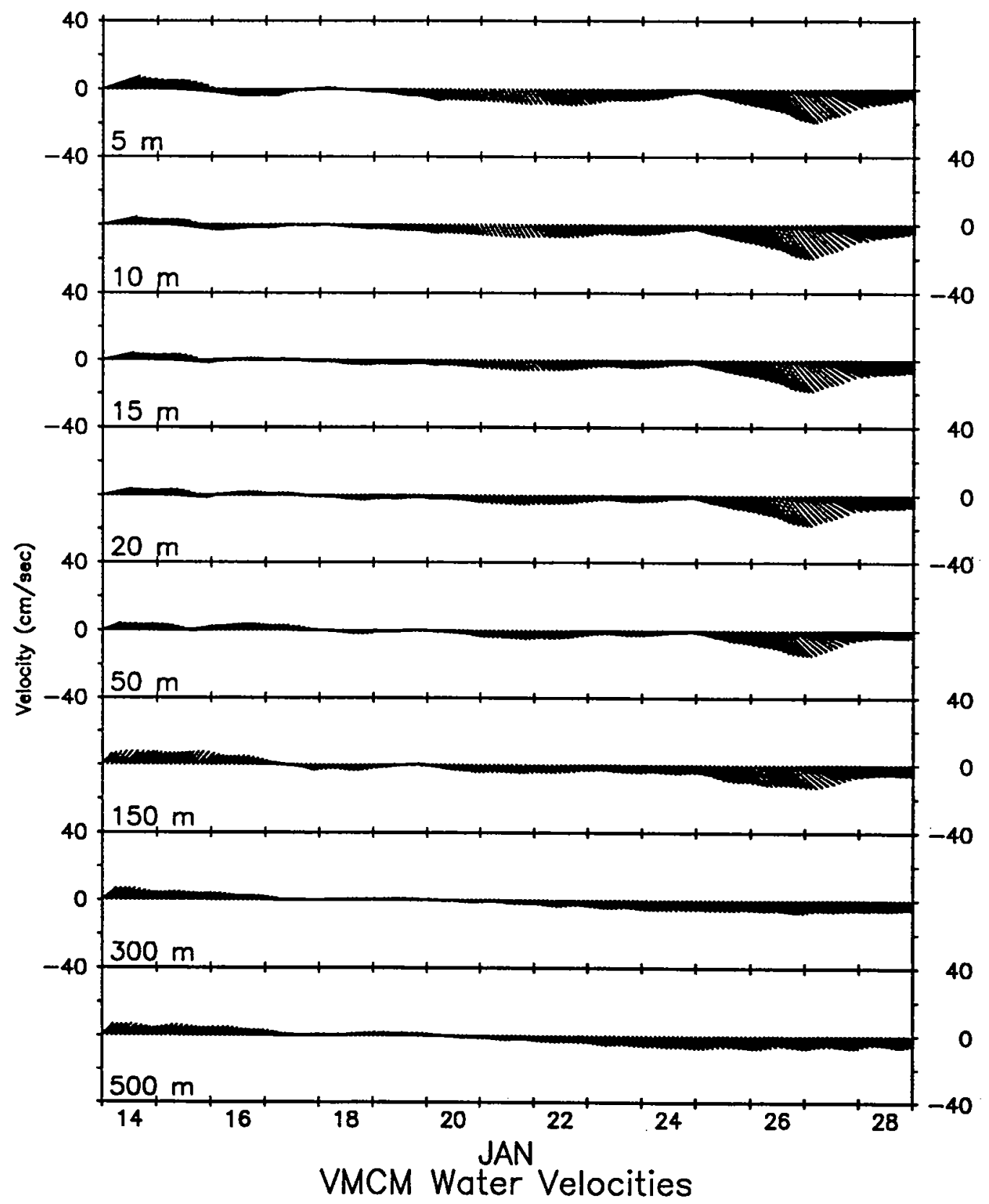

Figure 3.3.3: Sub-surface velocity vectors at 8 depths. Northerly component is towards top of page. Data is filtered over 48 hours and subsampled at 2 hours before plotting. 


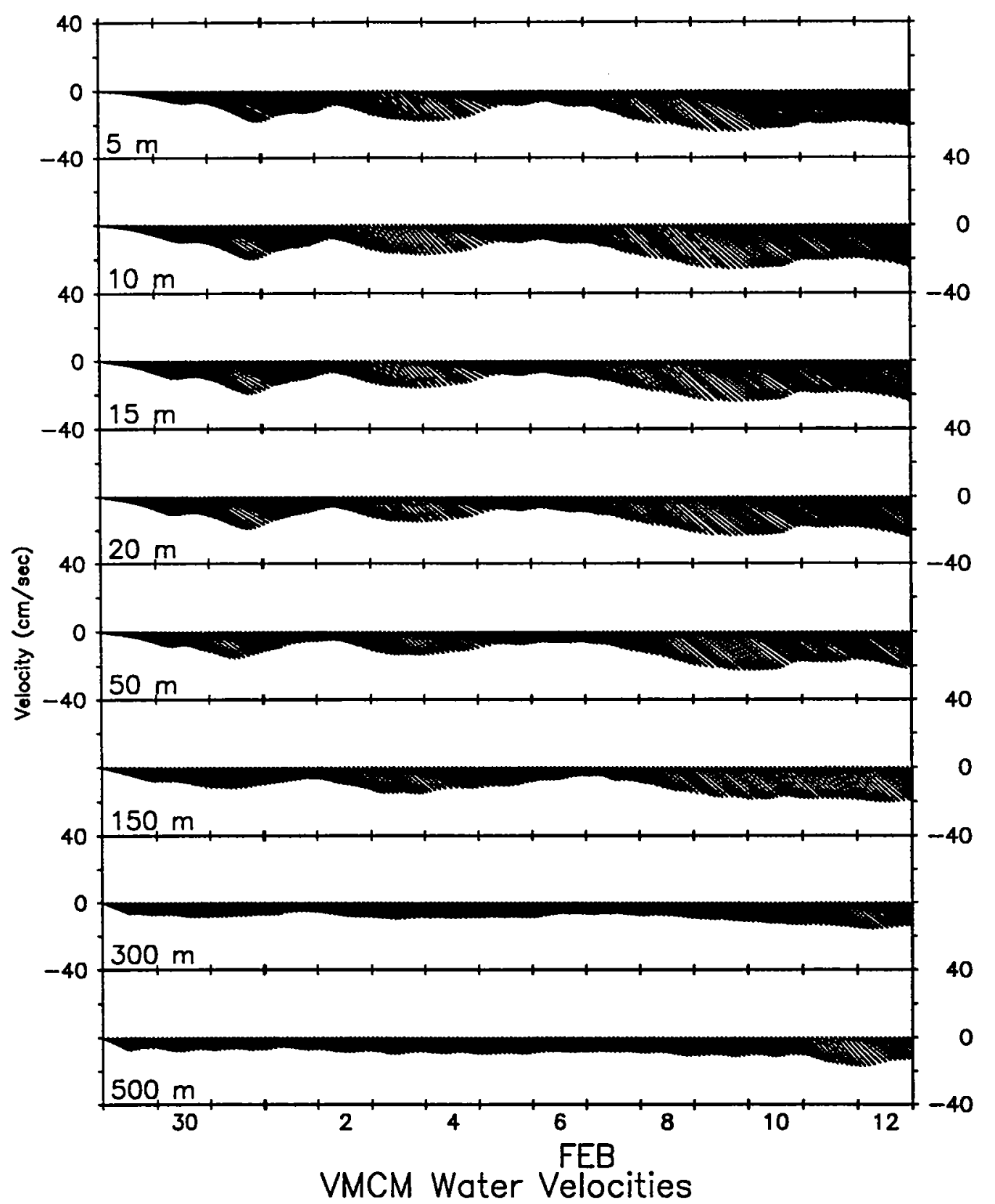

Figure 3.3.4: Sub-surface velocity vectors at 8 depths. Northerly component is towards top of page. Data is filtered over 48 hours and subsampled at 2 hours before plotting. 


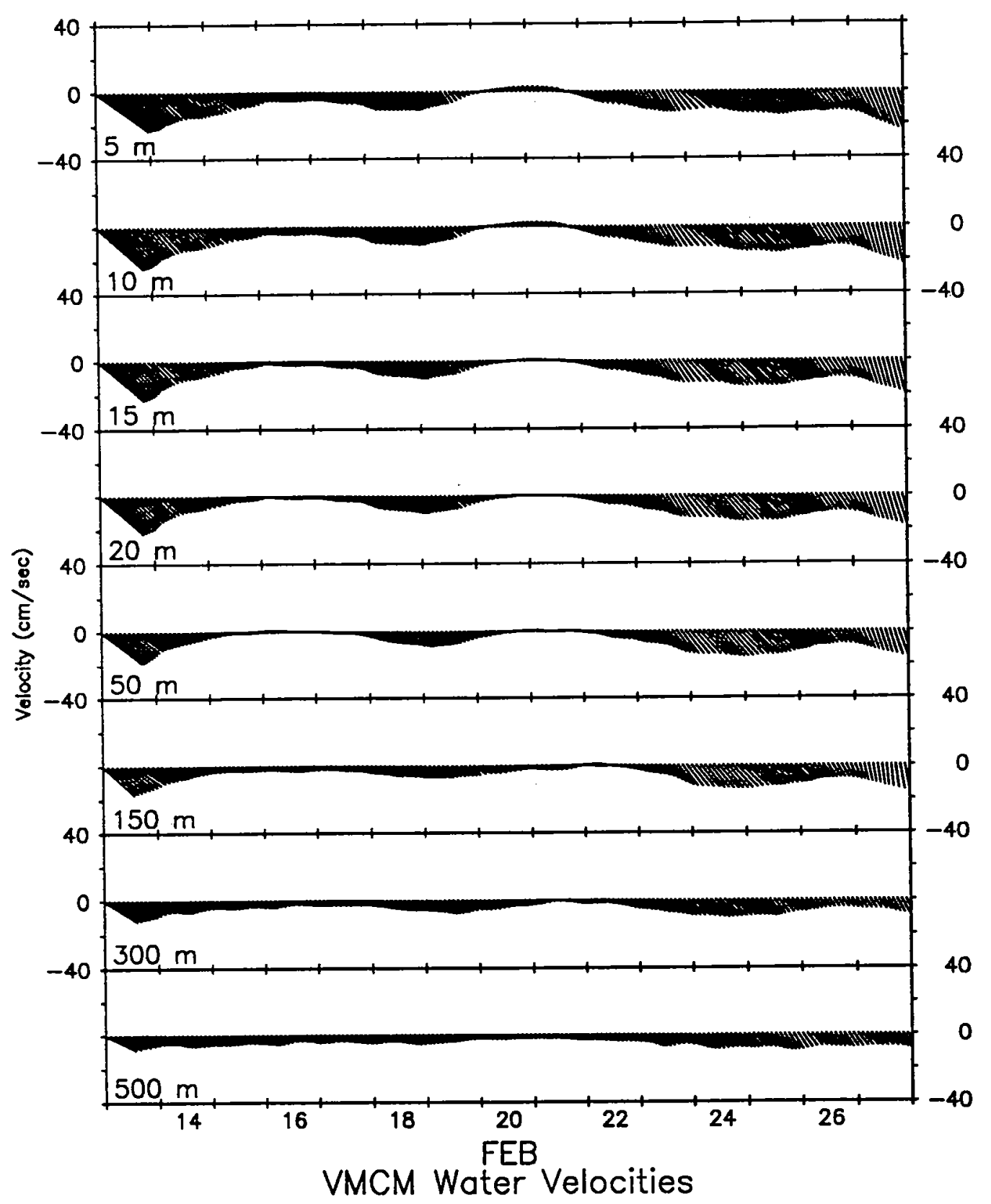

Figure 3.3.5: Sub-surface velocity vectors at 8 depths. Northerly component is towards top of page. Data is filtered over 48 hours and subsampled at 2 hours before plotting. 


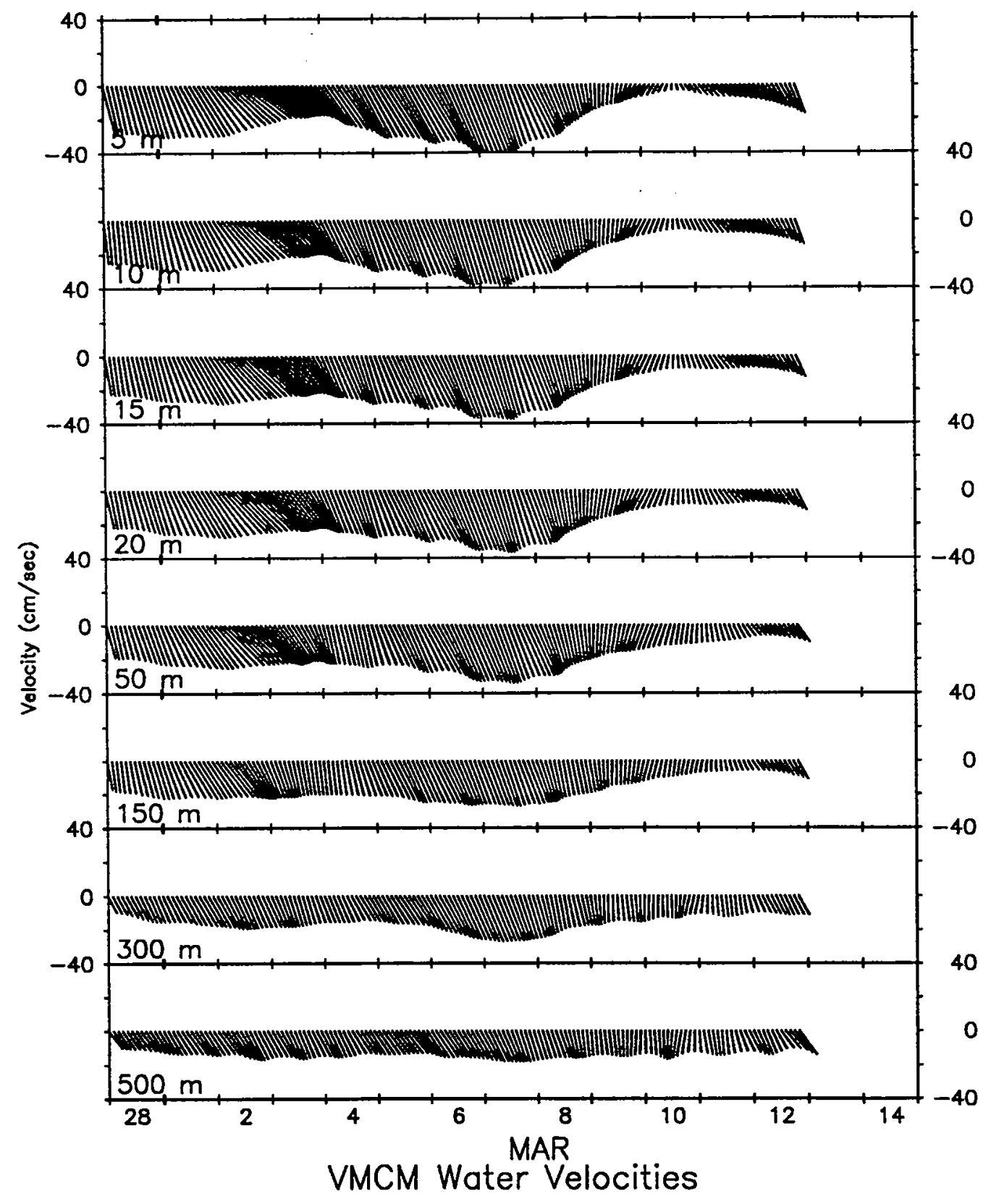

Figure 3.3.6: Sub-surface velocity vectors at 8 depths. Northerly component is towards top of page. Data is filtered over 48 hours and subsampled at 2 hours before plotting. 

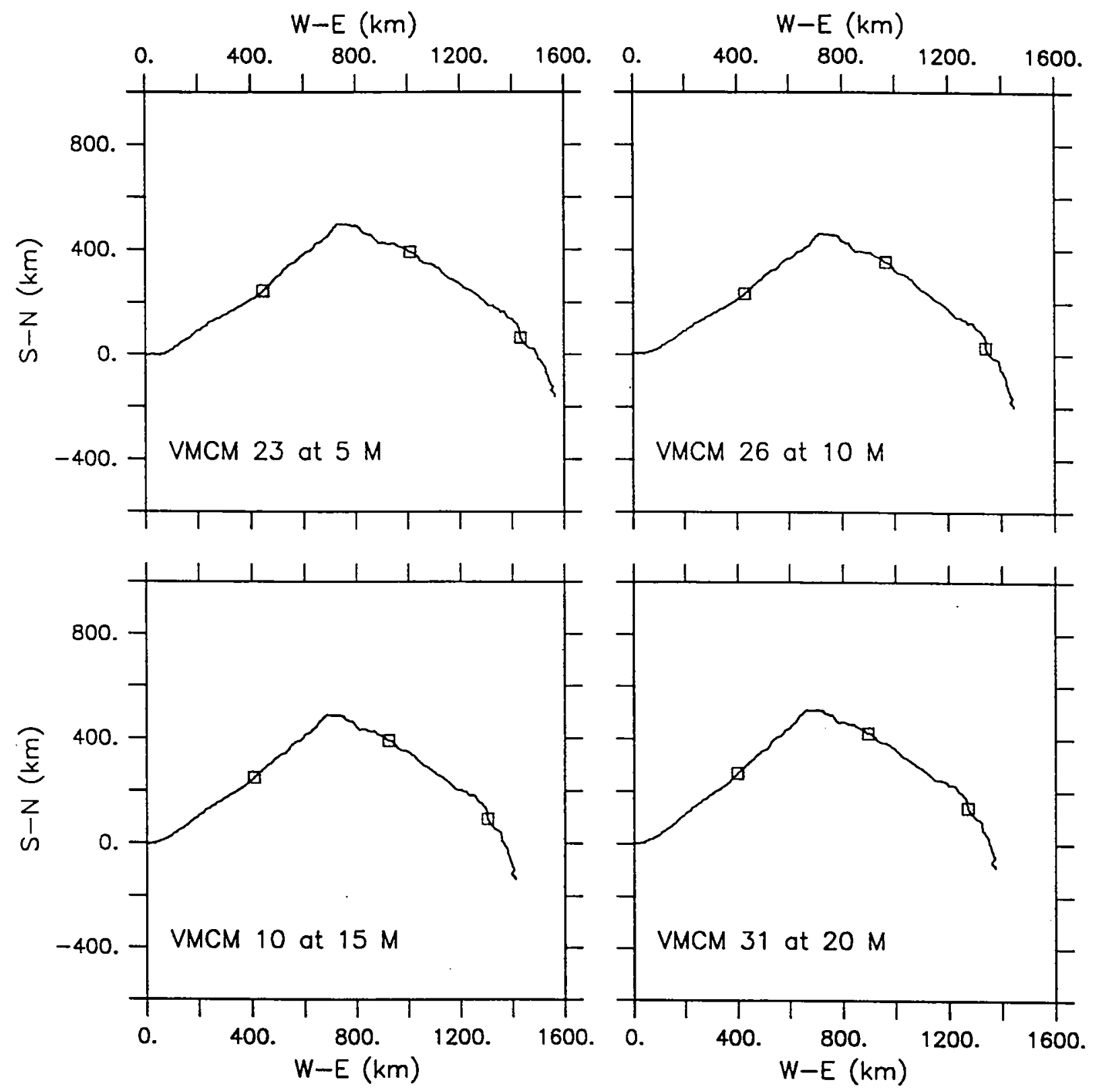

Start date $93 / 12 / 15$ 12:00

End date 94/03/13 12:00

Square symbols at new month

Figure 3.3.7: Progressive water velocity vectors at 4 depths, constructed from velocity data averaged over 4 hours. 

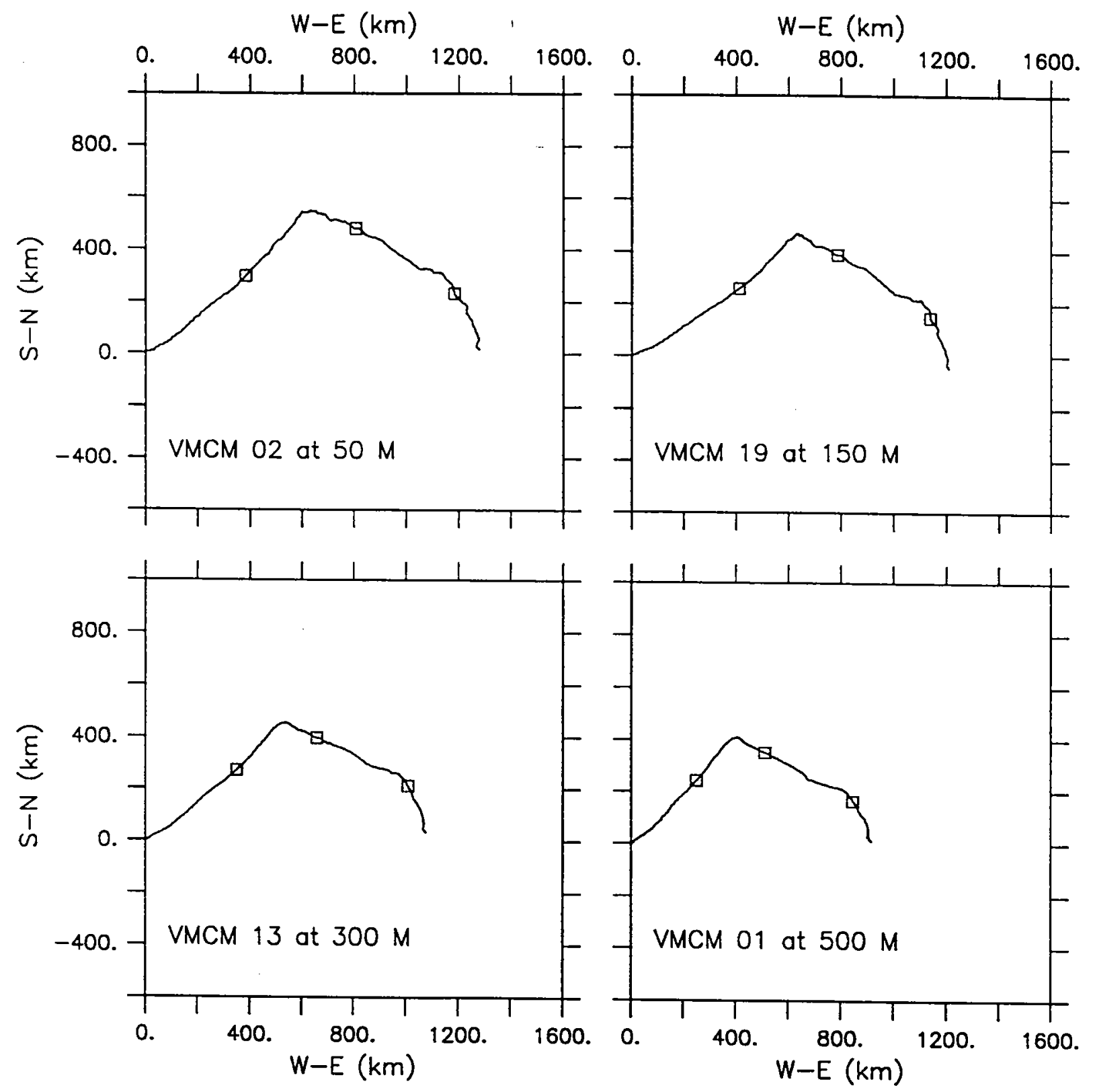

Start date $93 / 12 / 1512: 00$

End date $94 / 03 / 1312: 00$

Square symbols at new month

Figure 3.3.8: Progressive water velocity vectors at 4 depths, constructed from velocity data averaged over 4 hours. 

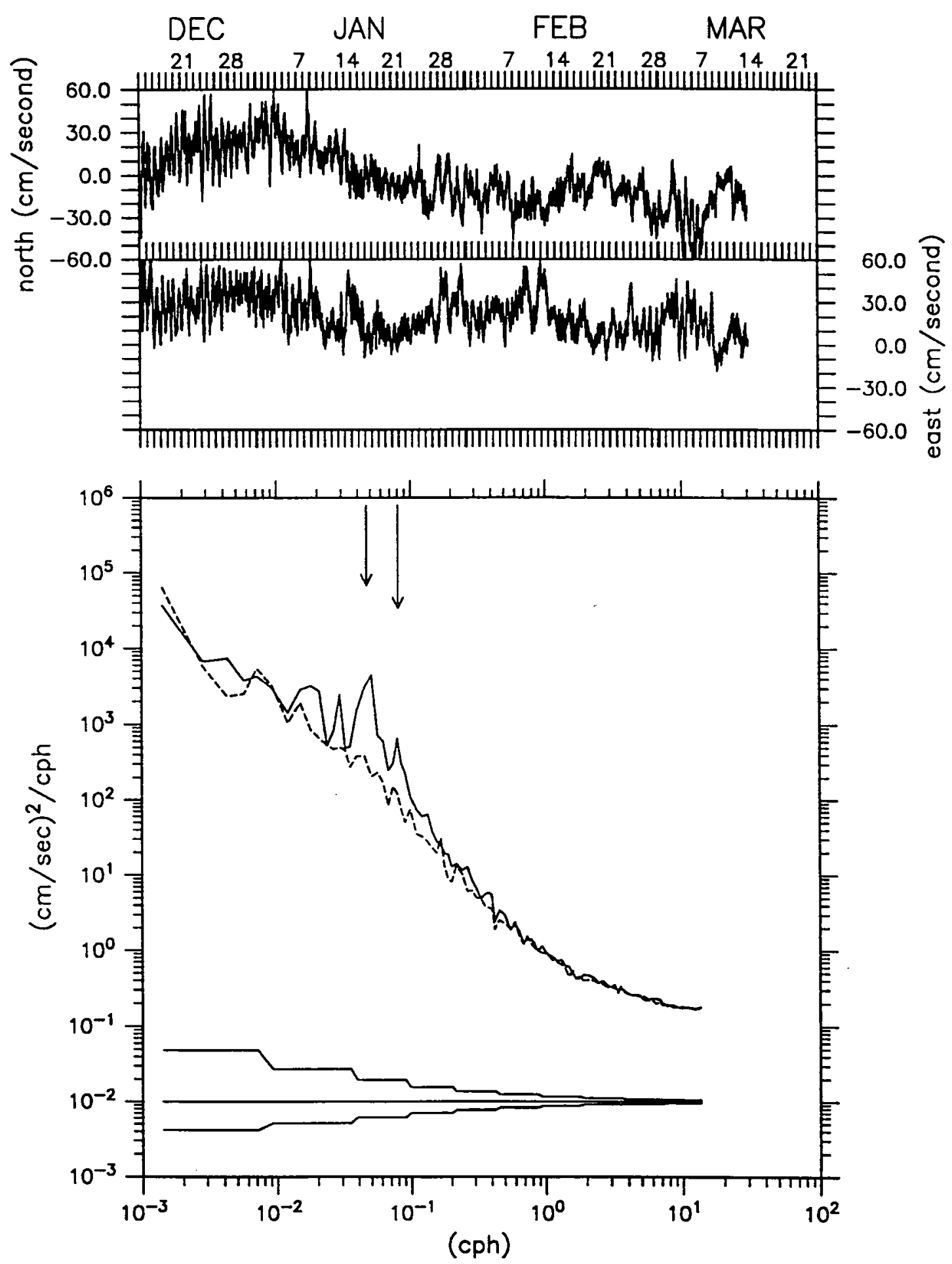

vmcm 23 at $5.0 \mathrm{~m}$

Figure 3.3.9: Velocity Time Series and Spectra at $5 \mathrm{~m}$. Solid curves show the clockwise component, and dashed curves show the counterclockwise component. Long arrow indicates semi-diurnal tidal frequency, short arrow indicates Coriolis frequency. 

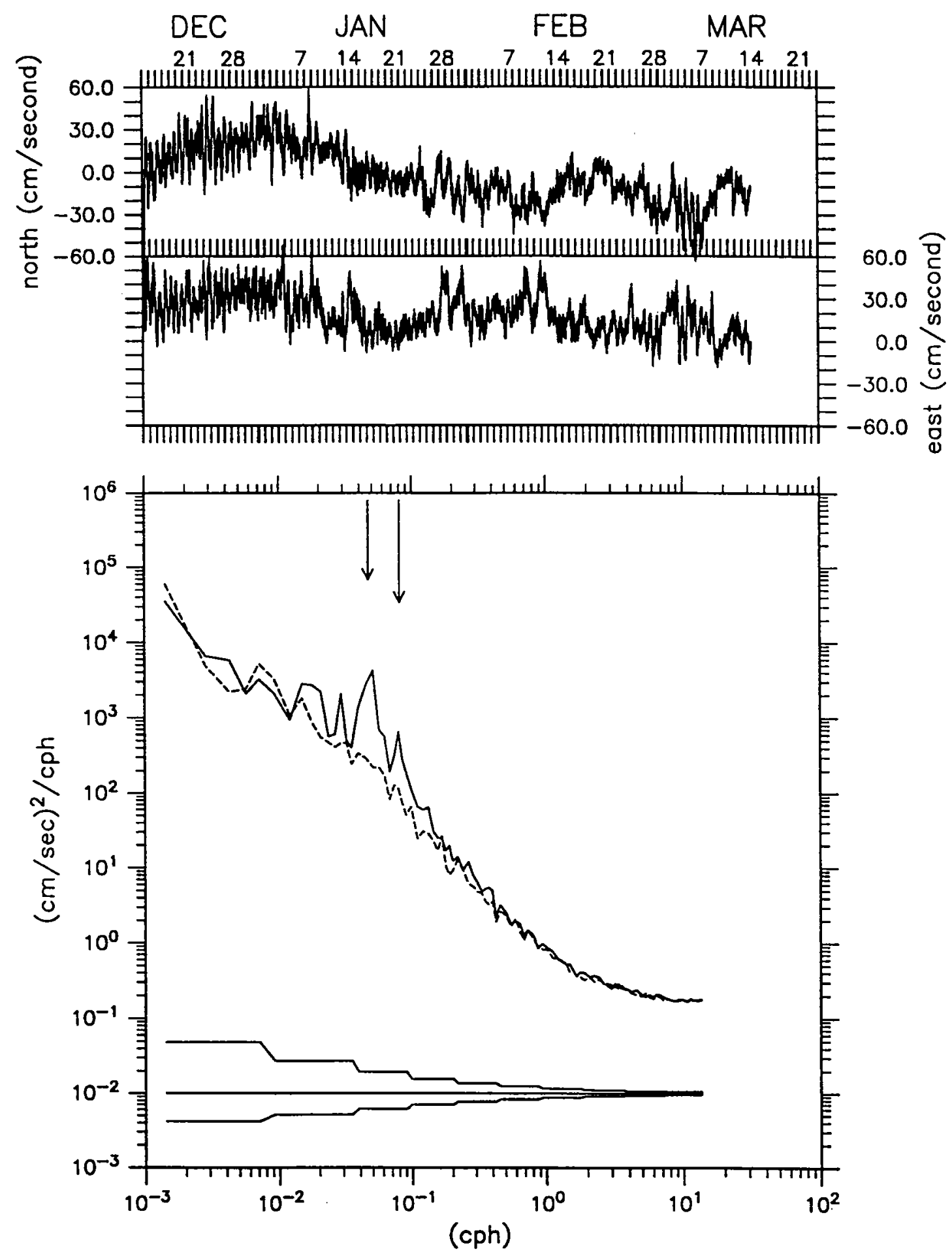

vmcm 26 at $10.0 \mathrm{~m}$

Figure 3.3.10: Velocity Time Series and Spectra at $10 \mathrm{~m}$. Solid curves show the clockwise component, and dashed curves show the counterclockwise component. Long arrow indicates semi-diurnal tidal frequency, short arrow indicates Coriolis frequency. 

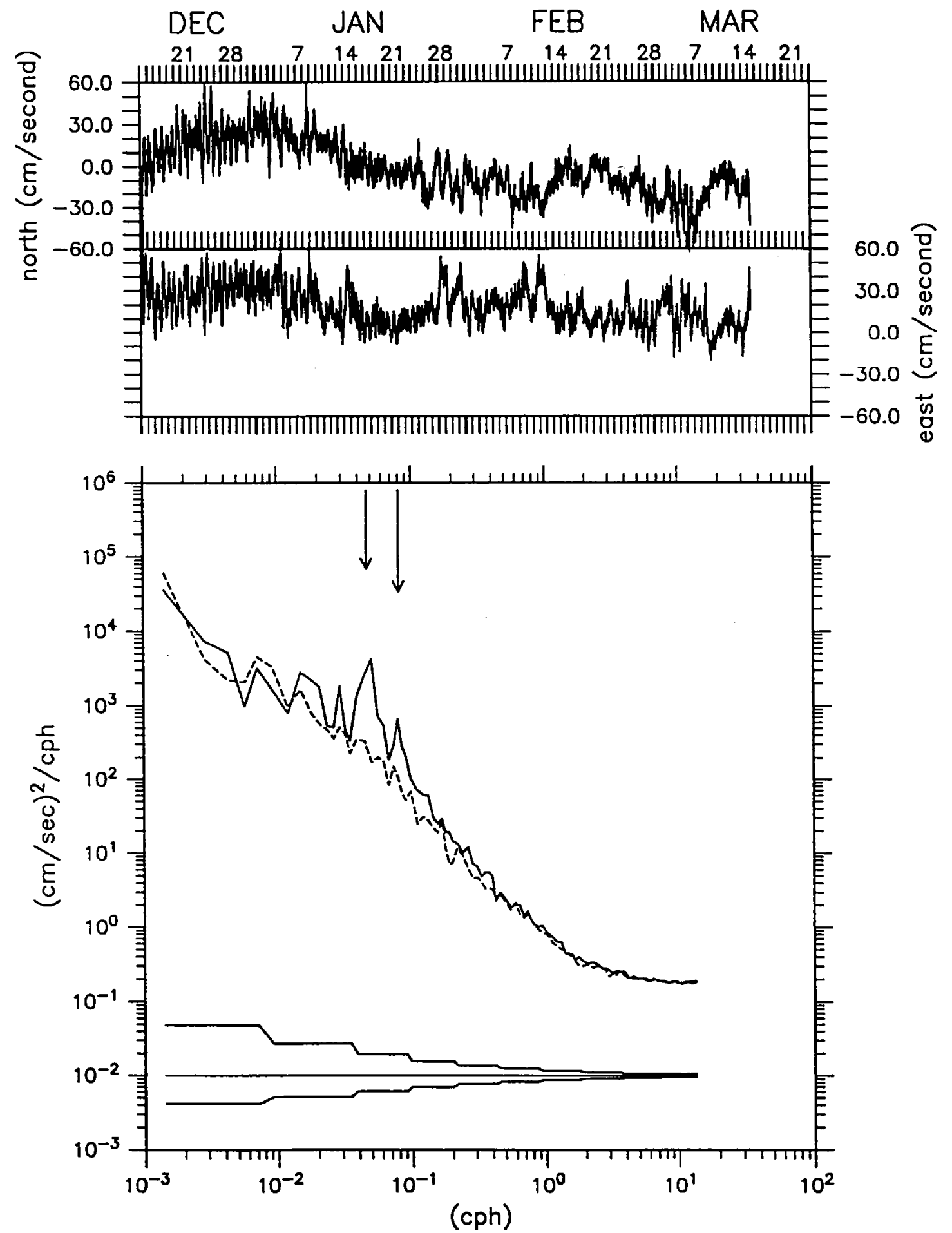

vmem 10 ot $15.0 \mathrm{~m}$

Figure 3.3.11: Velocity Time Series and Spectra at $15 \mathrm{~m}$. Solid curves show the clockwise component, and dashed curves show the counterclockwise component. Long arrow indicates semi-diurnal tidal frequency, short arrow indicates Coriolis frequency. 

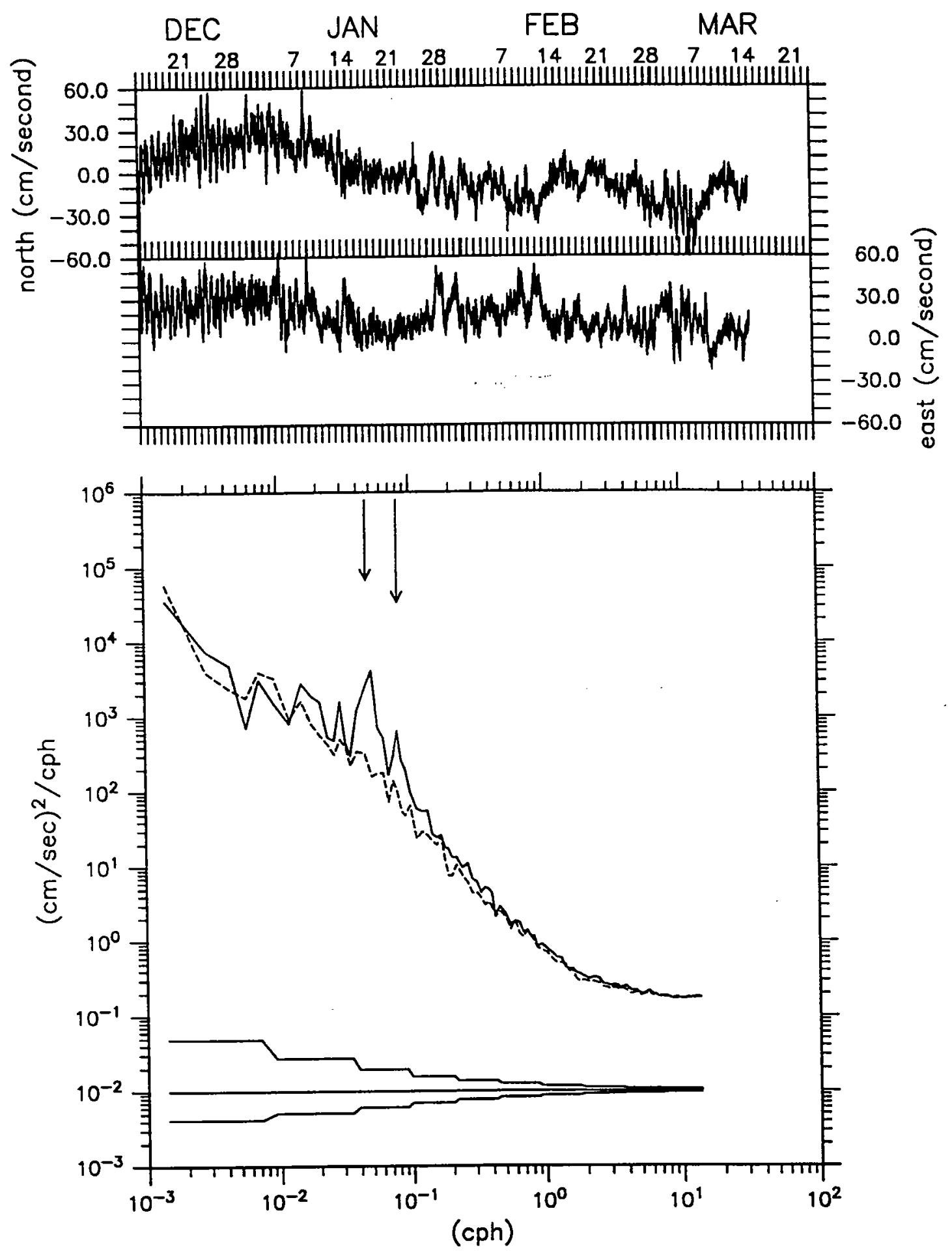

vmem 31 at $20.0 \mathrm{~m}$

Figure 3.3.12: Velocity Time Series and Spectra at $20 \mathrm{~m}$. Solid curves show the clockwise component, and dashed curves show the counterclockwise component. Long arrow indicates semi-diurnal tidal frequency, short arrow indicates Coriolis frequency. 

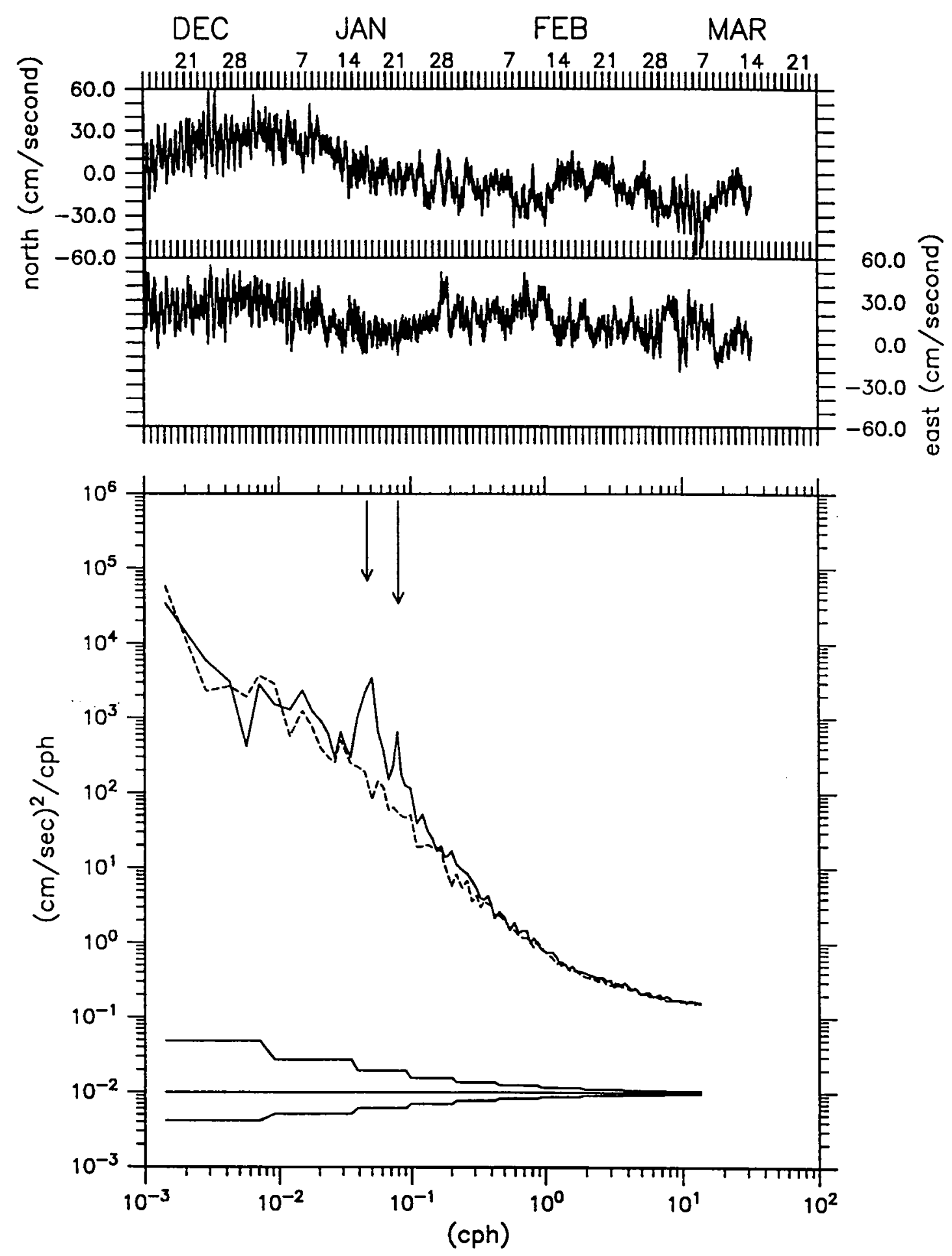

vmem 2 at $50.0 \mathrm{~m}$

Figure 3.3.13: Velocity Time Series and Spectra at $50 \mathrm{~m}$. Solid curves show the clockwise component, and dashed curves show the counterclockwise component. Long arrow indicates semi-diurnal tidal frequency, short arrow indicates Coriolis frequency. 

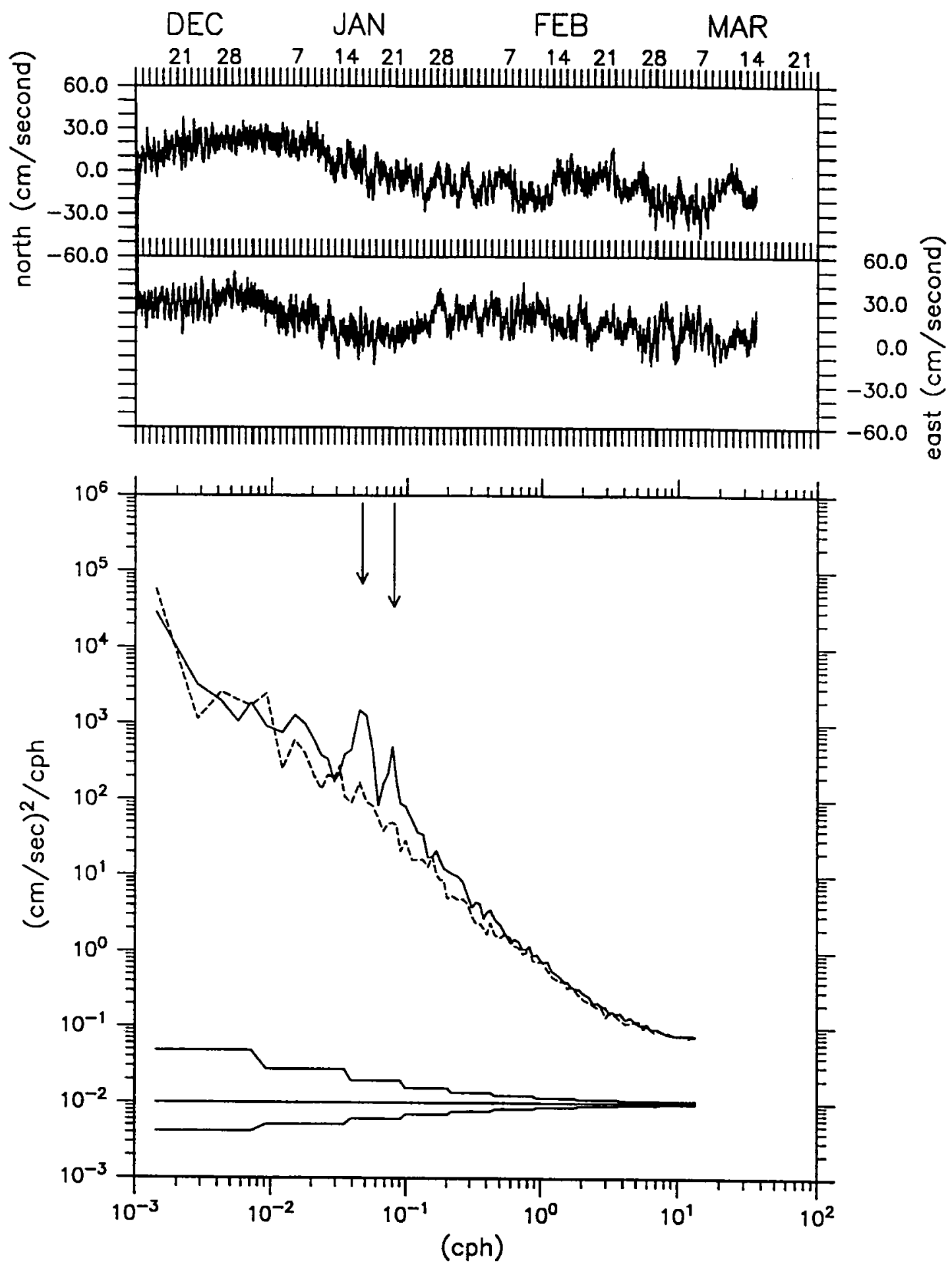

vmcm 19 at $150.0 \mathrm{~m}$

Figure 3.3.14: Velocity Time Series and Spectra at $150 \mathrm{~m}$. Solid curves show the clockwise component, and dashed curves show the counter-clockwise component. Long arrow indicates semi-diurnal tidal frequency, short arrow indicates Coriolis frequency. 

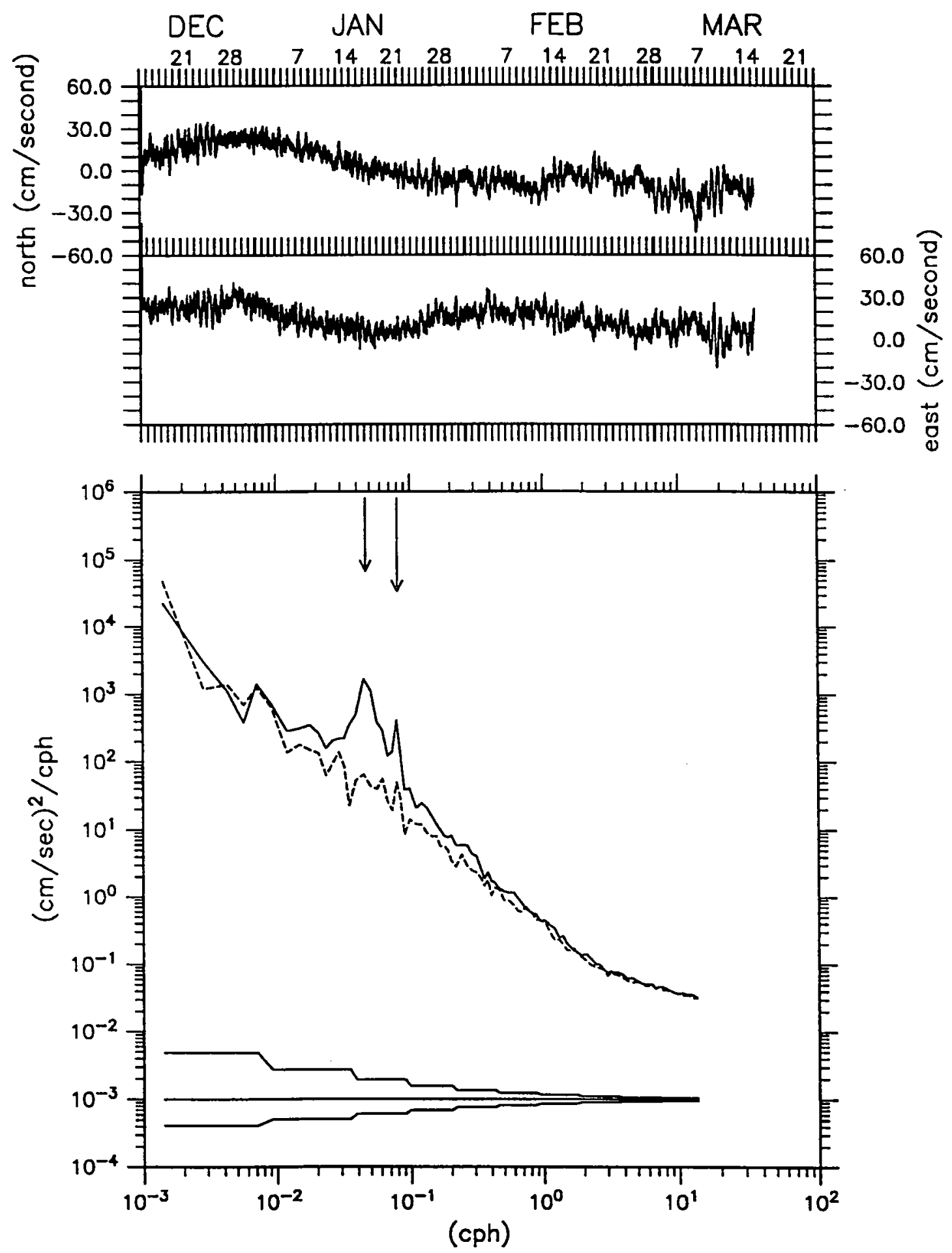

vmem 13 at $300.0 \mathrm{~m}$

Figure 3.3.15: Velocity Time Series and Spectra at $300 \mathrm{~m}$. Solid curves show the clockwise component, and dashed curves show the counter-clockwise component. Long arrow indicates semi-diurnal tidal frequency, short arrow indicates Coriolis frequency. 

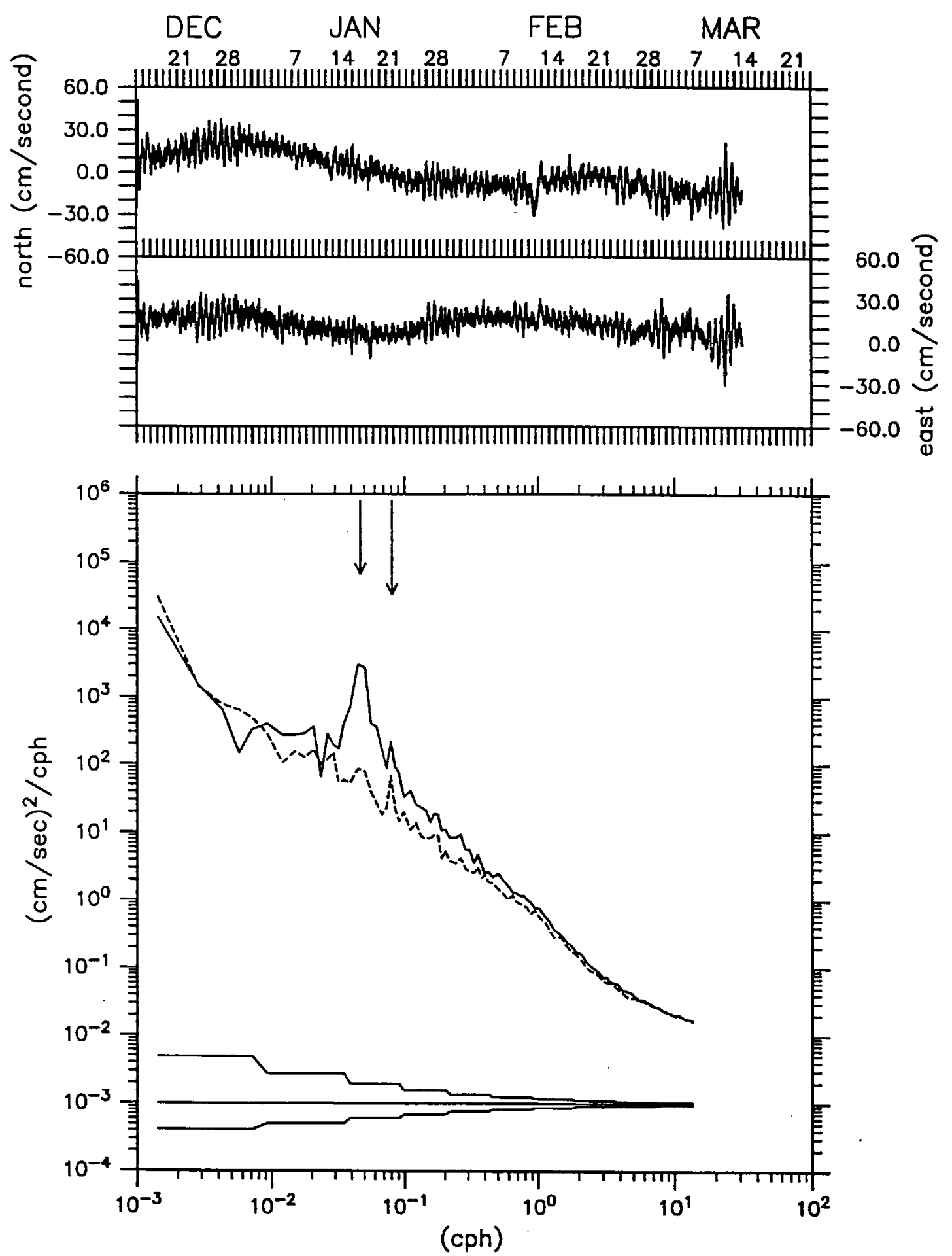

vmem 1 at $500.0 \mathrm{~m}$

Figure 3.3.16: Velocity Time Series and Spectra at 500m. Solid curves show the clockwise component, and dashed curves show the counter-clockwise component. Long arrow indicates semi-diurnal tidal frequency, short arrow indicates Coriolis frequency. 


\subsection{Wave Measurements}

\subsubsection{Nondirectional Wave Parameters}

Figures 3.4.1-3.4.3 shows time series of wave parameters measured from the Seatex buoy. The significant wave height and period were computed as follows. The interval between successive zero-up crossings of the sea-surface height was defined as corresponding to a single wave. The height of this wave was defined as the difference between the maximum and minimum surface heights. The period of the wave was defined as the time interval between the successive zero-up-crossings. The significant wave is defined as the height of the highest $1 / 3$ of the waves. The significant wave period is the mean period of the highest $1 / 3$ of the waves. The height of the largest wave seen during the 34 minute observing period is shown in the lower panel of each figure. During the deployment we see that the waves were in general quite large, with a peak significant height of 8.34 meters at $12 \mathrm{Z}$ on 2 March 94 . The largest wave seen during the entire deployment (12.7 meters in height) was seen earlier in the experiment (12Z on 26 Dec 93).

\subsubsection{Spectral Evolution}

Figures 3.4.4-3.4.6 show the evolution of the energy in the surface wave field as a function of frequency over the course of the ASREX III experiment. Contours are $\log 10$ spectral density. The heavy dashed lines show some of the clearly identifiable events corresponding to locally generated wind sea for which the frequency of the peak of the spectrum increases with time. The straight heavy solid lines show identifiable swell propagation events for which the frequency of the peak of the spectrum decreases with time.

Directional wave spectra were calculated using the Maximum Entropy Method of Lygre and Krogstad (1986). Corrections to the measured direction of orientation due to buoy tilt were calculated and applied. The tilts were then rotated into geographic coordinates. The spectra and cross-spectra of the heave and tilt were calculated with corrections being made for sensor response and buoy transfer function. The resulting heave and tilt spectra, quadrature spectrum of heave and north and east tilt, and cospectrum of north and east tilt were input to the Maximum Entropy routine of Lygre and Krogstad, and directional spectra were produced. The MATLAB code used to produce these spectra is given in Appendix 4. If the resulting spectra are integrated over frequency, one may get a sense of how the wave energy depends on direction. Figures 3.4.7-3.4.9 show contour plots of the wave energy as a function of direction. The plot shows the direction towards which the waves were propagating, with the wind direction superimposed. The directional distribution of wave energy in general reflects the wind direction, though there are some cases where there are differences. Figures 3.4.10-3.4.139 show the Seatex directional wave spectra. The wind direction is superimposed on each contour plot. No data was obtained from $03 Z 8$ February until $00 Z 9$ February or from 03Z 14 March to $00 Z 15$ March, due to tape write errors. 


\section{Acknowledgments}

The Seatex moorings were designed by George Tupper. The moorings were fabricated in the WHOI rigging shop by David Simoneau. John Kemp of the Ocean Acoustics Laboratory supervised the mooring deployment and recovery, which was carried out with expert help from the crews of the R/V Knorr and R/V Edwin Link. We would like to acknowledge assistance from Seatex A/S during the course of the experiment. This work was supported by the Ocean Acoustics Program (Code 324OA) of the Office of Naval Research under contract N00014-91$\mathrm{J}-1891$. 


\section{References}

Alados-Arboledas, L., J. Vida, and J. I. Jimenez, 1988. Effects of solar qradiation on the performance of pyrgeometers with silicon domes, J. Atmos. Oceanic Tech., 5:666-670.

Large, W. G. and S. Pond, 1981. Open ocean momentum flux measurements in moderate to strong winds. J. Phys. Oceanogr., 11:324-336.

Large, W. G. and S. Pond, 1982. Sensible and latent heat flux measurements over the ocean. J. Phys. Oceanogr., 12:464-482.

Lygre A., and H. E. Krogstad, 1986. Maximum Entropy Estimation of the Directional Distribution in Ocean Wave Spectra, J. Phys. Oceanogr., 16:2052-2060.

McDaniel, S. T., 1993. Sea surface reverberation: A review, J. Acous. Soc. Am., 94:19051922. 
Significant Wave Height

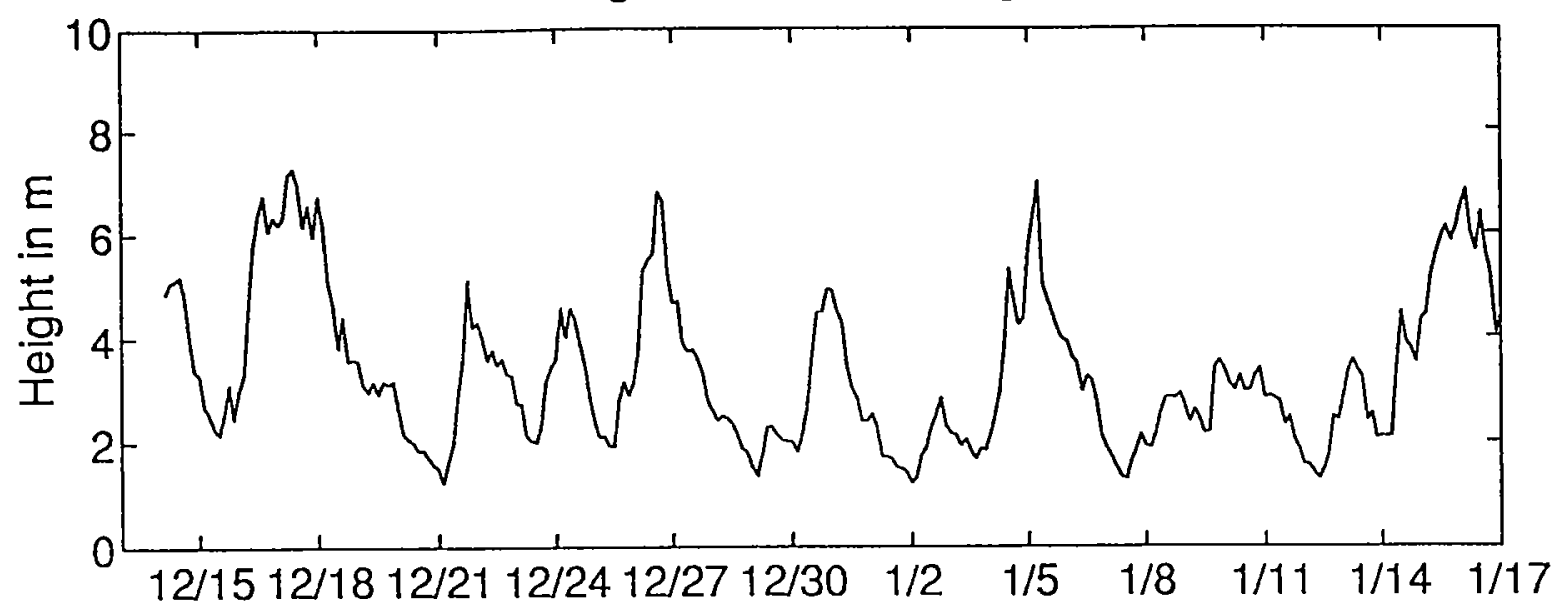

Maximum Wave Height

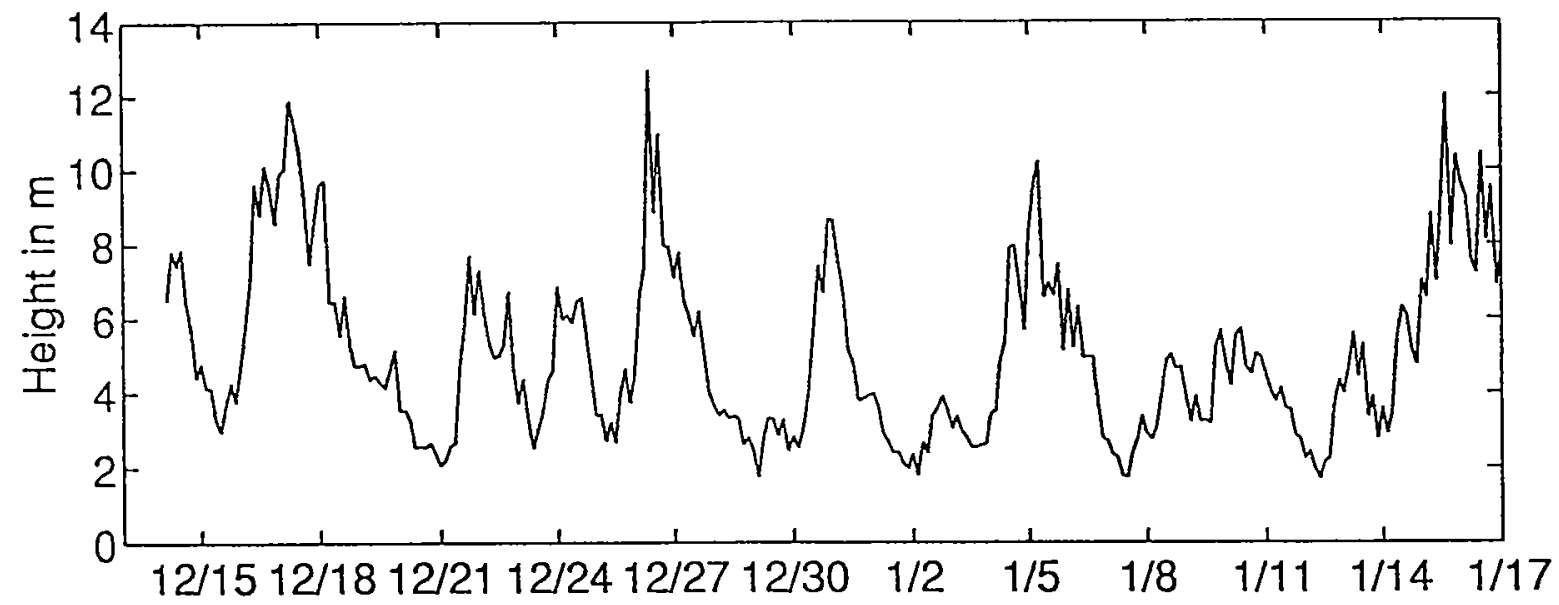

Significant Wave Period

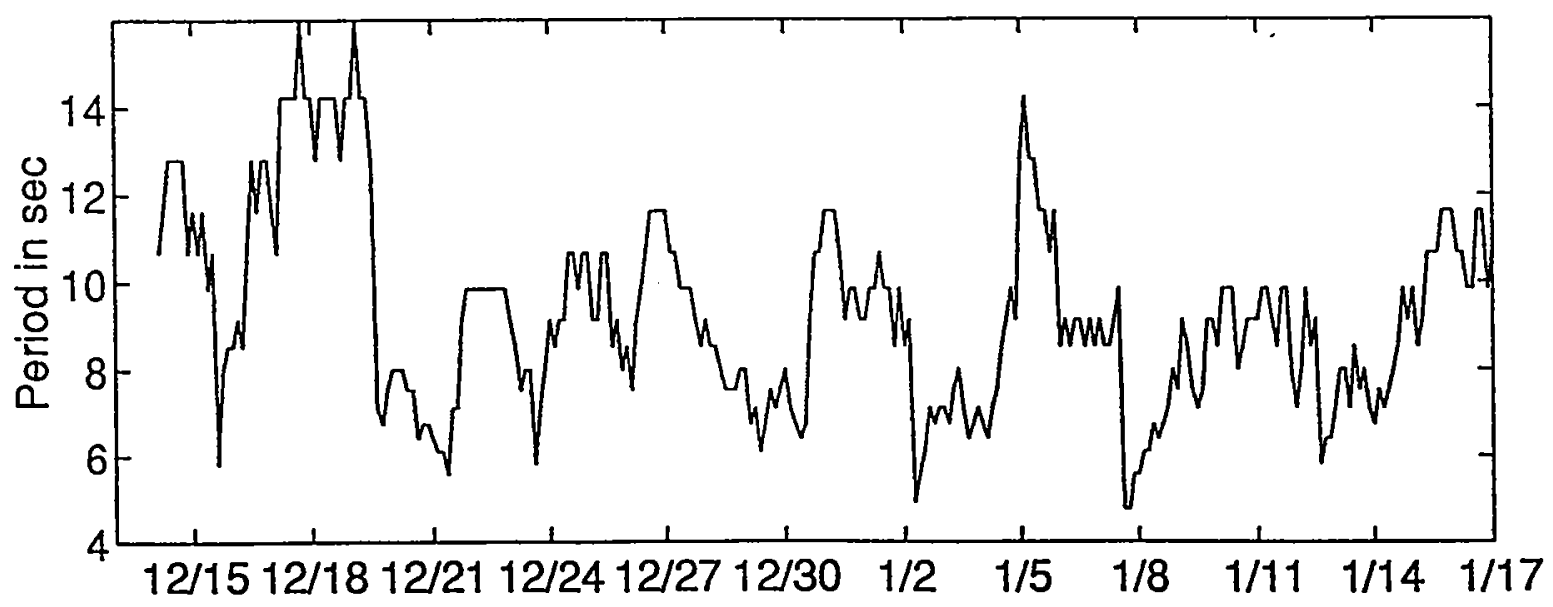

Figure 3.4.1: Nondirectional wave parameters. Significant wave height, maximum wave height, and significant wave period. 
Significant Wave Height
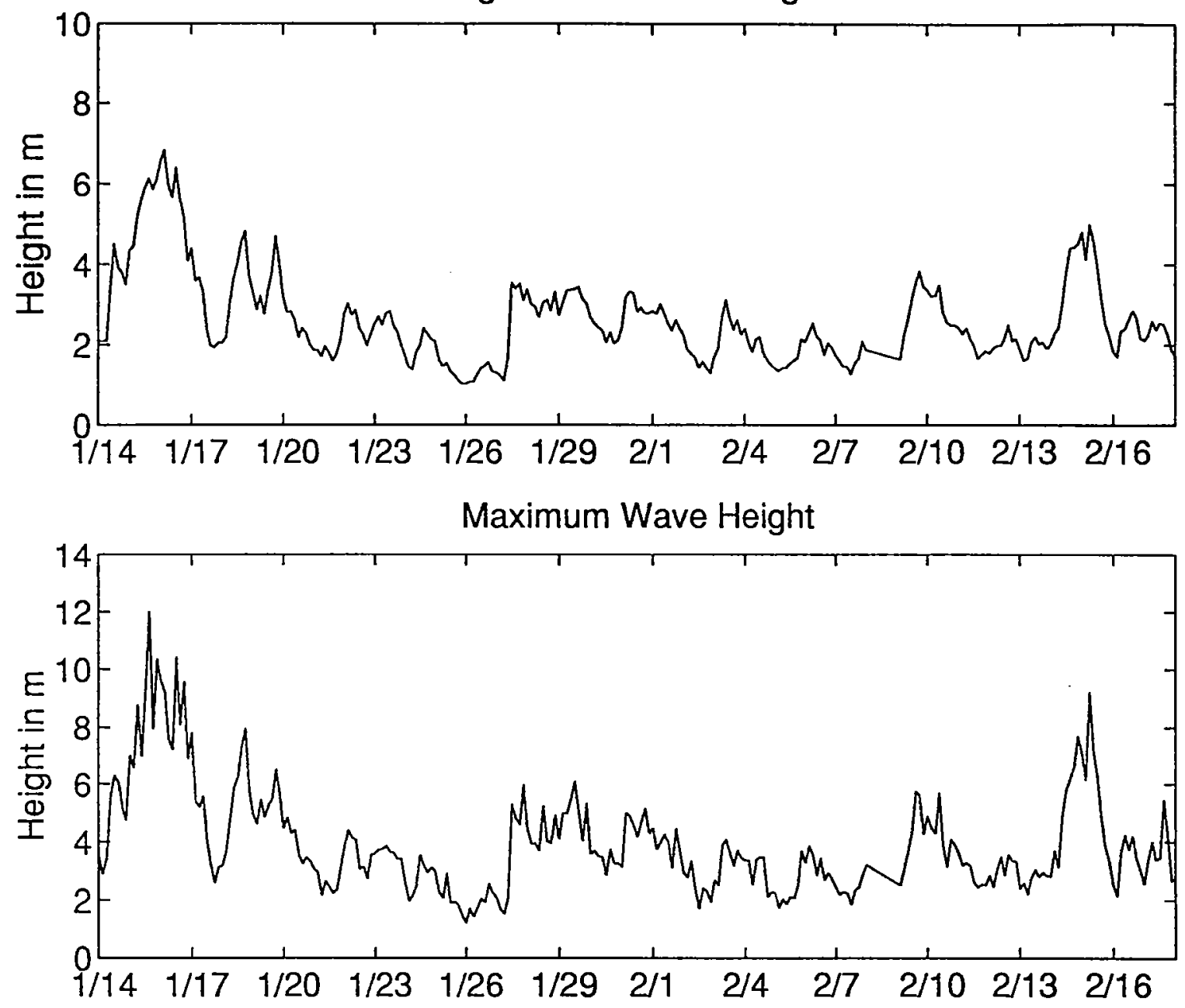

Significant Wave Period

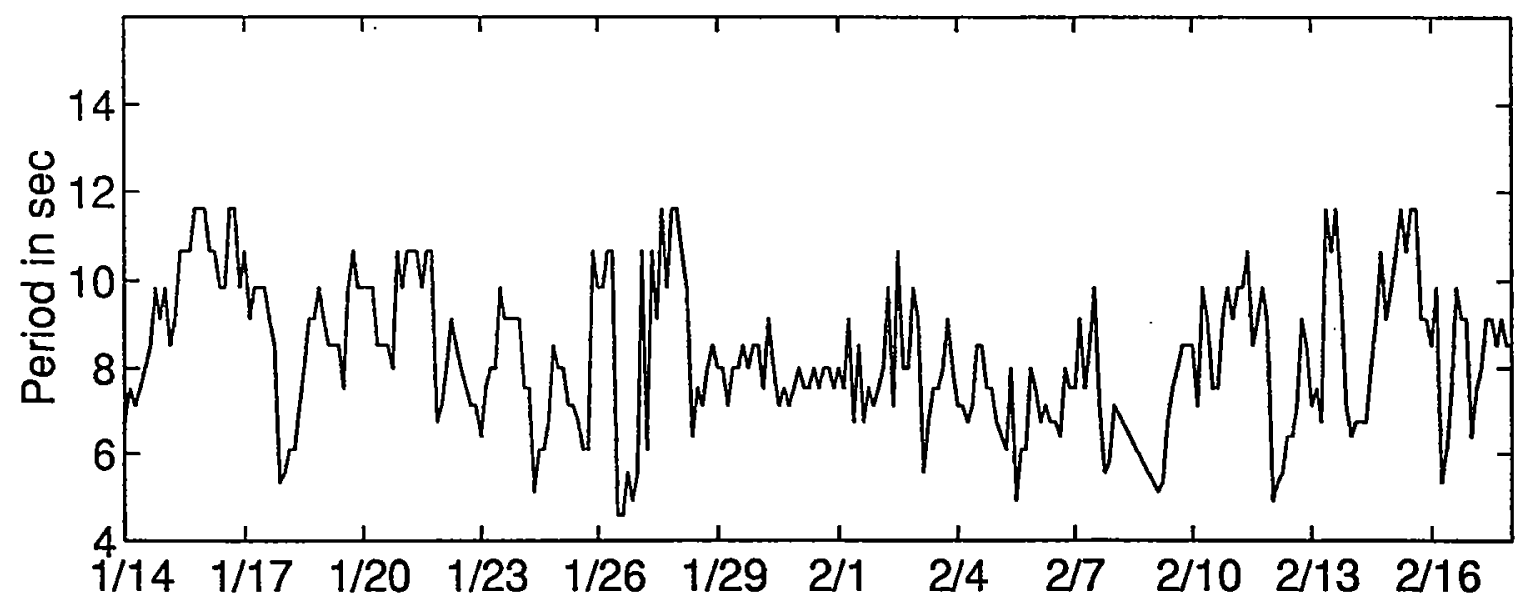

Figure 3.4.2: Nondirectional wave parameters. Significant wave height, maximum wave height, and significant wave period. 
Significant Wave Height
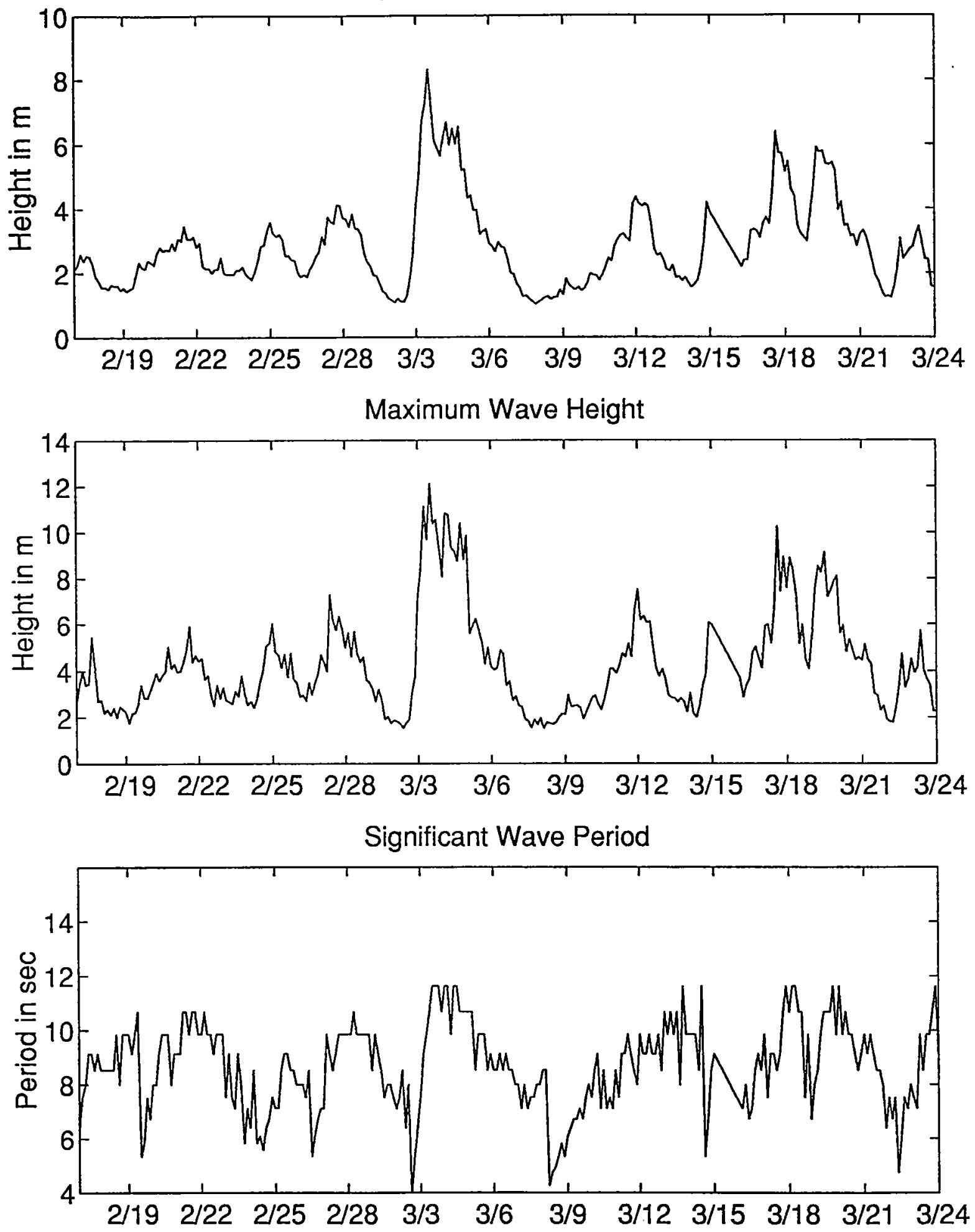

Figure 3.4.3: Nondirectional wave parameters. Significant wave height, maximum wave height, and significant wave period. 
Spectral Density

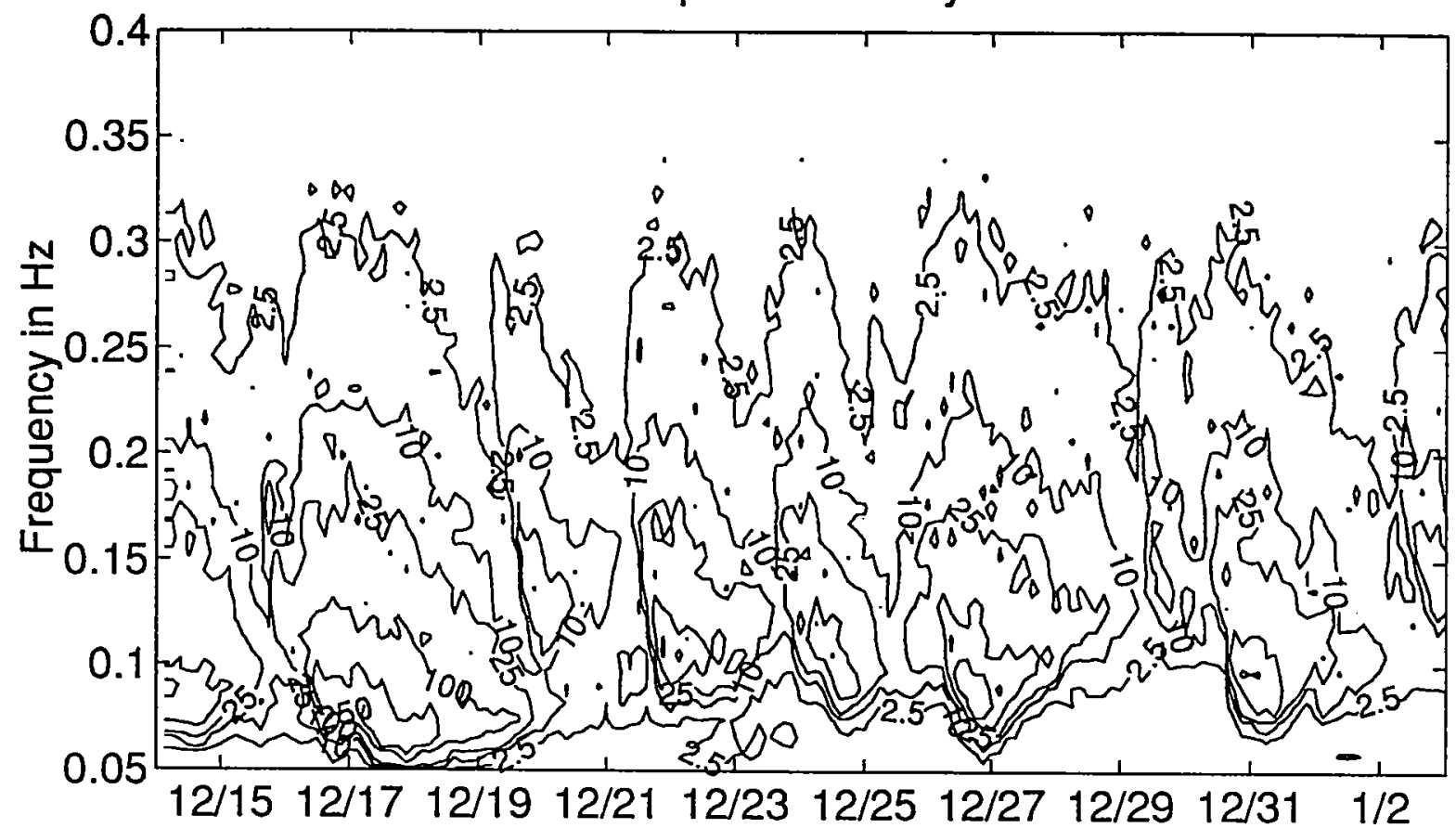

(a)

Spectral Density

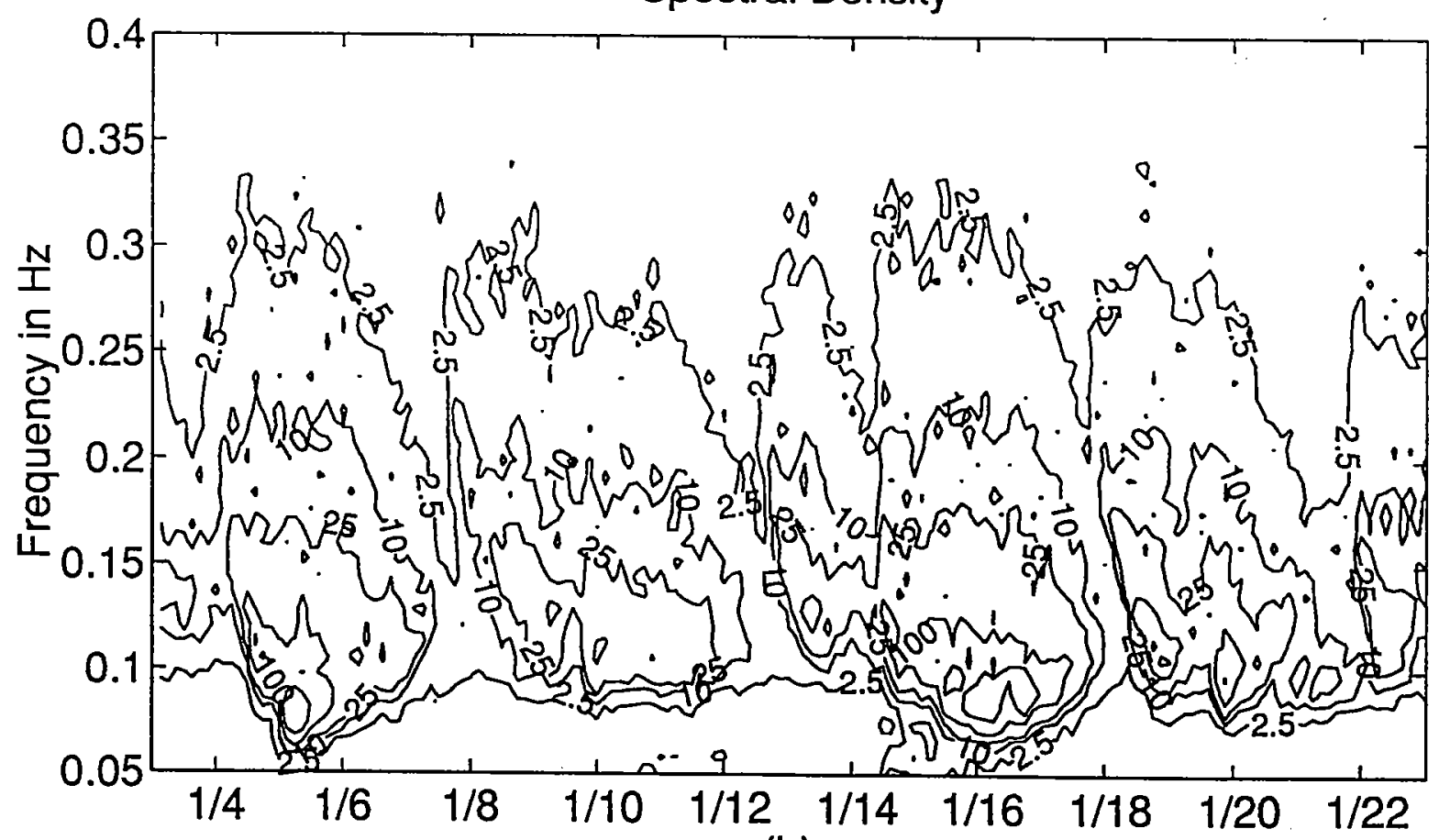

(b)

Figure 3.4.4: Spectral evolution of the surface waves. Contours of spectral density as a function of frequency over time. Contours are $2.5,10,25,100,250$. 


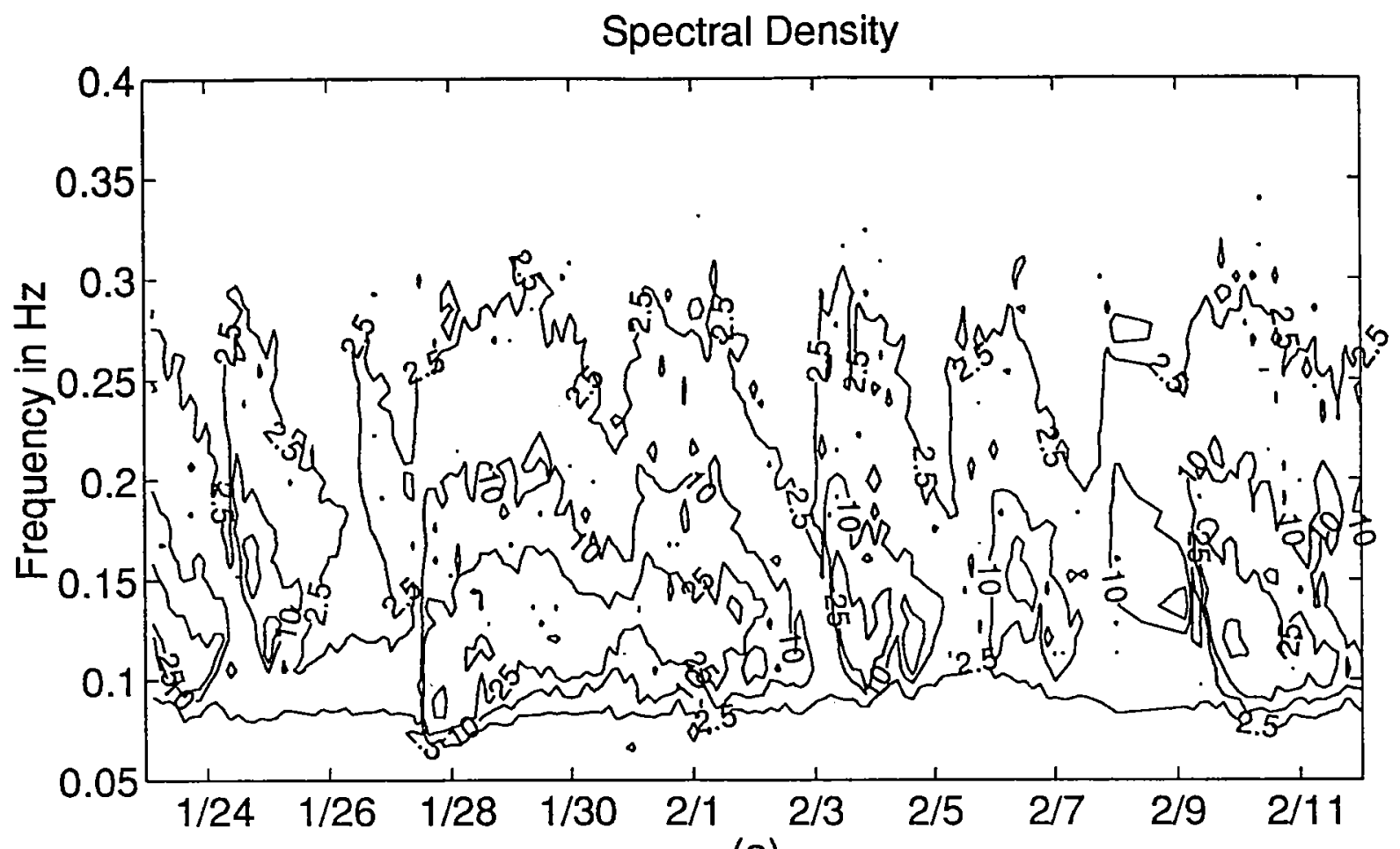

(a)

Spectral Density

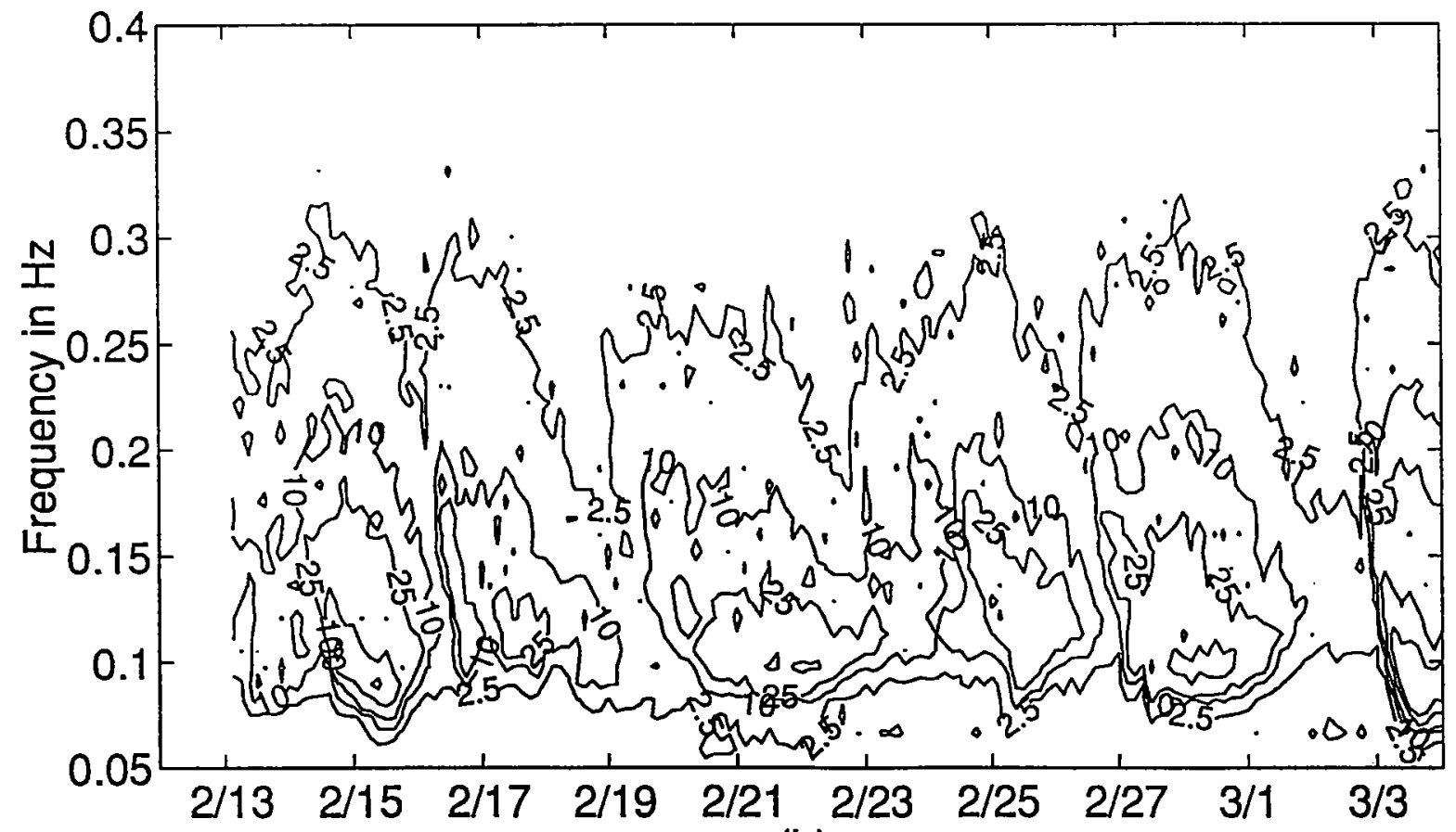

(b)

Figure 3.4.5: Spectral evolution of the surface waves. Contours of spectral density as a function of frequency over time. Contours ar 2.5, 10, 25, 100, 250. 


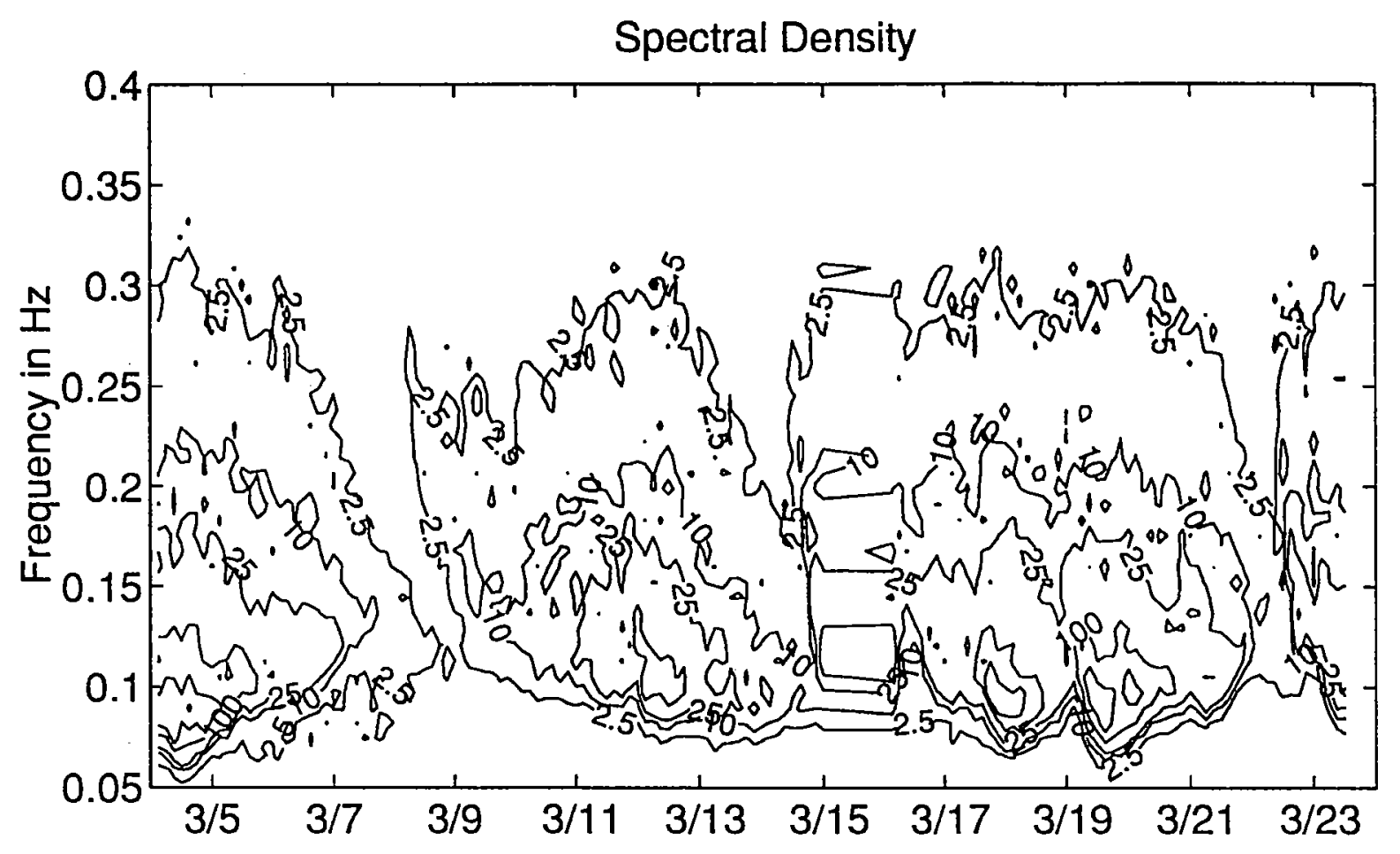

Figure 3.4.6: Spectral evolution of the surface waves. Contours of spectral density as a function of frequency over time. Contours are 2.5, 10, 25, 100, 250. 
Angular Spectral Density

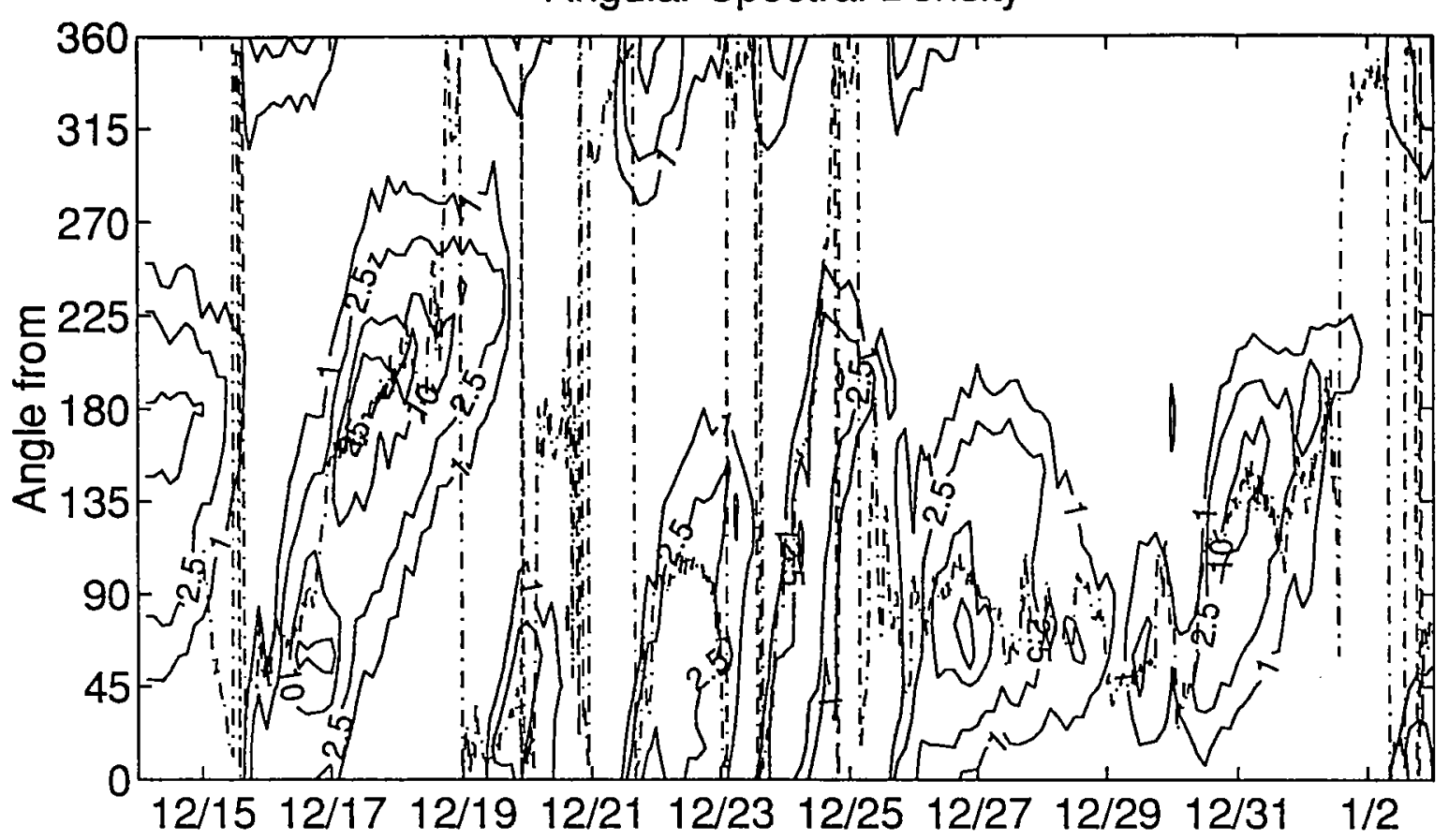

(a)

Angular Spectral Density

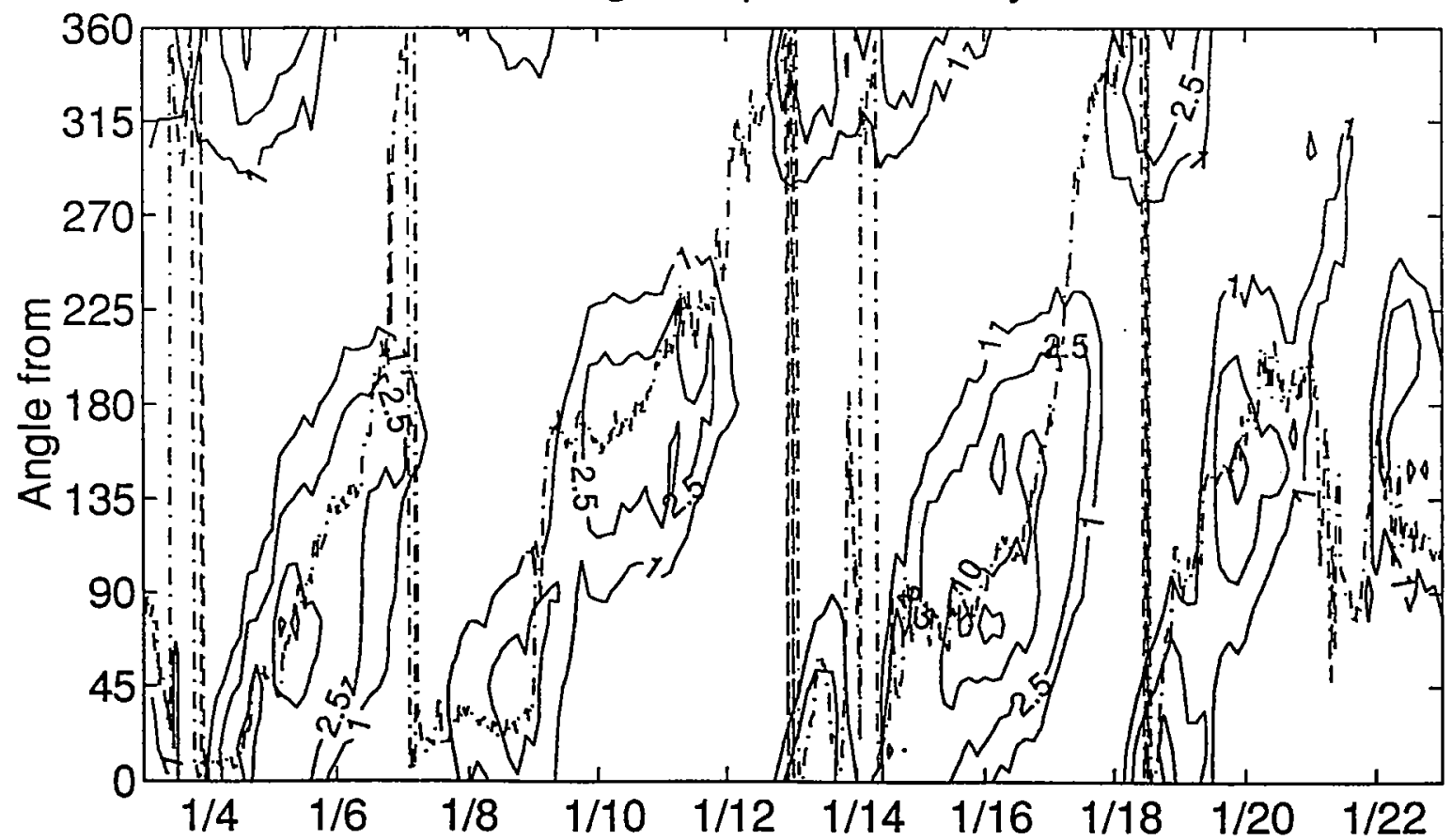

(b)

Figure 3.4.7: Directional evolution of the surface waves. Contours of spectral density as a function of direction. Contours are 1,2.5,10,25, 100, and 250. Wind direction is shown by chain-dot line. 

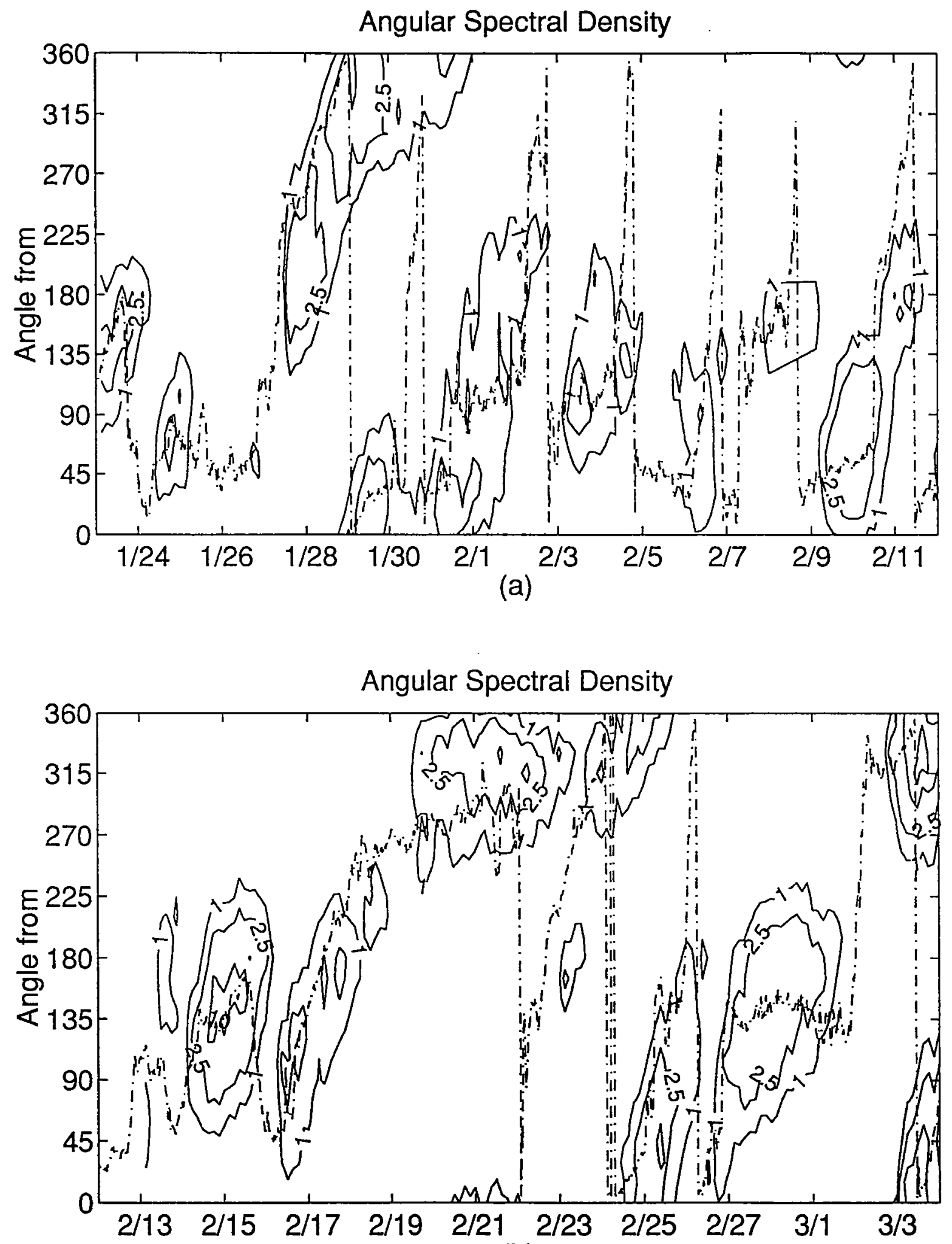

(b)

Figure 3.4.8: Directional evolution of the surface waves. Contours of spectral density as a function of direction. Contours are $1,2.5,10,25,100$, and 250. Wind direction is shown by chain-dot line. 
Angular Spectral Density

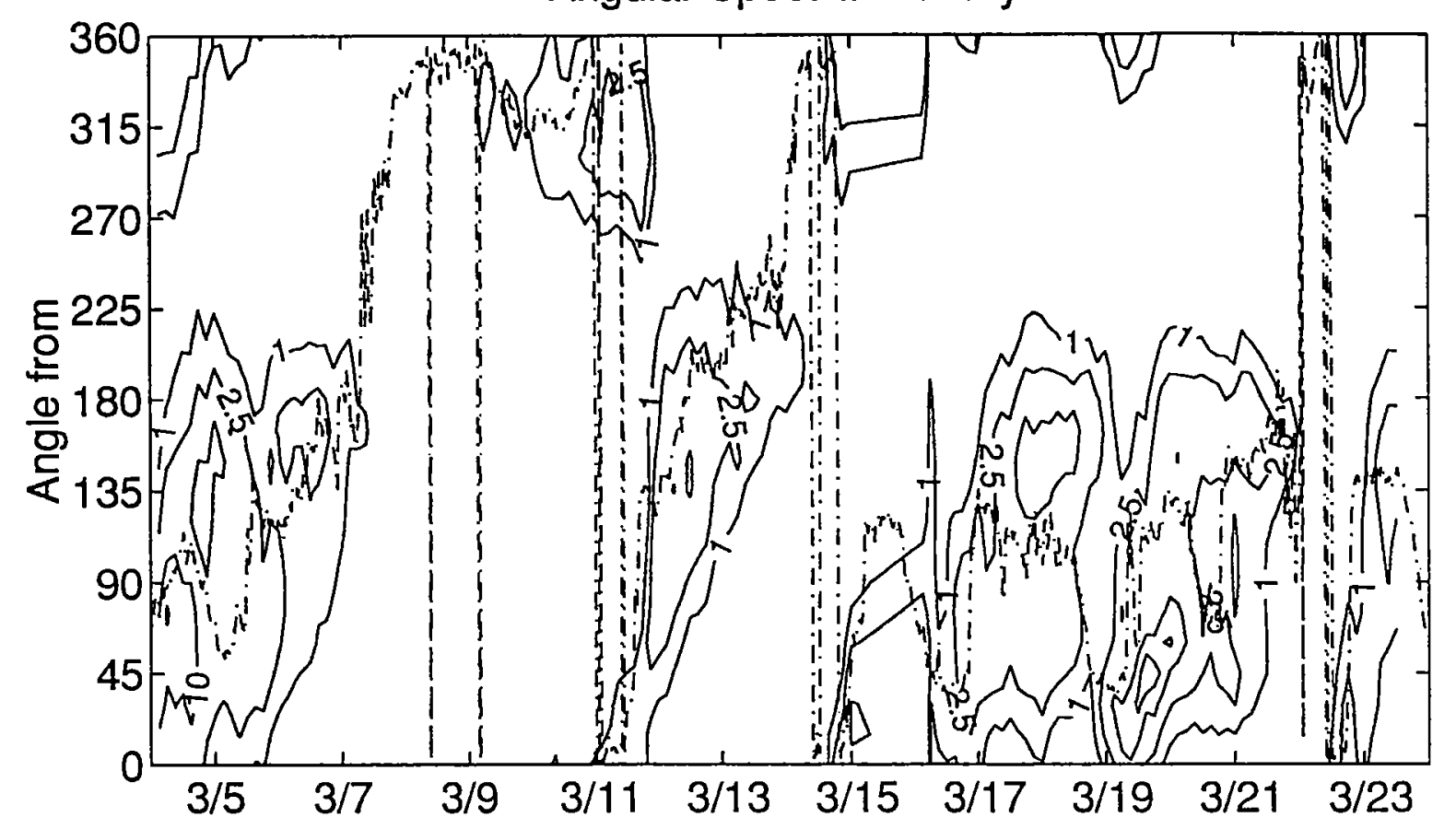

Figure 3.4.9: Directional evolution of the surface waves. Contours of spectral density as a function of direction. Contours are 1,2.5,10,25,100, and 250. Wind direction is shown by chain-dot line. 


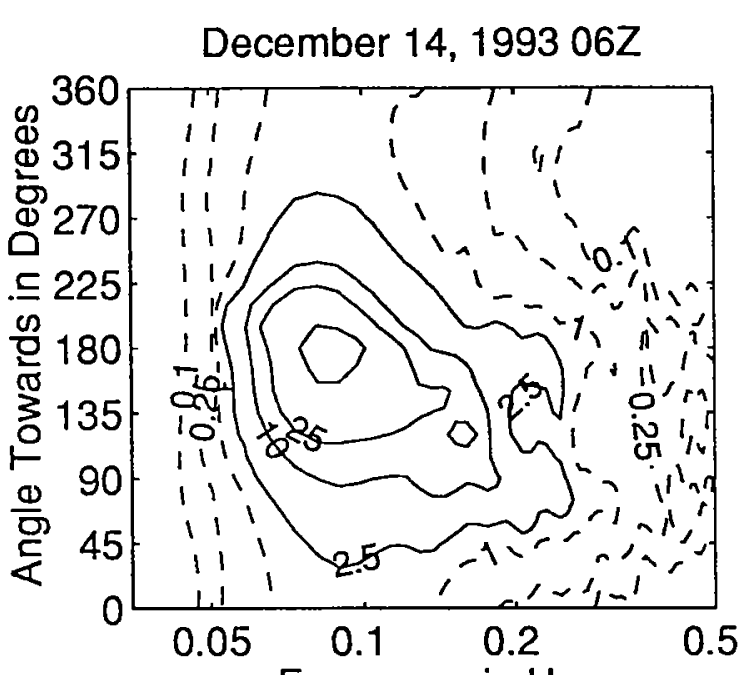

Frequency in $\mathrm{Hz}$

December 14, $199312 Z$

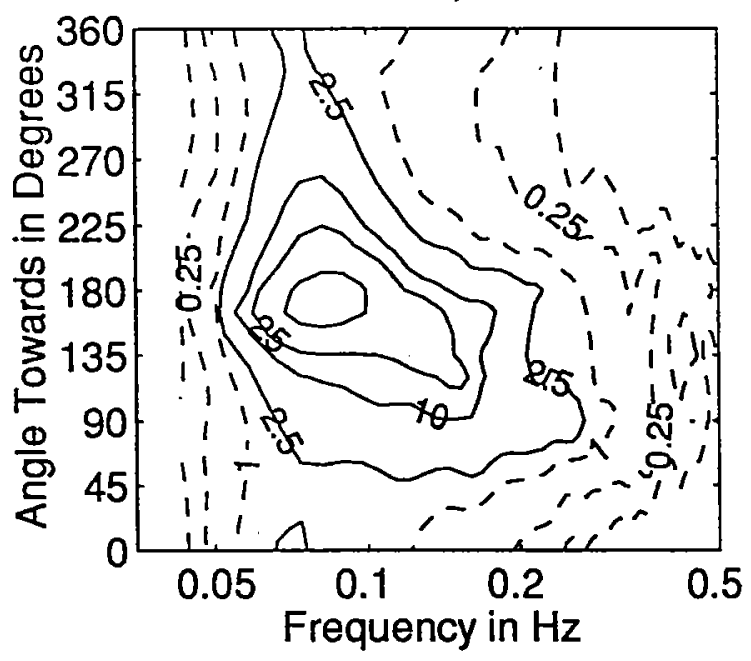

December 14, $199303 Z$

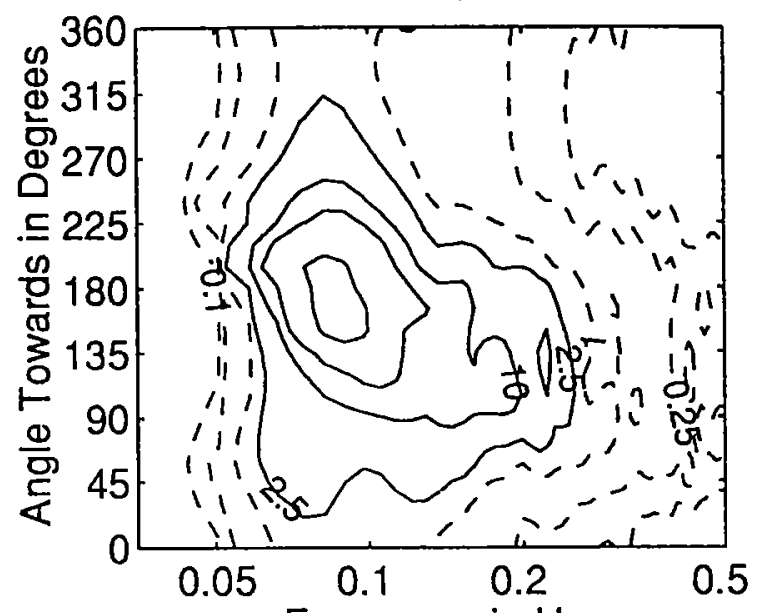

Frequency in $\mathrm{Hz}$

December 14, $199309 Z$

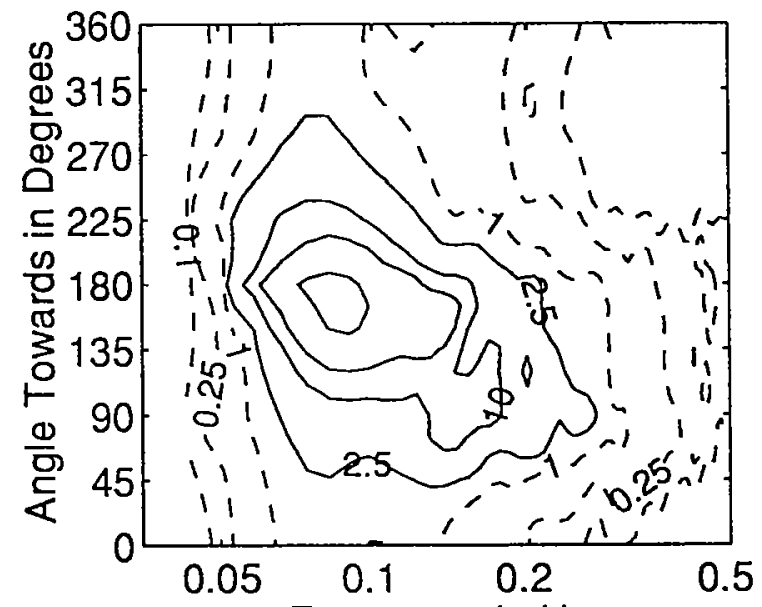

Frequency in $\mathrm{Hz}$

December $14,199315 Z$

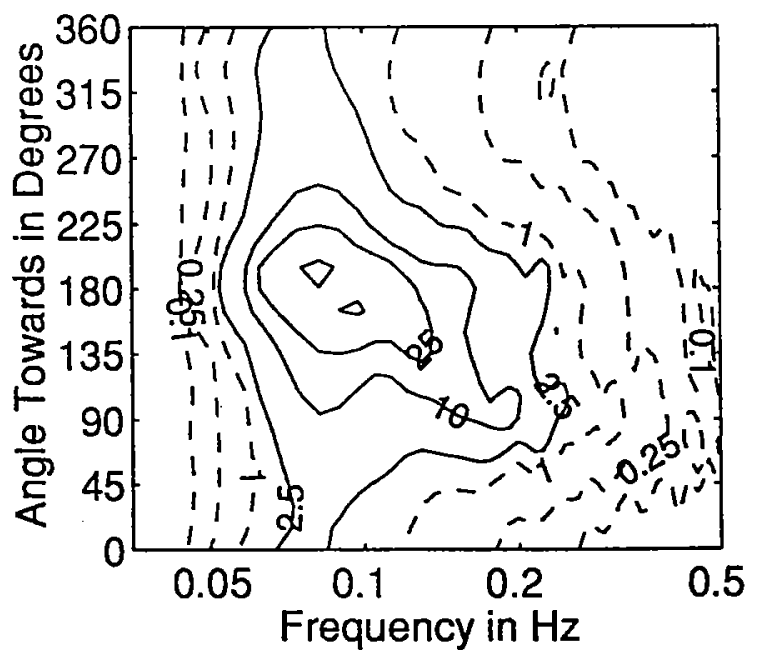

Figure 3.4.10: Directional wave spectra, computed using maximum entropy method. Contours of spectral density as a function of direction. Contours are 0.1, $0.25,1$ (dashed), $2.5,10,25,100$, and 250 (solid). Wind direction is shown by thick dashed line. 
December 14, $199318 Z$
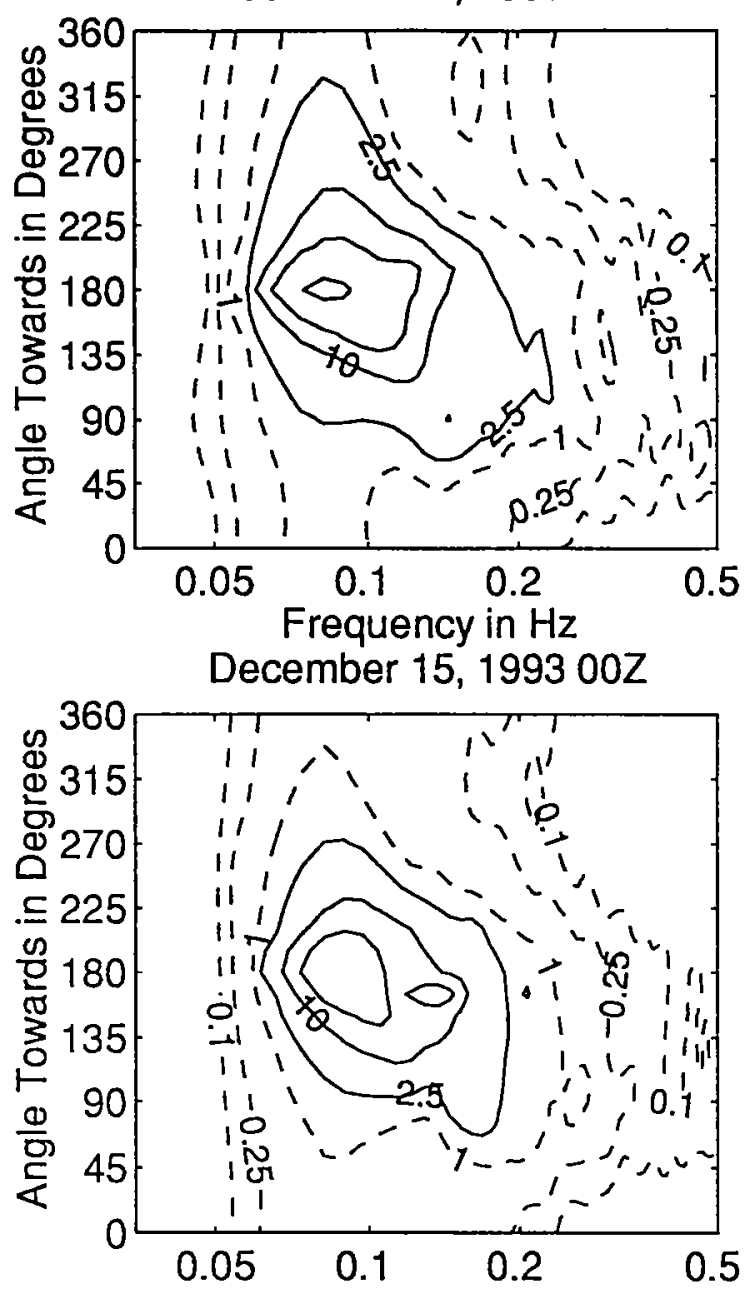

Frequency in $\mathrm{Hz}$ December 15, $199306 Z$

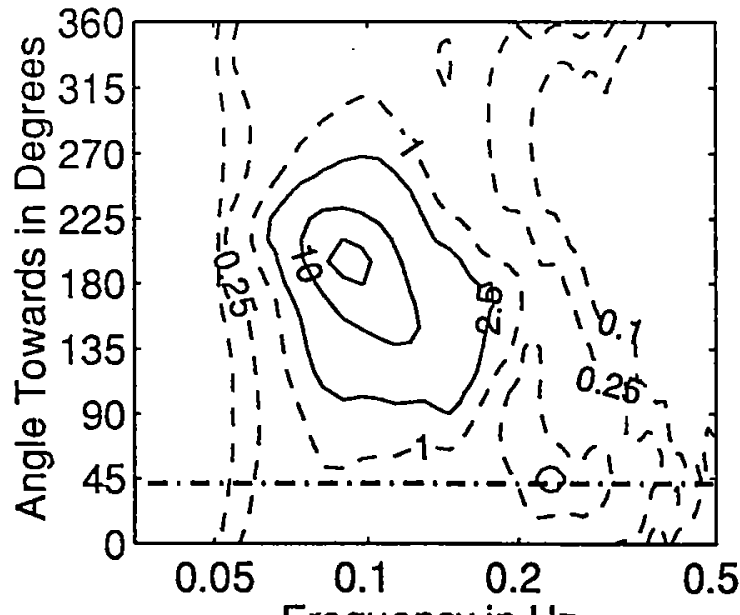

Frequency in $\mathrm{Hz}$
December 14, $199321 Z$
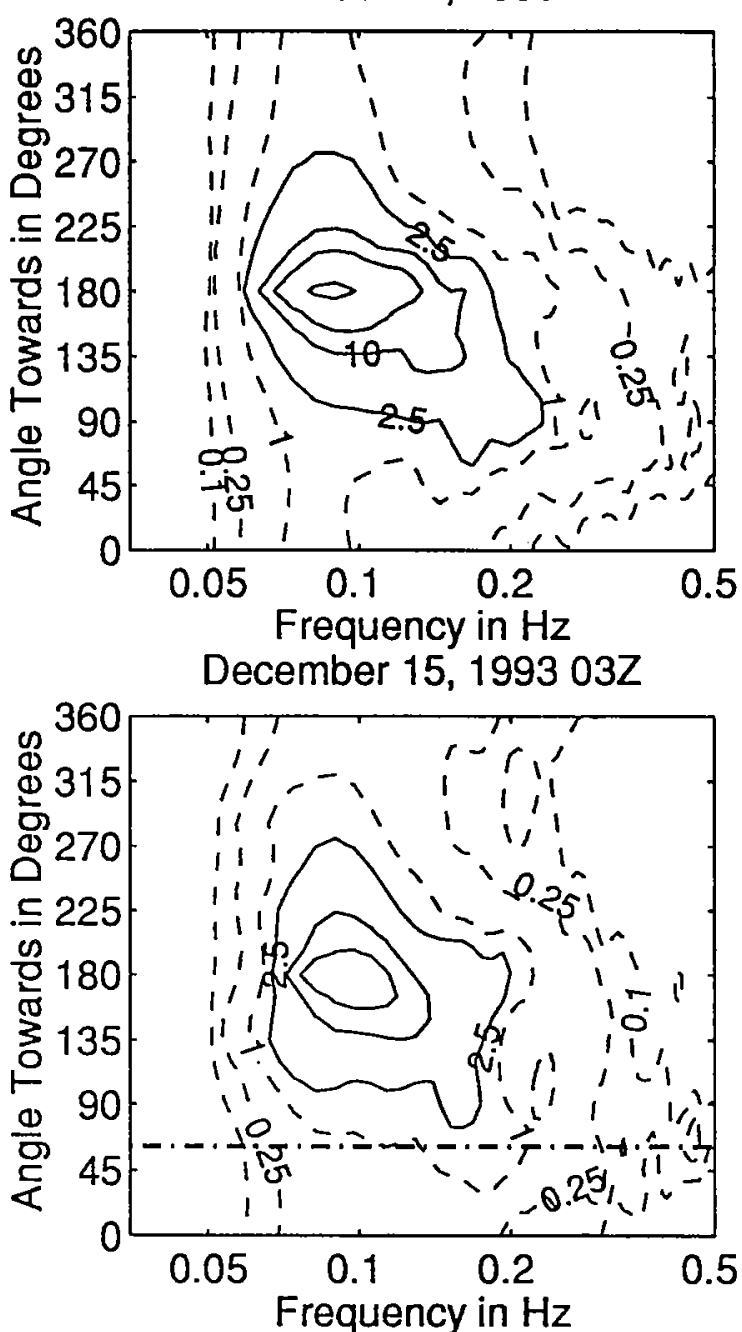

December 15, $199309 Z$

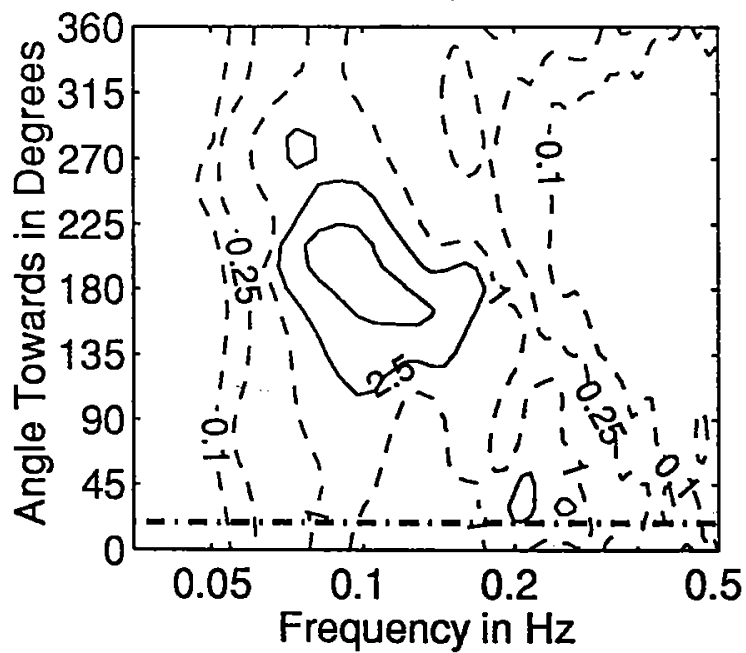

Figure 3.4.11: Directional wave spectra, computed using maximum entropy method. Contours of spectral density as a function of direction. Contours are 0.1, $0.25,1$ (dashed), $2.5,10,25,100$, and 250 (solid). Wind direction is shown by thick dashed line. 

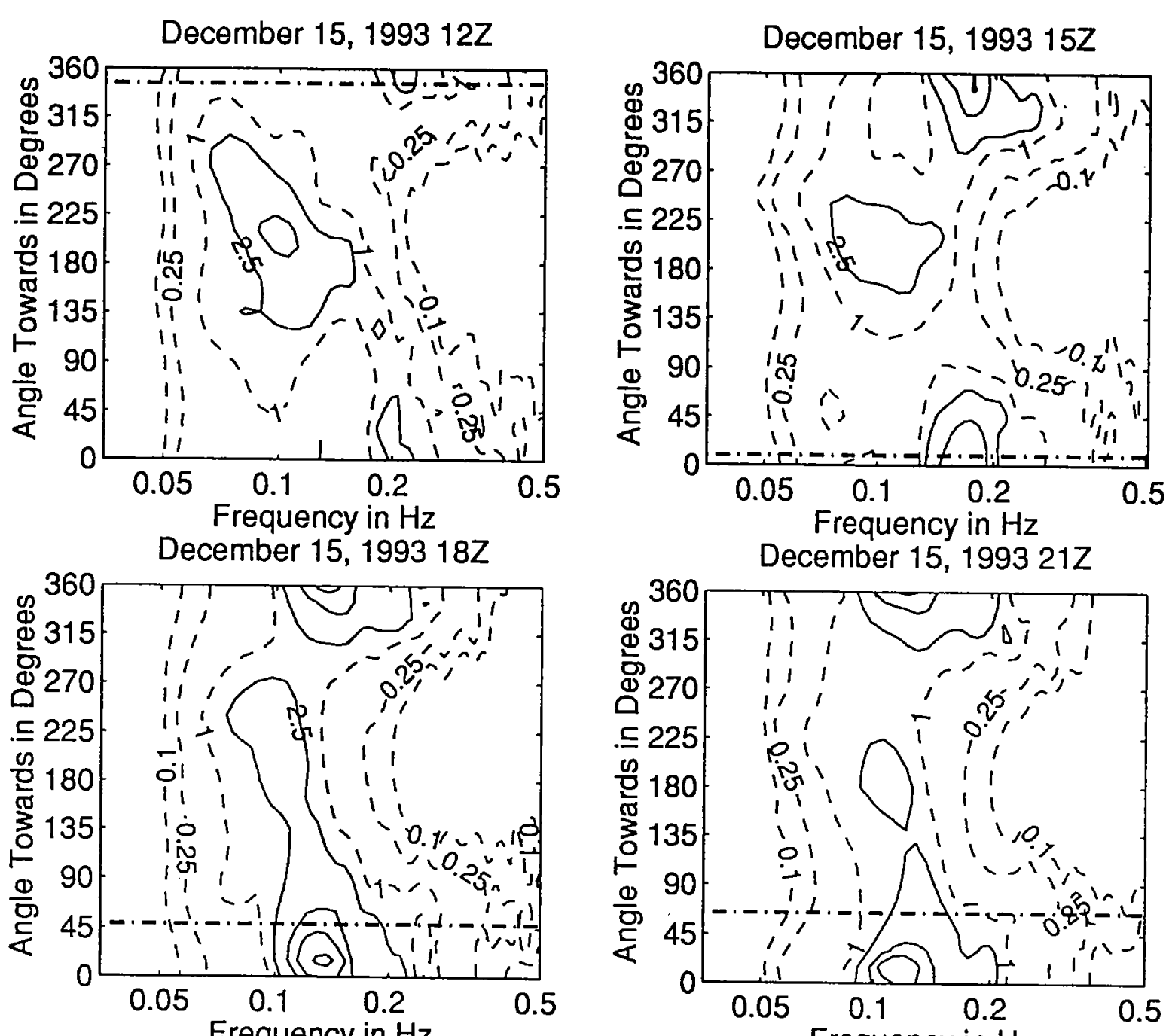

Frequency in $\mathrm{Hz}$
December $16,199300 \mathrm{Z}$

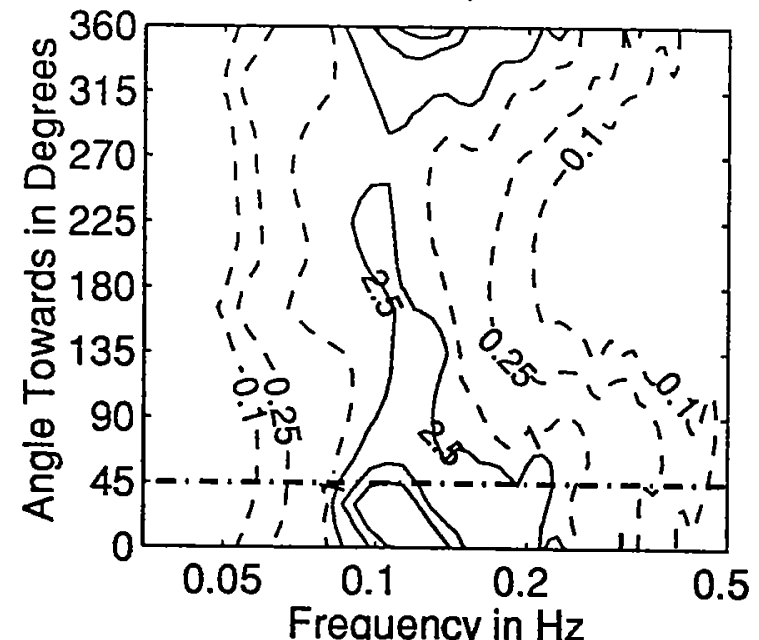

Frequency in $\mathrm{Hz}$

December 16, $199303 Z$

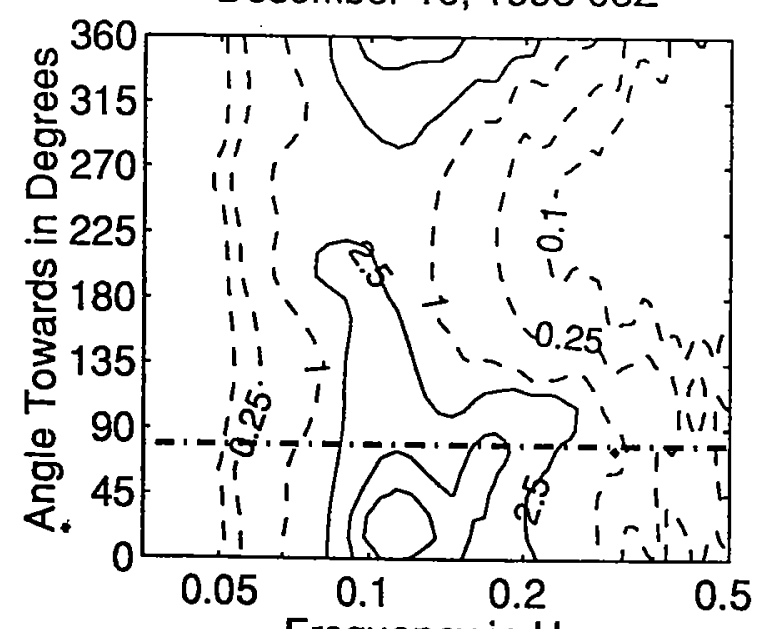

Figure 3.4.12: Directional wave spectra, computed using maximum entropy method. Contours of spectral density as a function of direction. Contours are 0.1 , $0.25,1$ (dashed), $2.5,10,25,100$, and 250 (solid). Wind direction is shown by
thick dashed line. 
December 16, $199306 Z$

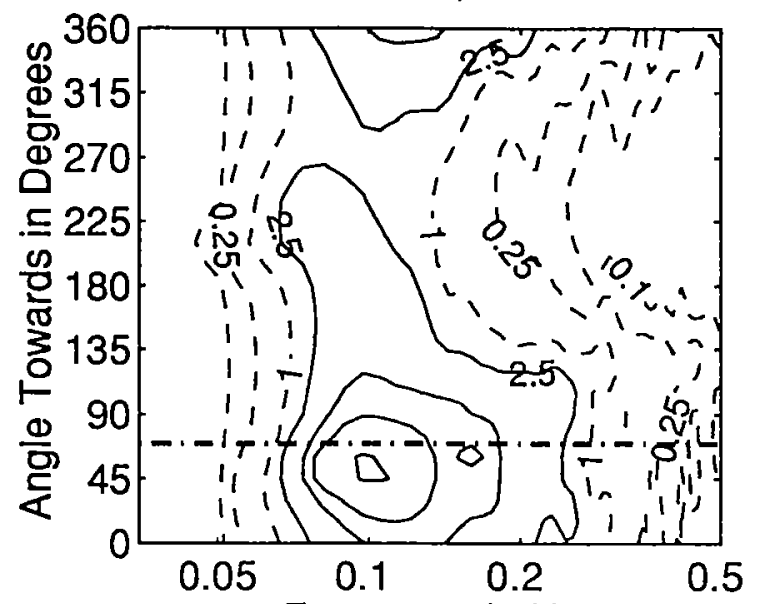

Frequency in $\mathrm{Hz}$

December 16, $199312 Z$

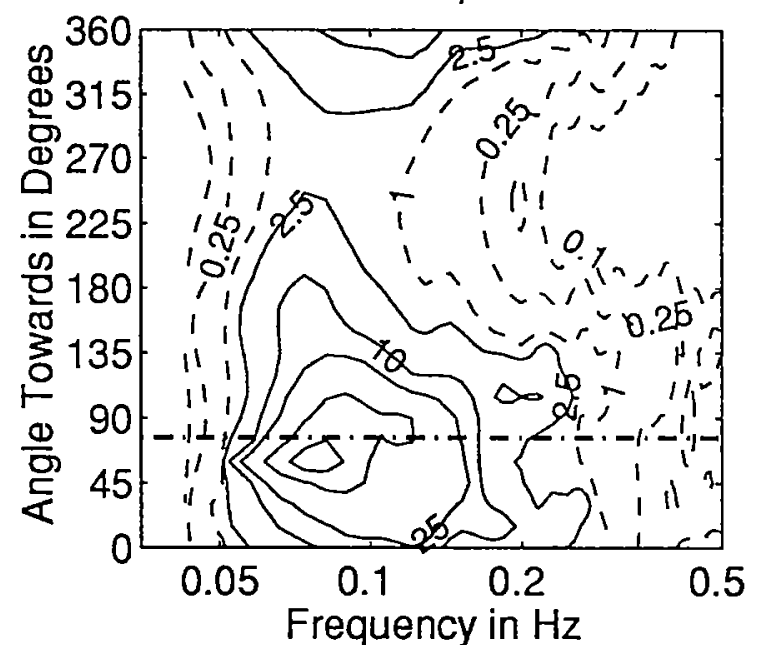

December 16, $199318 Z$

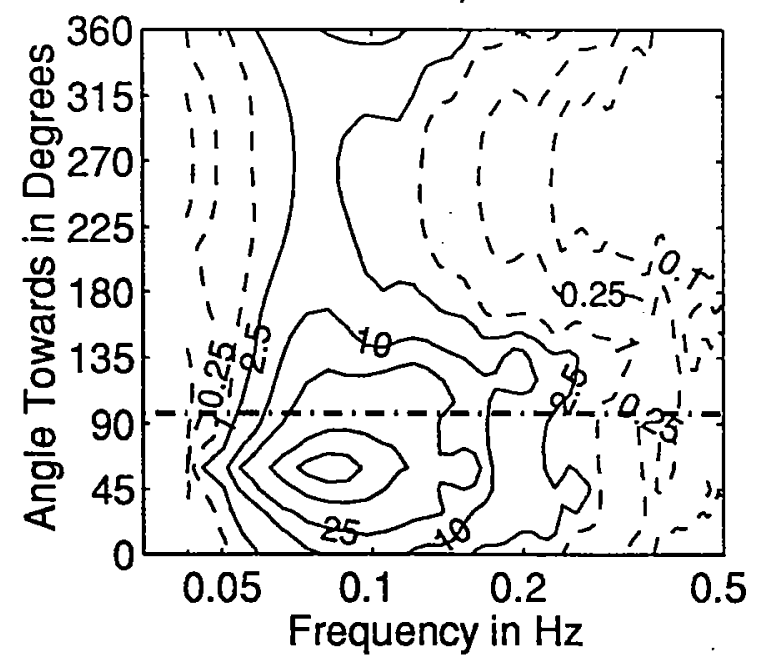

December 16, $199309 Z$

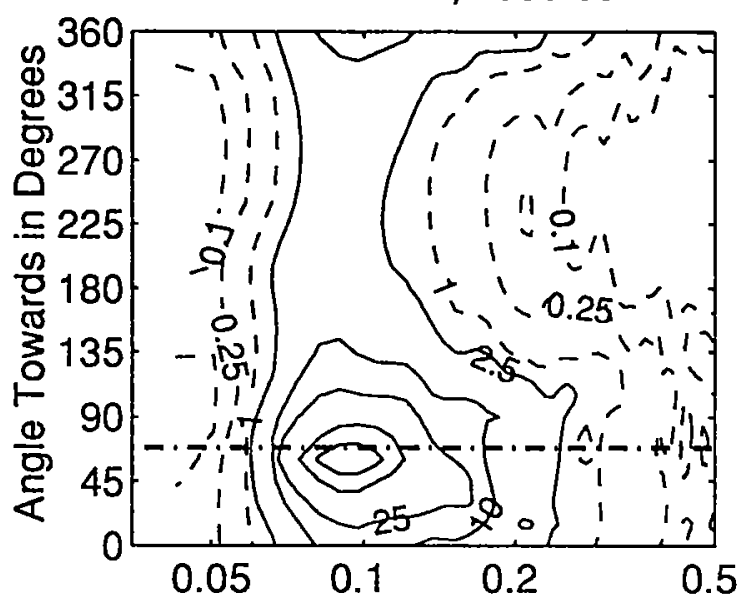

Frequency in $\mathrm{Hz}$

December 16, $199315 Z$
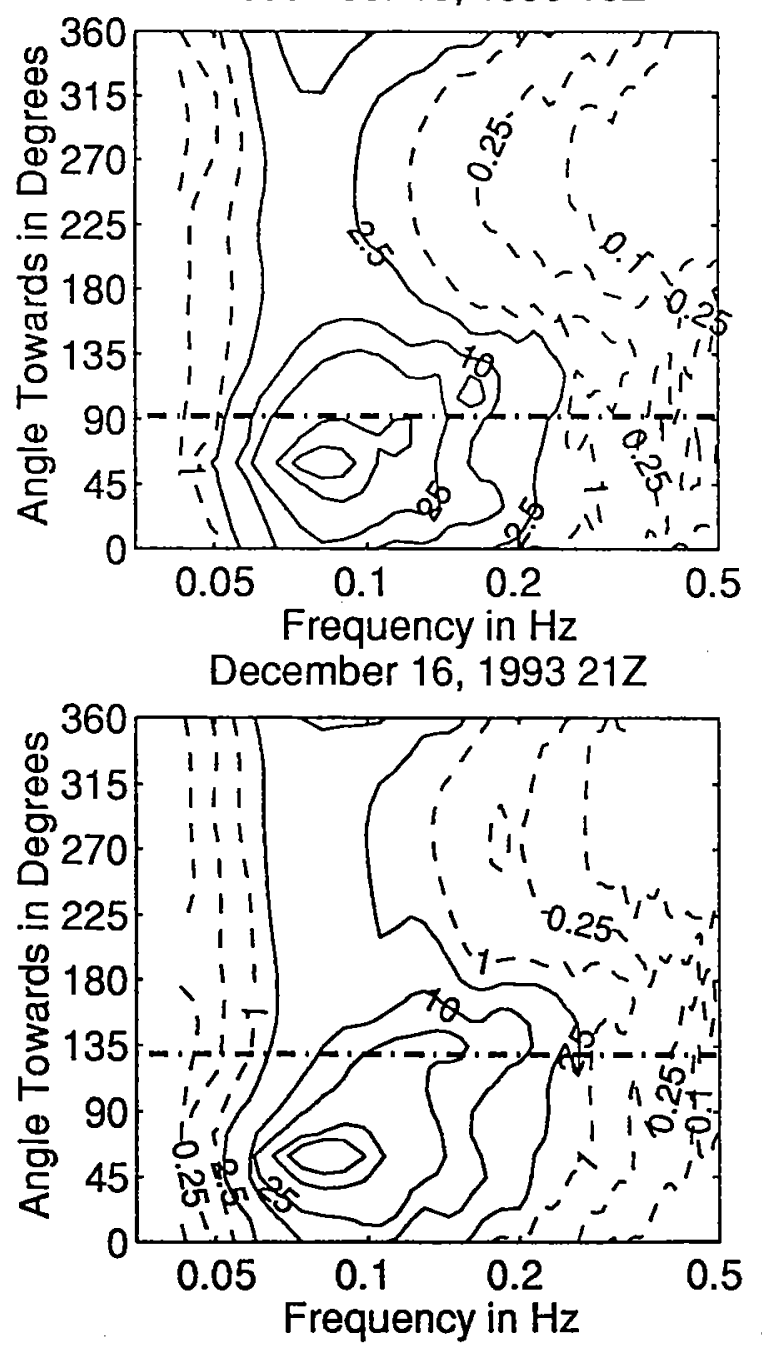

Figure 3.4.13: Directional wave spectra, computed using maximum entropy method. Contours of spectral density as a function of direction. Contours are 0.1, $0.25,1$ (dashed), $2.5,10,25,100$, and 250 (solid). Wind direction is shown by
thick dashed line. 
December 17, $199300 Z$

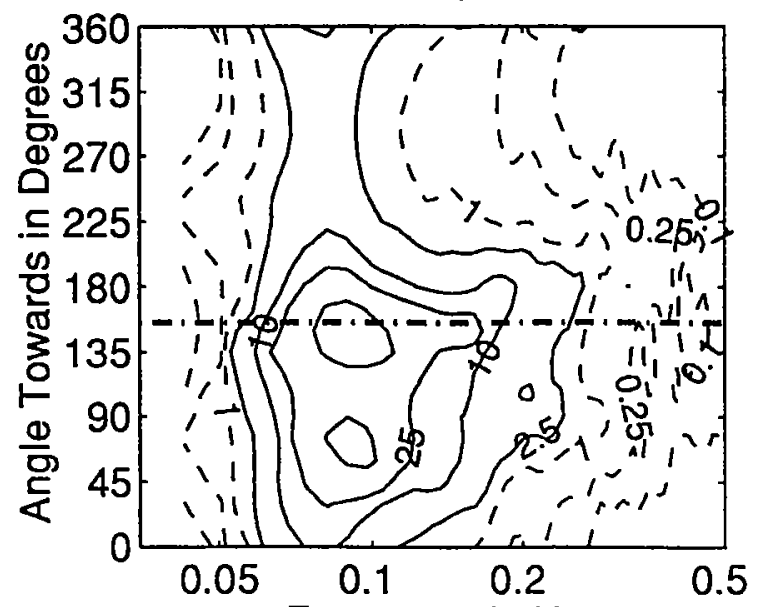

Frequency in $\mathrm{Hz}$

December 17, $199306 Z$

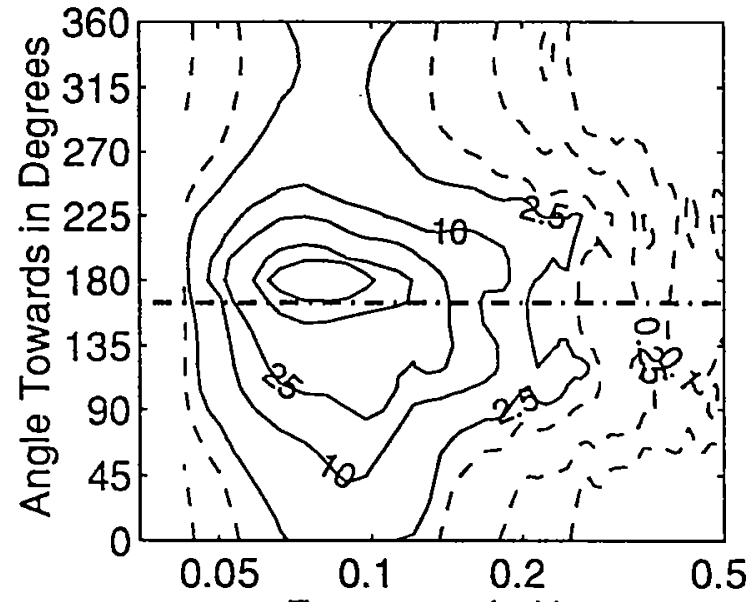

Frequency in $\mathrm{Hz}$

December 17, $199312 Z$

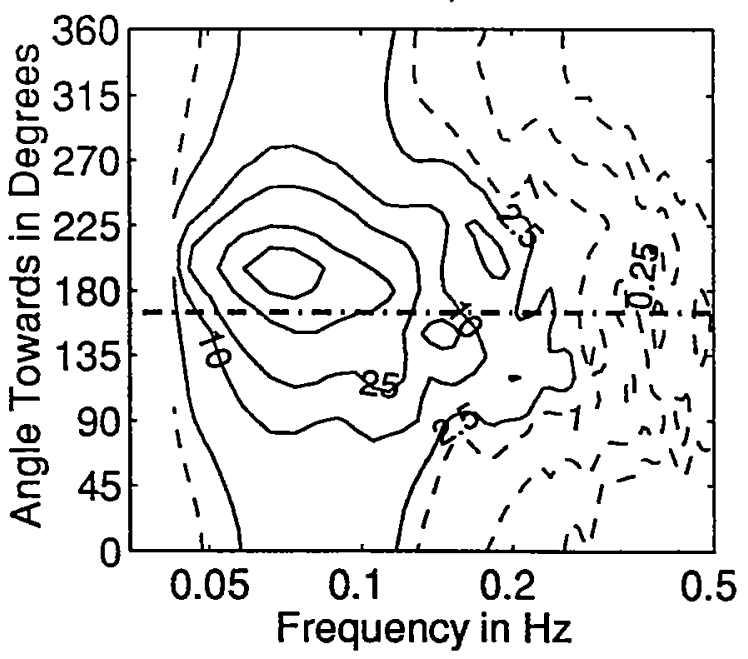

December 17, $199303 Z$

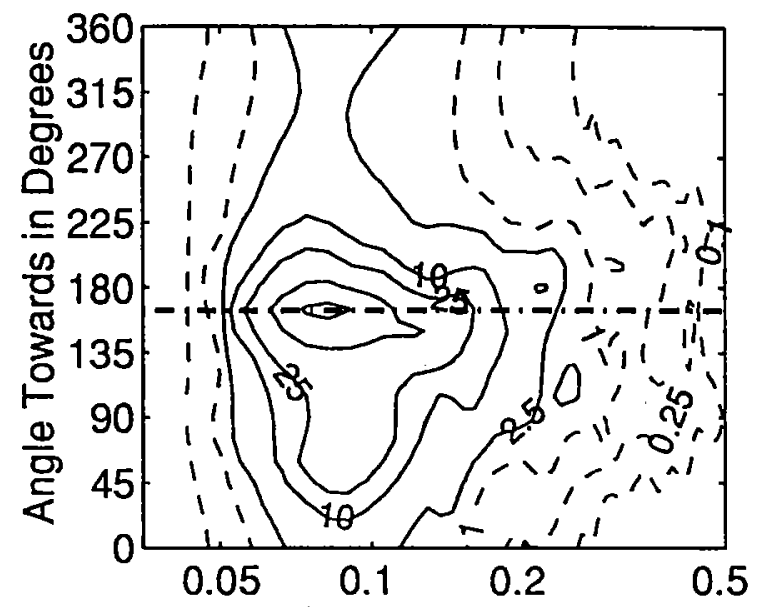

Frequency in $\mathrm{Hz}$

December 17, 199309 Z

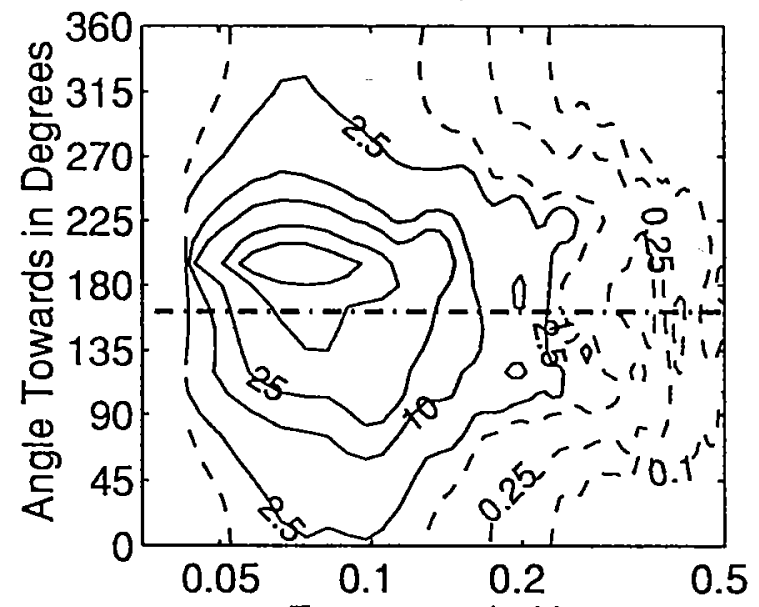

Frequency in $\mathrm{Hz}$

December 17, $199315 Z$

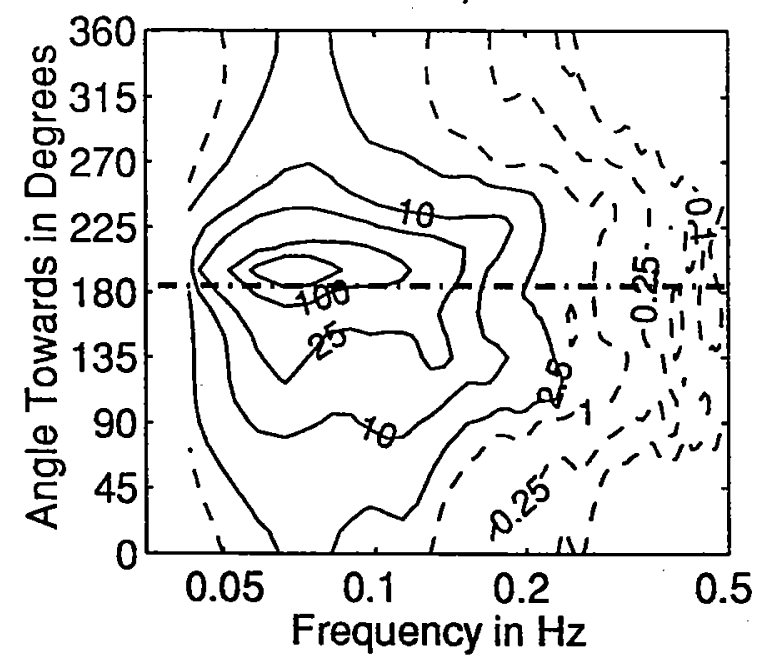

Figure 3.4.14: Directional wave spectra, computed using maximum entropy method. Contours of spectral density as a function of direction. Contours are 0.1 , $0.25,1$ (dashed), $2.5,10,25,100$, and 250 (solid). Wind direction is shown by thick dashed line. 
December 17, $199318 Z$
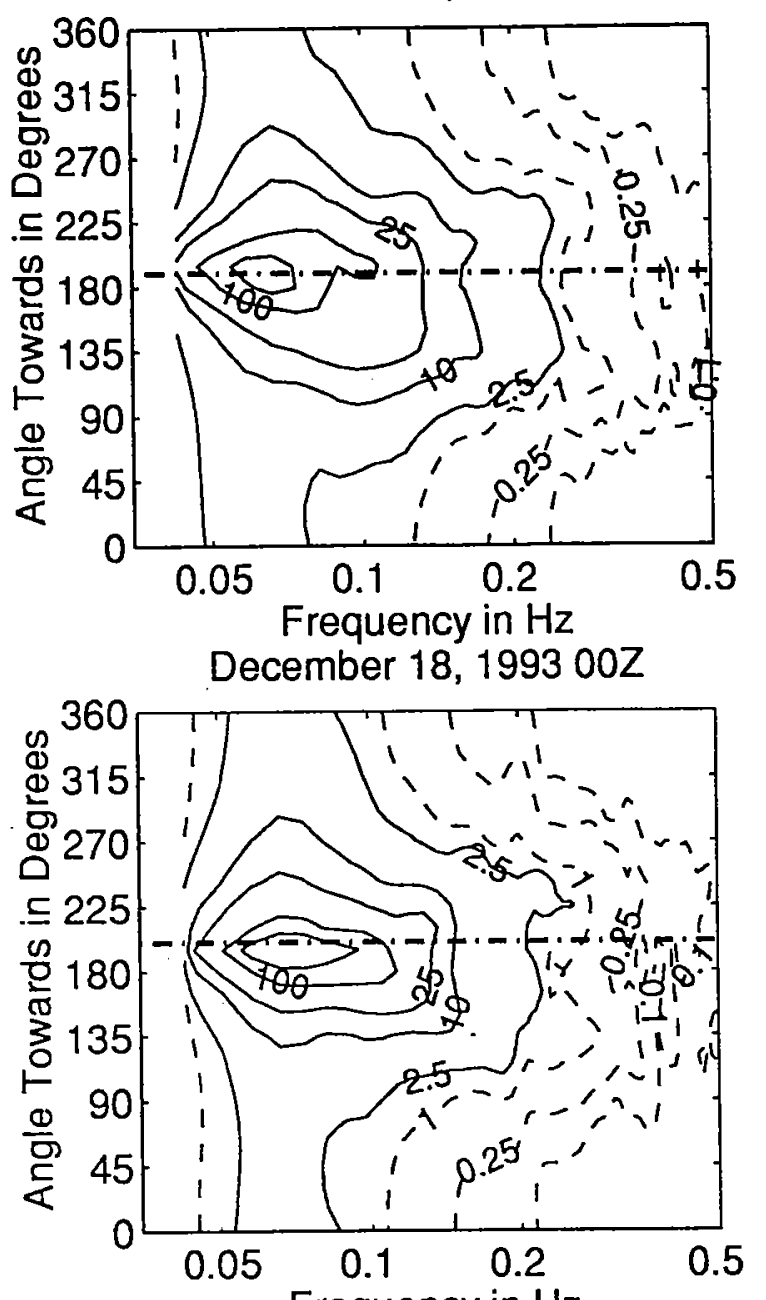

Frequency in $\mathrm{Hz}$ December 18, $199306 Z$

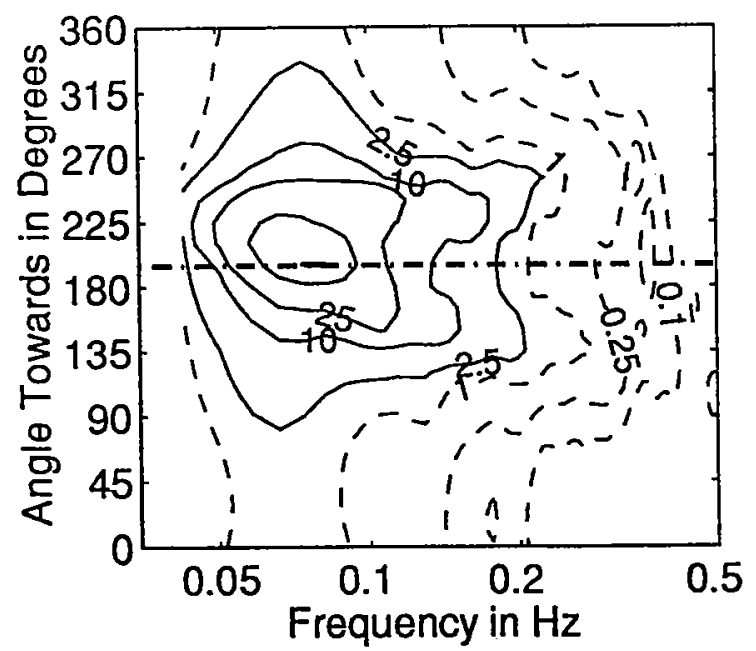

December 17, $199321 Z$

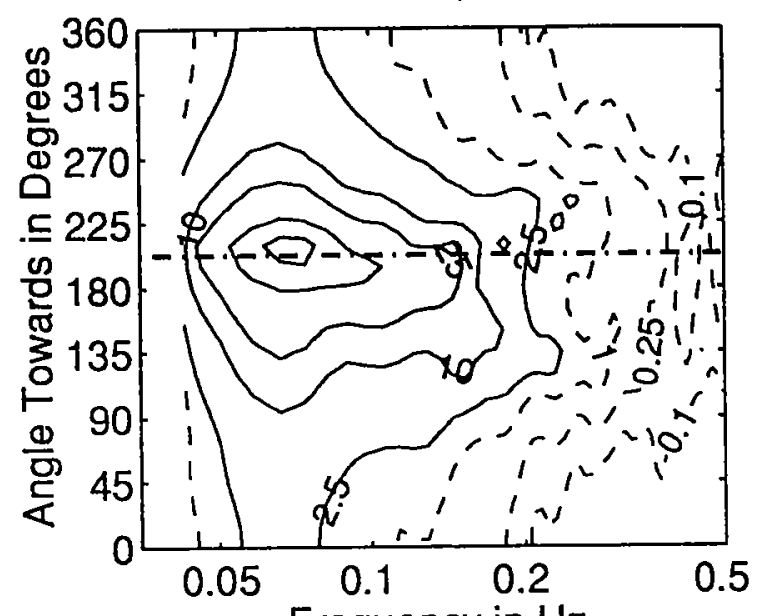

Frequency in $\mathrm{Hz}$

December 18, $199303 Z$

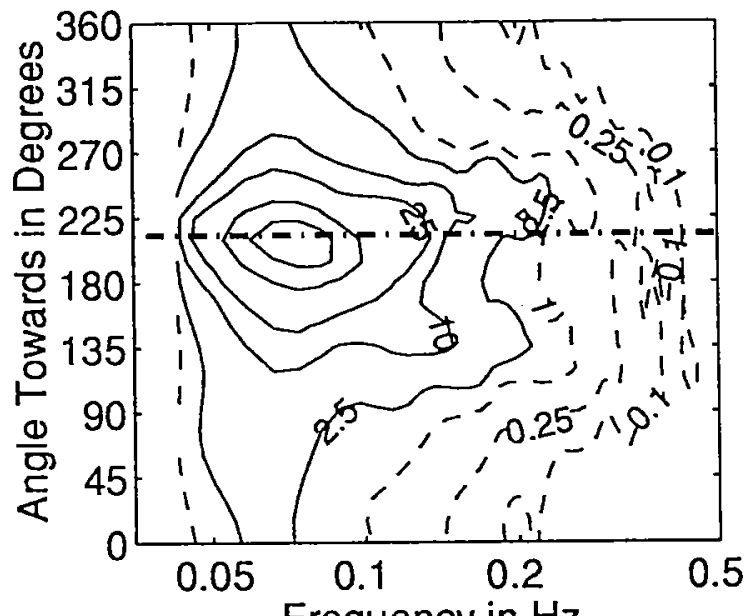

Frequency in $\mathrm{Hz}$

December 18, $199309 Z$

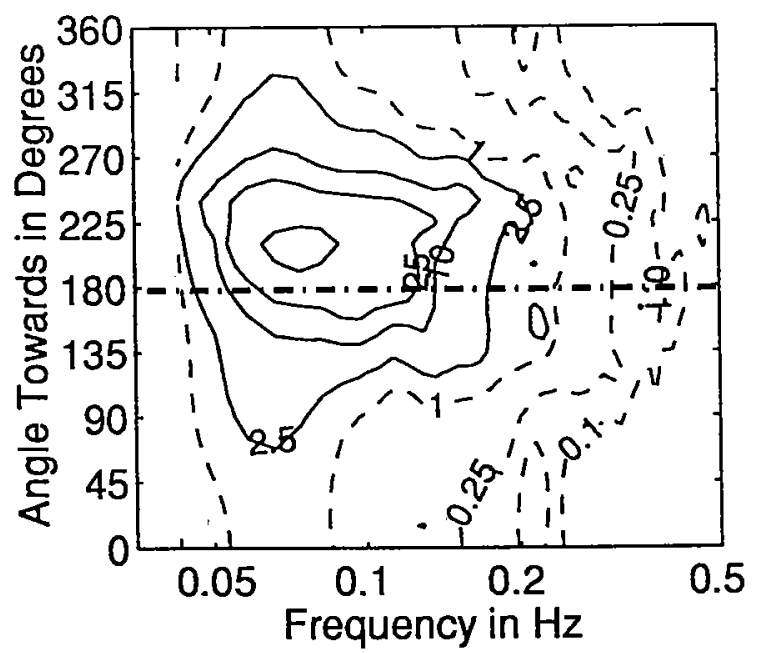

Figure 3.4.15: Directional wave spectra, computed using maximum entropy method. Contours of spectral density as a function of direction. Contours are 0.1 , $0.25,1$ (dashed), $2.5,10,25,100$, and 250 (solid). Wind direction is shown by thick dashed line. 
December 18, $199312 Z$

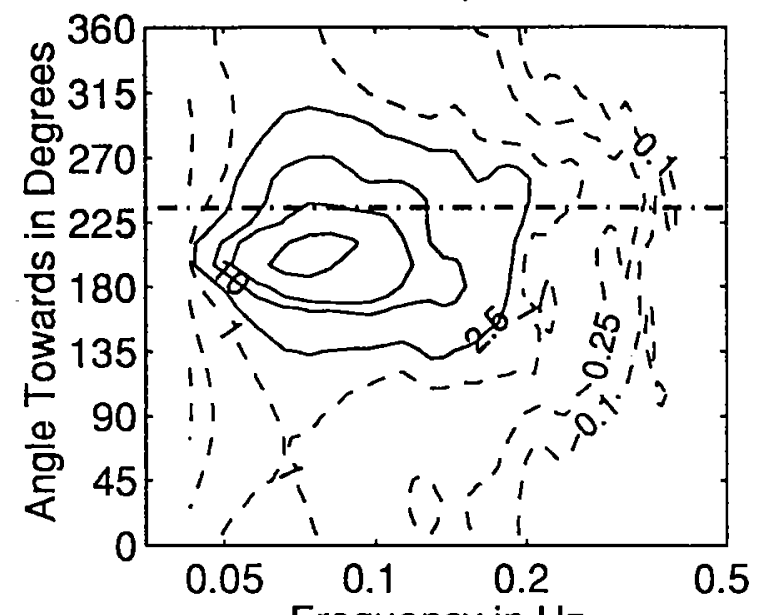

Frequency in $\mathrm{Hz}$

December 18, $199318 Z$

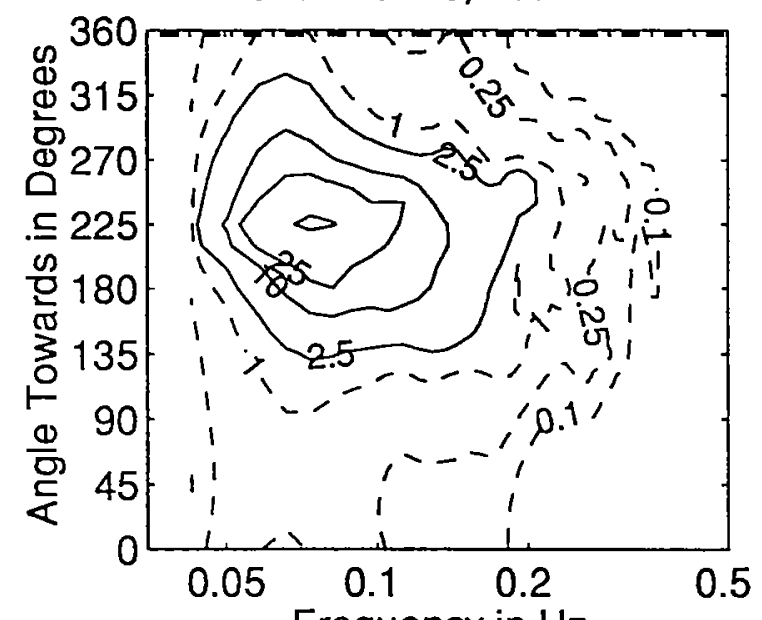

Frequency in $\mathrm{Hz}$

December 19, $199300 Z$

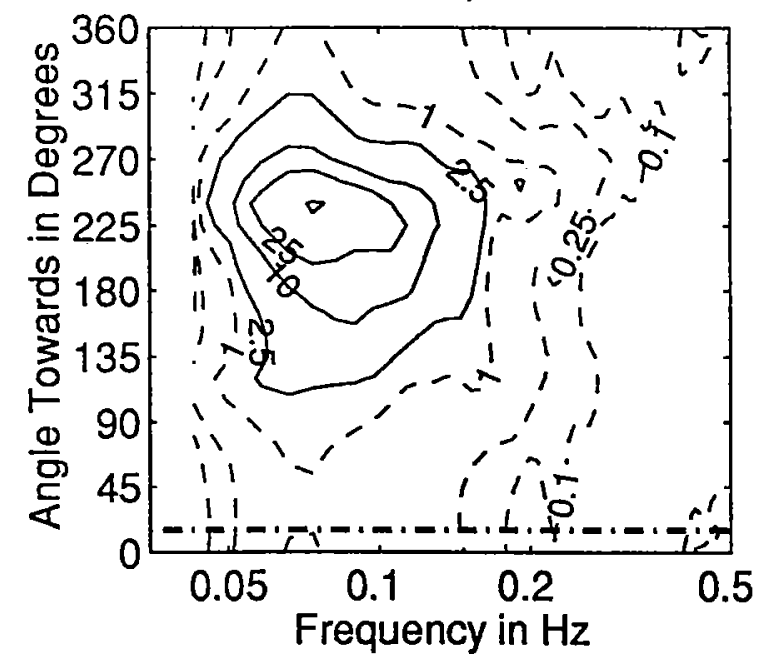

December 18, $199315 Z$

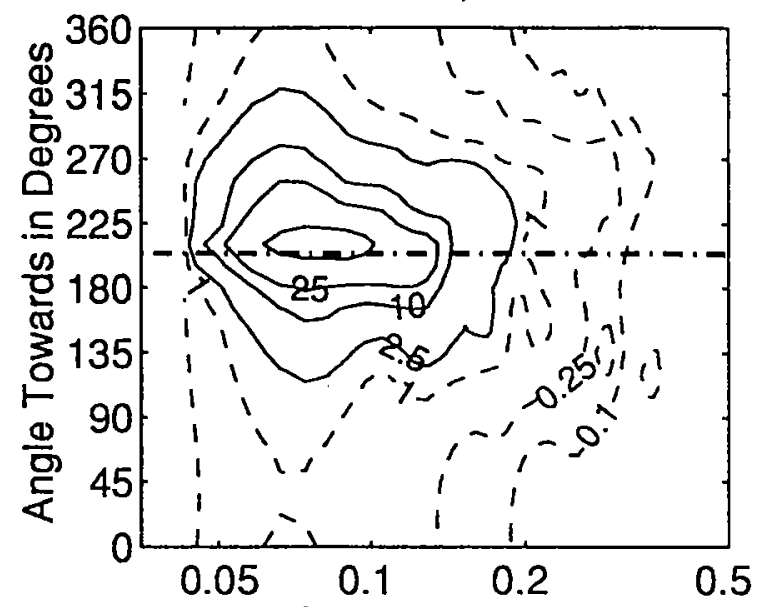

Frequency in $\mathrm{Hz}$

December 18, $199321 Z$

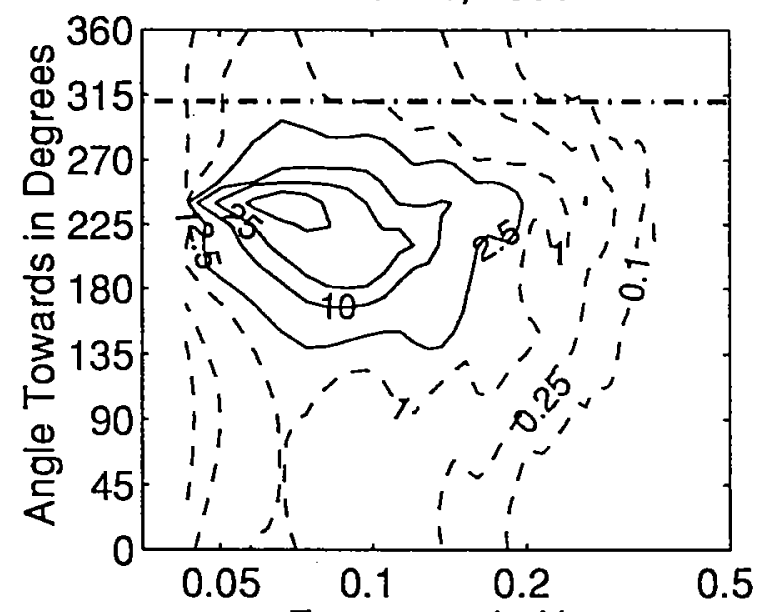

Frequency in $\mathrm{Hz}$

December 19, $199303 Z$

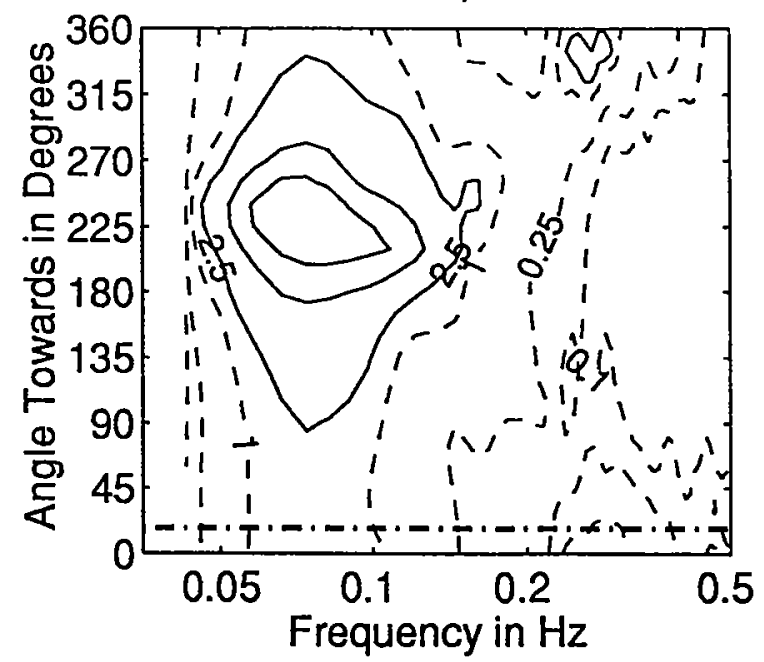

Figure 3.4.16: Directional wave spectra, computed using maximum entropy method. Contours of spectral density as a function of direction. Contours are 0.1, $0.25,1$ (dashed), $2.5,10,25,100$, and 250 (solid). Wind direction is shown by thick dashed line. 
December 19, $199306 Z$

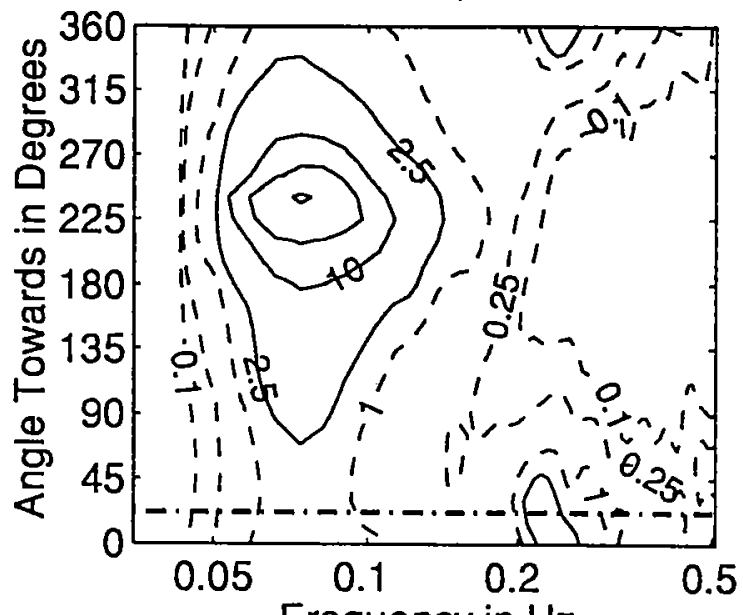

Frequency in $\mathrm{Hz}$

December 19, $199312 Z$

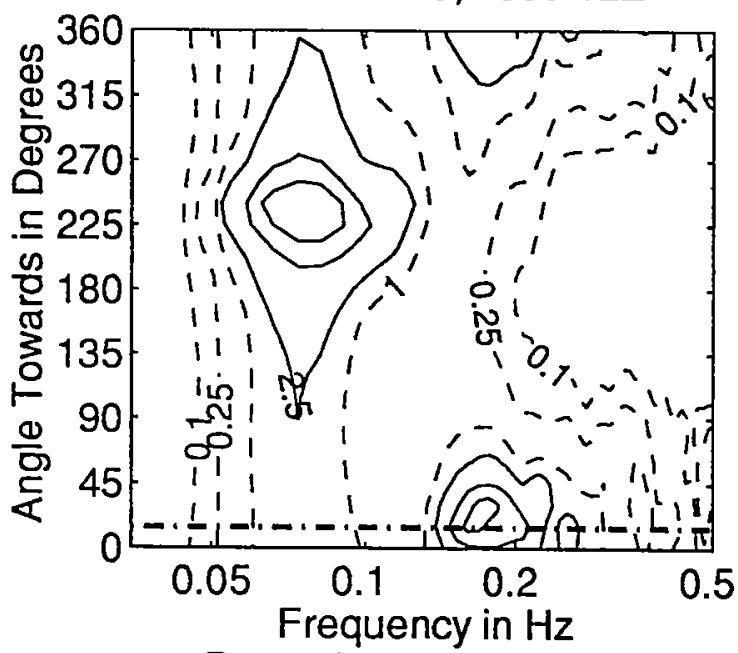

December 19, $199318 Z$

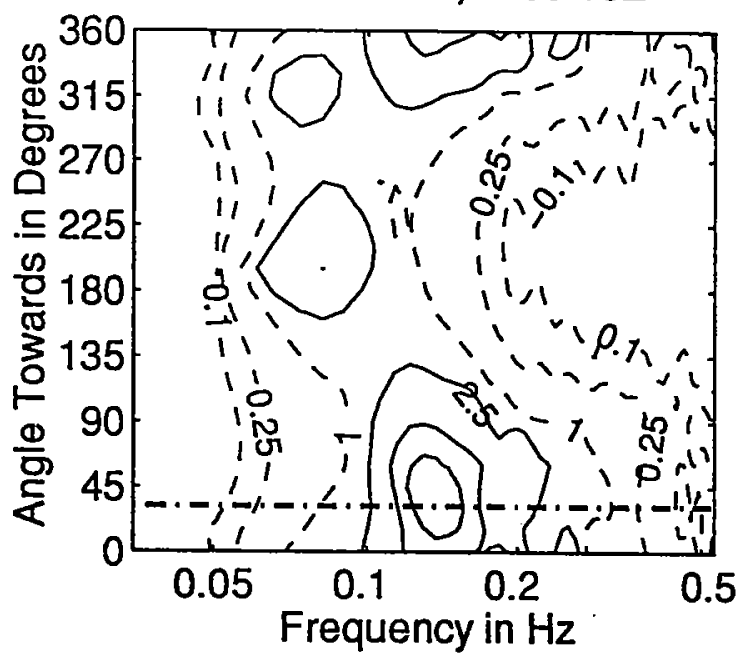

December 19, $199309 Z$
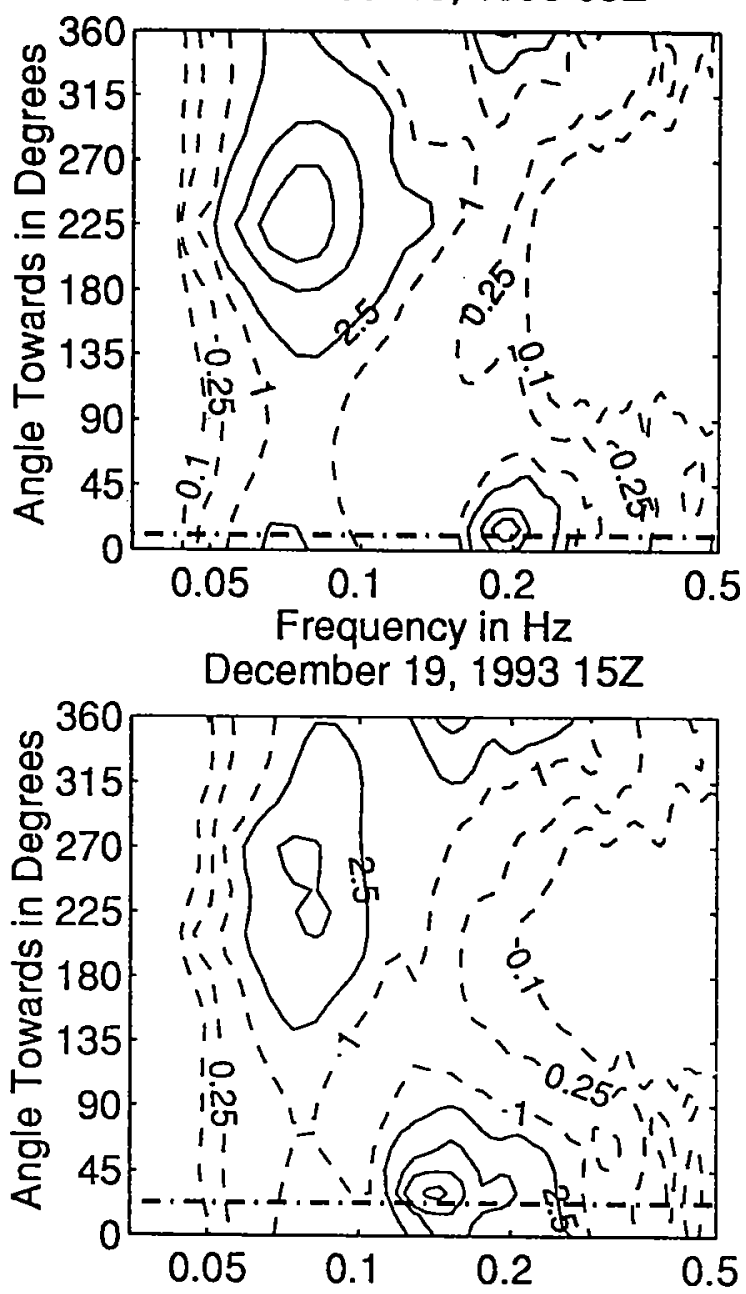

Frequency in $\mathrm{Hz}$

December 19, $199321 Z$

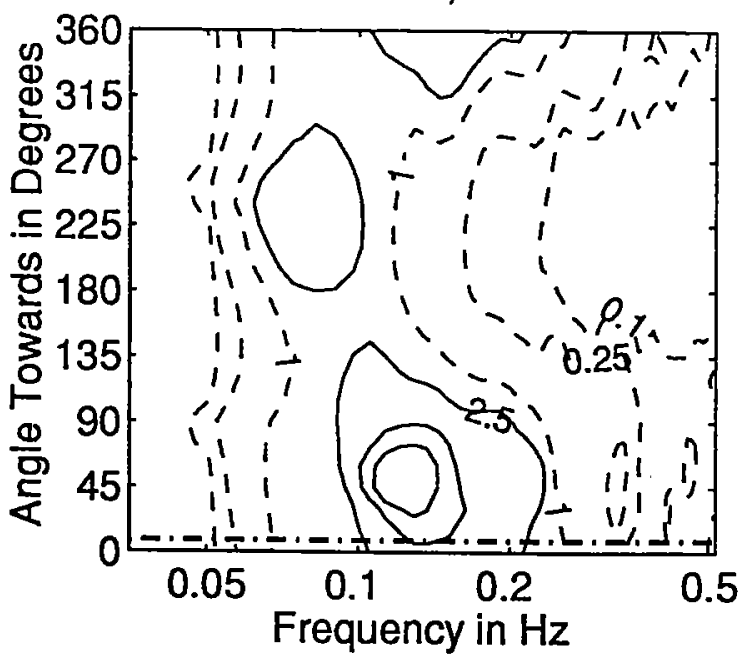

Figure 3.4.17: Directional wave spectra, computed using maximum entropy $0.25,1$ (dashed) 25. $0.25,1$ (dashed), $2.5,10,25,100$, and 250 (solid). Wind direction is shown by
thick dashed line. 
December 20, $199300 Z$

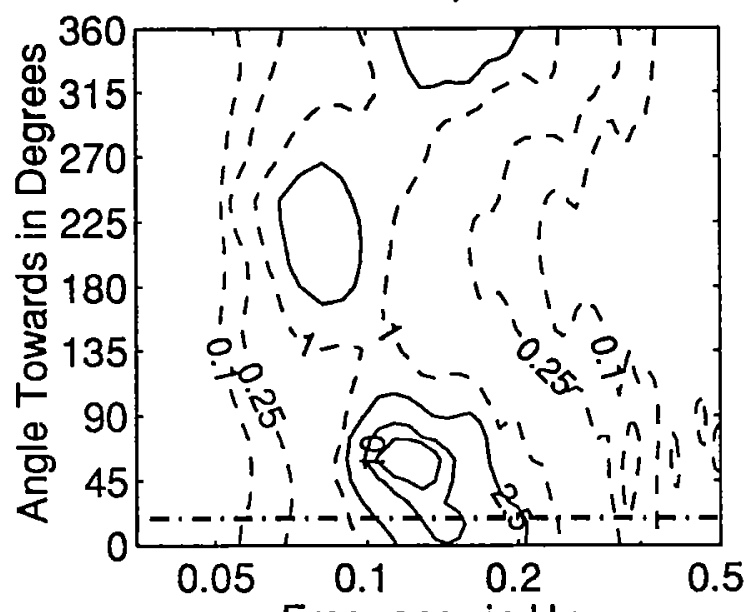

Frequency in $\mathrm{Hz}$

December 20, $199306 Z$

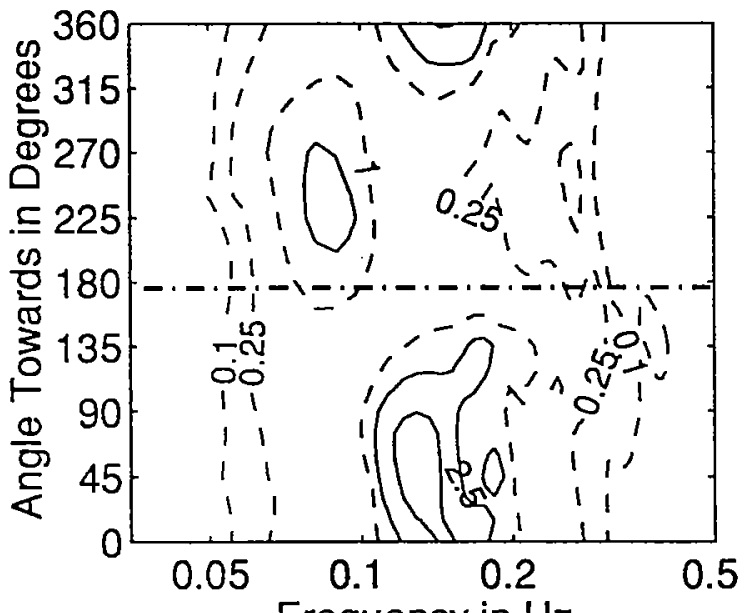

Frequency in $\mathrm{Hz}$

December 20, $199312 Z$

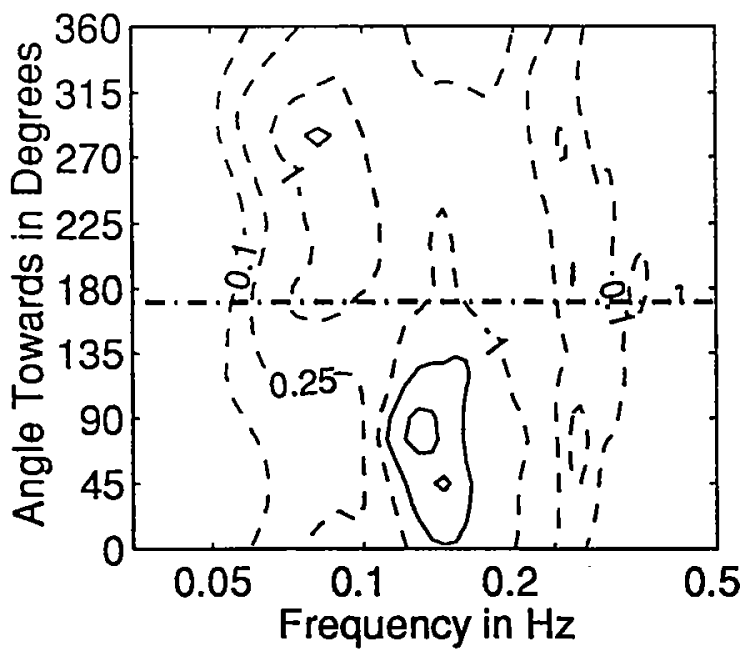

December 20, 1993032

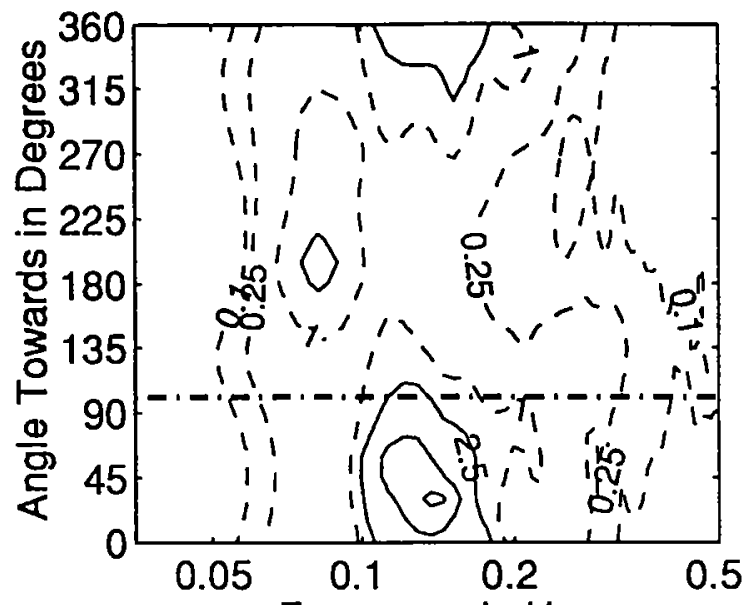

Frequency in $\mathrm{Hz}$

December 20, 1993092

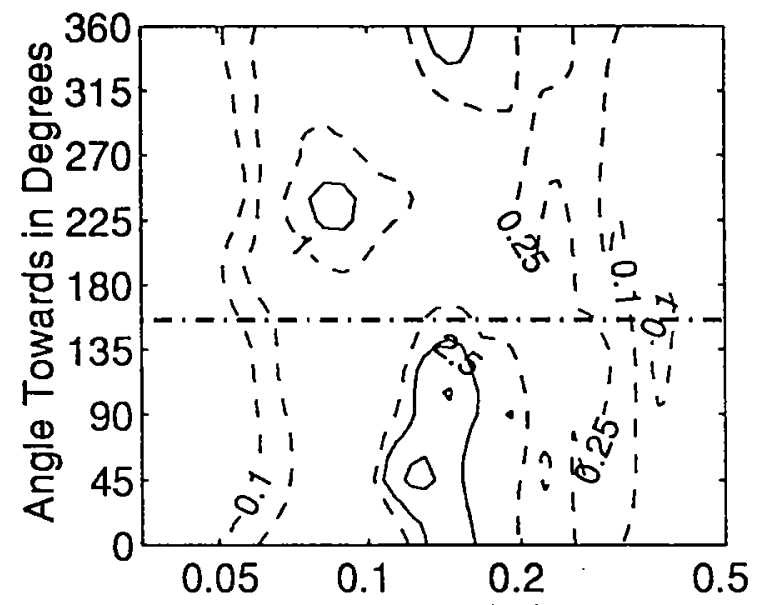

Frequency in $\mathrm{Hz}$

December 20, $199315 Z$

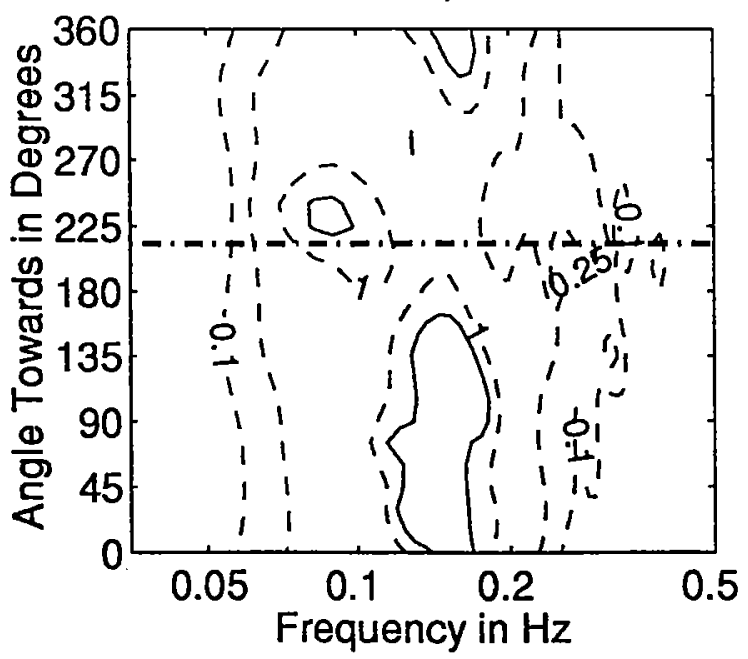

Figure 3.4.18: Directional wave spectra, computed using maximum entropy method. Contours of spectral density as a function of direction. Contours are 0.1, $0.25,1$ (dashed), $2.5,10,25,100$, and 250 (solid). Wind direction is shown by thick dashed line. 
December 20, $199318 Z$

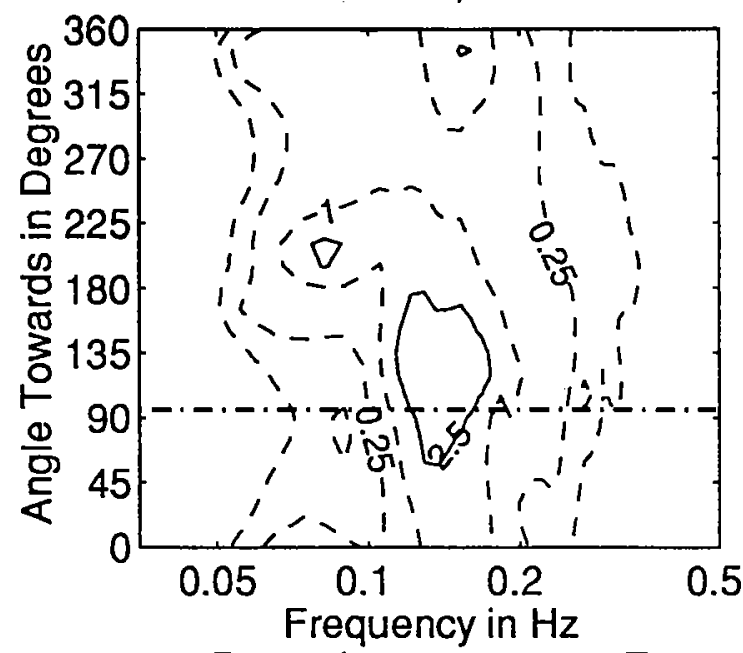

December 21, $199300 Z$

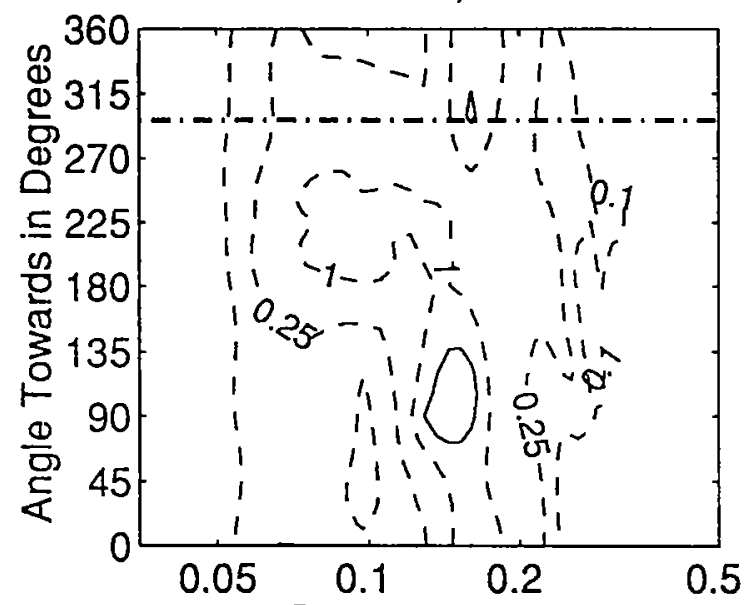

Frequency in $\mathrm{Hz}$

December 21, $199306 Z$

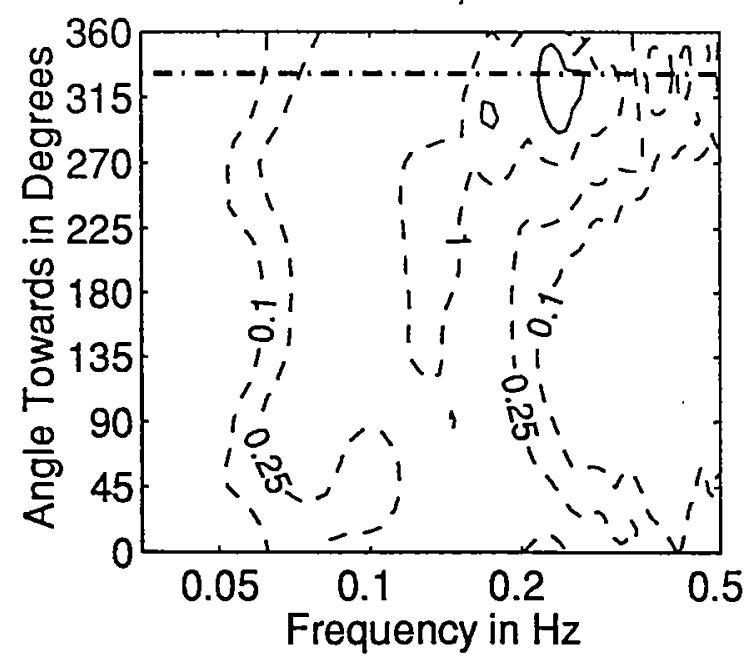

December 20, $199321 Z$
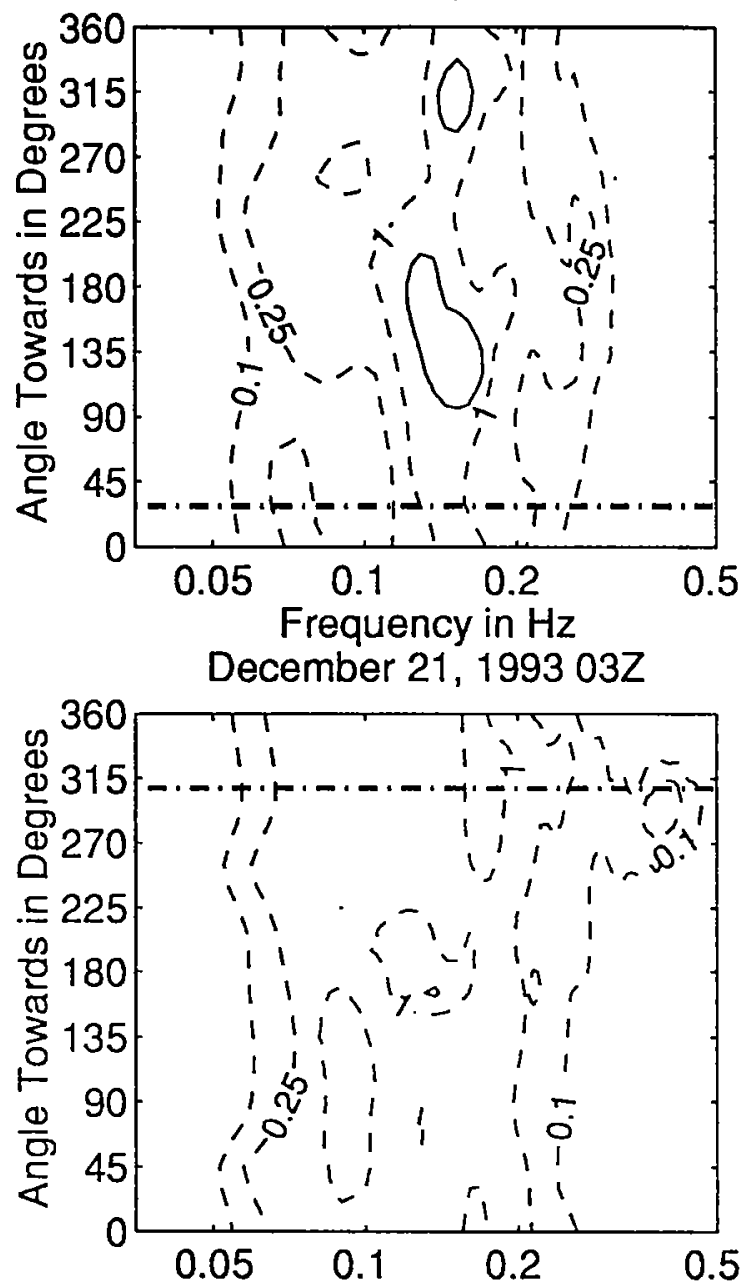

Frequency in $\mathrm{Hz}$

December 21, $199309 Z$

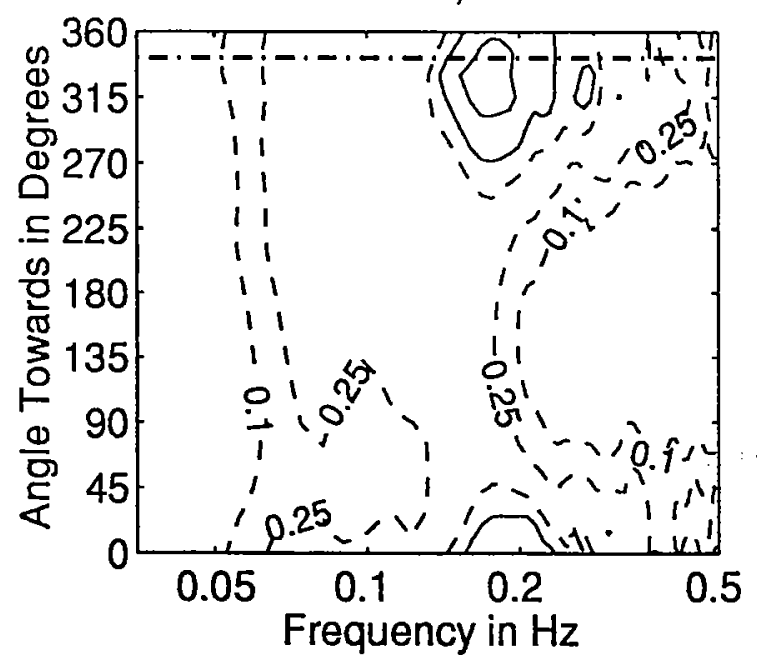

Figure 3.4.19: Directional wave spectra, computed using maximum entropy method. Contours of spectral density as a function of direction. Contours are 0.1, $0.25,1$ (dashed), $2.5,10,25,100$, and 250 (solid). Wind direction is shown by
thick dashed line. 
December 21, $199312 Z$

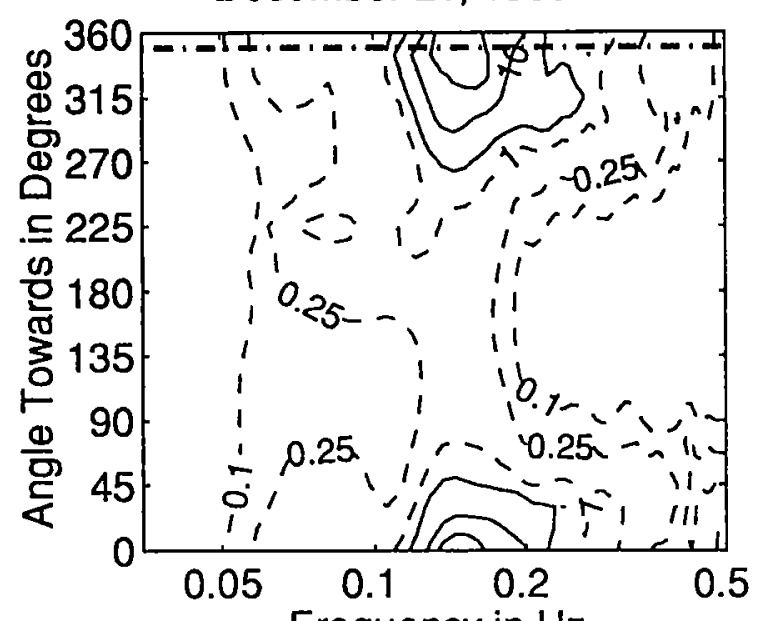

Frequency in $\mathrm{Hz}$

December 21, $199318 Z$

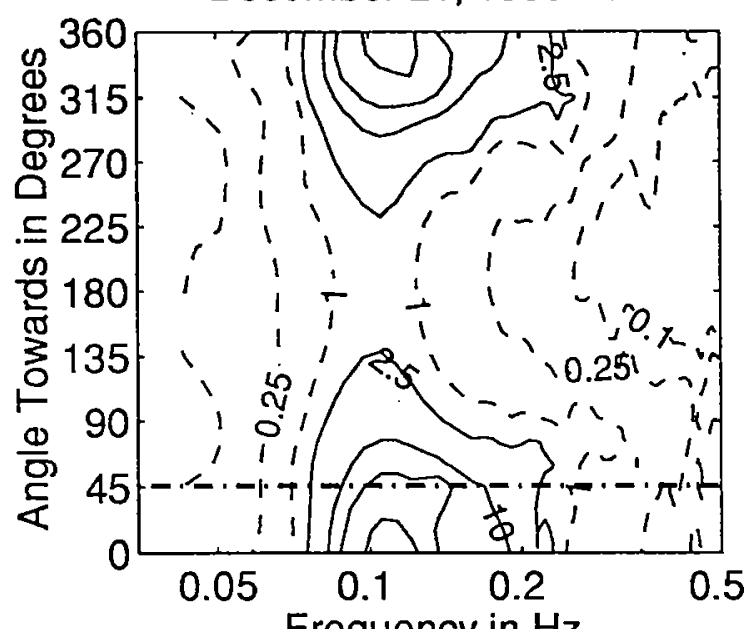

Frequency in $\mathrm{Hz}$

December 22, $199300 Z$

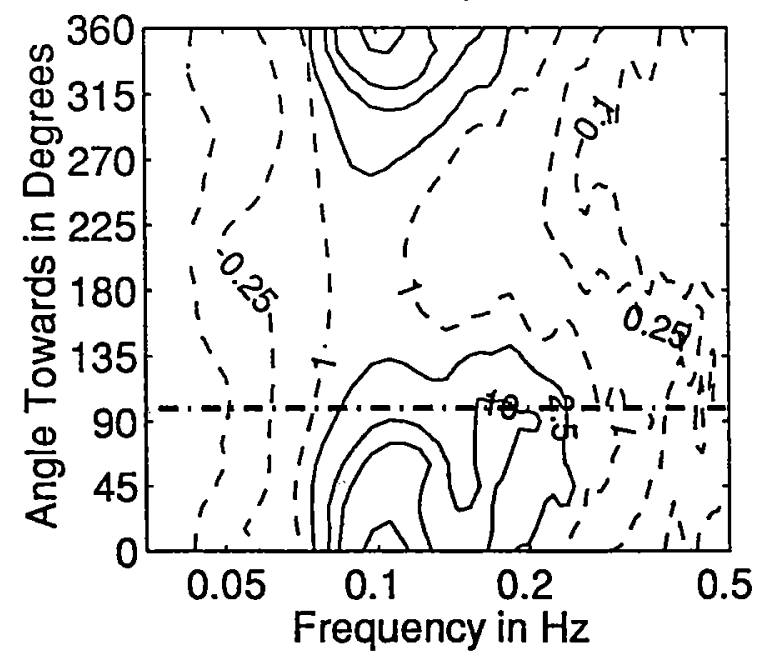

December 21, $199315 Z$

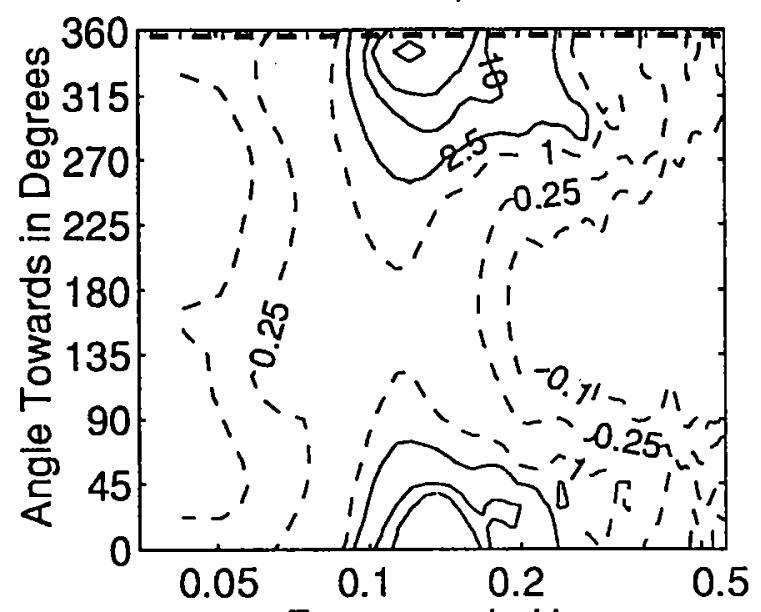

Frequency in $\mathrm{Hz}$

December 21, $199321 Z$

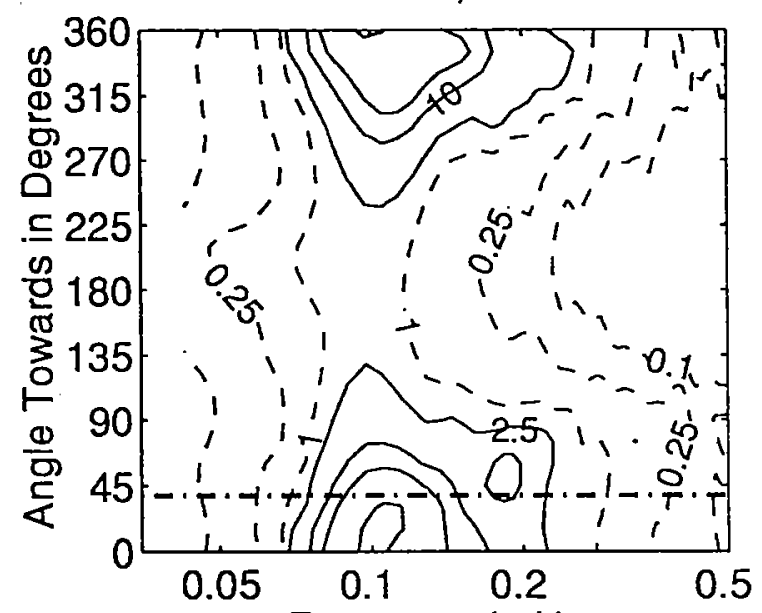

Frequency in $\mathrm{Hz}$

December 22, $199303 Z$

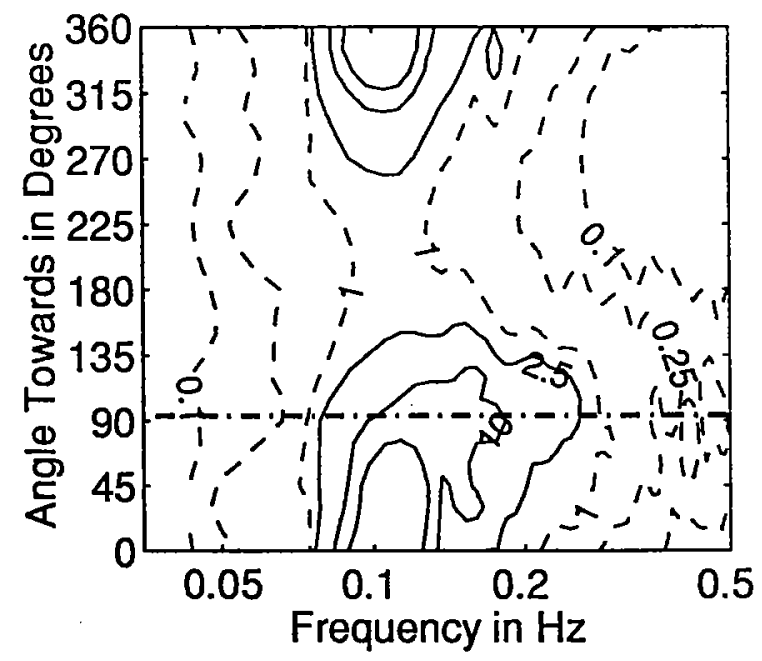

Figure 3.4.20: Directional wave spectra, computed using maximum entropy method. Contours of spectral density as a function of direction. Contours are 0.1, $0.25,1$ (dashed), $2.5,10,25,100$, and 250 (solid). Wind direction is shown by thick dashed line. 

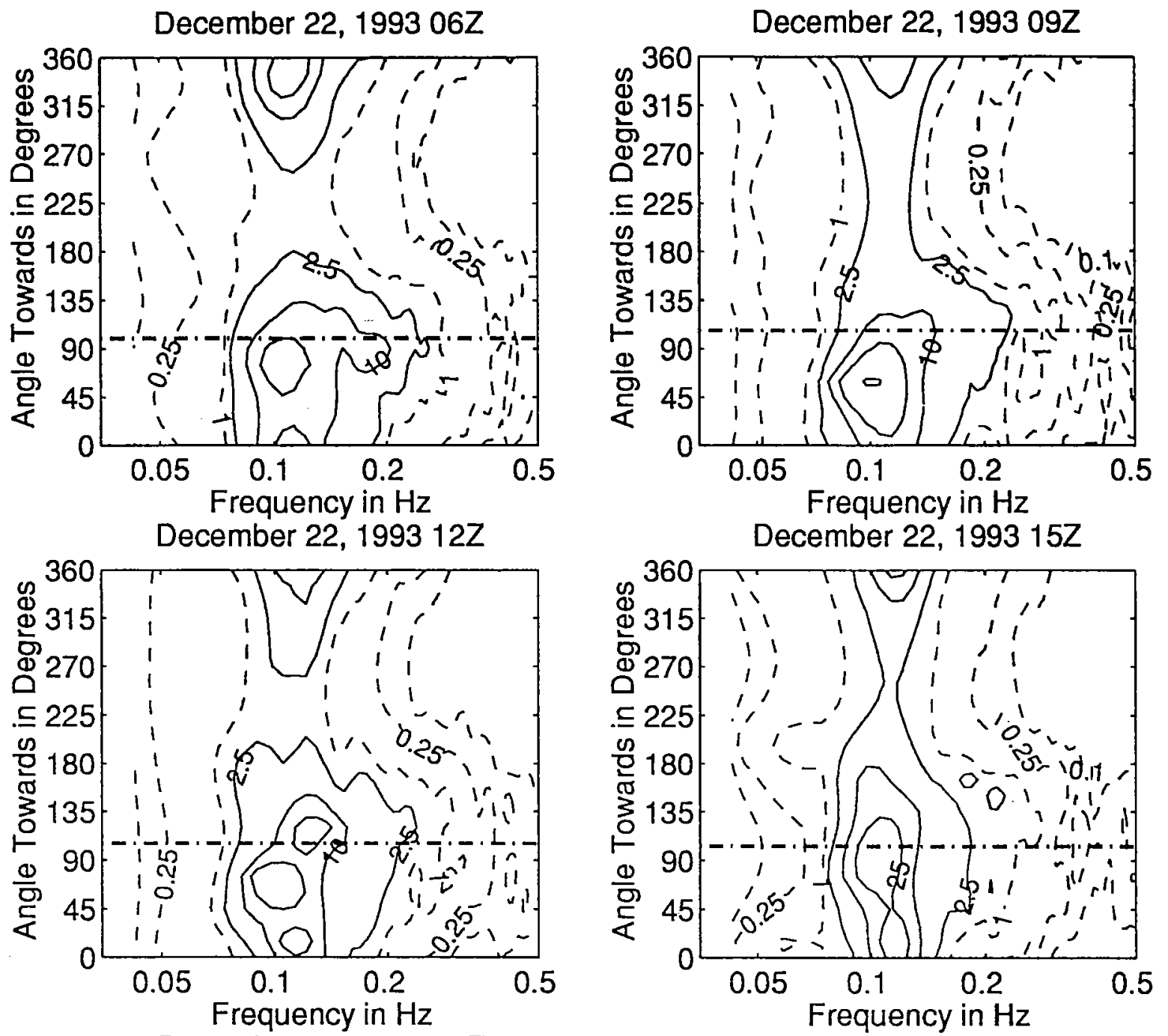

December 22, $199318 Z$
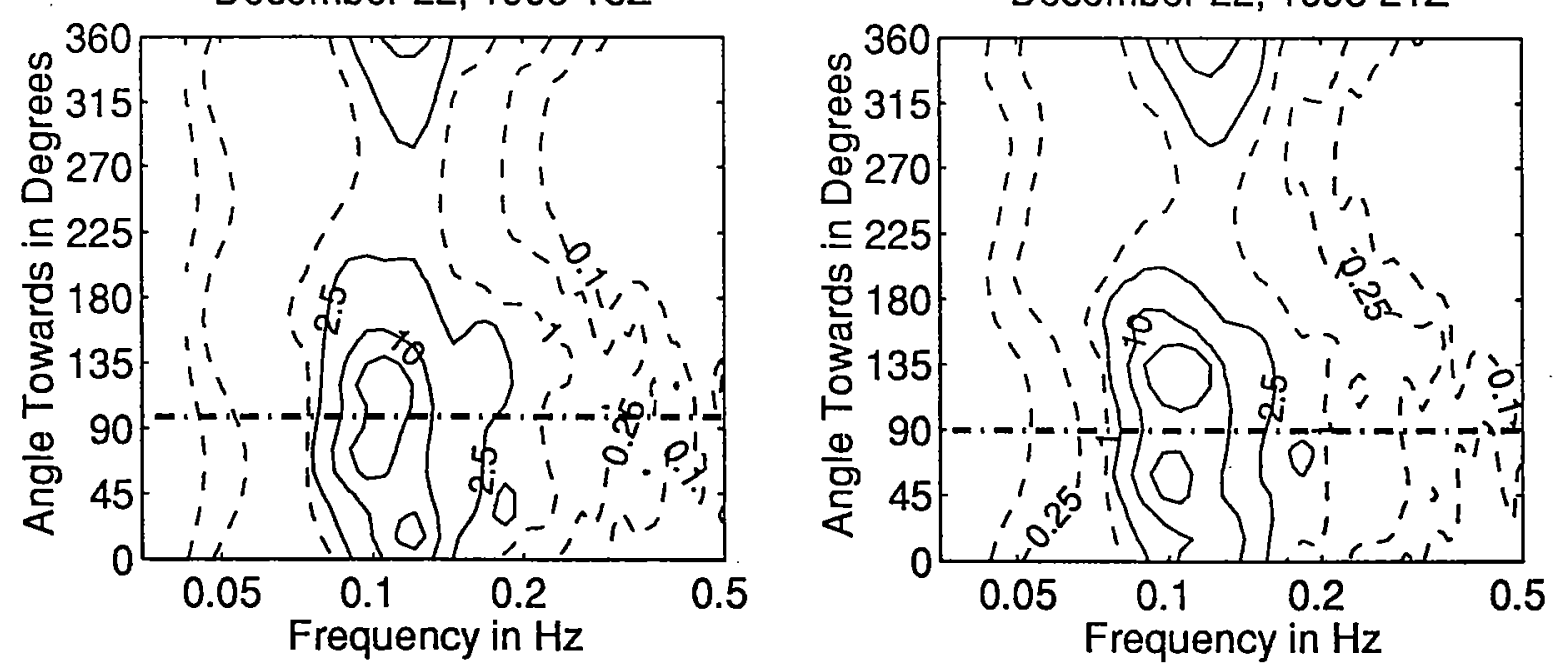

Figure 3.4.21: Directional wave spectra, computed using maximum entropy method. Contours of spectral density as a function of direction. Contours are 0.1, $0.25,1$ (dashed), $2.5,10,25,100$, and 250 (solid). Wind direction is shown by thick dashed line. 


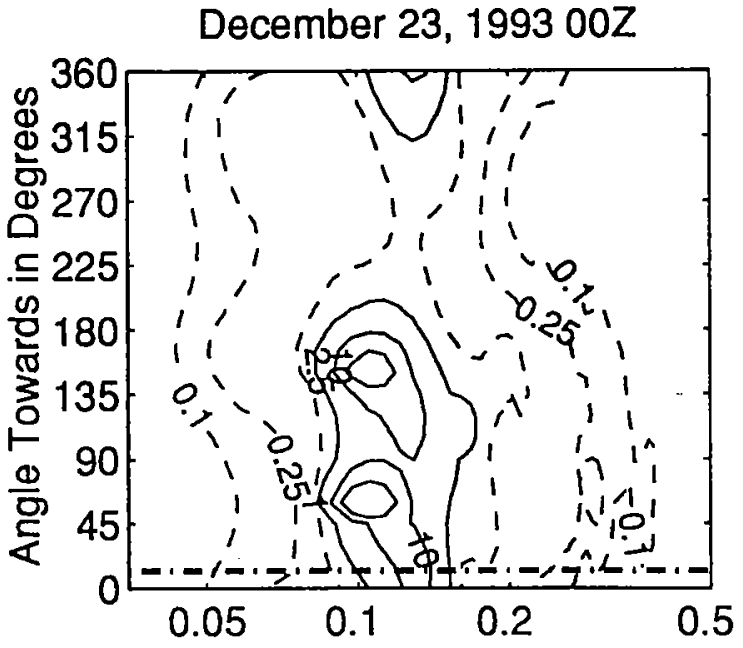

Frequency in $\mathrm{Hz}$

December 23, $199306 Z$

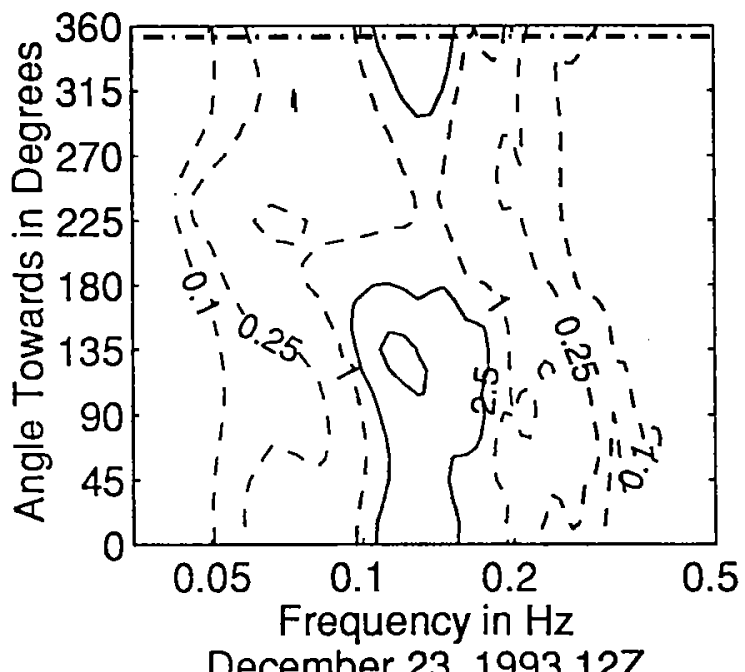

December 23, $199312 Z$

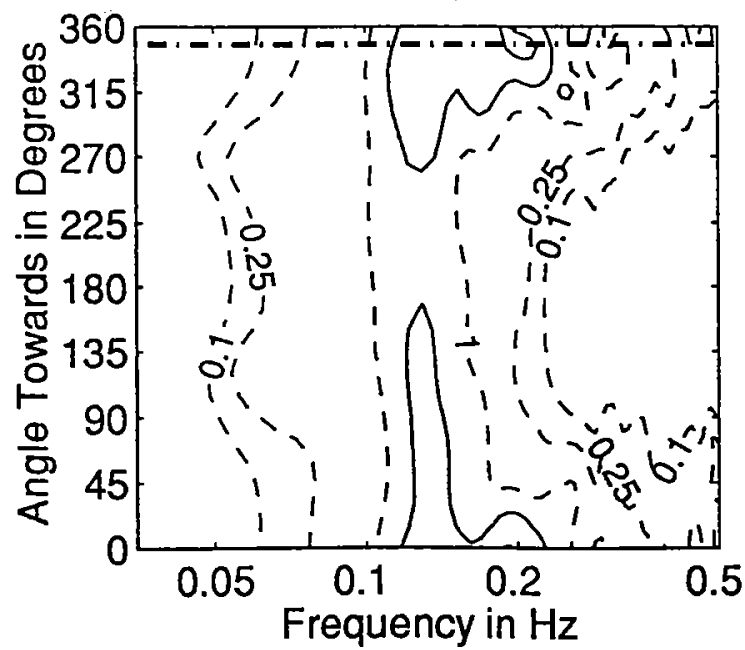

December 23, $199303 Z$

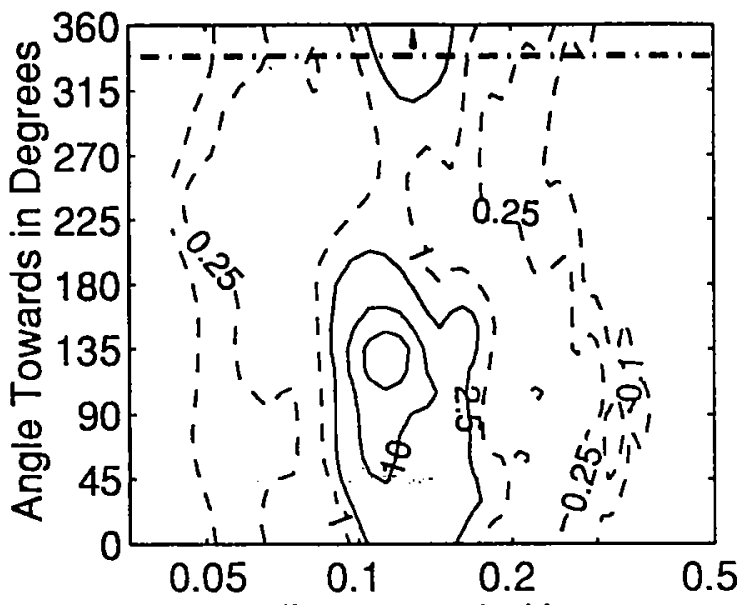

Frequency in $\mathrm{Hz}$

December 23, $199309 Z$

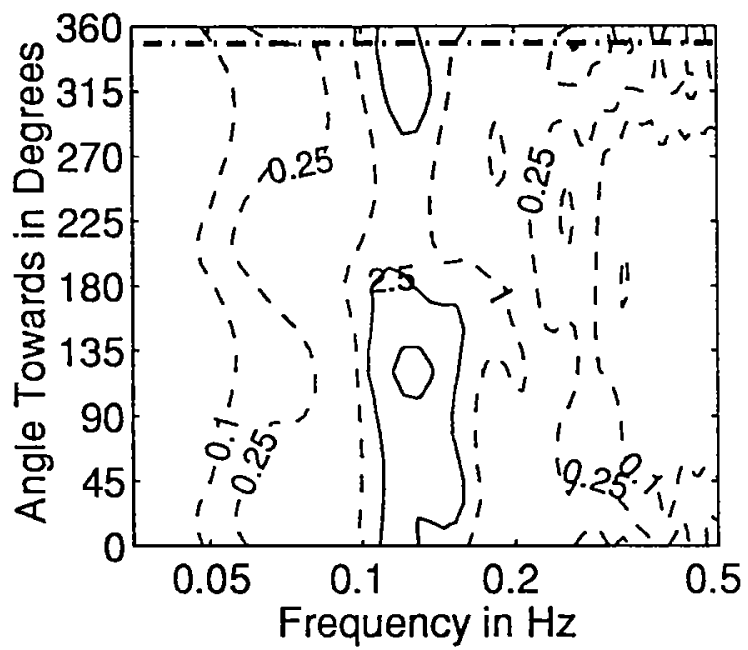

December 23, $199315 Z$

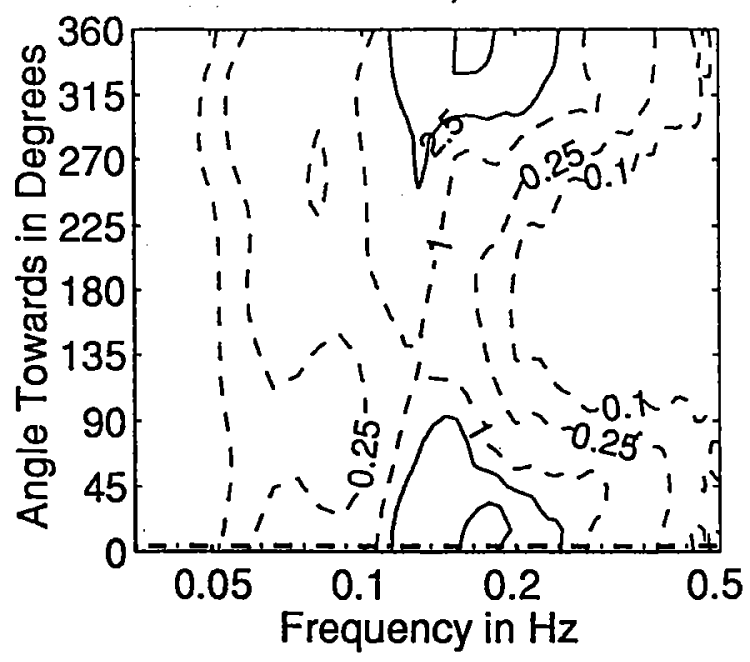

Figure 3.4.22: Directional wave spectra, computed using maximum entropy method. Contours of spectral density as a function of direction. Contours are 0.1, $0.25,1$ (dashed), $2.5,10,25,100$, and 250 (solid). Wind direction is shown by thick dashed line. 
December 23, $199318 Z$

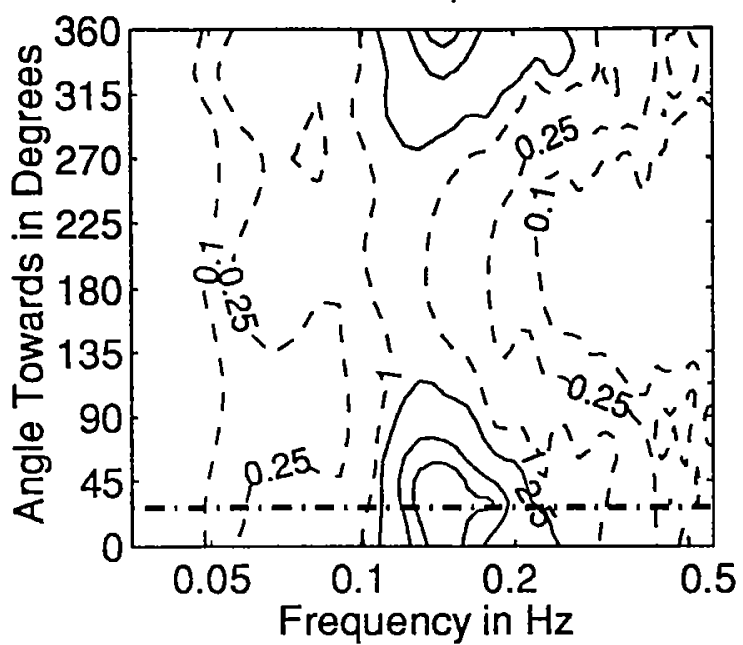

December 24, 1993 00Z

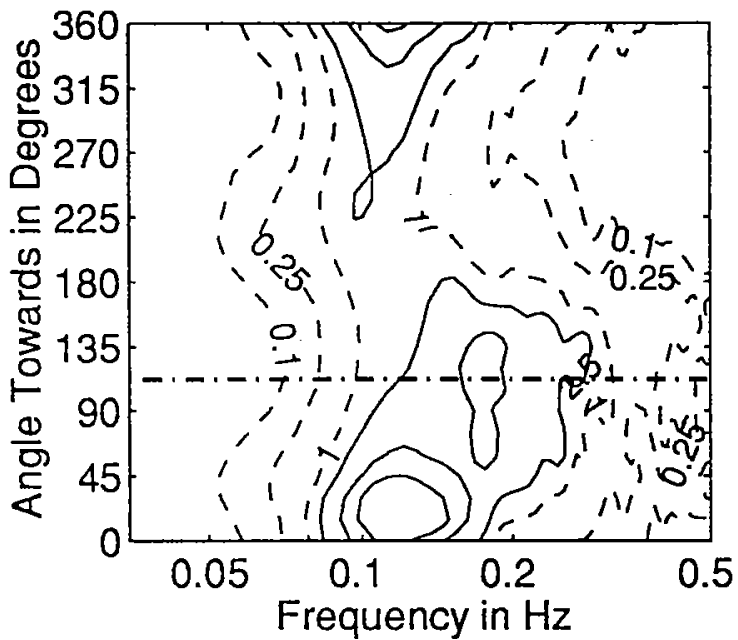

December 24, $199306 Z$

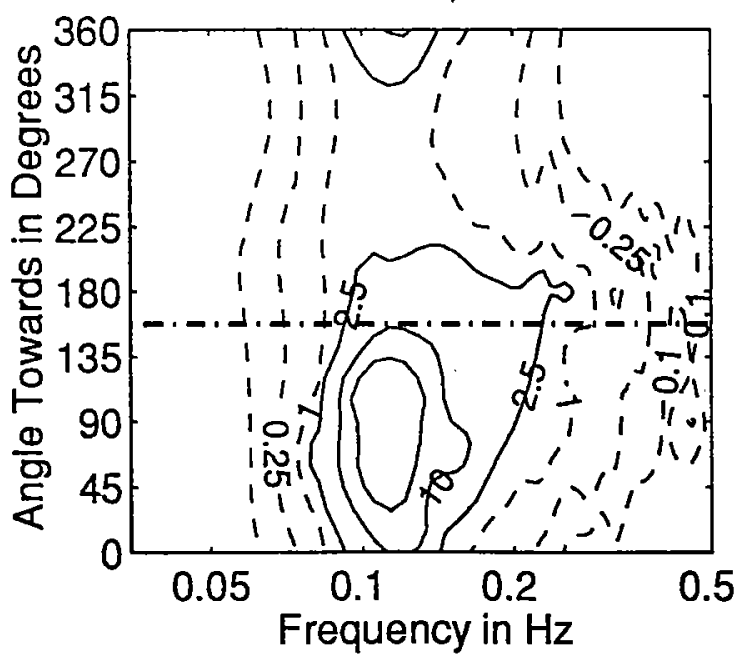

December 23, $199321 Z$

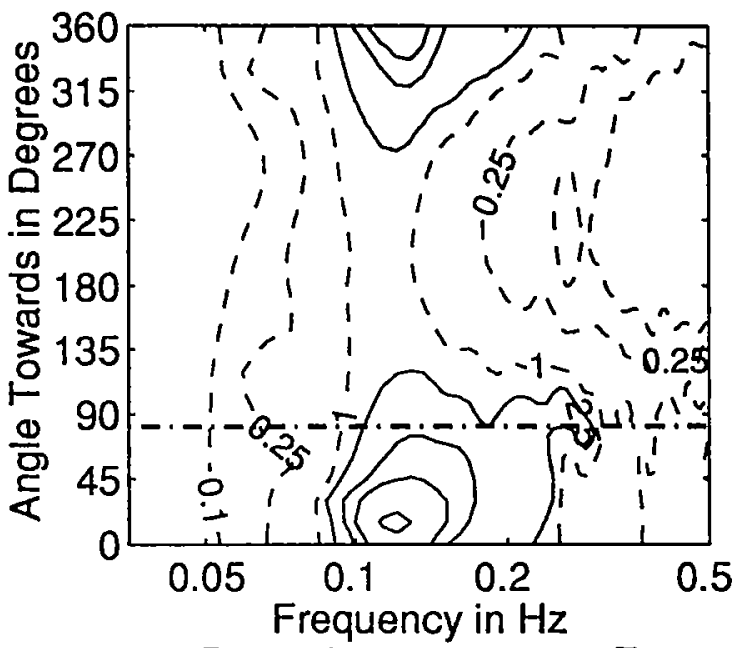

December 24, $199303 Z$

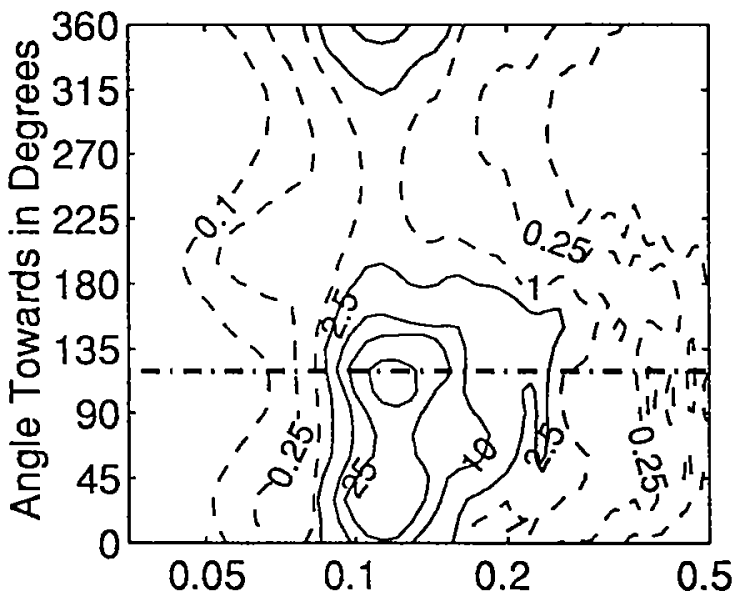

Frequency in $\mathrm{Hz}$

December 24, $199309 Z$

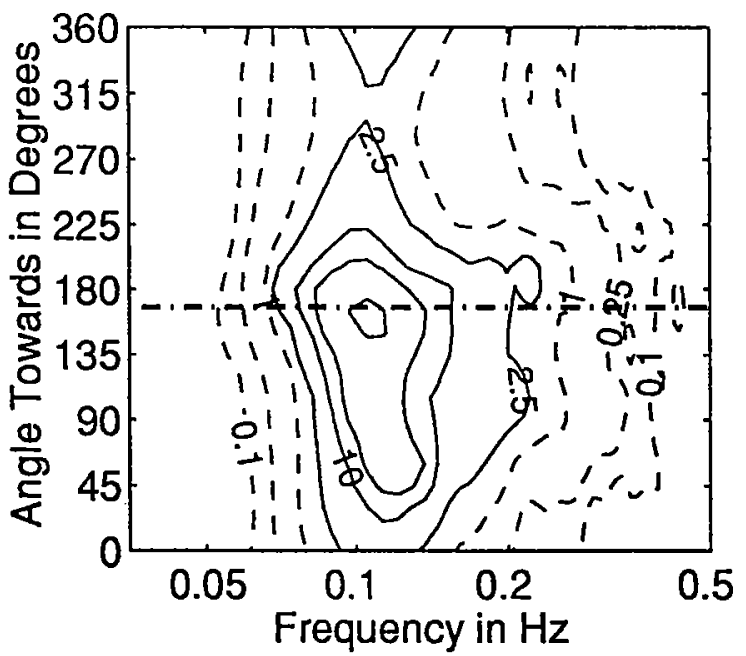

Figure 3.4.23: Directional wave spectra, computed using maximum entropy method. Contours of spectral density as a function of direction. Contours are 0.1 , $0.25,1$ (dashed), $2.5,10,25,100$, and 250 (solid). Wind direction is shown by thick dashed line. 

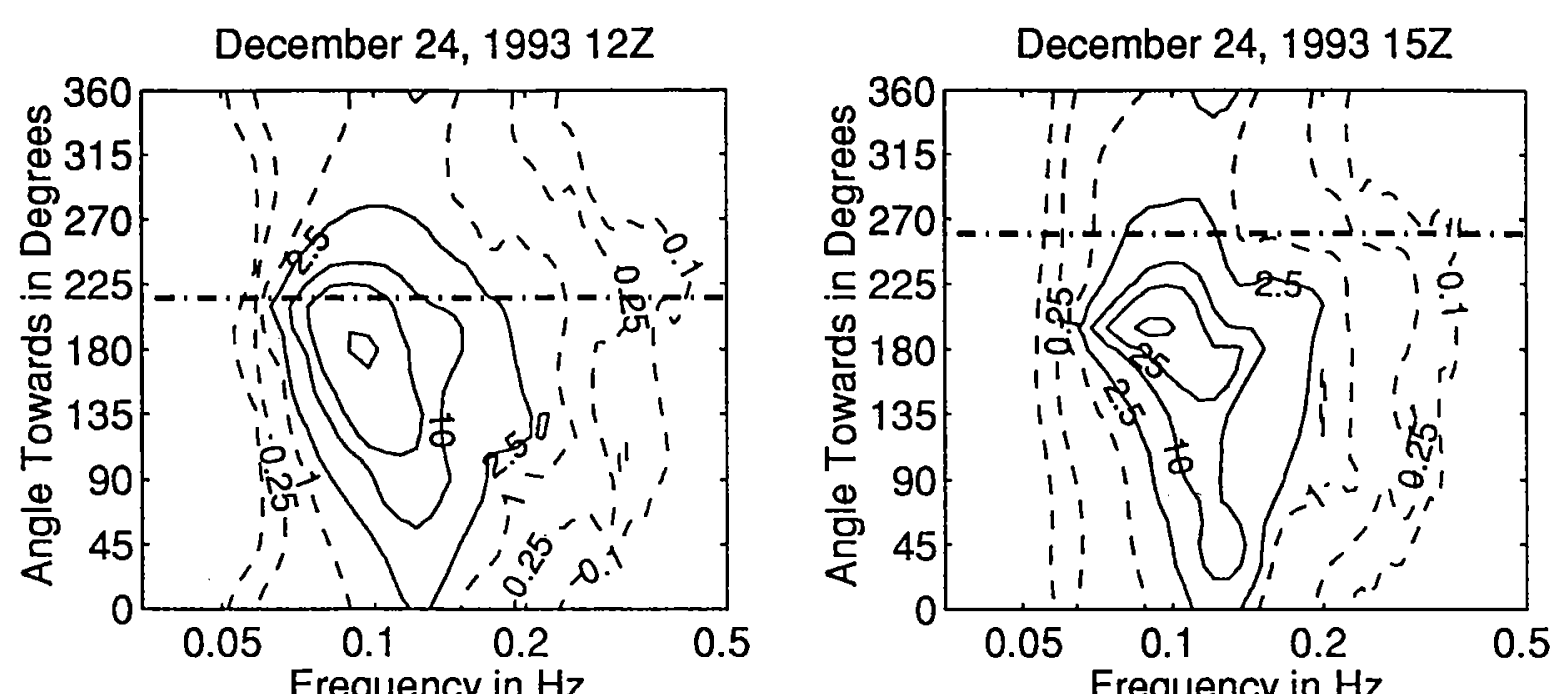

December 24, $199318 Z$

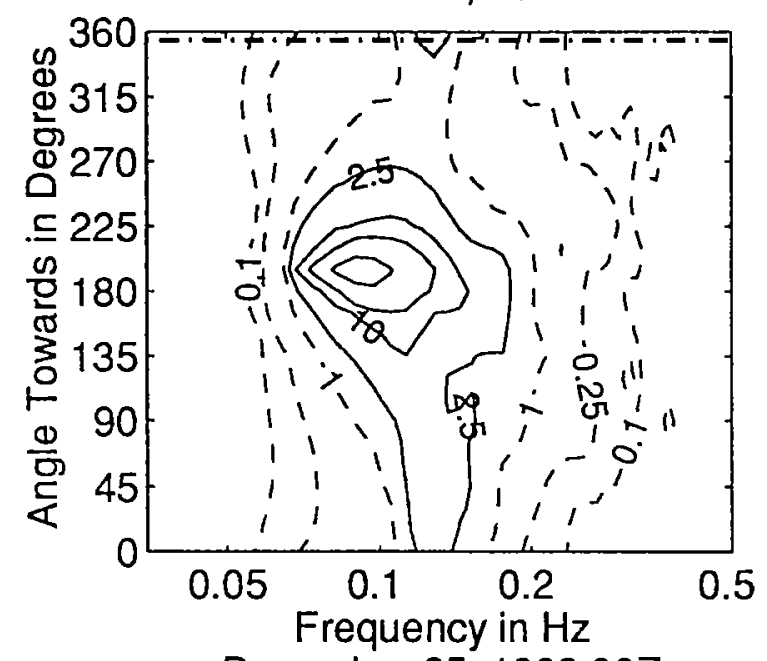

Frequency in $\mathrm{Hz}$

December 24, $199321 Z$
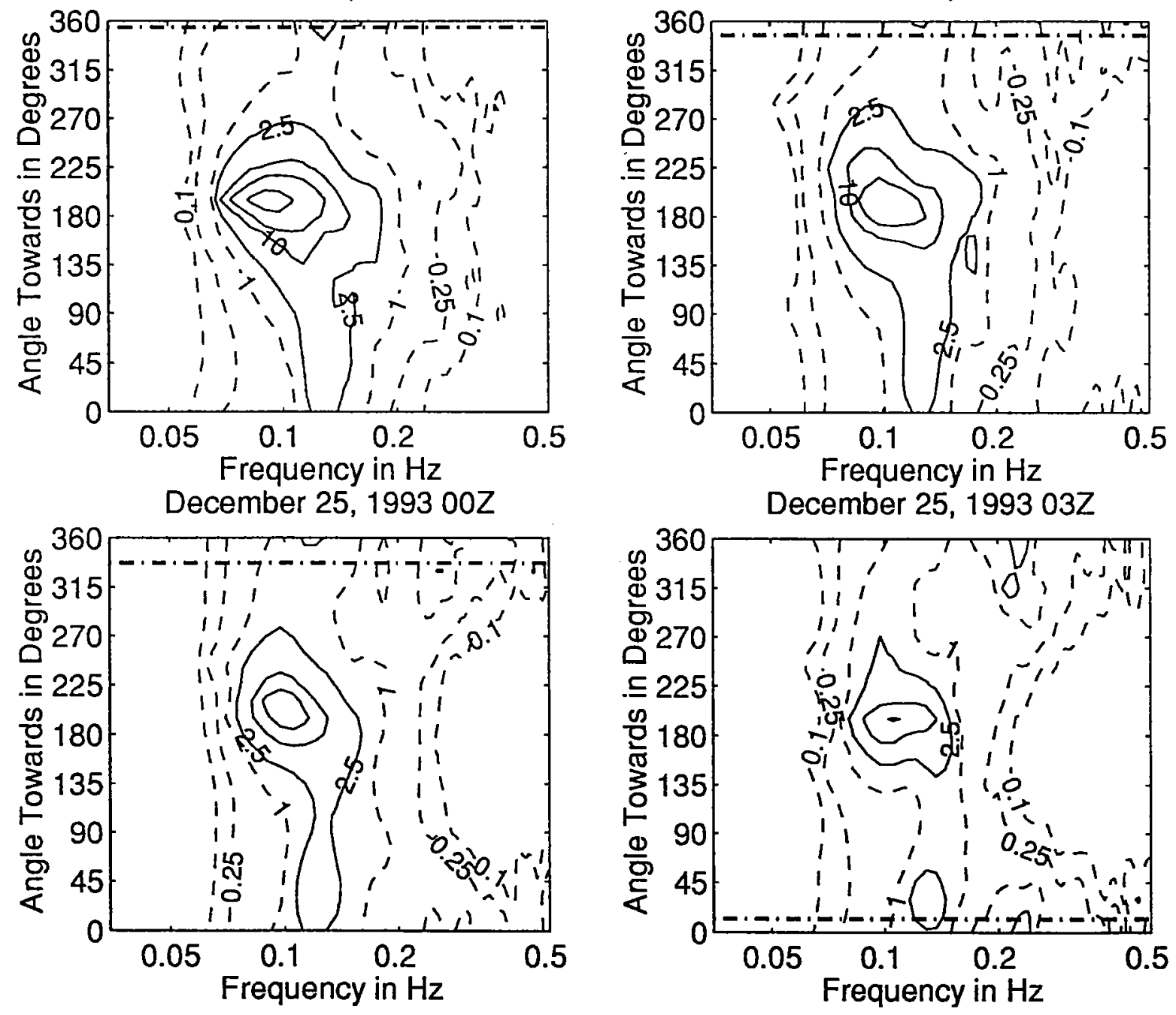

Figure 3.4.24: Directional wave spectra, computed using maximum entropy method. Contours of spectral density as a function of direction. Contours are 0.1, $0.25,1$ (dashed), $2.5,10,25,100$, and 250 (solid). Wind direction is shown by thick dashed line. 

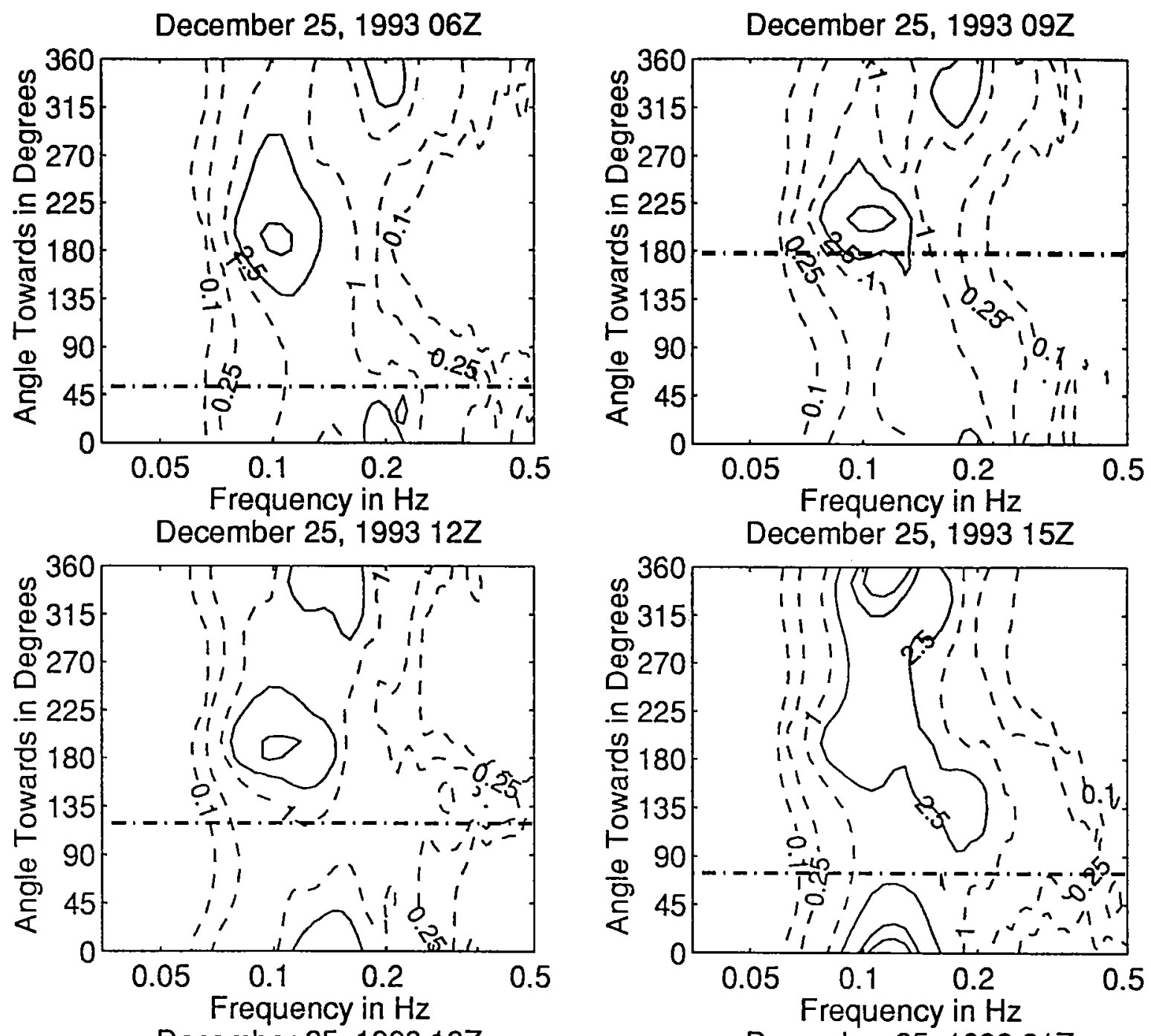

December 25, $199318 Z$
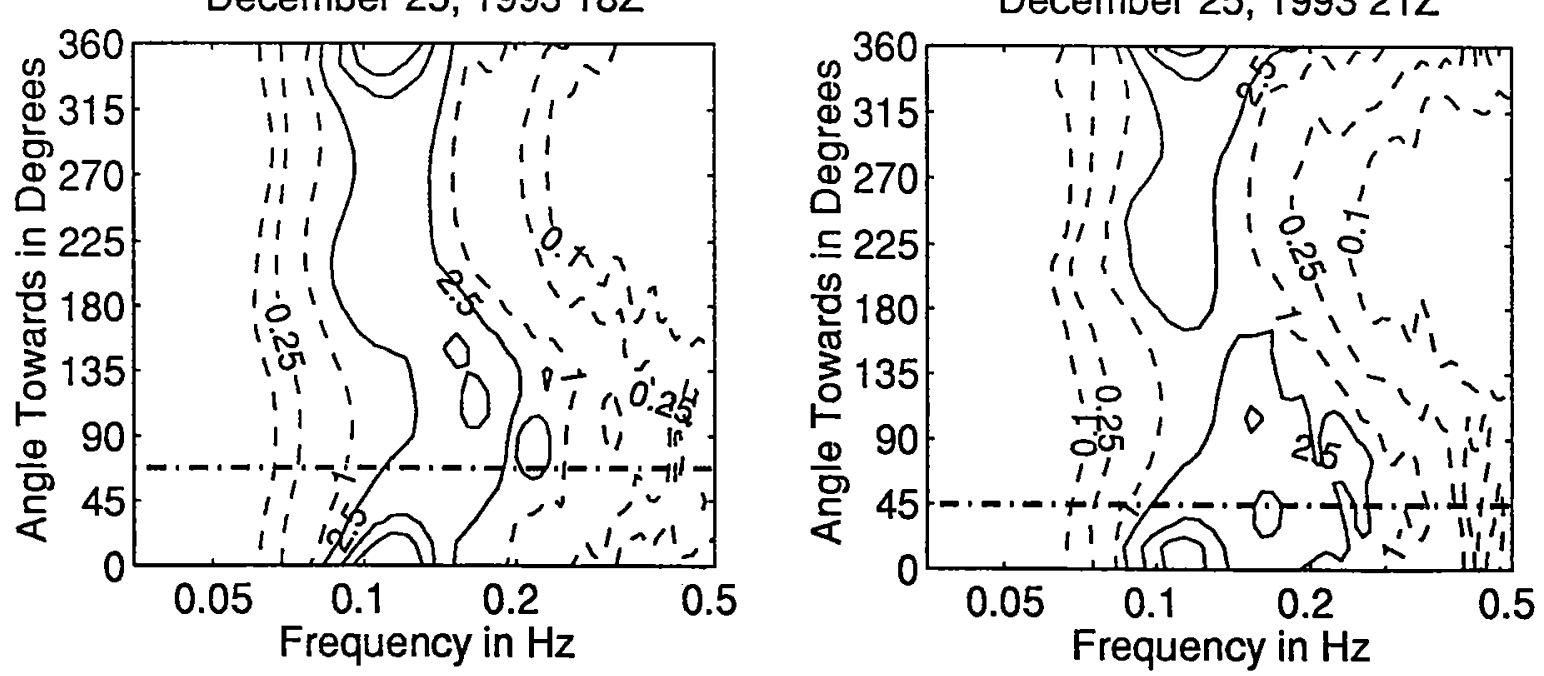

Figure 3.4.25: Directional wave spectra, computed using maximum entropy method. Contours of spectral density as a function of direction. Contours are 0.1, $0.25,1$ (dashed), $2.5,10,25,100$, and 250 (solid). Wind direction is shown by thick dashed line. 
December 26, $199300 Z$

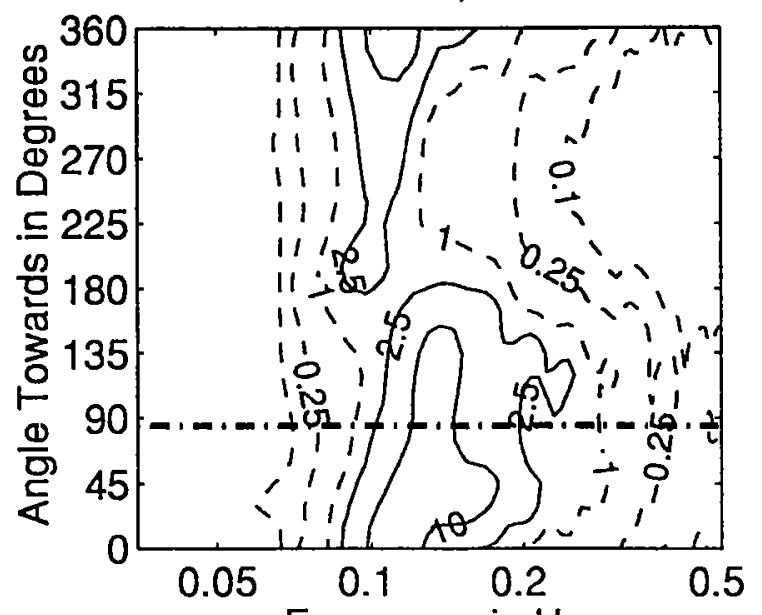

Frequency in $\mathrm{Hz}$

December 26, $199306 Z$

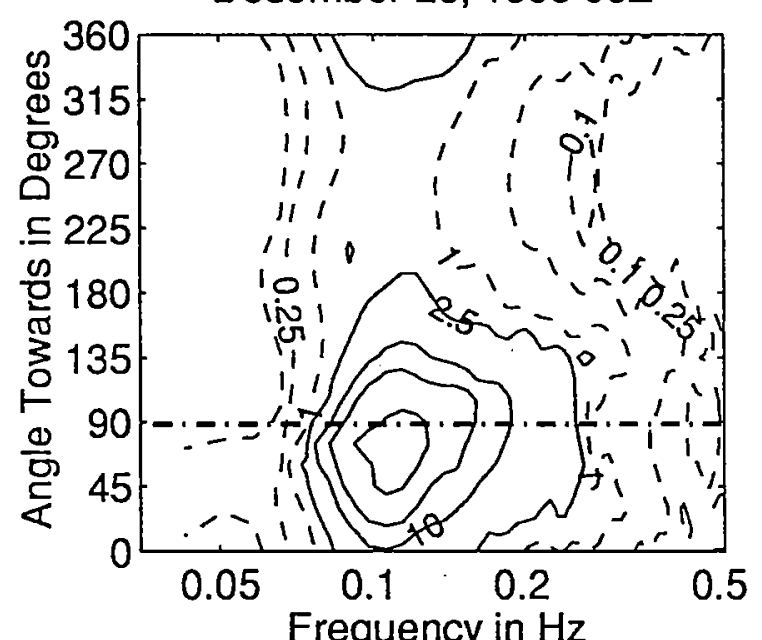

December 26, $199312 Z$

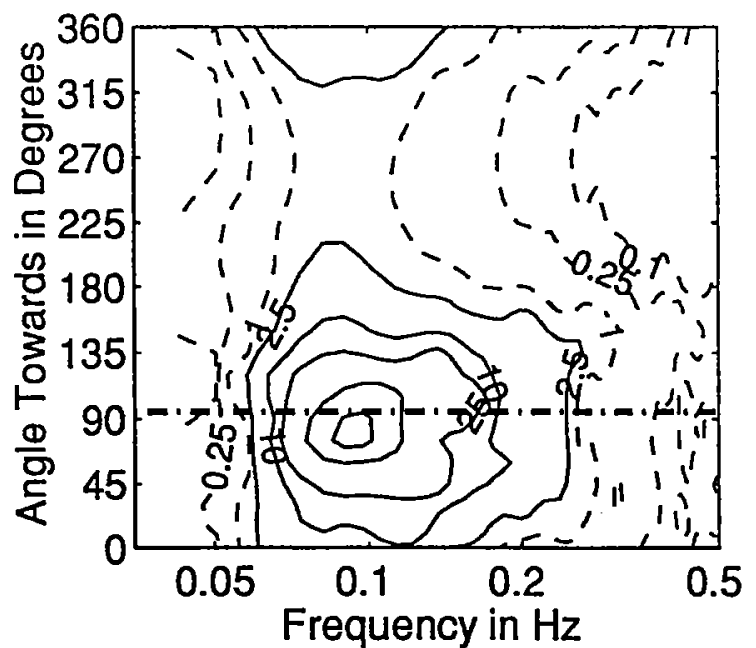

December 26, 1993032

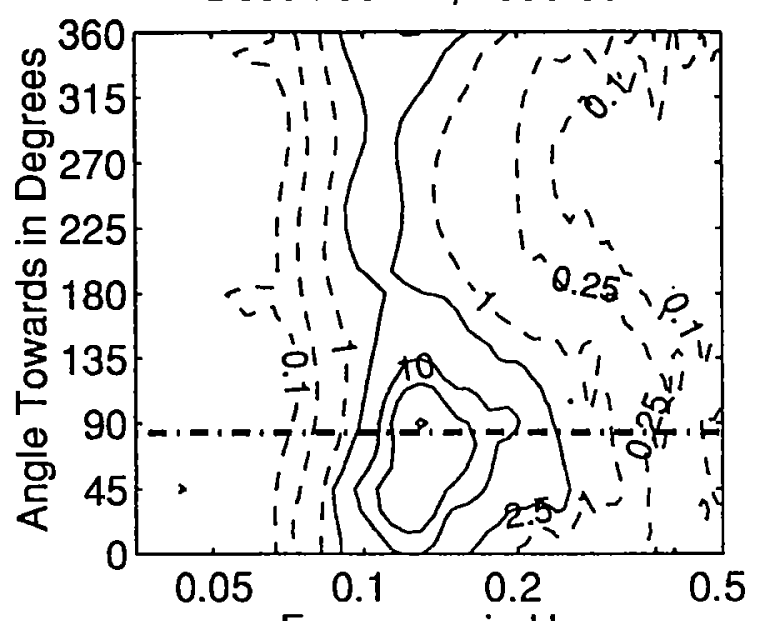

Frequency in $\mathrm{Hz}$

December 26, $199309 Z$

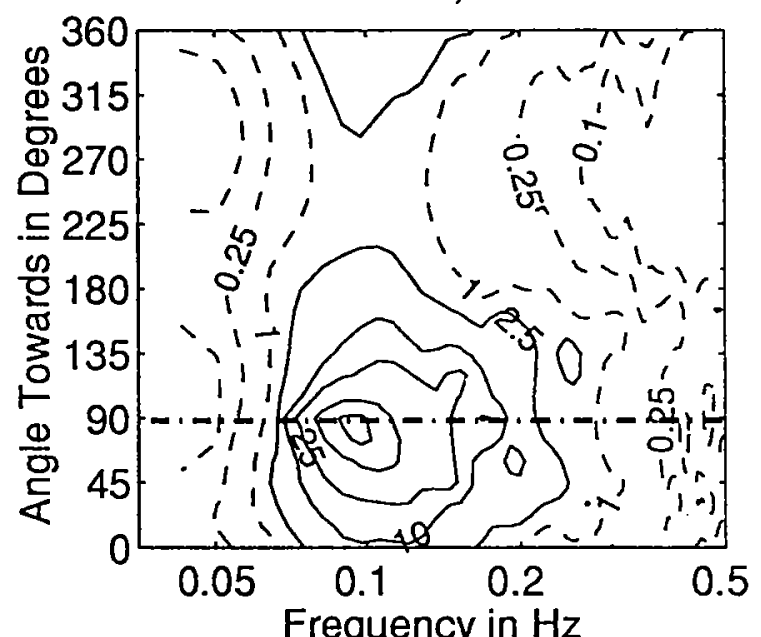

December 26, $199315 Z$

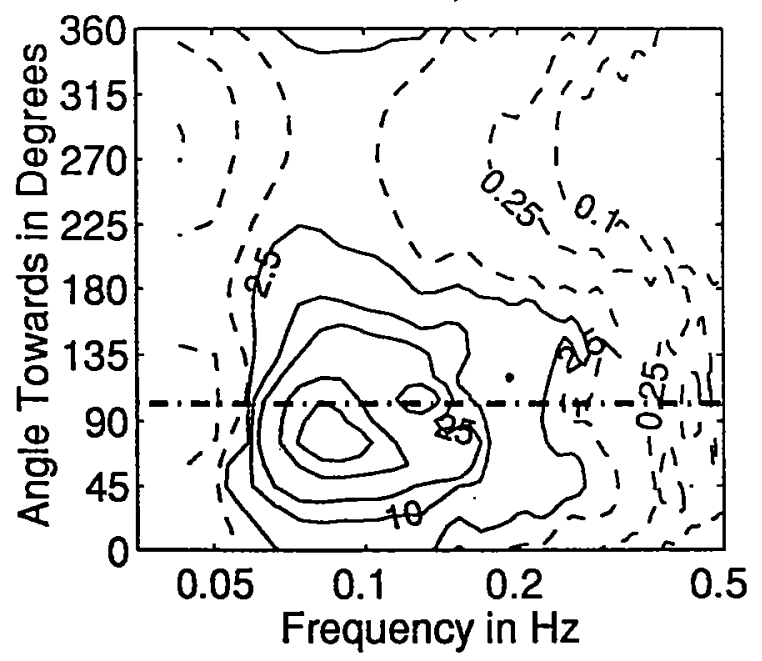

Figure 3.4.26: Directional wave spectra, computed using maximum entropy method. Contours of spectral density as a function of direction. Contours are 0.1 , $0.25,1$ (dashed), $2.5,10,25,100$, and 250 (solid). Wind direction is shown by thick dashed line. 
December 26, $199318 Z$

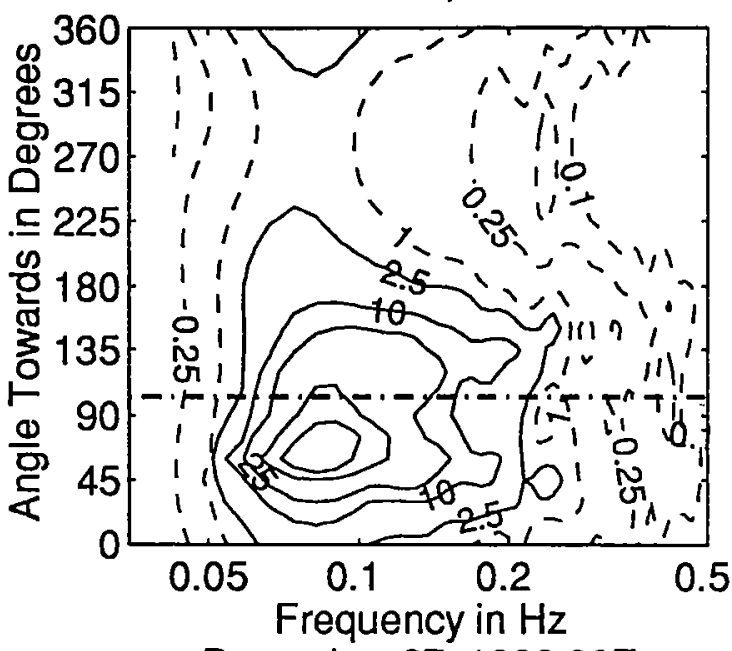

December 27, $199300 Z$

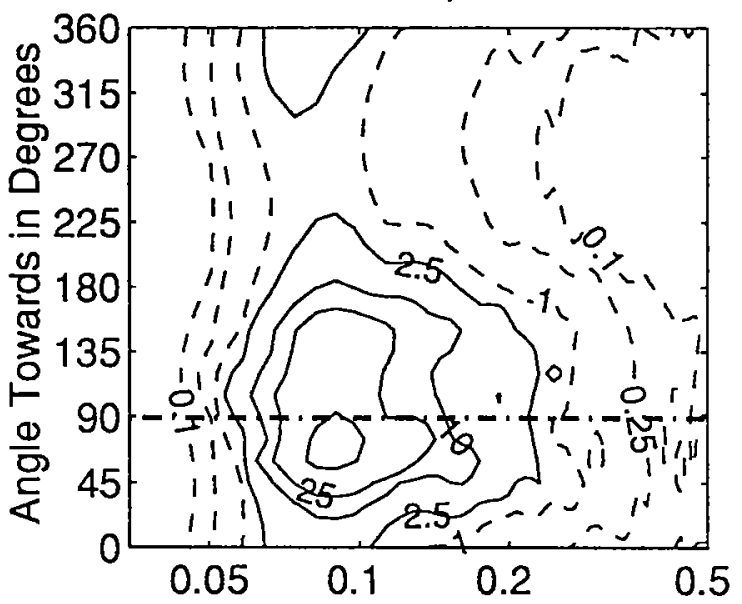

Frequency in $\mathrm{Hz}$

December 27, $199306 Z$

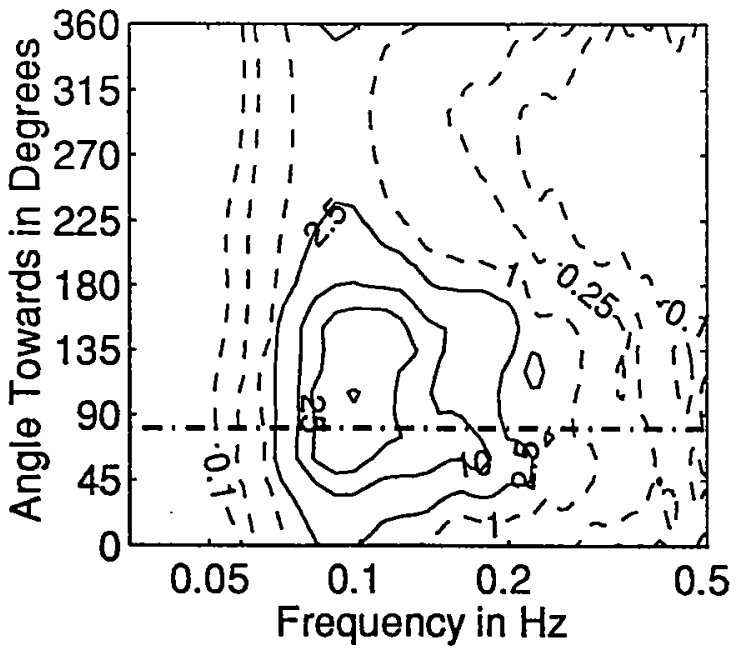

December 26, $199321 Z$
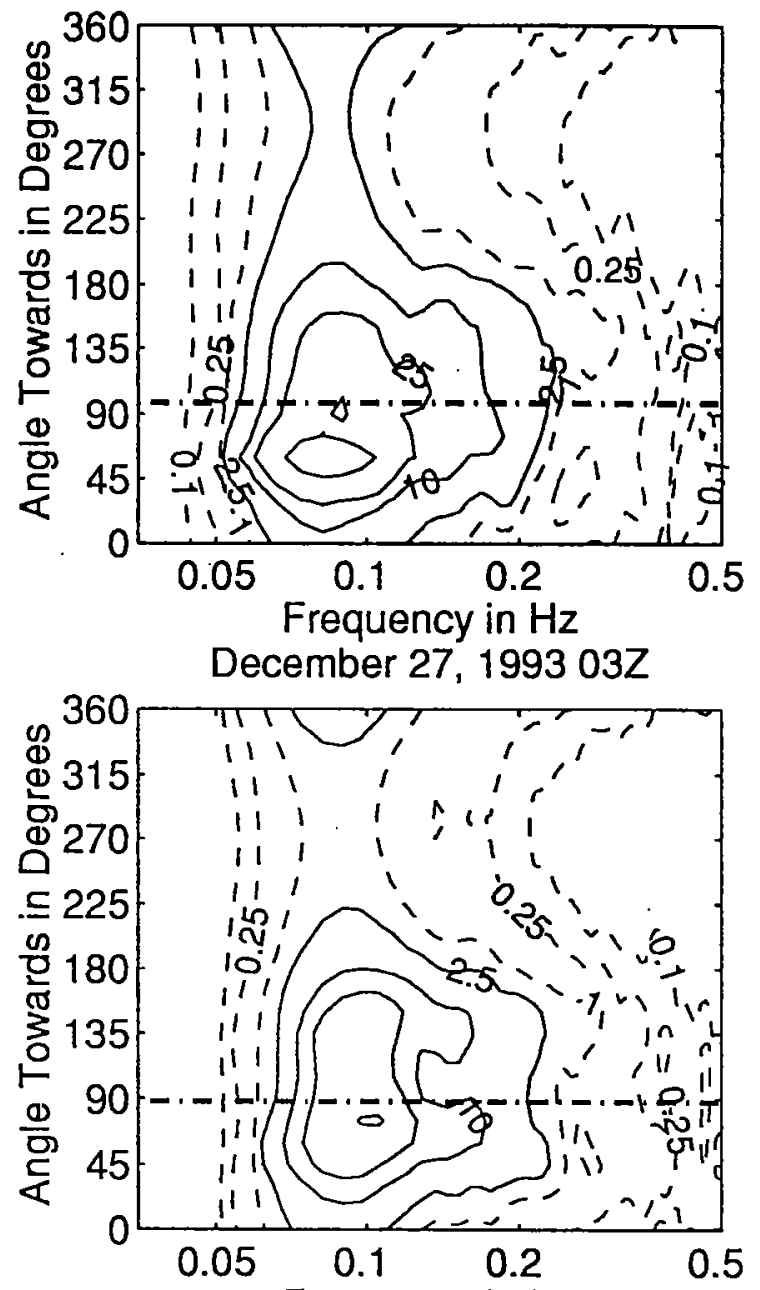

Frequency in $\mathrm{Hz}$

December 27, $199309 Z$

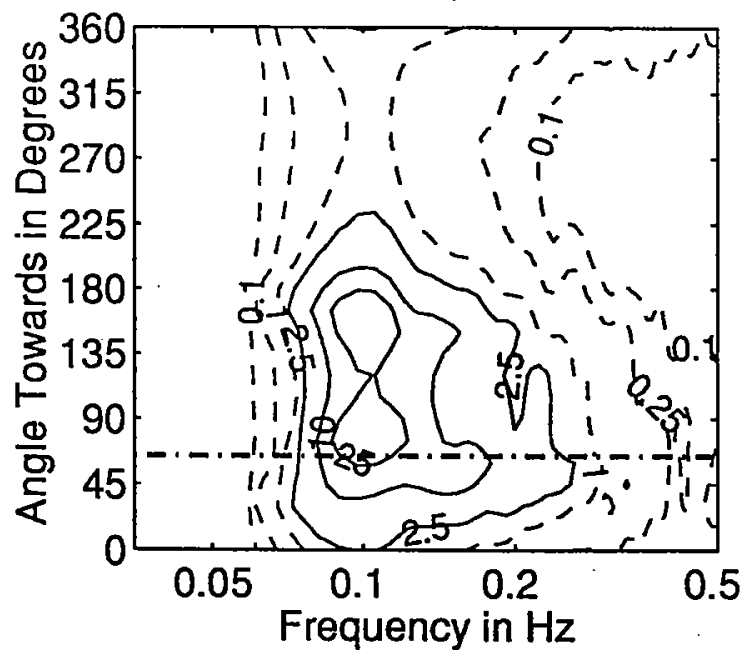

Figure 3.4.27: Directional wave spectra, computed using maximum entropy method. Contours of spectral density as a function of direction. Contours are 0.1 , $0.25,1$ (dashed), $2.5,10,25,100$, and 250 (solid). Wind direction is shown by thick dashed line. 

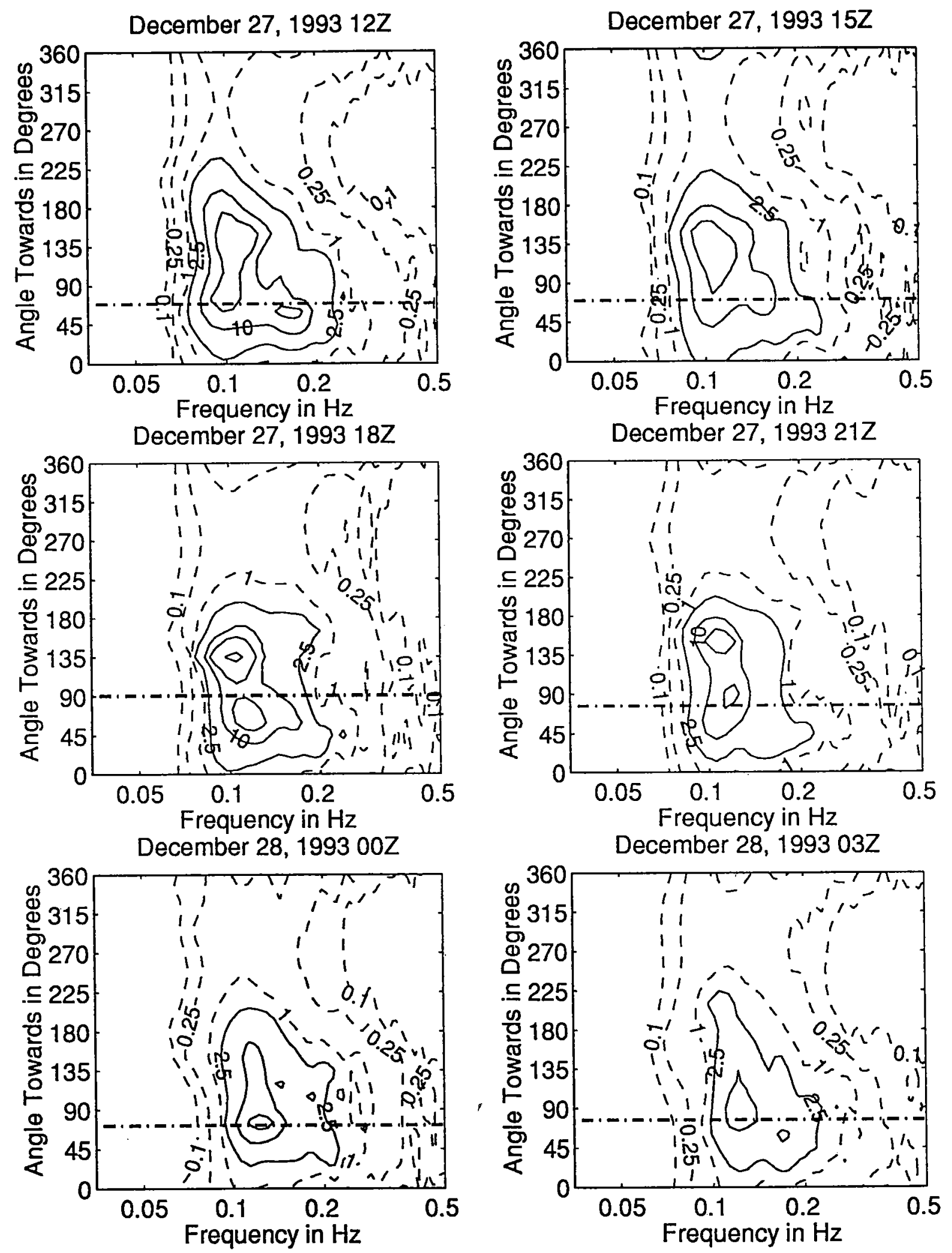

Figure 3.4.28: Directional wave spectra, computed using maximum entropy method. Contours of spectral density as a function of direction. Contours are 0.1 , $0.25,1$ (dashed), $2.5,10,25,100$, and 250 (solid). Wind direction is shown by thick dashed line. 
December 28, $199306 Z$

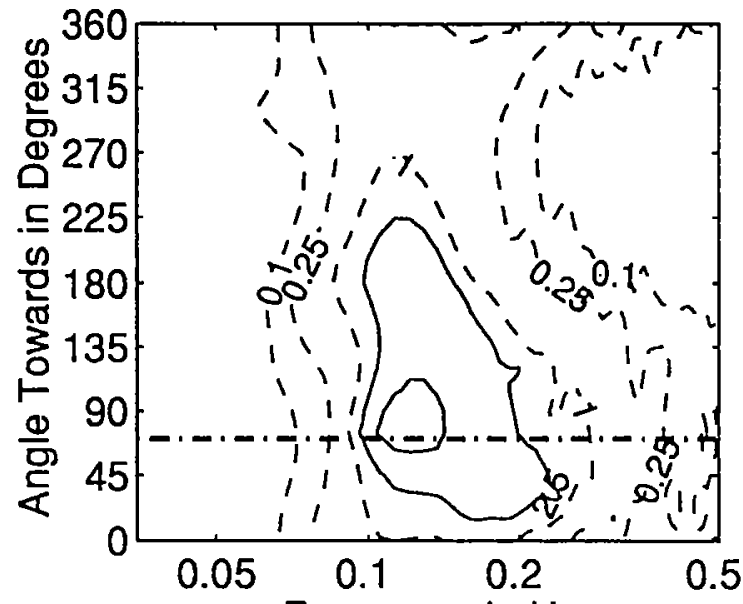

Frequency in $\mathrm{Hz}$

December 28, $199312 Z$

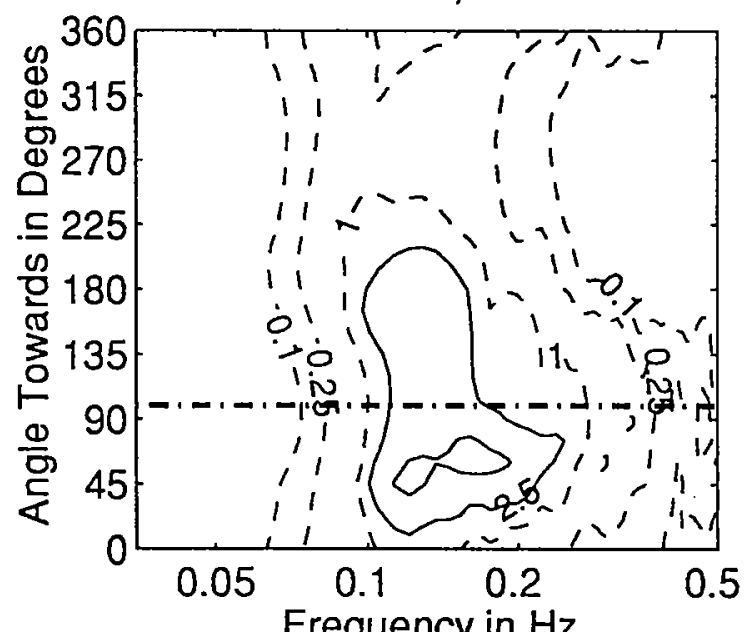

Frequency in $\mathrm{Hz}$

December 28, $199318 Z$

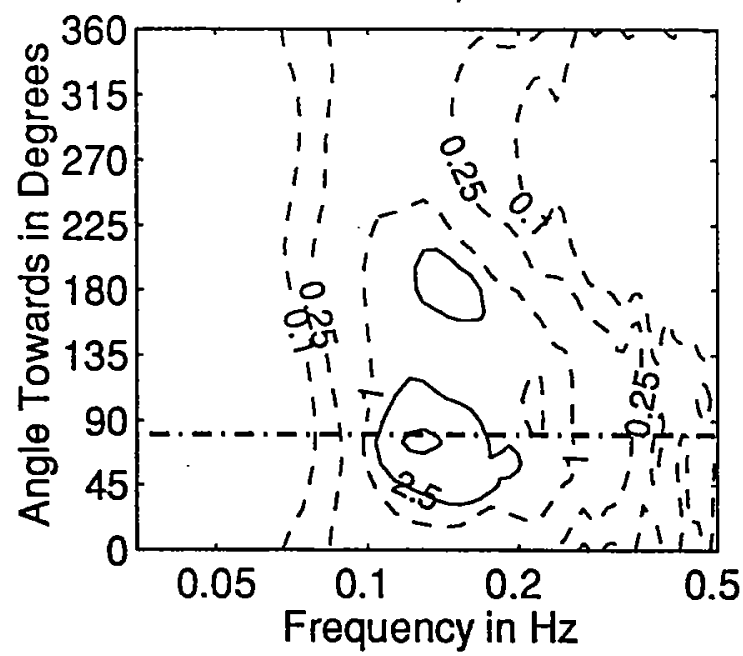

December 28, $199309 Z$

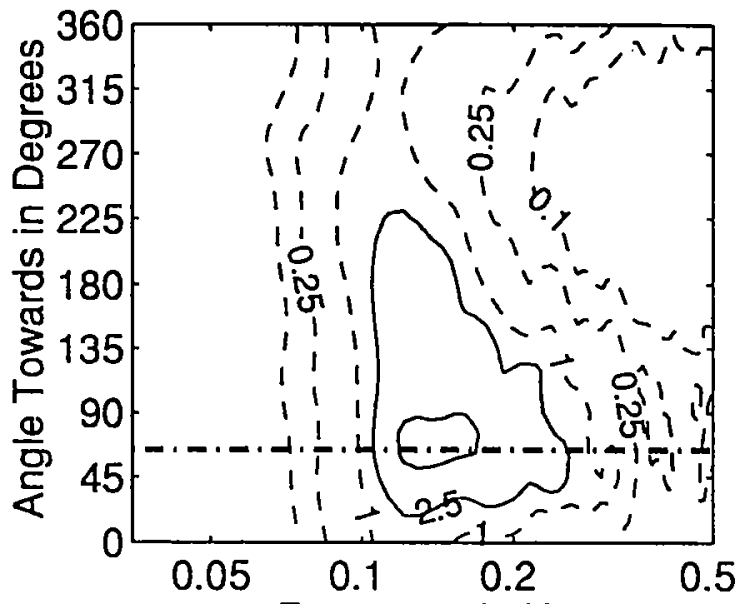

Frequency in $\mathrm{Hz}$

December 28, $199315 Z$

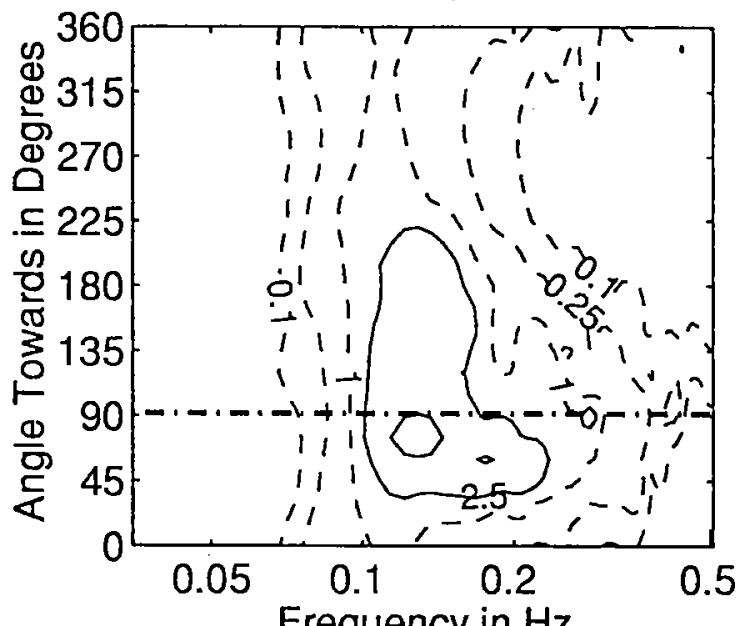

Frequency in $\mathrm{Hz}$

December 28, 1993212

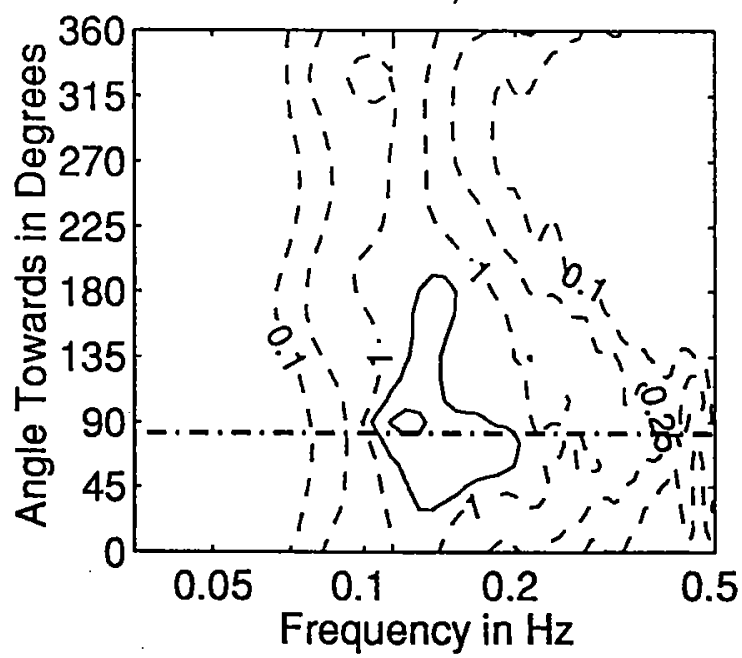

Figure 3.4.29: Directional wave spectra, computed using maximum entropy method. Contours of spectral density as a function of direction. Contours are 0.1 , $0.25,1$ (dashed), 2.5, 10,25, 100, and 250 (solid). Wind direction is shown by thick dashed line. 

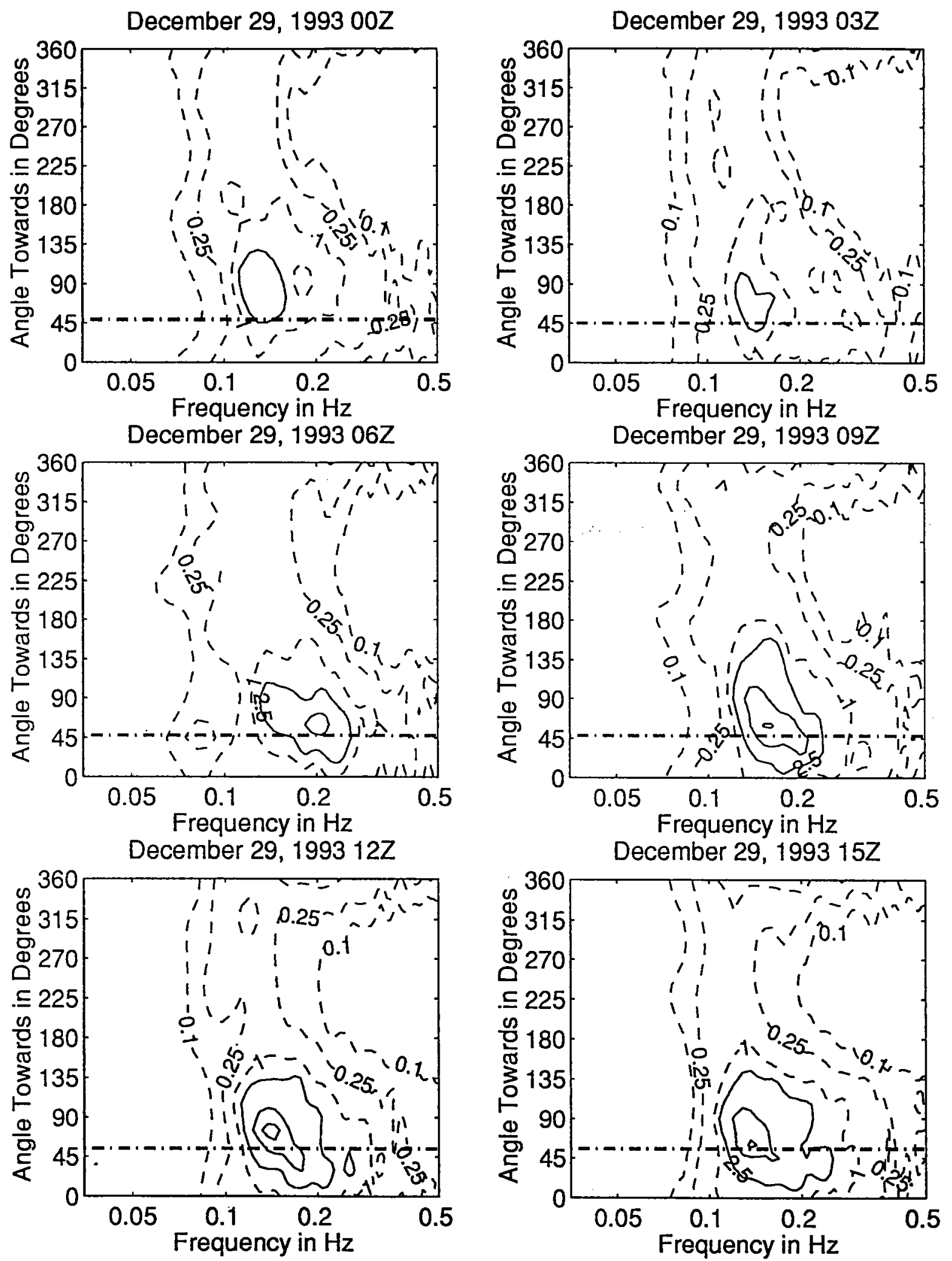

Figure 3.4.30: Directional wave spectra, computed using maximum entropy method. Contours of spectral density as a function of direction. Contours are 0.1, $0.25,1$ (dashed), $2.5,10,25,100$, and 250 (solid). Wind direction is shown by thick dashed line. 
December 29, $199318 Z$

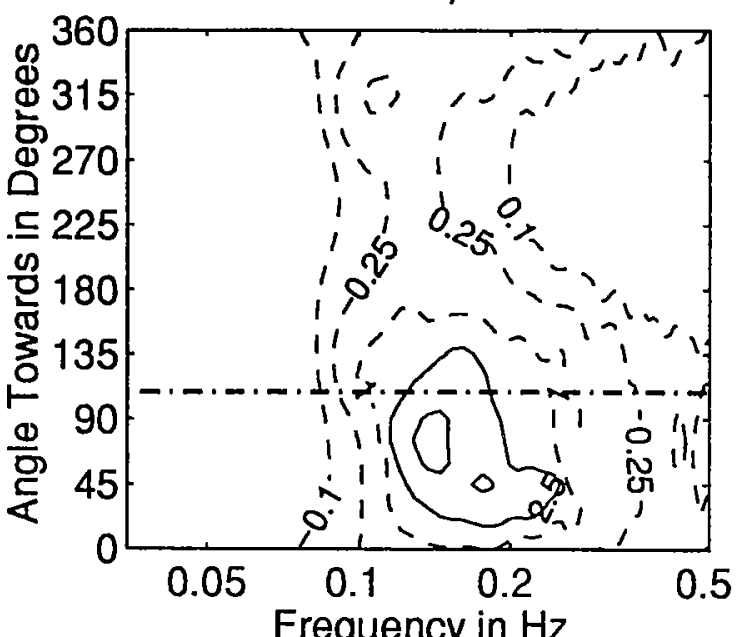

December 30, $199300 Z$

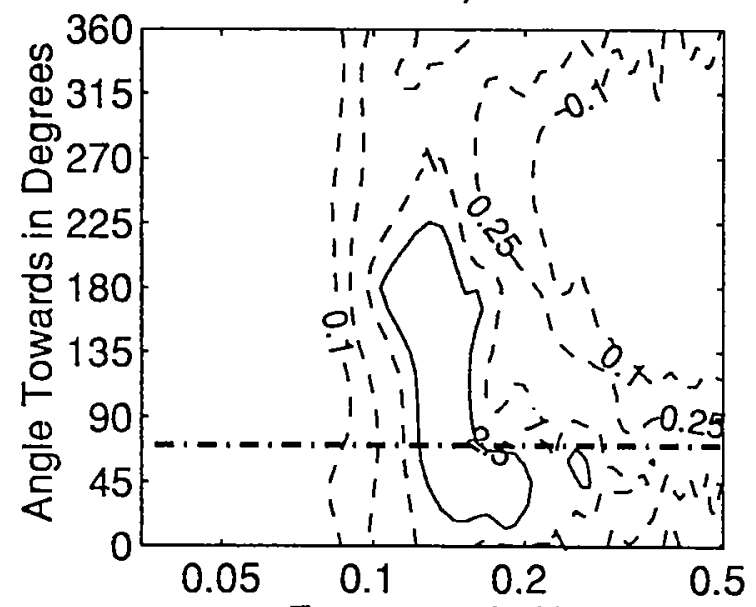

Frequency in $\mathrm{Hz}$

December 30, $199306 Z$

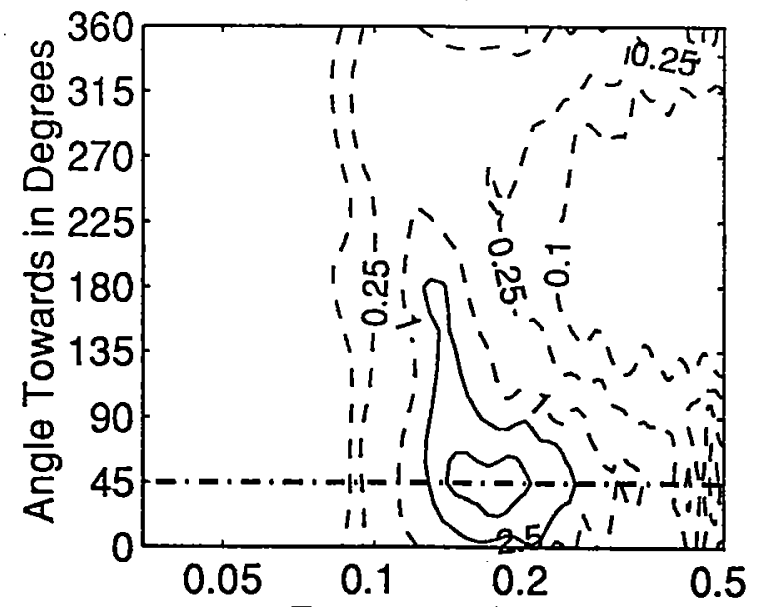

Frequency in $\mathrm{Hz}$
December 29, $199321 Z$

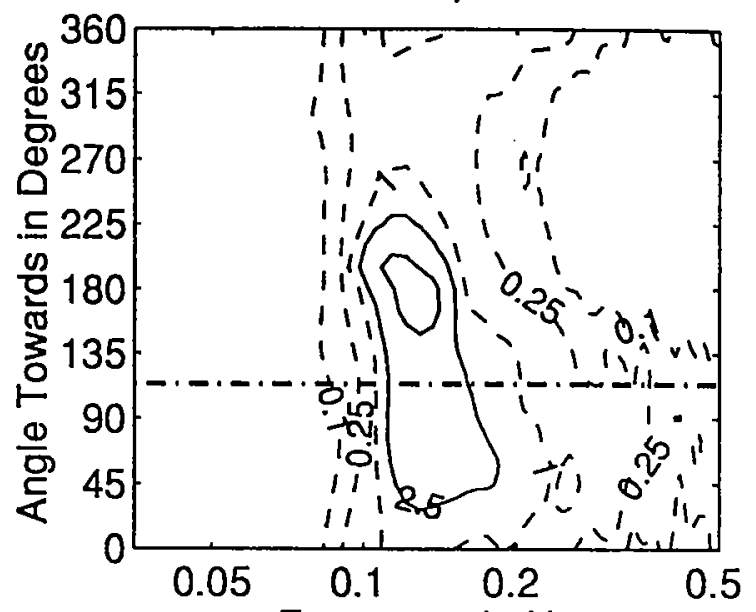

Frequency in $\mathrm{Hz}$

December 30, $199303 Z$
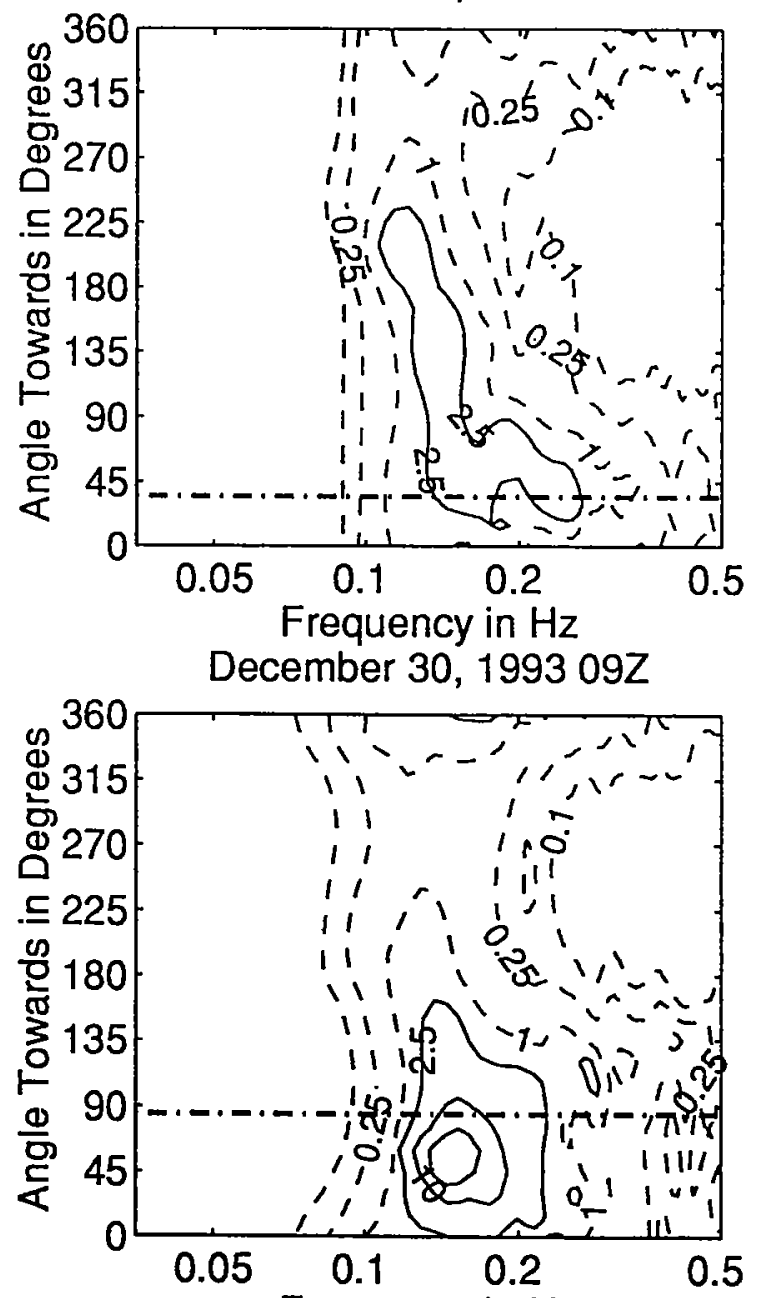

Frequency in $\mathrm{Hz}$

Figure 3.4.31: Directional wave spectra, computed using maximum entropy method. Contours of spectral density as a function of direction. Contours are 0.1, $0.25,1$ (dashed), $2.5,10,25,100$, and 250 (solid). Wind direction is shown by thick dashed line. 

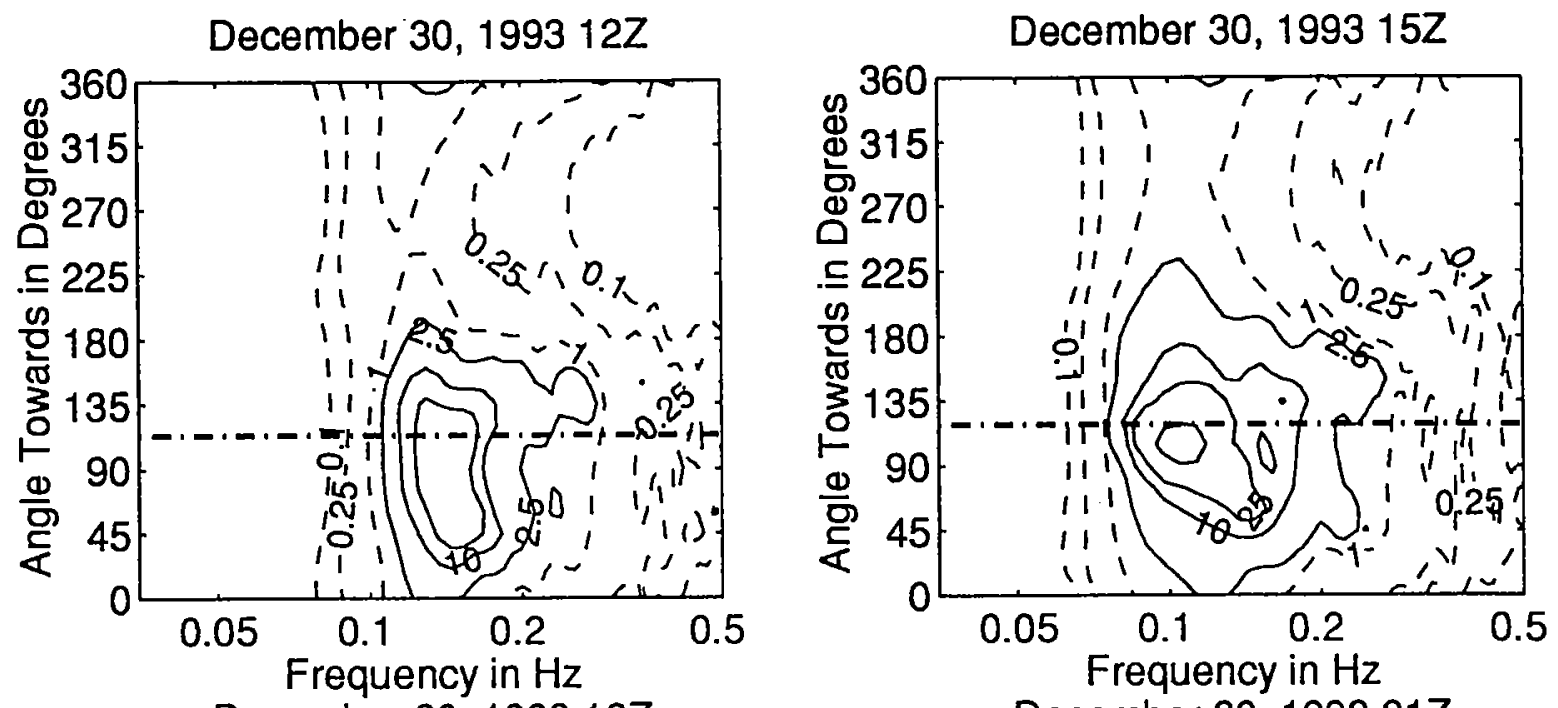

December 30, $199318 Z$

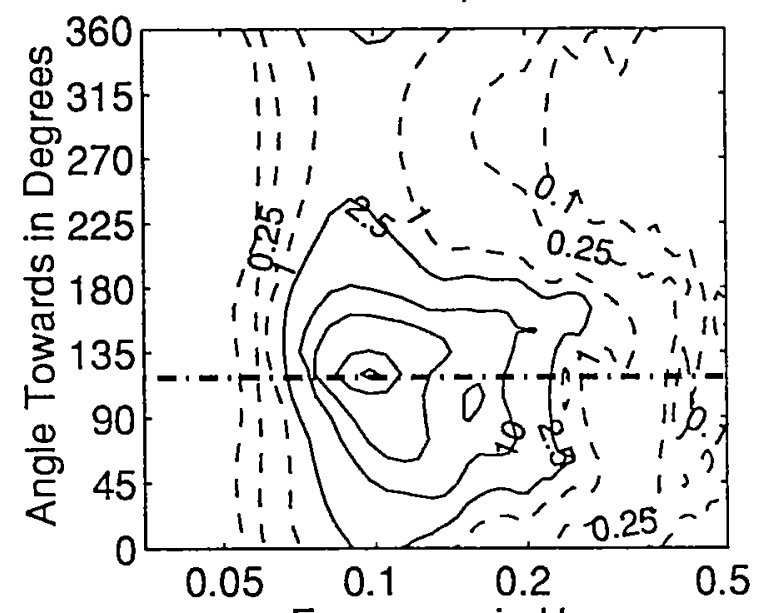

Frequency in $\mathrm{Hz}$

December 31, $199300 Z$

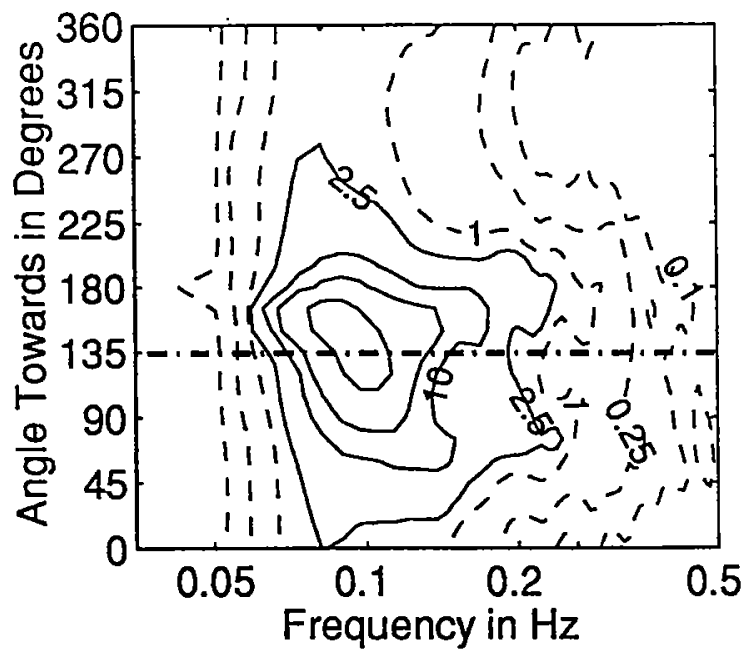

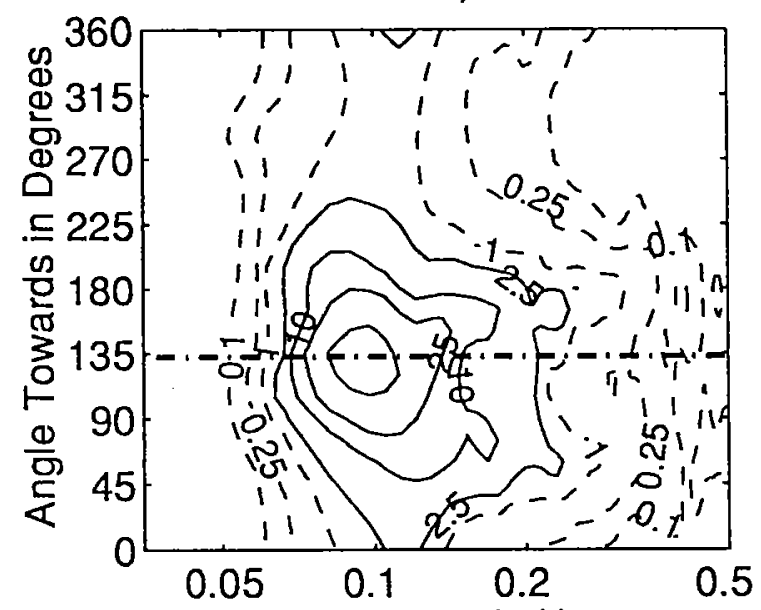

Frequency in $\mathrm{Hz}$

December 31, $199303 Z$

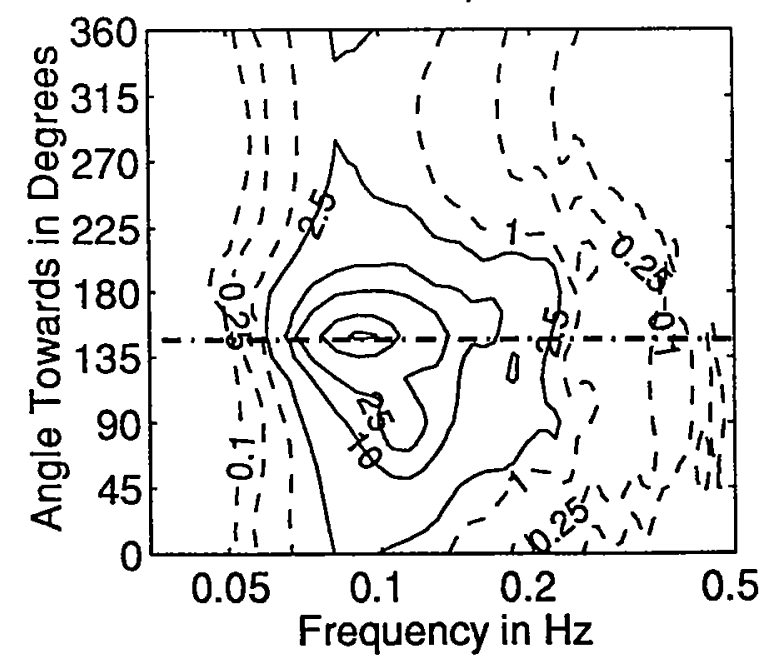

Figure 3.4.32: Directional wave spectra, computed using maximum entropy method. Contours of spectral density as a function of direction. Contours are 0.1, $0.25,1$ (dashed), $2.5,10,25,100$, and 250 (solid). Wind direction is shown by
thick dashed line. 
December 31, $199306 Z$

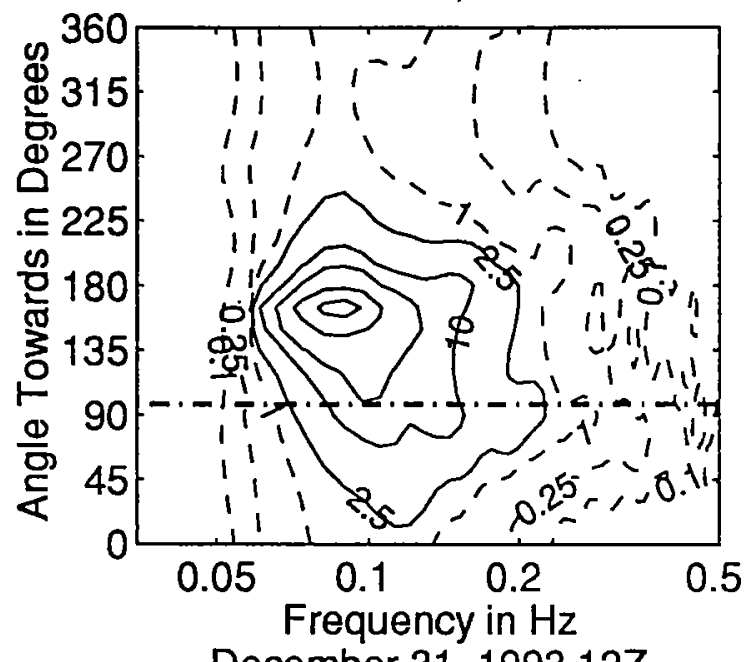

December 31, $199312 Z$
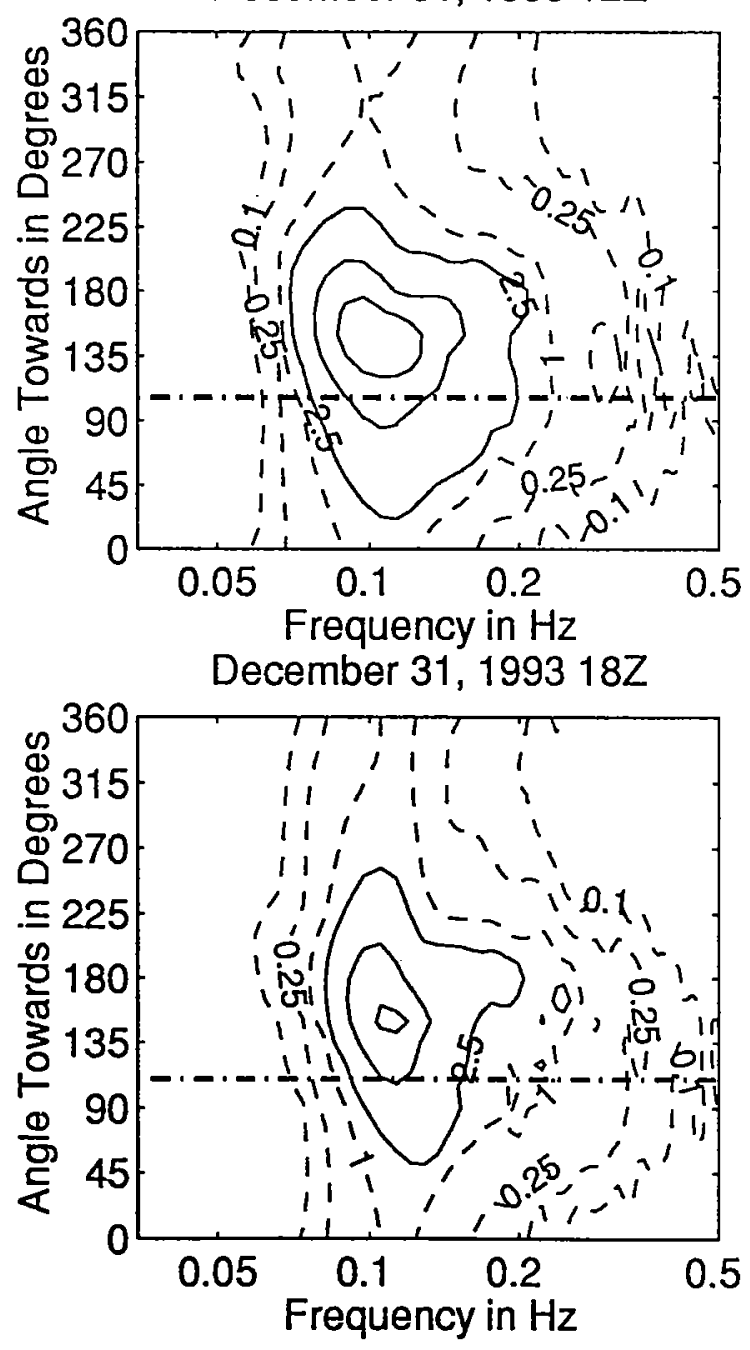

December 31, $199309 Z$

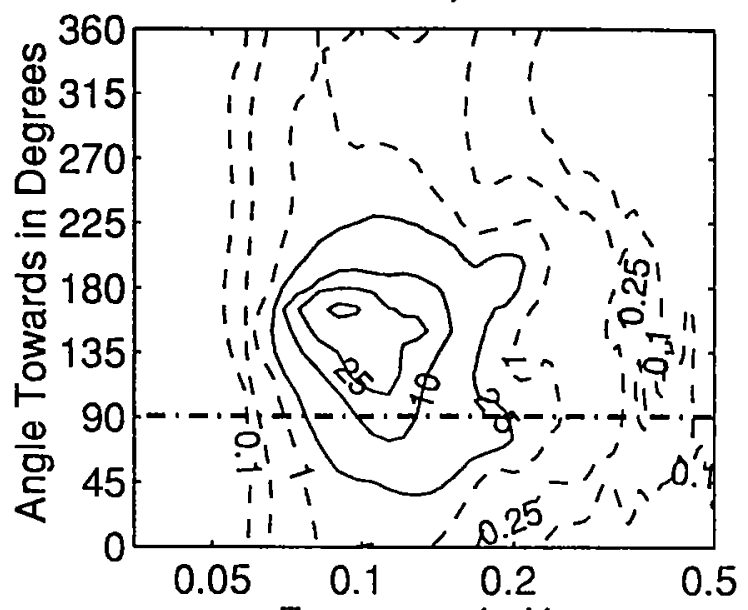

Frequency in $\mathrm{Hz}$

December 31, $199315 Z$
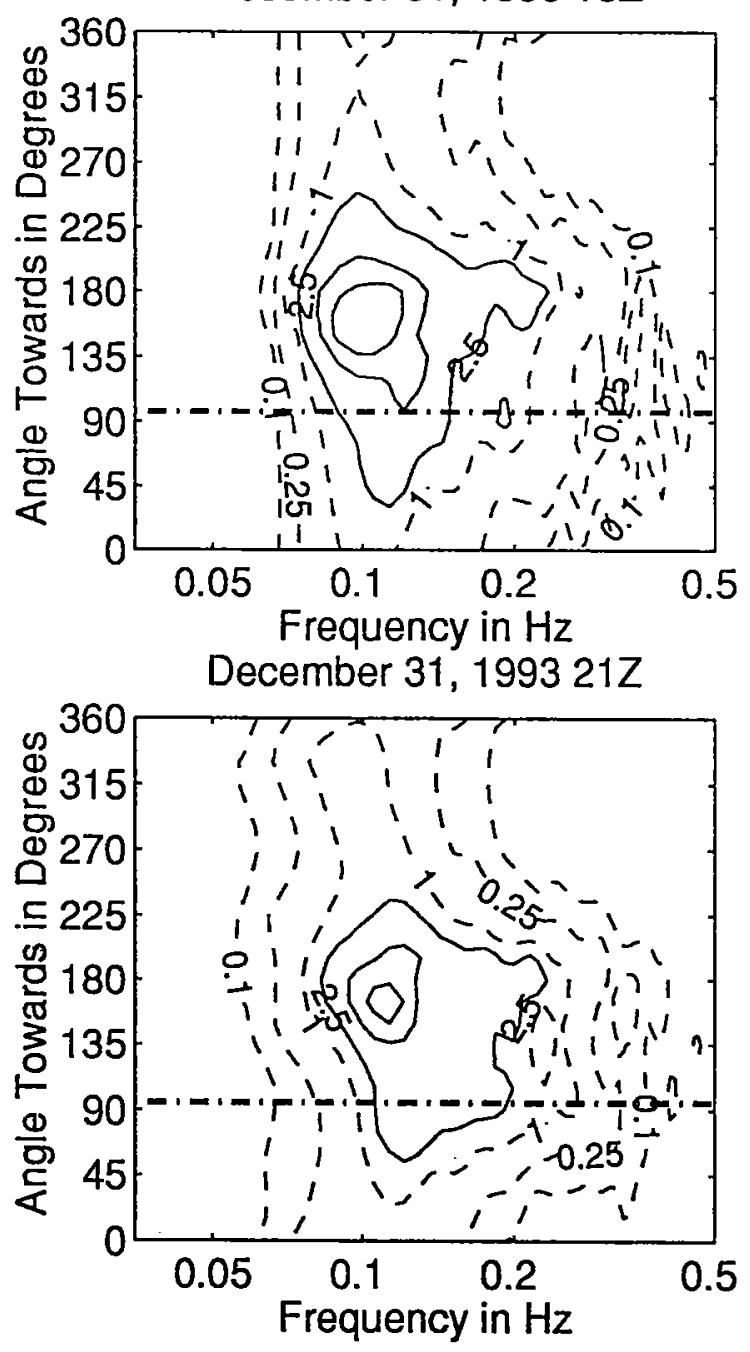

Figure 3.4.33: Directional wave spectra, computed using maximum entropy method. Contours of spectral density as a function of direction. Contours are 0.1 , $0.25,1$ (dashed), $2.5,10,25,100$, and 250 (solid). Wind direction is shown by thick dashed line. 

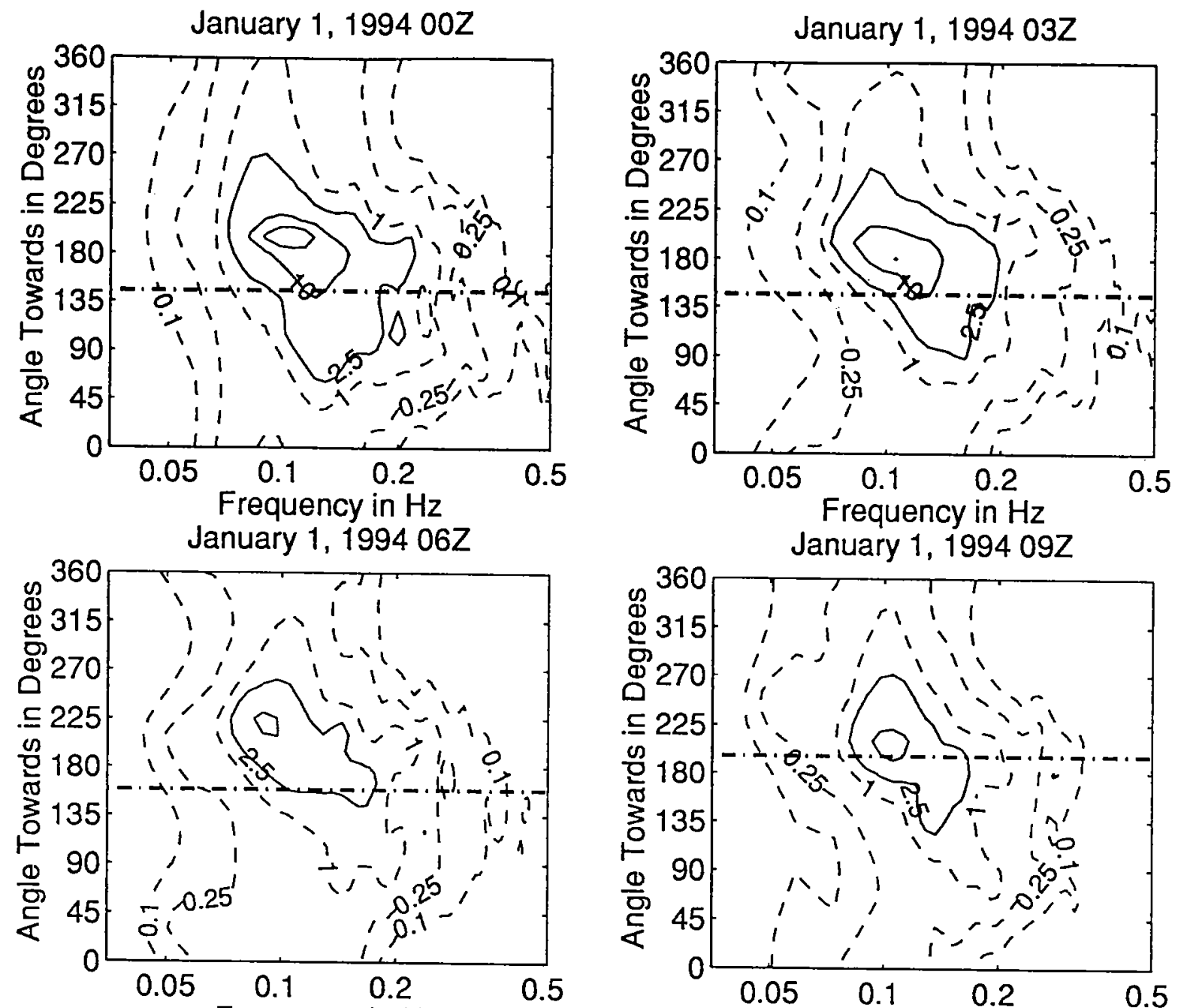

Frequency in $\mathrm{Hz}$
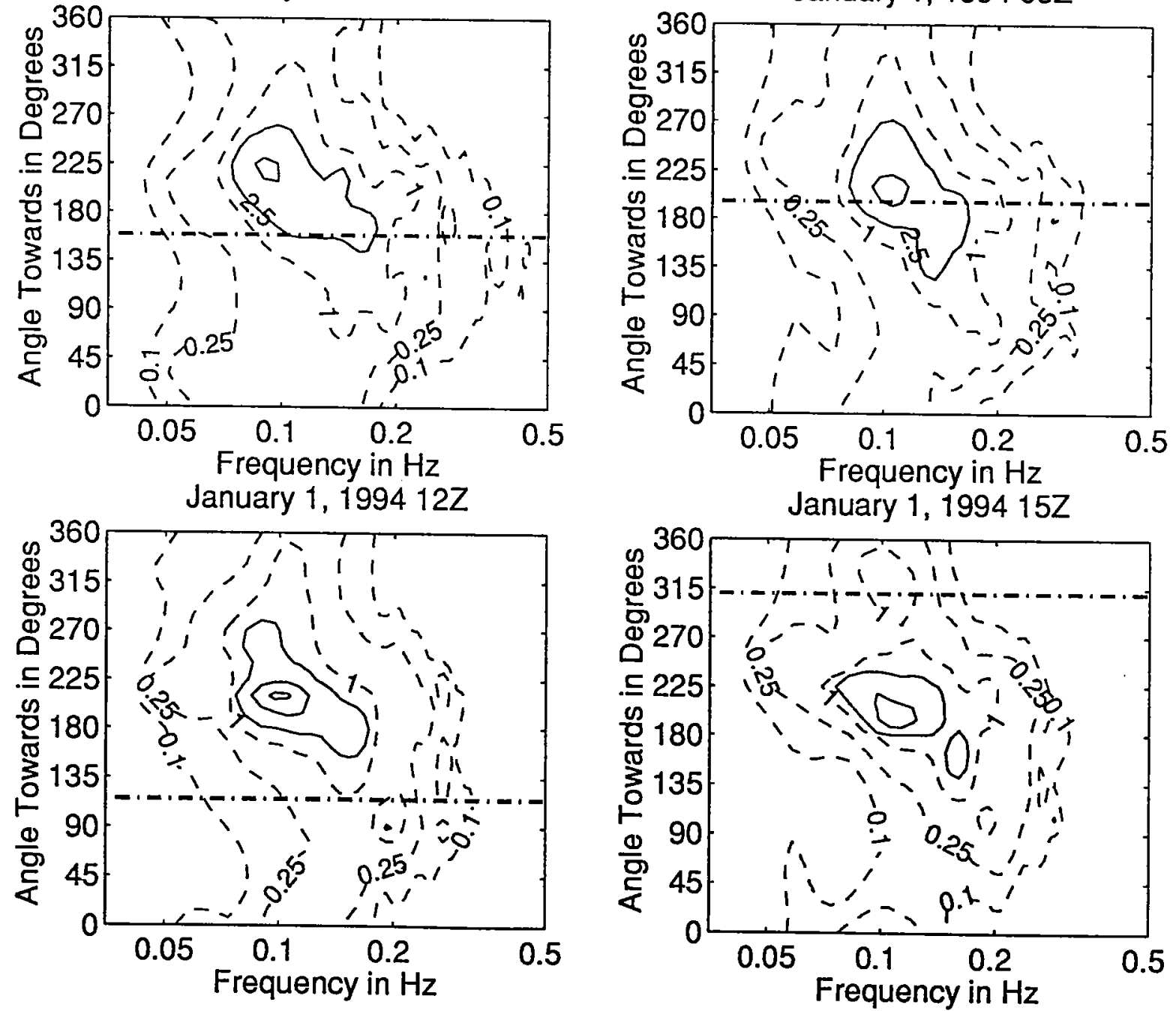

Frequency in $\mathrm{Hz}$

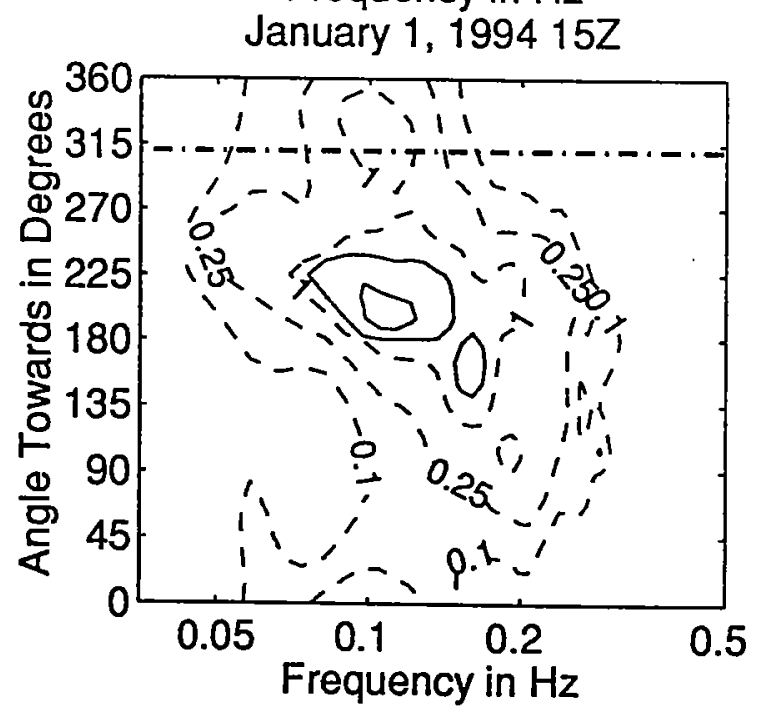

Figure 3.4.34: Directional wave spectra, computed using maximum entropy method. Contours of spectral density as a function of direction. Contours are 0.1, $0.25,1$ (dashed), $2.5,10,25,100$, and 250 (solid). Wind direction is shown by thick dashed line. 

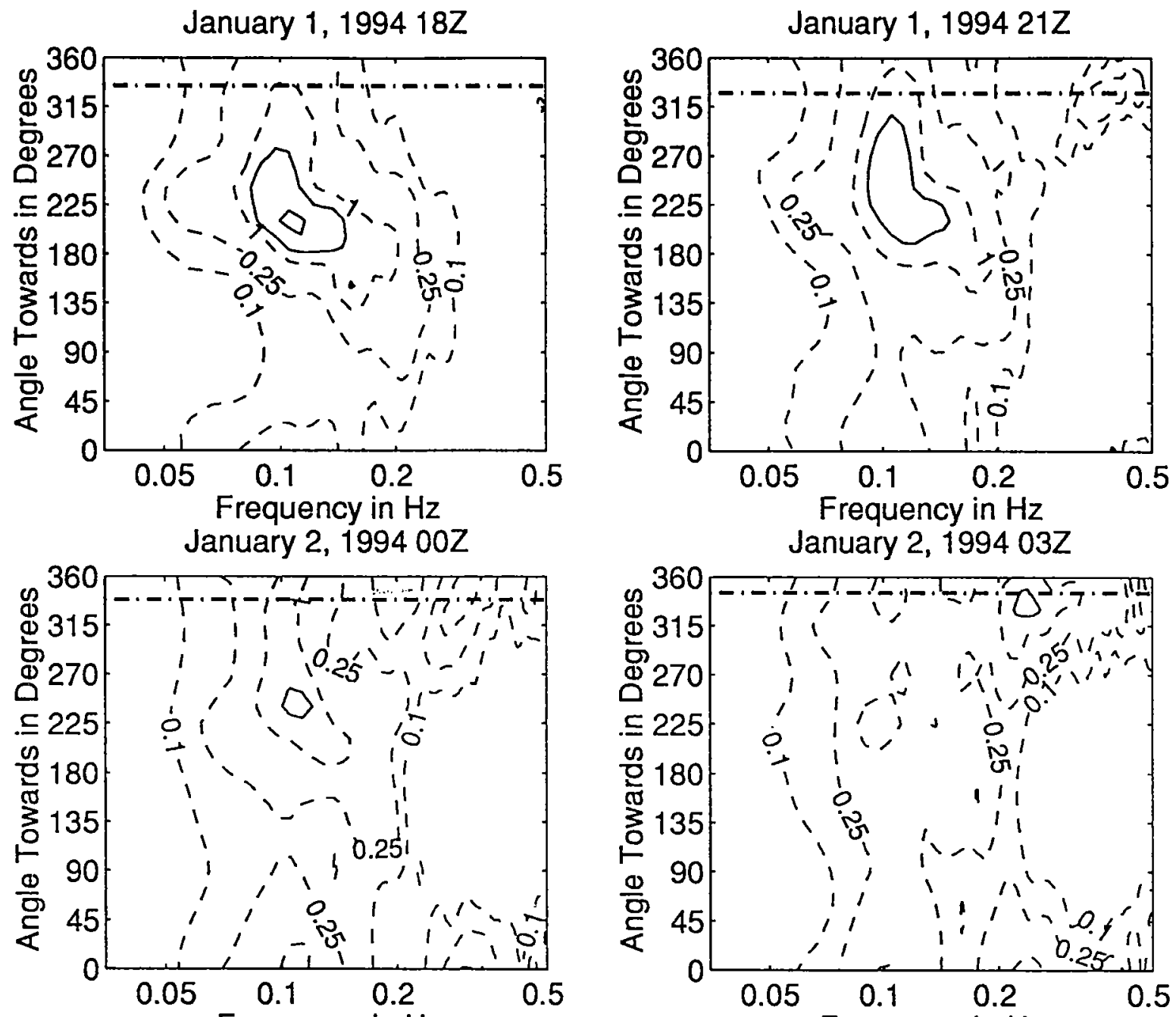

Frequency in $\mathrm{Hz}$ January 2, $199406 Z$
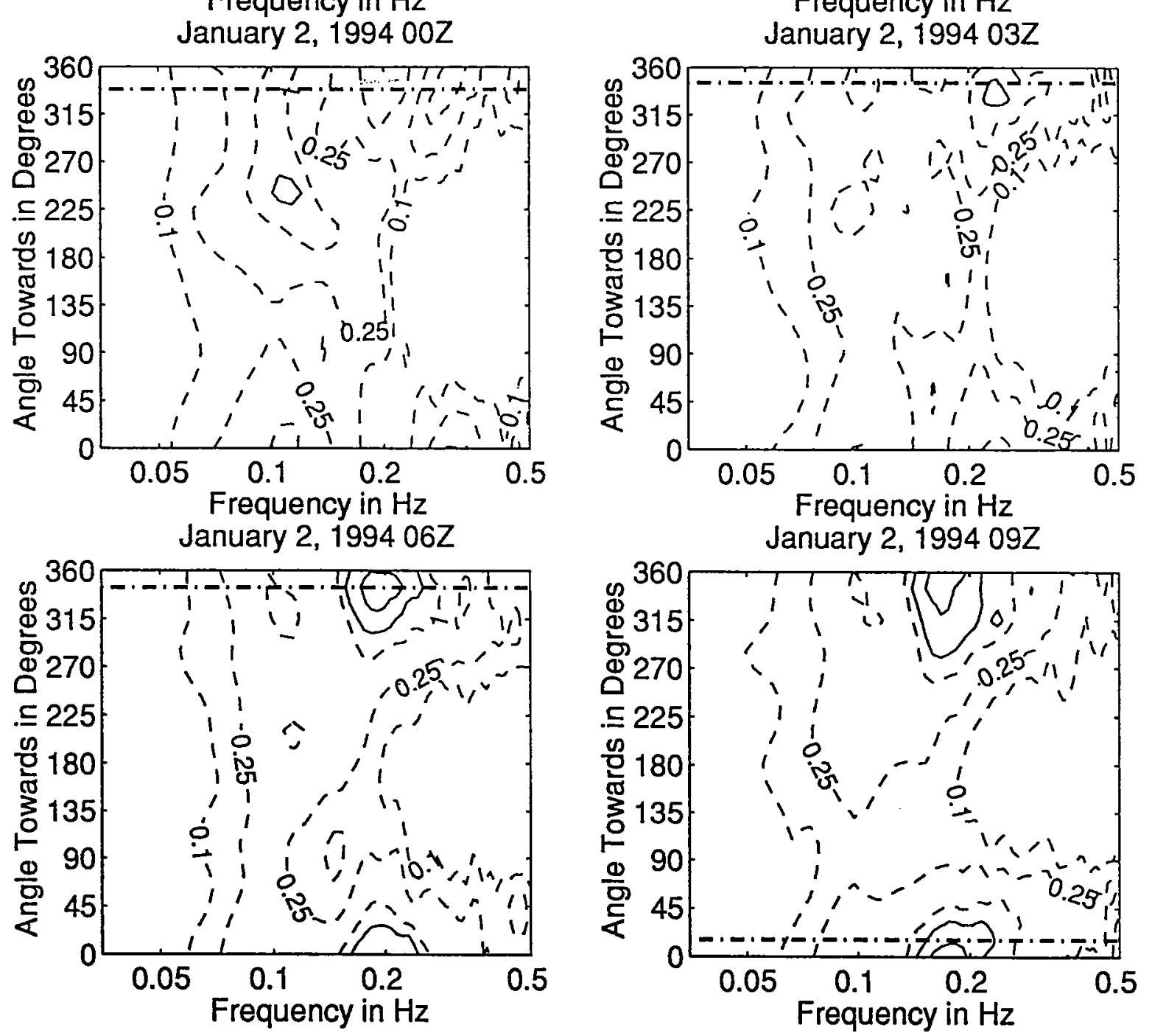

Figure 3.4.35: Directional wave spectra, computed using maximum entropy method. Contours of spectral density as a function of direction. Contours are 0.1 , $0.25,1$ (dashed), $2.5,10,25,100$, and 250 (solid). Wind direction is shown by thick dashed line. 

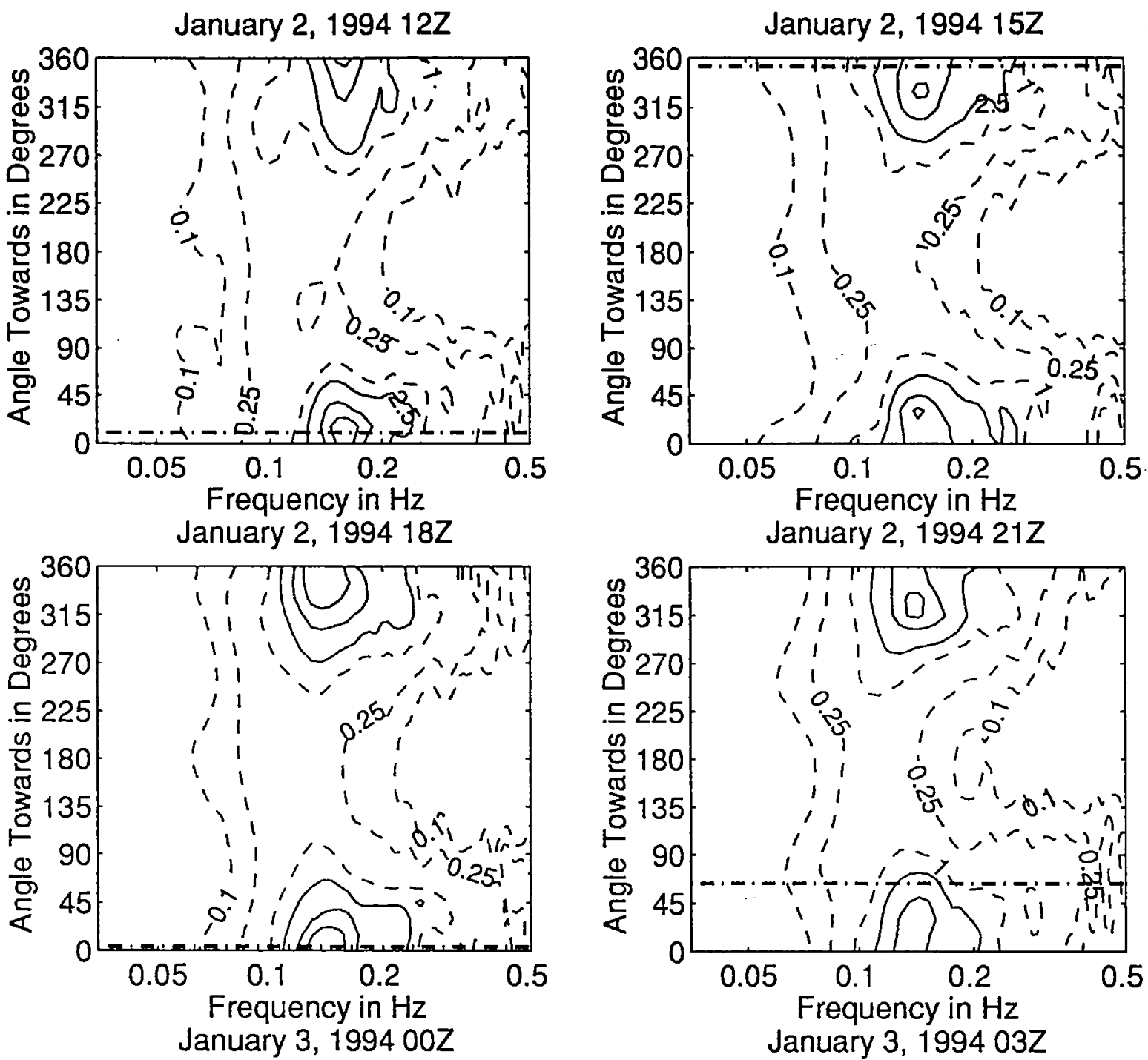

Frequency in $\mathrm{Hz}$
January $3,199403 \mathrm{Z}$
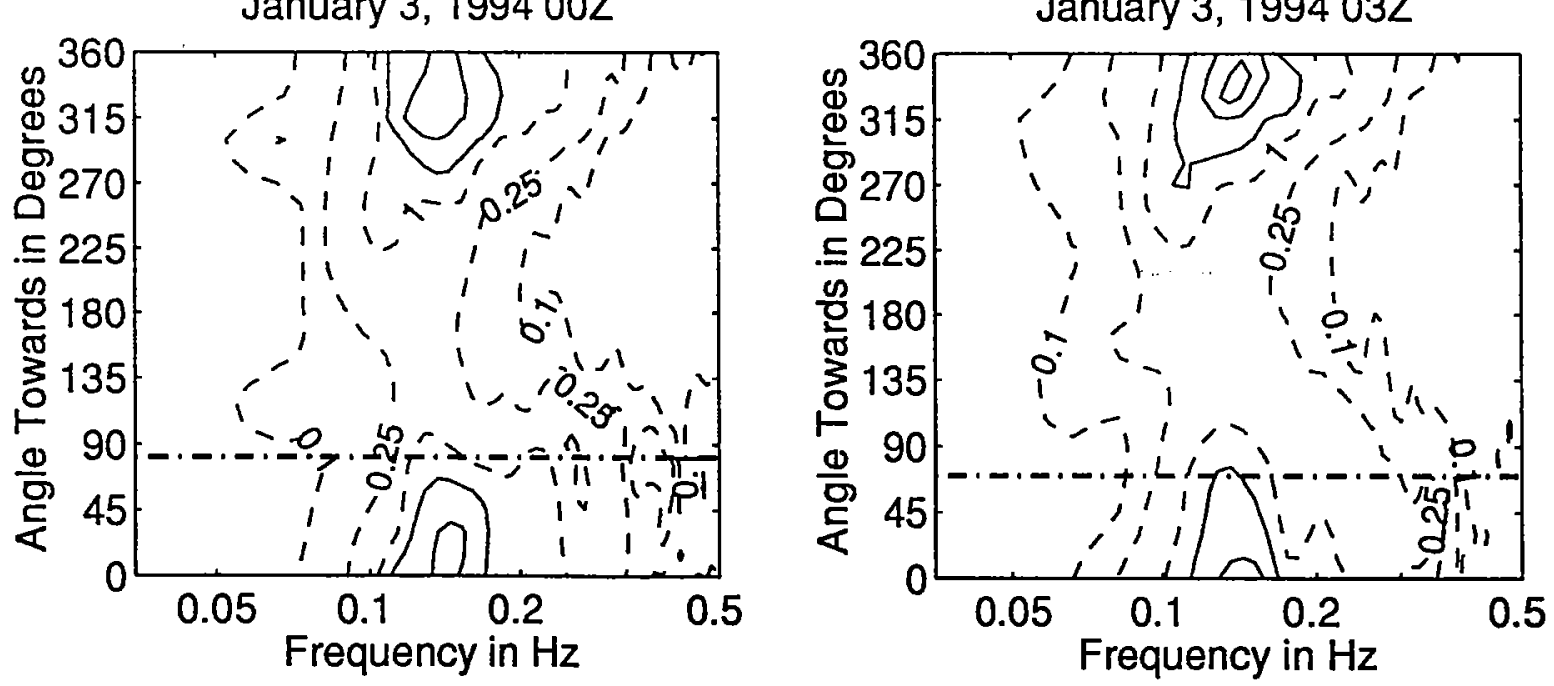

Figure 3.4.36: Directional wave spectra, computed using maximum entropy method. Contours of spectral density as a function of direction. Contours are 0.1 , $0.25,1$ (dashed), $2.5,10,25,100$, and 250 (solid). Wind direction is shown by thick dashed line. 

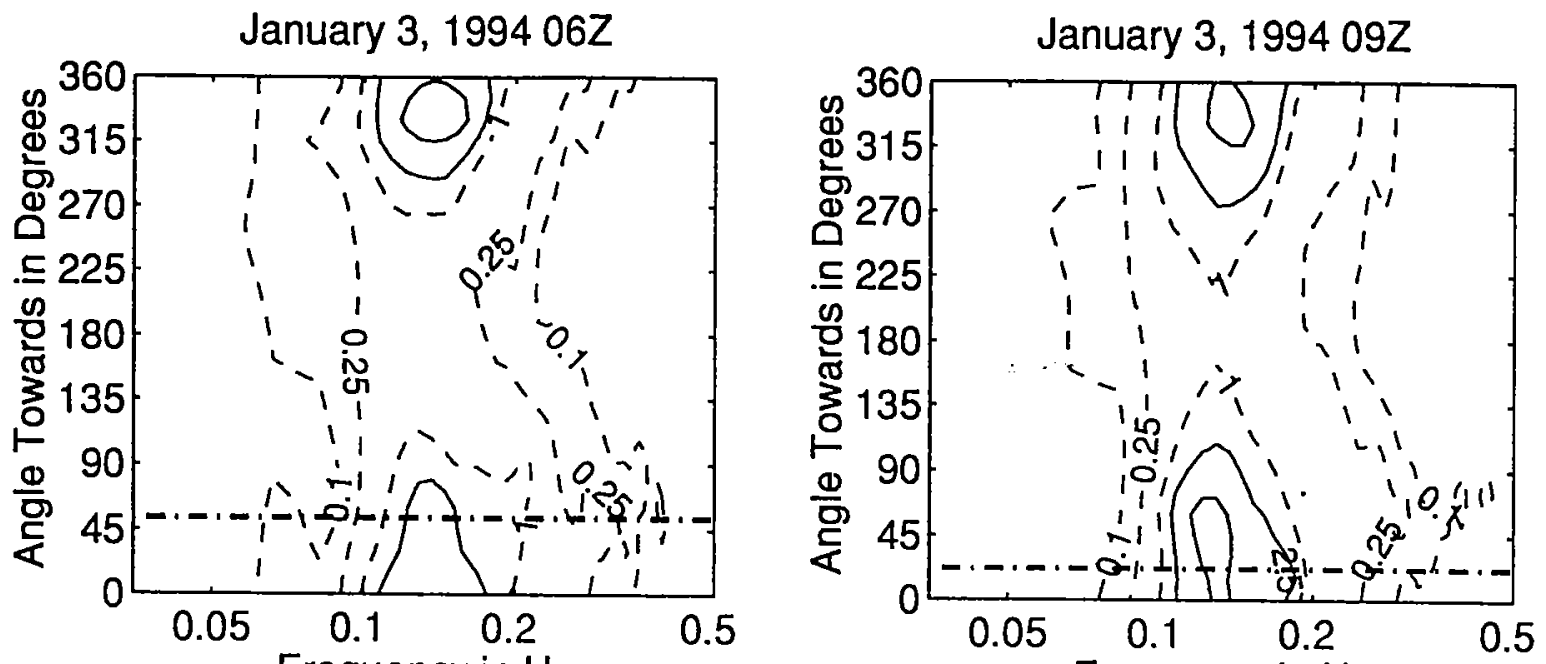

Frequency in $\mathrm{Hz}$
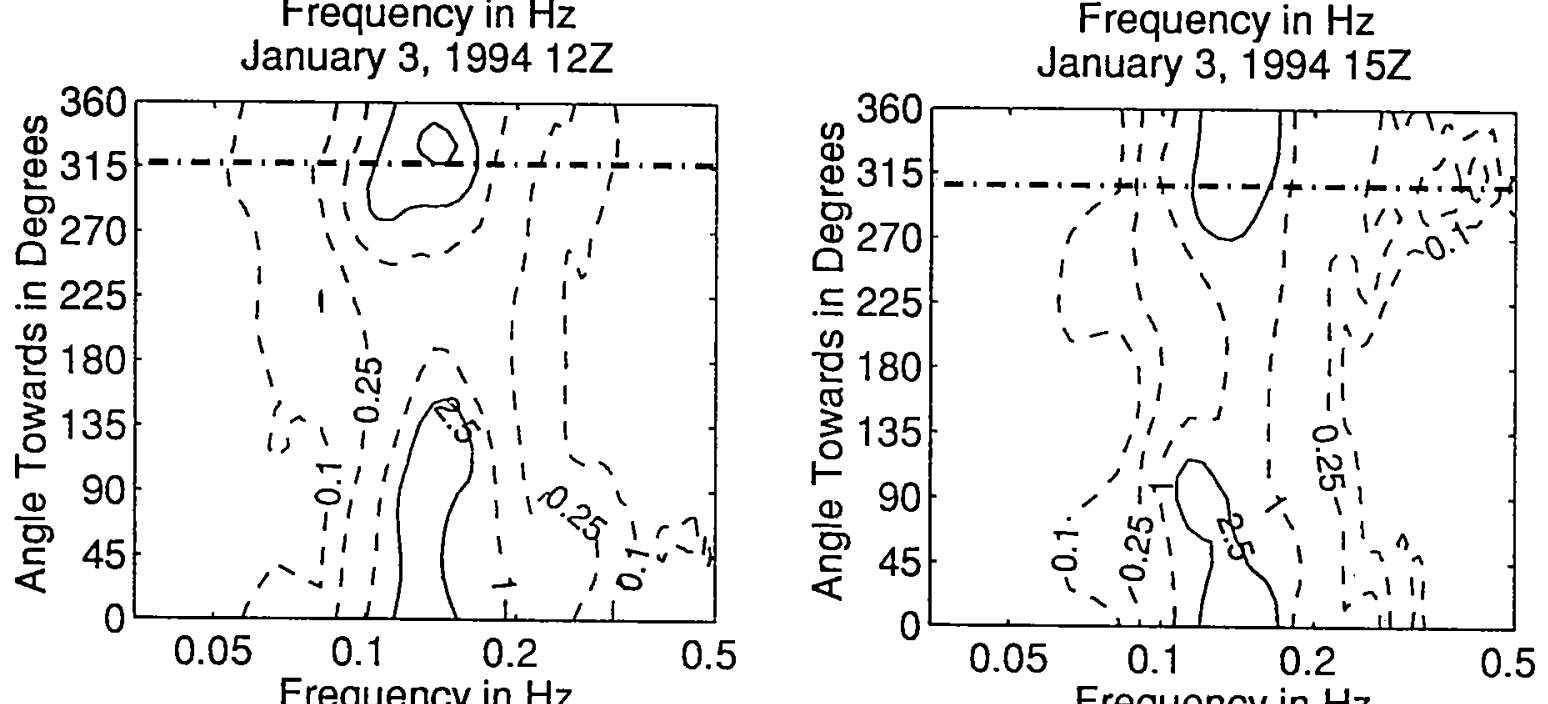

Frequency in $\mathrm{Hz}$ January 3, $199418 Z$

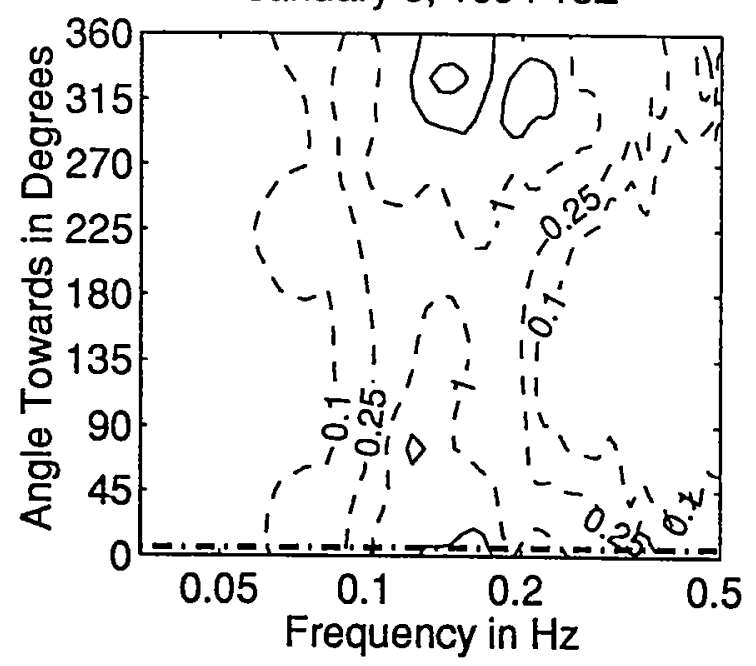

Frequency in $\mathrm{Hz}$ January 3, $199421 Z$

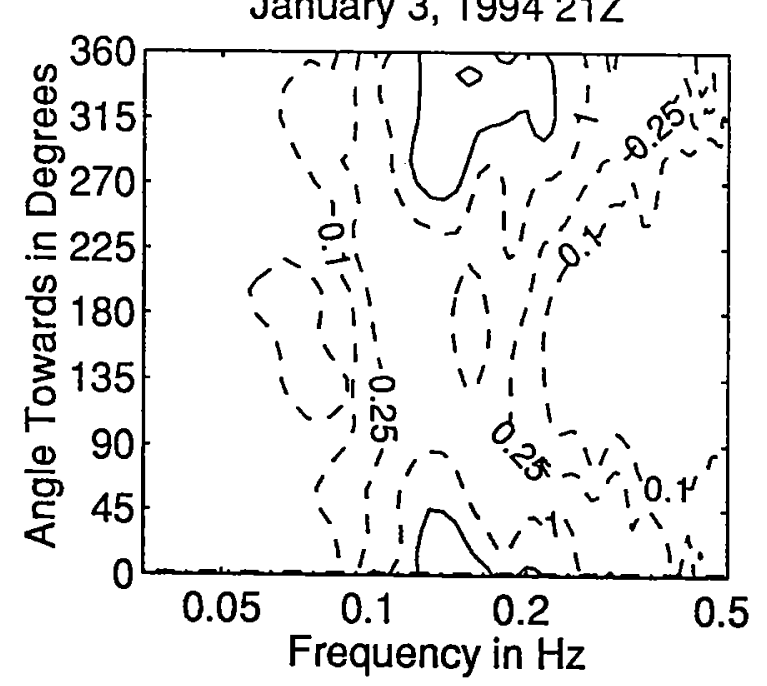

Figure 3.4.37: Directional wave spectra, computed using maximum entropy method. Contours of spectral density as a function of direction. Contours are 0.1 , $0.25,1$ (dashed), $2.5,10,25,100$, and 250 (solid). Wind direction is shown by thick dashed line. 
January 4, $199400 Z$

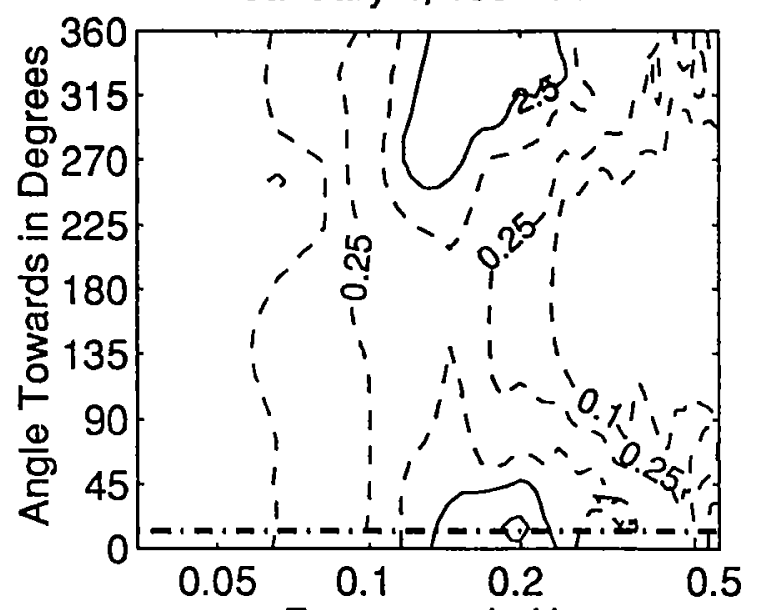

Frequency in $\mathrm{Hz}$

January 4, $199406 Z$

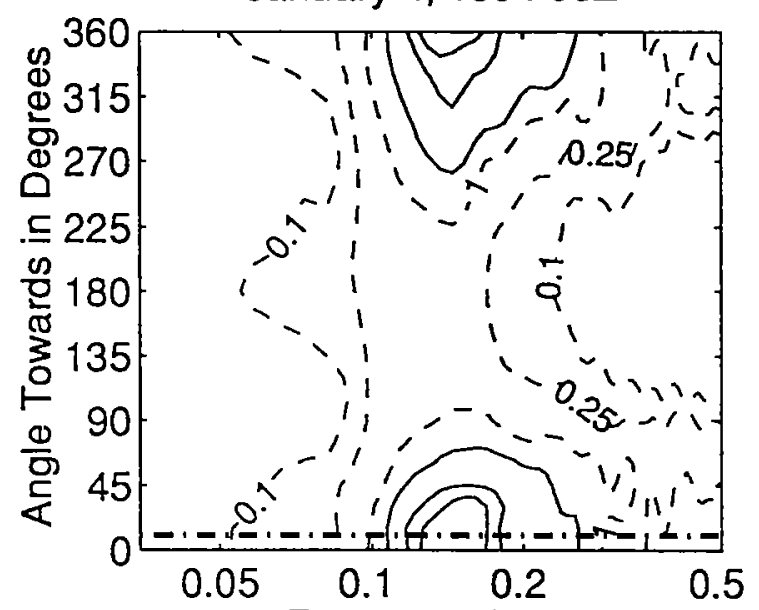

Frequency in $\mathrm{Hz}$

January 4, $199412 Z$

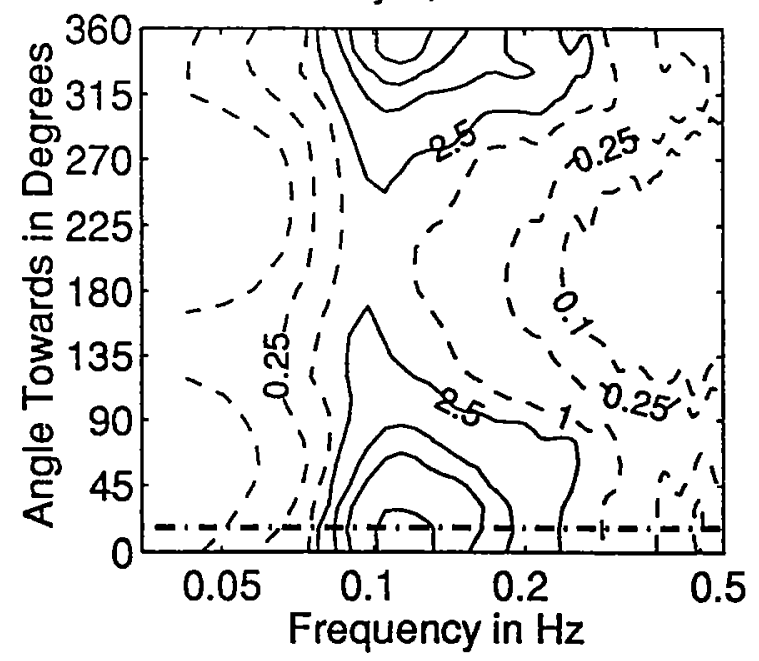

January 4, $199403 Z$

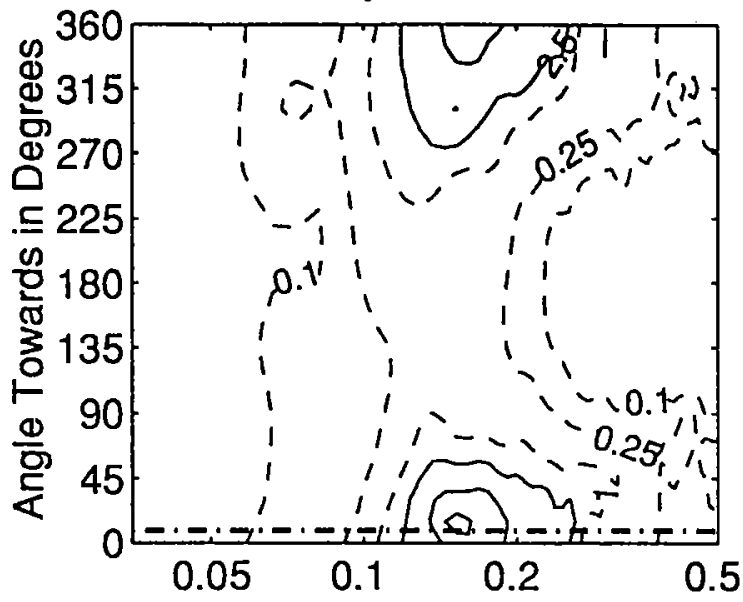

Frequency in $\mathrm{Hz}$ January 4, $199409 Z$

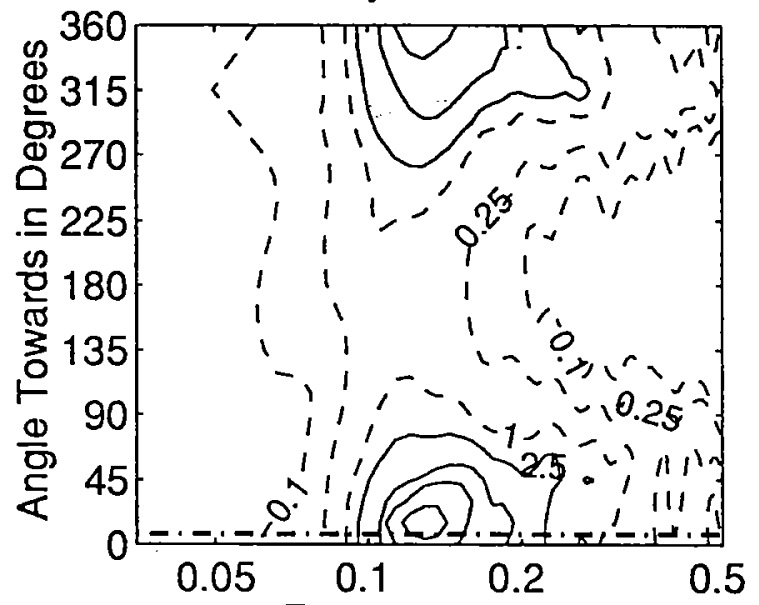

Frequency in $\mathrm{Hz}$ January 4, $199415 Z$

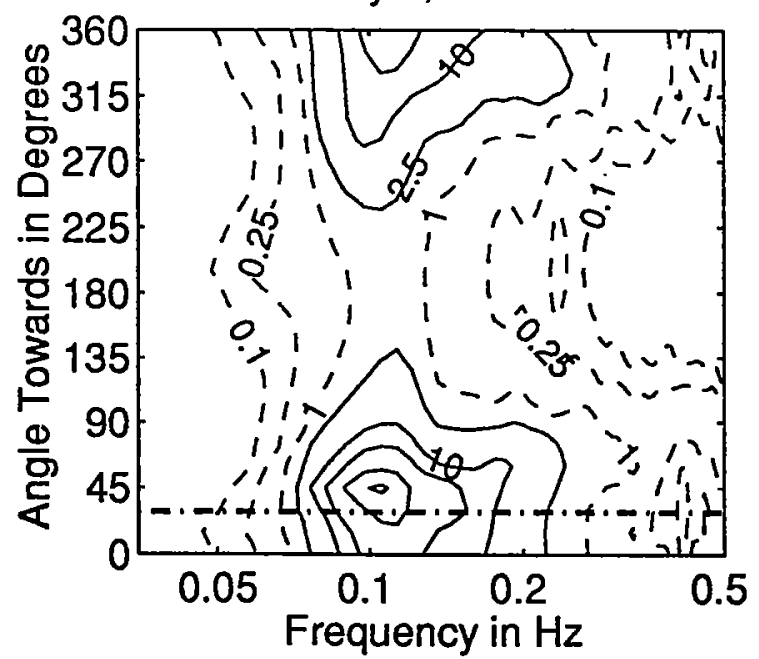

Figure 3.4.38: Directional wave spectra, computed using maximum entropy method. Contours of spectral density as a function of direction. Contours are 0.1 , $0.25,1$ (dashed), $2.5,10,25,100$, and 250 (solid). Wind direction is shown by thick dashed line. 


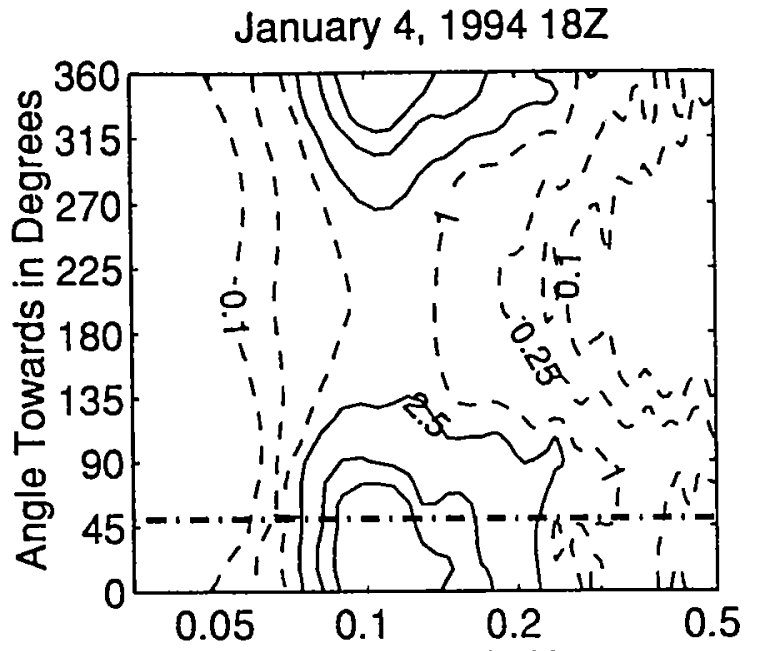

Frequency in $\mathrm{Hz}$

January 5, $199400 Z$

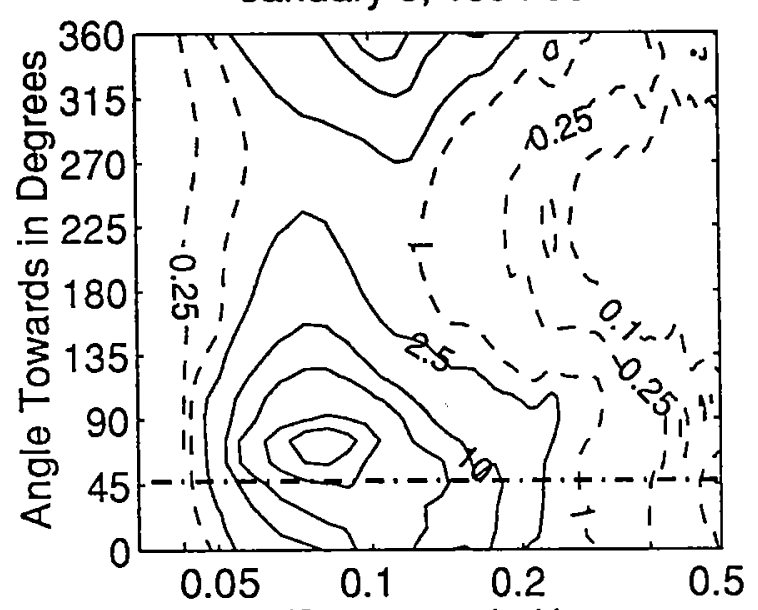

Frequency in $\mathrm{Hz}$ January 5, $199406 Z$

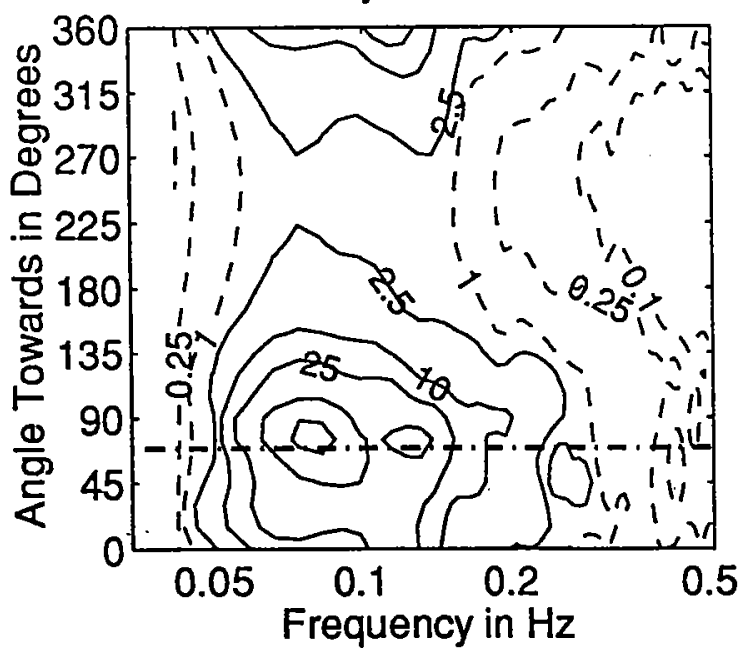

January 4, $199421 Z$

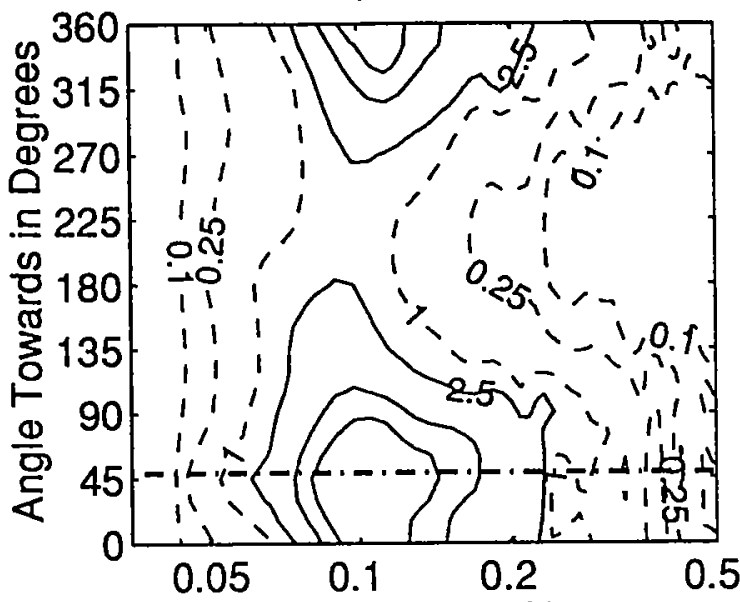

Frequency in $\mathrm{Hz}$ January $5,199403 Z$

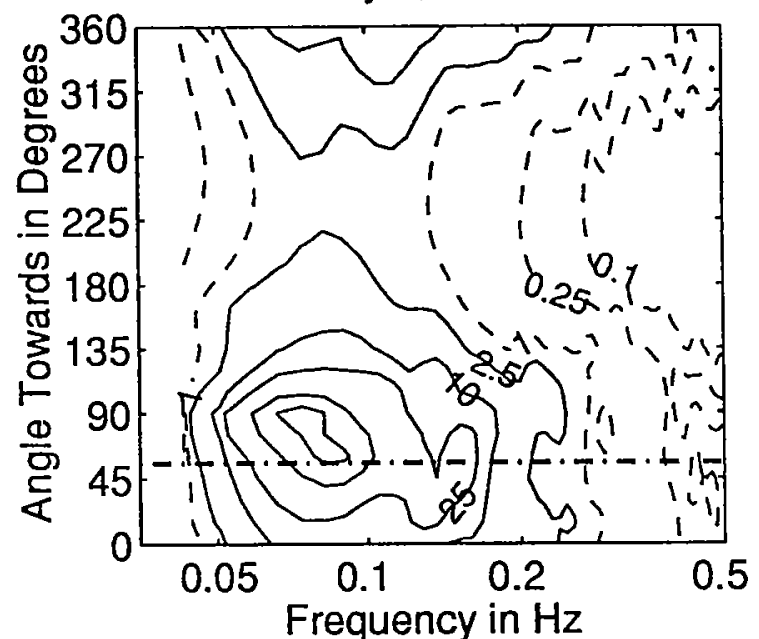
January 5, $199409 Z$

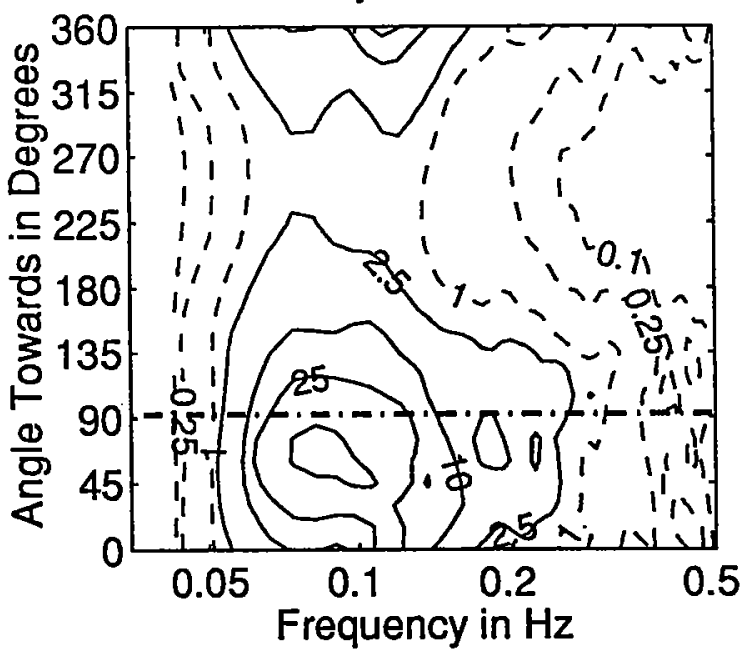

Figure 3.4.39: Directional wave spectra, computed using maximum entropy method. Contours of spectral density as a function of direction. Contours are 0.1 , $0.25,1$ (dashed), $2.5,10,25,100$, and 250 (solid). Wind direction is shown by thick dashed line. 
January 5, $199412 Z$

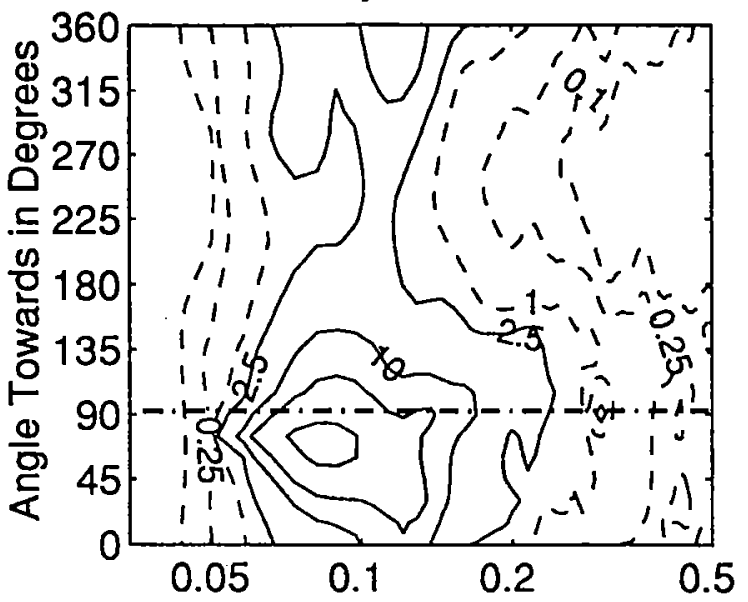

Frequency in $\mathrm{Hz}$

January $5,199418 Z$
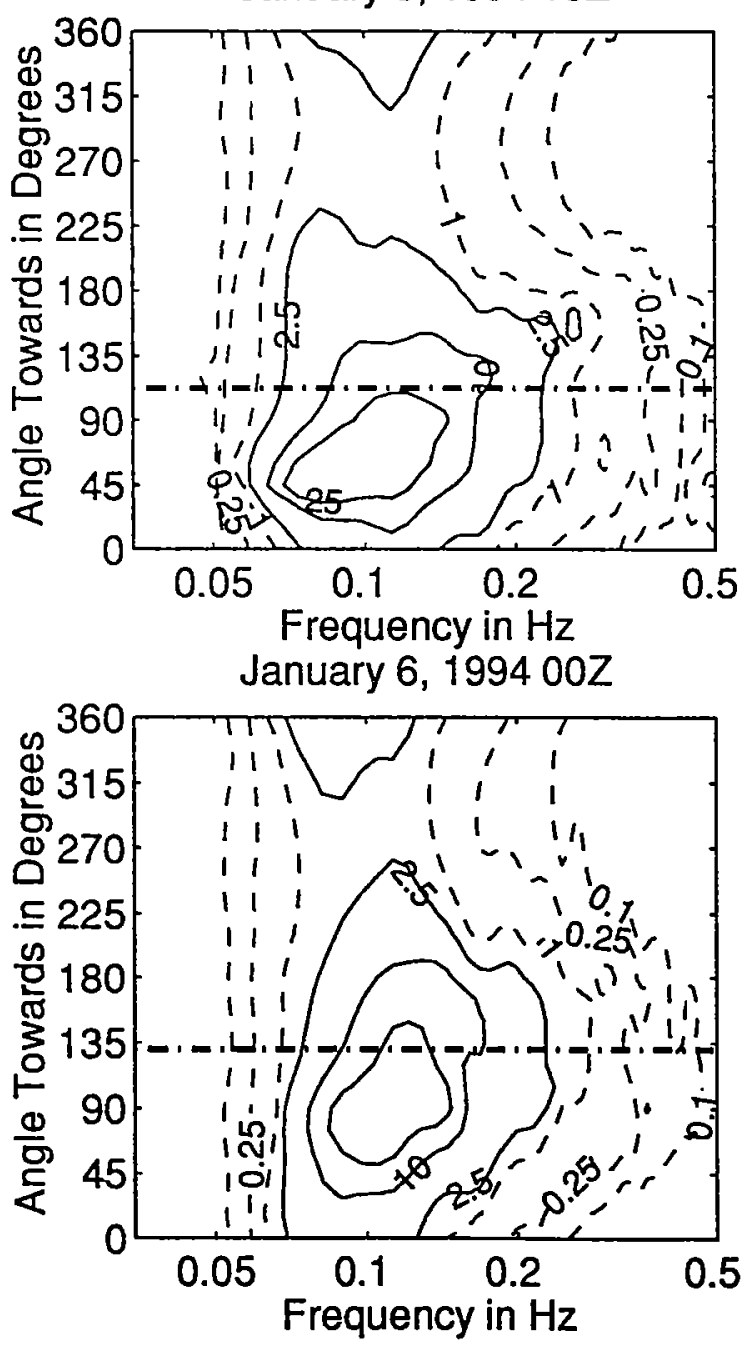

January 5, $199415 Z$

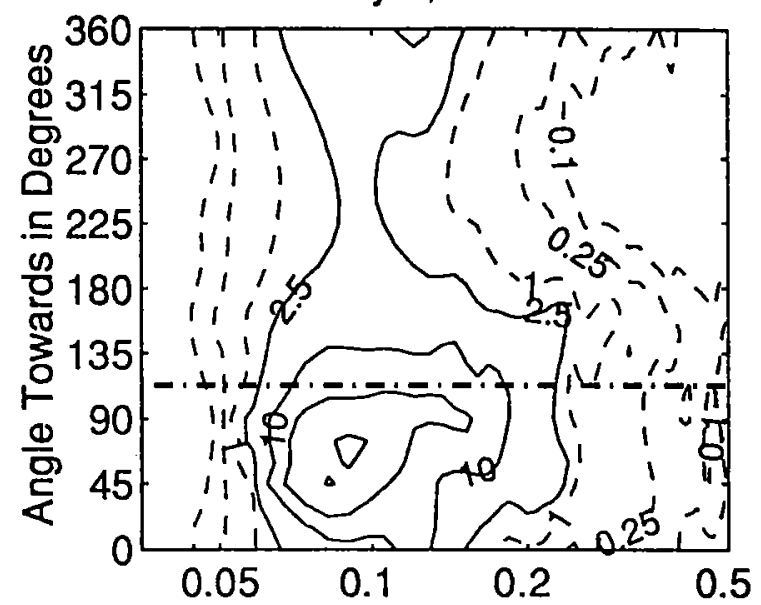

Frequency in $\mathrm{Hz}$

January 5, 1994212

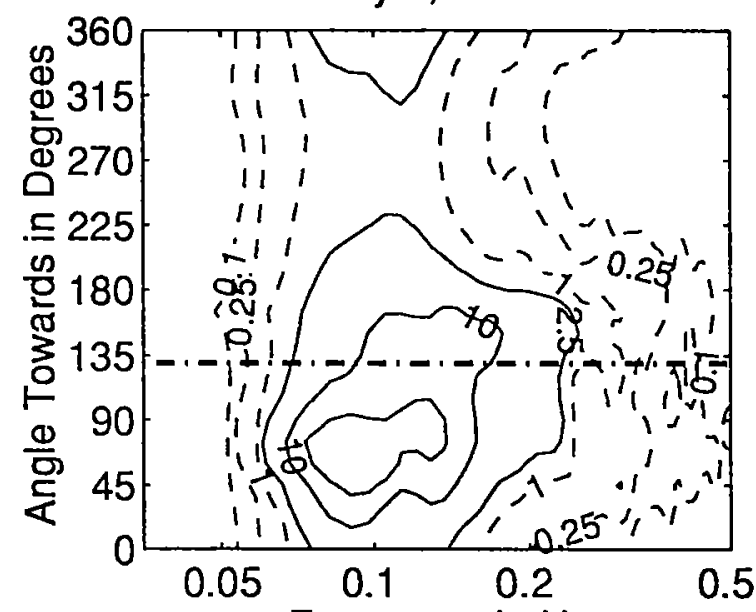

Frequency in $\mathrm{Hz}$ January $6,199403 Z$

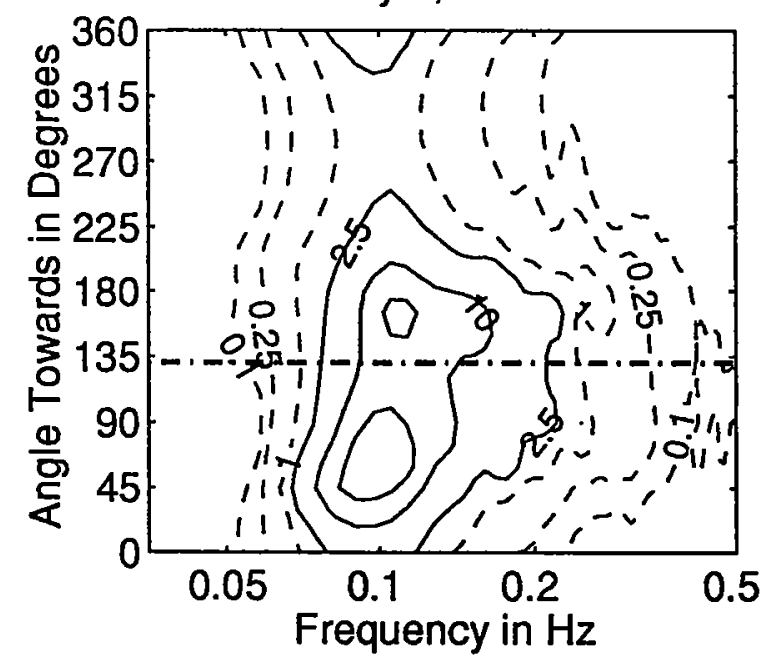

Figure 3.4.40: Directional wave spectra, computed using maximum entropy method. Contours of spectral density as a function of direction. Contours are 0.1, $0.25,1$ (dashed), $2.5,10,25,100$, and 250 (solid). Wind direction is shown by thick dashed line. 
January 6, $199406 Z$
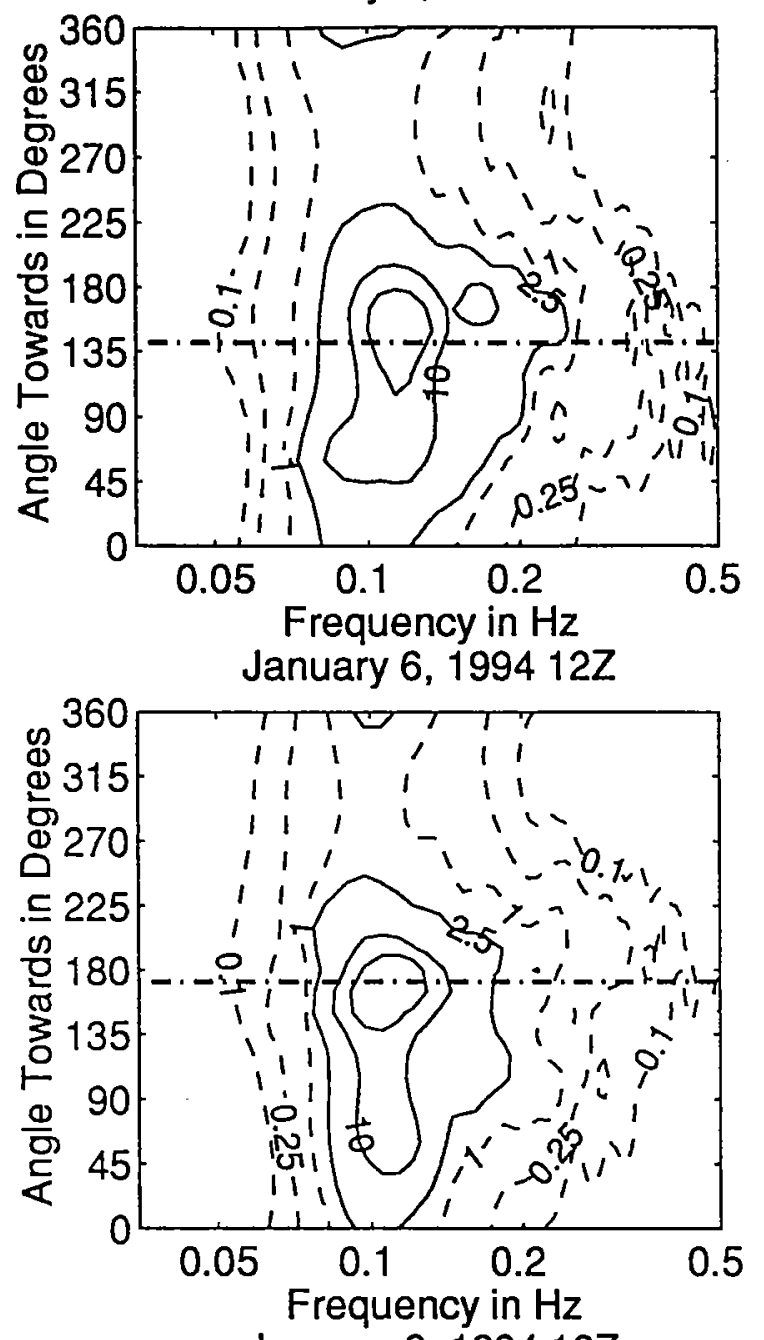

January 6, $199418 Z$

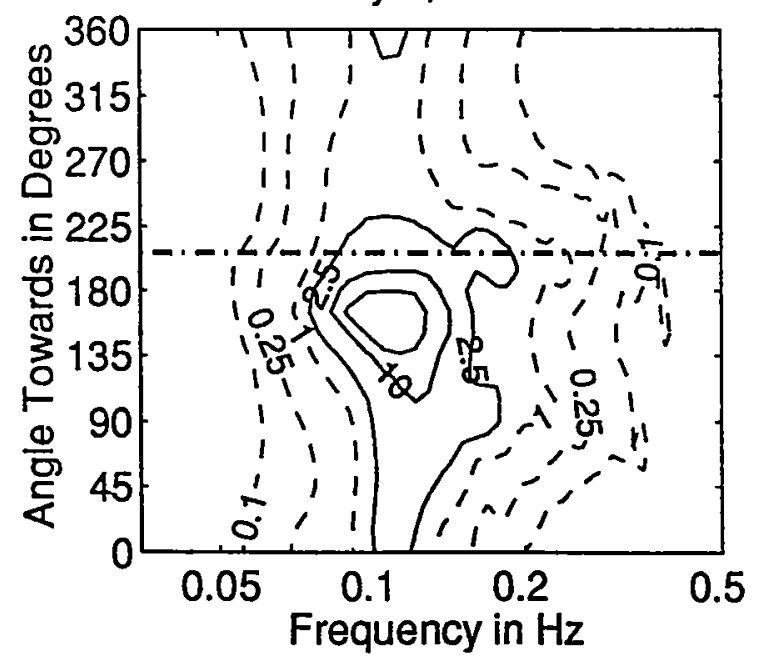

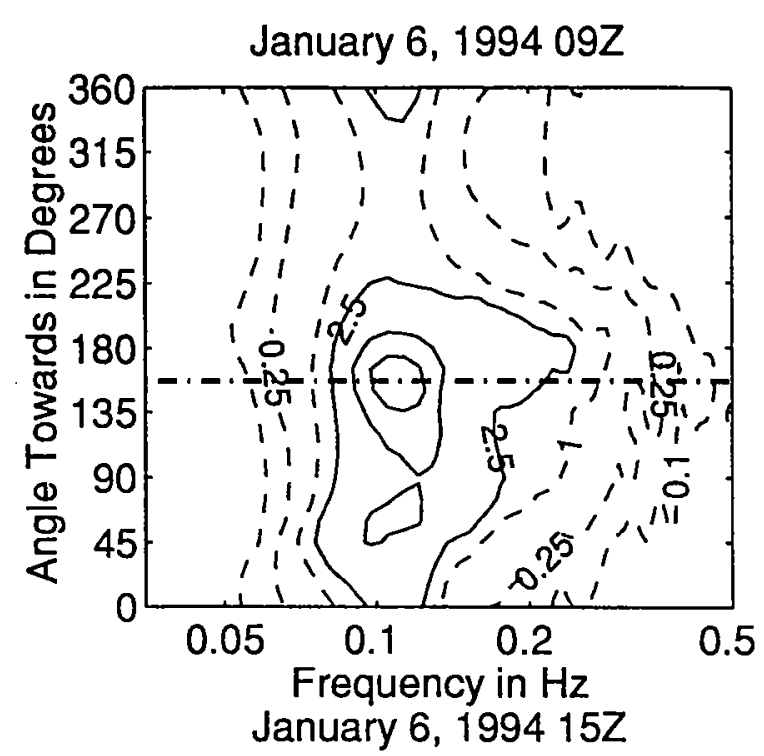
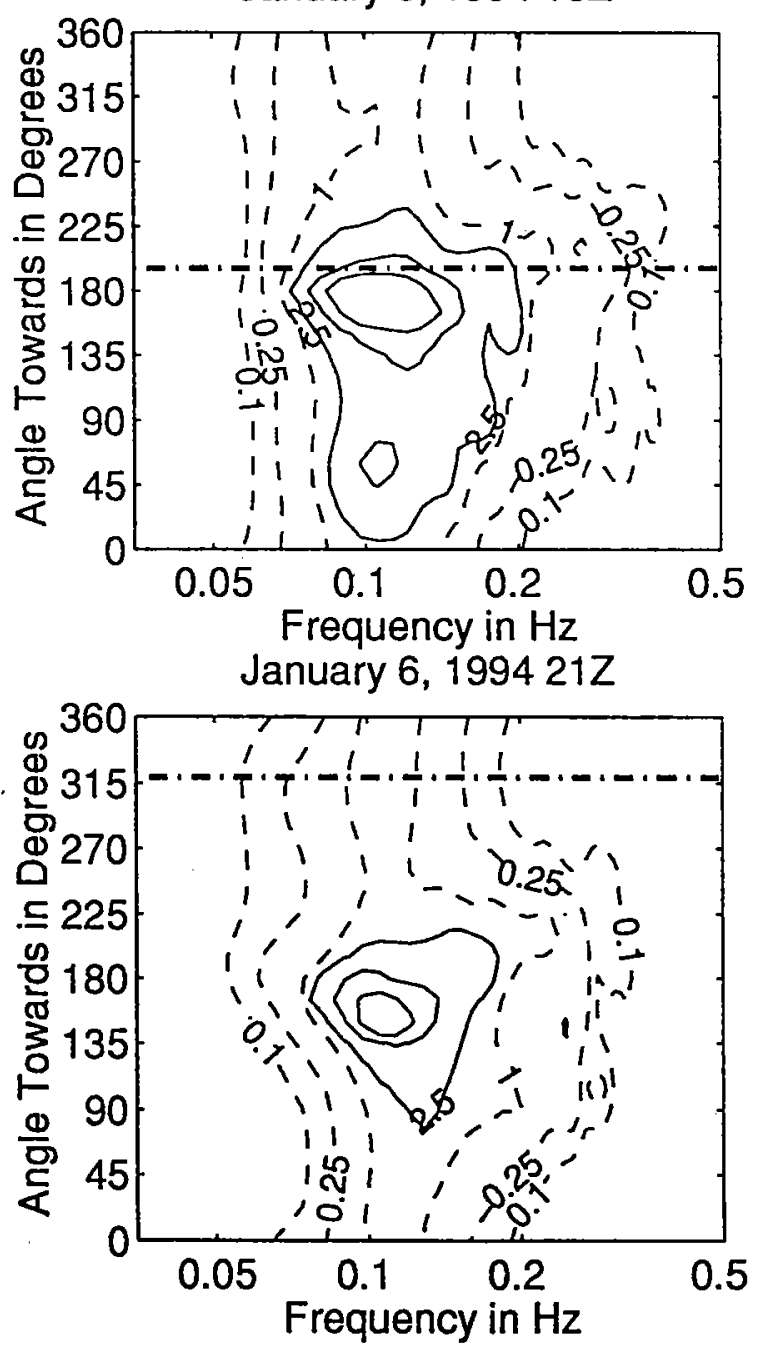

Figure 3.4.41: Directional wave spectra, computed using maximum entropy method. Contours of spectral density as a function of direction. Contours are 0.1 , $0.25,1$ (dashed), $2.5,10,25,100$, and 250 (solid). Wind direction is shown by thick dashed line. 

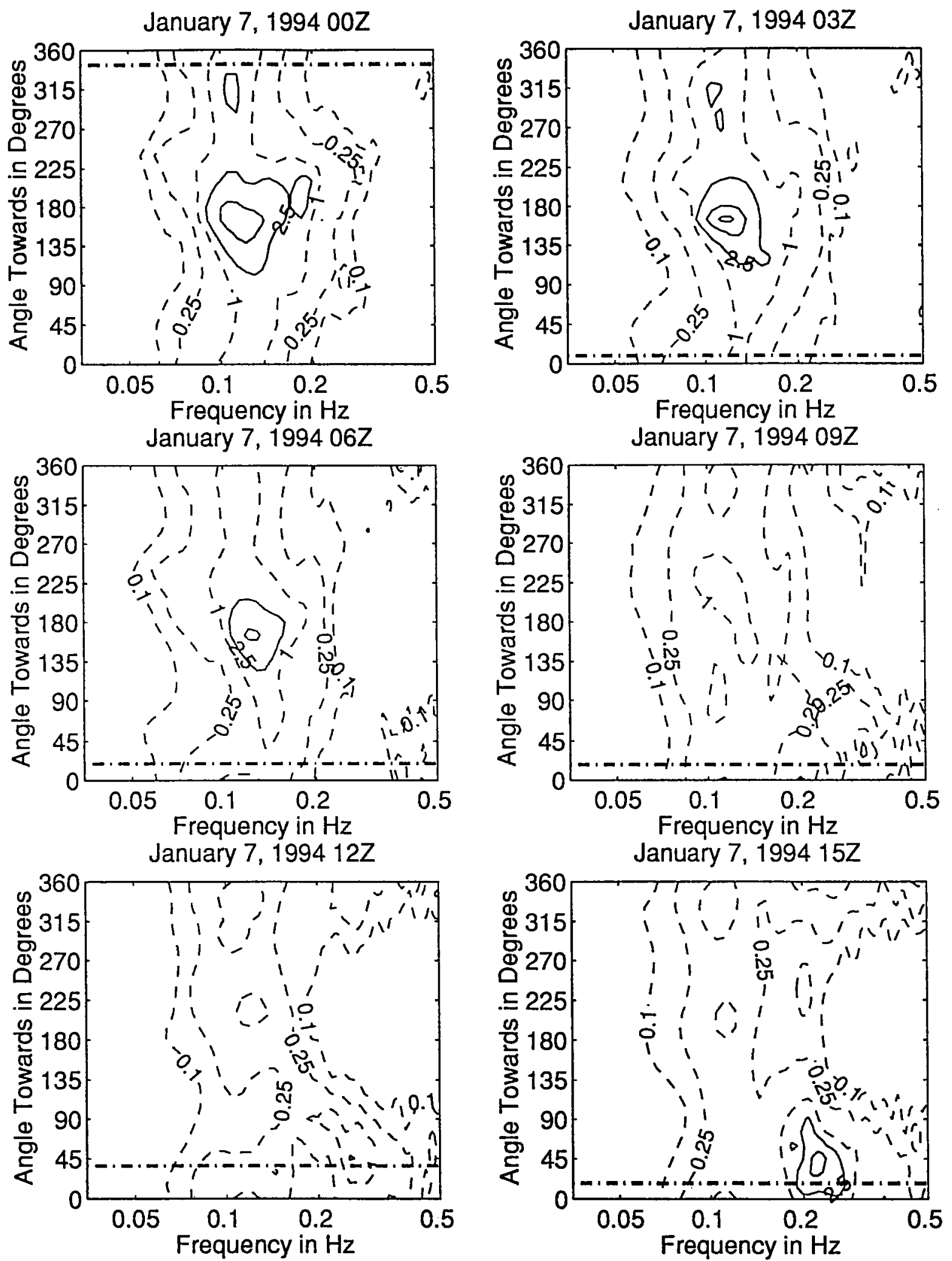

Figure 3.4.42: Directional wave spectra, computed using maximum entropy method. Contours of spectral density as a function of direction. Contours are 0.1 , $0.25,1$ (dashed), $2.5,10,25,100$, and 250 (solid). Wind direction is shown by thick dashed line. 
January 7, $199418 Z$

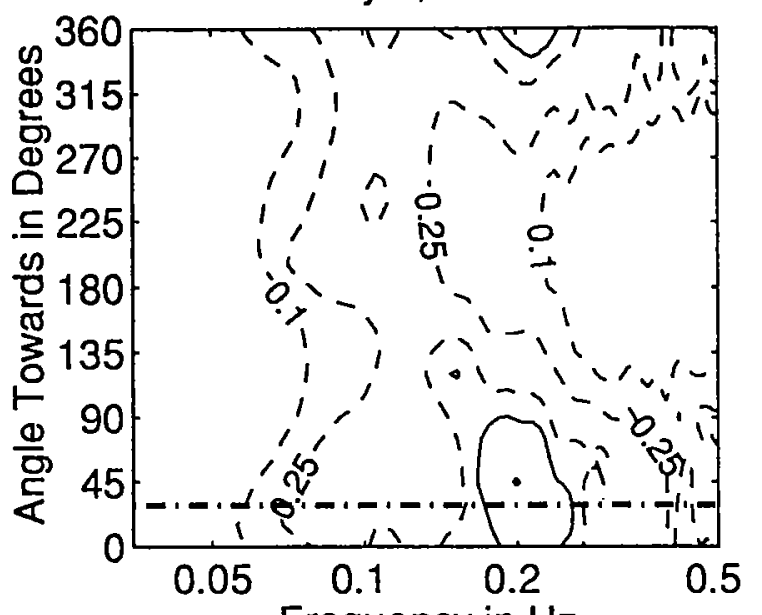

Frequency in $\mathrm{Hz}$

January 8, $199400 Z$

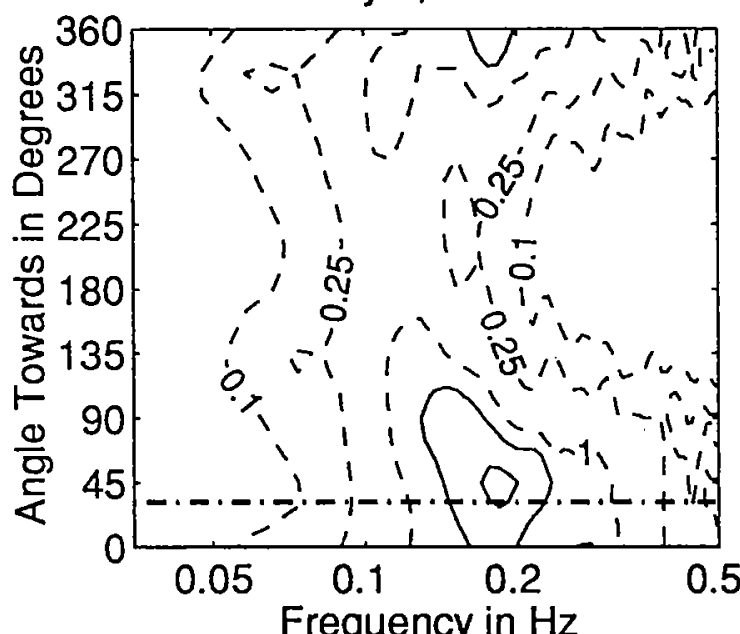

Frequency in $\mathrm{Hz}$ January 8, $199406 Z$

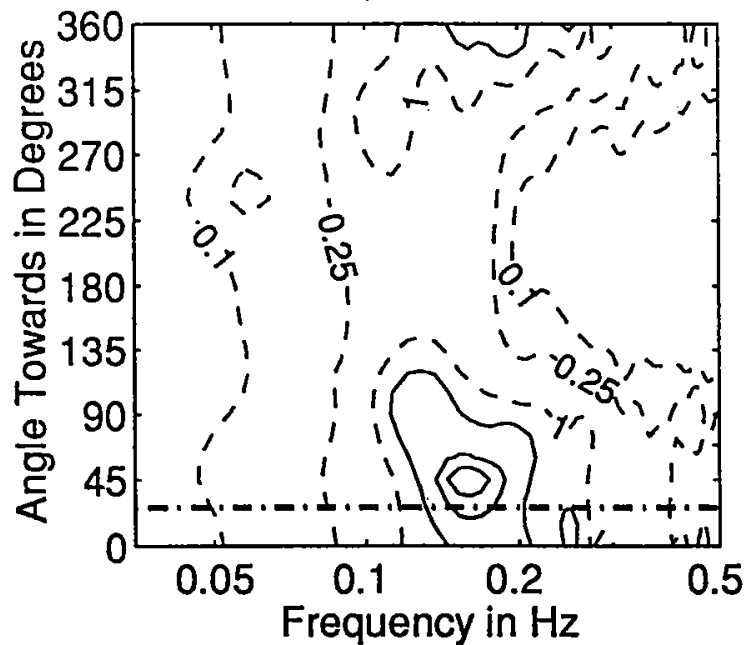

January 7, $199421 Z$

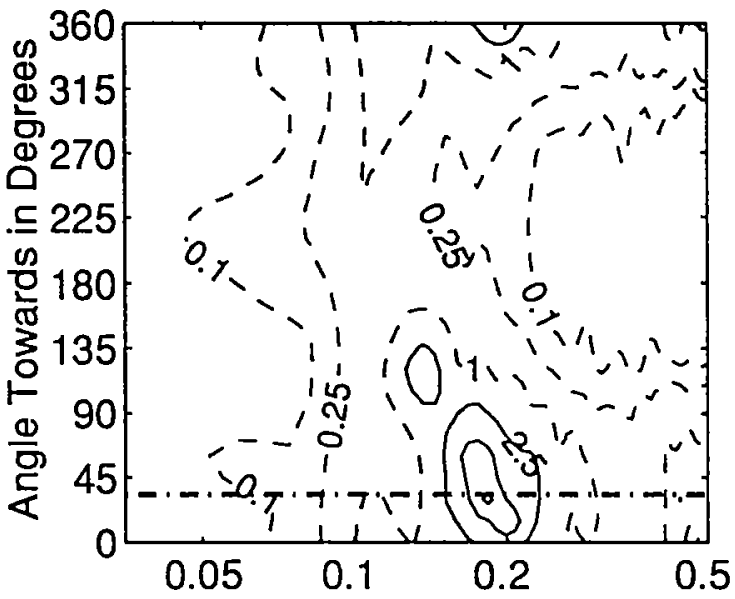

Frequency in $\mathrm{Hz}$ January 8, $199403 Z$

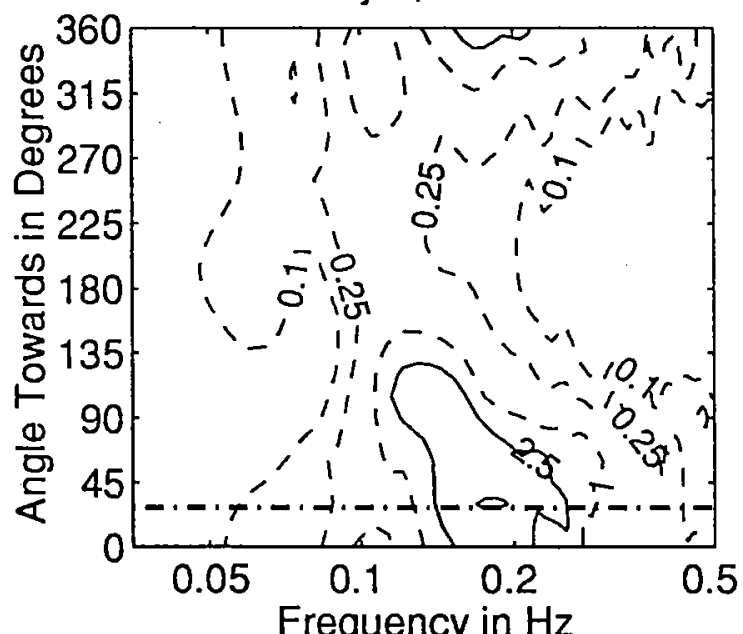
January 8, $199409 Z$

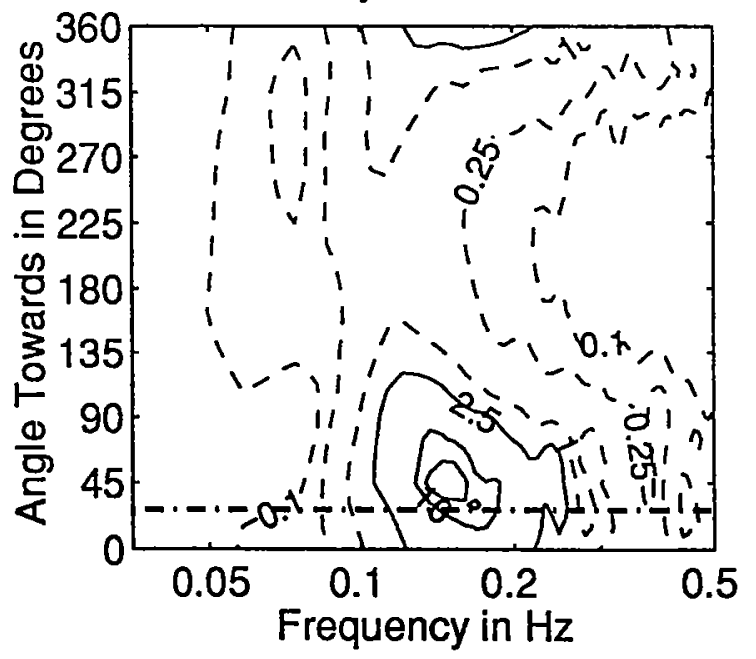

Figure 3.4.43: Directional wave spectra, computed using maximum entropy method. Contours of spectral density as a function of direction. Contours are 0.1, $0.25,1$ (dashed), $2.5,10,25,100$, and 250 (solid). Wind direction is shown by thick dashed line. 
January $8,199412 Z$

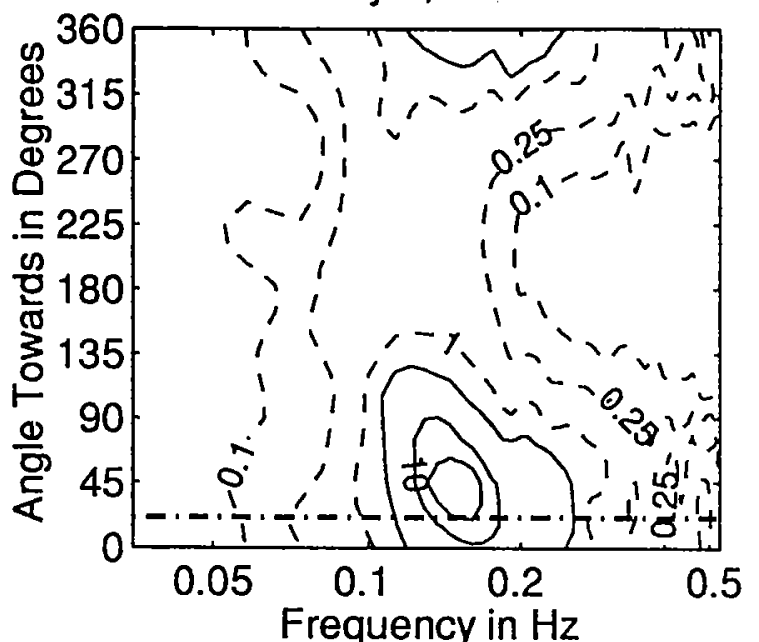

Frequency in $\mathrm{Hz}$

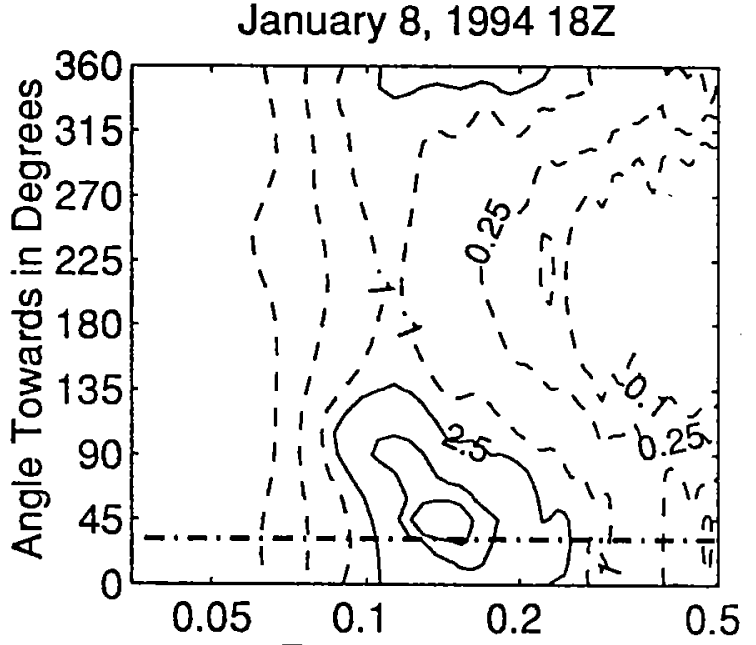

Frequency in $\mathrm{Hz}$ January 9, $199400 Z$

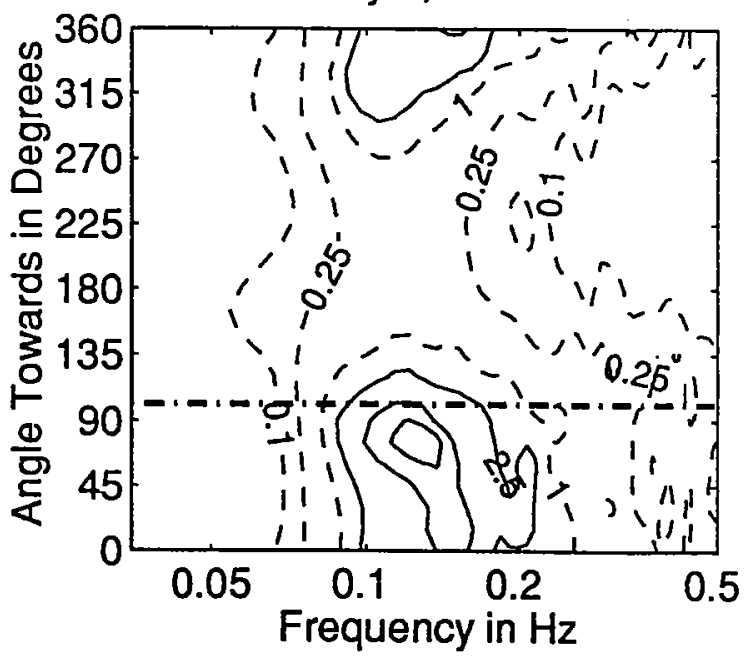

January 8, $199415 Z$

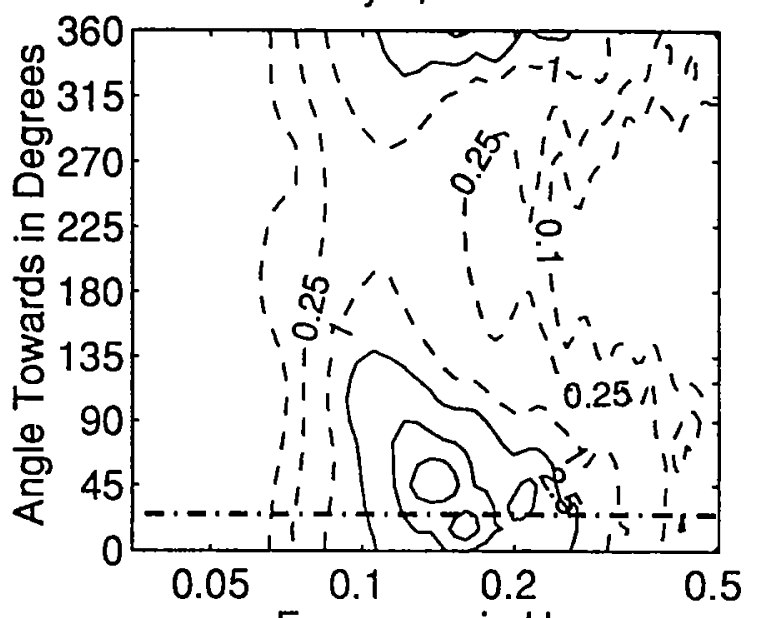

Frequency in $\mathrm{Hz}$ January 8, $199421 Z$

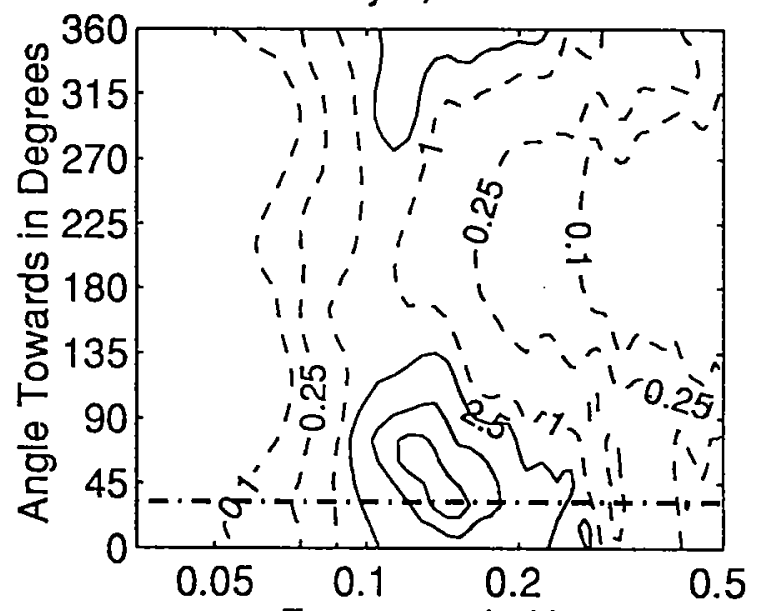

Frequency in $\mathrm{Hz}$ January 9, $199403 Z$

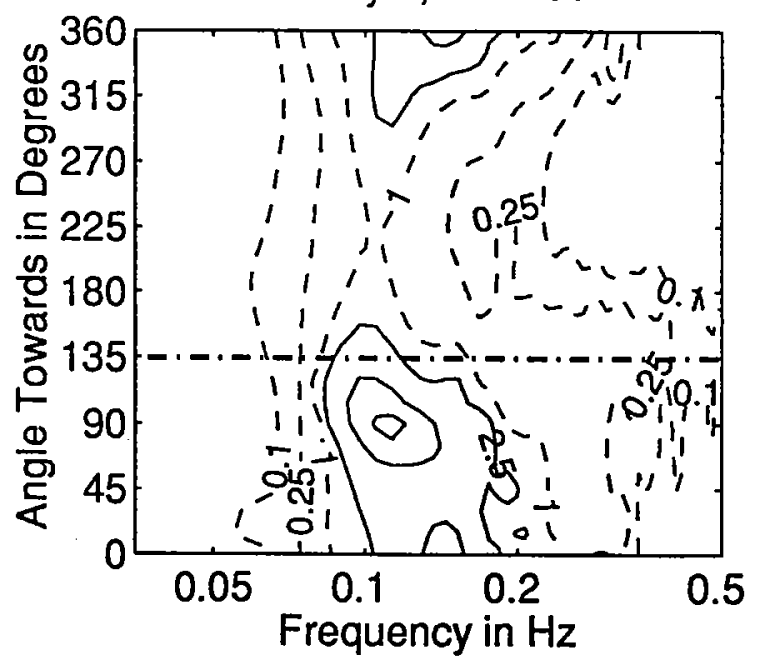

Figure 3.4.44: Directional wave spectra, computed using maximum entropy method. Contours of spectral density as a function of direction. Contours are 0.1 , $0.25,1$ (dashed), $2.5,10,25,100$, and 250 (solid). Wind direction is shown by thick dashed line. 

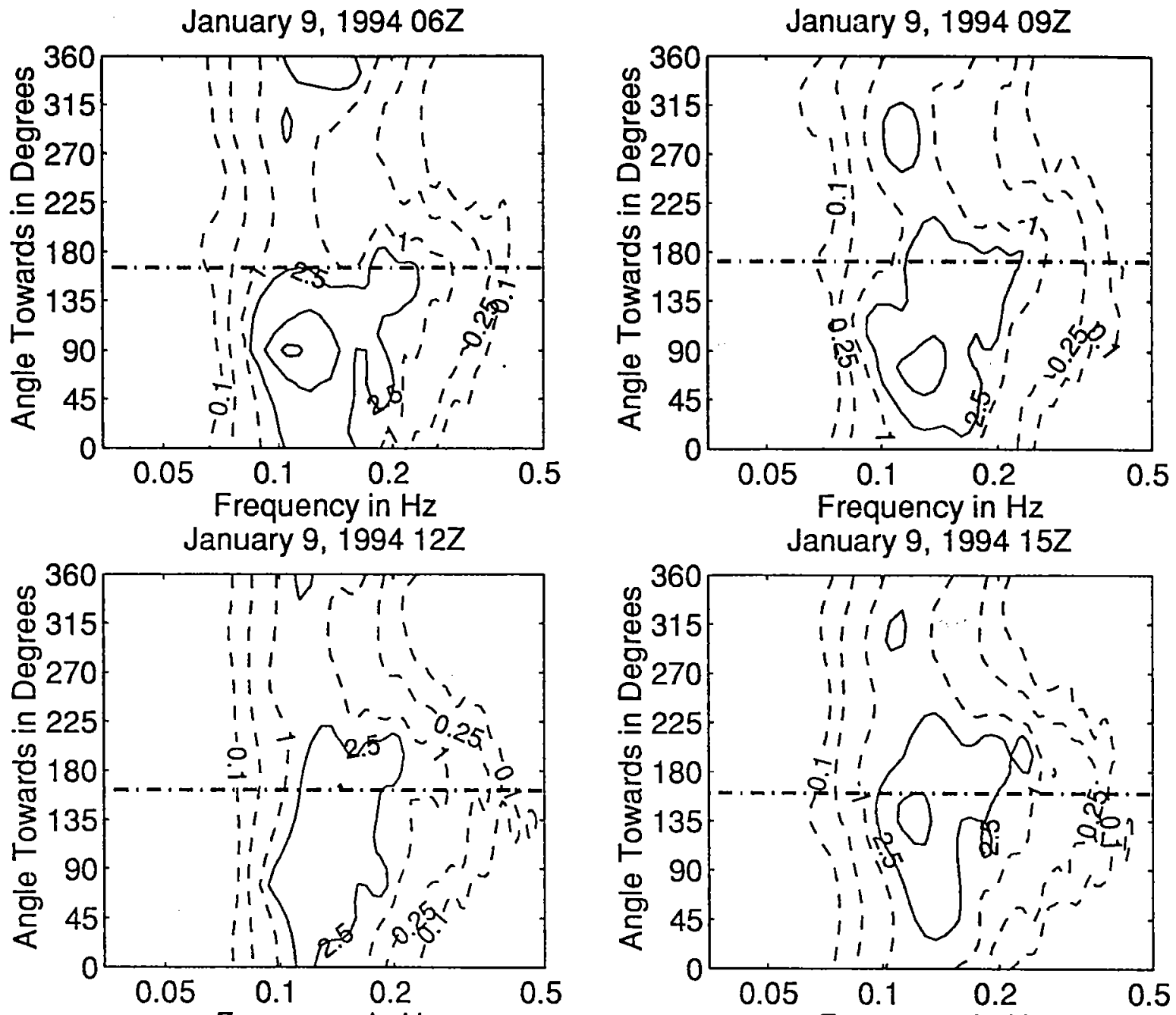

Frequency in $\mathrm{Hz}$ January $9,199418 Z$
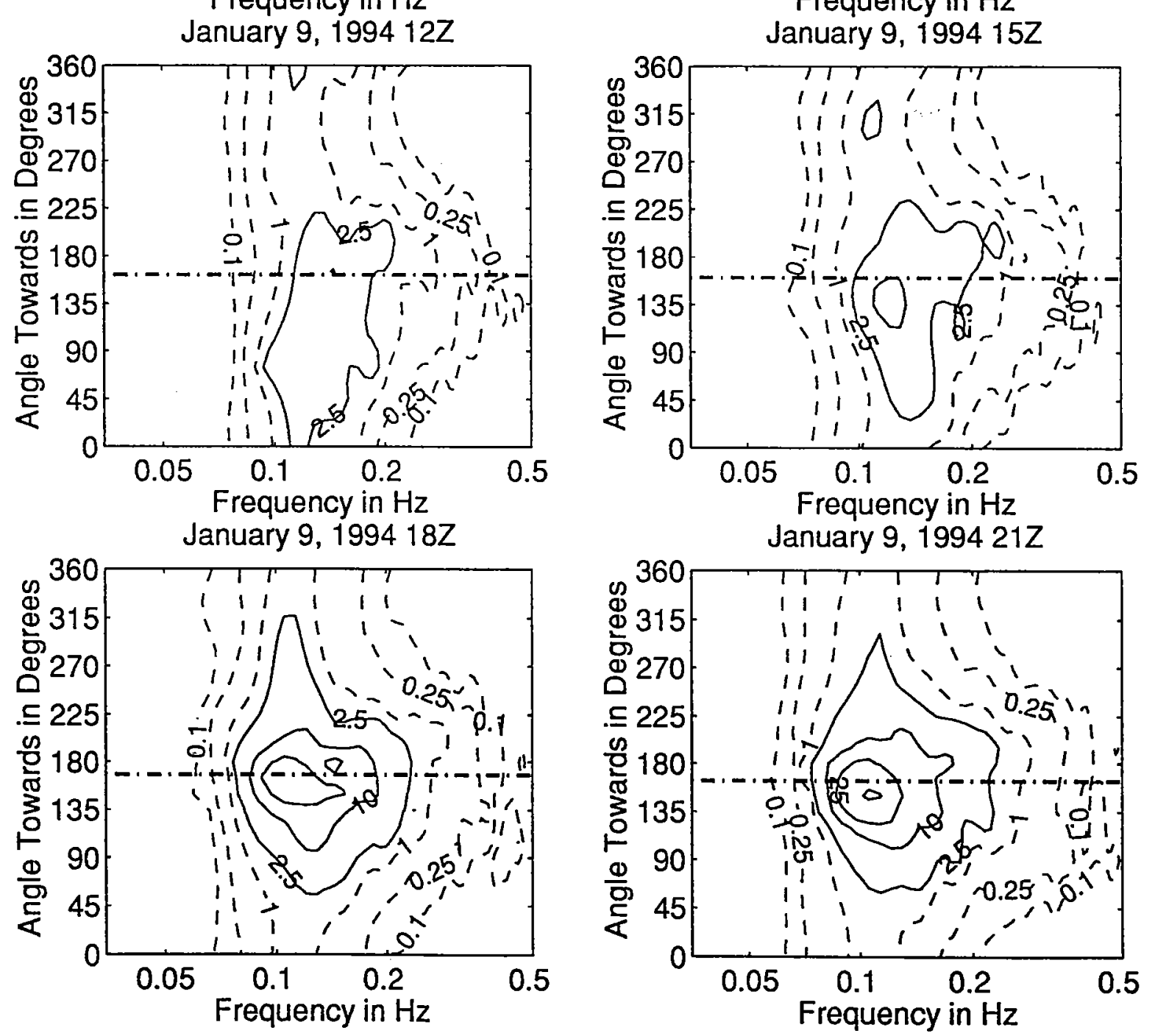

Figure 3.4.45: Directional wave spectra, computed using maximum entropy method. Contours of spectral density as a function of direction. Contours are $\mathbf{0 . 1}$, $0.25,1$ (dashed), $2.5,10,25,100$, and 250 (solid). Wind direction is shown by thick dashed line. 

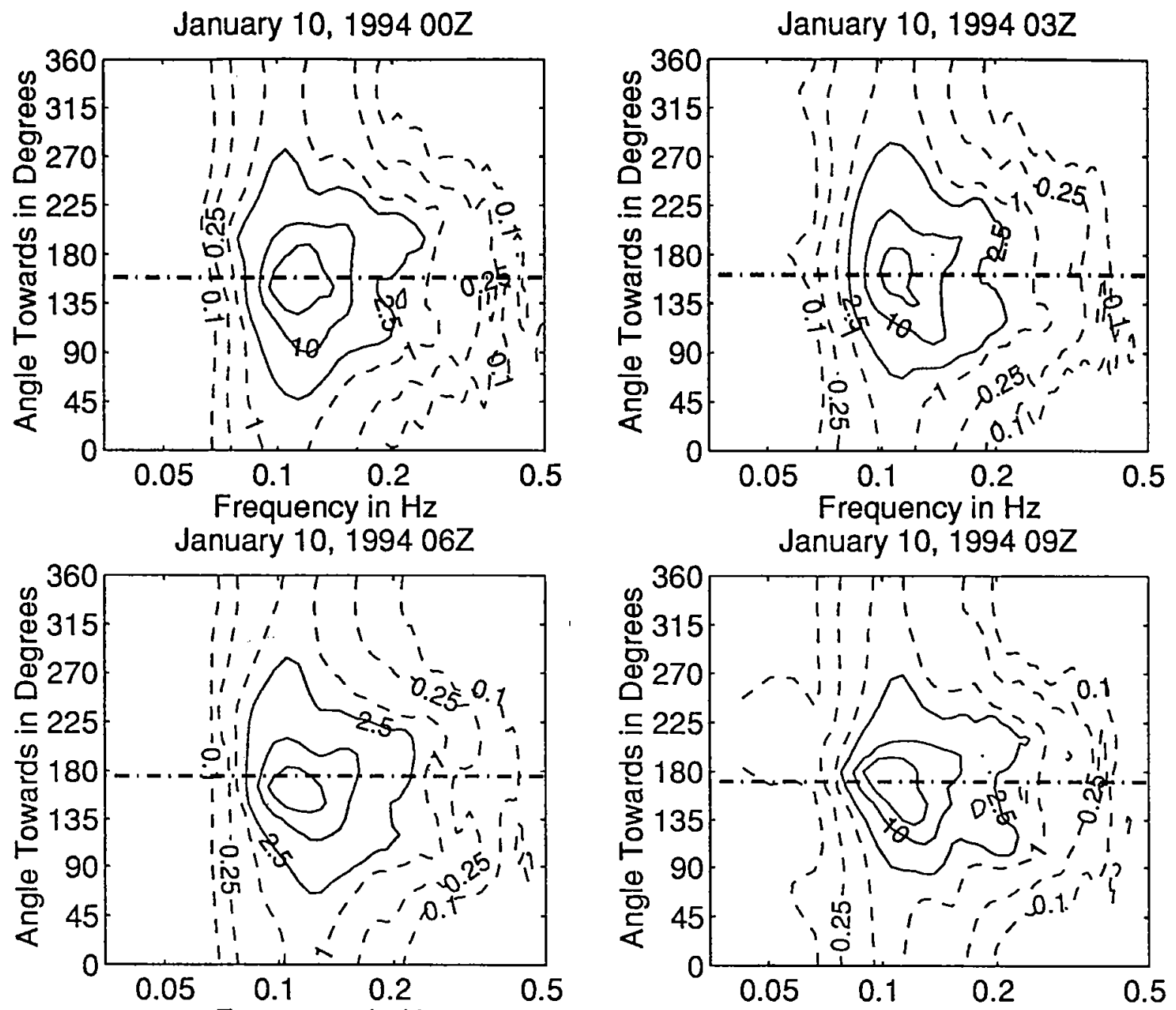

Frequency in $\mathrm{Hz}$
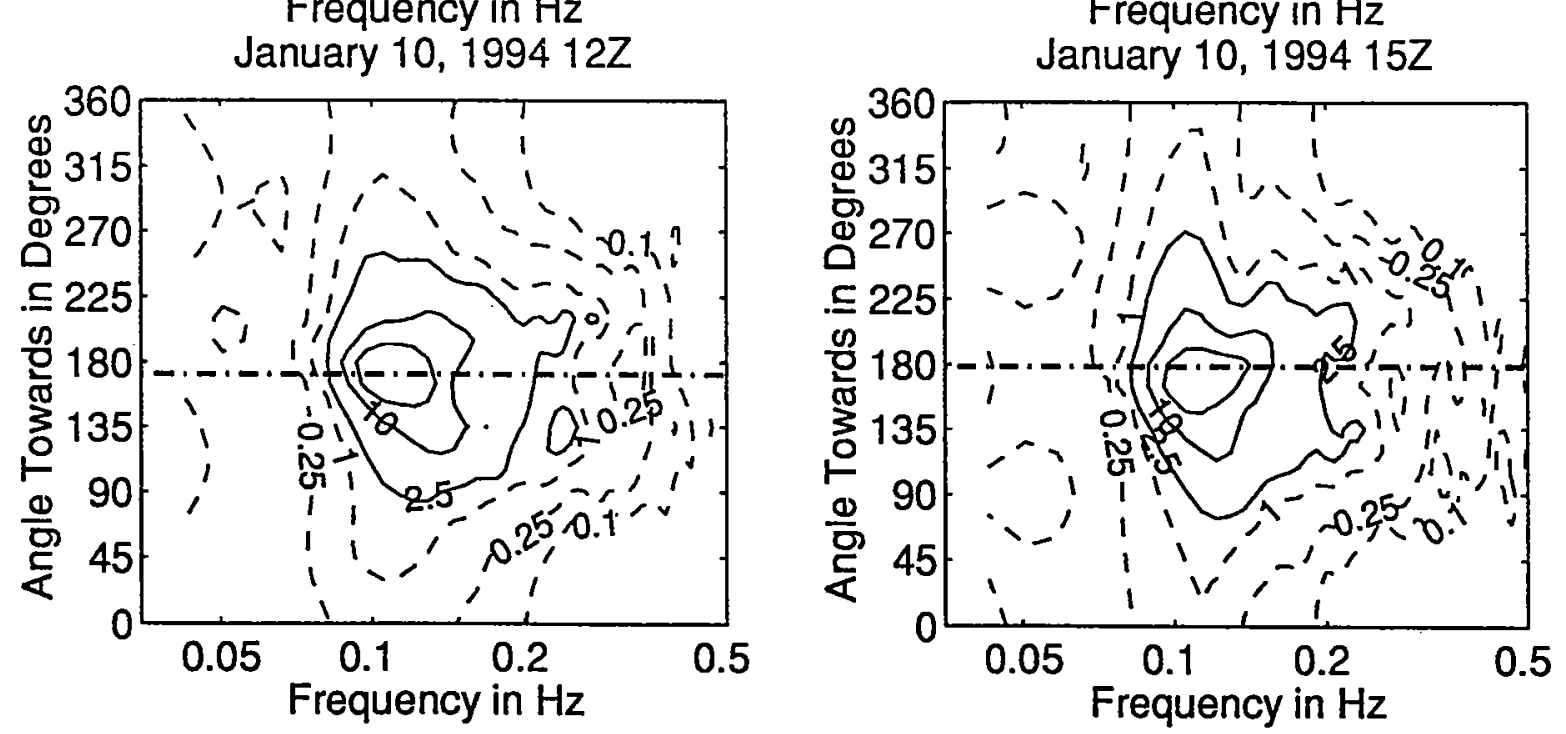

Figure 3.4.46: Directional wave spectra, computed using maximum entropy method. Contours of spectral density as a function of direction. Contours are 0.1, $0.25,1$ (dashed), $2.5,10,25,100$, and 250 (solid). Wind direction is shown by thick dashed line. 
January 10, $199418 Z$

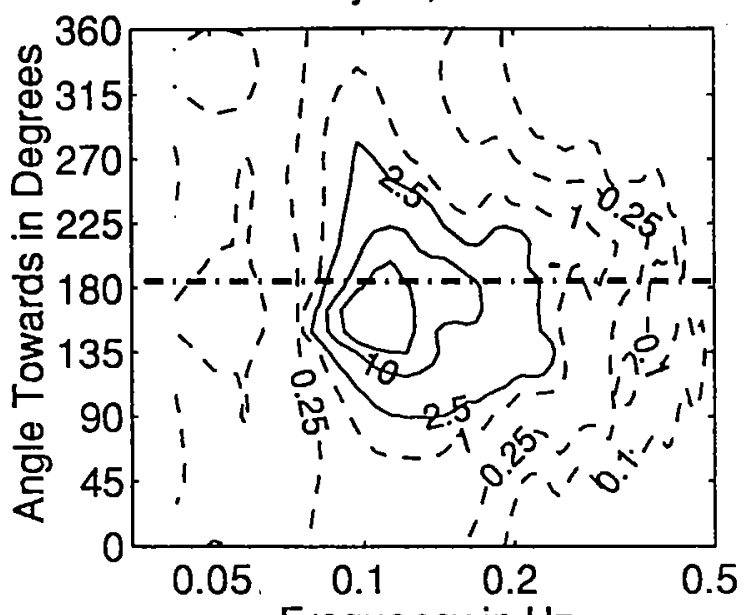

Frequency in $\mathrm{Hz}$

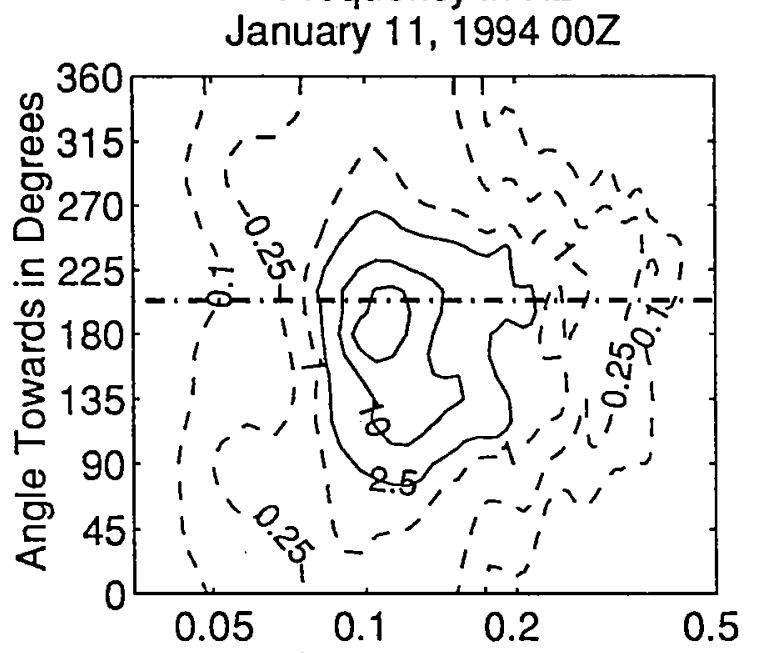

Frequency in $\mathrm{Hz}$ January $11,199406 Z$

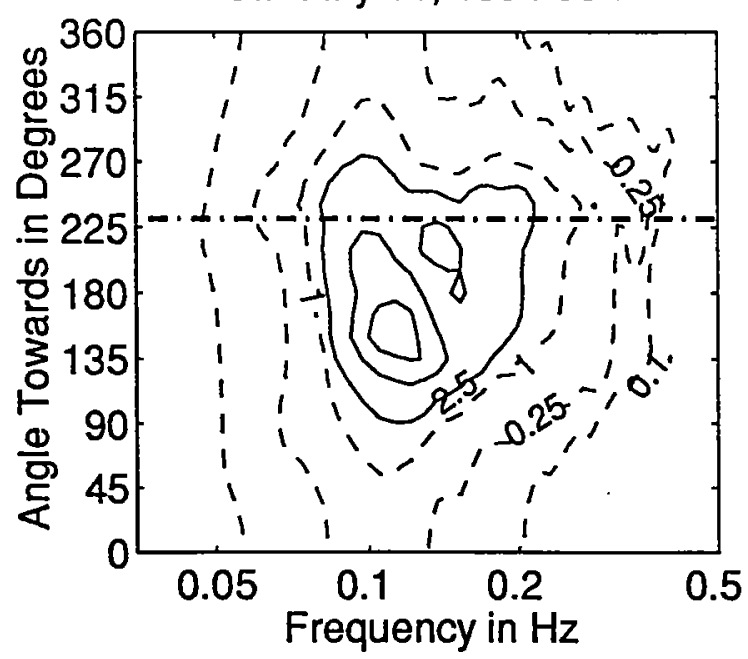

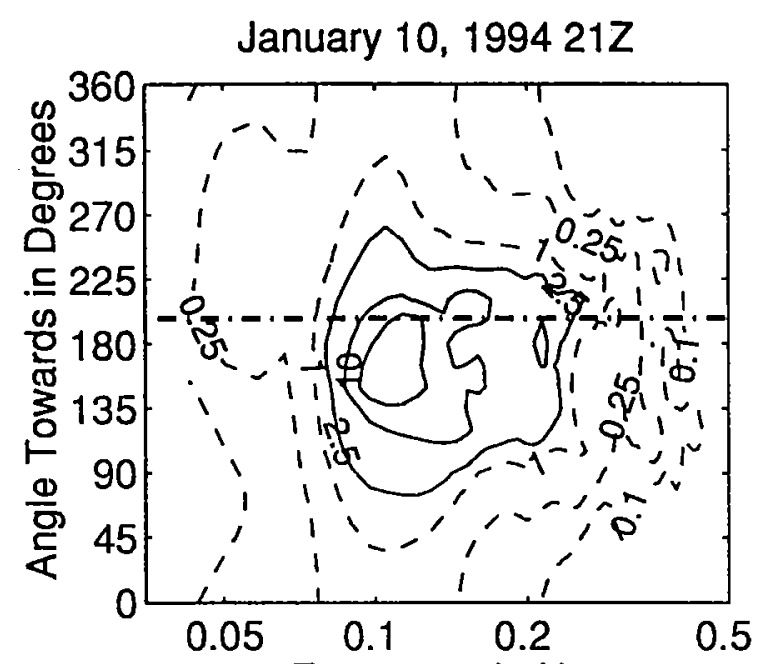

Frequency in $\mathrm{Hz}$ January $11,199403 Z$

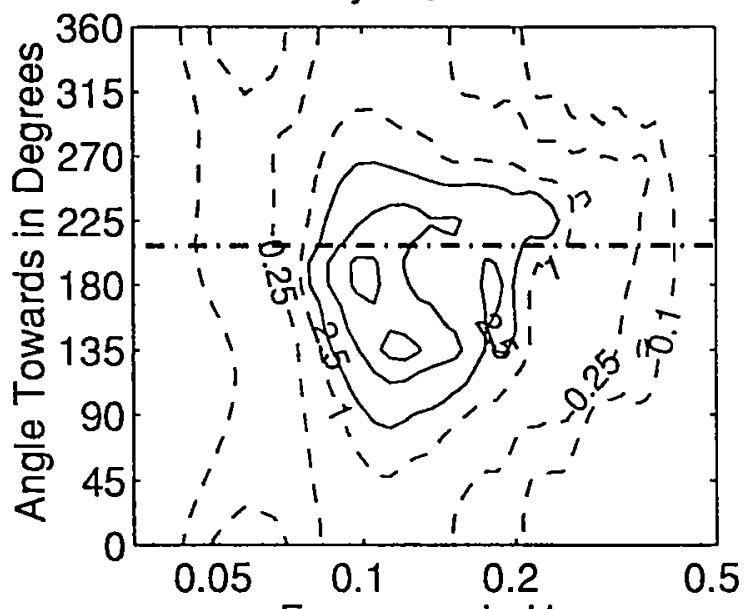

Frequency in $\mathrm{Hz}$ January 11, $199409 Z$

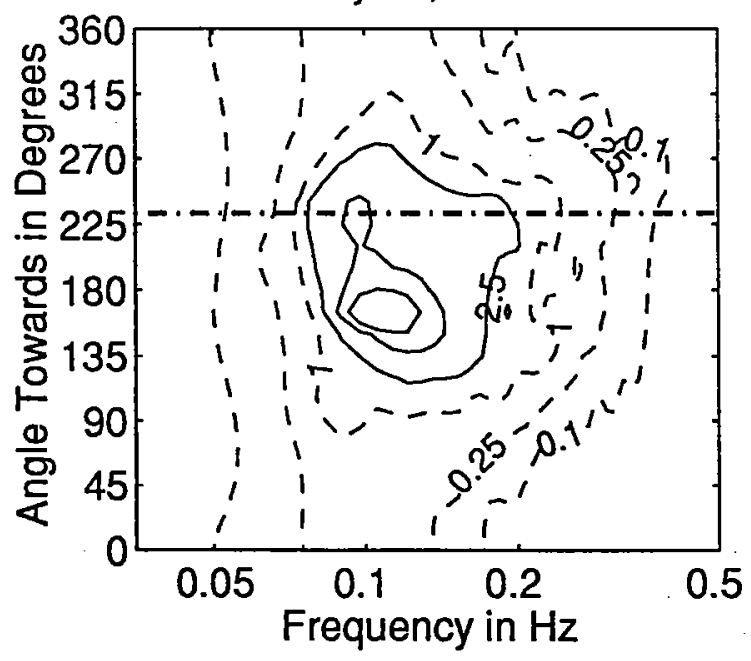

Figure 3.4.47: Directional wave spectra, computed using maximum entropy method. Contours of spectral density as a function of direction. Contours are 0.1, $0.25,1$ (dashed), $2.5,10,25,100$, and 250 (solid). Wind direction is shown by thick dashed line. 
January $11,199412 Z$

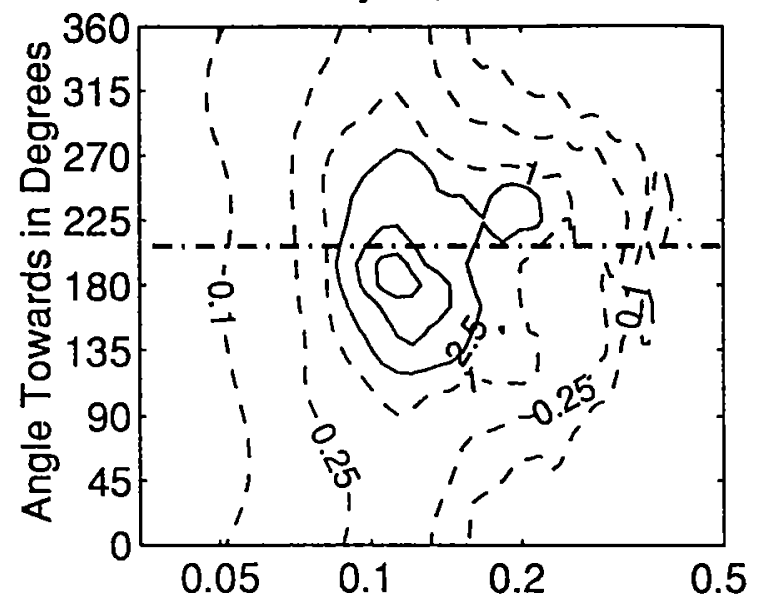

Frequency in $\mathrm{Hz}$

January $11,199418 Z$

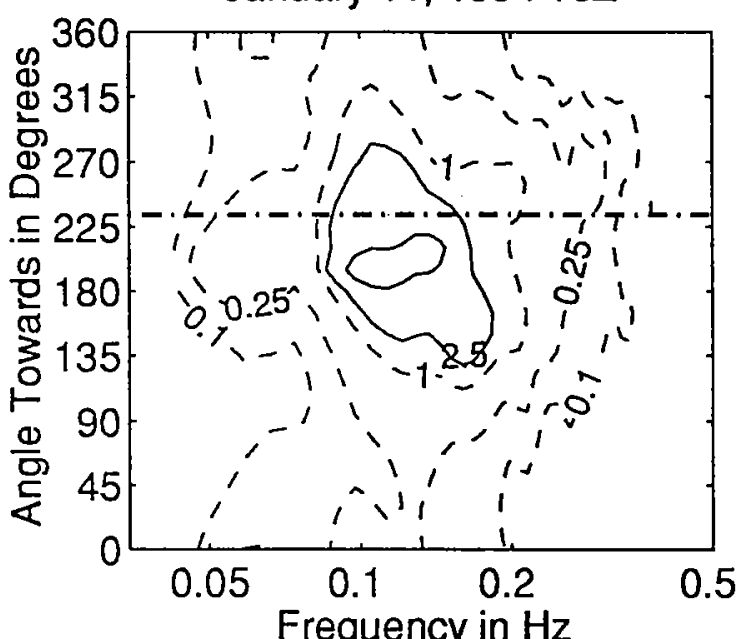

Frequency in $\mathrm{Hz}$ January $12,199400 Z$

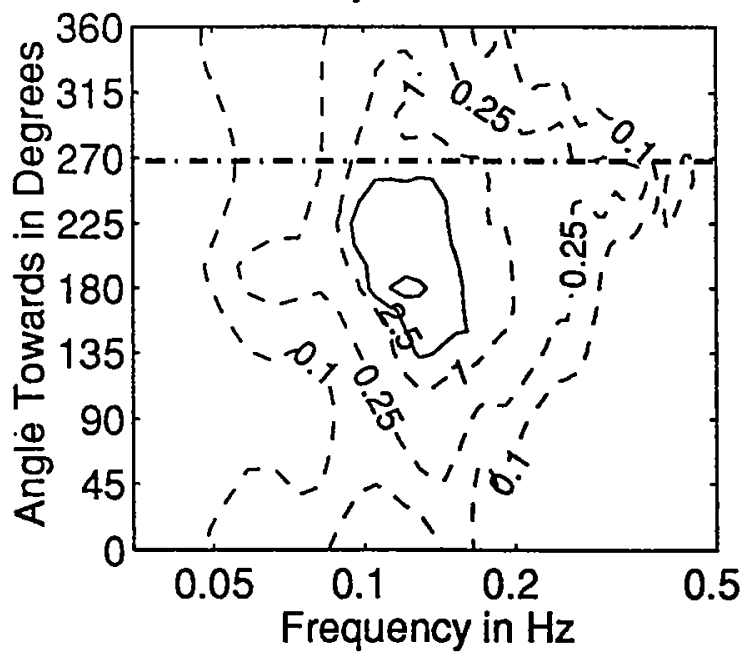

January $11,199415 Z$

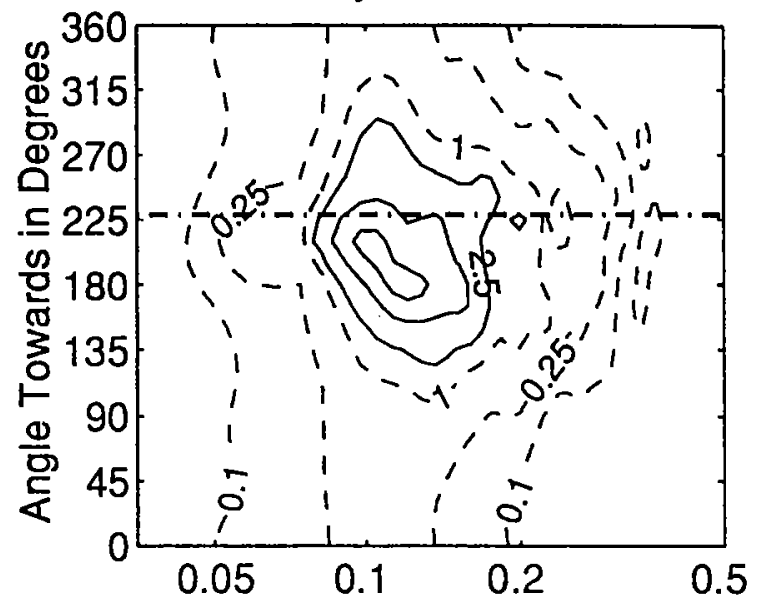

Frequency in $\mathrm{Hz}$

January 11, $199421 Z$

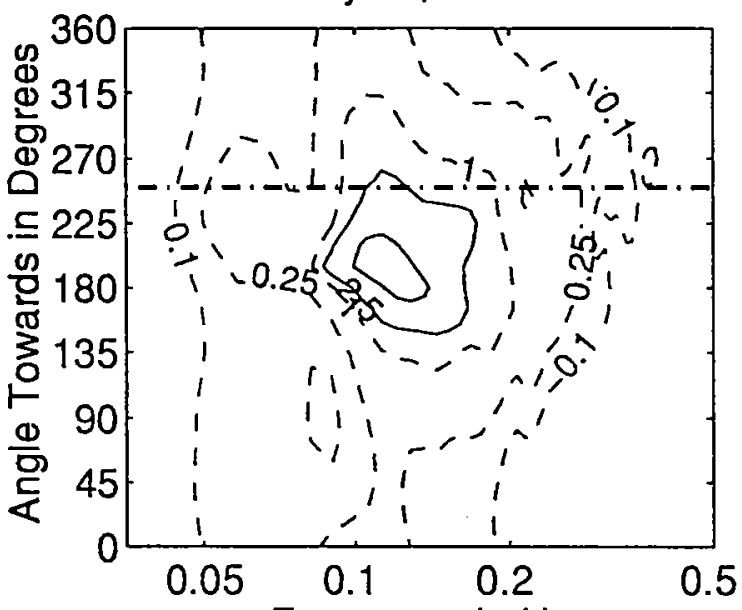

Frequency in $\mathrm{Hz}$ January 12, $199403 Z$

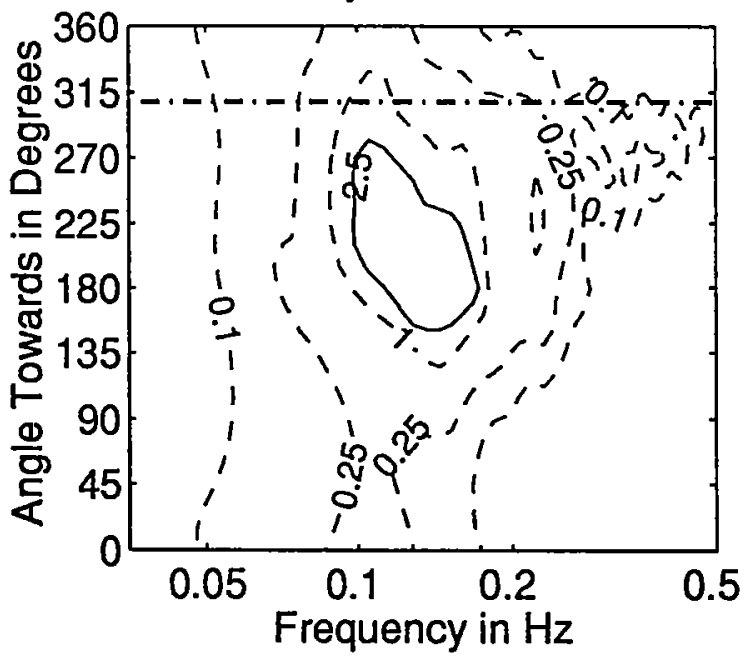

Figure 3.4.48: Directional wave spectra, computed using maximum entropy method. Contours of spectral density as a function of direction. Contours are 0.1, $0.25,1$ (dashed), $2.5,10,25,100$, and 250 (solid). Wind direction is shown by thick dashed line. 

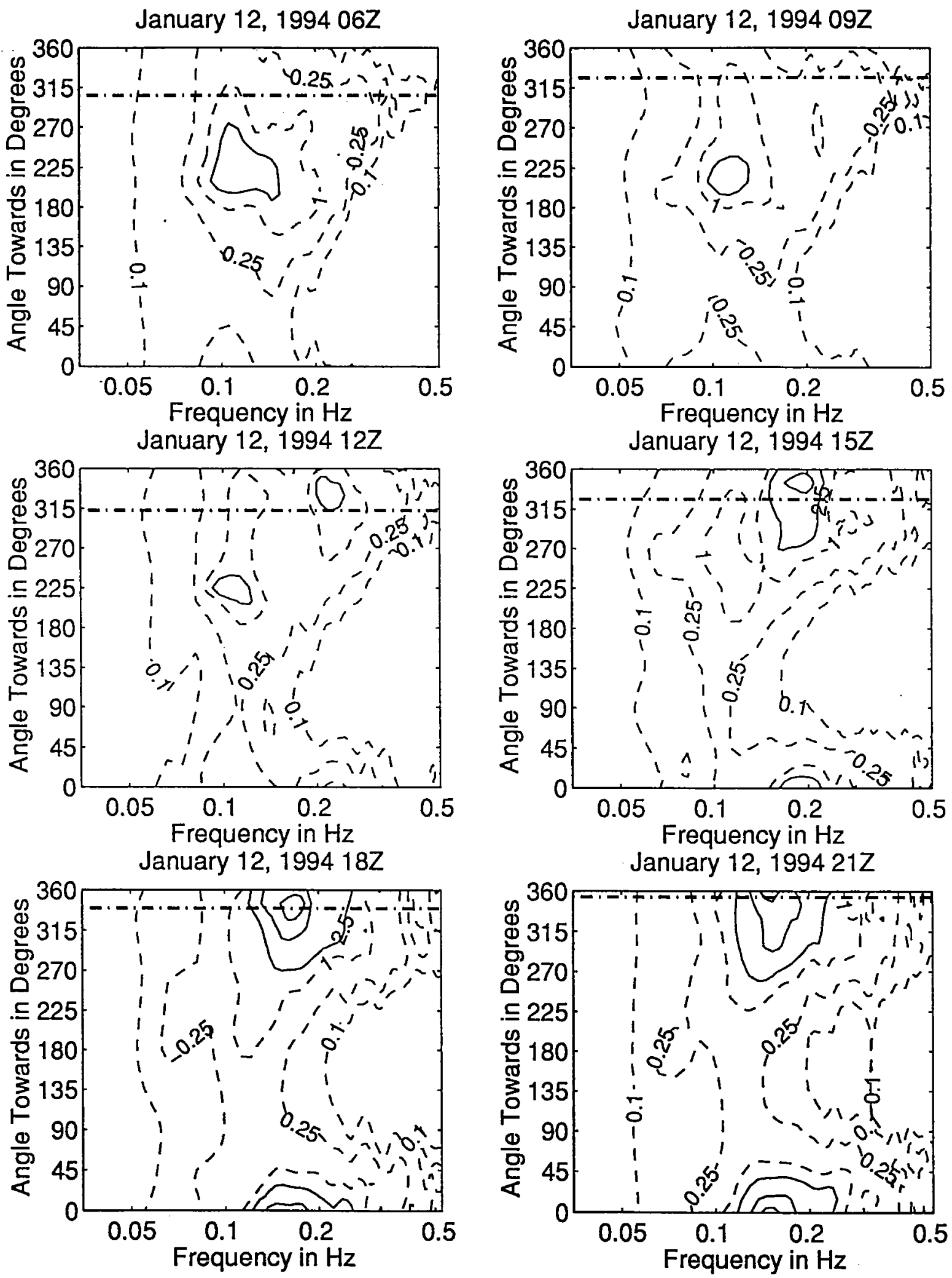

Figure 3.4.49: Directional wave spectra, computed using maximum entropy method. Contours of spectral density as a function of direction. Contours are 0.1 , $0.25,1$ (dashed), $2.5,10,25,100$, and 250 (solid). Wind direction is shown by thick dashed line. 

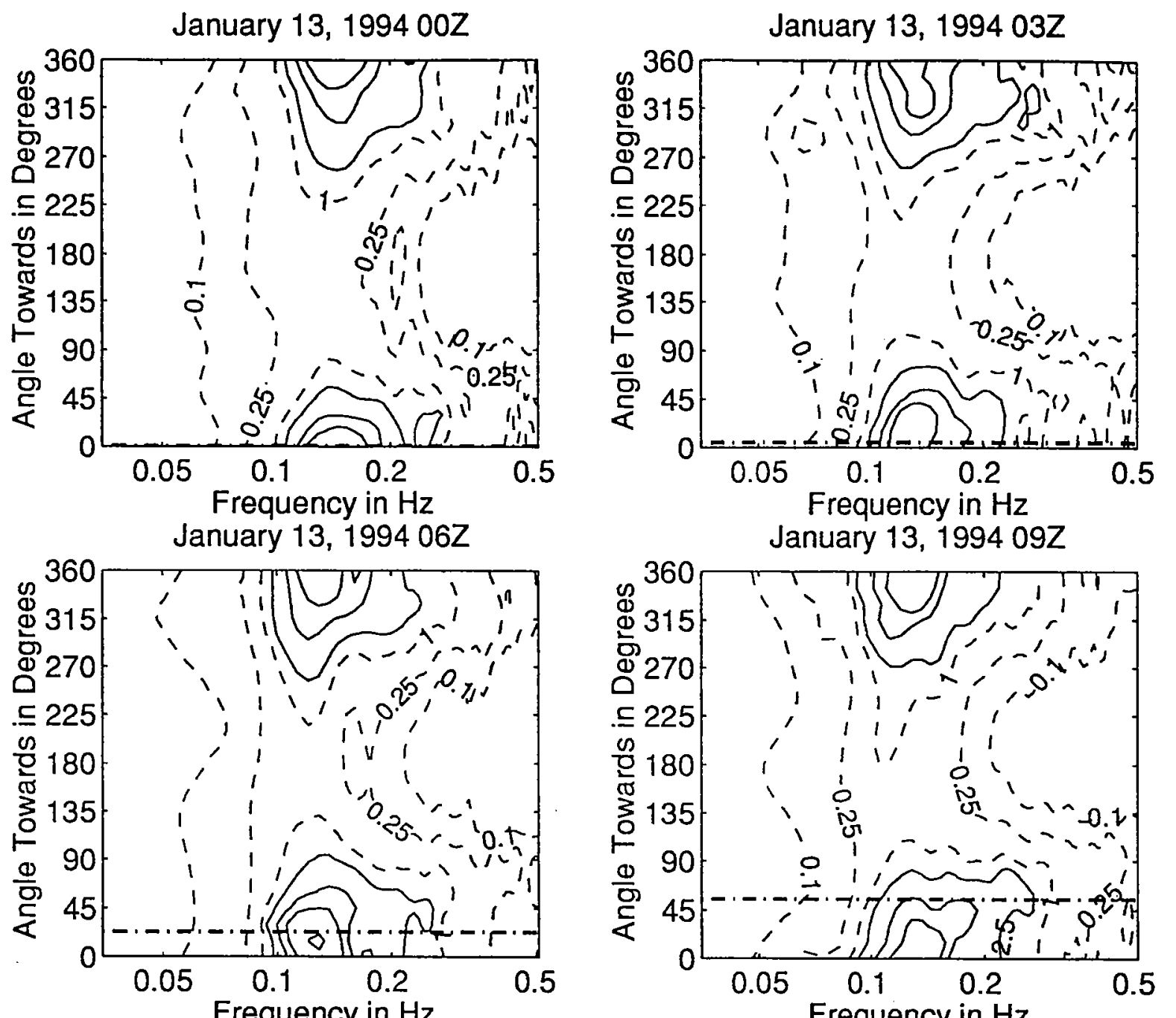

Frequency in $\mathrm{Hz}$
January $13,199412 \mathrm{z}$

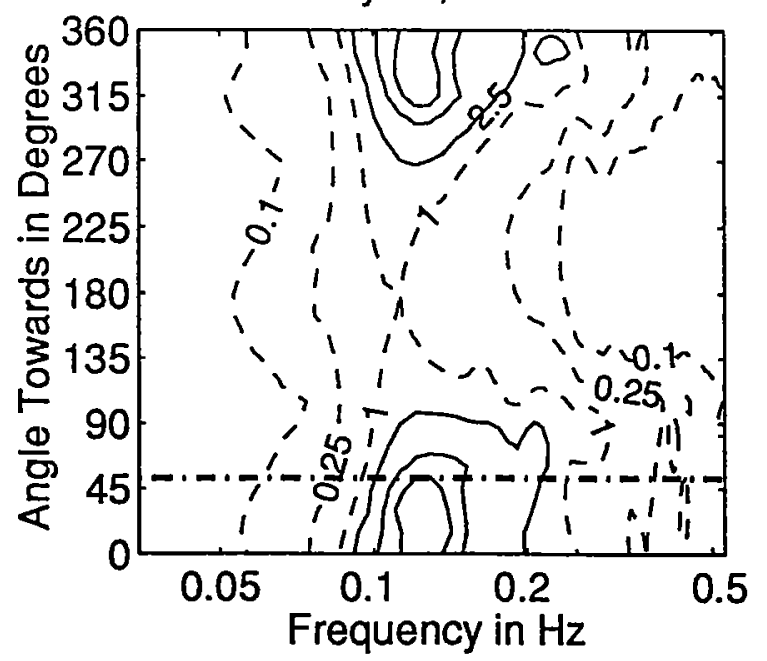

Frequency in $\mathrm{Hz}$

January 13, $199415 Z$

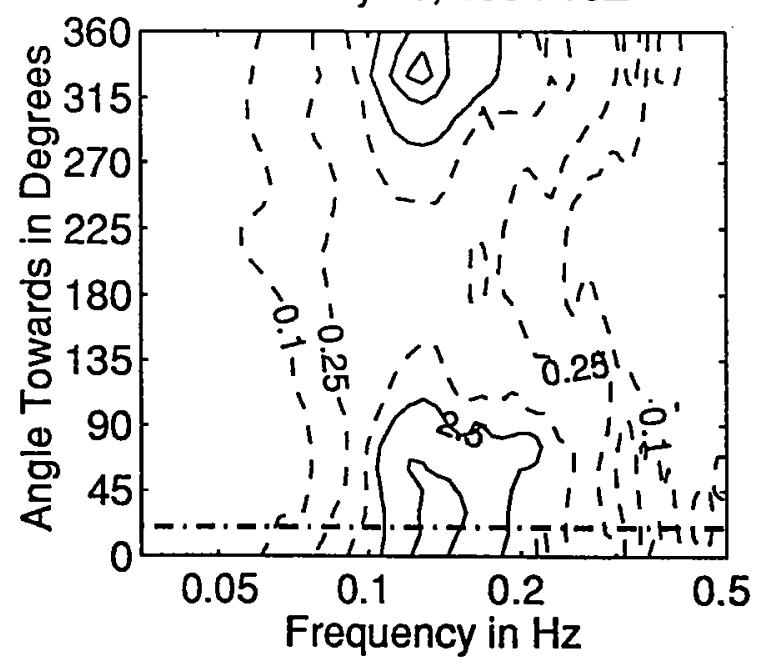

Figure 3.4.50: Directional wave spectra, computed using maximum entropy method. Contours of spectral density as a function of direction. Contours are 0.1, $0.25,1$ (dashed), $2.5,10,25,100$, and 250 (solid). Wind direction is shown by
thick dashed line. 

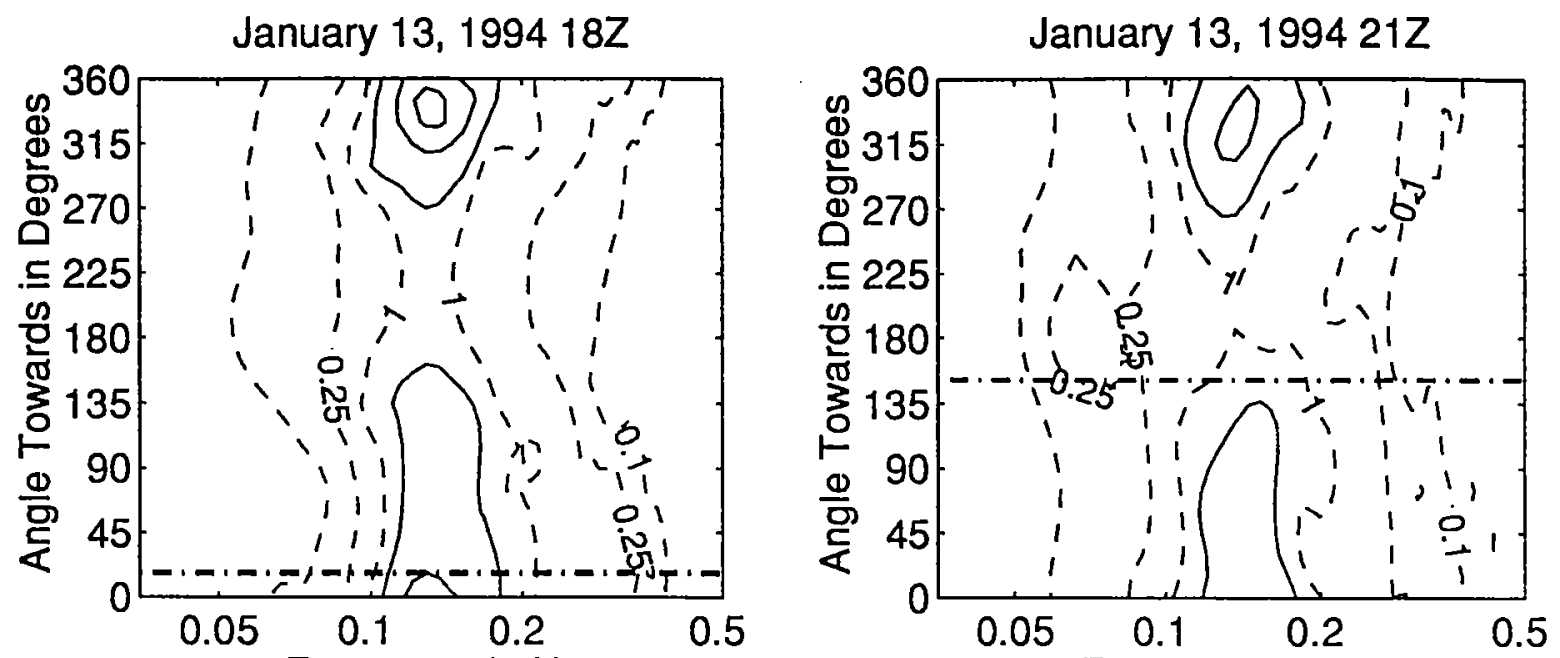

Frequency in $\mathrm{Hz}$

January $14,199400 Z$

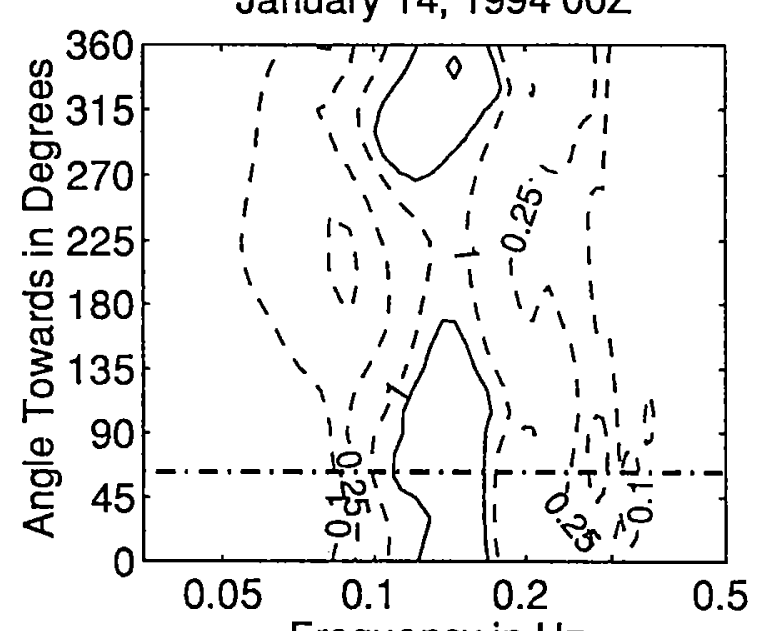

Frequency in $\mathrm{Hz}$

January 14, $199406 Z$

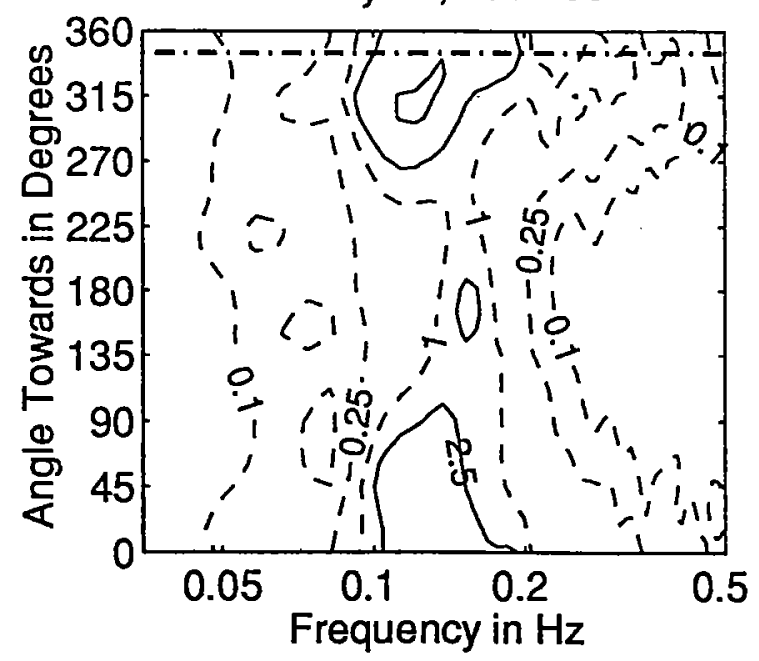

Frequency in $\mathrm{Hz}$

January 14, $199403 Z$

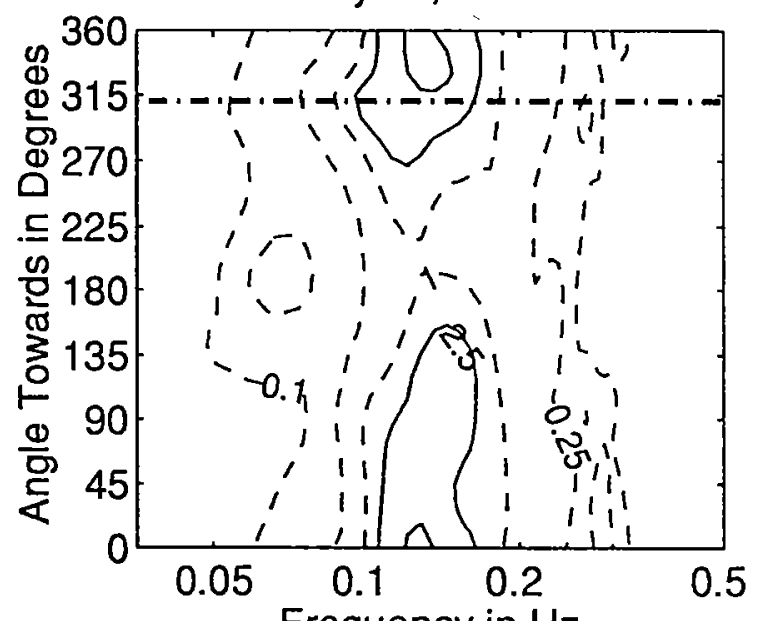

Frequency in $\mathrm{Hz}$

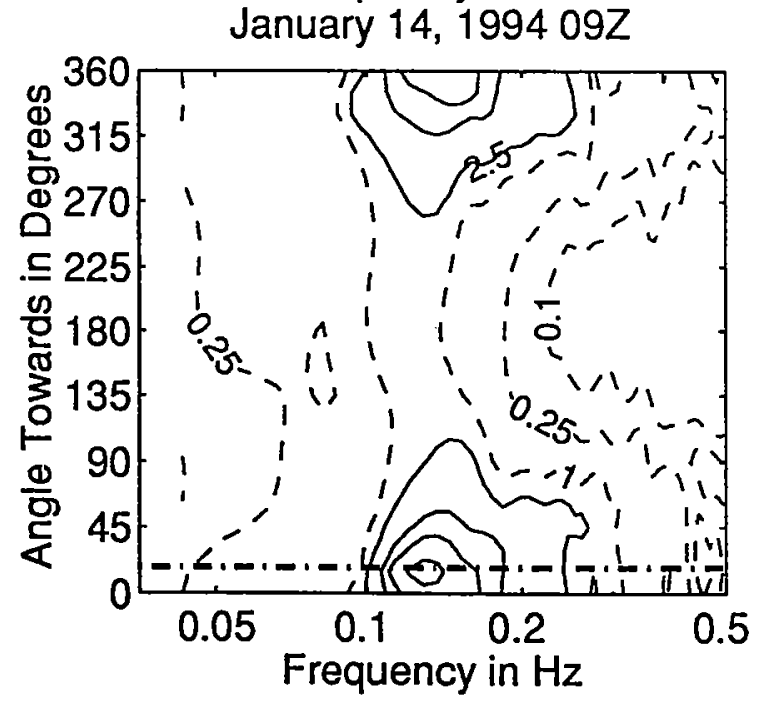

Figure 3.4.51: Directional wave spectra, computed using maximum entropy method. Contours of spectral density as a function of direction. Contours are 0.1 , $0.25,1$ (dashed), $2.5,10,25,100$, and 250 (solid). Wind direction is shown by thick dashed line. 

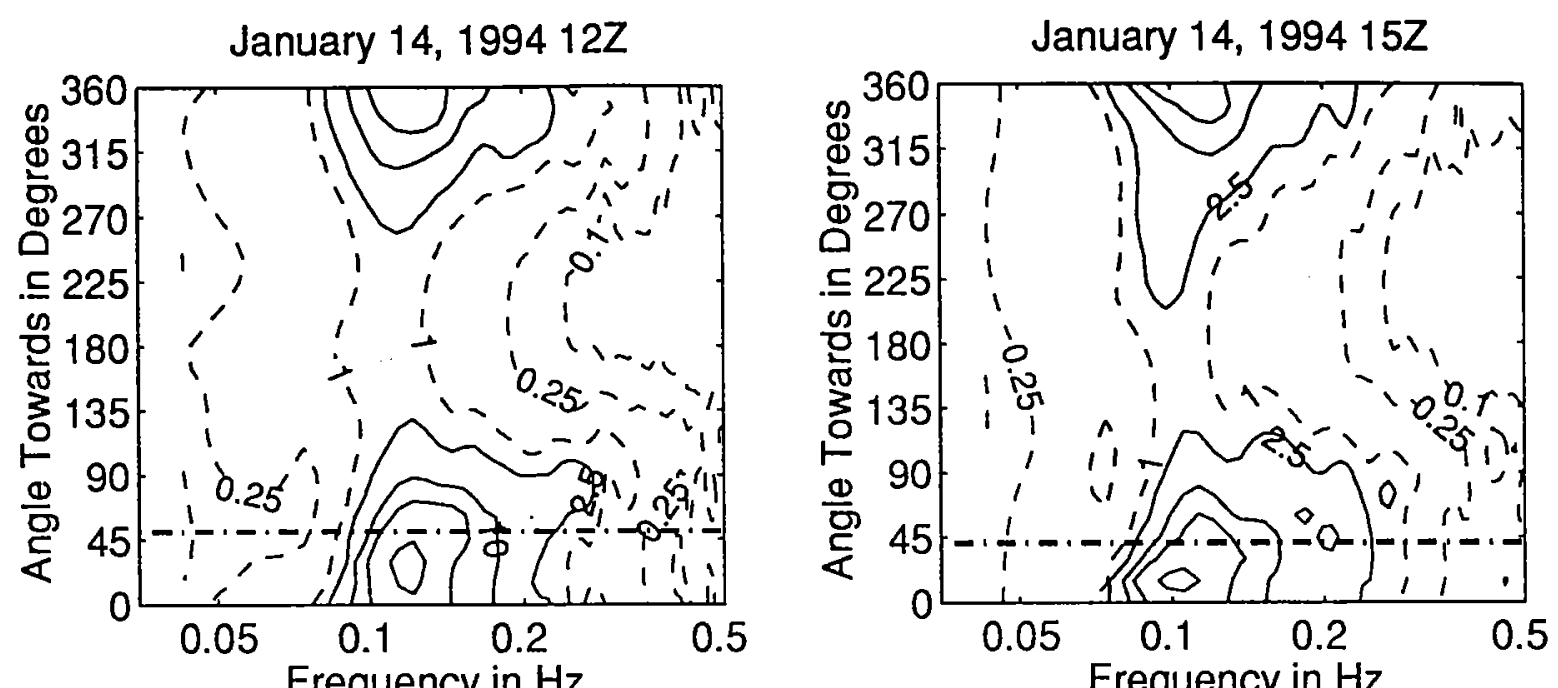

Frequency in $\mathrm{Hz}$

January 14, $199418 Z$

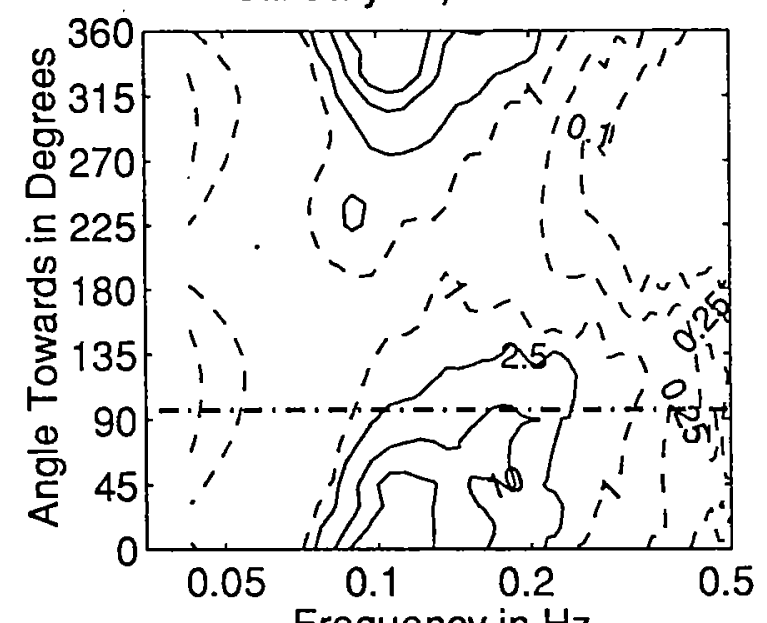

Frequency in $\mathrm{Hz}$

January 15, $199400 Z$
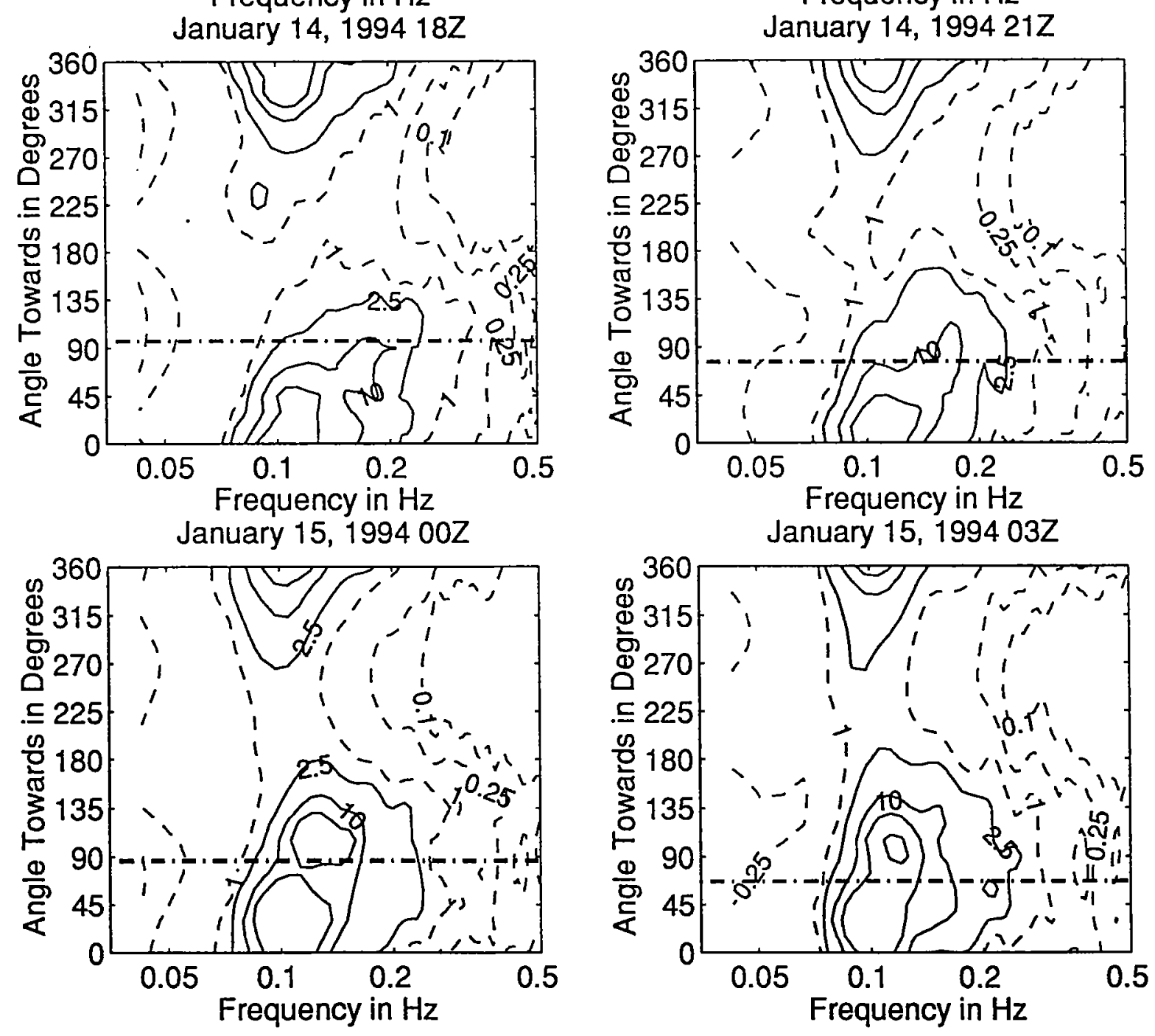

Figure 3.4.52: Directional wave spectra, computed using maximum entropy method. Contours of spectral density as a function of direction. Contours are 0.1 , $0.25,1$ (dashed), $2.5,10,25,100$, and 250 (solid). Wind direction is shown by thick dashed line. 

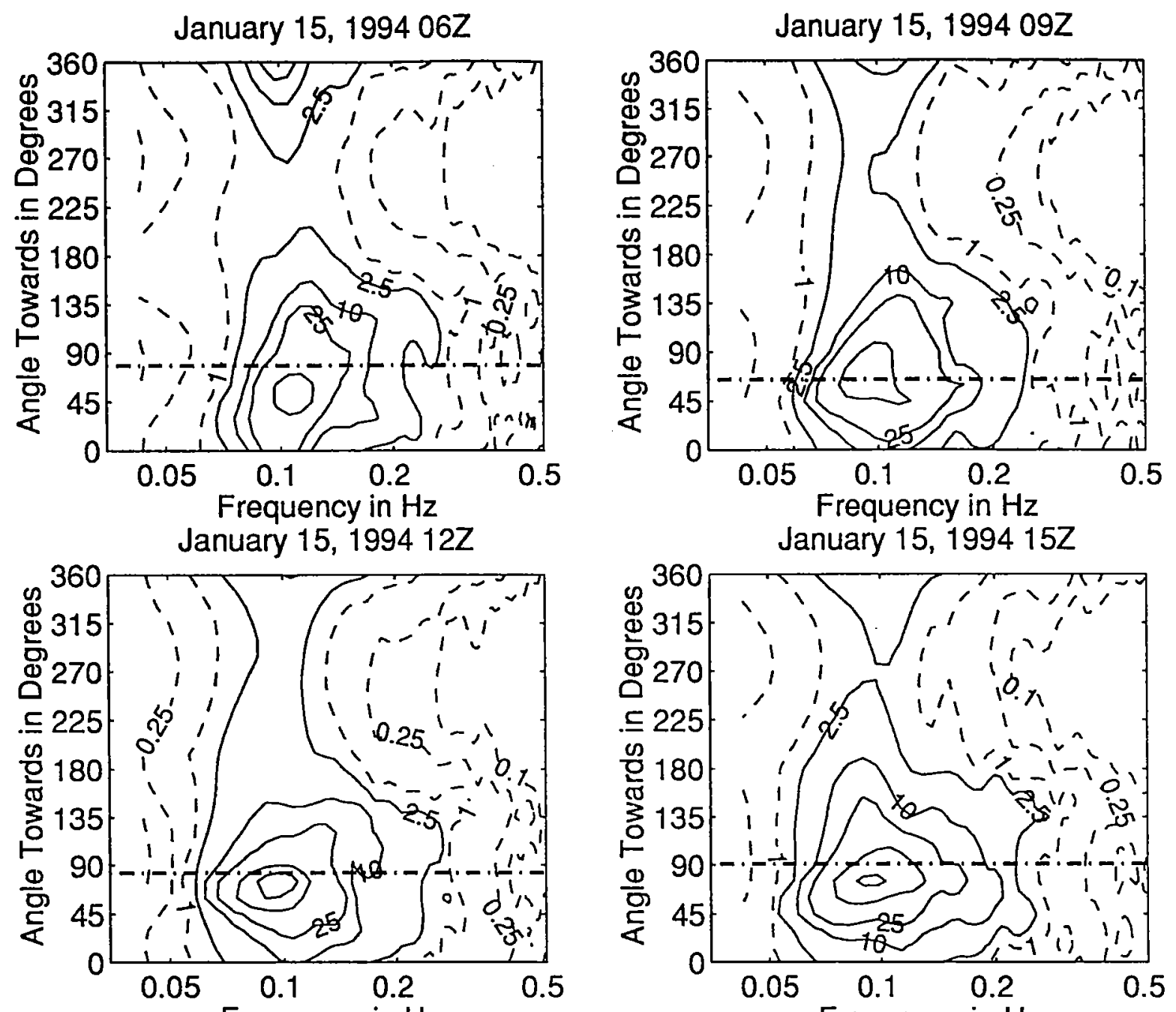

Frequency in $\mathrm{Hz}$ January 15, $199418 Z$

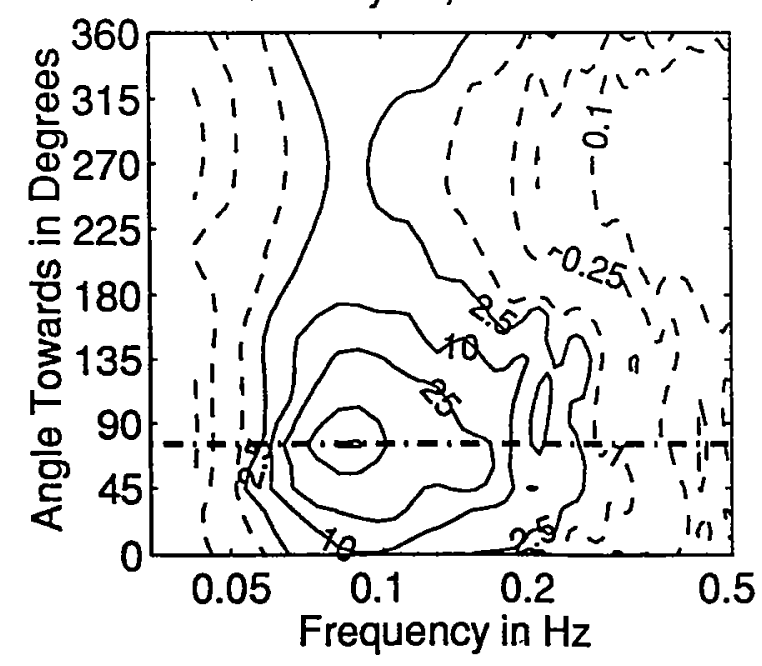

Frequency in $\mathrm{Hz}$ January $15,199421 Z$

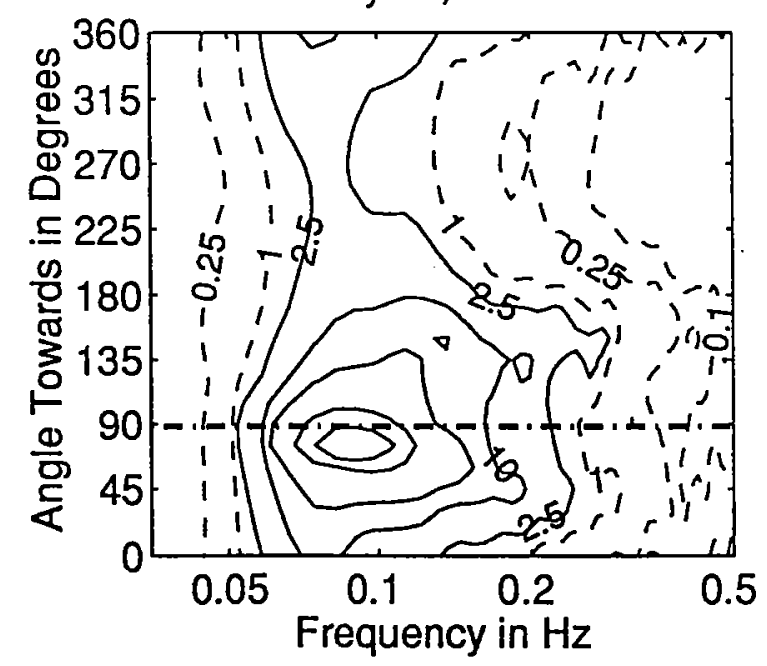

Figure 3.4.53: Directional wave spectra, computed using maximum entropy method. Contours of spectral density as a function of direction. Contours are 0.1, $0.25,1$ (dashed), $2.5,10,25,100$, and 250 (solid). Wind direction is shown by thick dashed line. 
January $16,199400 Z$
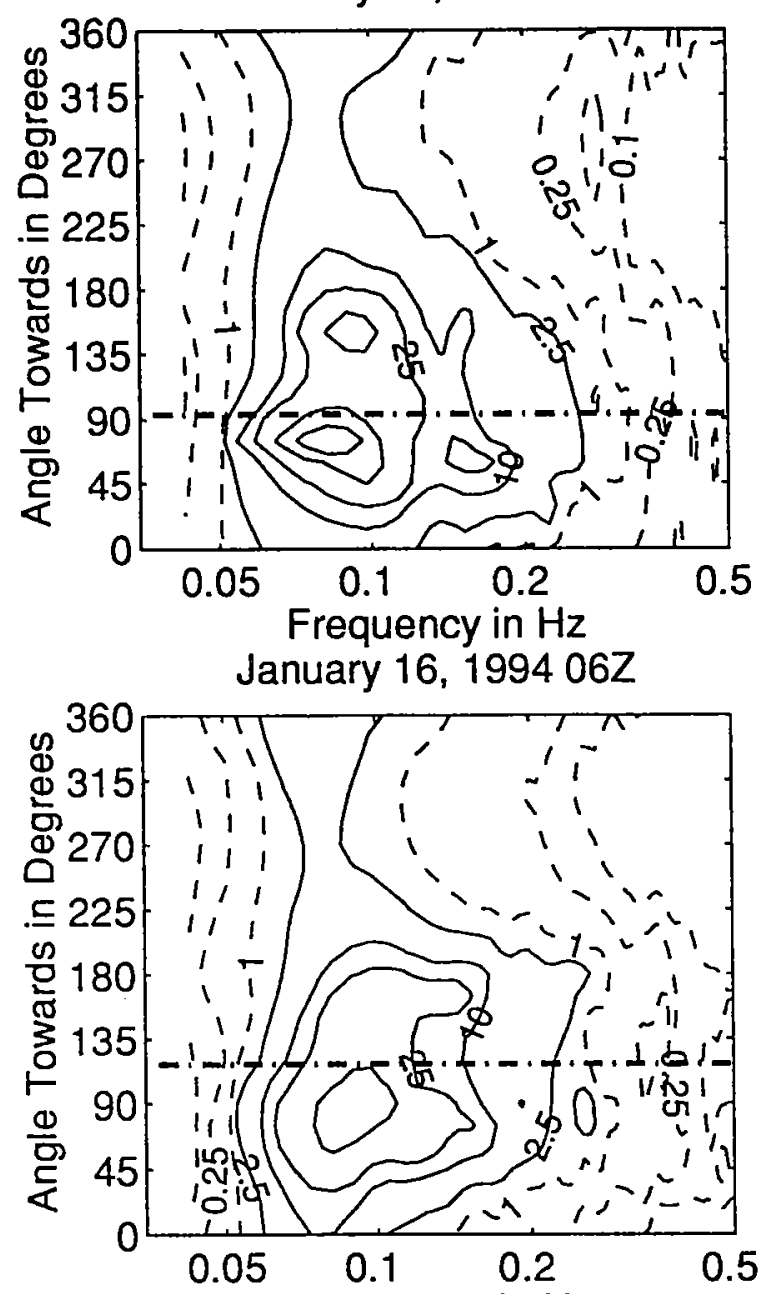

Frequency in $\mathrm{Hz}$ January 16, $199412 Z$

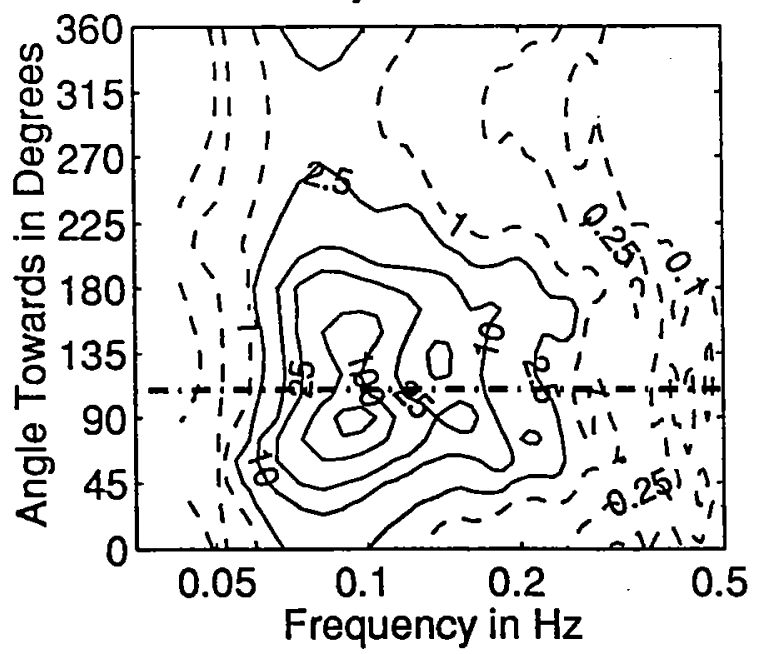

January 16, $199403 Z$

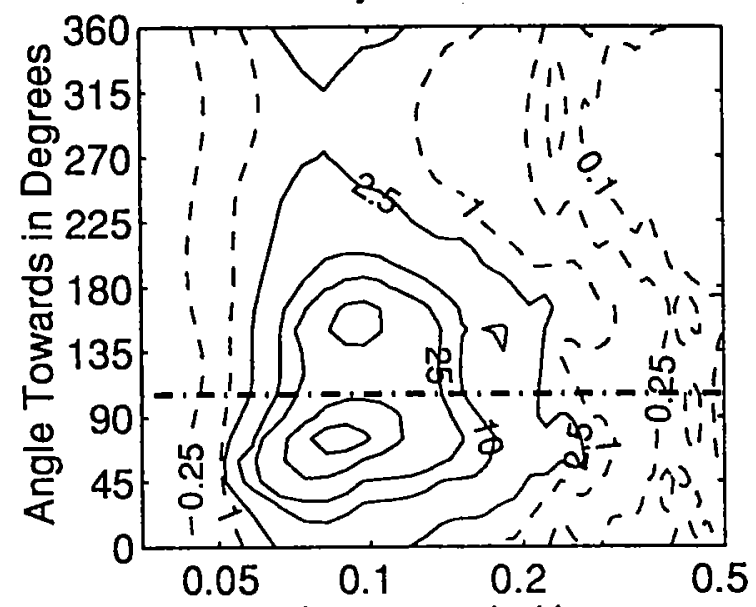

Frequency in $\mathrm{Hz}$ January 16, $199409 Z$

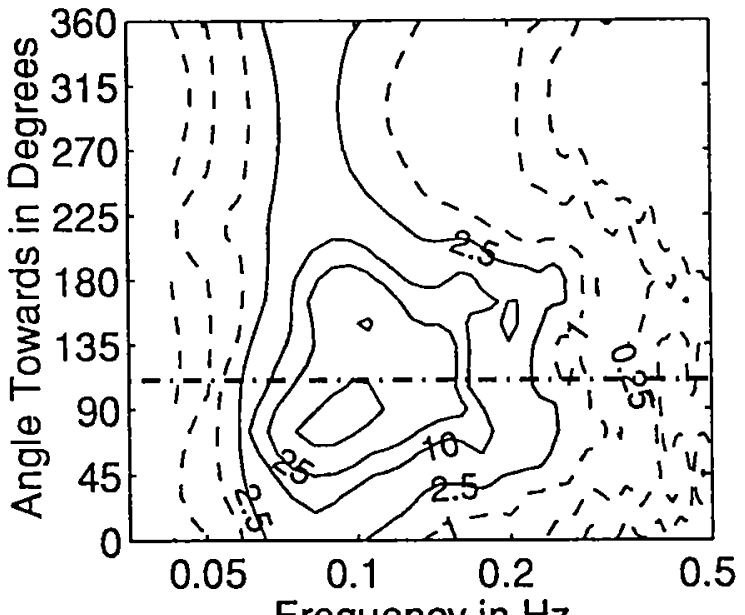

Frequency in $\mathrm{Hz}$ January $16,199415 Z$

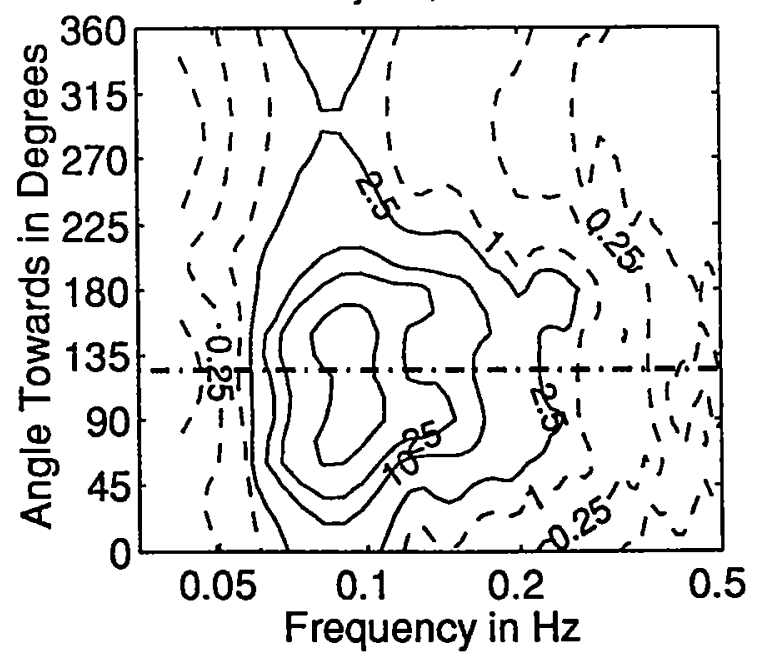

Figure 3.4.54: Directional wave spectra, computed using maximum entropy method. Contours of spectral density as a function of direction. Contours are 0.1, $0.25,1$ (dashed), $2.5,10,25,100$, and 250 (solid). Wind direction is shown by thick dashed line. 
January 16, $199418 Z$

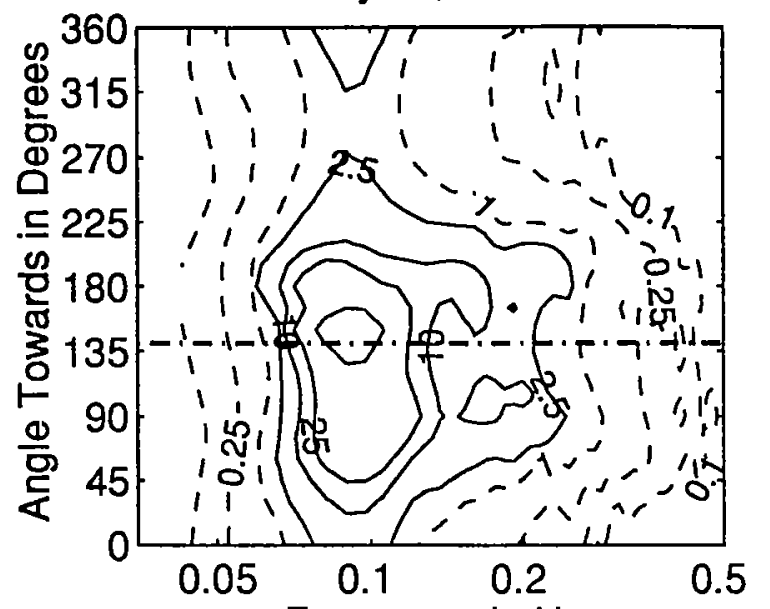

Frequency in $\mathrm{Hz}$

January 17, $199400 Z$

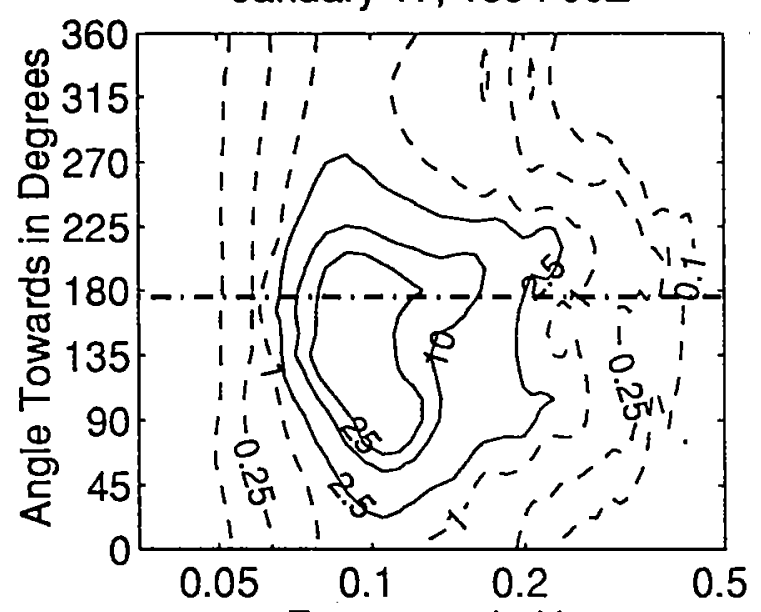

Frequency in $\mathrm{Hz}$

January 17, $199406 Z$

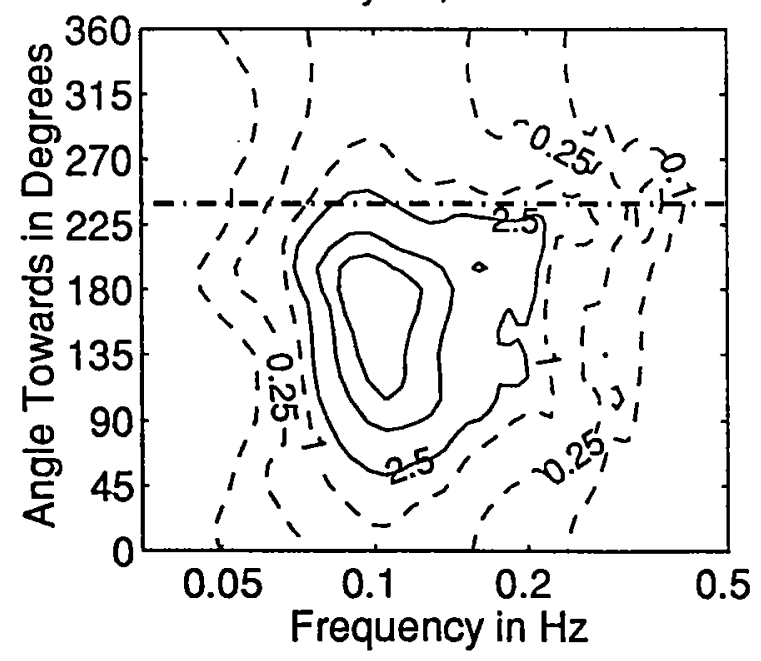

January 16, $199421 Z$

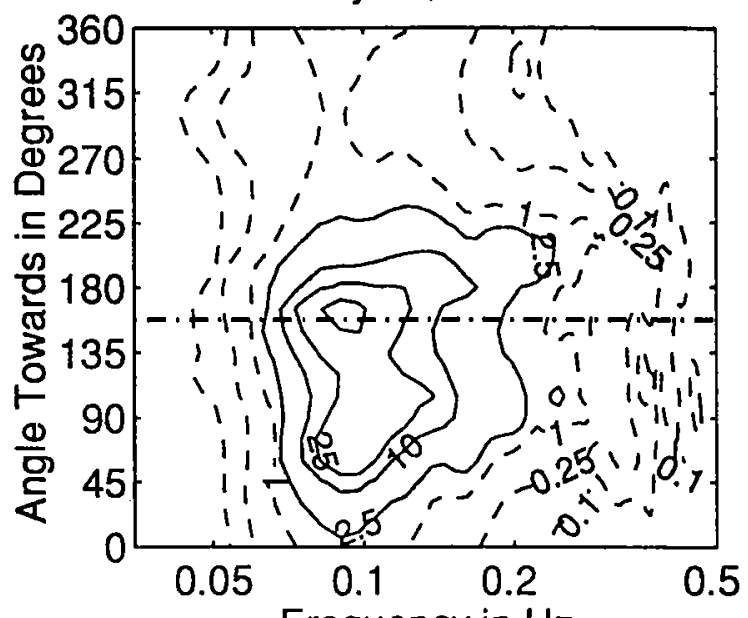

Frequency in $\mathrm{Hz}$ January 17,1994032

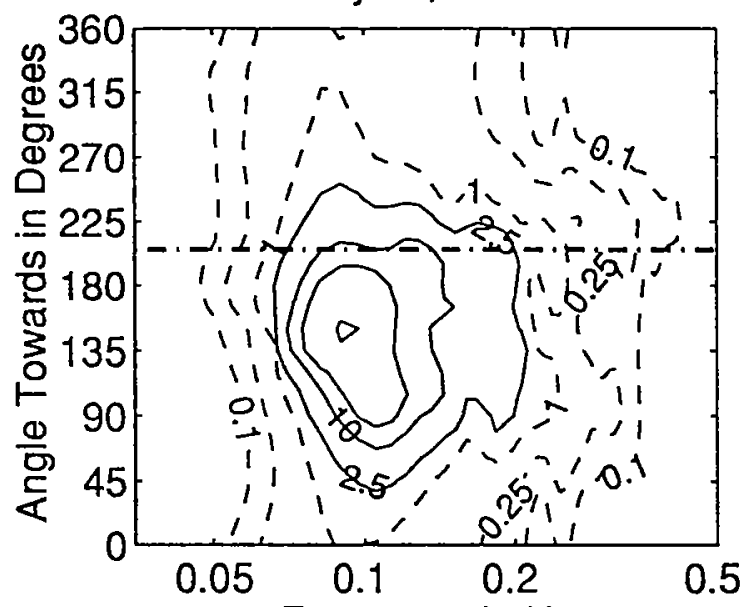

Frequency in $\mathrm{Hz}$

January 17, $199409 Z$

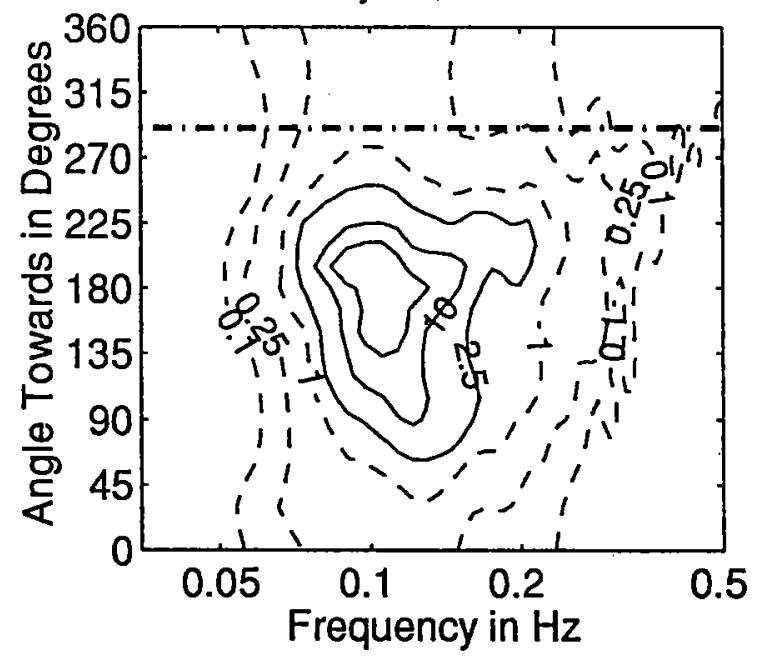

Figure 3.4.55: Directional wave spectra, computed using maximum entropy method. Contours of spectral density as a function of direction. Contours are 0.1 , $0.25,1$ (dashed), $2.5,10,25,100$, and 250 (solid). Wind direction is shown by thick dashed line. 

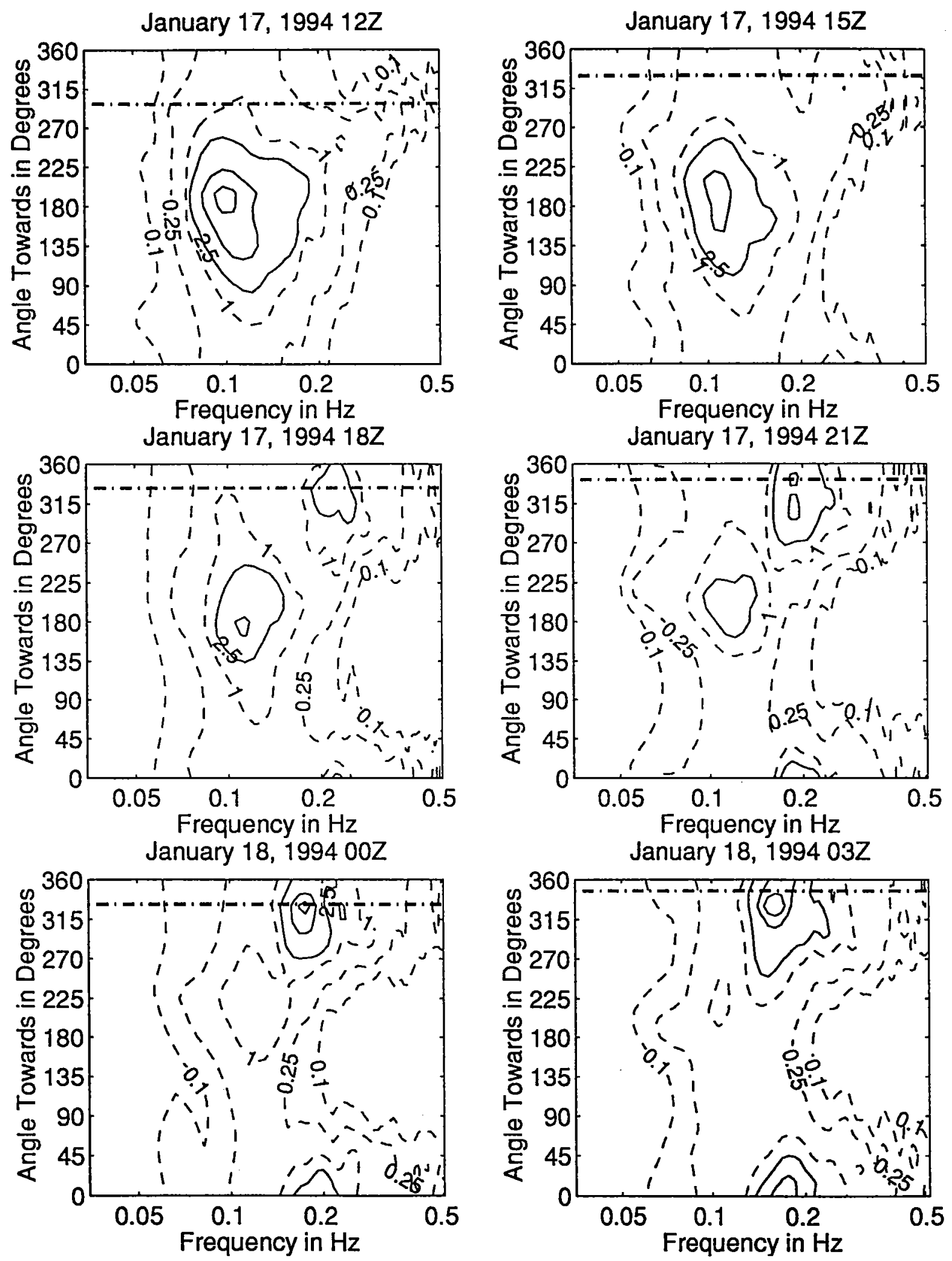

Figure 3.4.56: Directional wave spectra, computed using maximum entropy method. Contours of spectral density as a function of direction. Contours are 0.1, $0.25,1$ (dashed) $2.5,10,25,100$, and 250 (solid). Wind direction is shown by thick dashed line. 

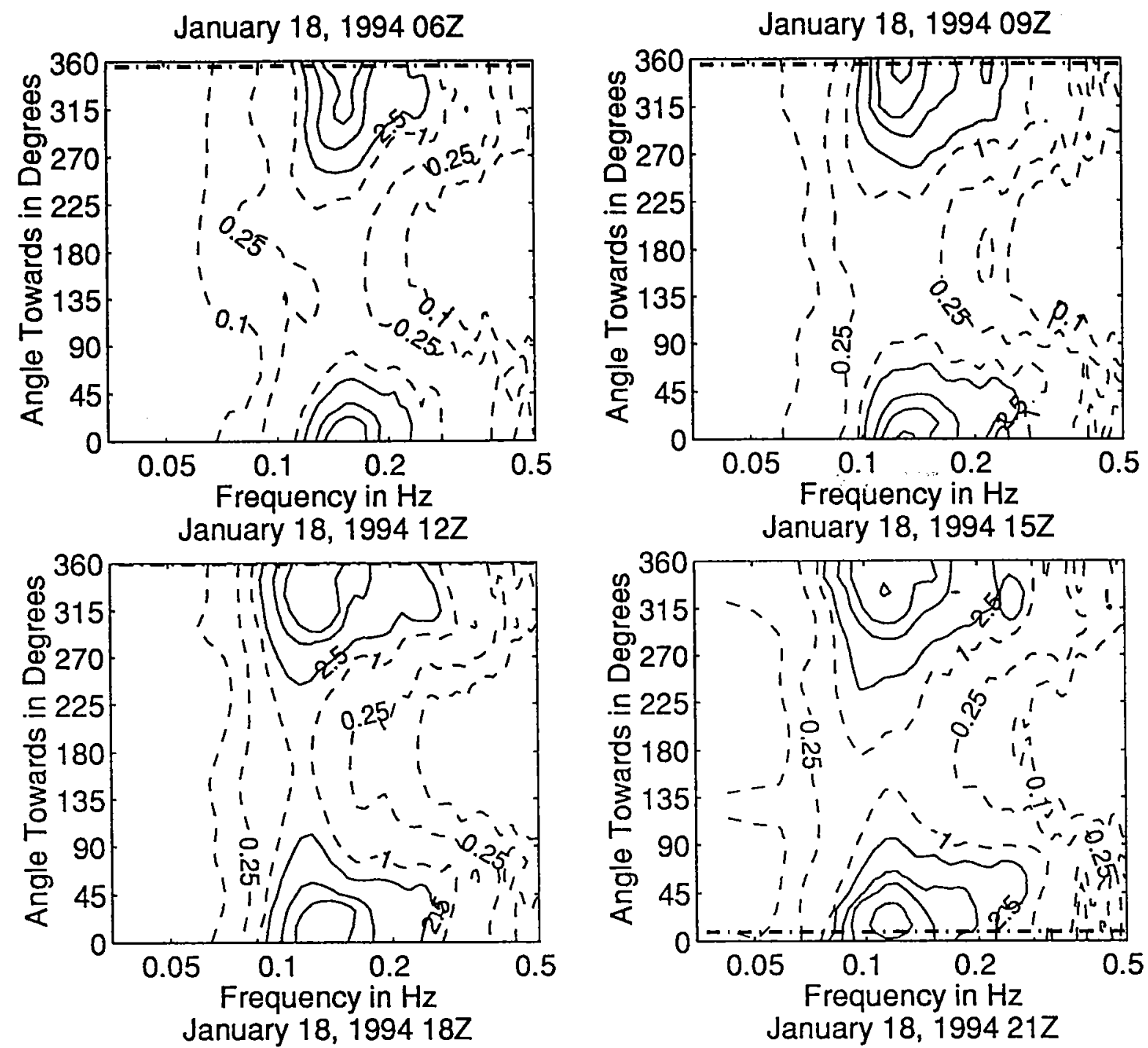

\section{Frequency in $\mathrm{Hz}$}

January 18, $199421 Z$
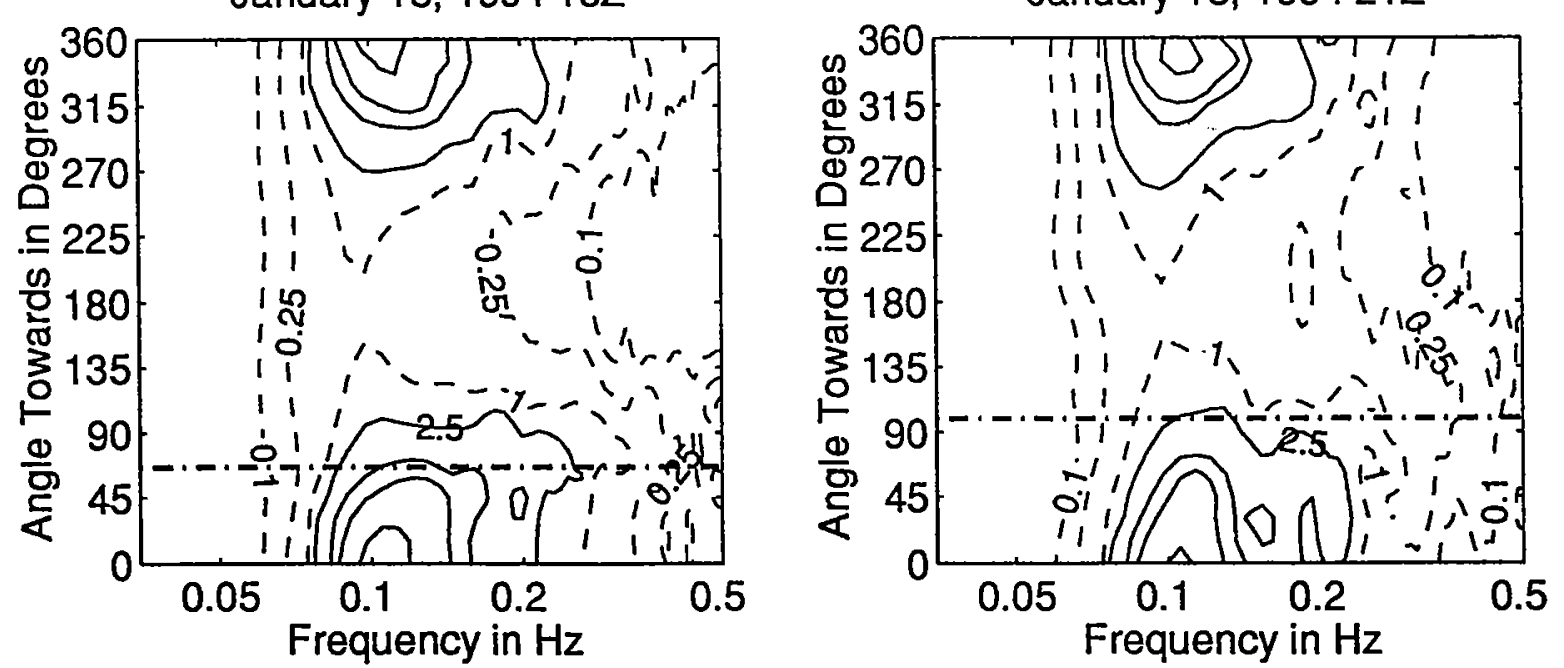

Figure 3.4.57: Directional wave spectra, computed using maximum entropy method. Contours of spectral density as a function of direction. Contours are 0.1, $0.25,1$ (dashed), $2.5,10,25,100$, and 250 (solid). Wind direction is shown by
thick dashed line. 

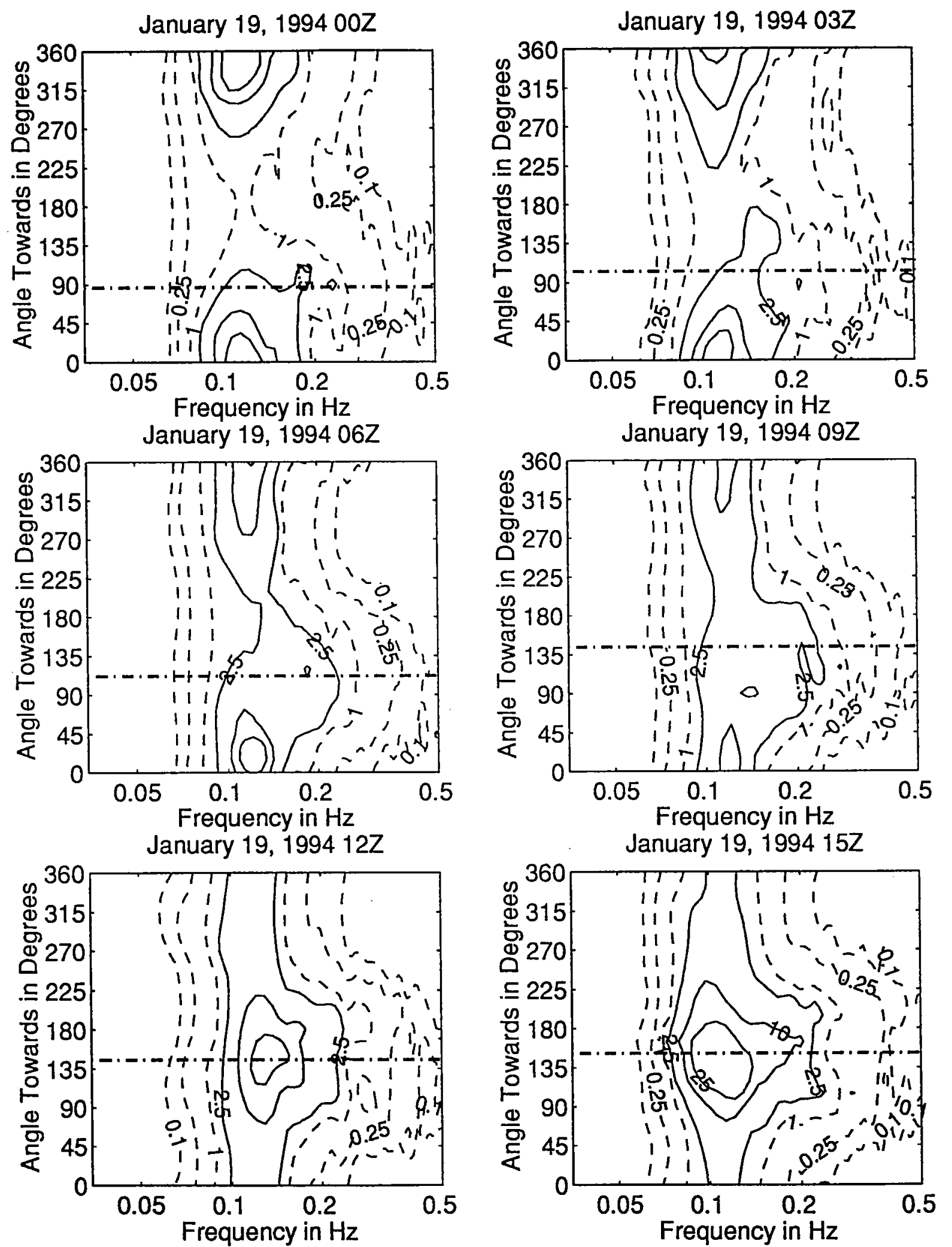

Figure 3.4.58: Directional wave spectra, computed using maximum entropy method. Contours of spectral density as a function of direction. Contours are 0.1 , $0.25,1$ (dashed), $2.5,10,25,100$, and 250 (solid). Wind direction is shown by thick dashed line. 

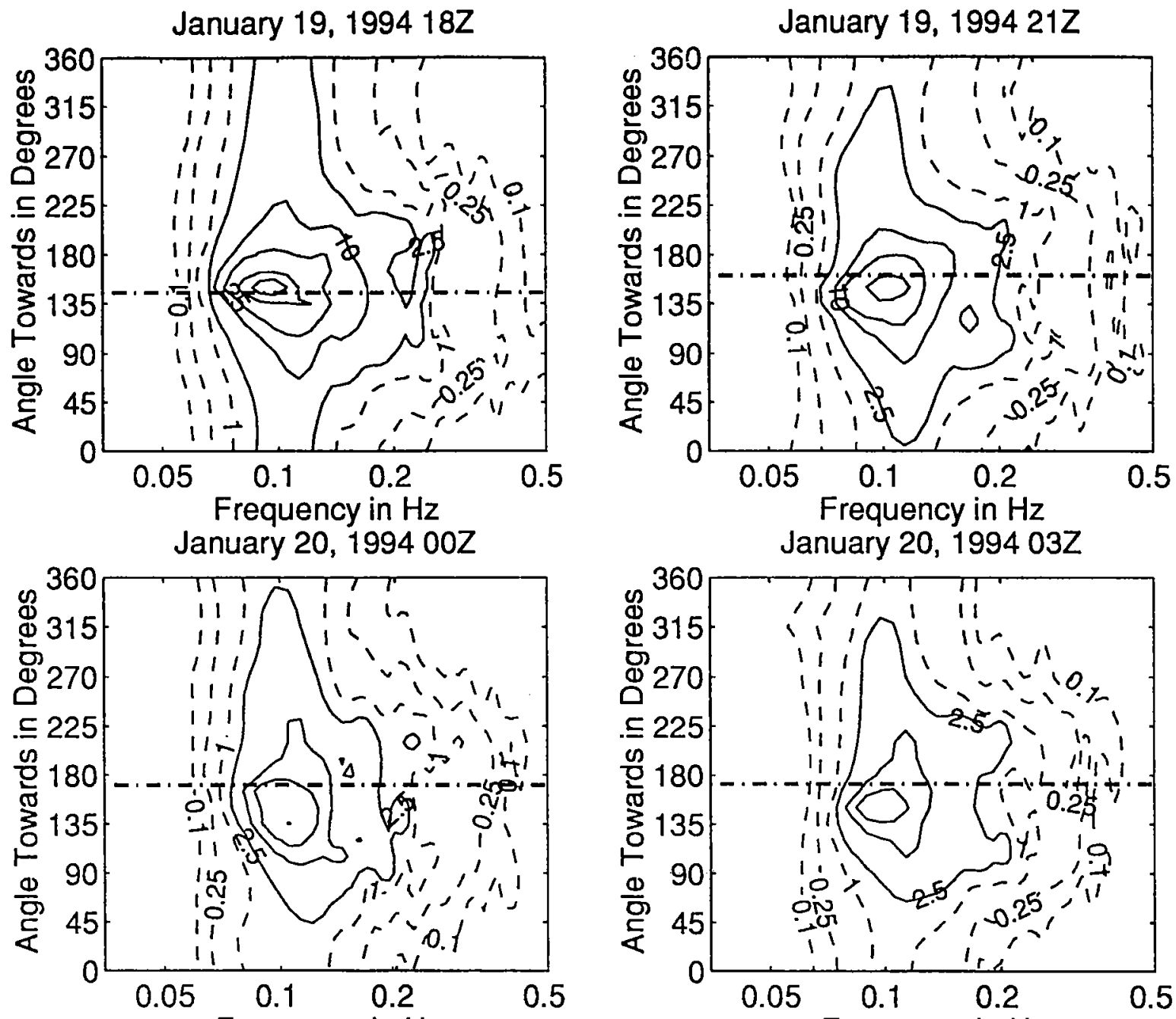

Frequency in $\mathrm{Hz}$

January 20, $199406 Z$
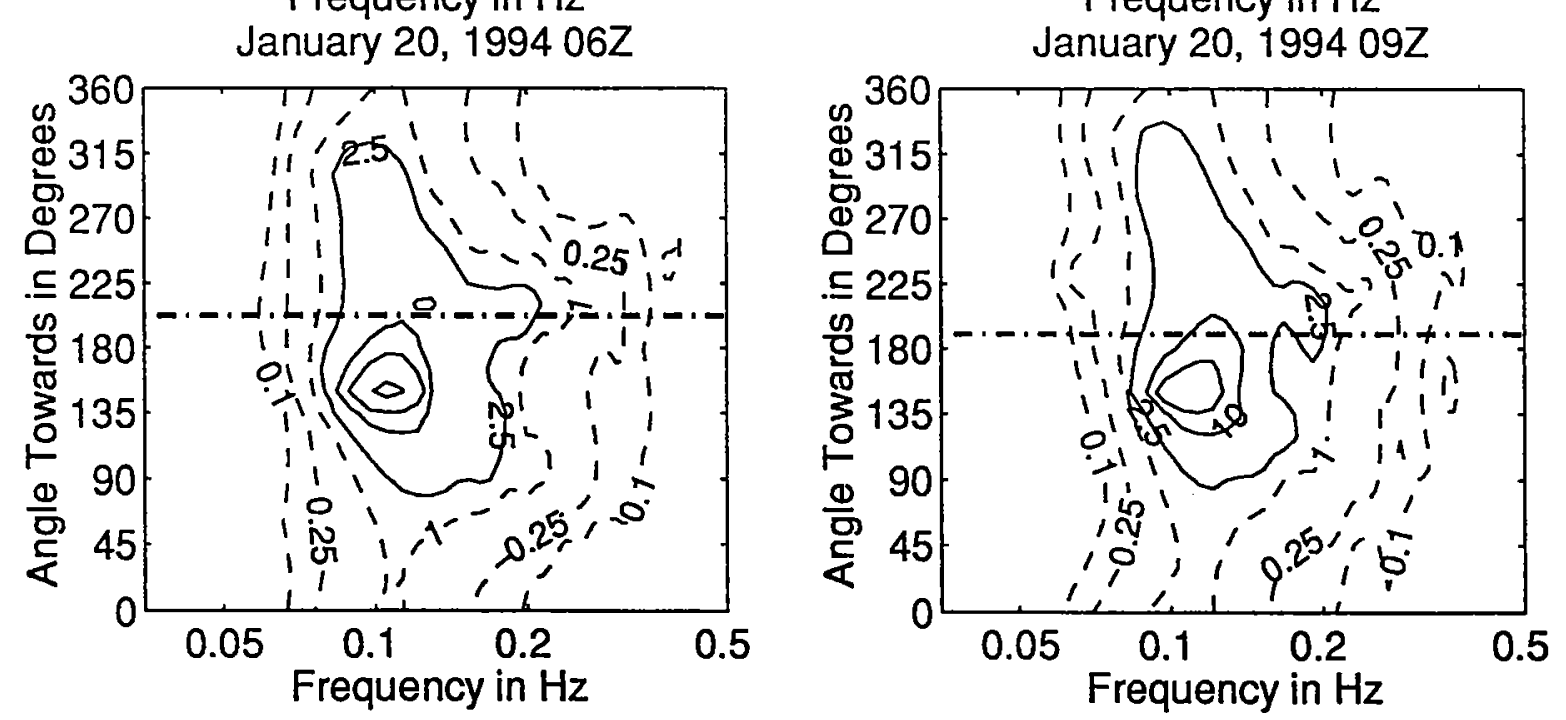

Figure 3.4.59: Directional wave spectra, computed using maximum entropy method. Contours of spectral density as a function of direction. Contours are 0.1, $0.25,1$ (dashed), $2.5,10,25,100$, and 250 (solid). Wind direction is shown by thick dashed line. 

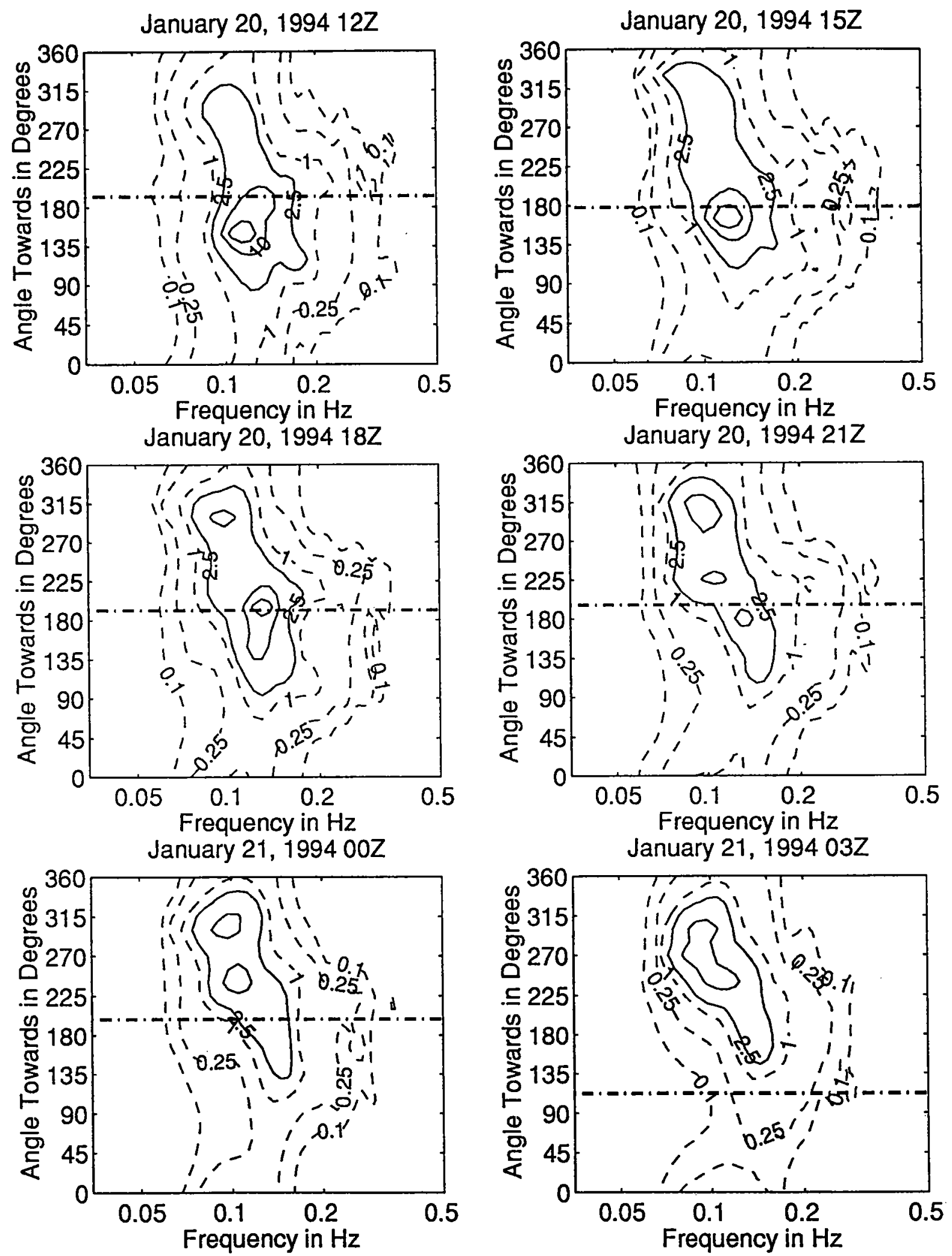

Figure 3.4.60: Directional wave spectra, computed using maximum entropy method. Contours of spectral density as a function of direction. Contours are 0.1 , $0.25,1$ (dashed), $2.5,10,25,100$, and 250 (solid). Wind direction is shown by thick dashed line. 

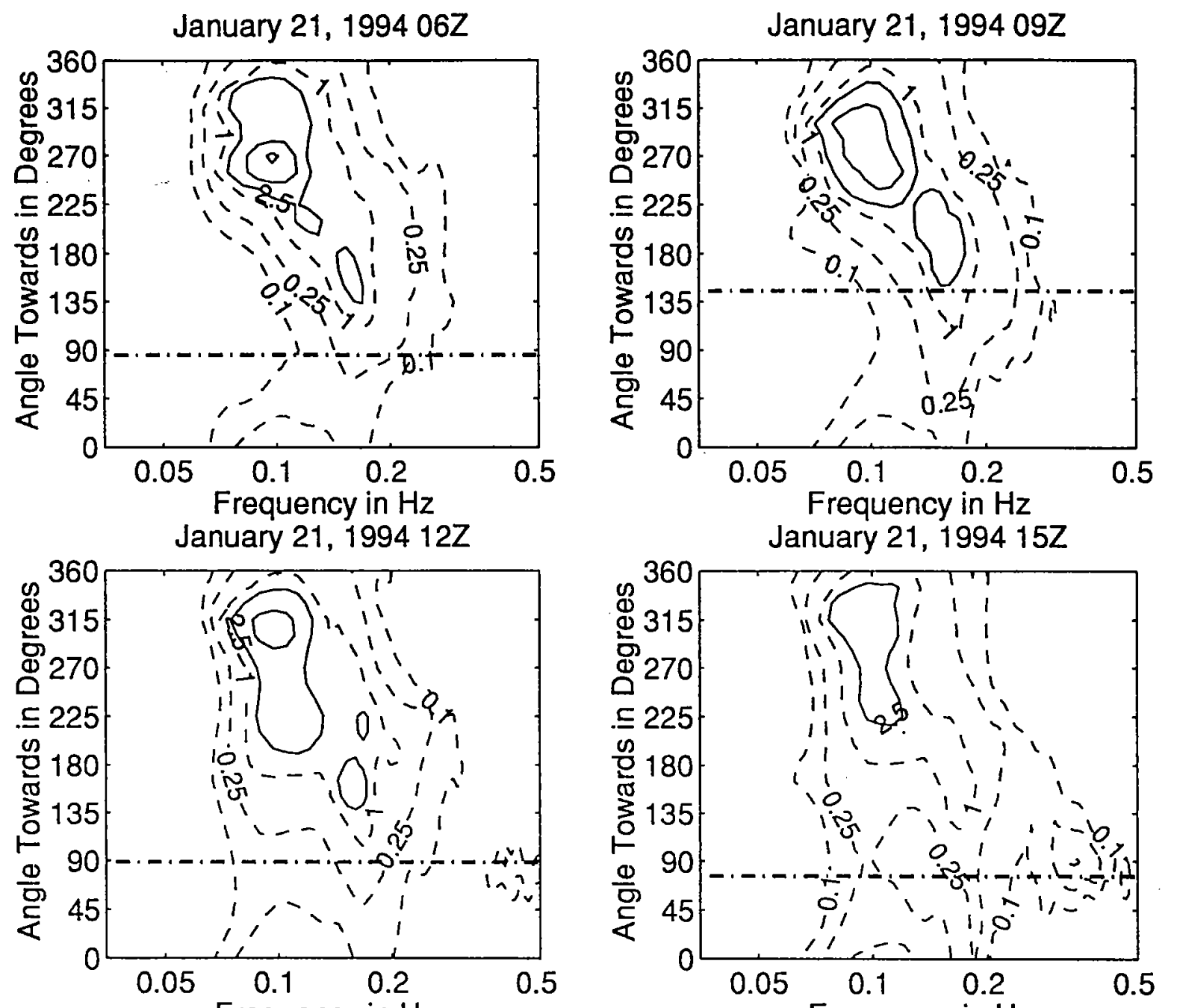

Frequency in $\mathrm{Hz}$

January 21, $199418 Z$
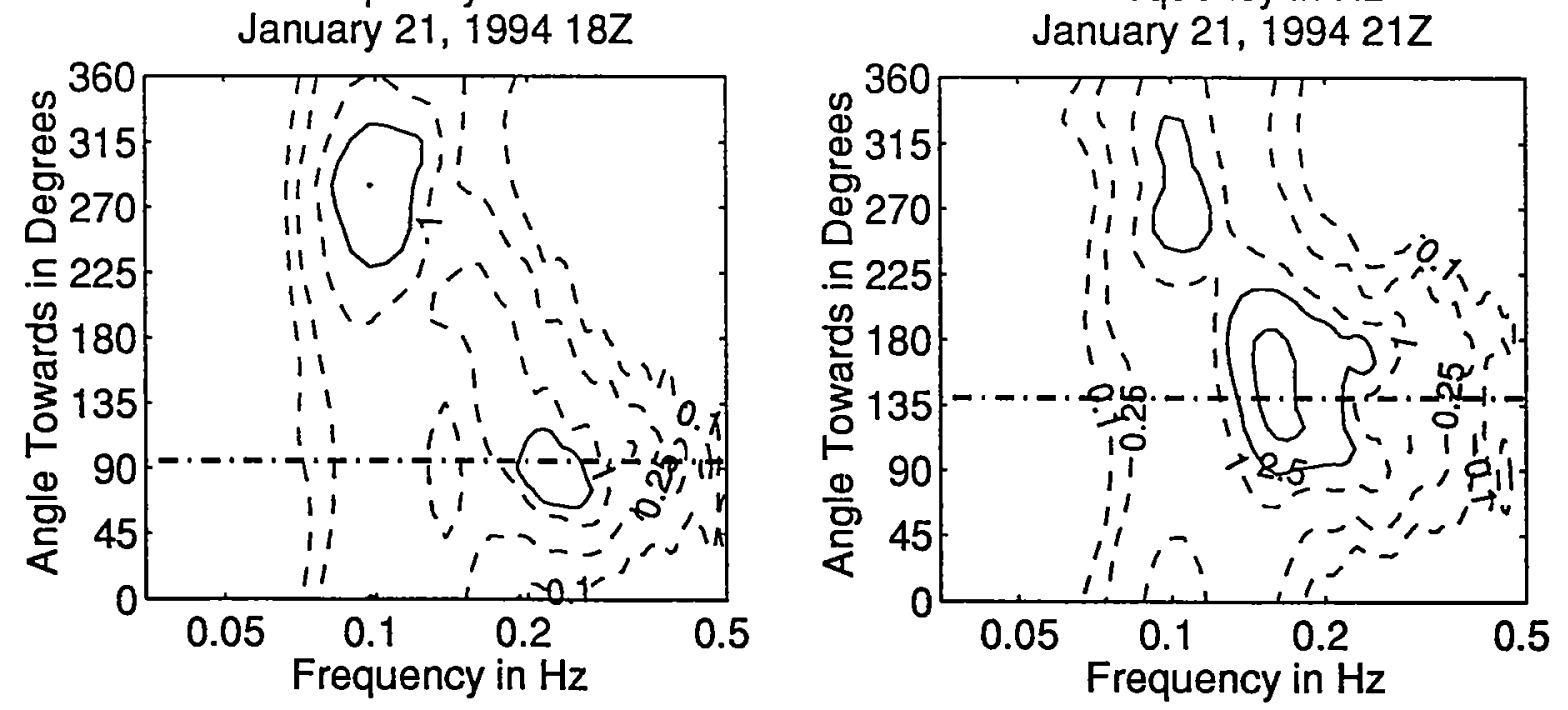

Figure 3.4.61: Directional wave spectra, computed using maximum entropy method. Contours of spectral density as a function of direction. Contours are 0.1, $0.25,1$ (dashed), $2.5,10,25,100$, and 250 (solid). Wind direction is shown by
thick dashed line. 

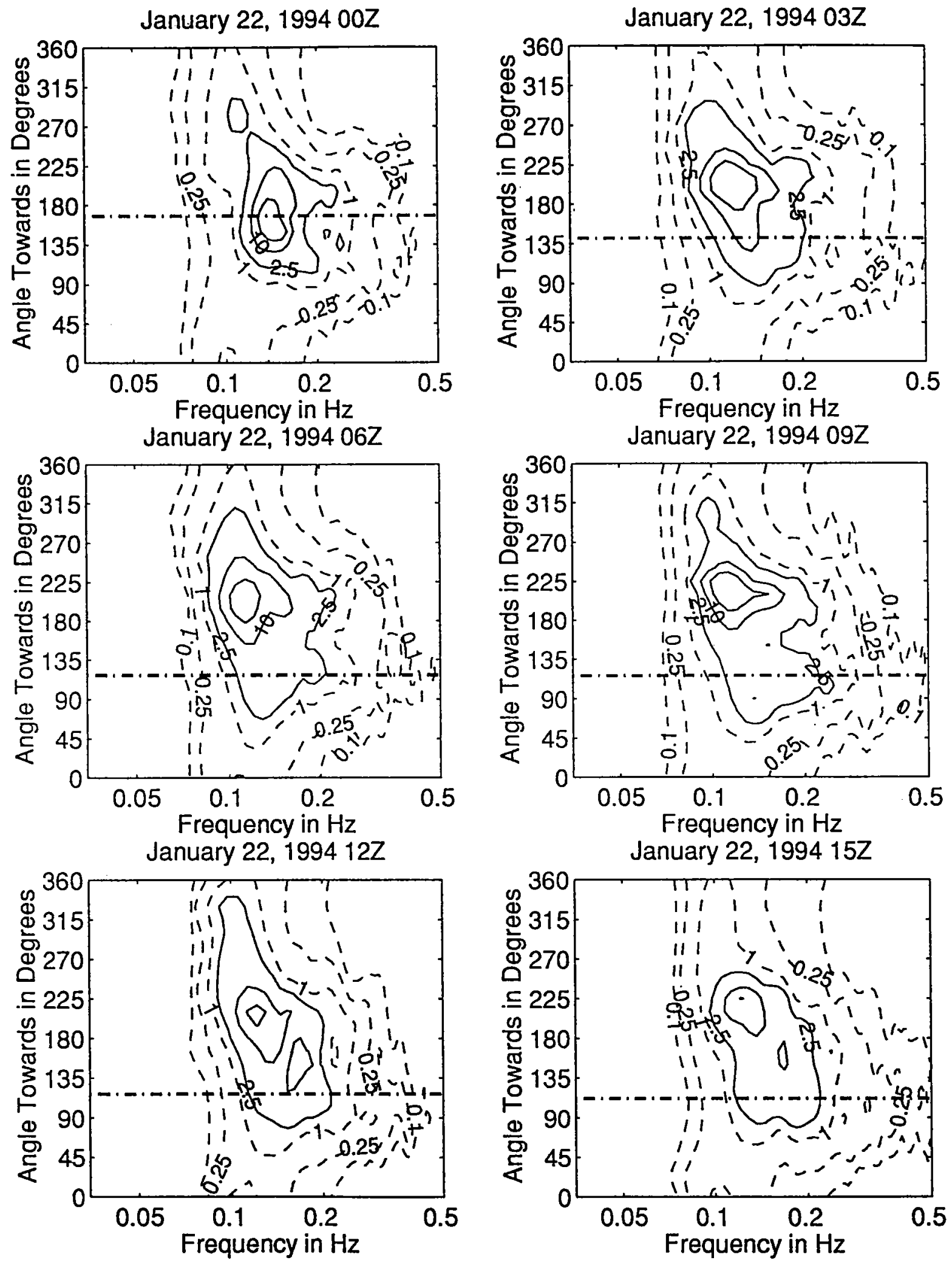

Figure 3.4.62: Directional wave spectra, computed using maximum entropy method. Contours of spectral density as a function of direction. Contours are 0.1, $0.25,1$ (dashed), $2.5,10,25,100$, and 250 (solid). Wind direction is shown by
thick dashed line. 
January 22, $199418 Z$

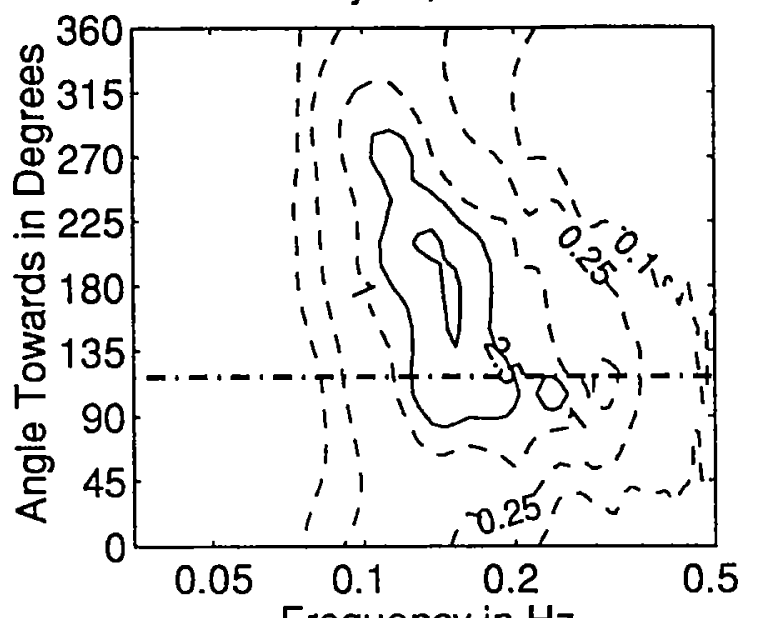

Frequency in $\mathrm{Hz}$ January 23, $199400 Z$

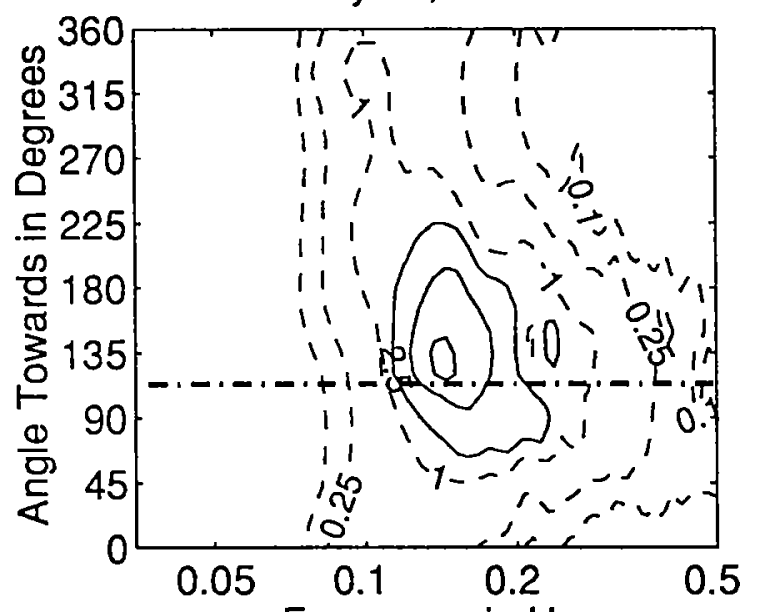

Frequency in $\mathrm{Hz}$ January 23, $199406 Z$

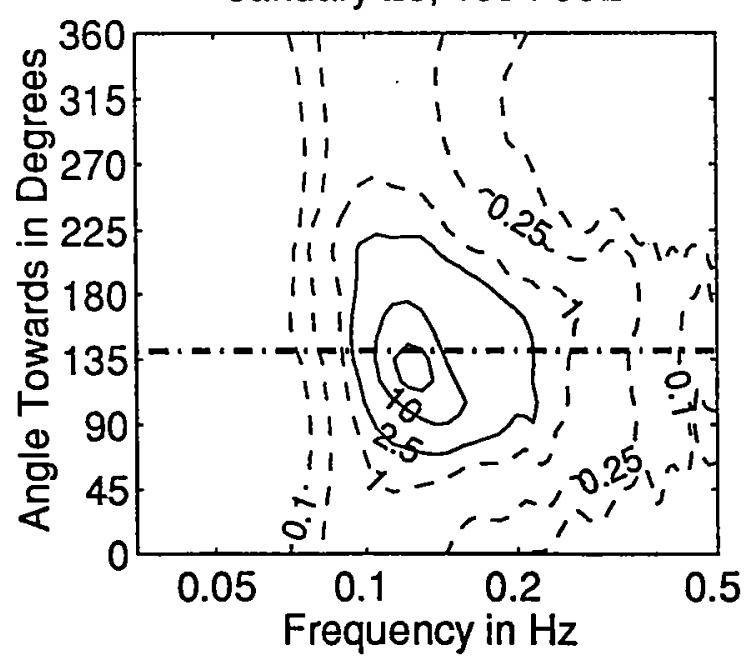

January 22, $199421 Z$

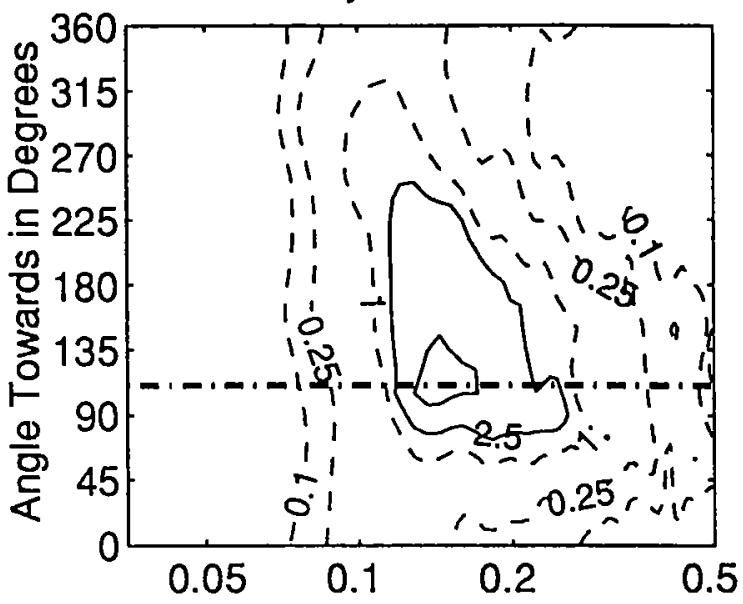

Frequency in $\mathrm{Hz}$ January 23, 1994032

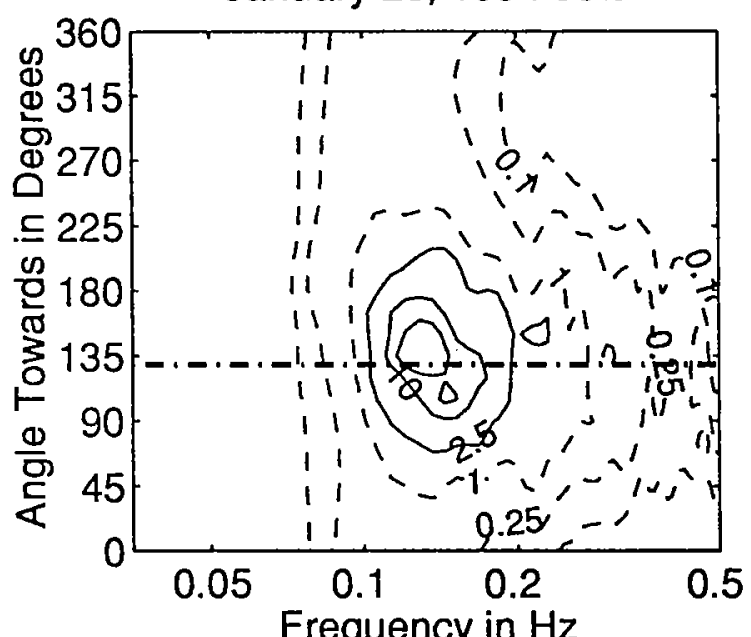

Frequency in $\mathrm{Hz}$ January 23, $199409 Z$

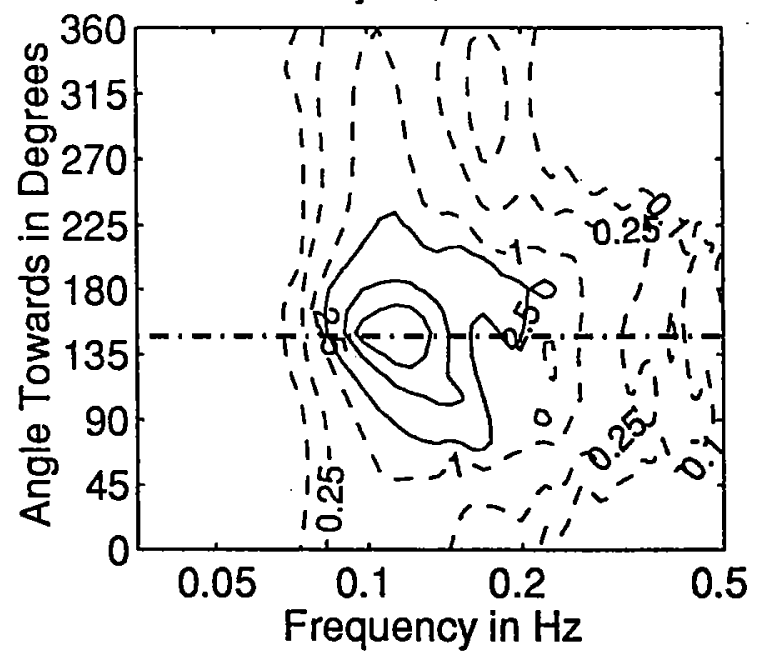

Figure 3.4.63: Directional wave spectra, computed using maximum entropy method. Contours of spectral density as a function of direction. Contours are 0.1, $0.25,1$ (dashed), $2.5,10,25,100$, and 250 (solid). Wind direction is shown by thick dashed line. 

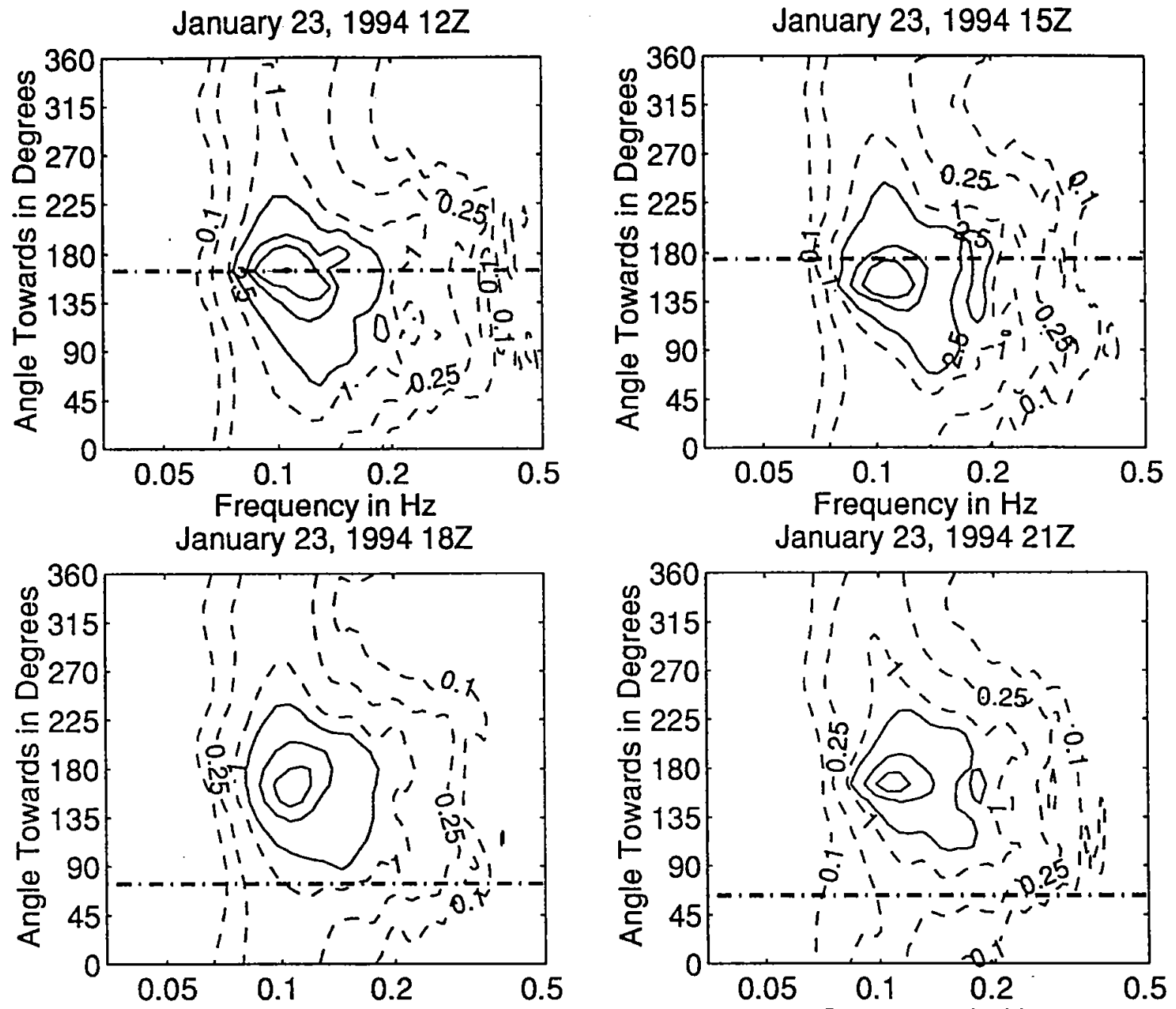

Frequency in $\mathrm{Hz}$
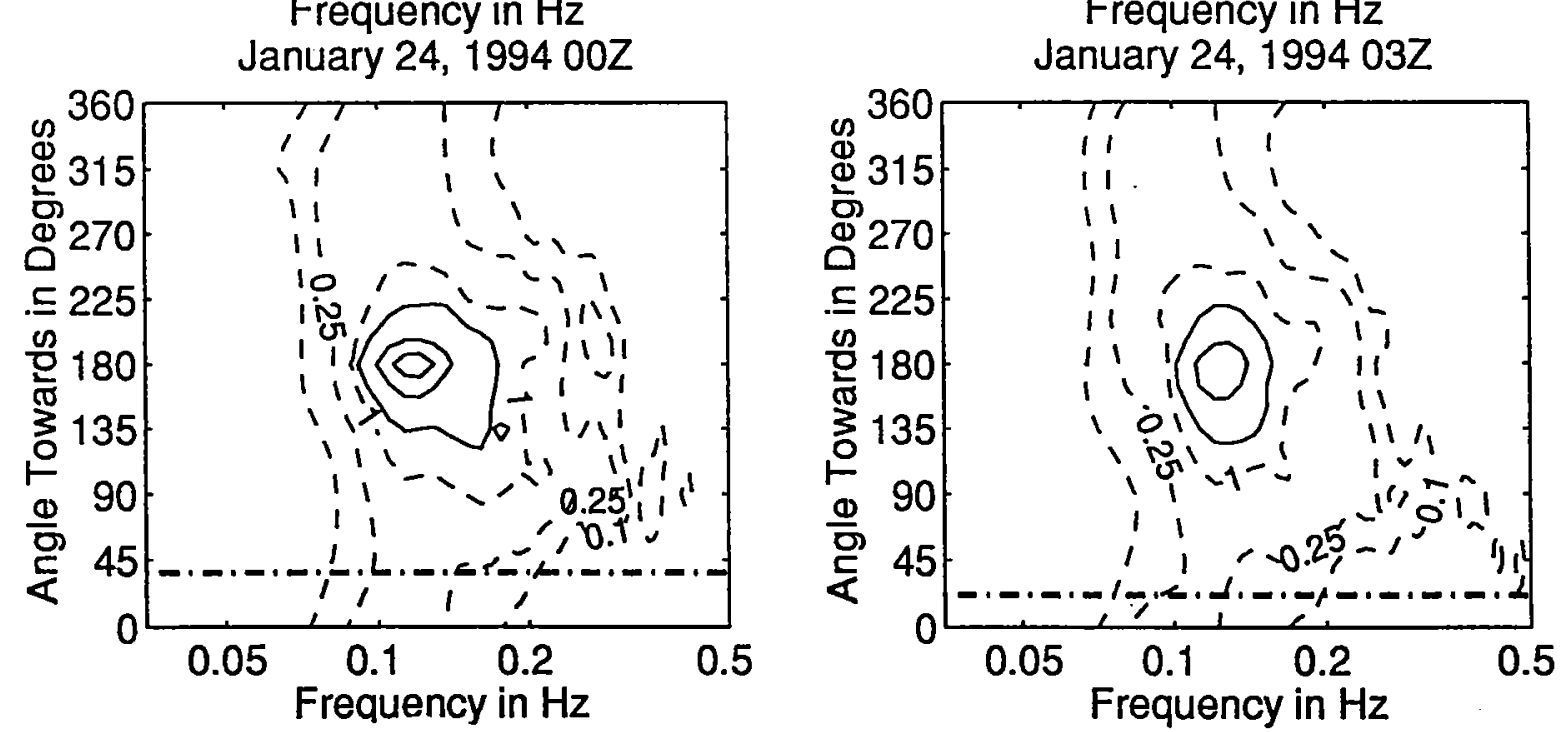

Figure 3.4.64: Directional wave spectra, computed using maximum entropy method. Contours of spectral density as a function of direction. Contours are 0.1, $0.25,1$ (dashed), $2.5,10,25,100$, and 250 (solid). Wind direction is shown by thick dashed line. 

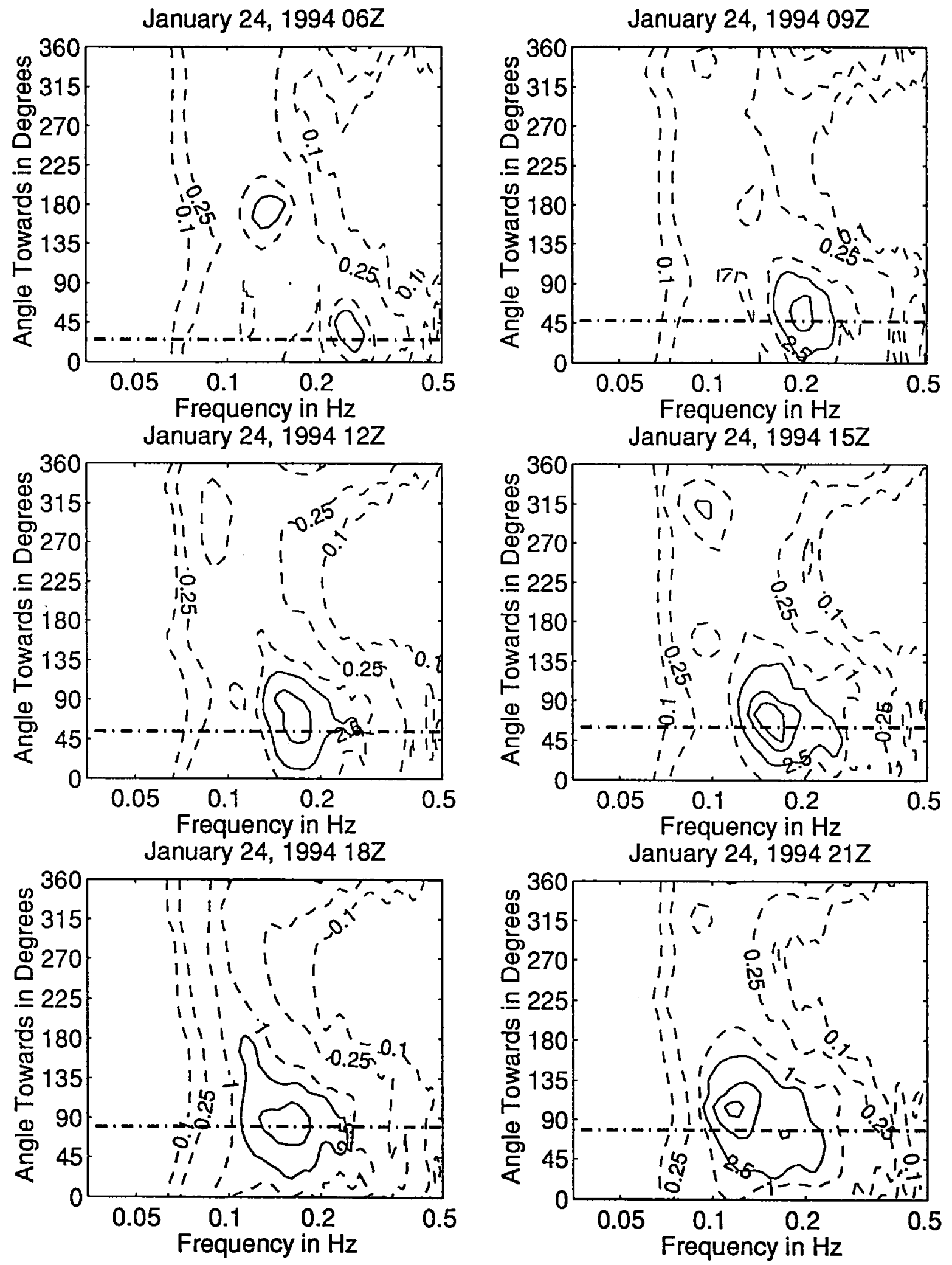

Figure 3.4.65: Directional wave spectra, computed using maximum entropy method. Contours of spectral density as a function of direction. Contours are $\mathbf{0 . 1}$, $0.25,1$ (dashed), 2.5, 10,25, 100, and 250 (solid). Wind direction is shown by thick dashed line. 

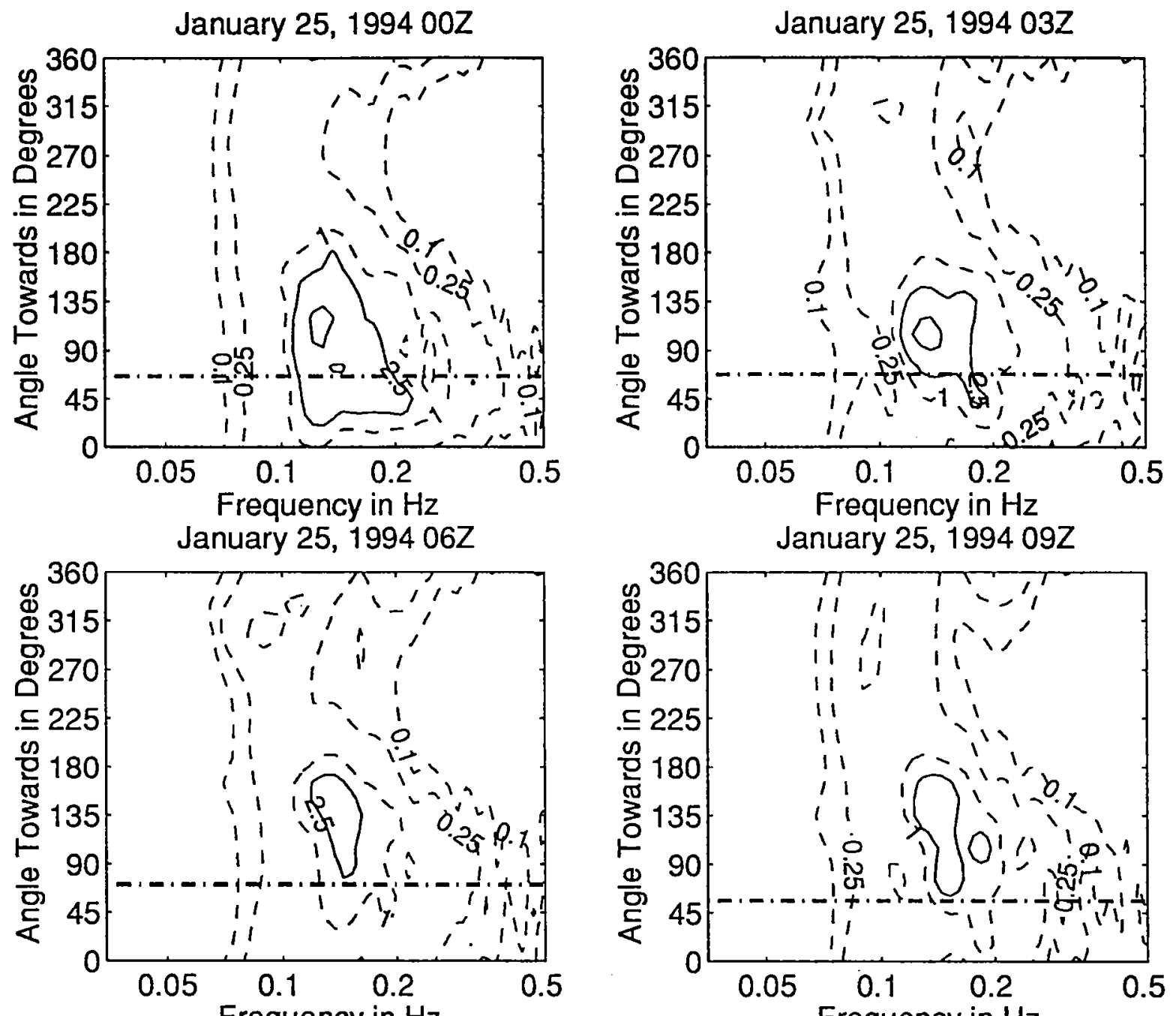

Frequency in $\mathrm{Hz}$

January 25, $199412 Z$

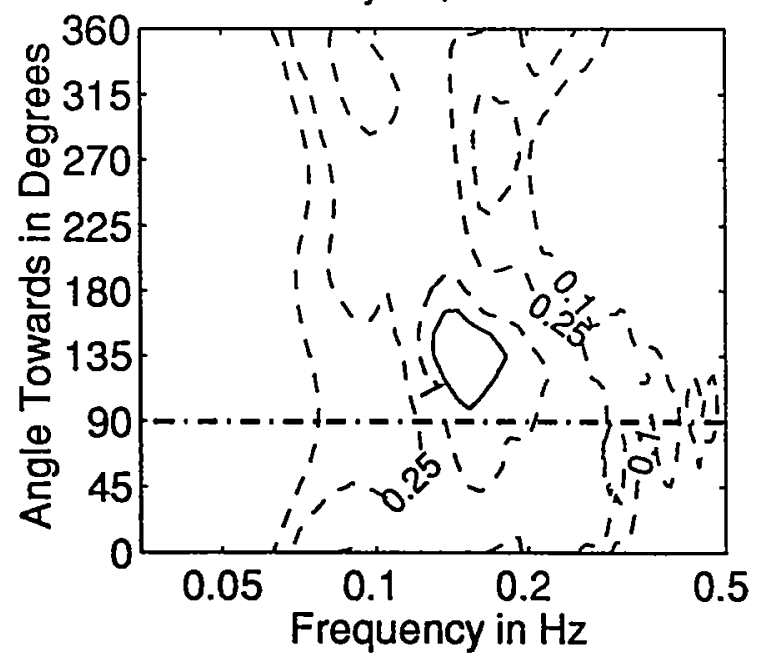

Frequency in $\mathrm{Hz}$

January 25, $199415 Z$

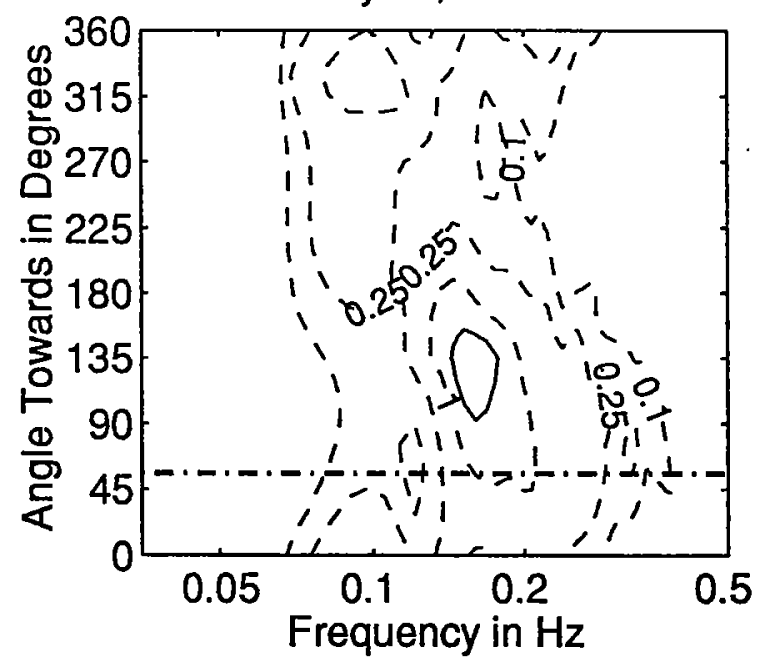

Figure 3.4.66: Directional wave spectra, computed using maximum entropy method. Contours of spectral density as a function of direction. Contours are 0.1 , $0.25,1$ (dashed), $2.5,10,25,100$, and 250 (solid). Wind direction is shown by thick dashed line. 

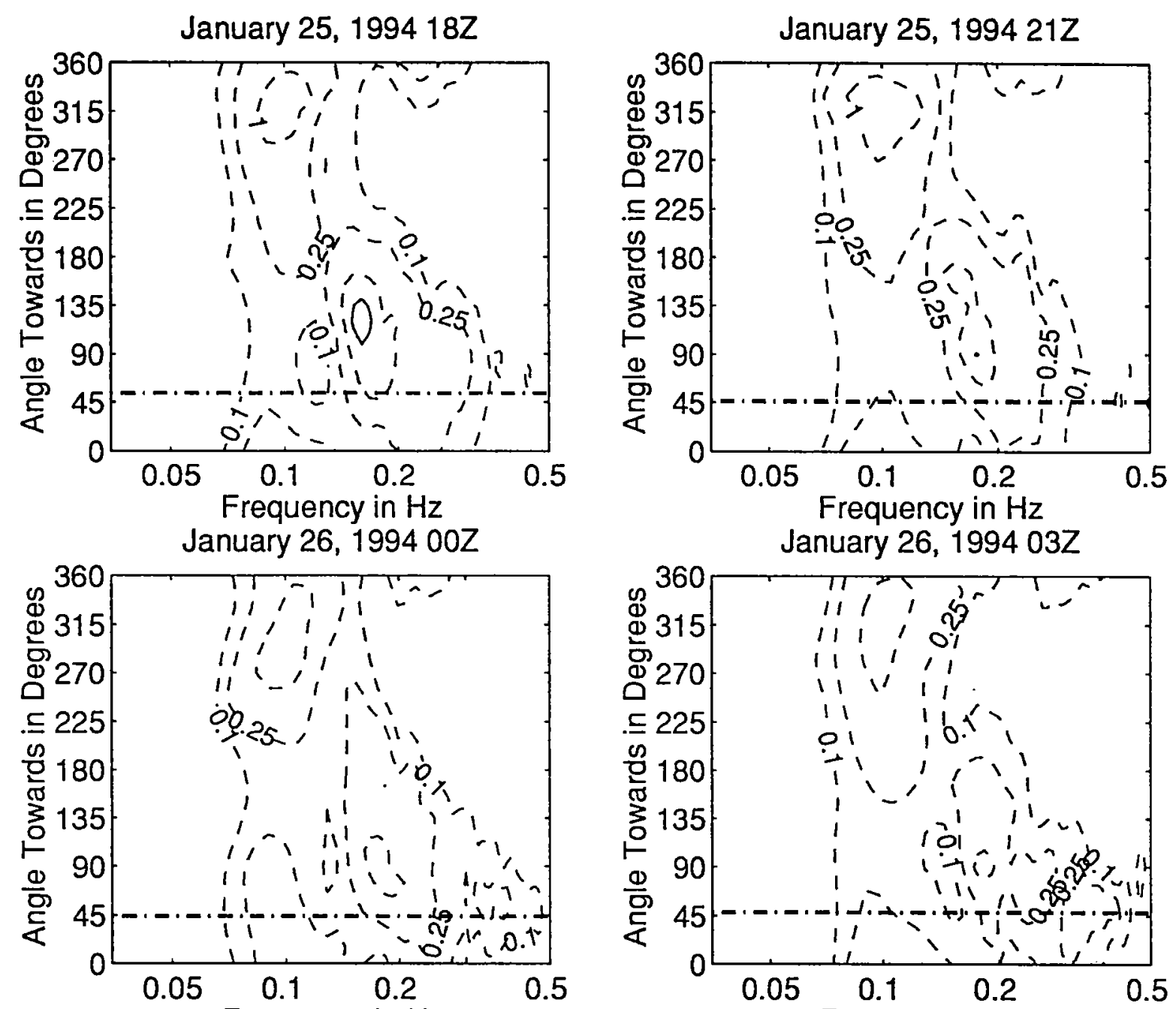

Frequency in $\mathrm{Hz}$
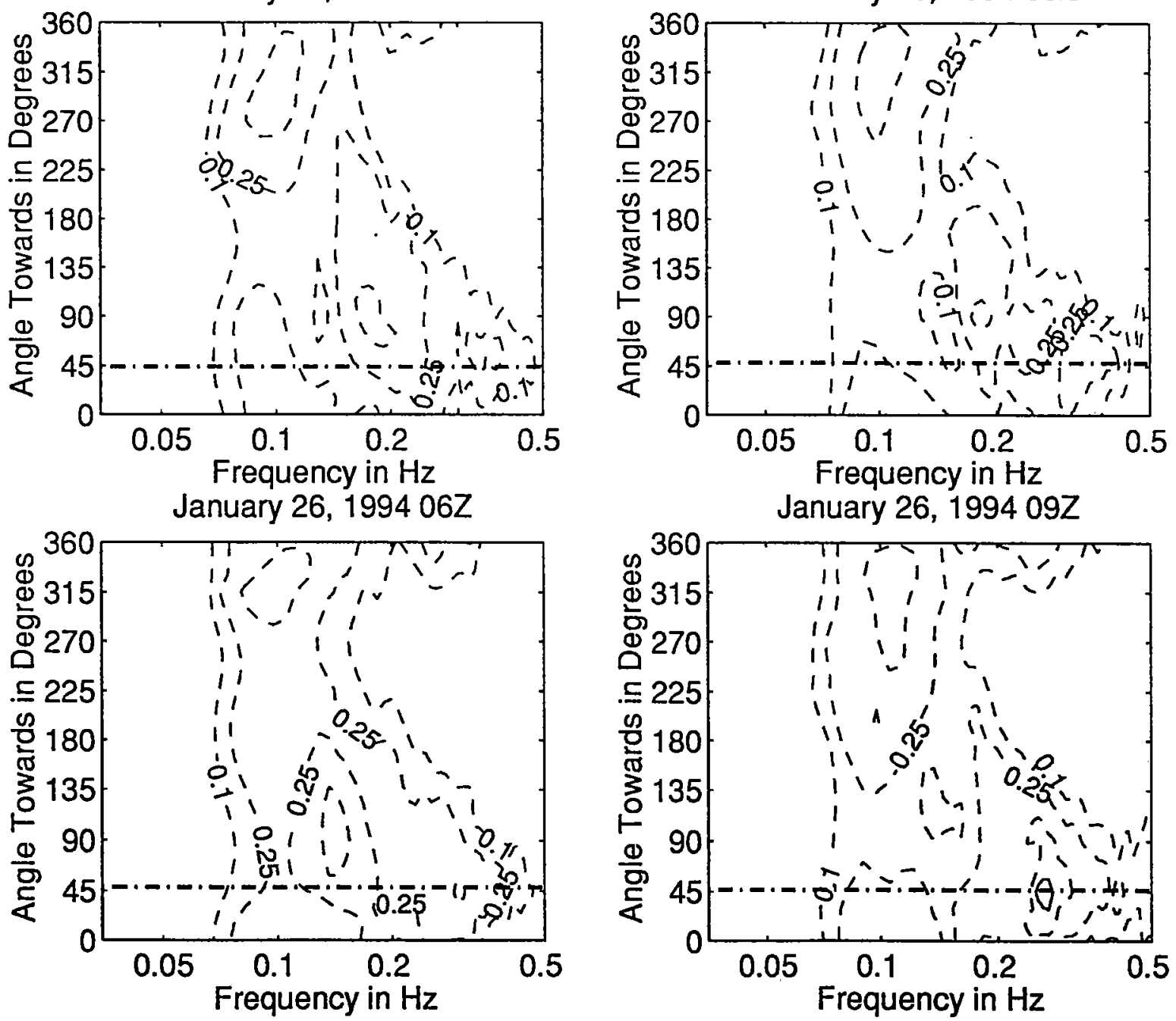

Frequency in $\mathrm{Hz}$

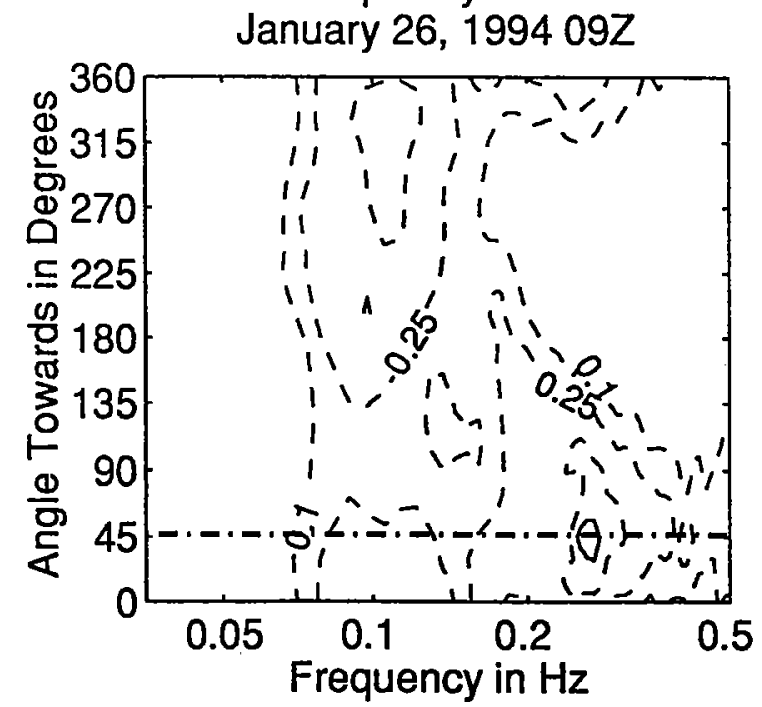

Figure 3.4.67: Directional wave spectra, computed using maximum entropy method. Contours of spectral density as a function of direction. Contours are 0.1 , $0.25,1$ (dashed), $2.5,10,25,100$, and 250 (solid). Wind direction is shown by thick dashed line. 

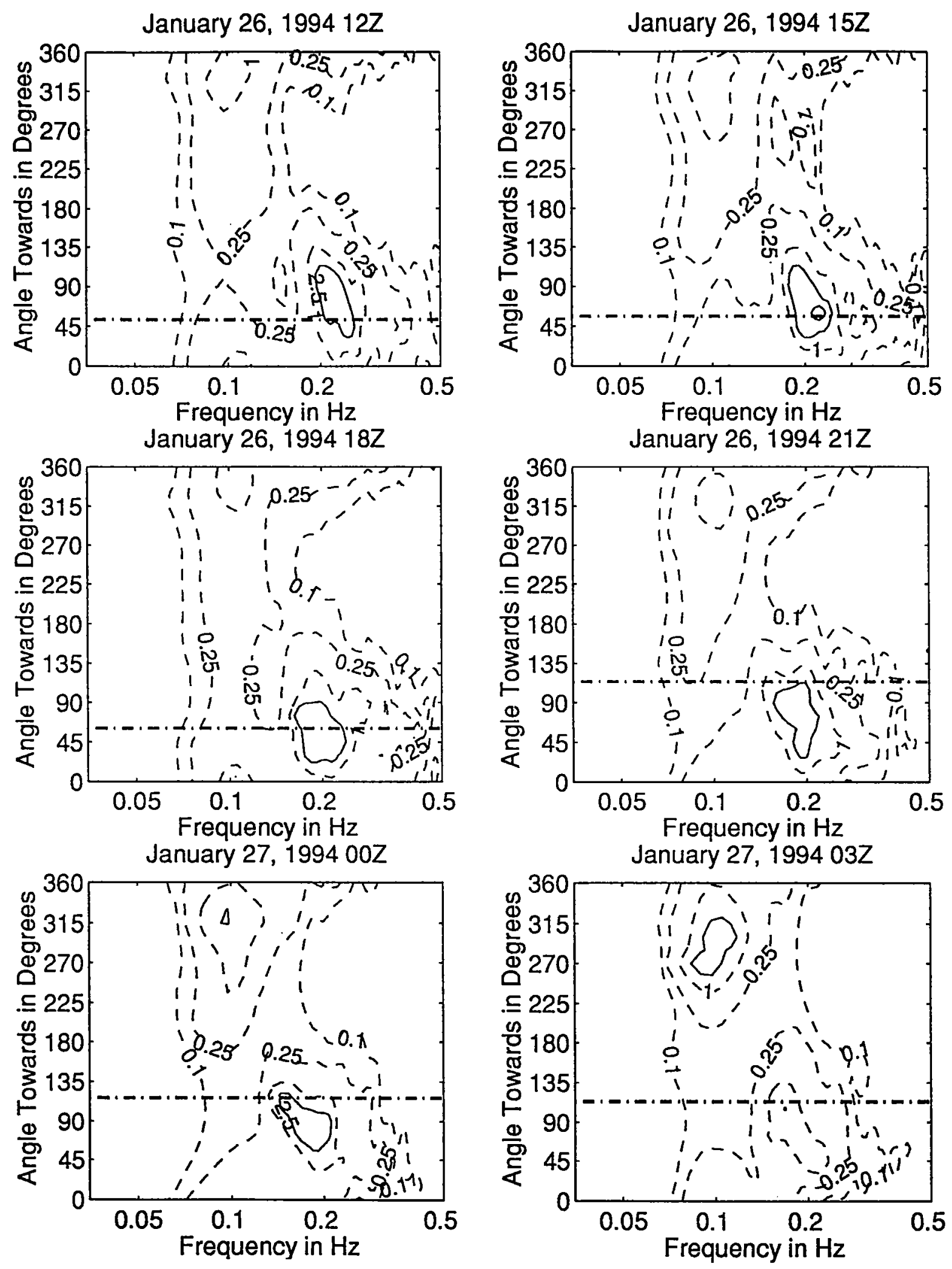

Figure 3.4.68: Directional wave spectra, computed using maximum entropy method. Contours of spectral density as a function of direction. Contours are 0.1, $0.25,1$ (dashed), $2.5,10,25,100$, and 250 (solid). Wind direction is shown by thick dashed line. 

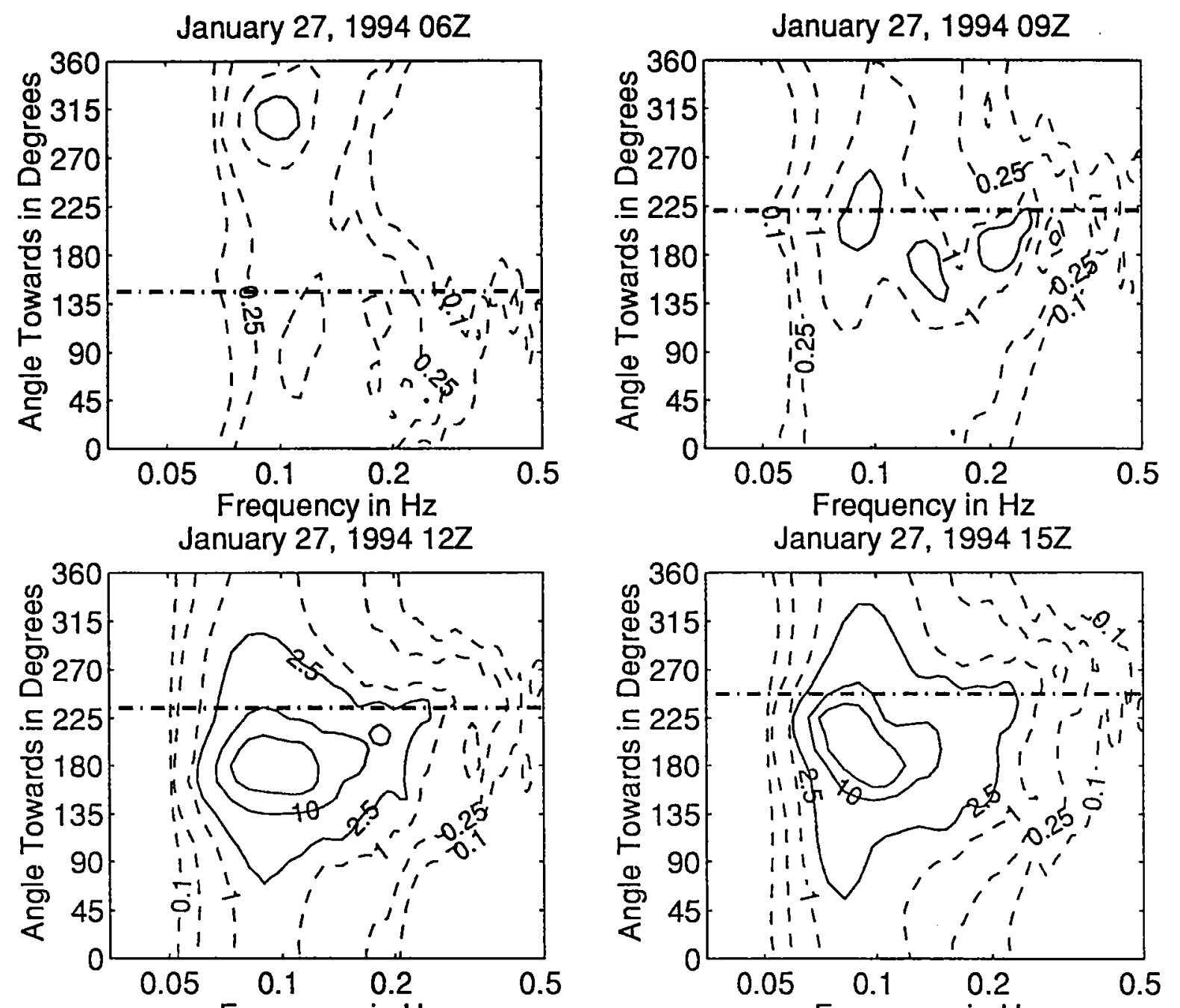

Frequency in $\mathrm{Hz}$ January 27, $199418 Z$
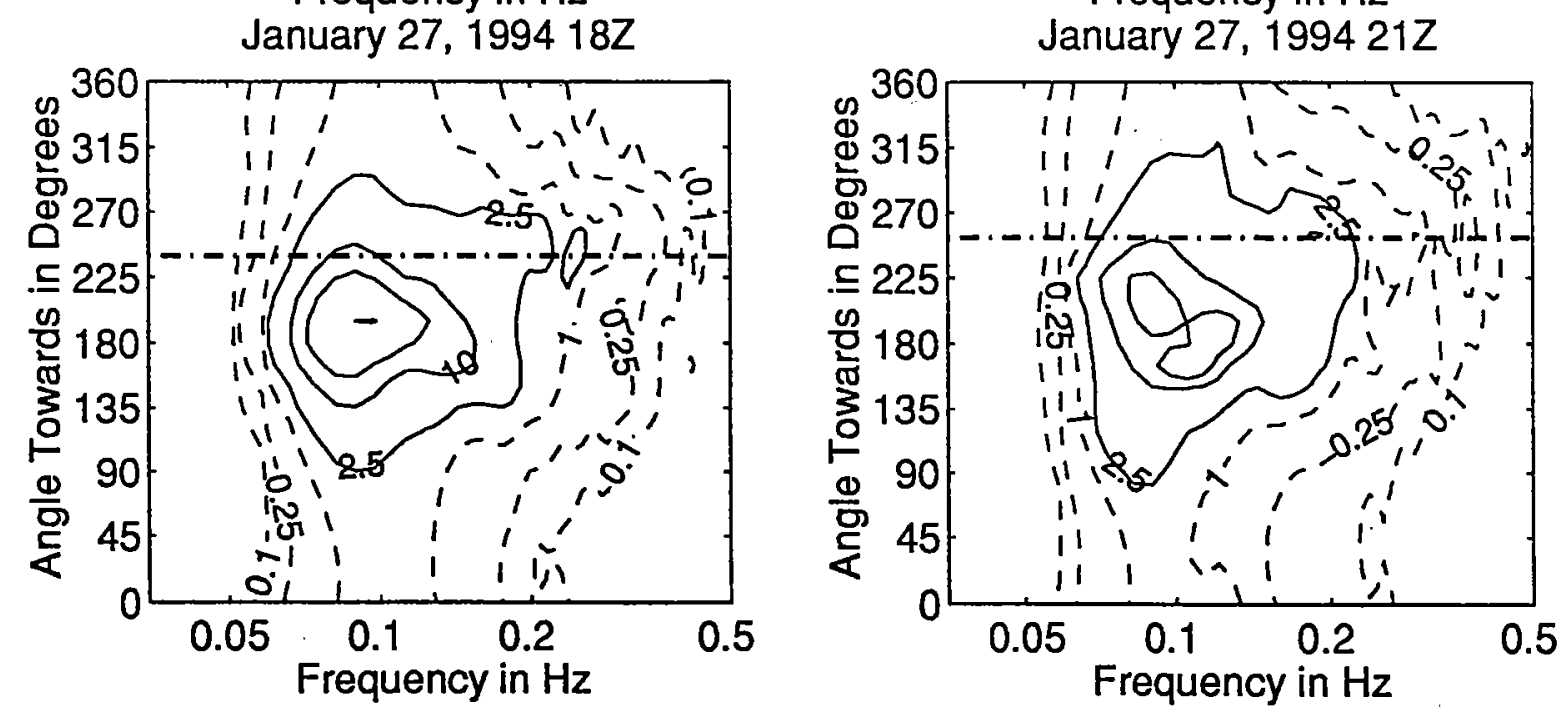

Figure 3.4.69: Directional wave spectra, computed using maximum entropy method. Contours of spectral density as a function of direction. Contours are 0.1 , $0.25,1$ (dashed), $2.5,10,25,100$, and 250 (solid). Wind direction is shown by thick dashed line. 

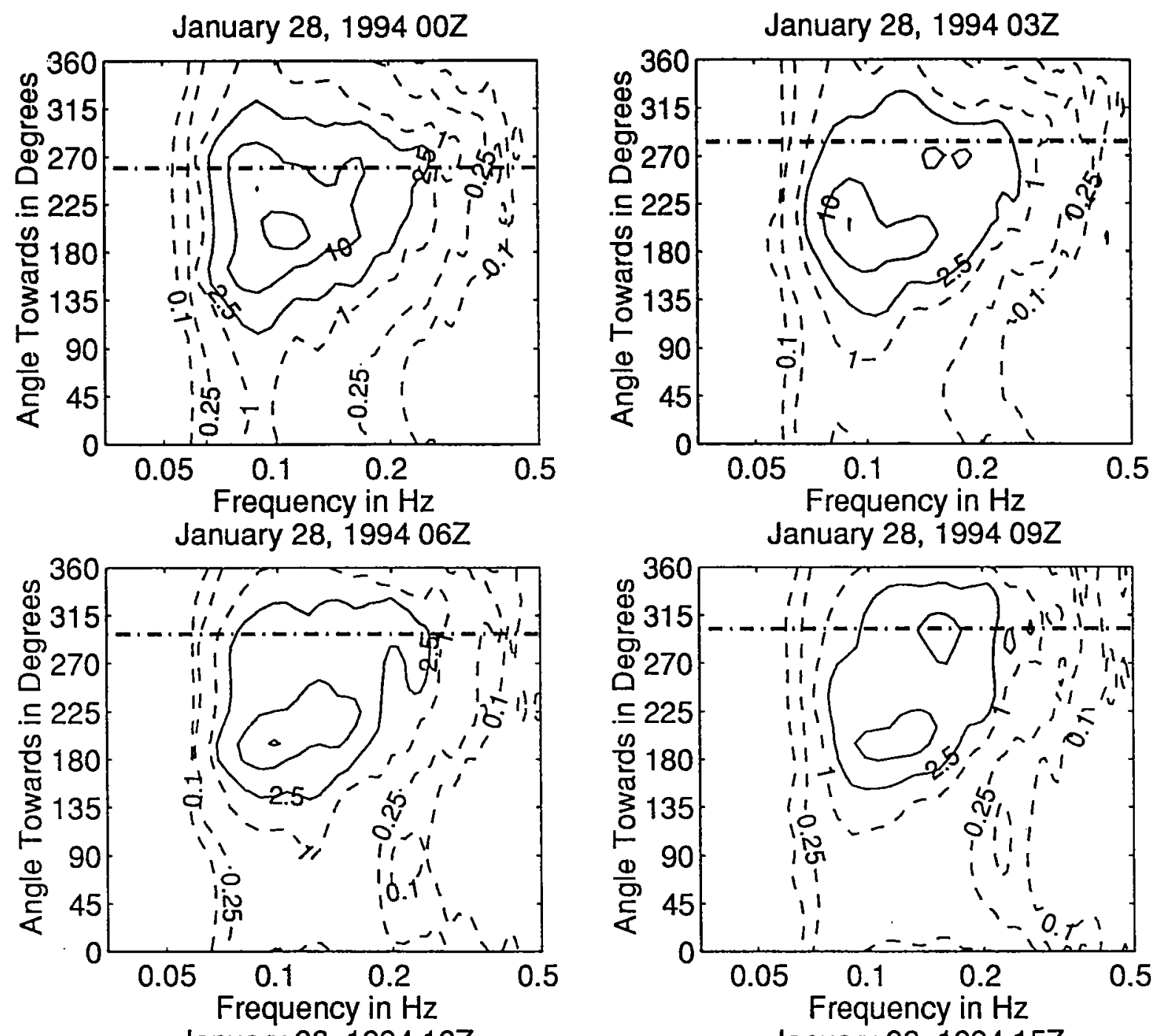

January 28, $199412 Z$
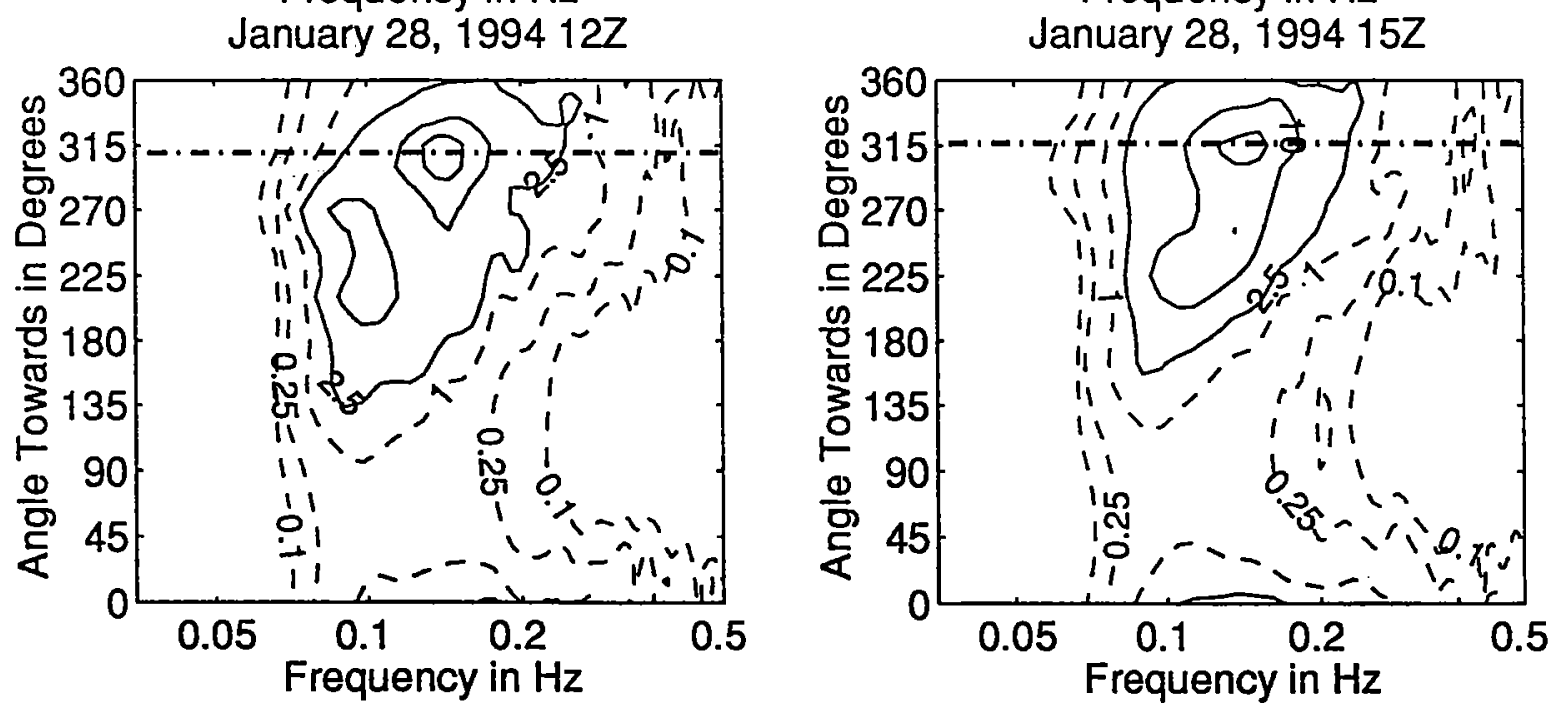

Figure 3.4.70: Directional wave spectra, computed using maximum entropy method. Contours of spectral density as a function of direction. Contours are 0.1, $0.25,1$ (dashed), $2.5,10,25,100$, and 250 (solid). Wind direction is shown by thick dashed line. 

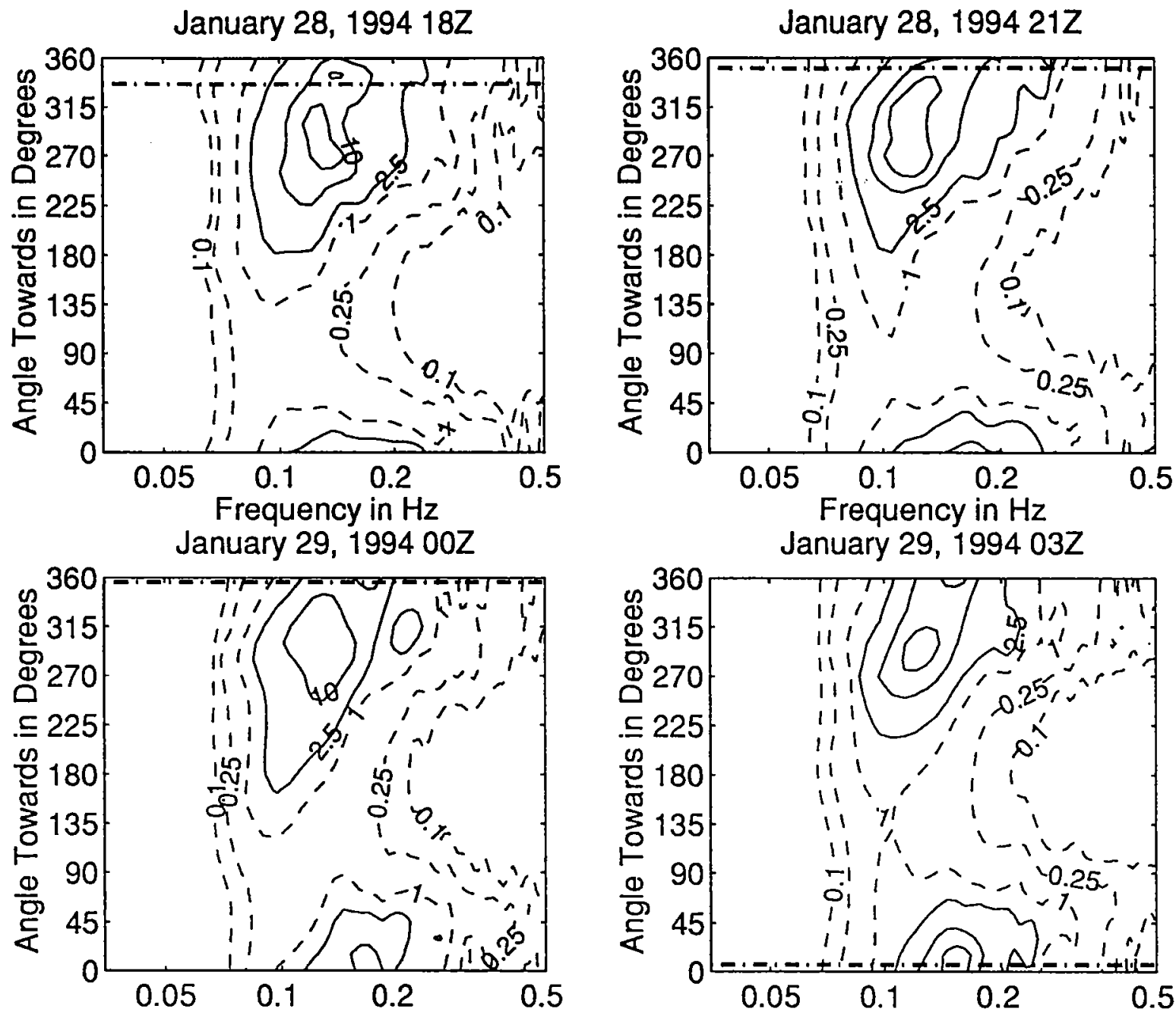

Frequency in $\mathrm{Hz}$ January 29, $199406 Z$
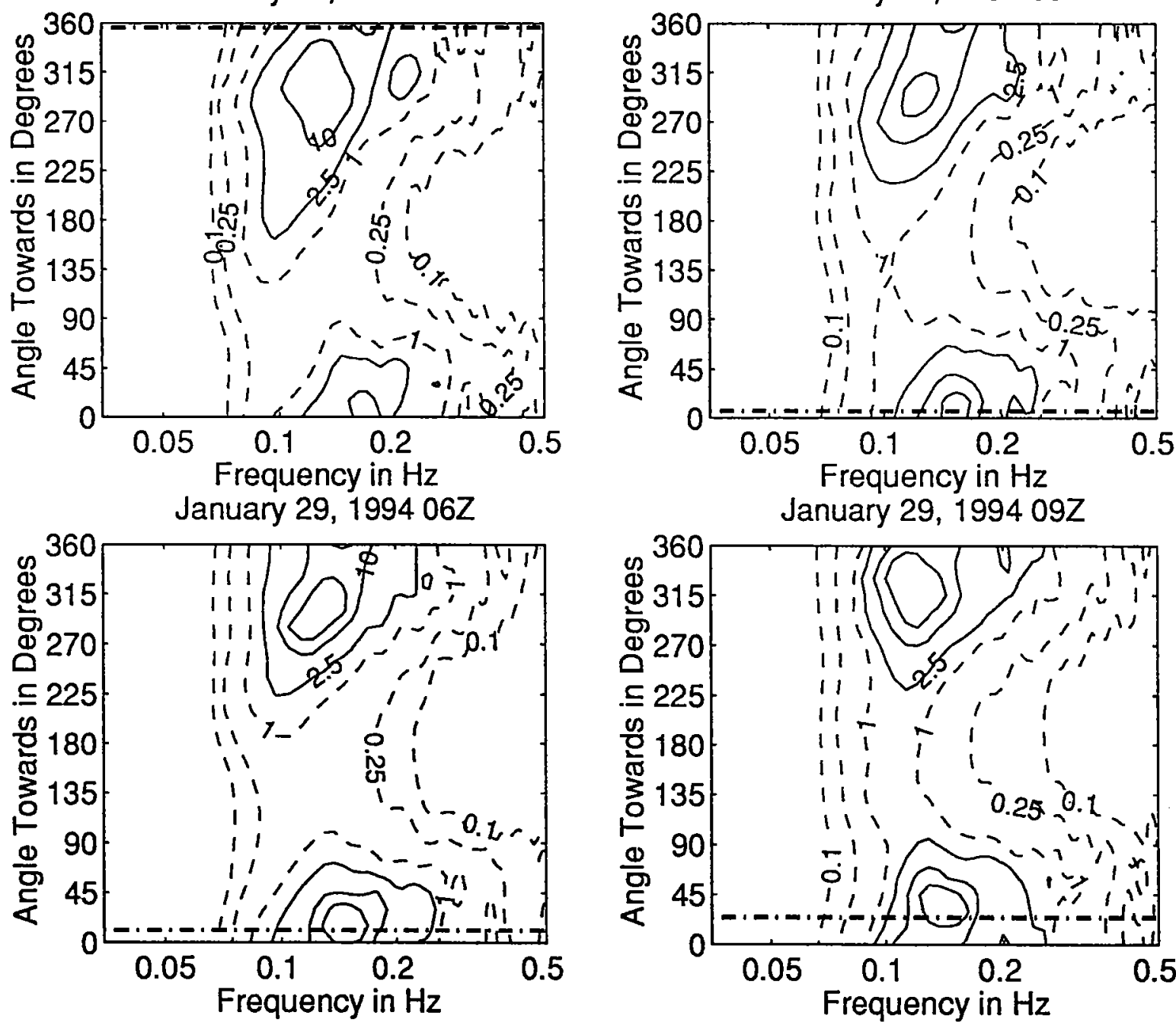

Frequency in $\mathrm{Hz}$ January 29, $199409 \mathrm{Z}$

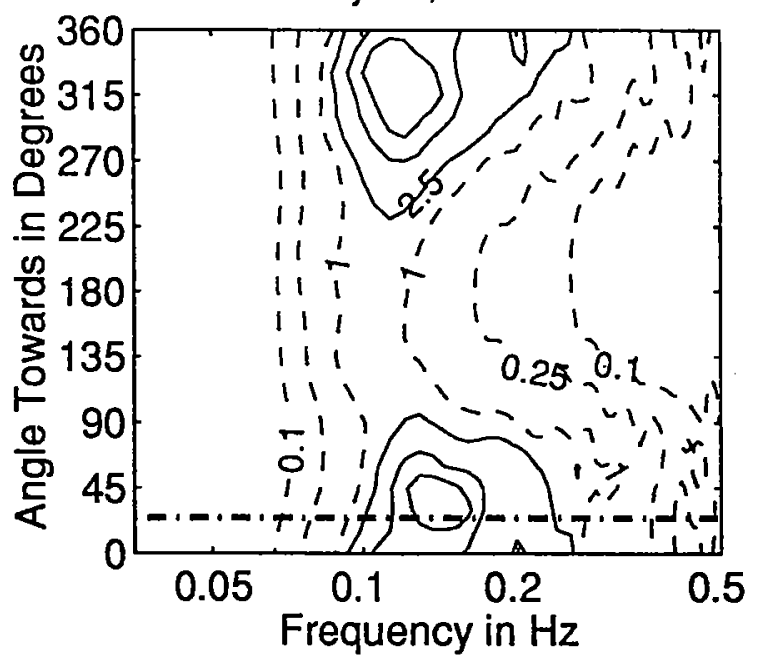

Figure 3.4.71: Directional wave spectra, computed using maximum entropy method. Contours of spectral density as a function of direction. Contours are 0.1, $0.25,1$ (dashed), 2.5, 10,25, 100, and 250 (solid). Wind direction is shown by thick dashed line. 
January 29, $199412 Z$

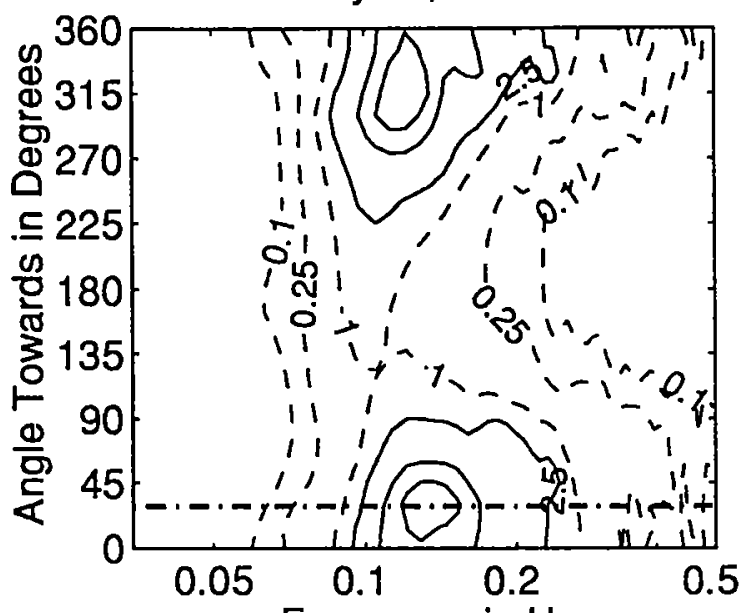

Frequency in $\mathrm{Hz}$

January 29, $199418 Z$

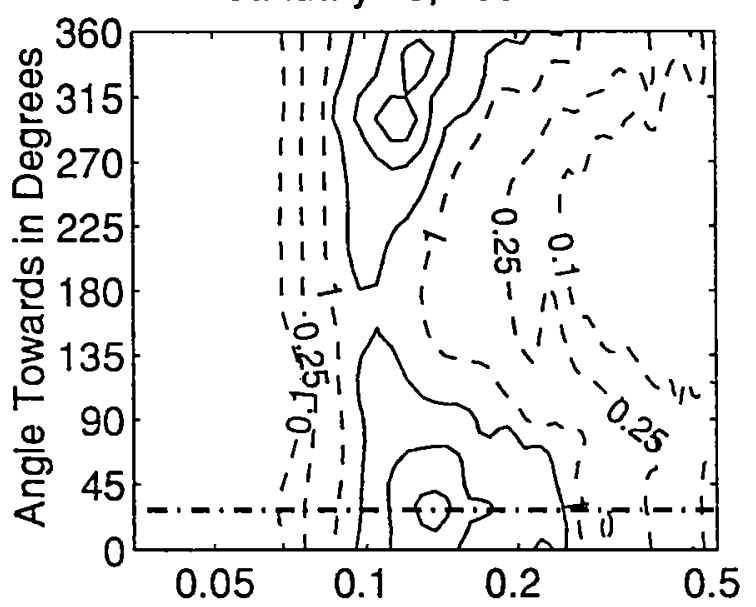

Frequency in $\mathrm{Hz}$

January 30, $199400 Z$

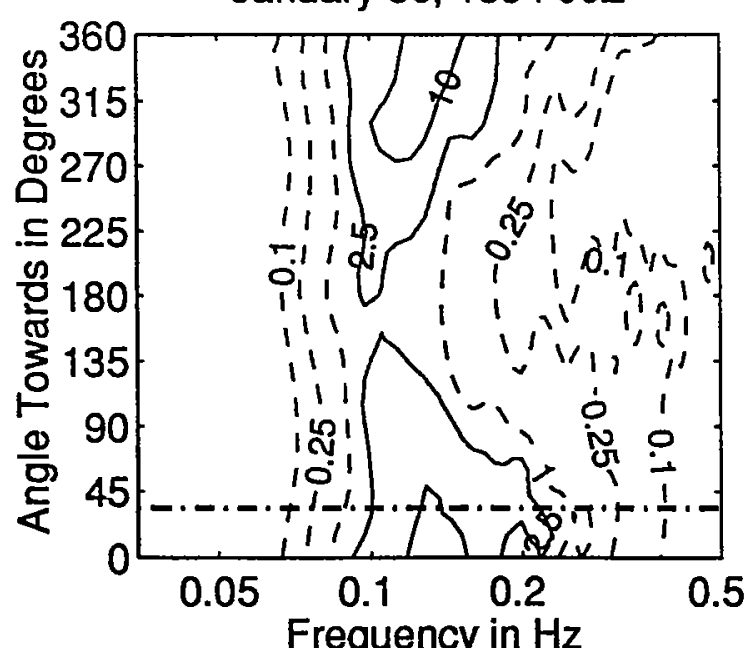

January 29, $199415 Z$

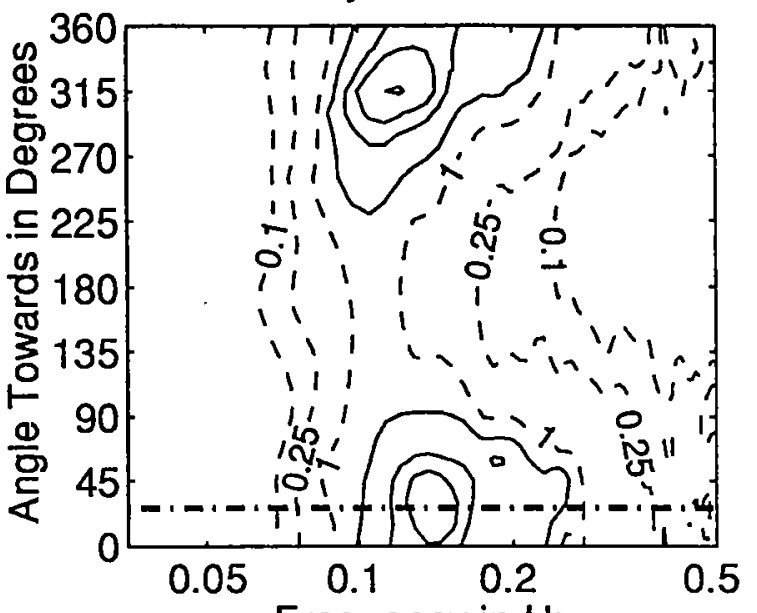

Frequency in $\mathrm{Hz}$

January 29, 1994212

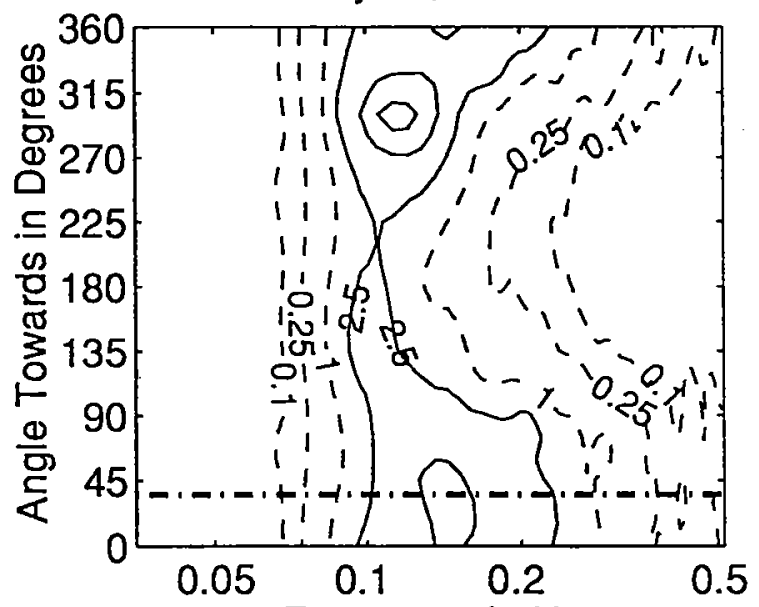

Frequency in $\mathrm{Hz}$

January 30, $199403 Z$

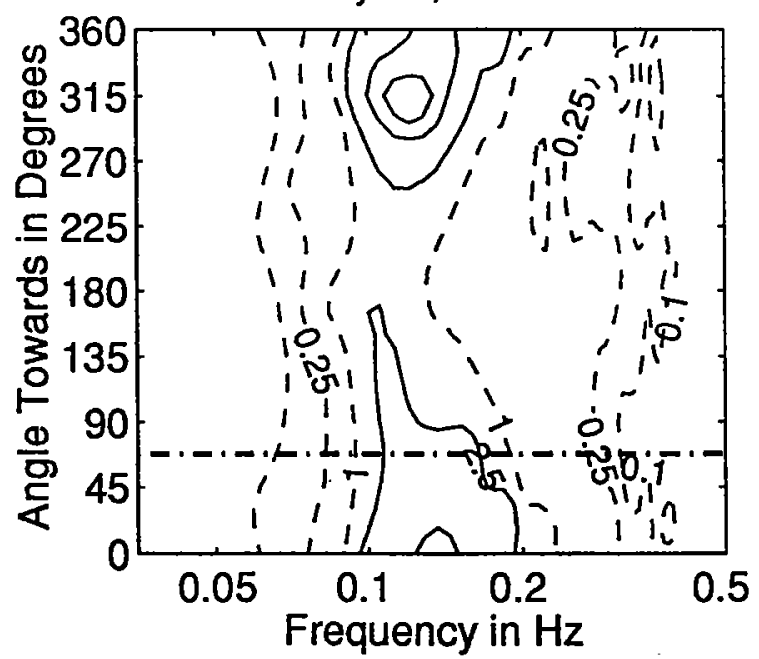

Figure 3.4.72: Directional wave spectra, computed using maximum entropy method. Contours of spectral density as a function of direction. Contours are 0.1 , $0.25,1$ (dashed), $2.5,10,25,100$, and 250 (solid). Wind direction is shown by thick dashed line. 

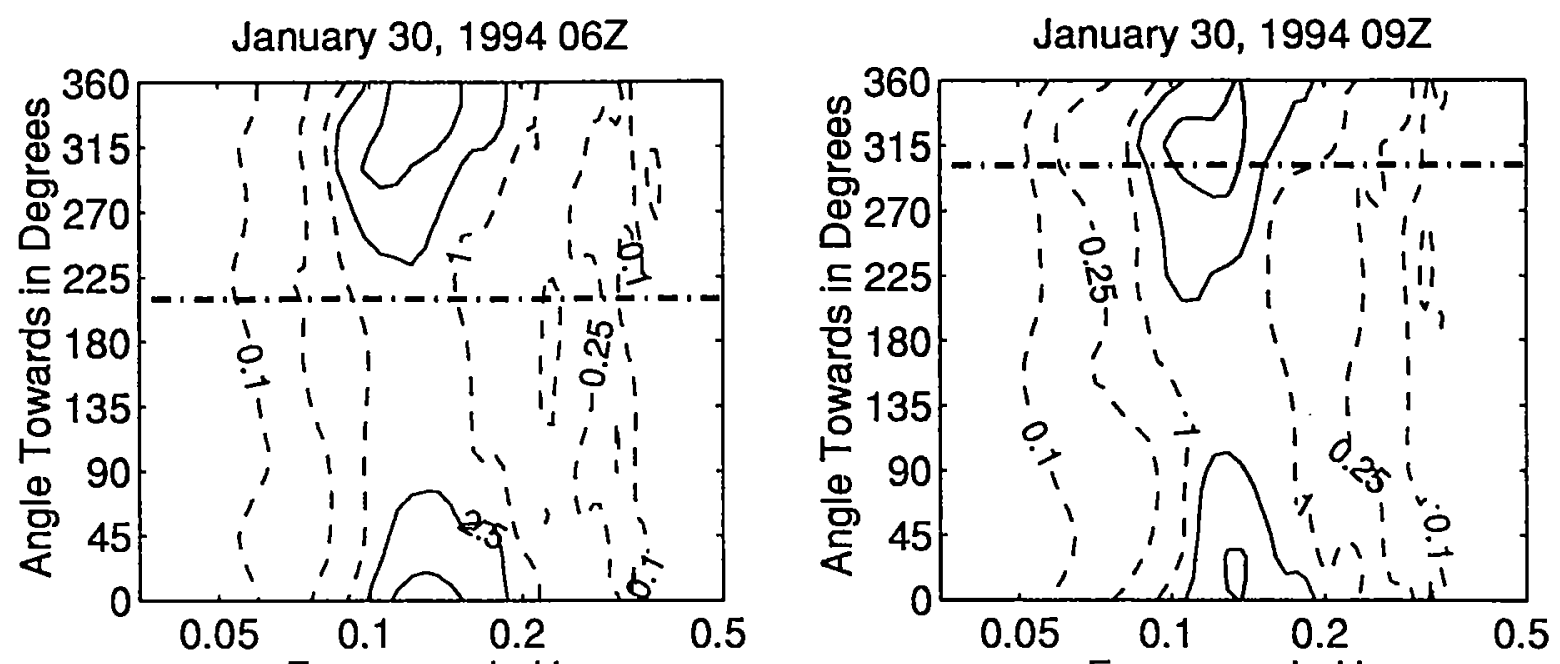

Frequency in $\mathrm{Hz}$

January 30, $199412 Z$

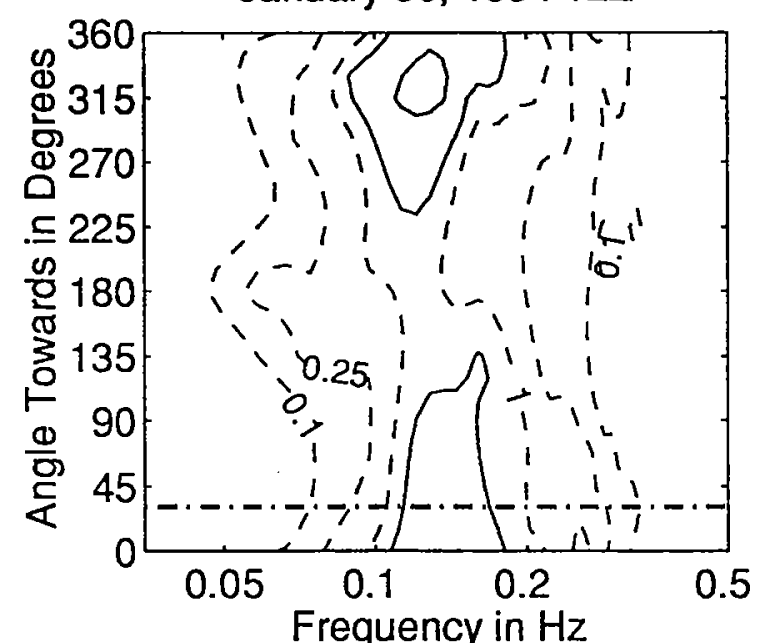

Frequency in $\mathrm{Hz}$

January 30, $199415 Z$

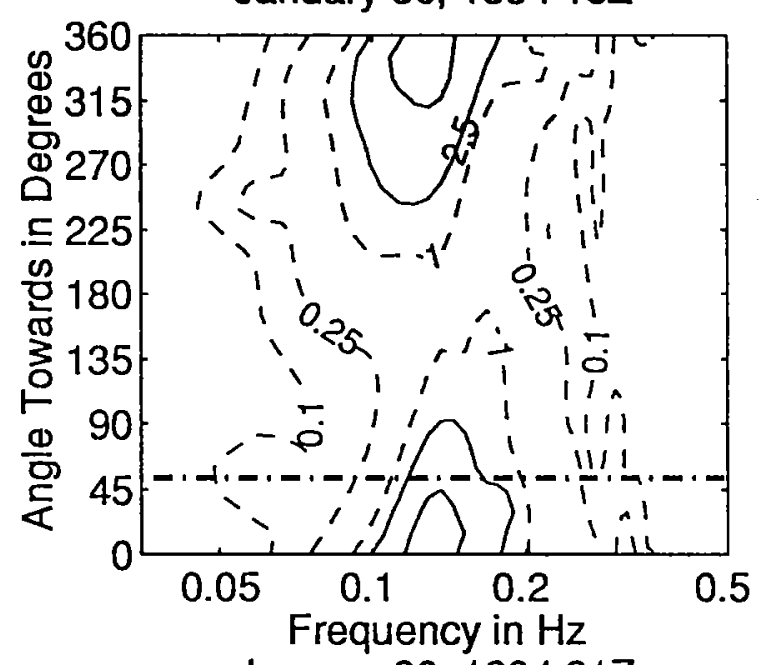

January 30, $199418 Z$
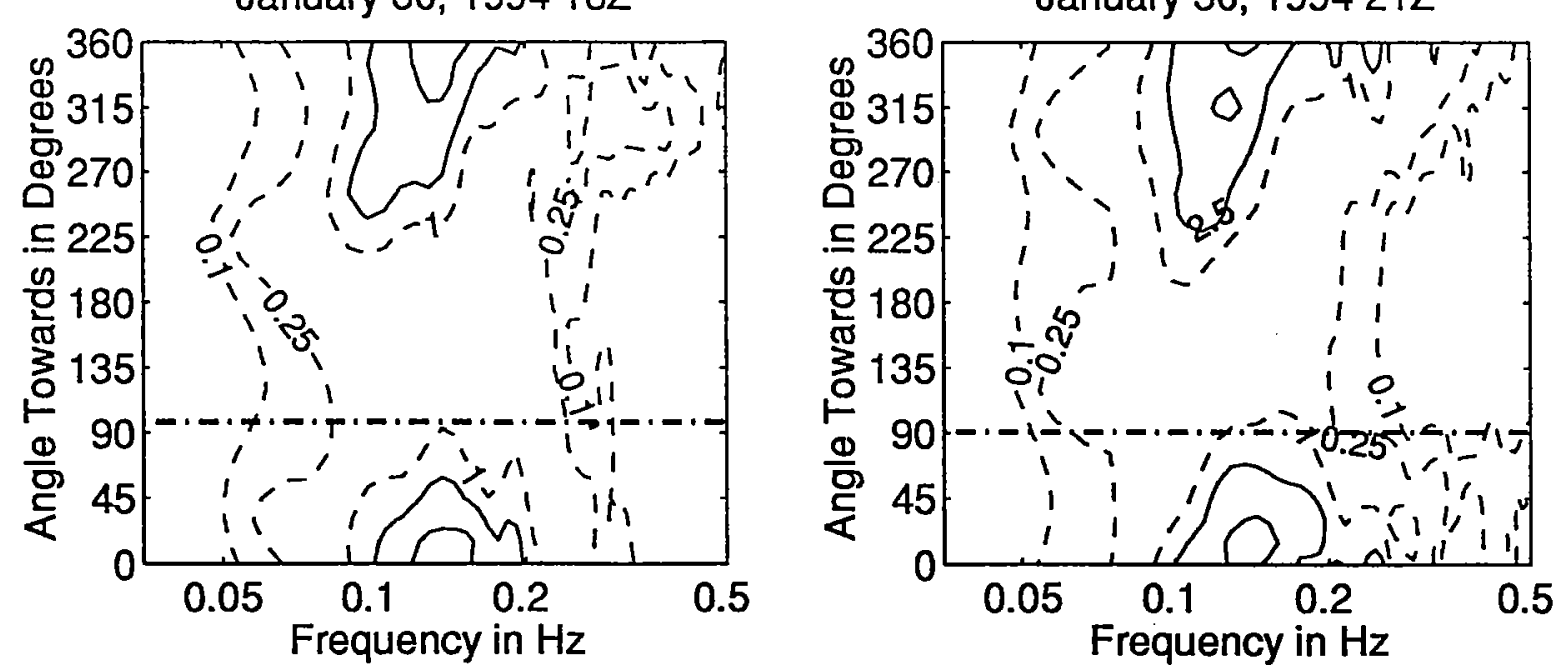

Figure 3.4.73: Directional wave spectra, computed using maximum entropy method. Contours of spectral density as a function of direction. Contours are 0.1 , $0.25,1$ (dashed), $2.5,10,25,100$, and 250 (solid). Wind direction is shown by thick dashed line. 

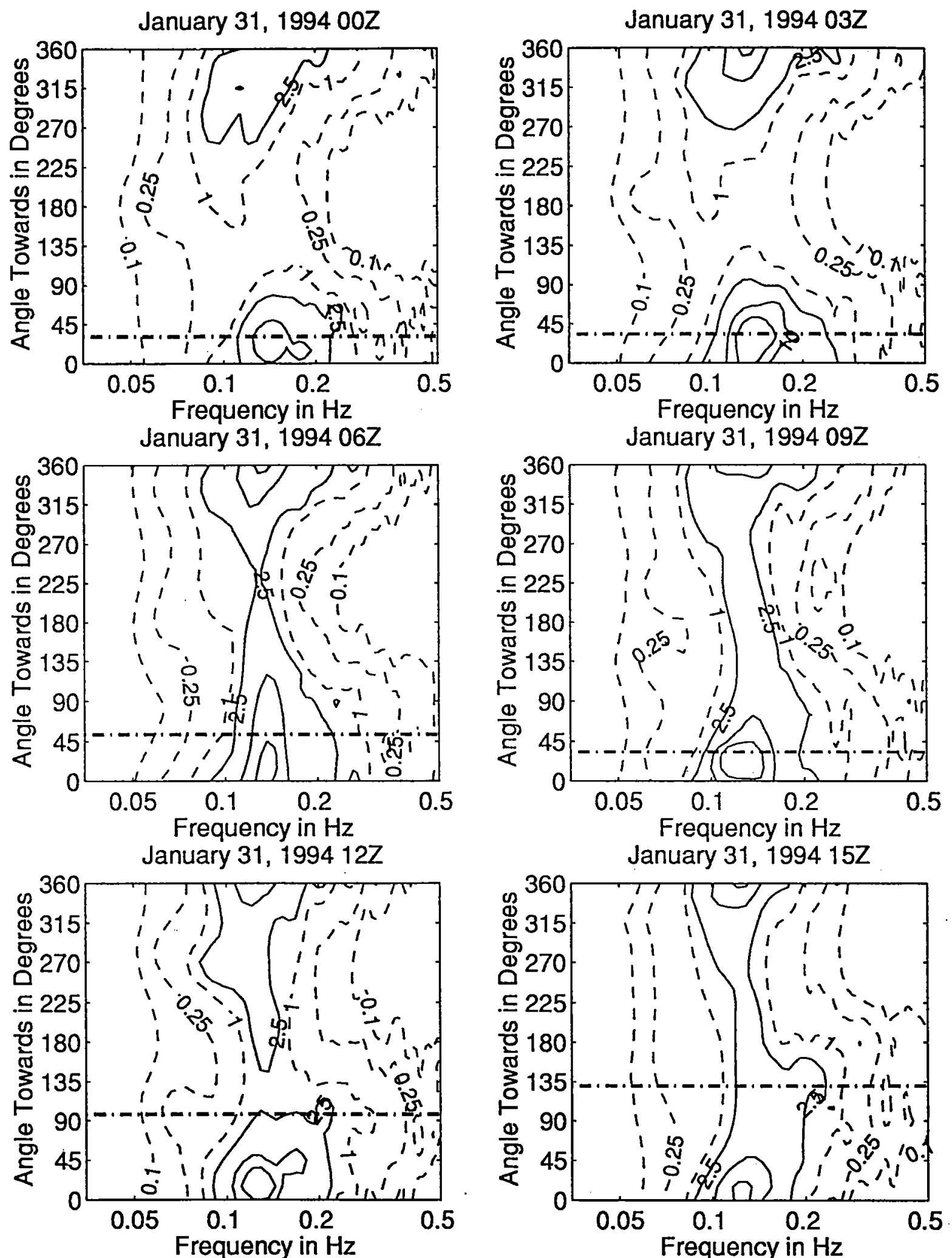

Figure 3.4.74: Directional wave spectra, computed using maximum entropy method. Contours of spectral density as a function of direction. Contours are 0.1, $0.25,1$ (dashed), $2.5,10,25,100$, and 250 (solid). Wind direction is shown by thick dashed line. 
January 31, $199418 Z$

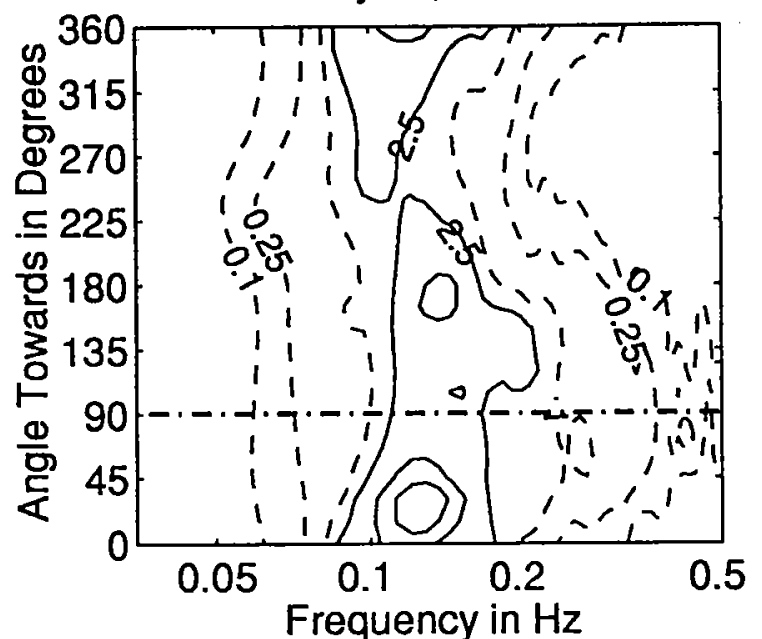

February 1, $199400 Z$

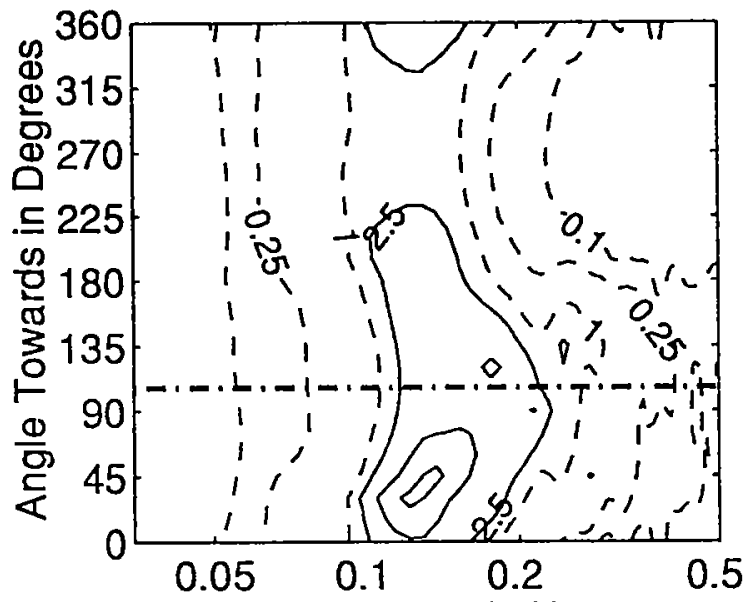

Frequency in $\mathrm{Hz}$

February 1, $199406 Z$

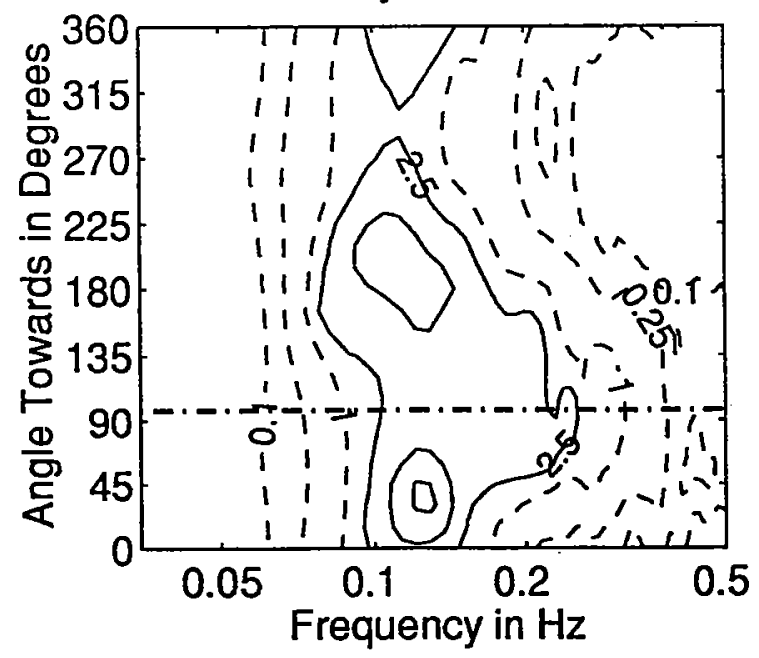

January $31,199421 Z$

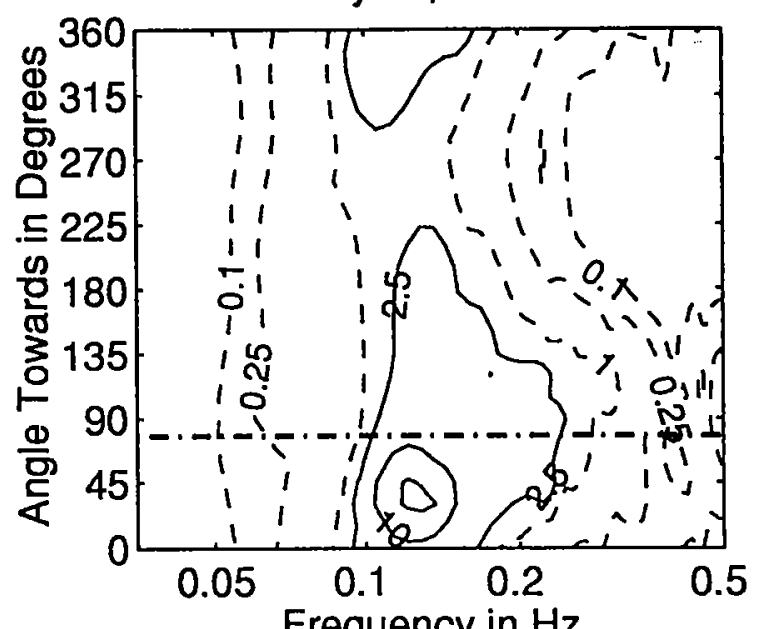

Frequency in $\mathrm{Hz}$

February 1, $199403 Z$

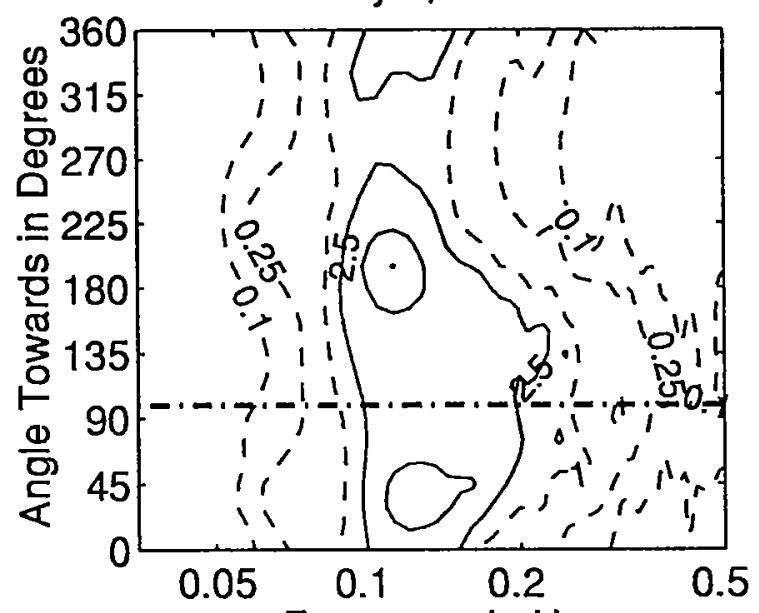

Frequency in $\mathrm{Hz}$

February 1, $199409 Z$

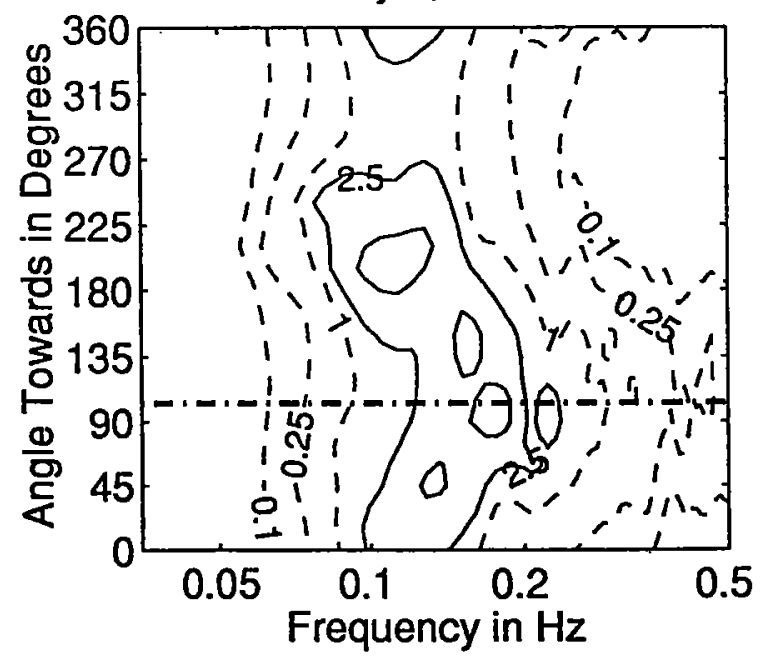

Figure 3.4.75: Directional wave spectra, computed using maximum entropy method. Contours of spectral density as a function of direction. Contours are 0.1, $0.25,1$ (dashed), $2.5,10,25,100$, and 250 (solid). Wind direction is shown by thick dashed line. 
February 1, $199412 Z$

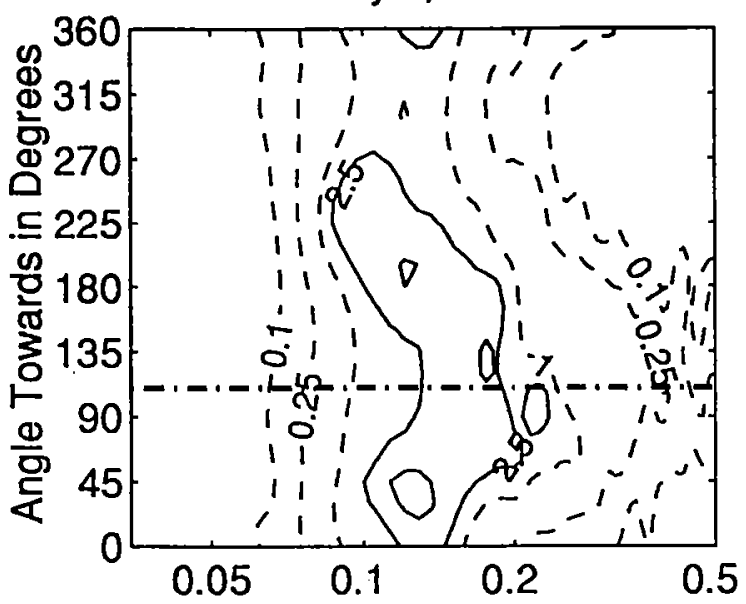

Frequency in $\mathrm{Hz}$

February 1, $199418 Z$

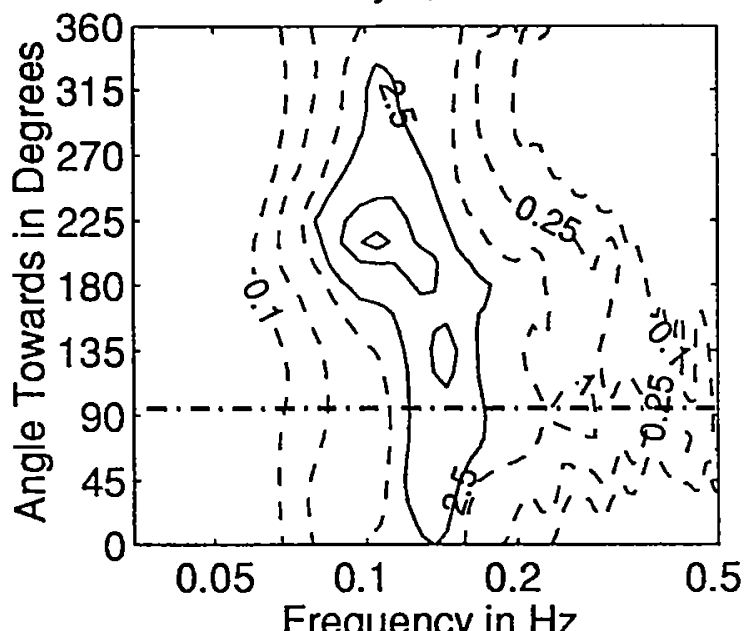

February 2, $199400 \mathrm{Z}$

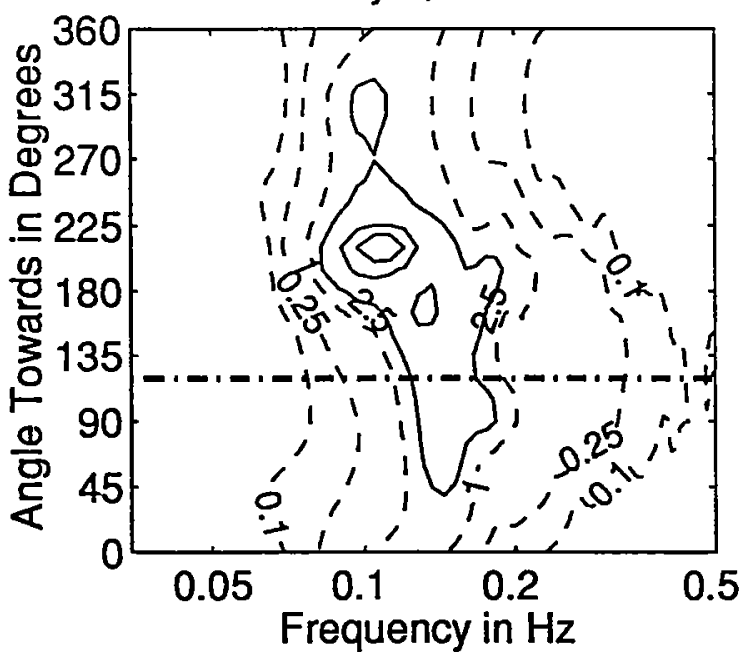

February 1, $199415 Z$

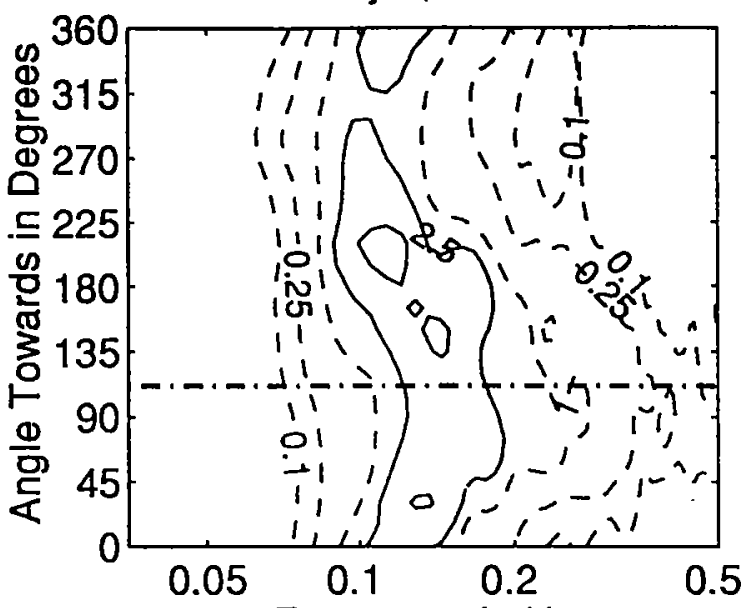

Frequency in $\mathrm{Hz}$

February $1,199421 Z$

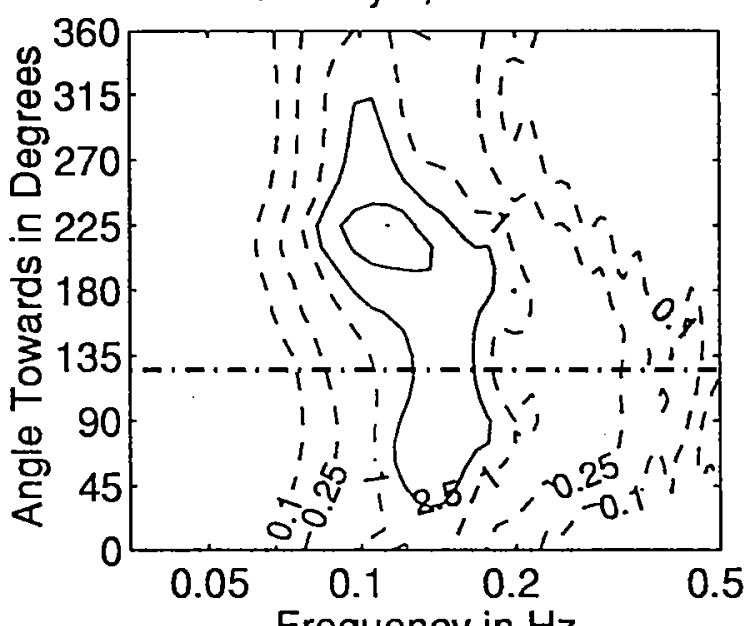

Frequency in $\mathrm{Hz}$

February 2, $199403 Z$

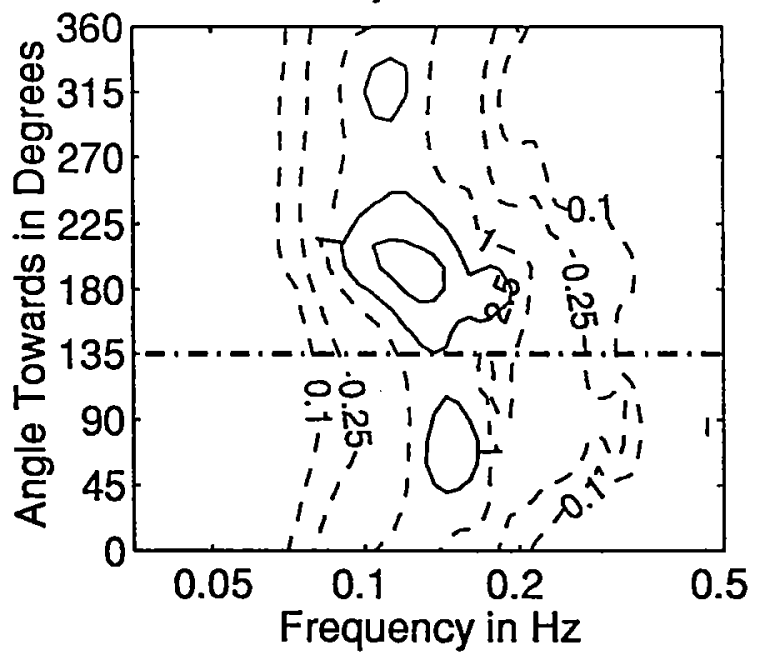

Figure 3.4.76: Directional wave spectra, computed using maximum entropy method. Contours of spectral density as a function of direction. Contours are 0.1 , $0.25,1$ (dashed), $2.5,10,25,100$, and 250 (solid). Wind direction is shown by thick dashed line. 
February 2, $199406 Z$

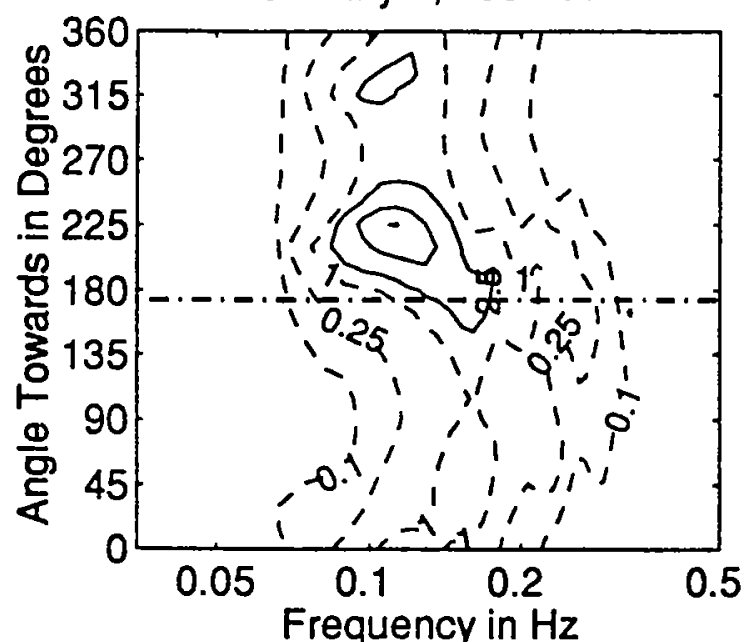

February 2, $199412 Z$

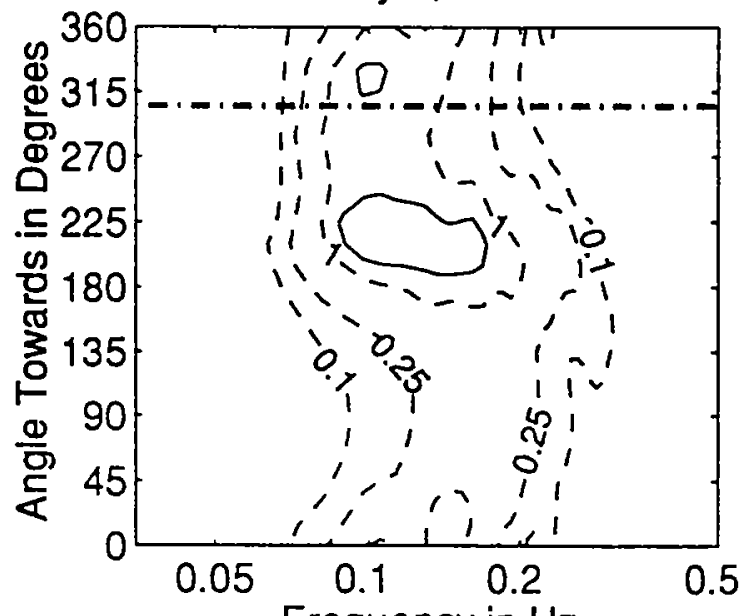

Frequency in $\mathrm{Hz}$

February 2, 1994182

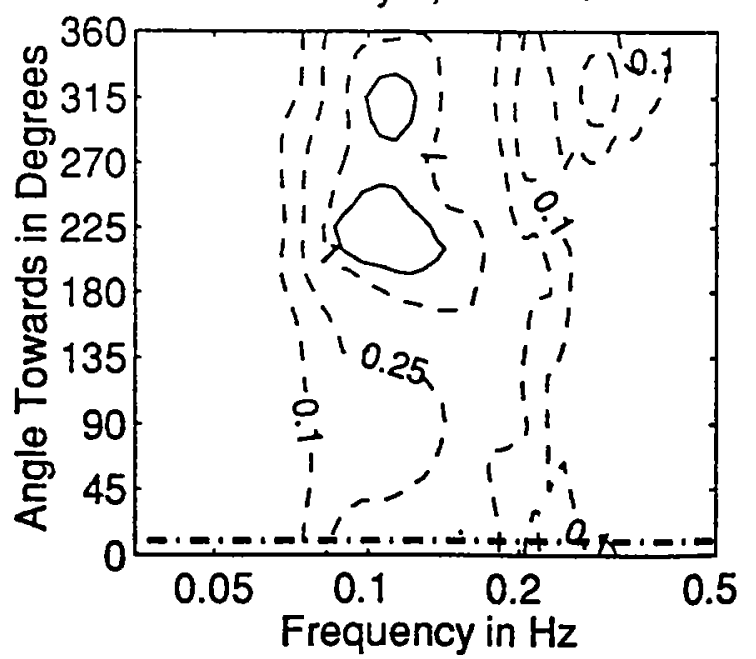

February 2, $199409 Z$

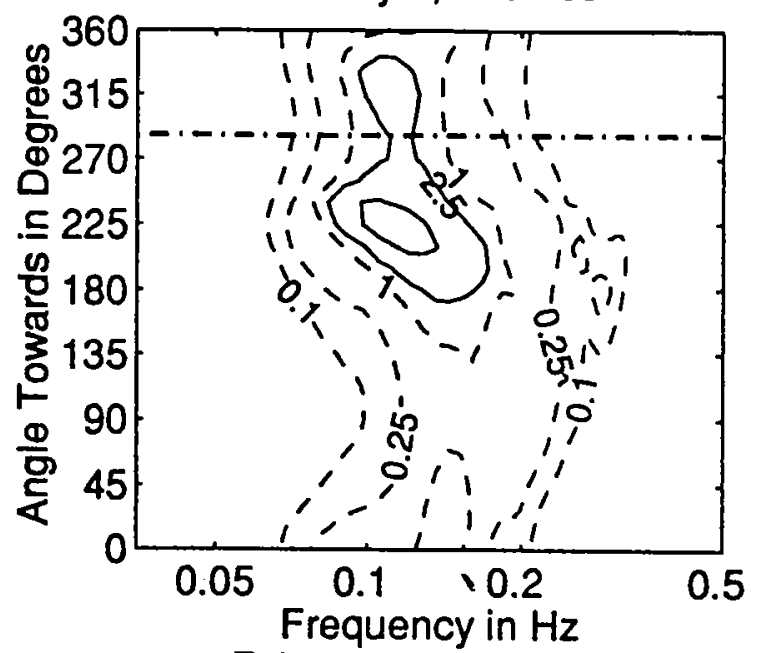

February 2, $199415 Z$

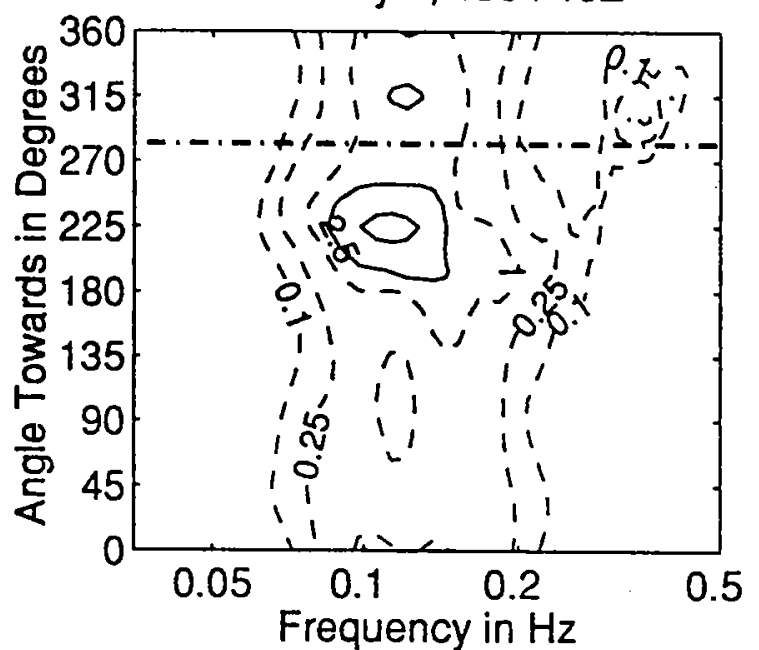

February 2, $199421 Z$

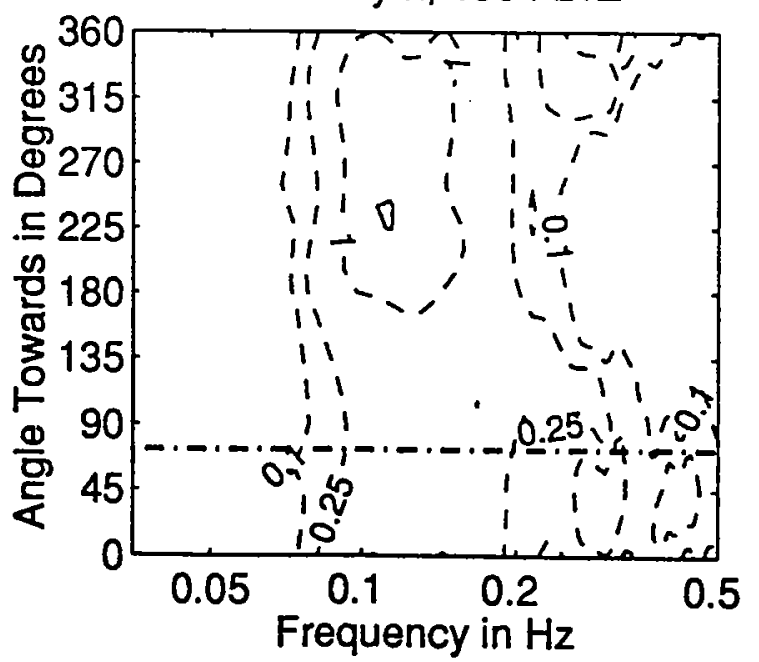

Figure 3.4.77: Directional wave spectra, computed using maximum entropy method. Contours of spectral density as a function of direction. Contours are 0.1 , $0.25,1$ (dashed), $2.5,10,25,100$, and 250 (solid). Wind direction is shown by thick dashed line. 
February 3, $199400 Z$

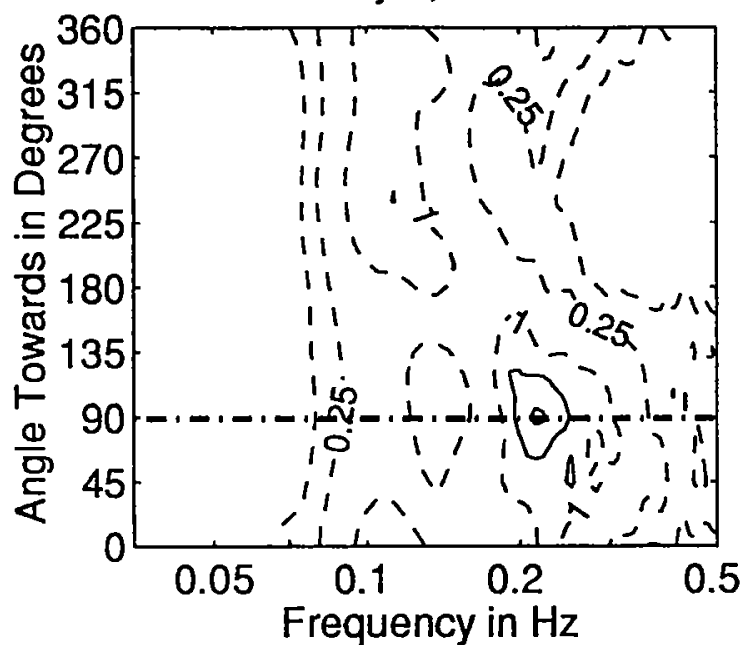

February 3, $199406 Z$

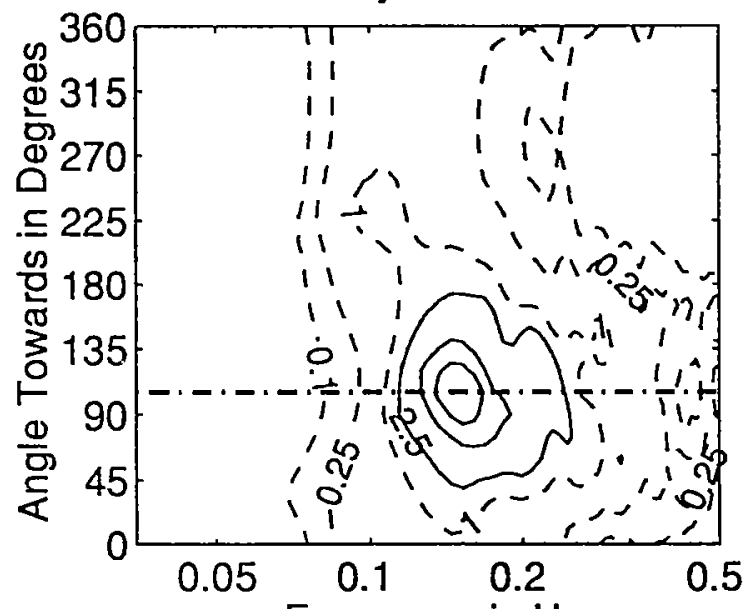

Frequency in $\mathrm{Hz}$

February 3, $199412 Z$

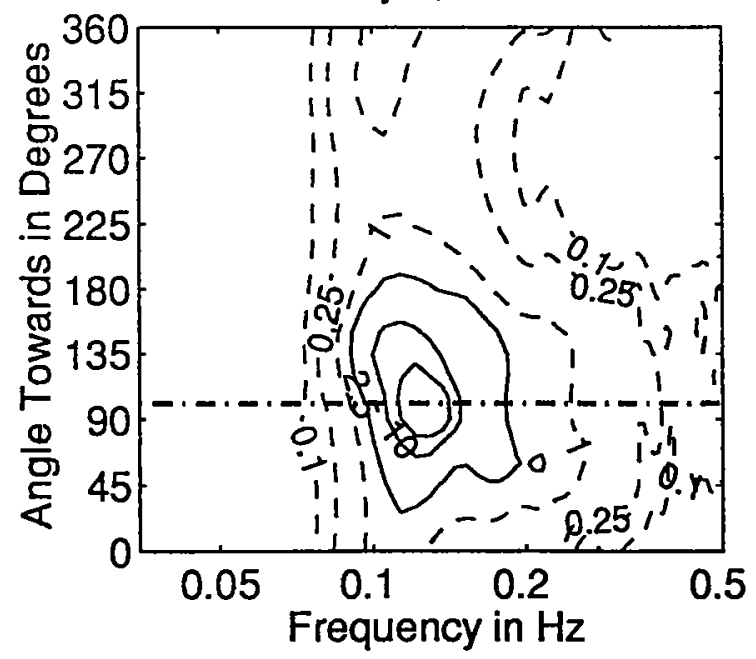

February 3, $199403 Z$

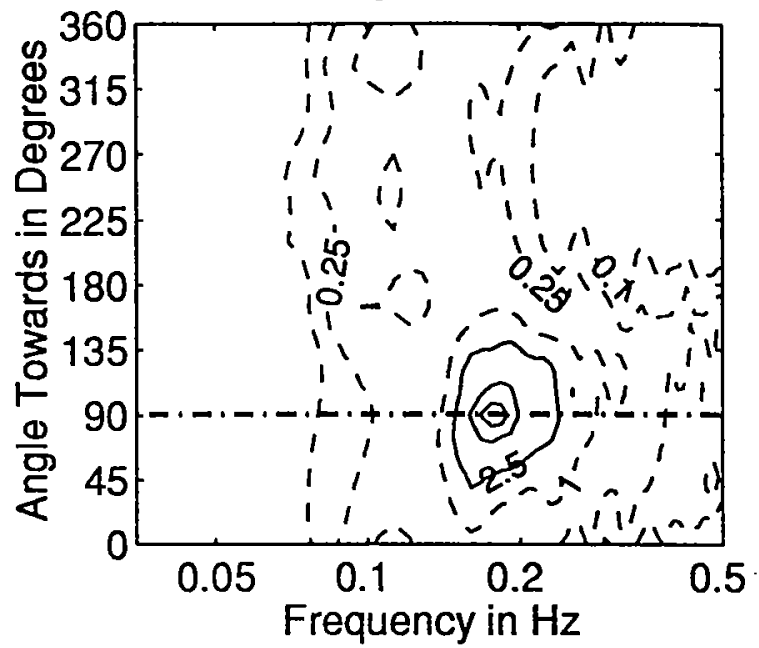

February 3, $199409 Z$

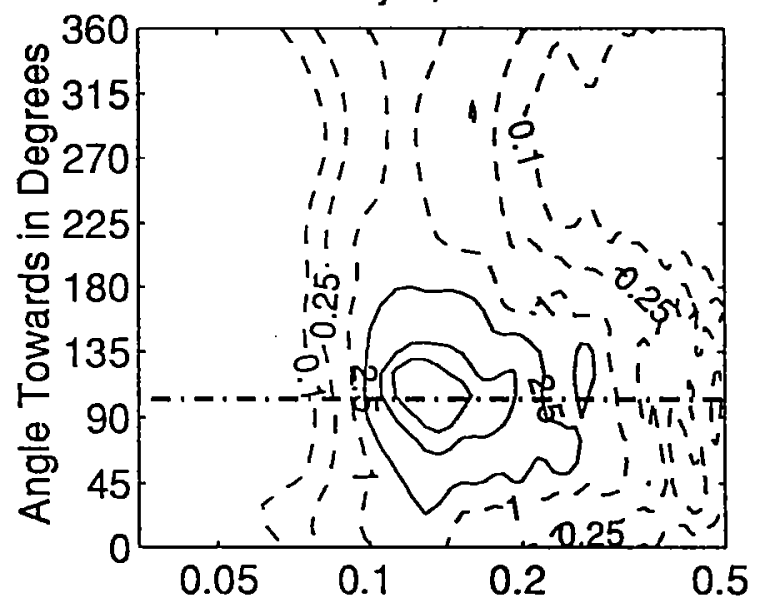

Frequency in $\mathrm{Hz}$

February 3, $199415 Z$

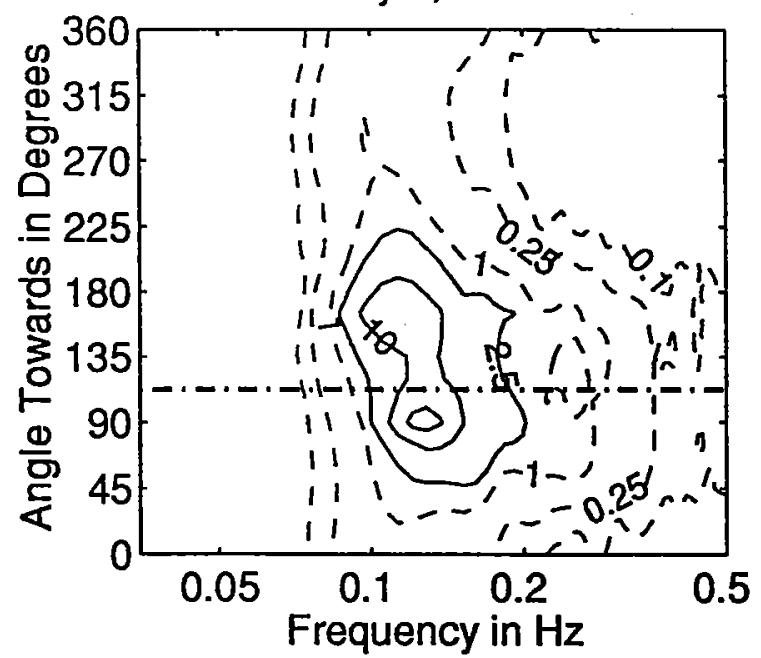

Figure 3.4.78: Directional wave spectra, computed using maximum entropy method. Contours of spectral density as a function of direction. Contours are 0.1, $0.25,1$ (dashed), 2.5, 10, 25, 100, and 250 (solid). Wind direction is shown by thick dashed line. 
February 3, $199418 Z$

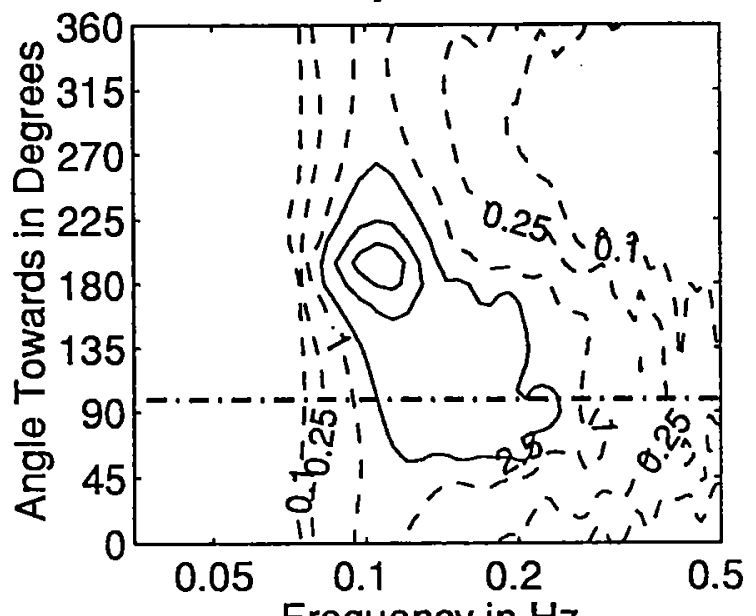

Frequency in $\mathrm{Hz}$

February 4, $199400 Z$

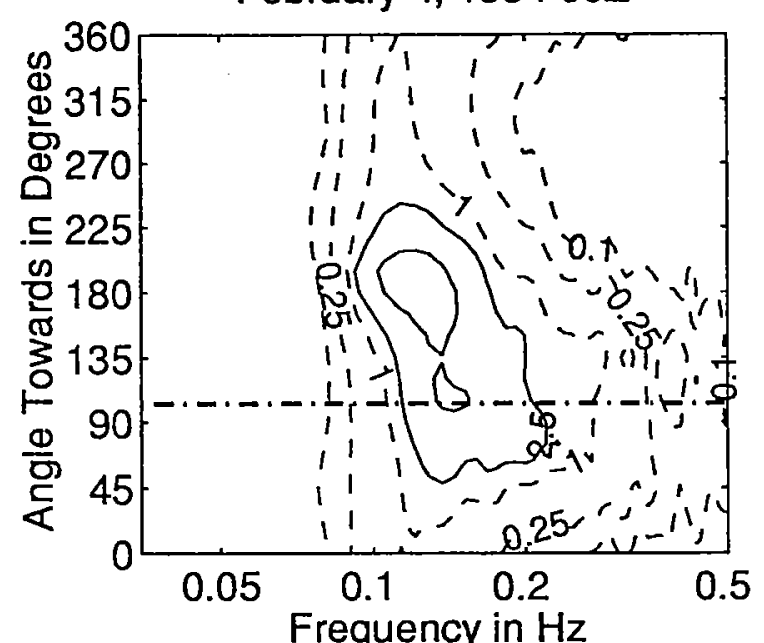

February 4, $199406 Z$

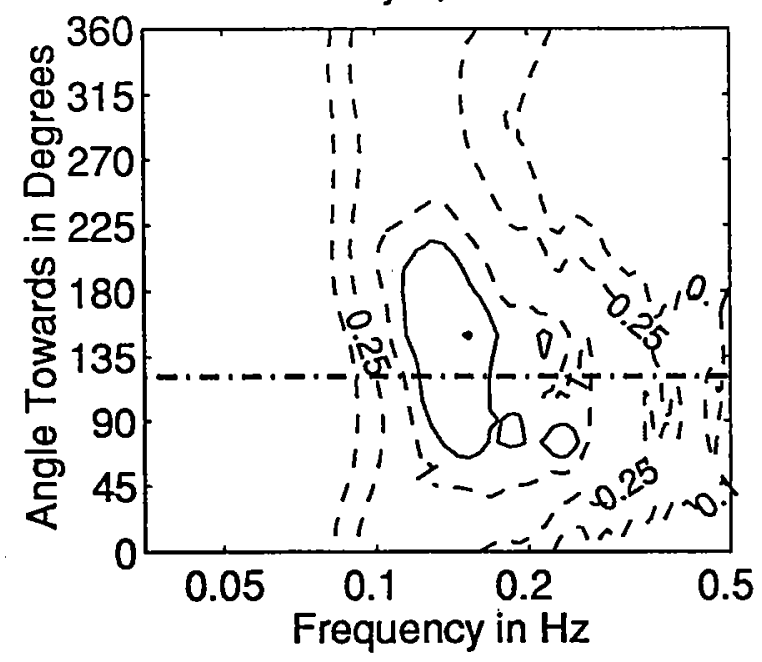

February 3, $199421 Z$

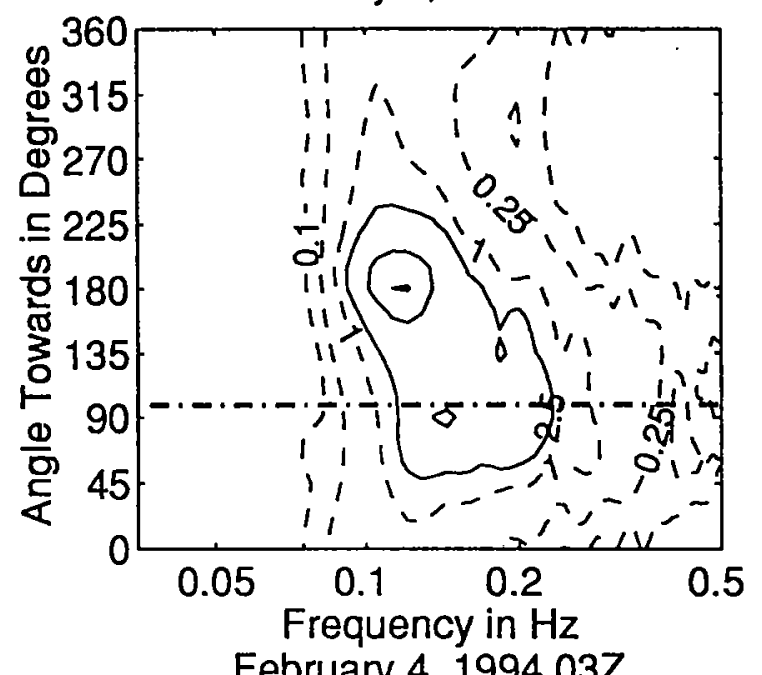

February 4, $199403 Z$

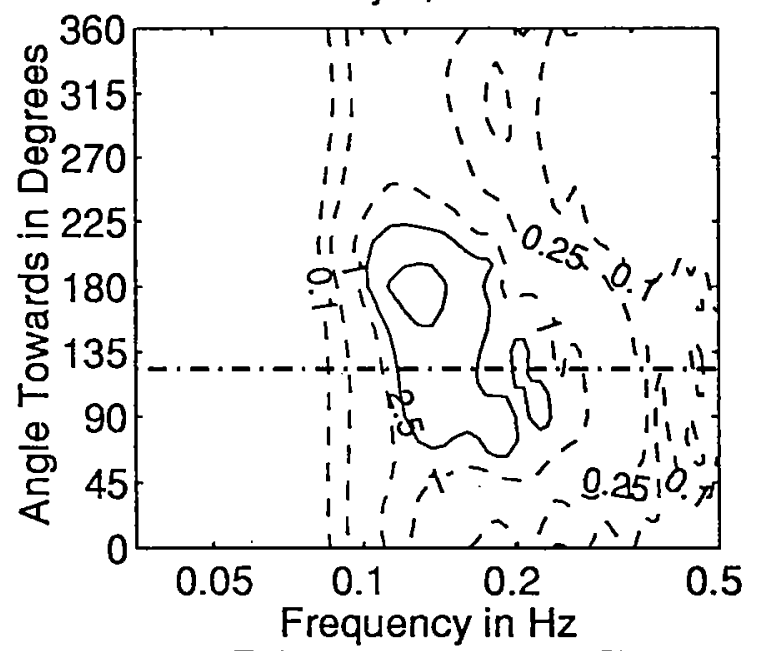

February 4, $199409 Z$

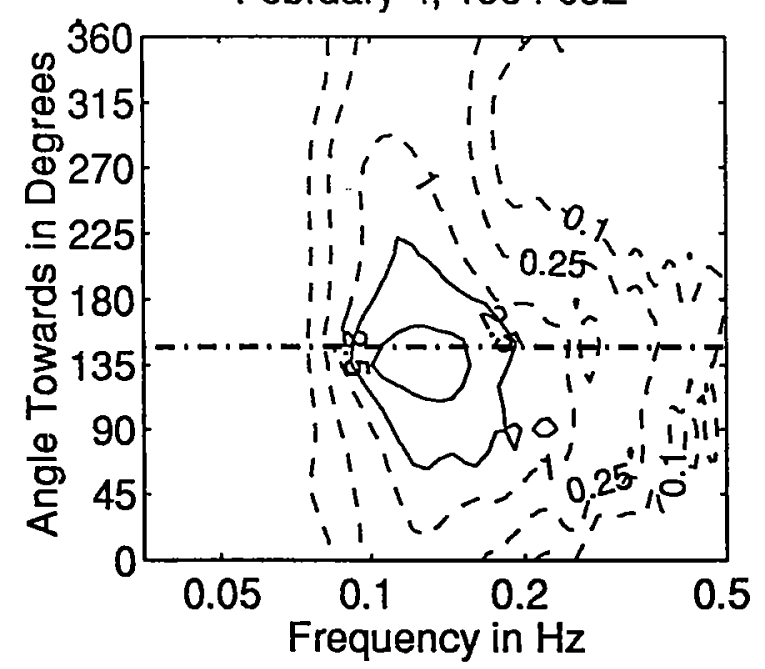

Figure 3.4.79: Directional wave spectra, computed using maximum entropy method. Contours of spectral density as a function of direction. Contours are 0.1 , $0.25,1$ (dashed), $2.5,10,25,100$, and 250 (solid). Wind direction is shown by thick dashed line. 
February 4, $199412 Z$

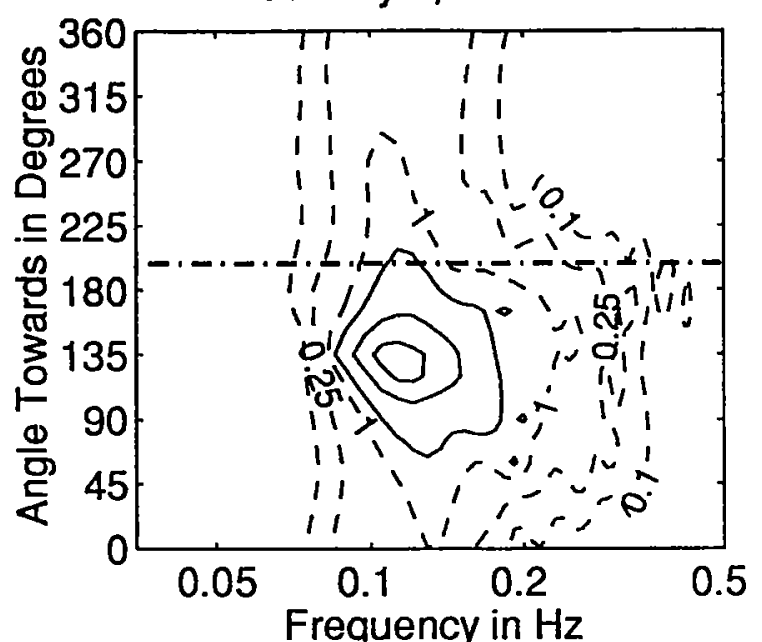

February 4, $199418 Z$

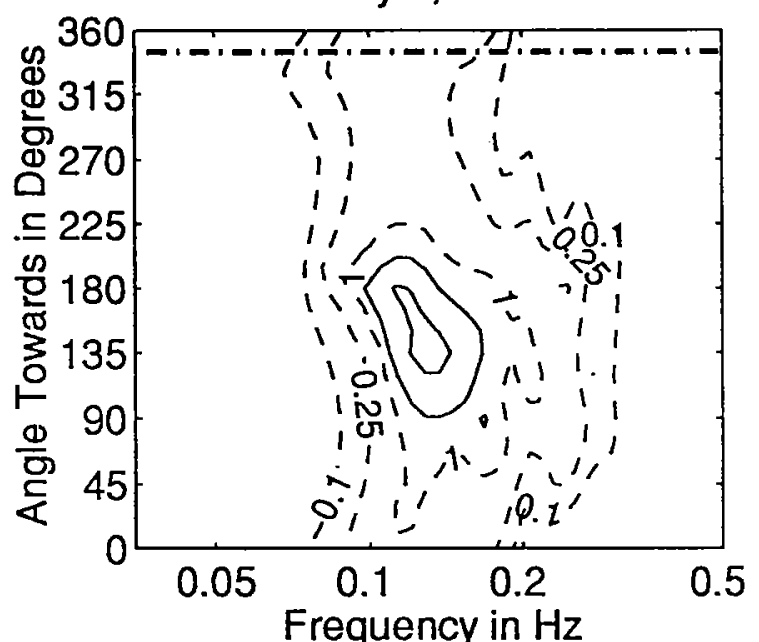

February 5, $199400 Z$

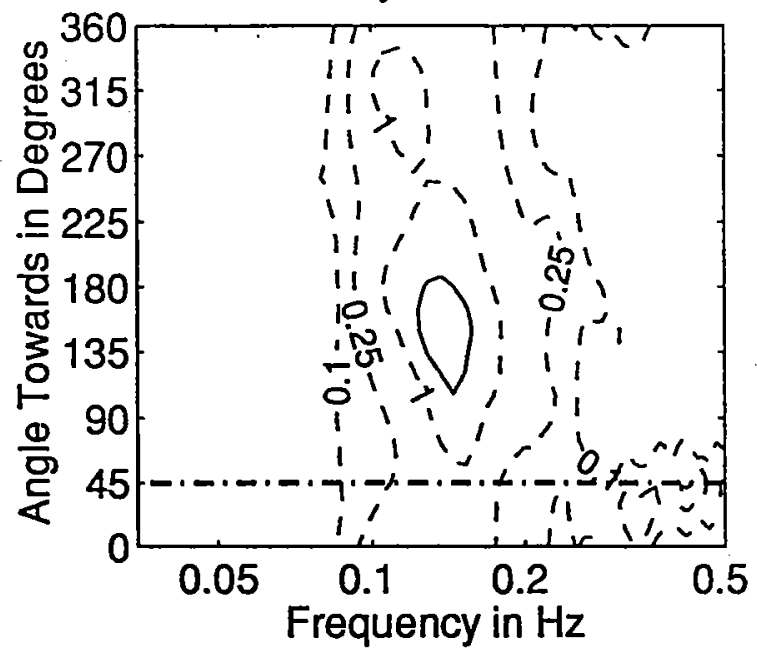

February 4, $199415 Z$

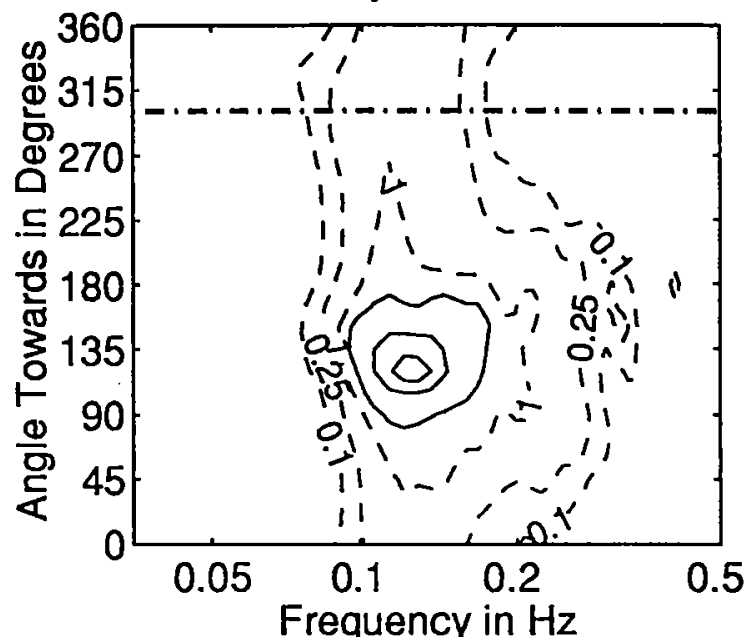

February 4, $199421 \mathrm{Z}$

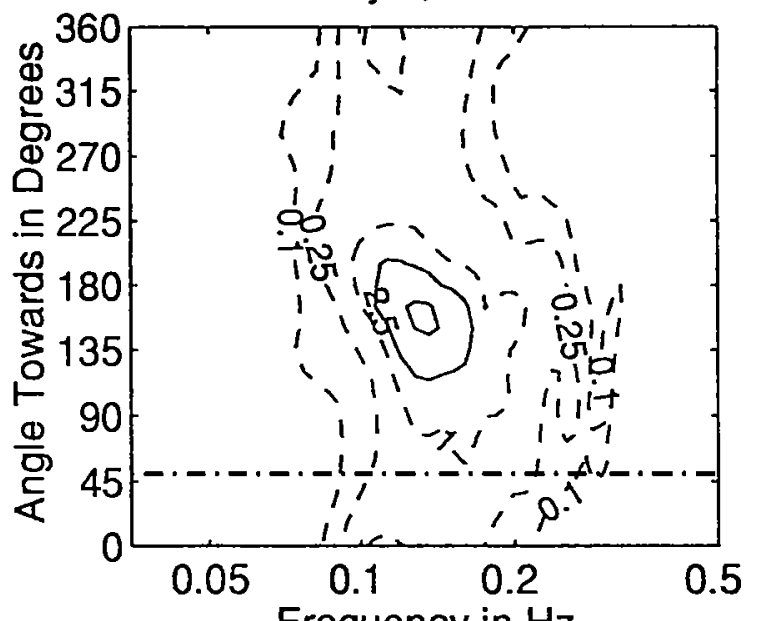

Frequency in $\mathrm{Hz}$

February 5, $199403 Z$

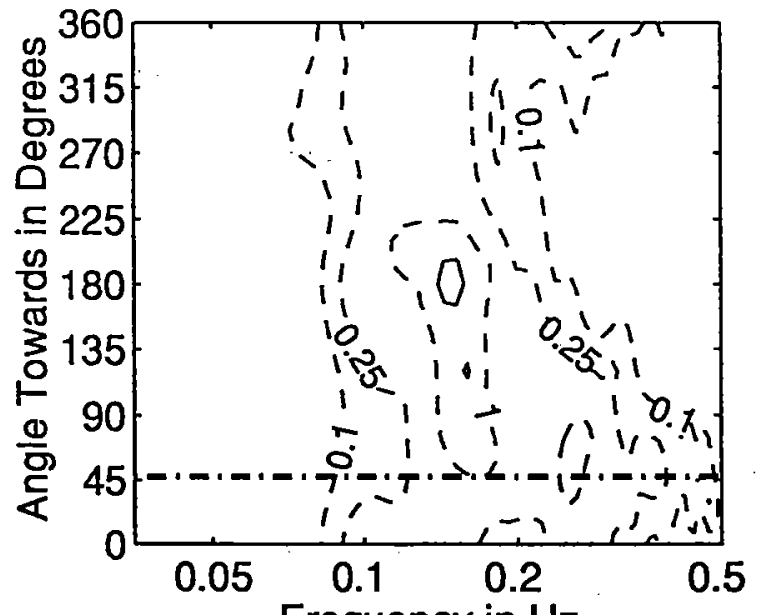

Frequency in $\mathrm{Hz}$

Figure 3.4.80: Directional wave spectra, computed using maximum entropy method. Contours of spectral density as a function of direction. Contours are 0.1 , $0.25,1$ (dashed), $2.5,10,25,100$, and 250 (solid). Wind direction is shown by thick dashed line. 
February 5, $199406 Z$

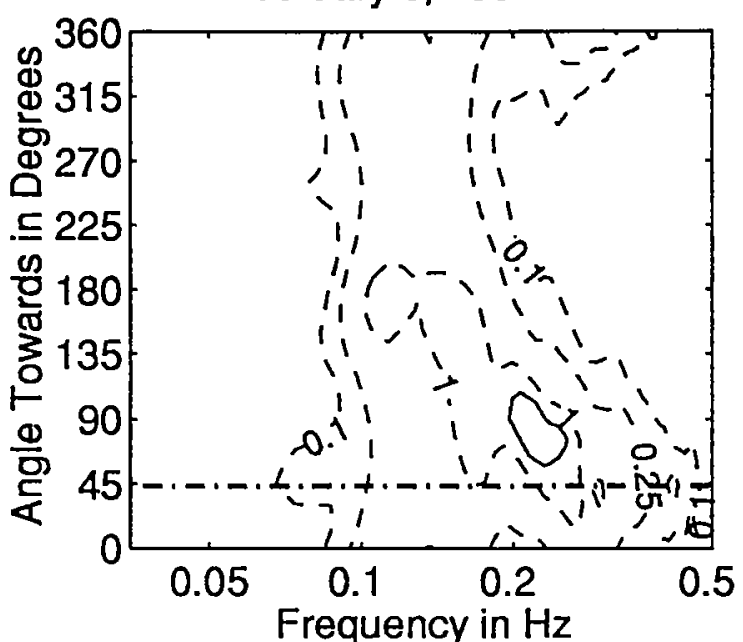

February 5, $199412 Z$

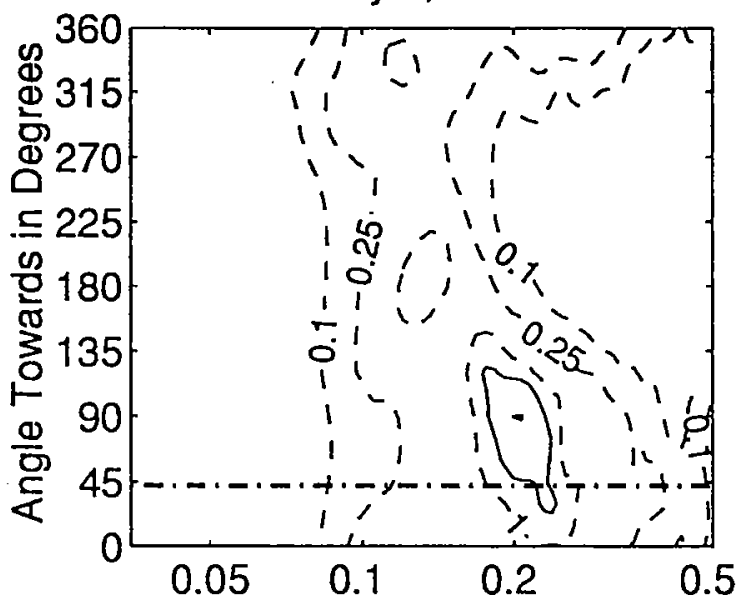

Frequency in $\mathrm{Hz}$

February 5, $199418 Z$

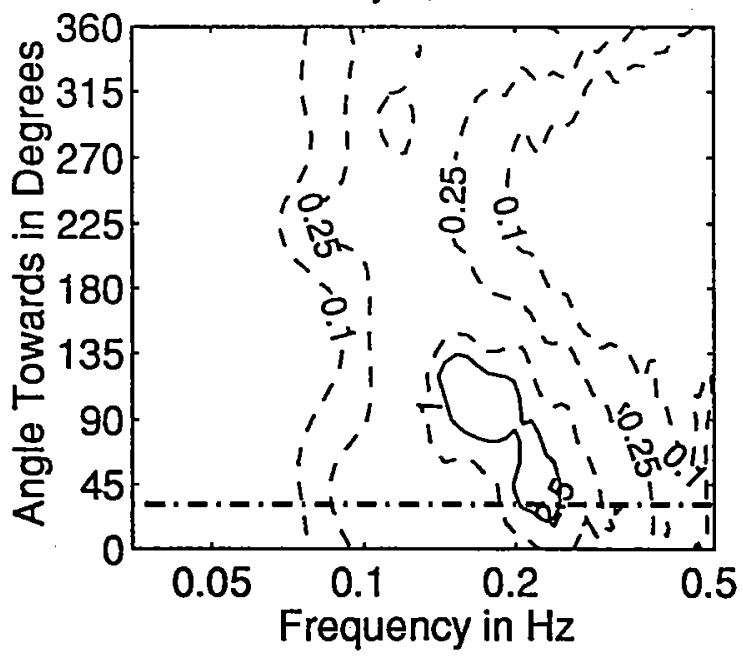

February 5, $199409 Z$

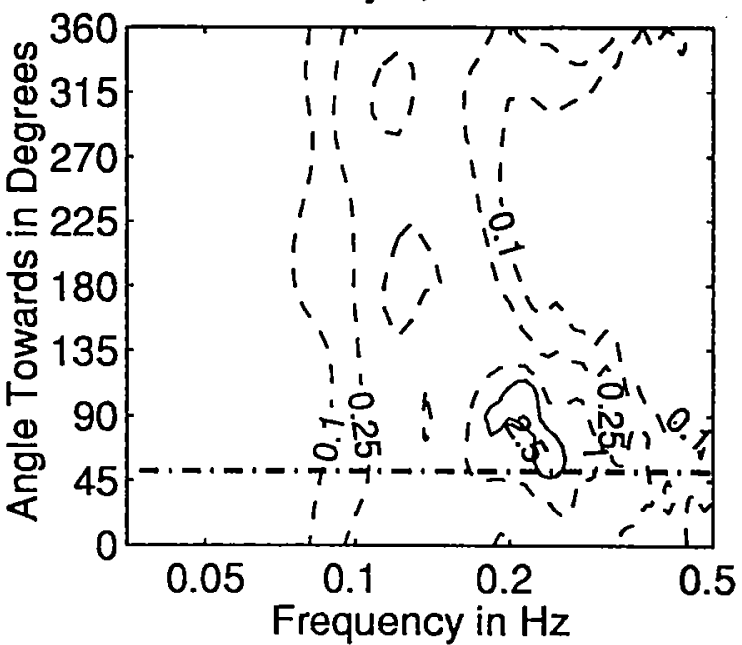

February 5, $199415 Z$

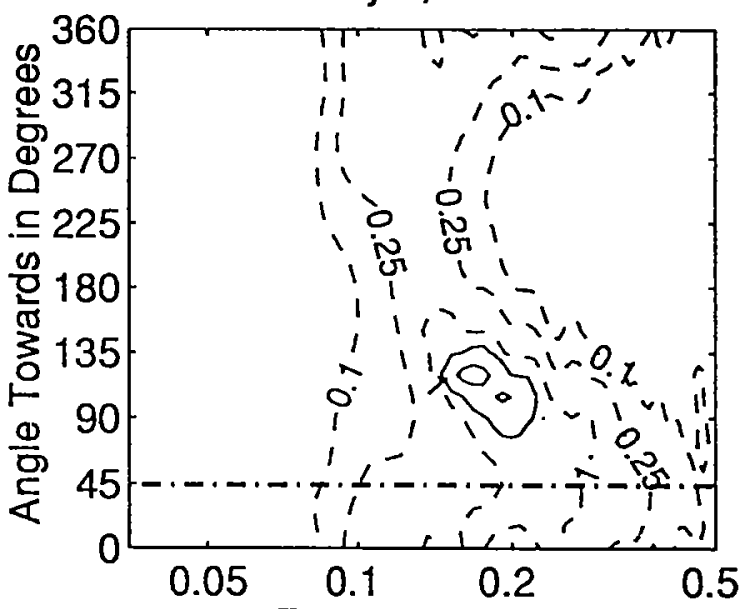

Frequency in $\mathrm{Hz}$

February 5, $199421 Z$

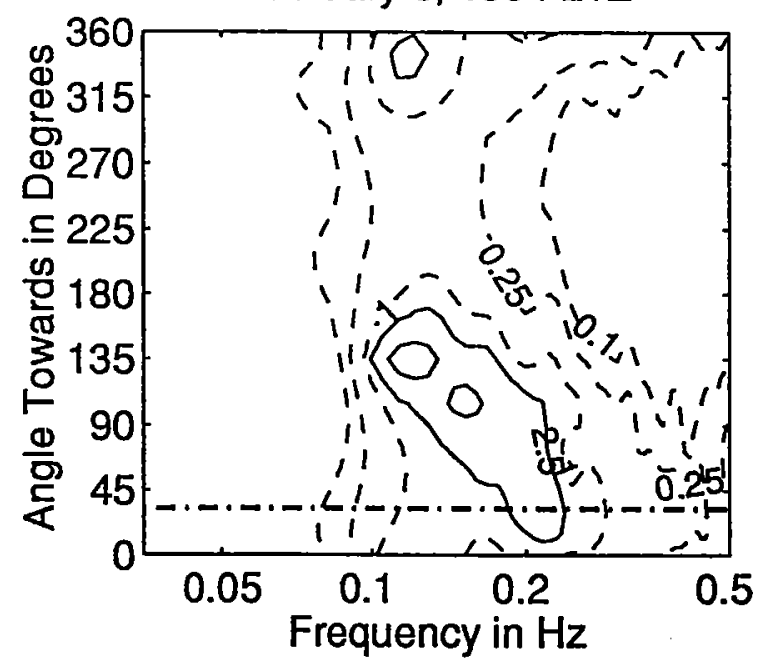

Figure 3.4.81: Directional wave spectra, computed using maximum entropy method. Contours of spectral density as a function of direction. Contours are 0.1, $0.25,1$ (dashed), $2.5,10,25,100$, and 250 (solid). Wind direction is shown by thick dashed line. 
February 6, $1994.00 Z$

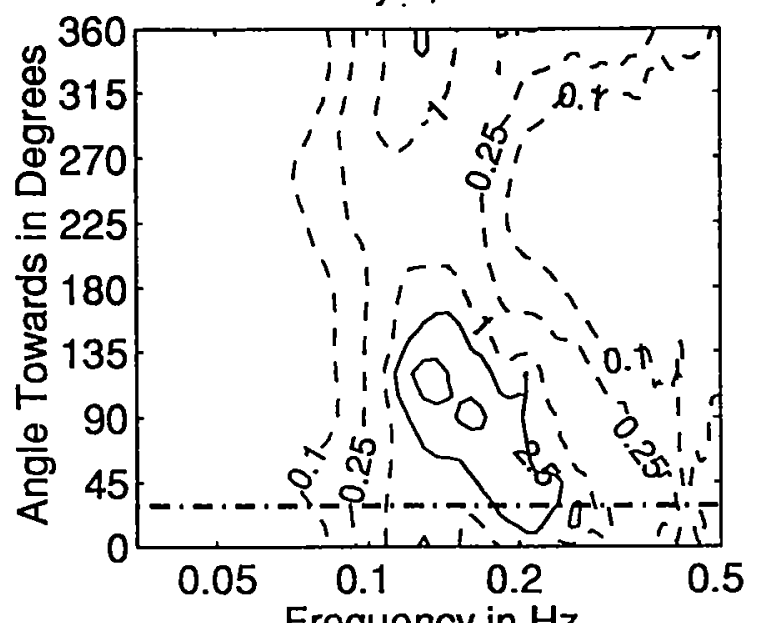

Frequency in $\mathrm{Hz}$

February 6, $199406 Z$

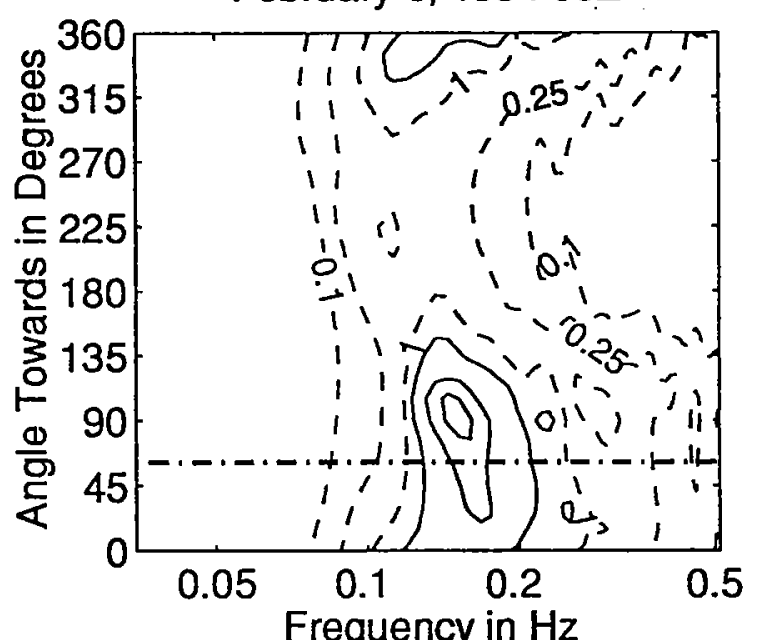

February 6, $199412 Z$

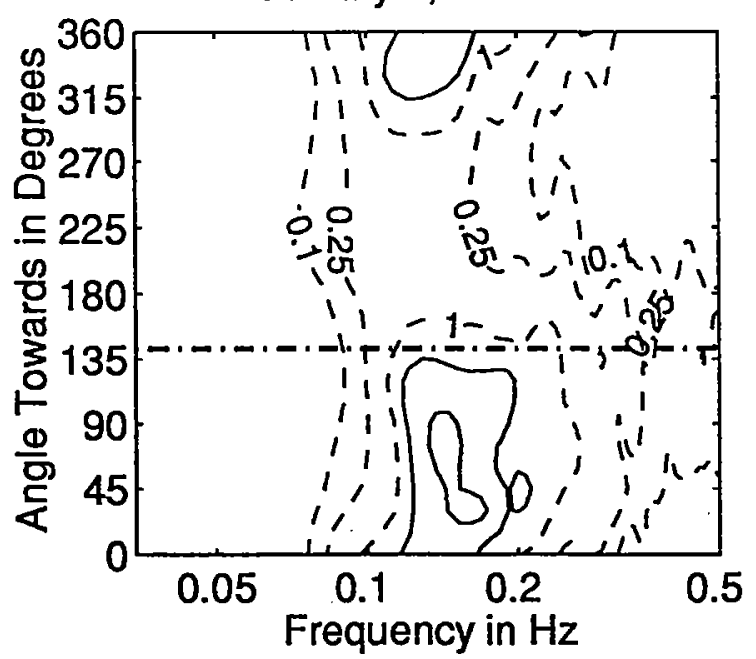

February 6, $199403 Z$

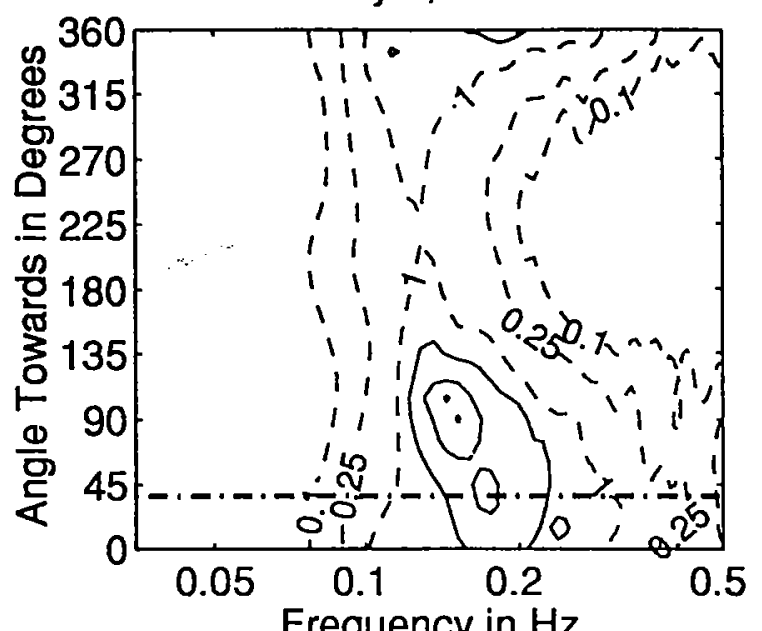

February 6, $199409 Z$

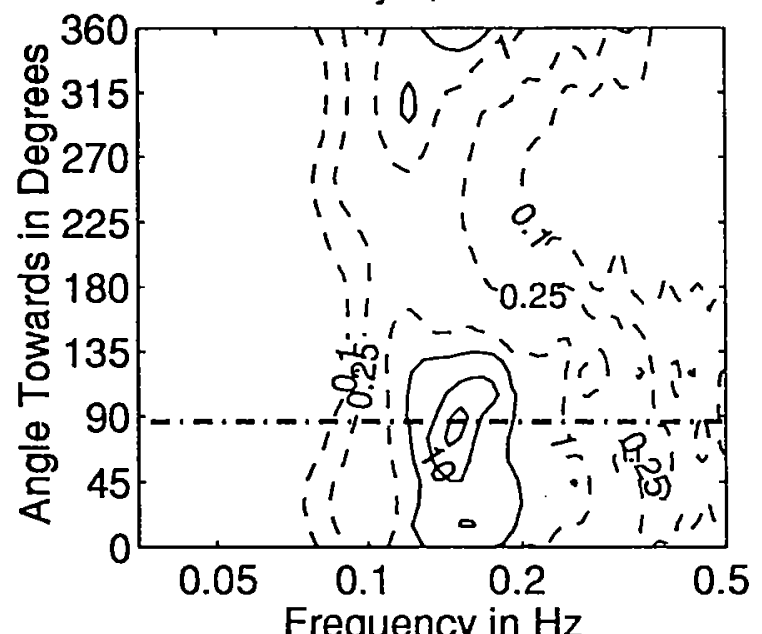

February 6, $199415 Z$

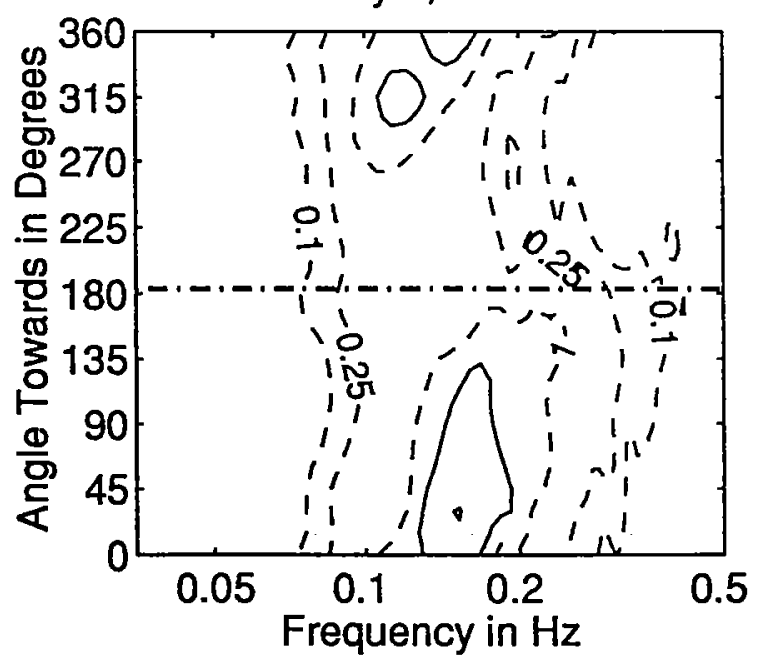

Figure 3.4.82: Directional wave spectra, computed using maximum entropy method. Contours of spectral density as a function of direction. Contours are 0.1 , $0.25,1$ (dashed), $2.5,10,25,100$, and 250 (solid). Wind direction is shown by thick dashed line. 
February 6, $199418 Z$

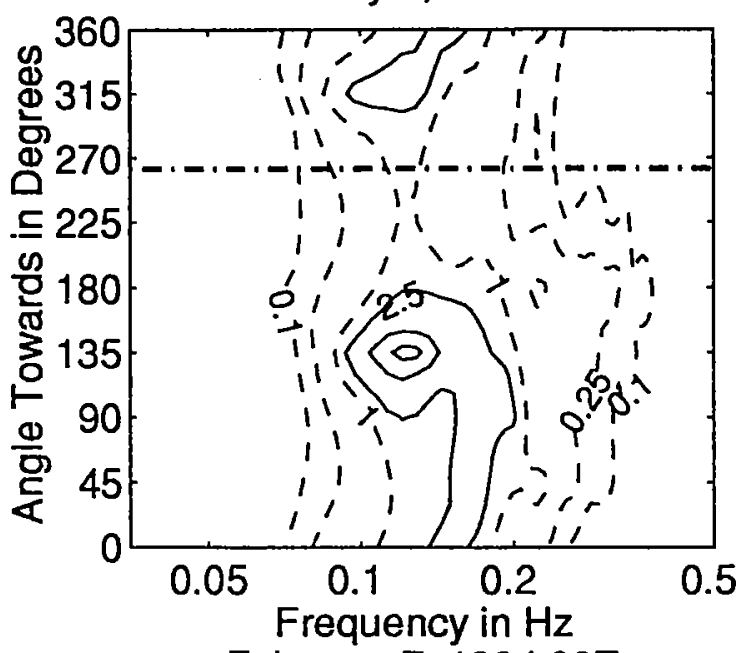

February 7, $199400 Z$

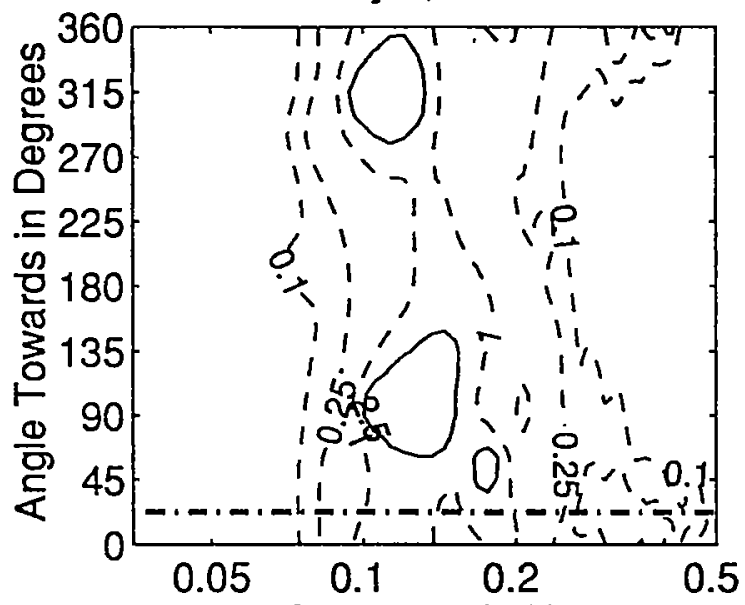

Frequency in $\mathrm{Hz}$

February 7, $199406 Z$

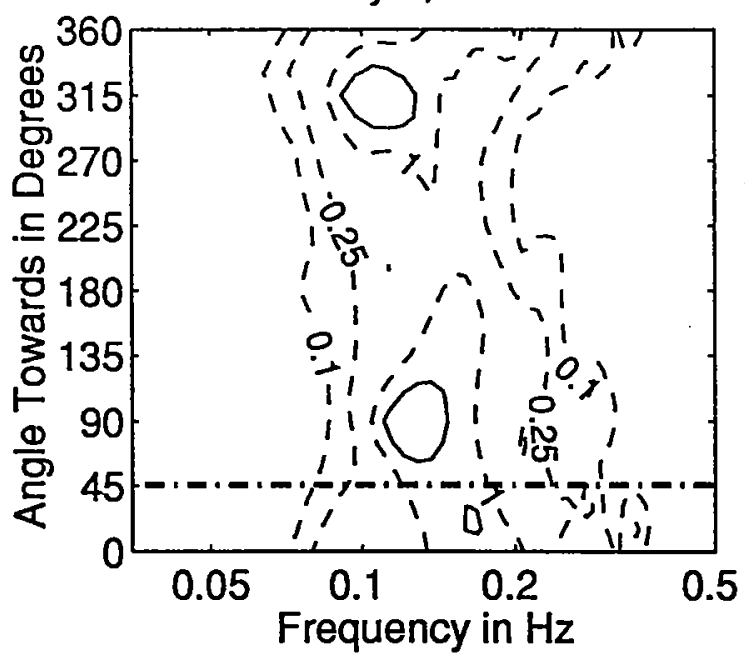

February 6, $199421 Z$

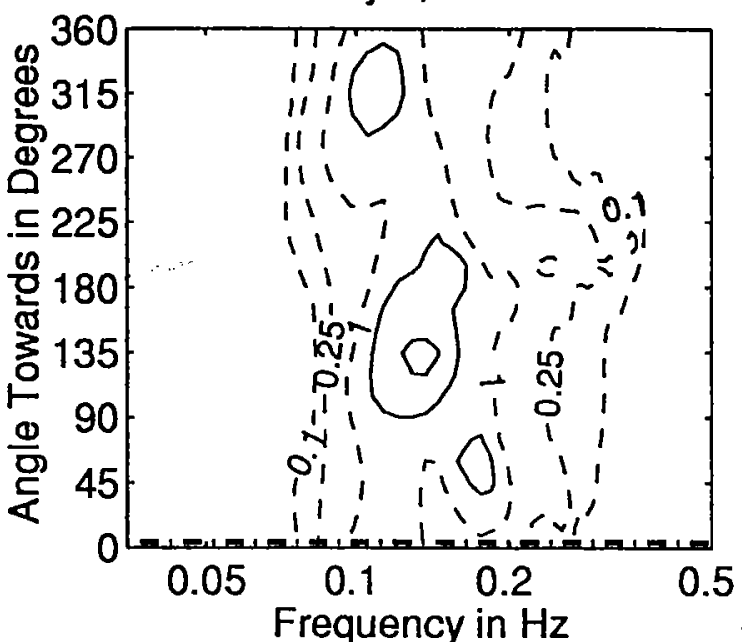

February 7, $199403 Z$

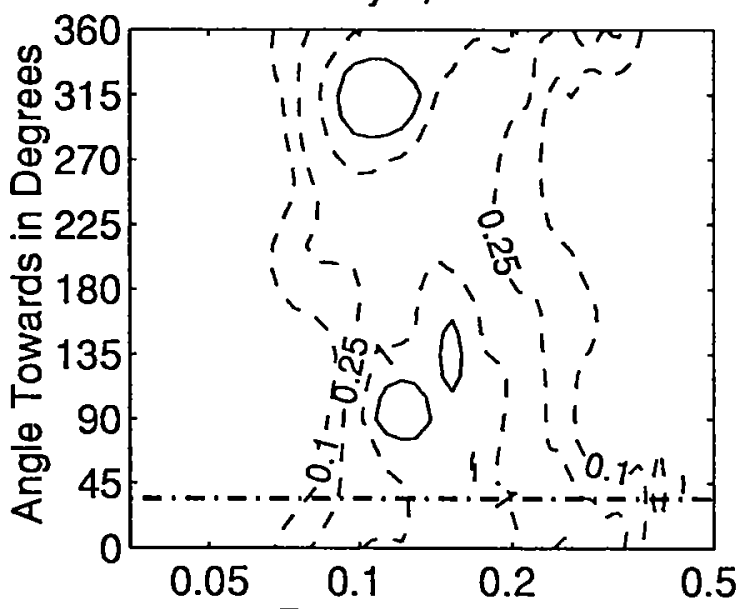

Frequency in $\mathrm{Hz}$

February 7, $199409 Z$

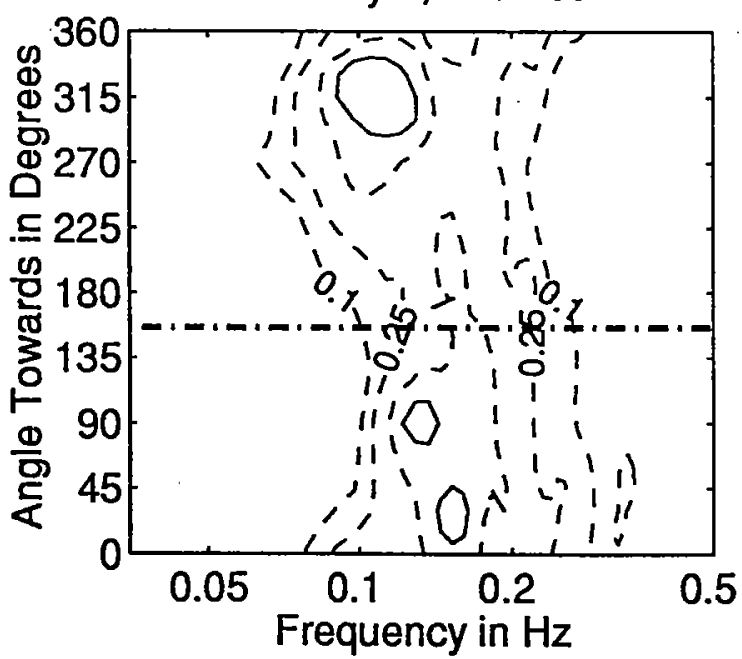

Figure 3.4.83: Directional wave spectra, computed using maximum entropy method. Contours of spectral density as a function of direction. Contours are 0.1 , $0.25,1$ (dashed), $2.5,10,25,100$, and 250 (solid). Wind direction is shown by thick dashed line. 
February 7, $199412 Z$

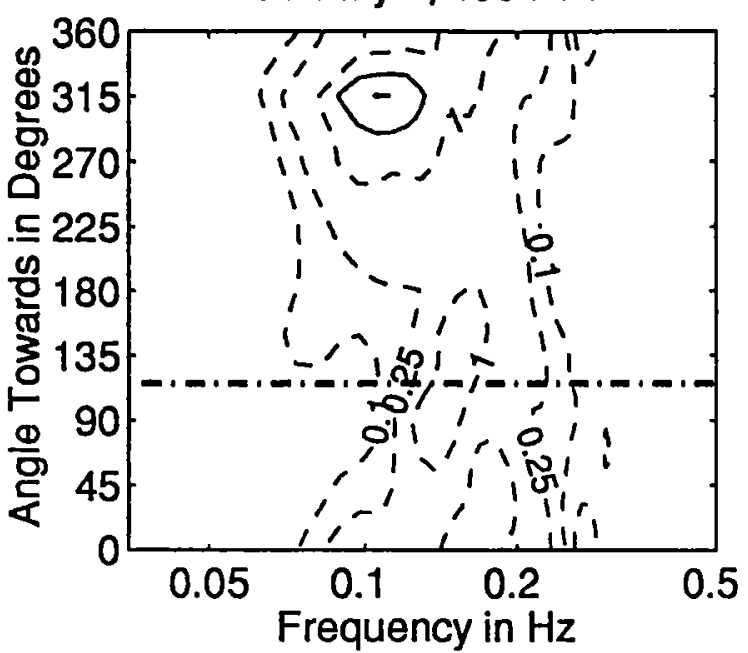

February 7, 1994182

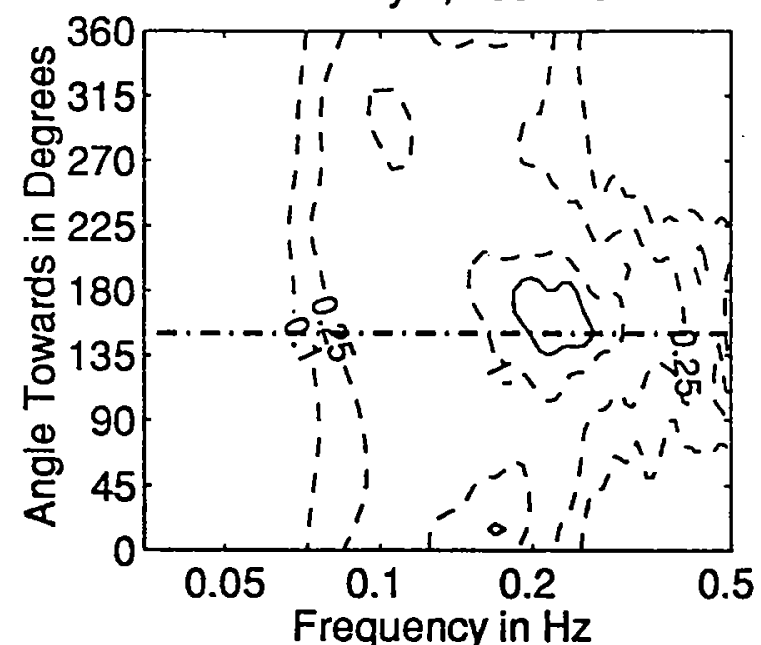

February 8, $199400 Z$

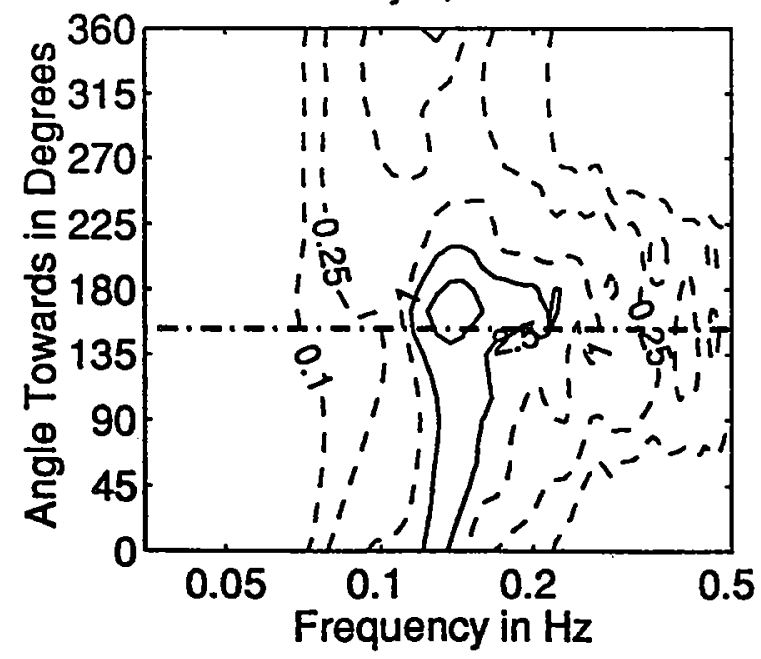

February 7, 1994152

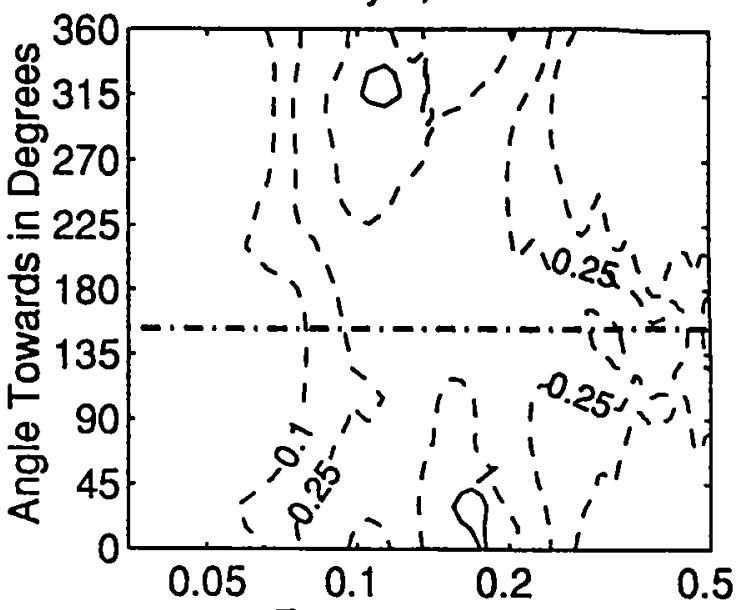

Frequency in $\mathrm{Hz}$

February 7, 1994212

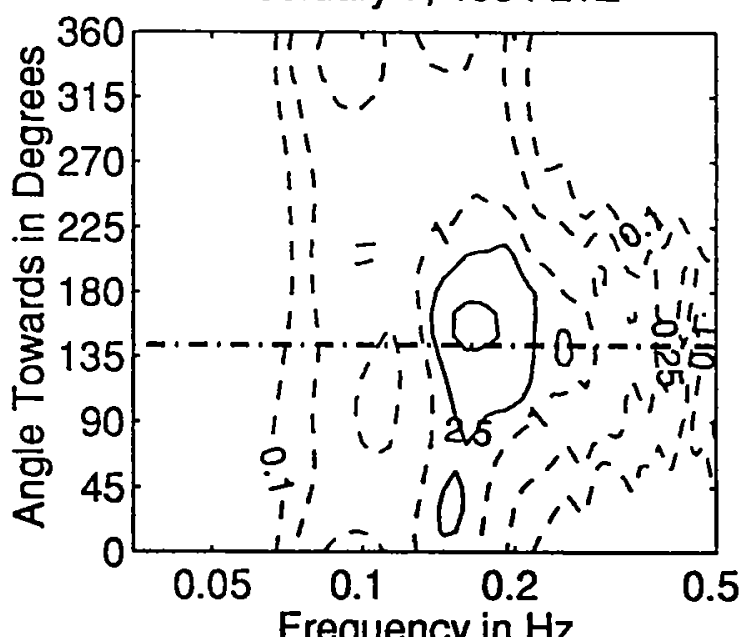

February 9, $199403 Z$

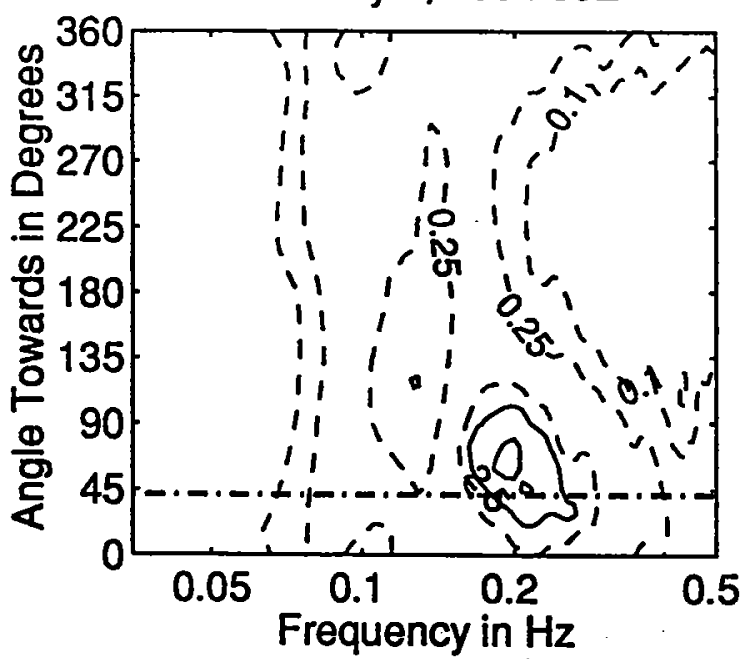

Figure 3.4.84: Directional wave spectra, computed using maximum entropy method. Contours of spectral density as a function of direction. Contours are 0.1, $0.25,1$ (dashed), $2.5,10,25,100$, and 250 (solid). Wind direction is shown by thick dashed line. 
February 9, $199406 Z$

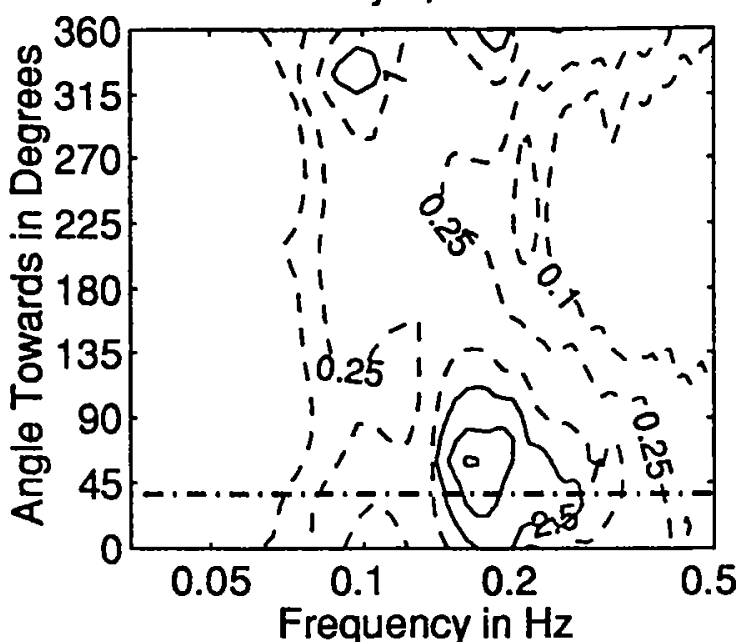

February 9, $199412 Z$

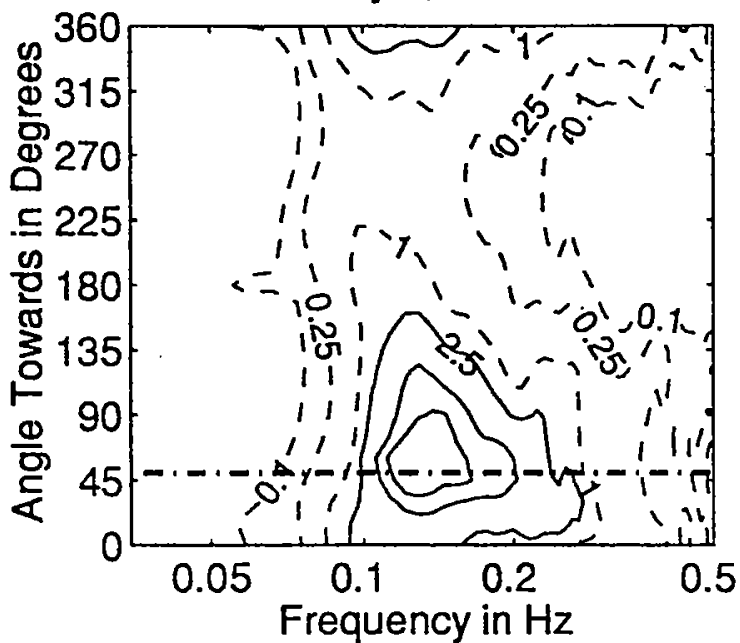

February 9, $199418 Z$

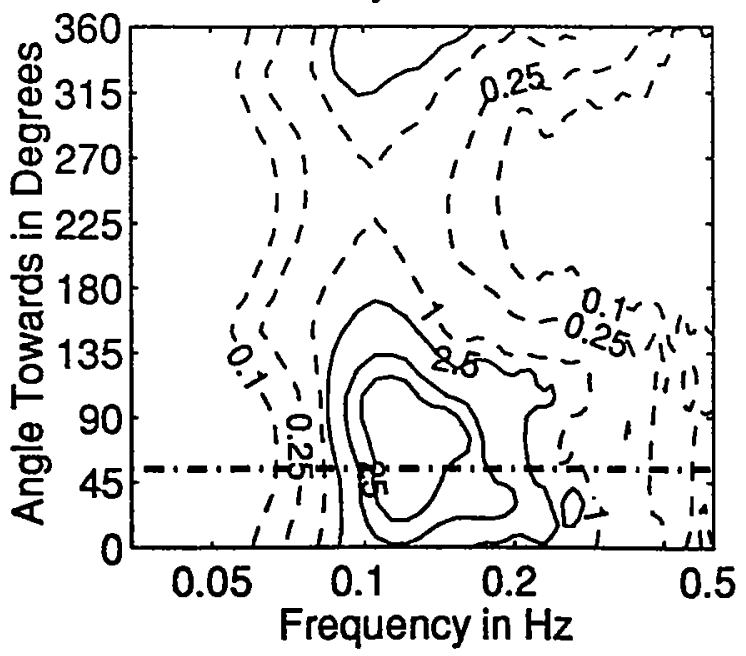

February 9, $199409 Z$

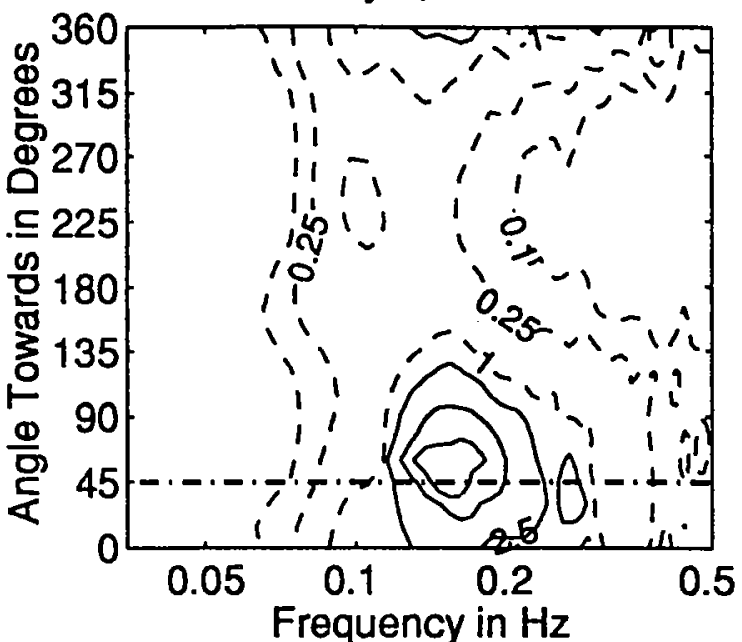

February 9, $199415 Z$

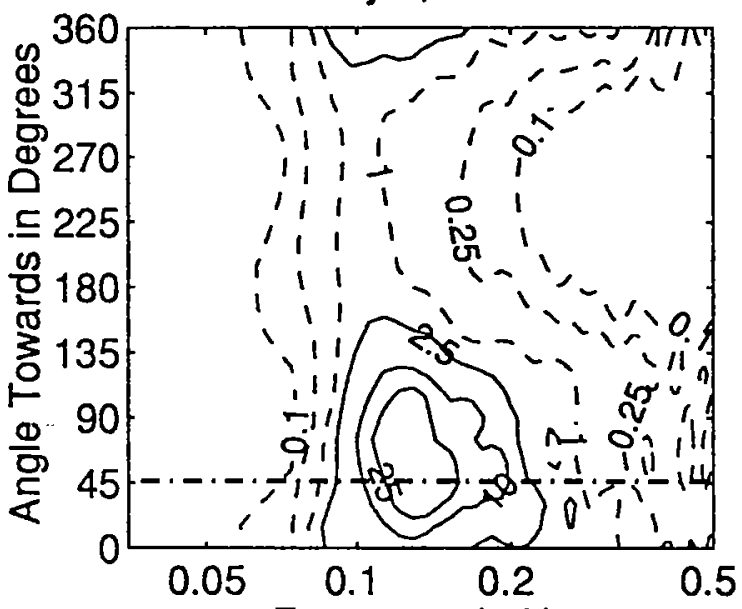

Frequency in $\mathrm{Hz}$

February 9, $199421 Z$

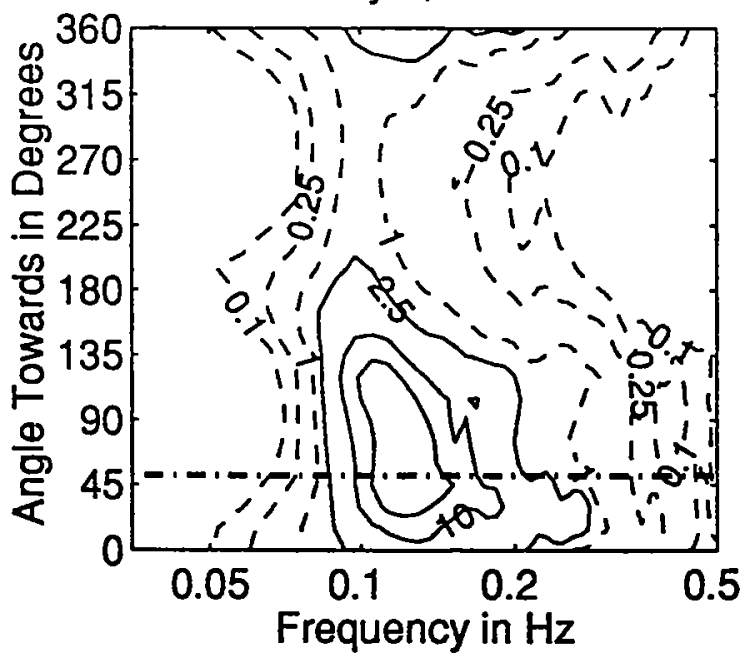

Figure 3.4.85: Directional wave spectra, computed using maximum entropy method. Contours of spectral density as a function of direction. Contours are 0.1 , $0.25,1$ (dashed), 2.5, 10,25, 100, and 250 (solid). Wind direction is shown by thick dashed line. 
February 10, $199400 Z$

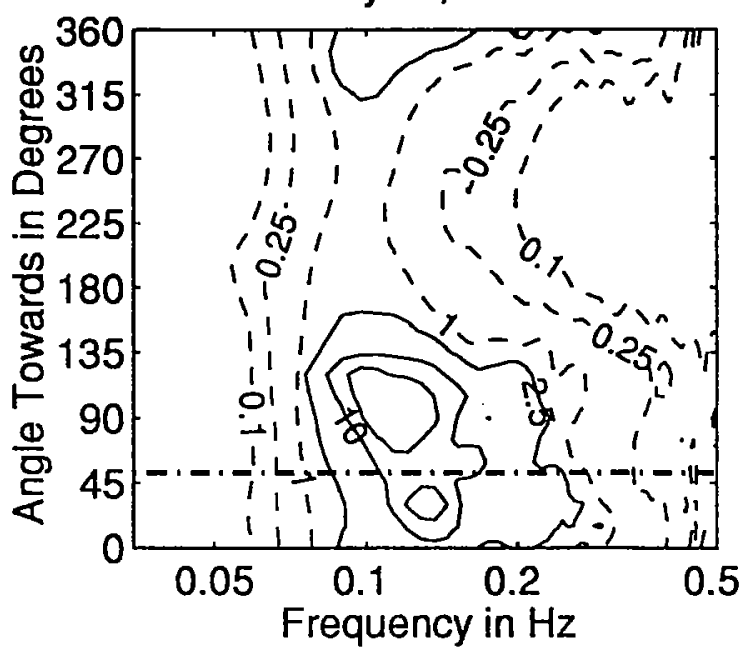

February 10, $199406 Z$

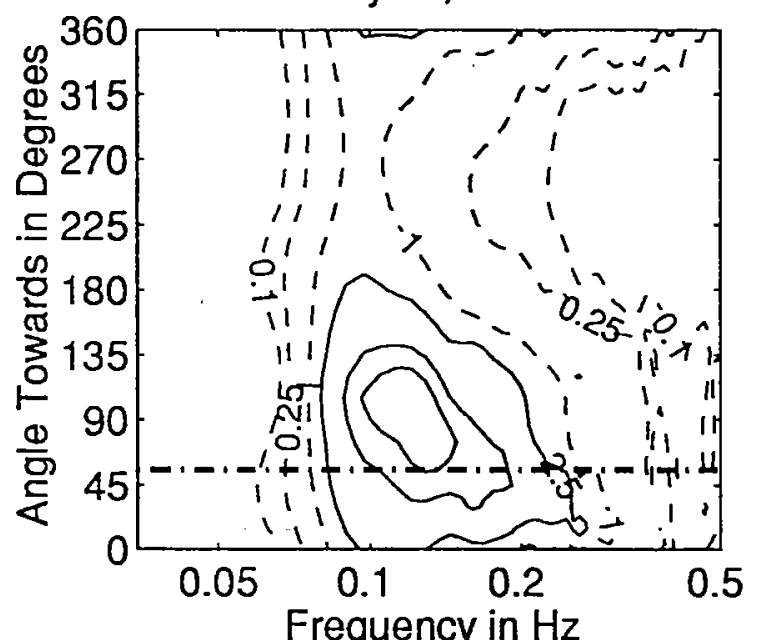

February 10, $199412 Z$

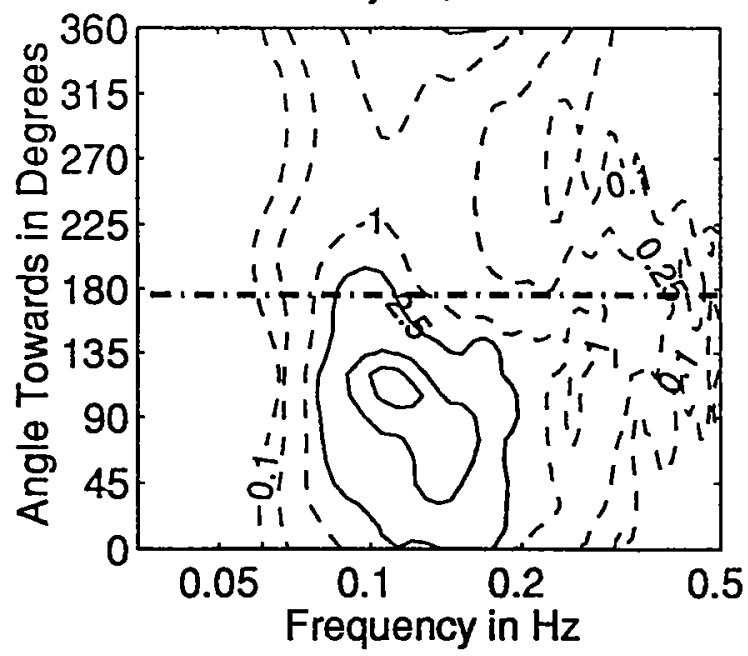

February 10, $199403 Z$

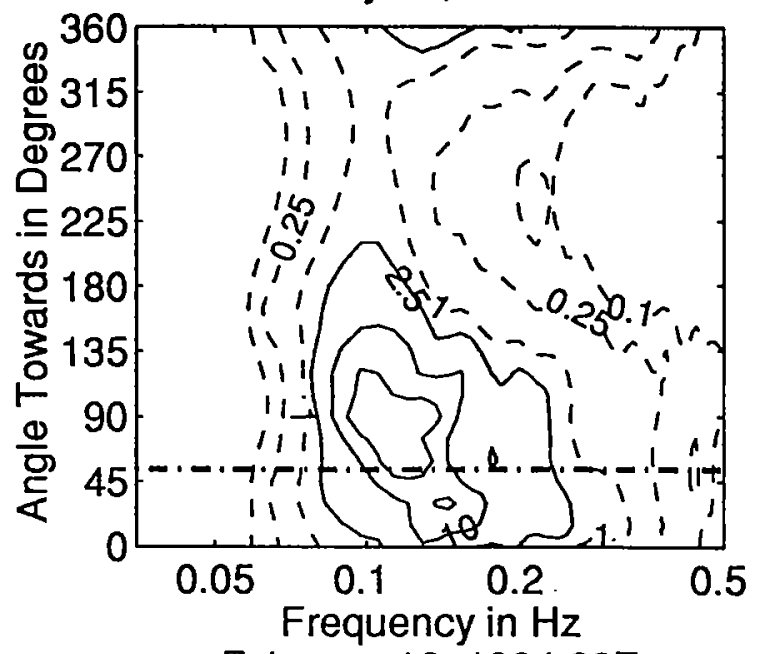

February 10, $199409 Z$

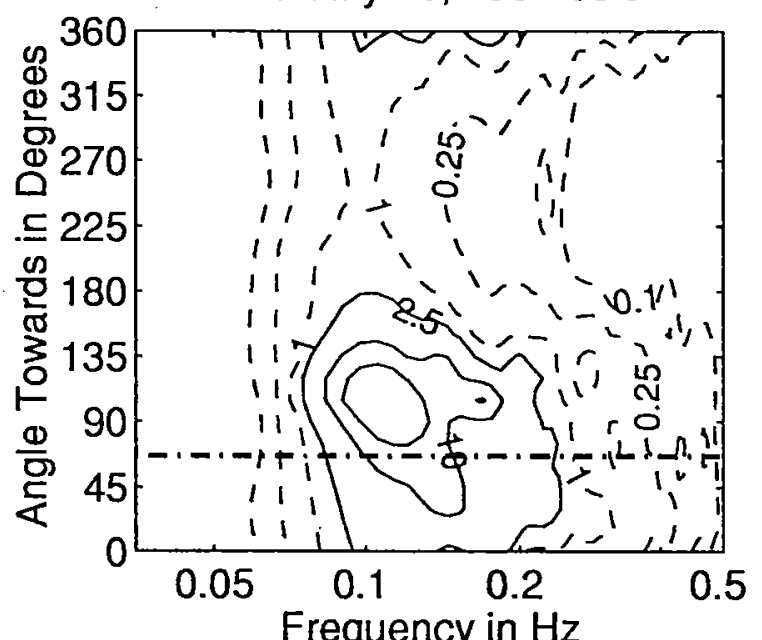

February 10, $199415 Z$

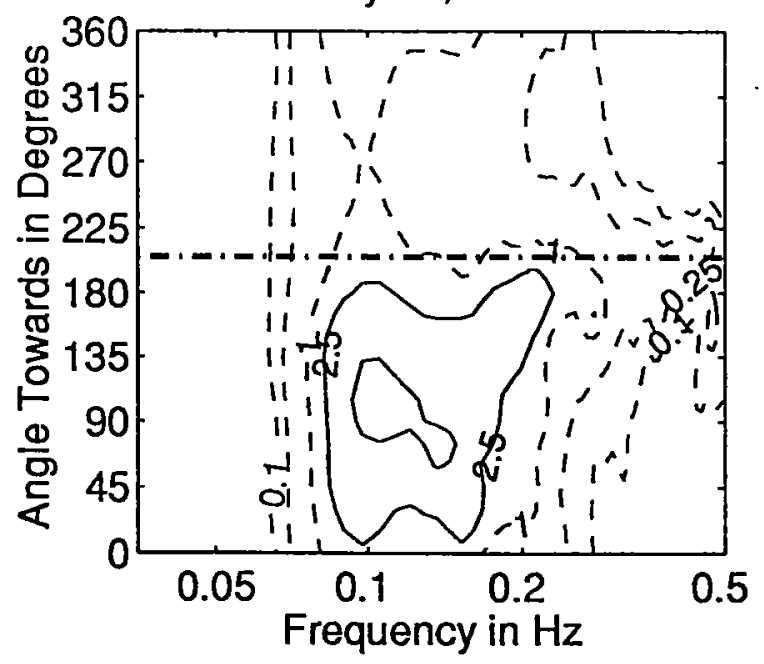

Figure 3.4.86: Directional wave spectra, computed using maximum entropy method. Contours of spectral density as a function of direction. Contours are 0.1, $0.25,1$ (dashed), $2.5,10,25,100$, and 250 (solid). Wind direction is shown by thick dashed line. 
February 10, $199418 Z$

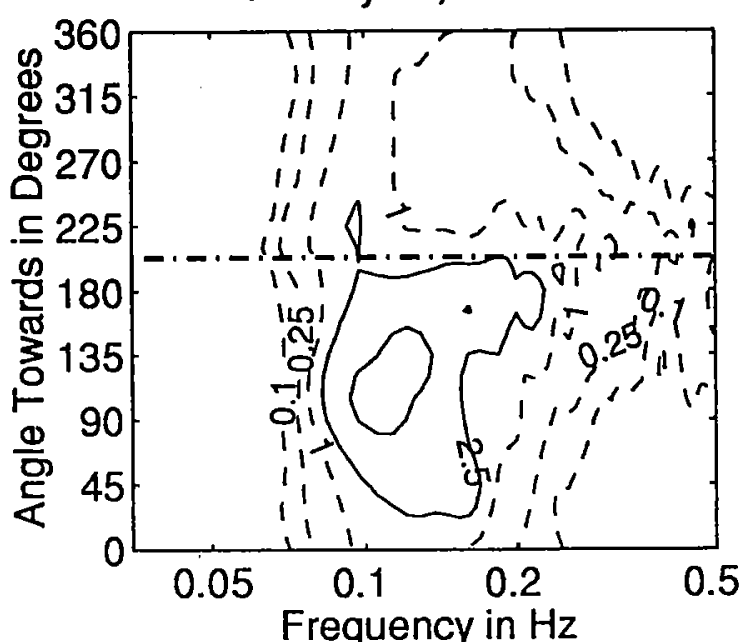

February 11, $199400 Z$

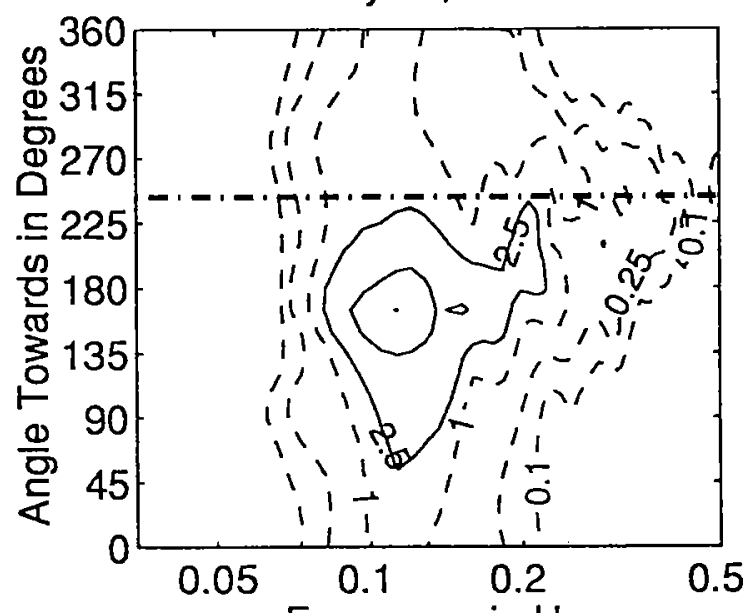

Frequency in $\mathrm{Hz}$

February 11, $199406 Z$

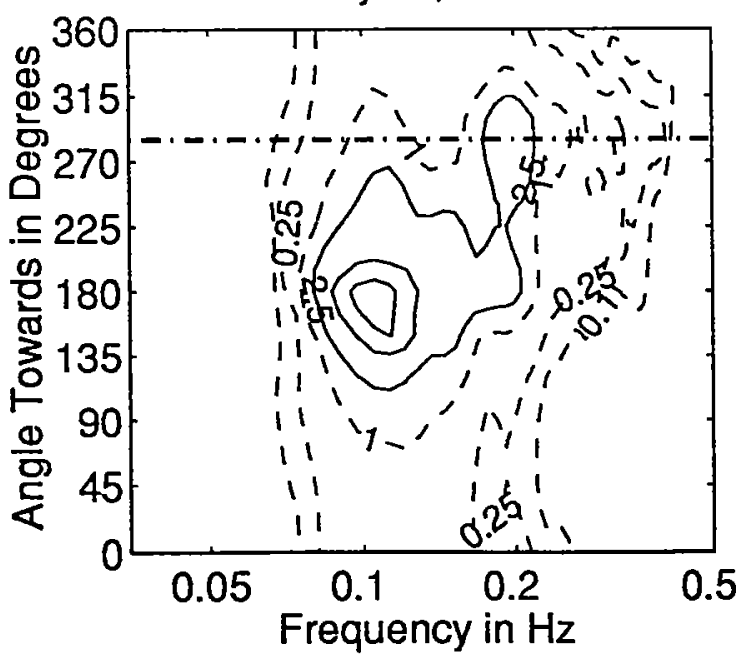

February 10, $199421 Z$

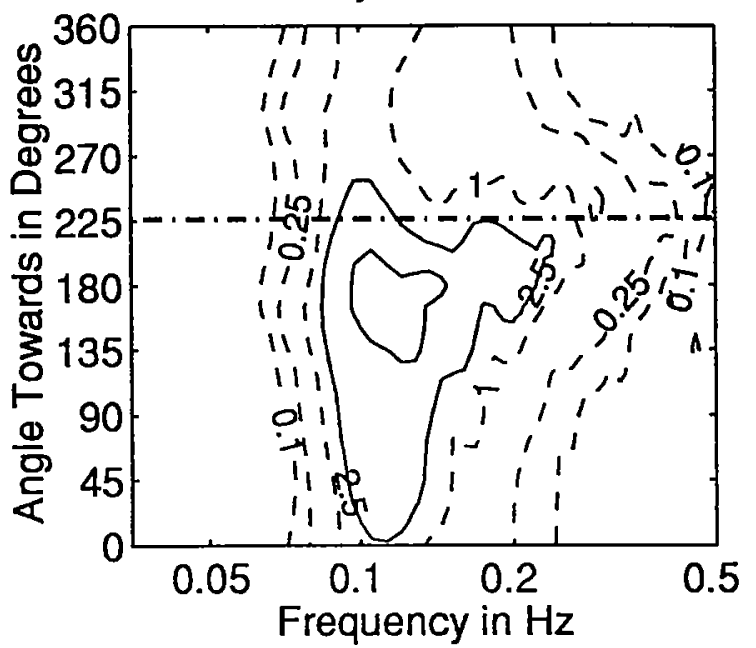

February 11, $199403 Z$

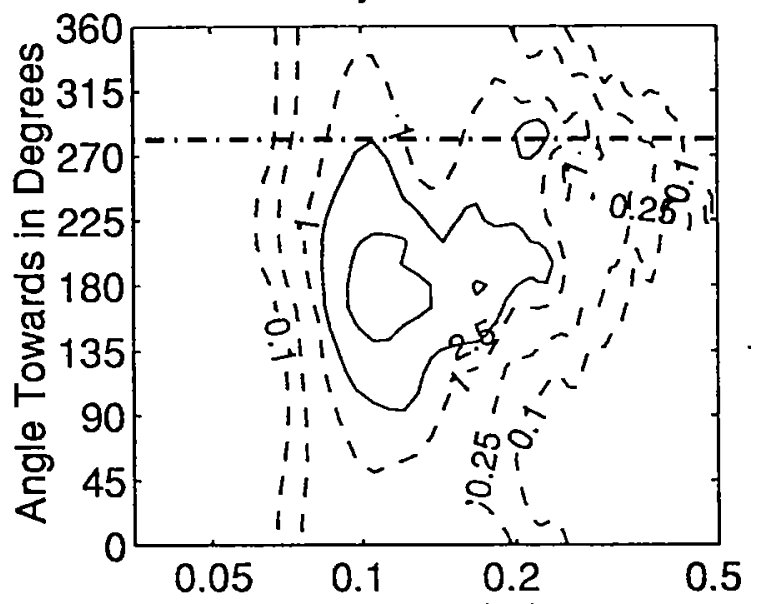

Frequency in $\mathrm{Hz}$

February 11, $199409 Z$

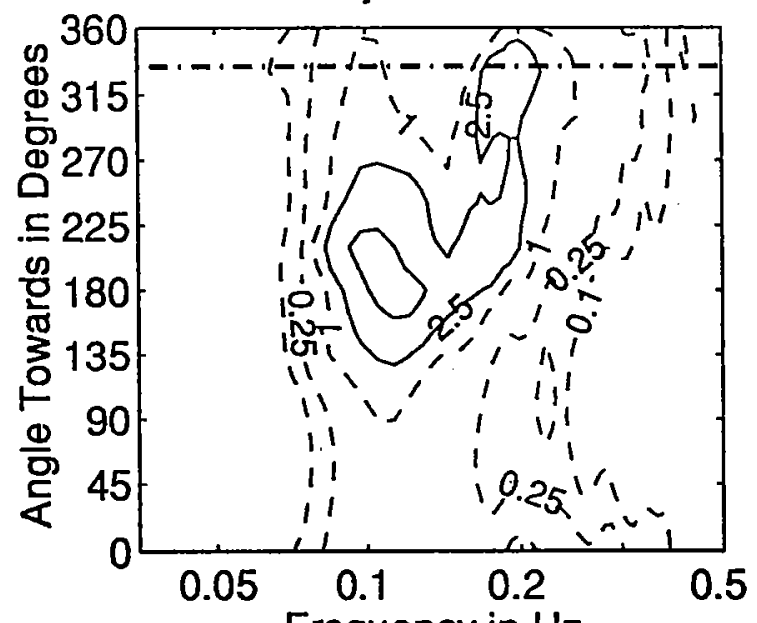

Frequency in $\mathrm{Hz}$

Figure 3.4.87: Directional wave spectra, computed using maximum entropy method. Contours of spectral density as a function of direction. Contours are 0.1, $0.25,1$ (dashed), $2.5,10,25,100$, and 250 (solid). Wind direction is shown by thick dashed line. 
February 11, $199412 Z$

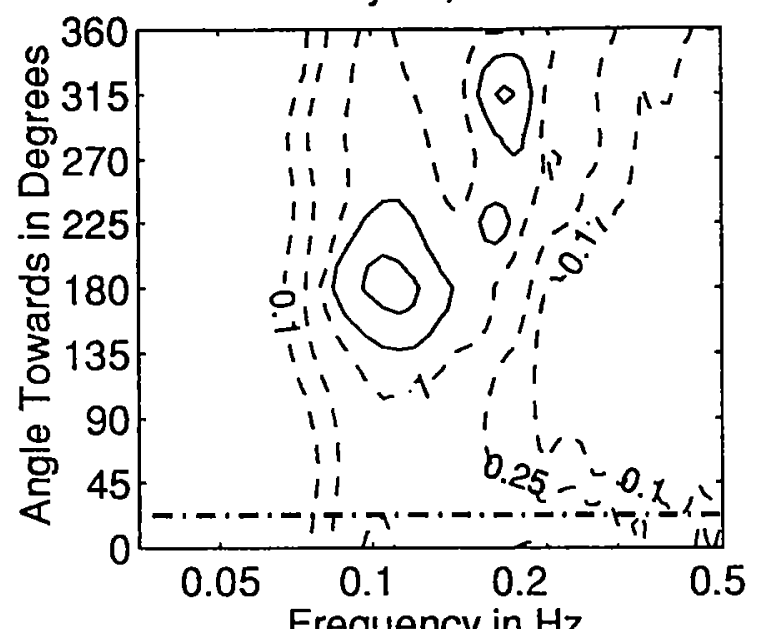

February 11, 1994182

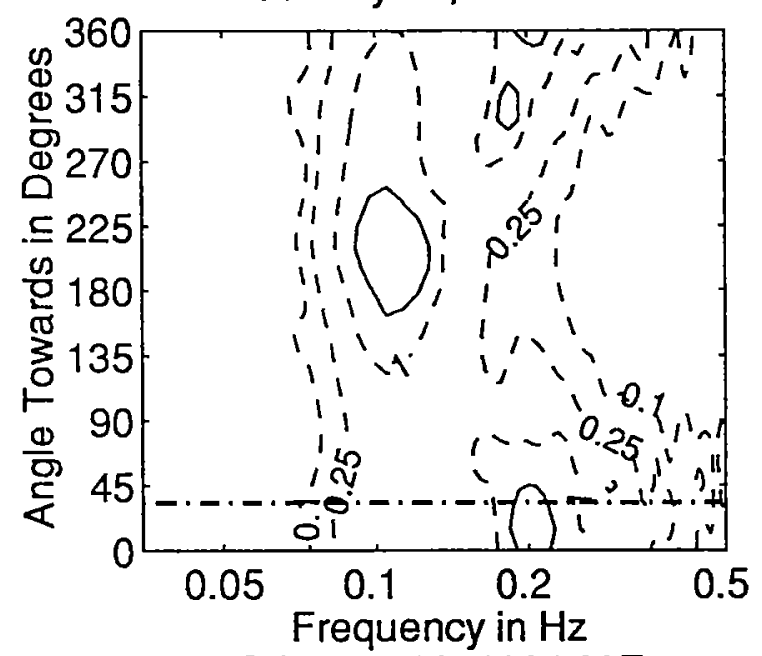

February 12, $199400 \mathrm{Z}$

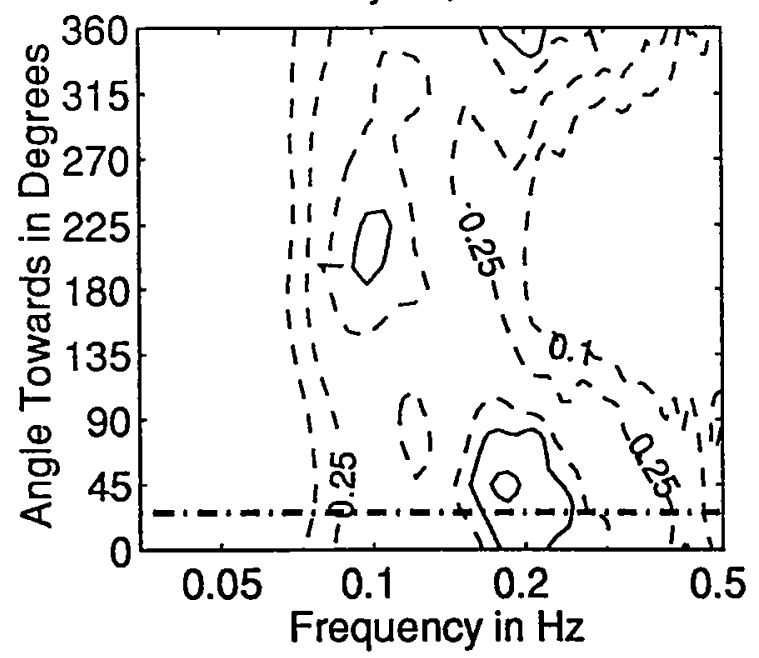

February 11, $199415 Z$

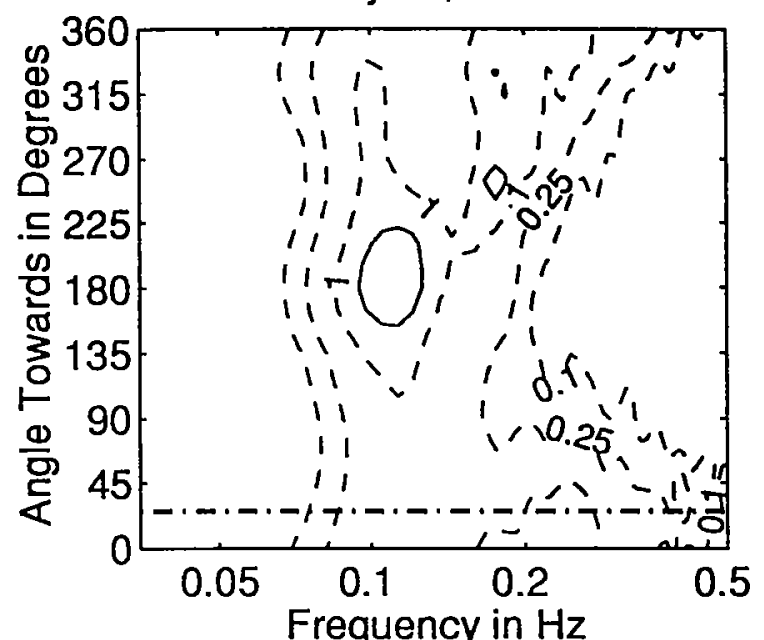

February 11, $199421 Z$

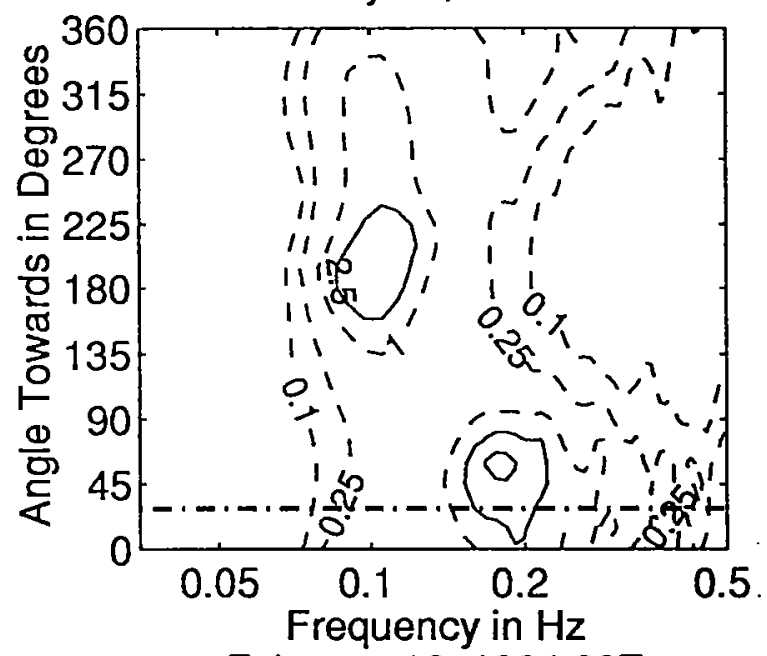

February. 12, $199403 Z$

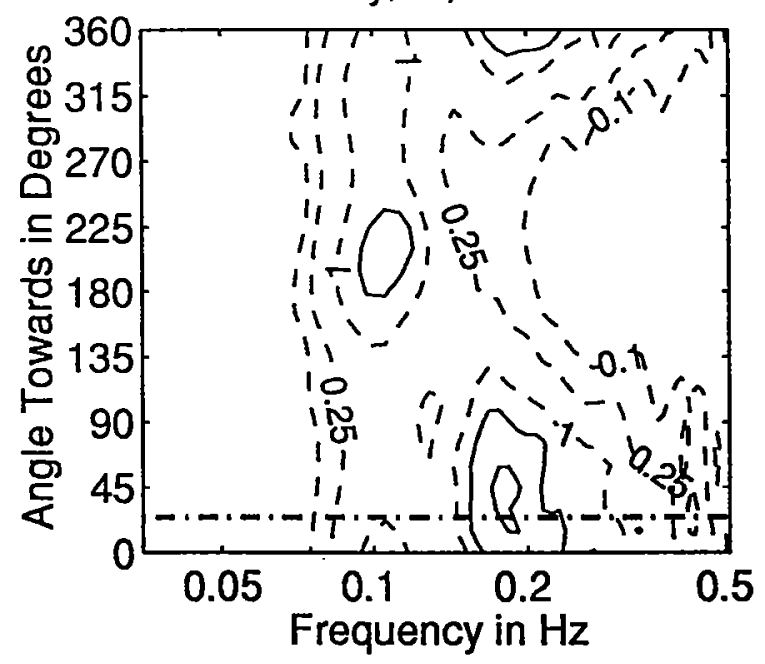

Figure 3.4.88: Directional wave spectra, computed using maximum entropy method. Contours of spectral density as a function of direction. Contours are 0.1 , $0.25,1$ (dashed), $2.5,10,25,100$, and 250 (solid). Wind direction is shown by thick dashed line. 
February 12, $199406 Z$

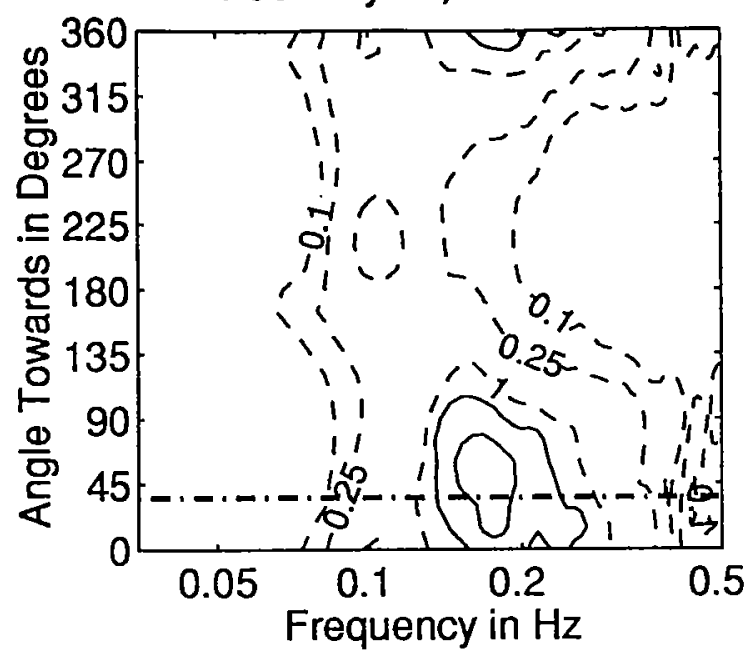

February 12, $199412 Z$

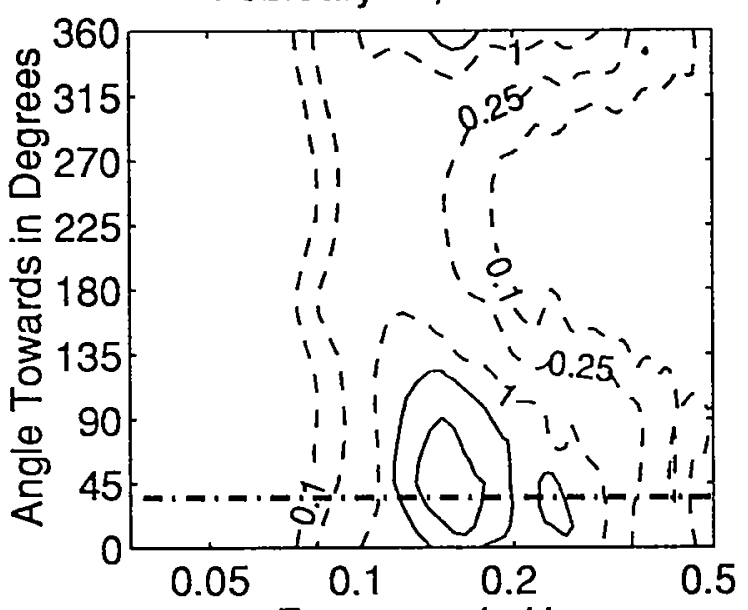

Frequency in $\mathrm{Hz}$

February 12, $199418 Z$

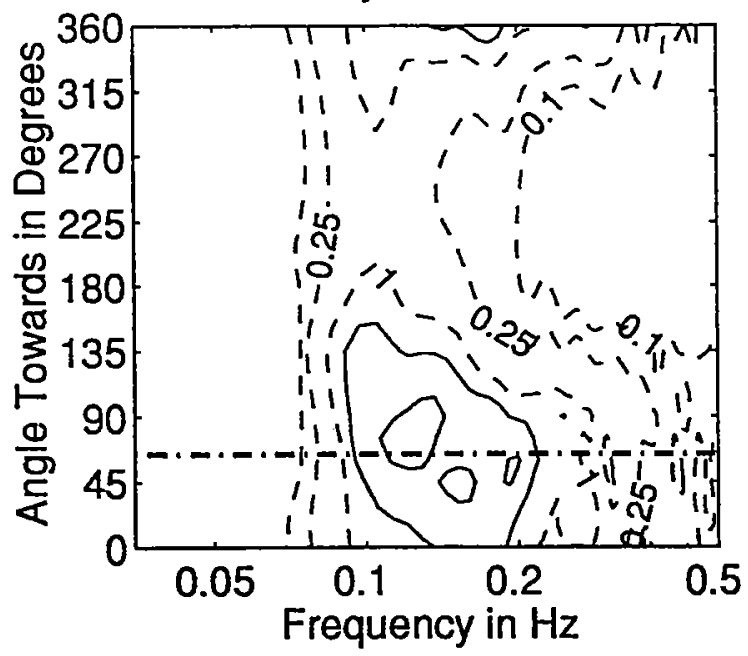

February 12, $199409 Z$

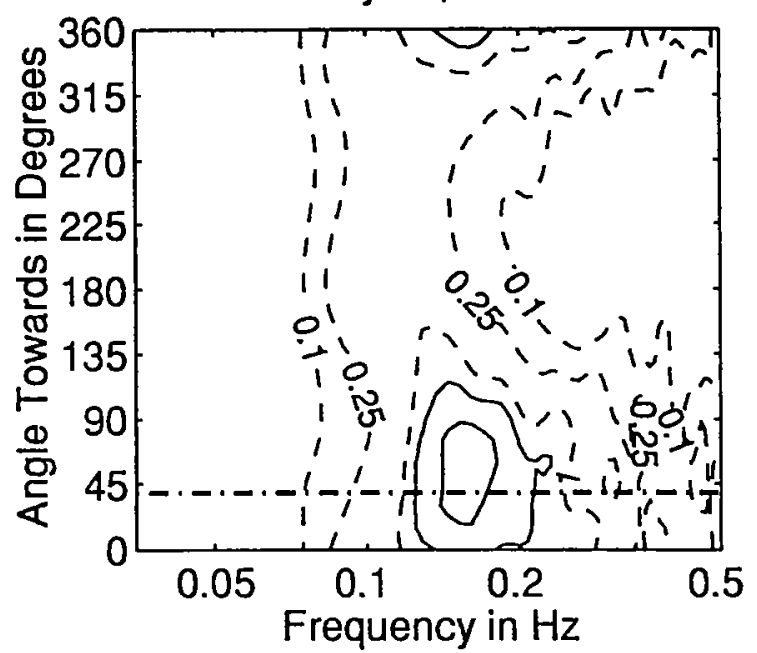

February 12, $199415 Z$

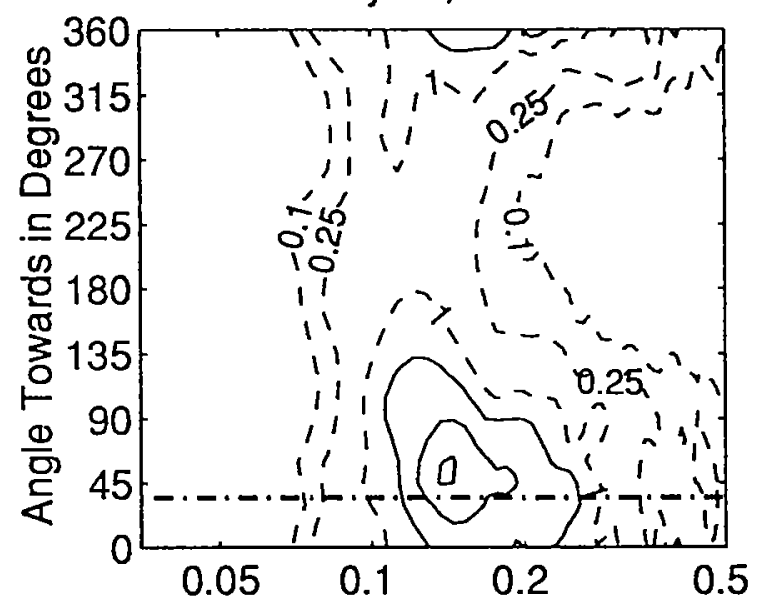

Frequency in $\mathrm{Hz}$

February 12, 1994 21Z

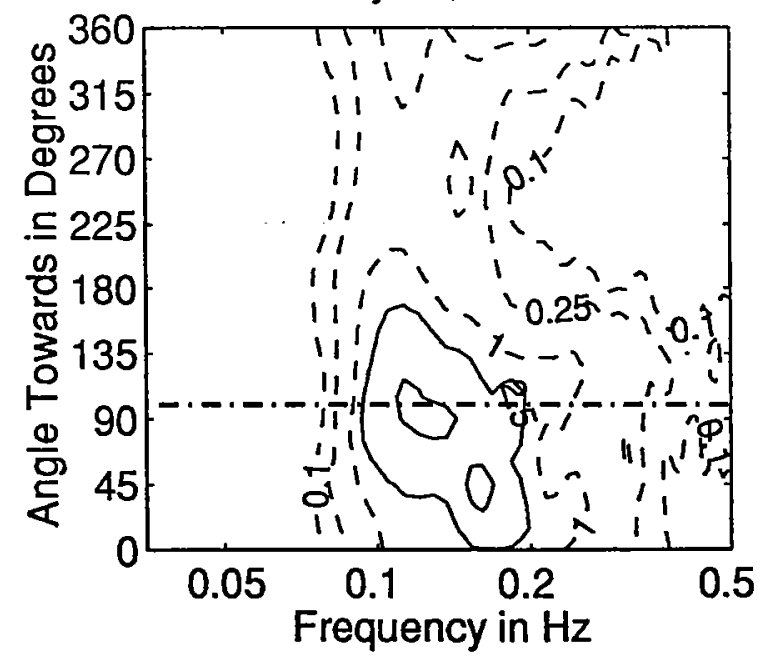

Figure 3.4.89: Directional wave spectra, computed using maximum entropy method. Contours of spectral density as a function of direction. Contours are 0.1 , $0.25,1$ (dashed), $2.5,10,25,100$, and 250 (solid). Wind direction is shown by thick dashed line. 
February 13, $199400 Z$

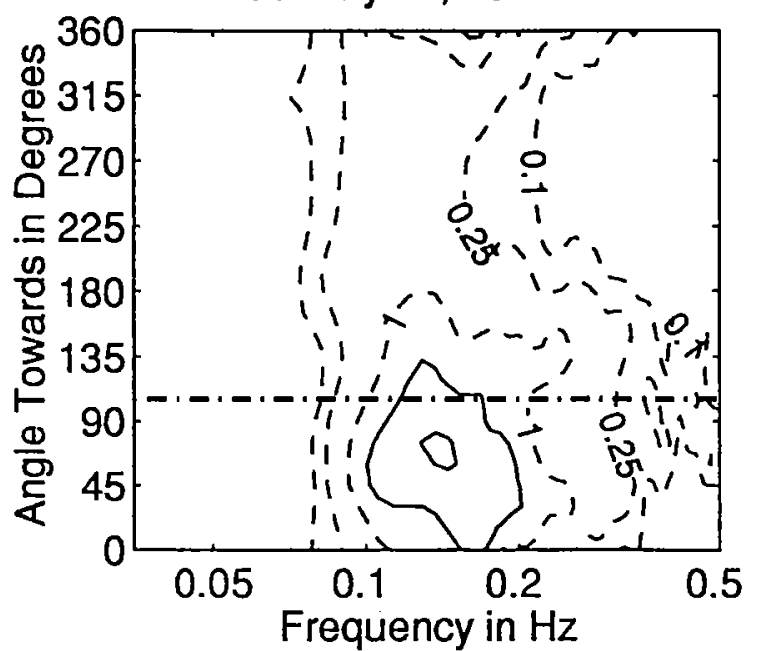

February 13, 1994062

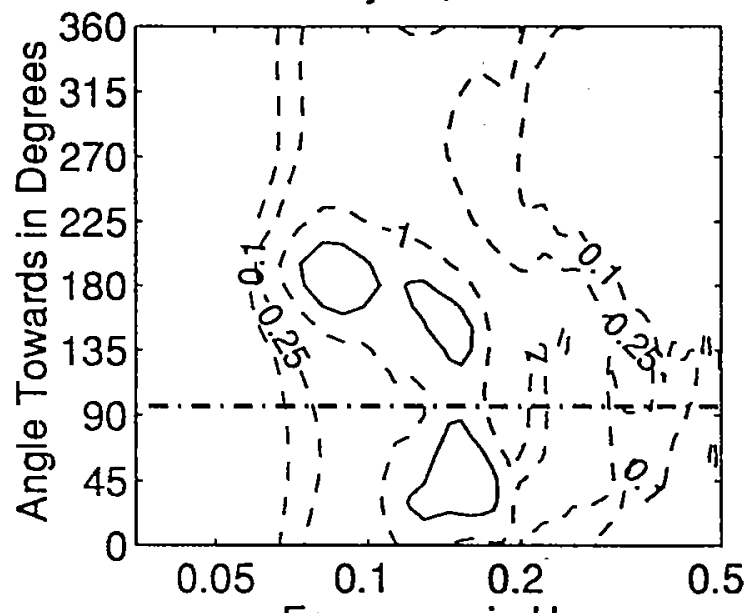

Frequency in $\mathrm{Hz}$

February 13, $199412 Z$

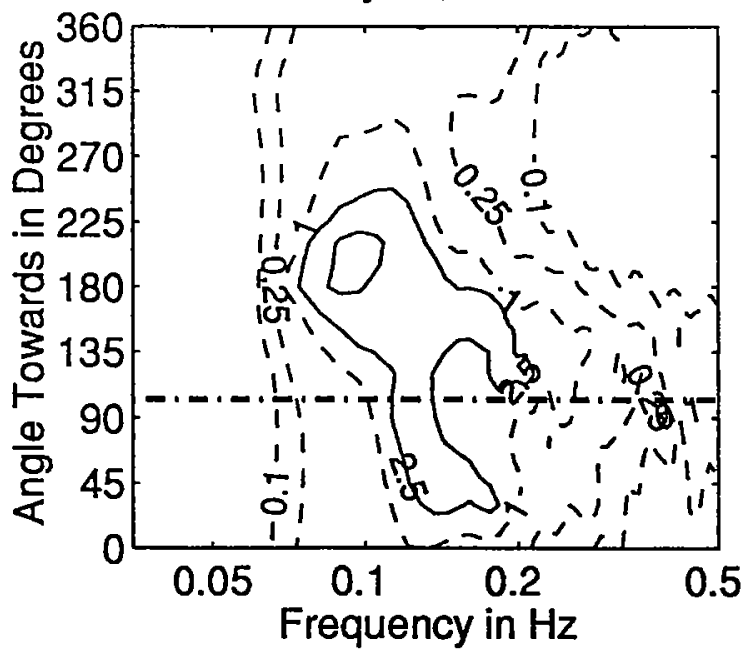

February 13, 1994032

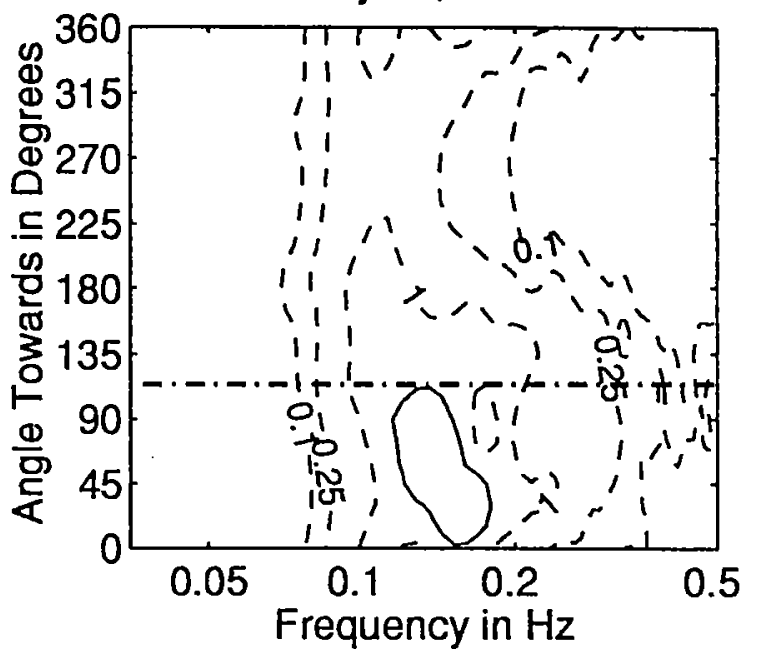

February 13, $199409 Z$

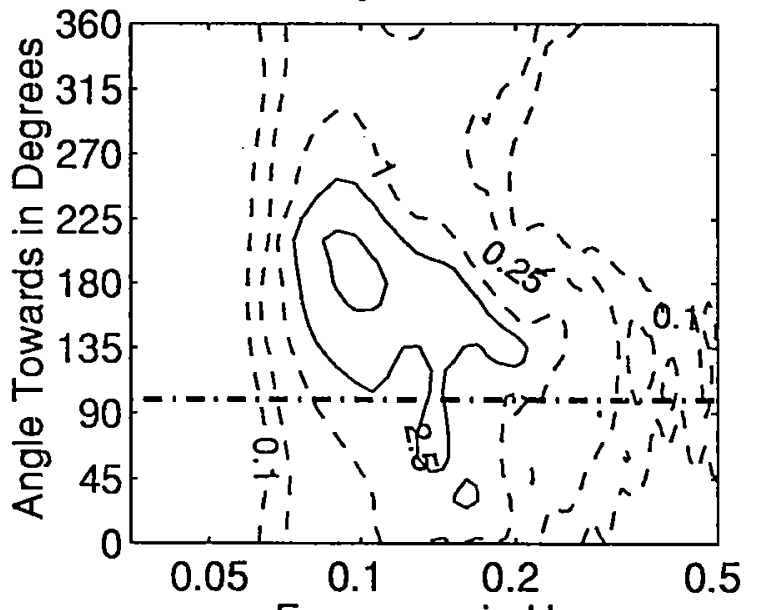

Frequency in $\mathrm{Hz}$

February 13, $199415 Z$

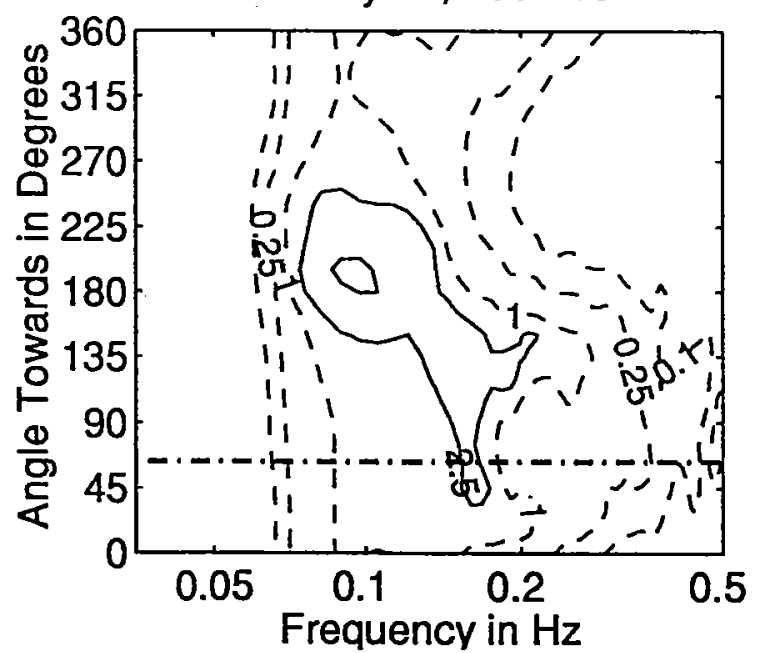

Figure 3.4.90: Directional wave spectra, computed using maximum entropy method. Contours of spectral density as a function of direction. Contours are 0.1, $0.25,1$ (dashed), $2.5,10,25,100$, and 250 (solid). Wind direction is shown by thick dashed line. 
February 13, $199418 Z$

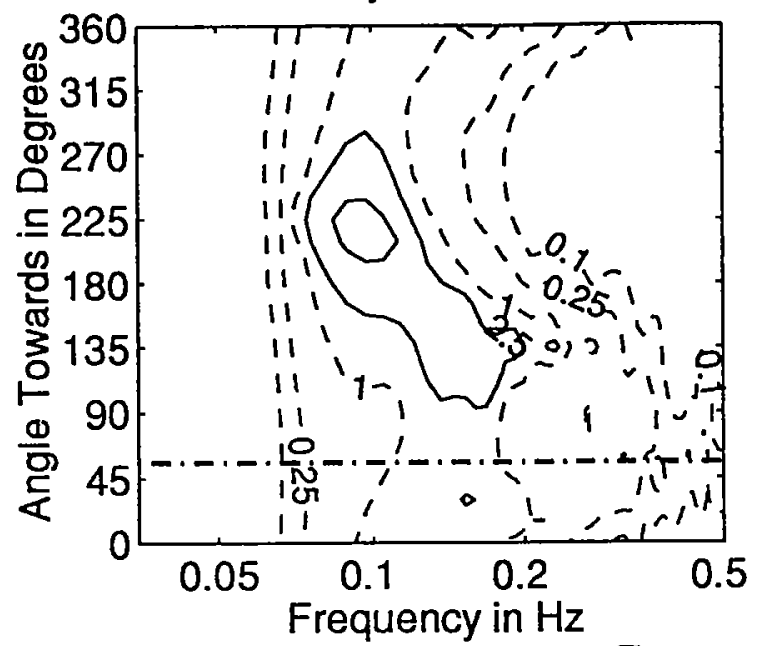

February 14, $199400 Z$

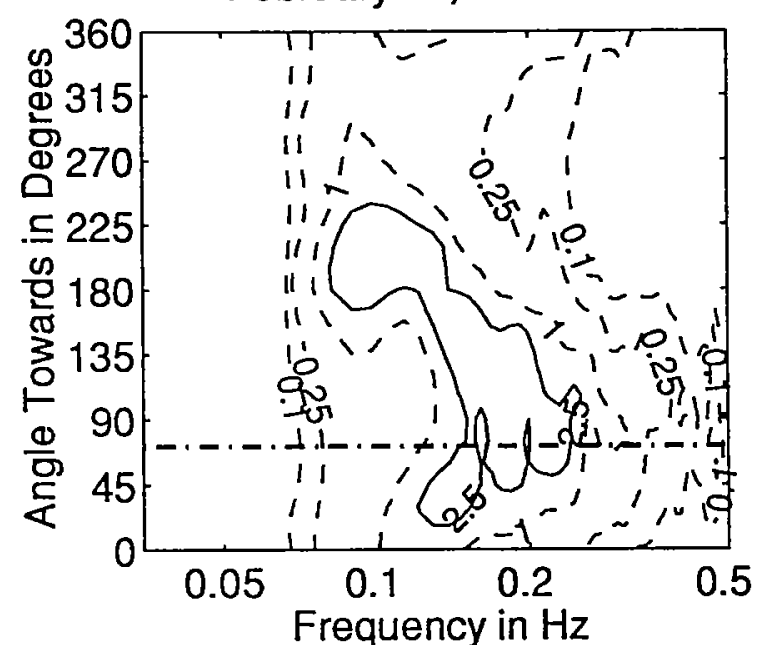

February 14, 1994062

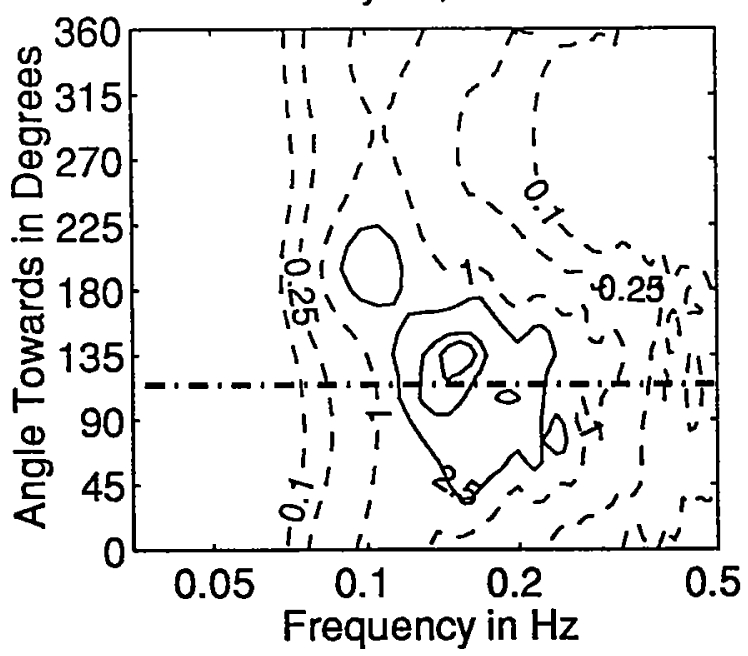

February 13, $199421 \mathrm{Z}$

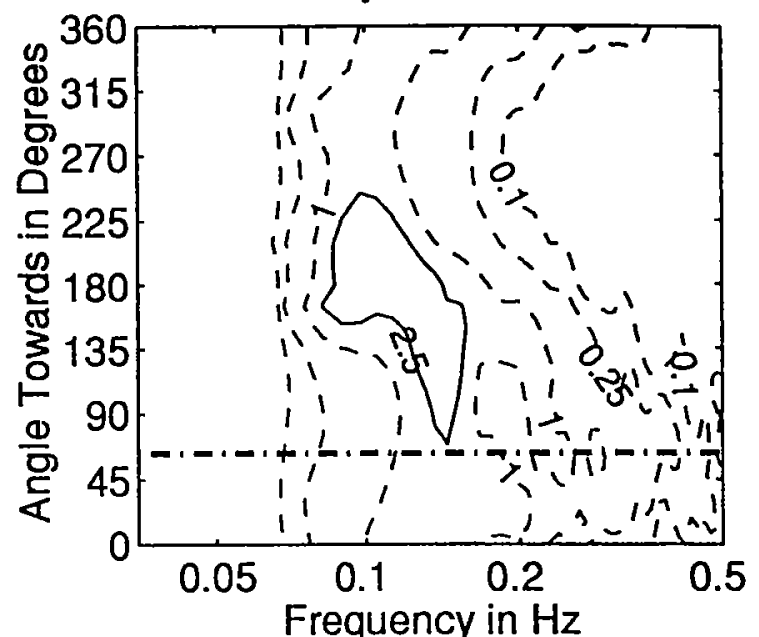

February 14, $199403 Z$

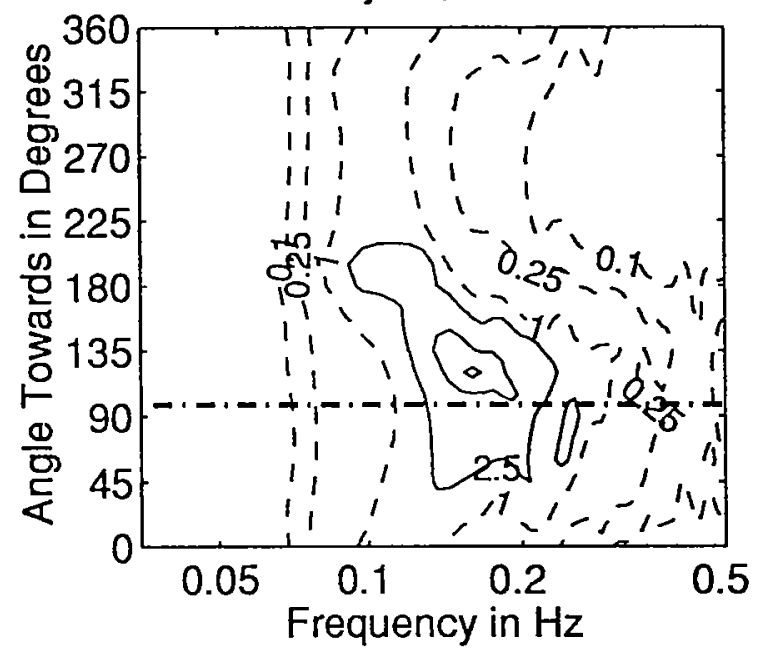

February 14, $199409 Z$

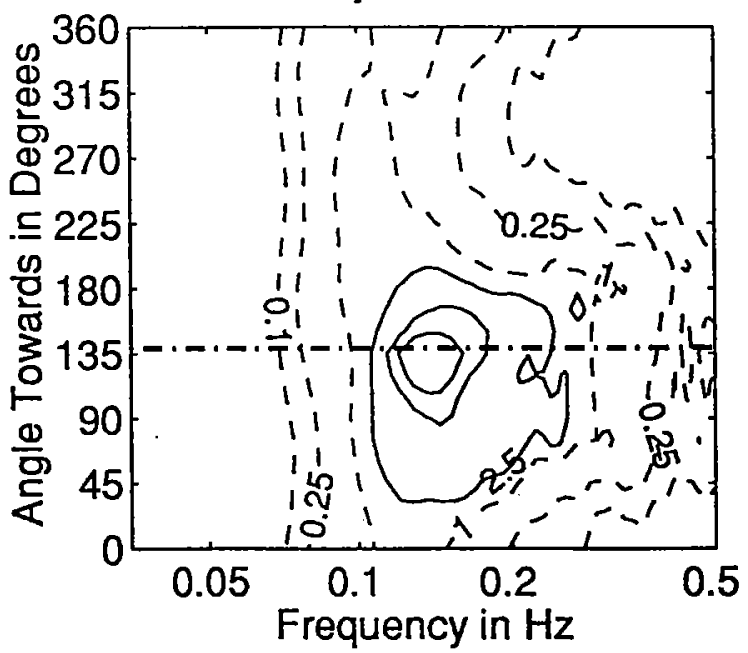

Figure 3.4.91: Directional wave spectra, computed using maximum entropy method. Contours of spectral density as a function of direction. Contours are 0.1 , $0.25,1$ (dashed), $2.5,10,25,100$, and 250 (solid). Wind direction is shown by thick dashed line. 
February 14, $199412 Z$

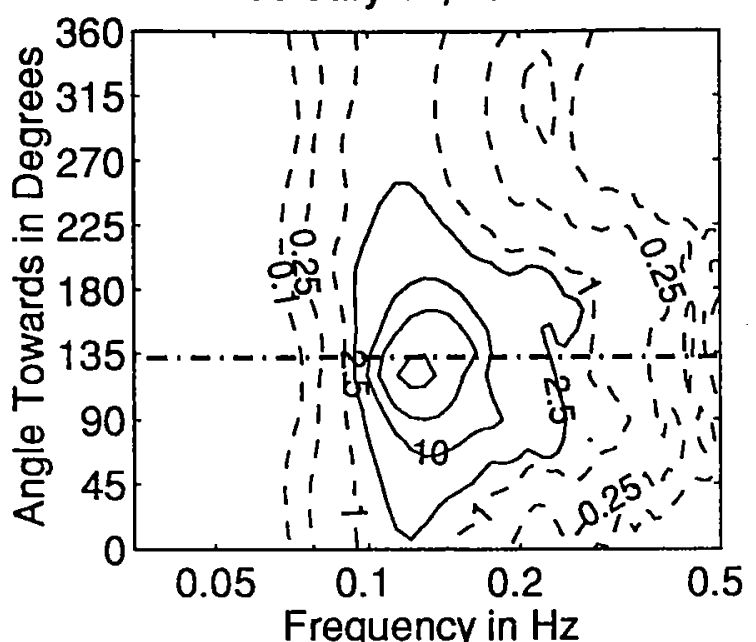

February 14, $199418 Z$

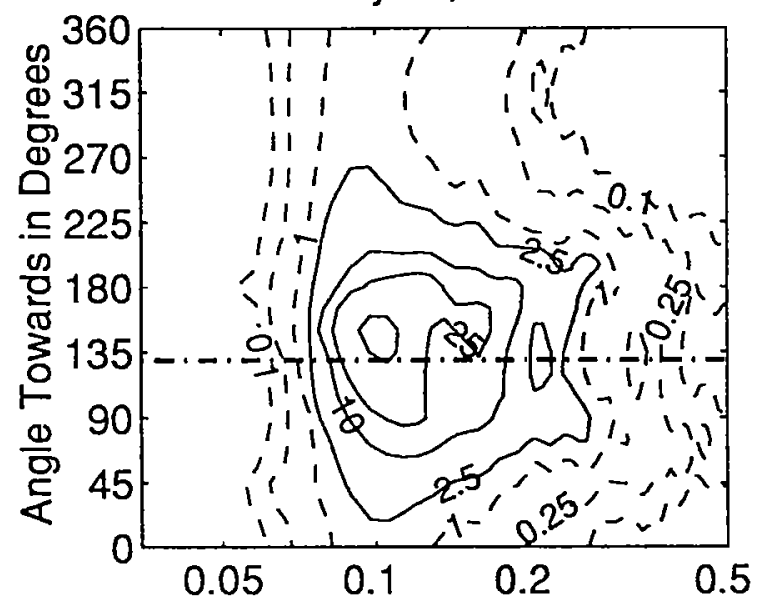

Frequency in $\mathrm{Hz}$

February 15, 1994 00Z

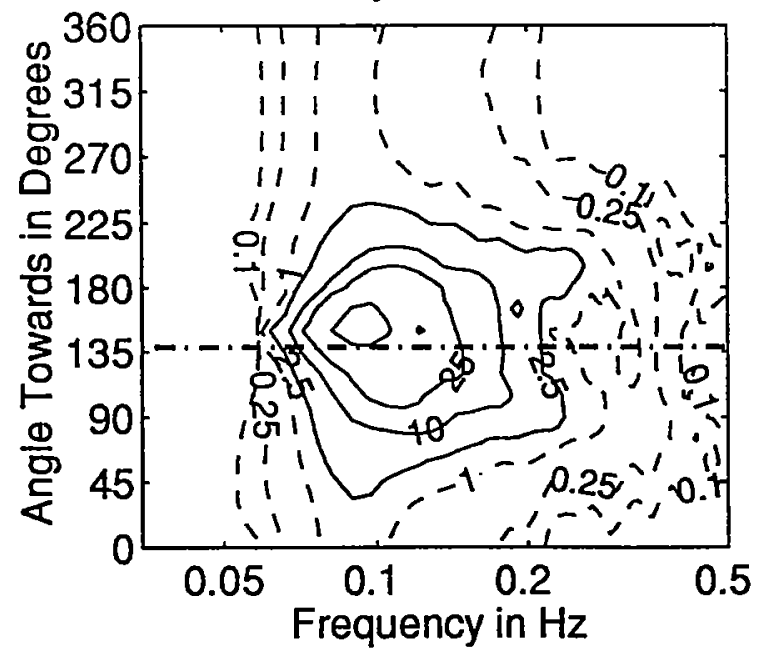

February 14, $199415 Z$

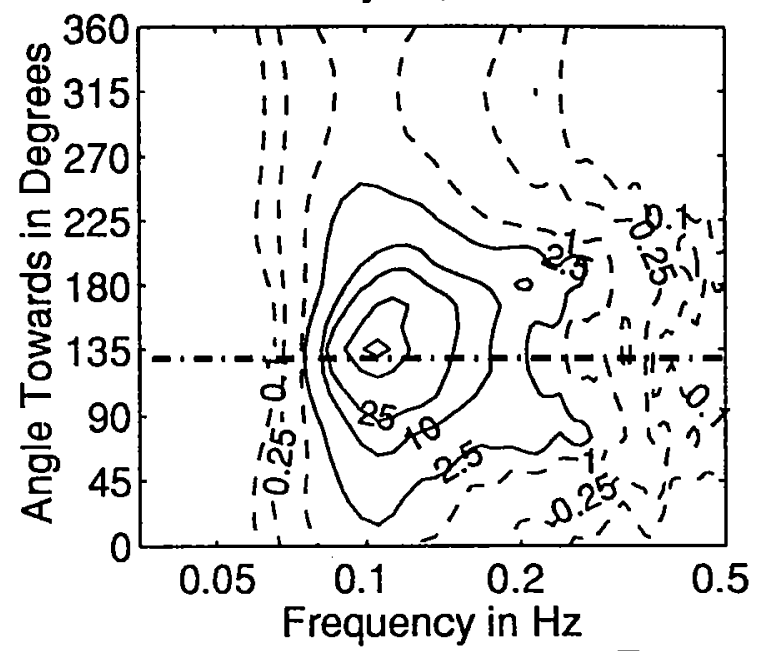

February 14, $199421 Z$

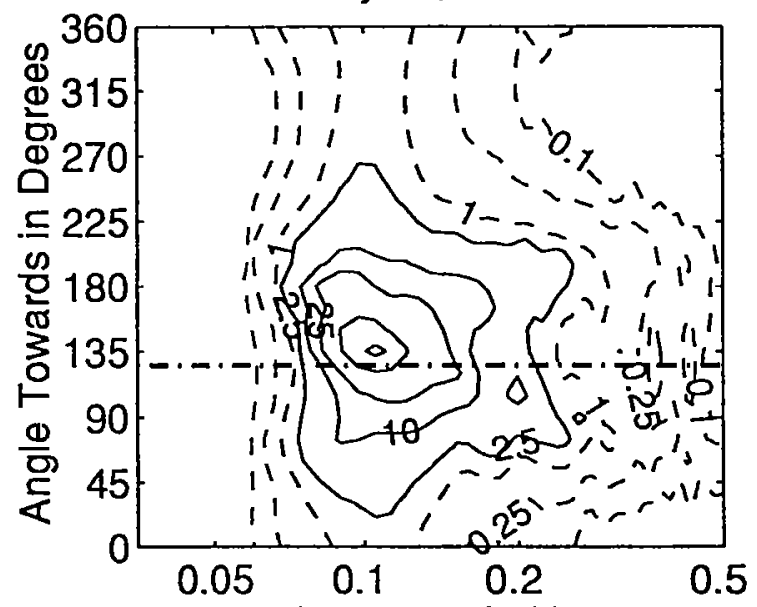

Frequency in $\mathrm{Hz}$

February 15, $199403 Z$

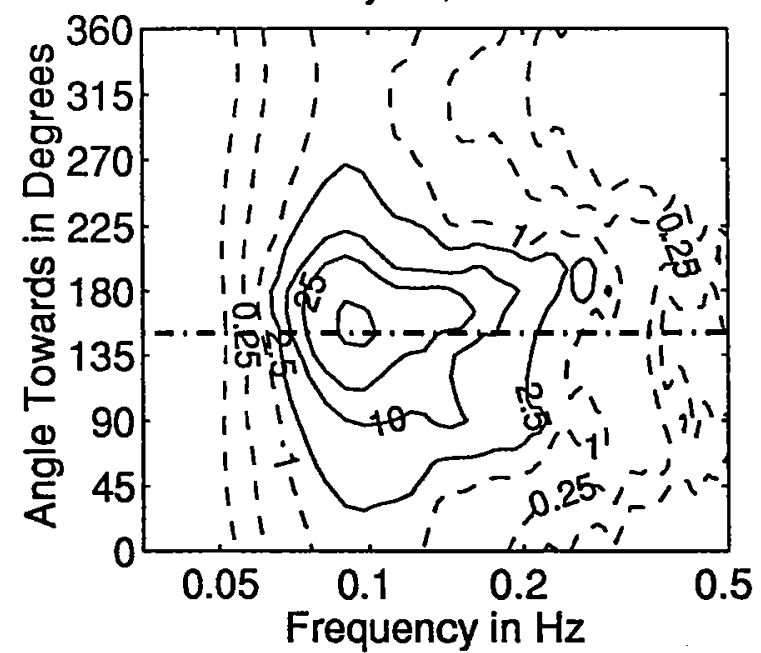

Figure 3.4.92: Directional wave spectra, computed using maximum entropy method. Contours of spectral density as a function of direction. Contours are 0.1, $0.25,1$ (dashed), $2.5,10,25,100$, and 250 (solid). Wind direction is shown by thick dashed line. 
February 15, $199406 Z$

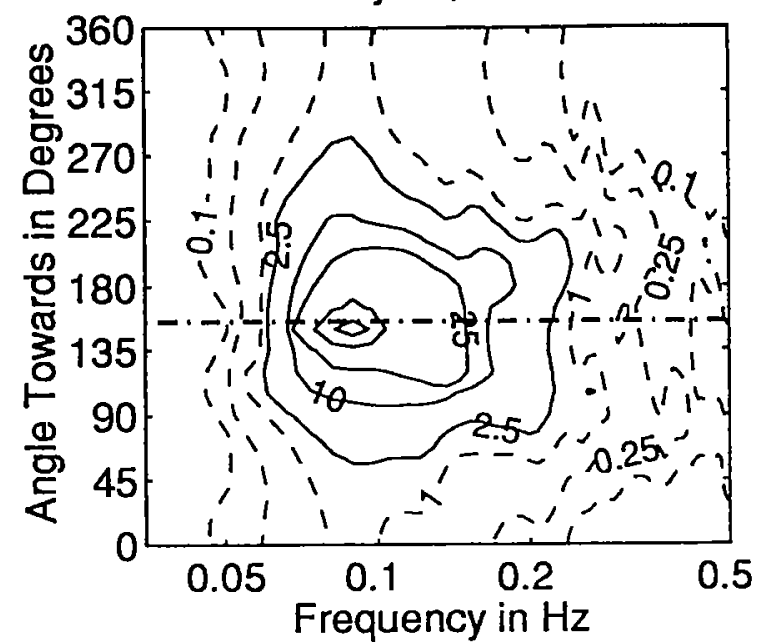

February 15, $199412 Z$

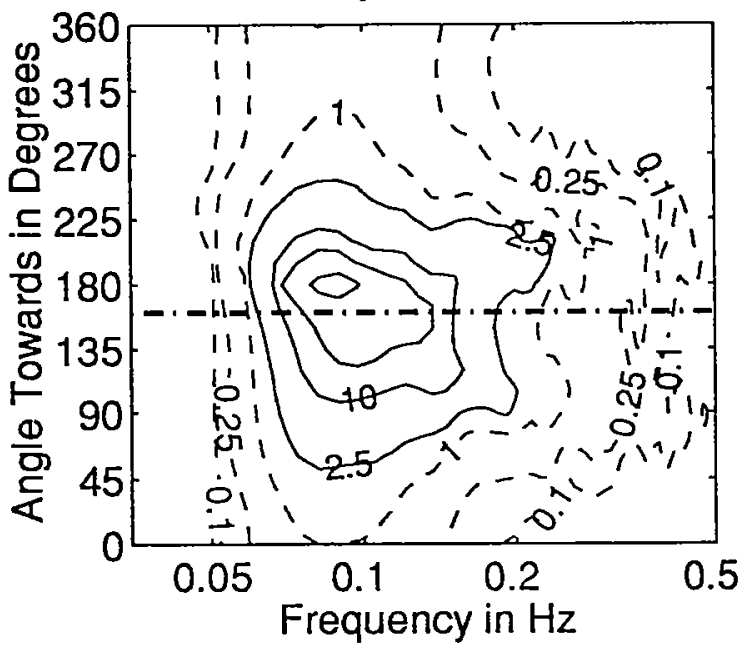

February 15, $199418 Z$

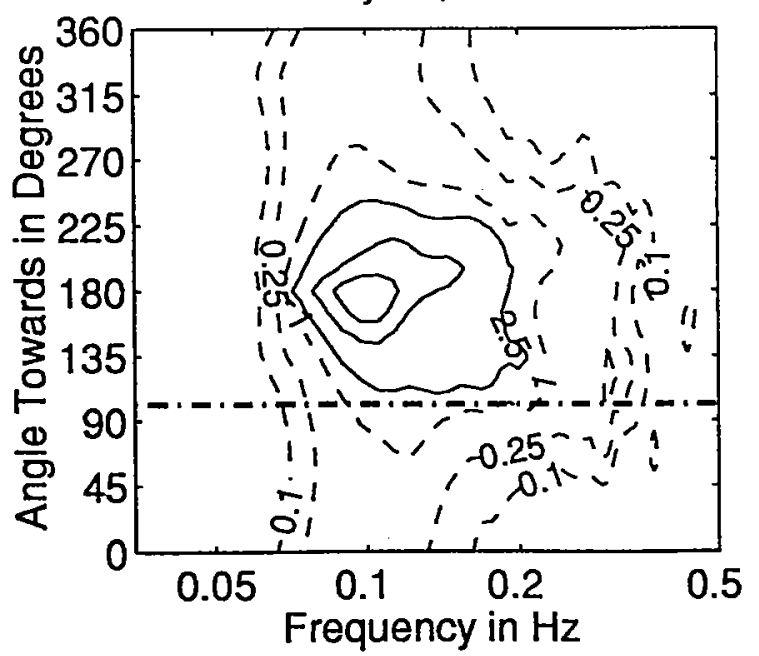

February 15, $199409 Z$

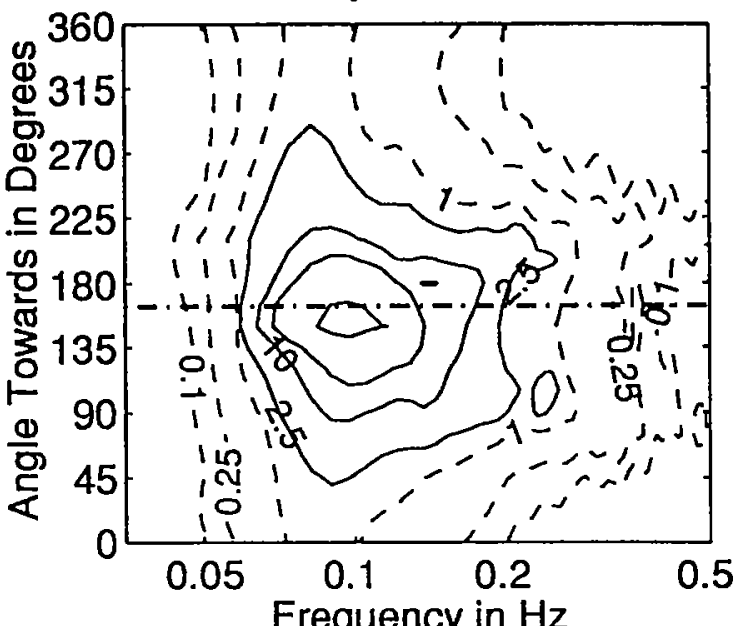

February 15, $199415 Z$

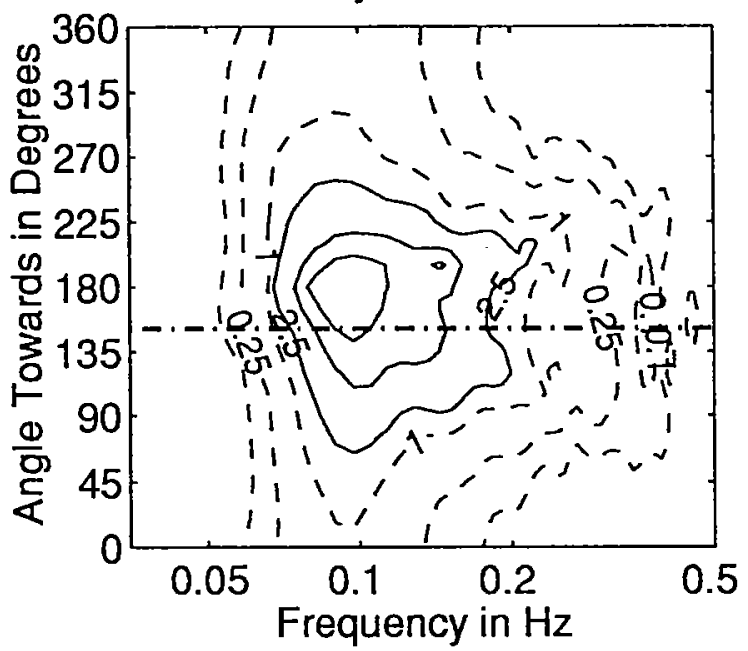

February 15, $199421 \mathrm{Z}$

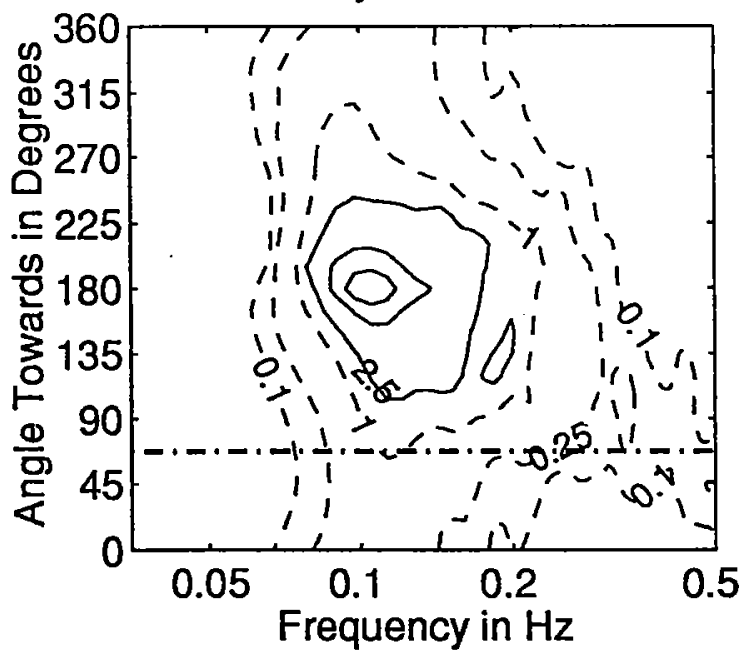

Figure 3.4.93: Directional wave spectra, computed using maximum entropy method. Contours of spectral density as a function of direction. Contours are 0.1, $0.25,1$ (dashed), $2.5,10,25,100$, and 250 (solid). Wind direction is shown by thick dashed line. 
February 16, $199400 Z$

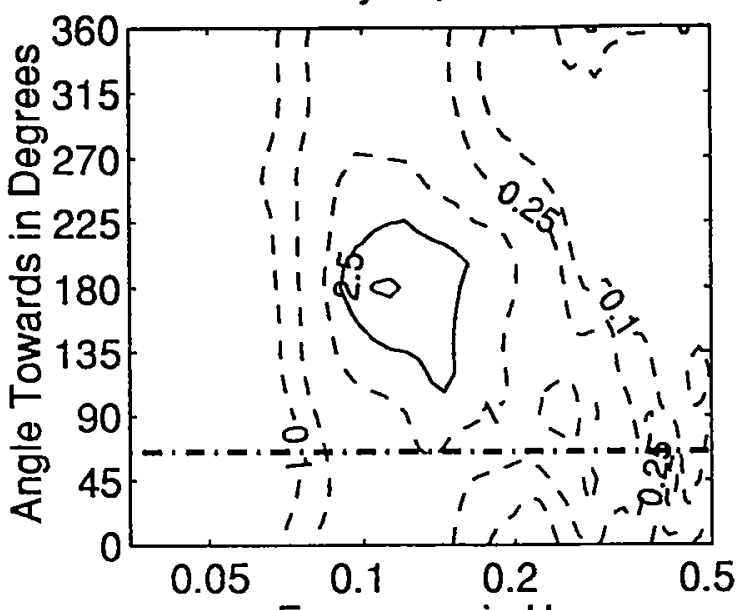

Frequency in $\mathrm{Hz}$

February 16, $199406 Z$

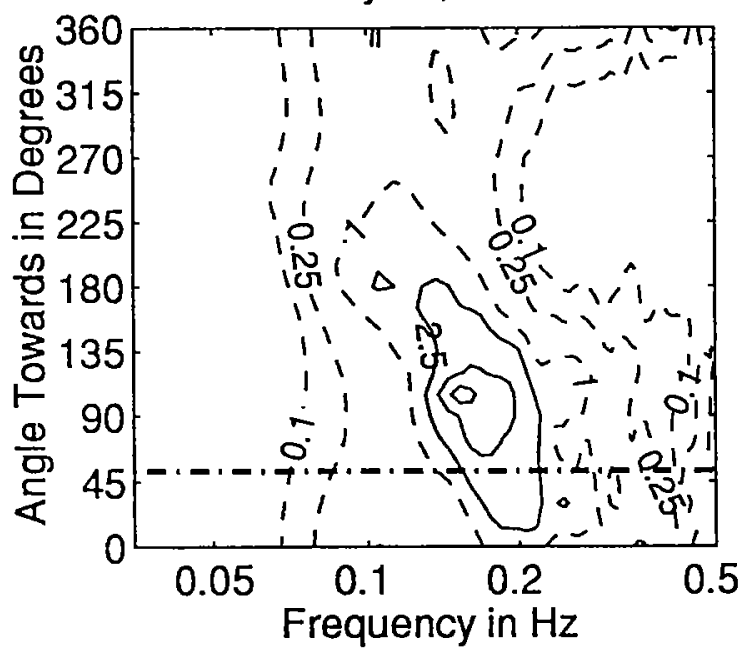

February 16, $199412 Z$

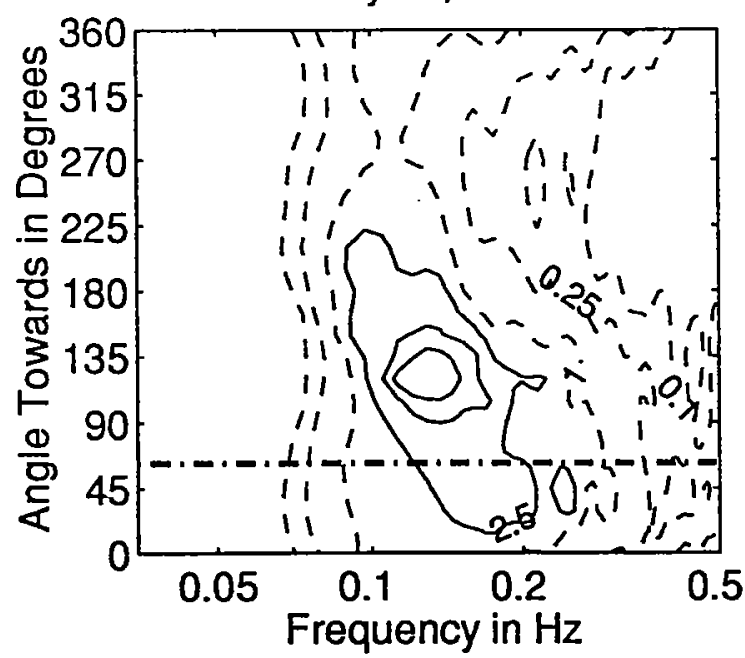

February 16, $199403 Z$

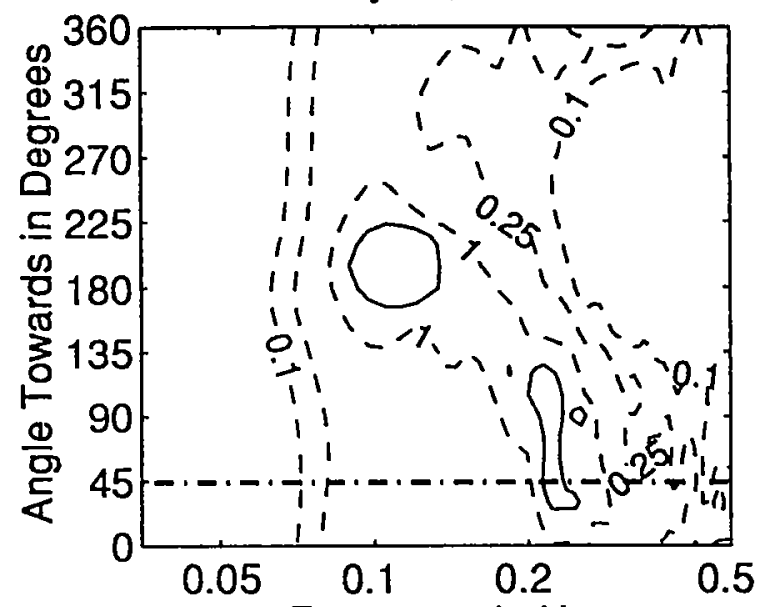

Frequency in $\mathrm{Hz}$

February 16, $199409 Z$

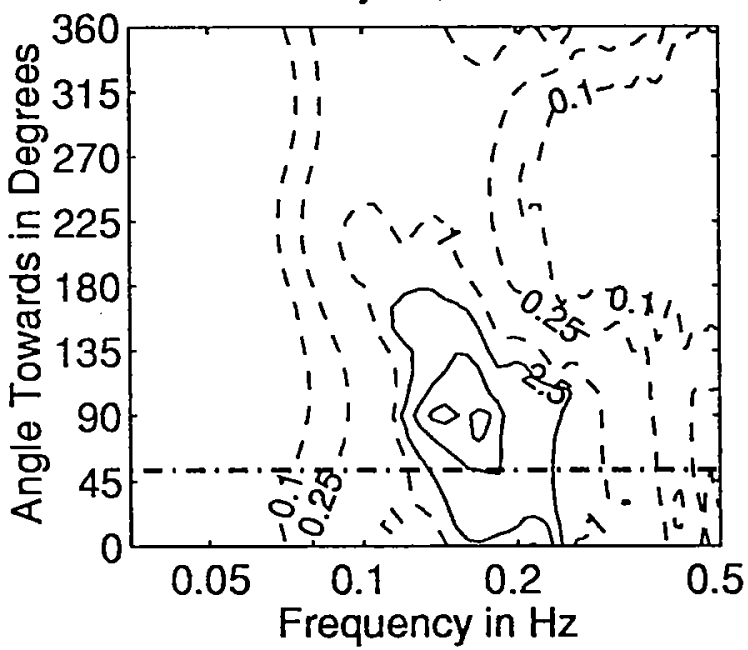

February 16, $199415 Z$

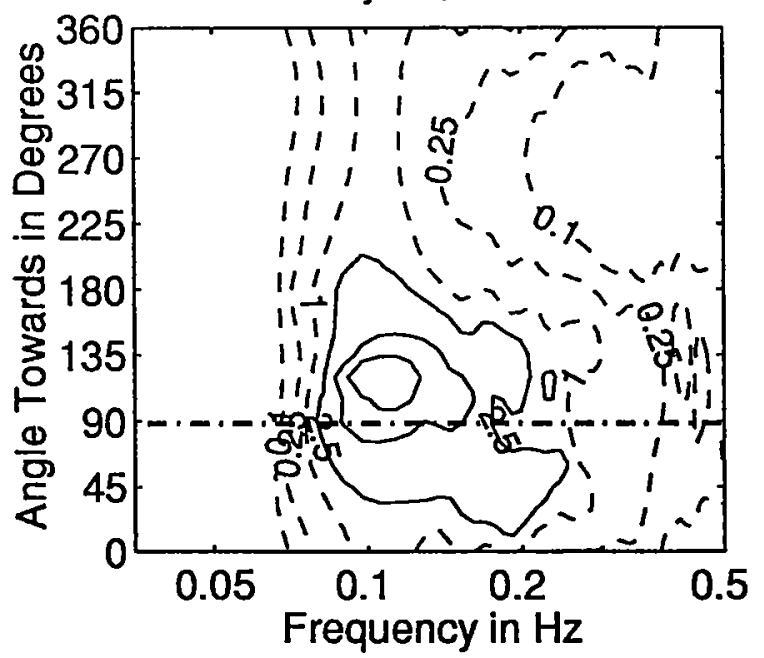

Figure 3.4.94: Directional wave spectra, computed using maximum entropy method. Contours of spectral density as a function of direction. Contours are 0.1, $0.25,1$ (dashed), $2.5,10,25,100$, and 250 (solid). Wind direction is shown by thick dashed line. 
February 16, $199418 Z$

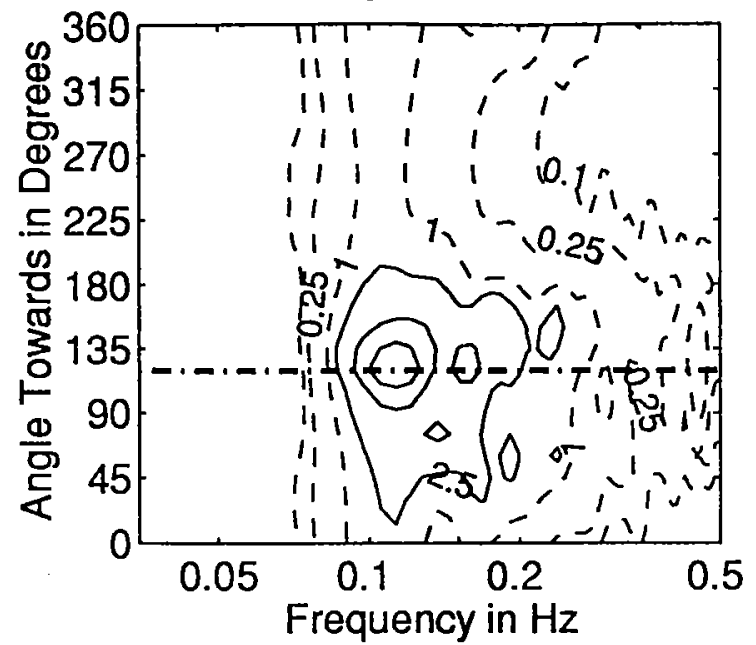

February 17, $199400 Z$

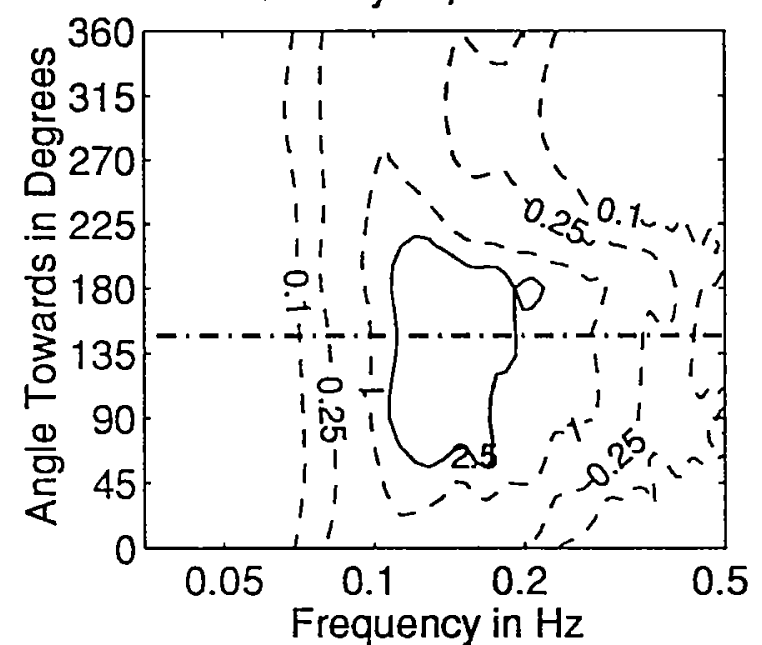

February 17, $199406 Z$

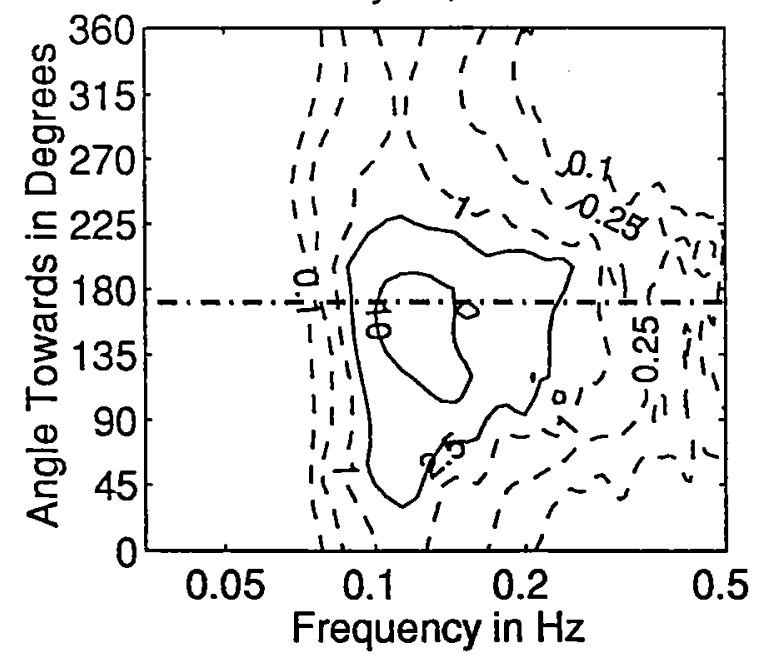

February 16, $199421 Z$

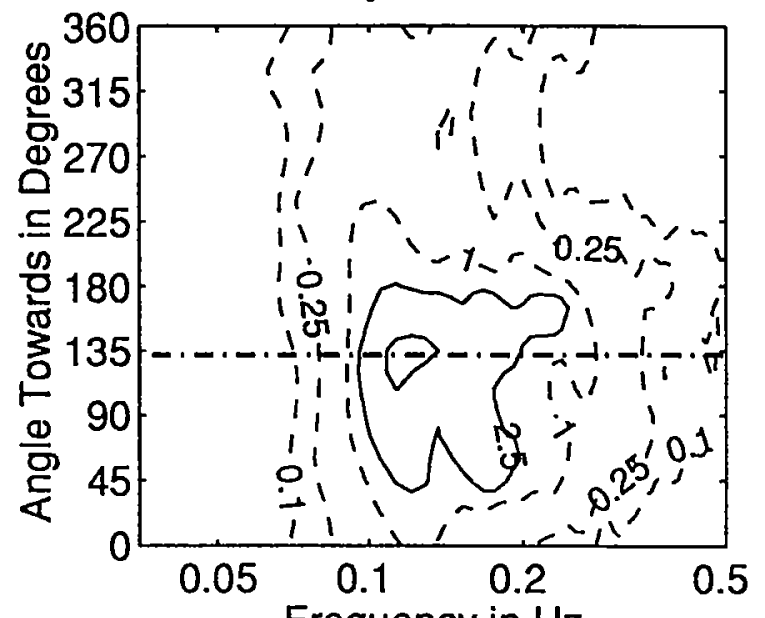

Frequency in $\mathrm{Hz}$

February 17, 1994032

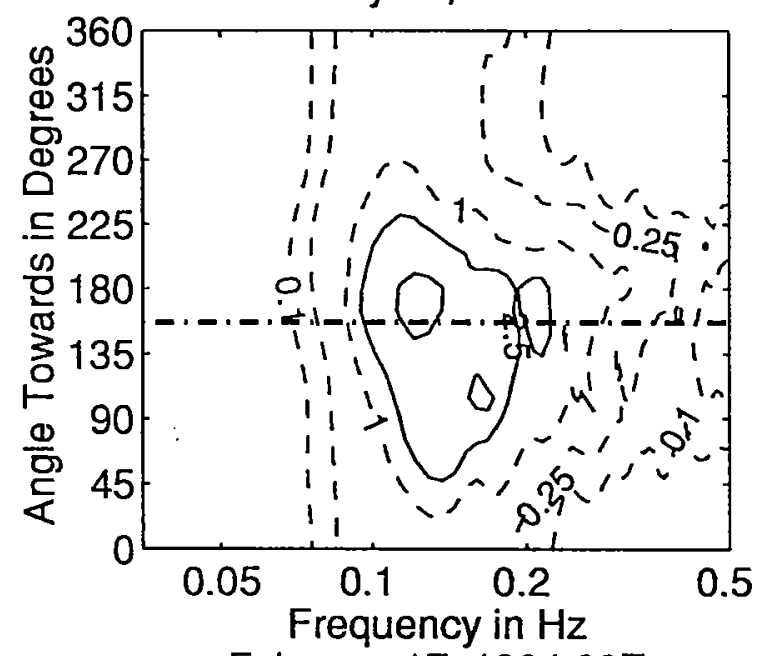

February 17, $199409 Z$

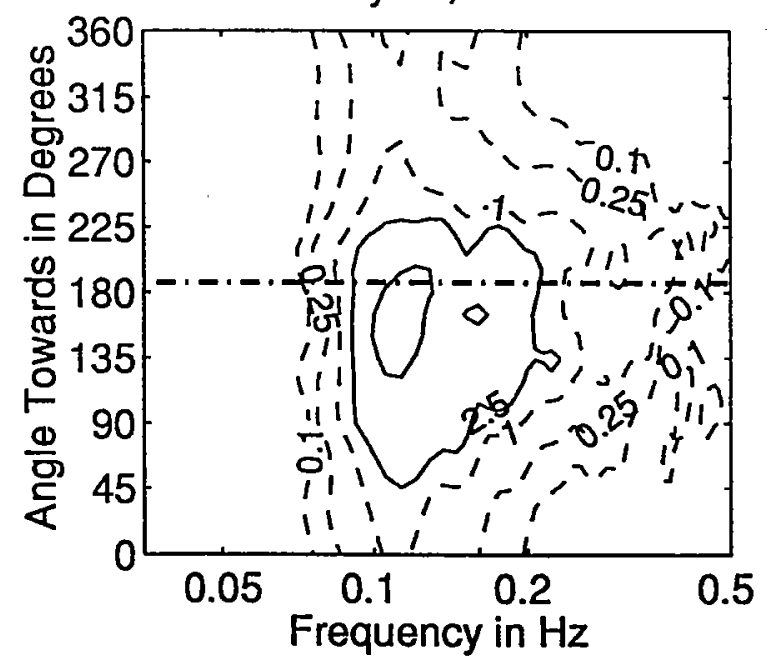

Figure 3.4.95: Directional wave spectra, computed using maximum entropy method. Contours of spectral density as a function of direction. Contours are 0.1, $0.25,1$ (dashed), $2.5,10,25,100$, and 250 (solid). Wind direction is shown by thick dashed line. 
February 17, $199412 Z$

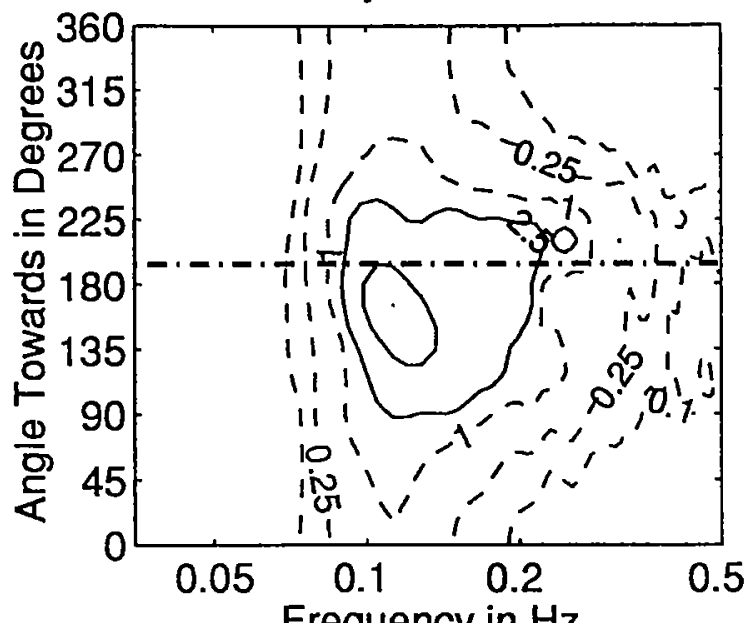

Frequency in $\mathrm{Hz}$

February 17, 1994182

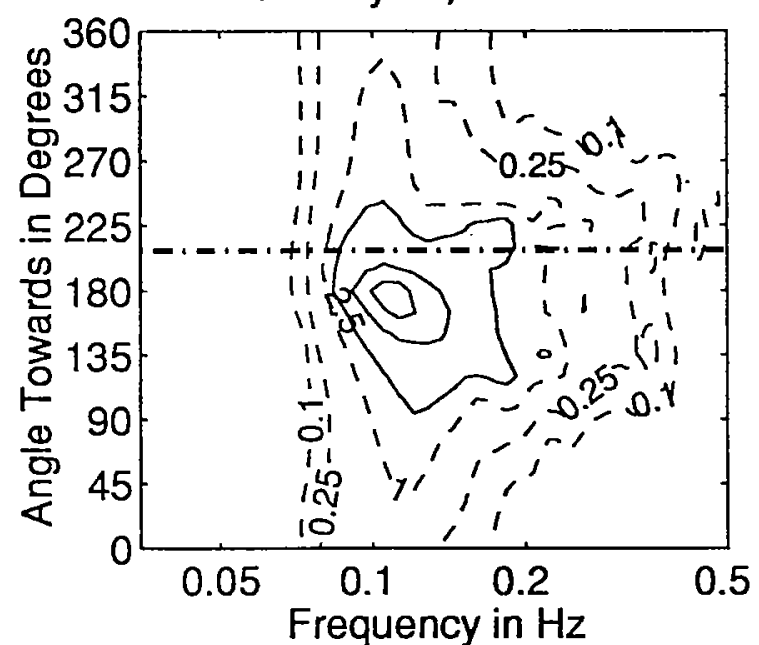

February 18, $199400 Z$

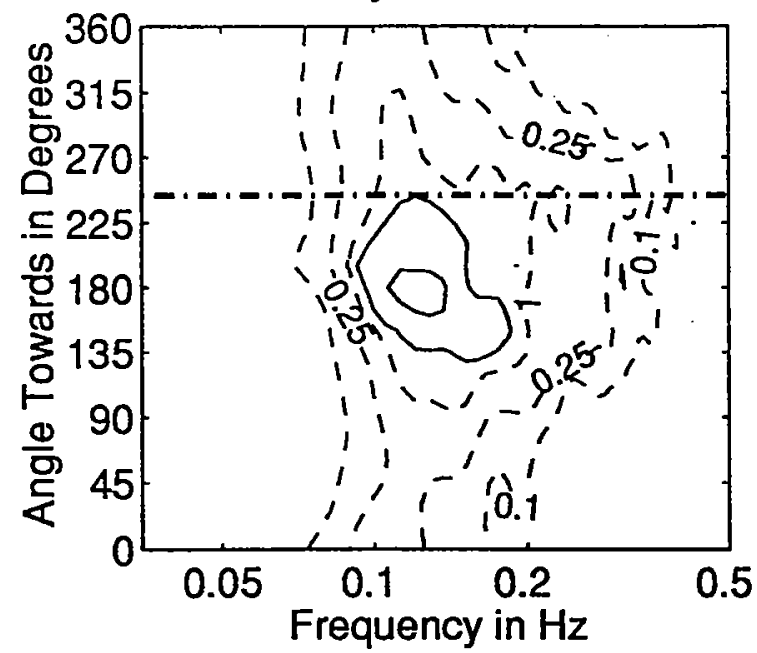

February 17, $199415 Z$

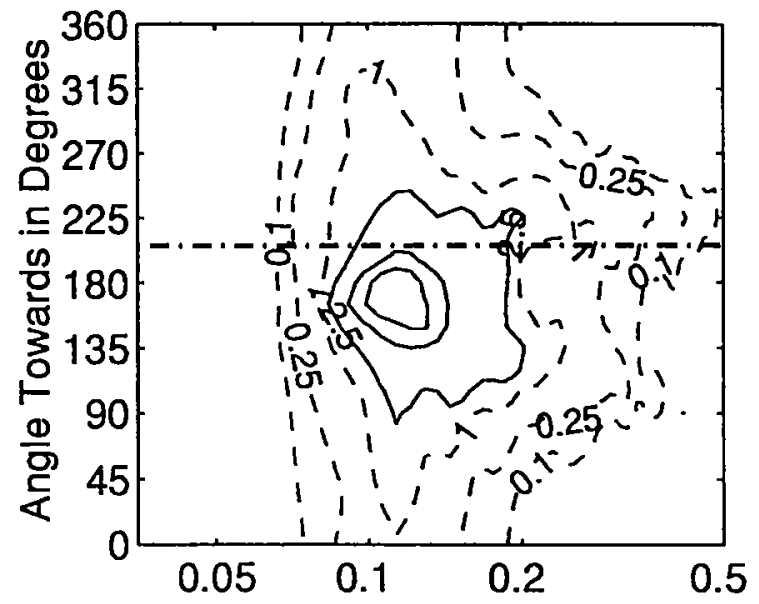

Frequency in $\mathrm{Hz}$

February 17, $199421 Z$

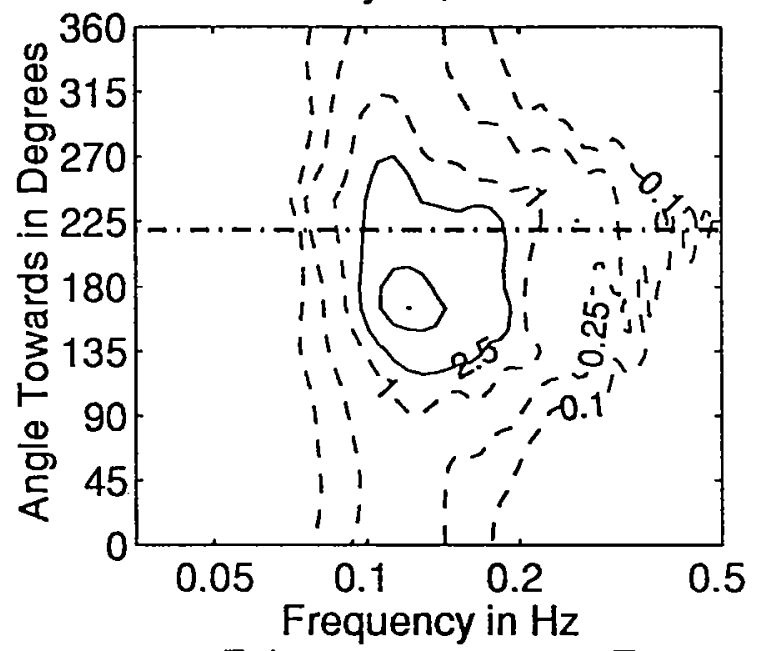

February 18, 1994032

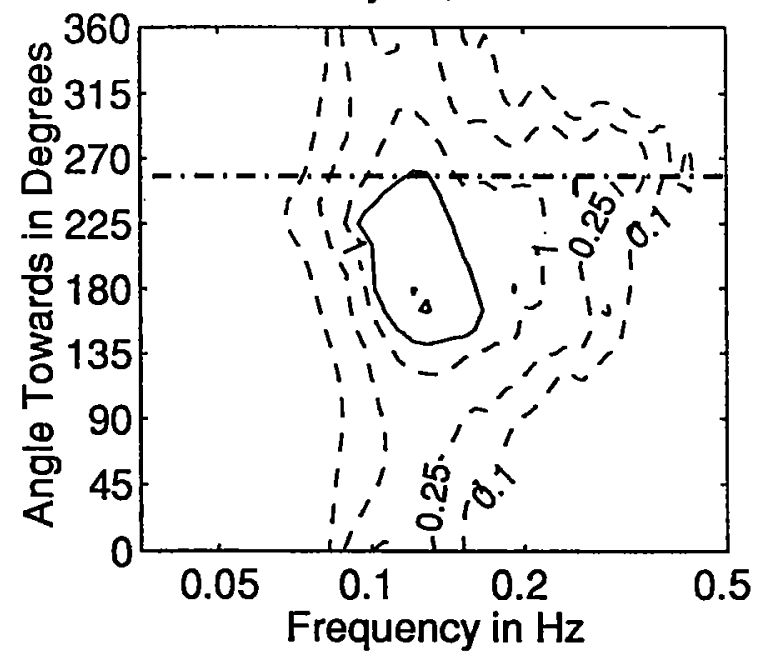

Figure 3.4.96: Directional wave spectra, computed using maximum entropy method. Contours of spectral density as a function of direction. Contours are 0.1 , $0.25,1$ (dashed), $2.5,10,25,100$, and 250 (solid). Wind direction is shown by thick dashed line. 
February 18, $199406 Z$

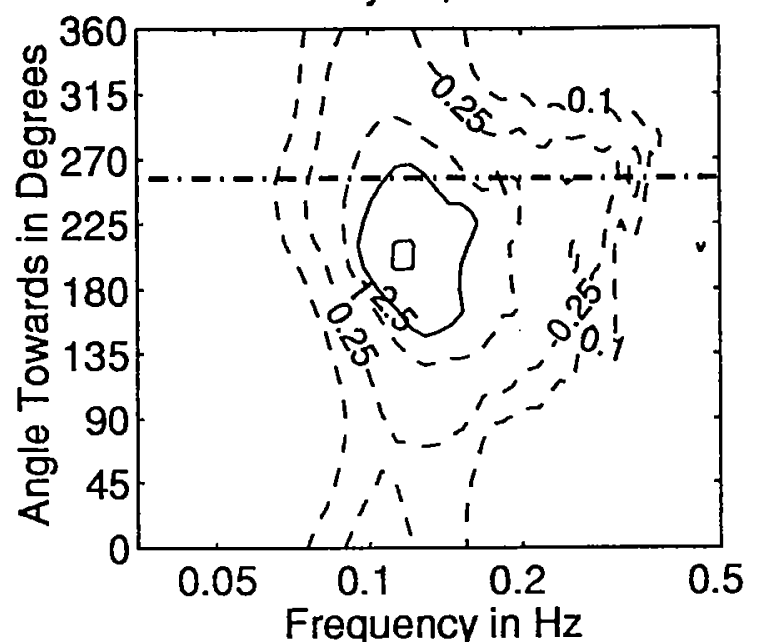

February 18, 1994122

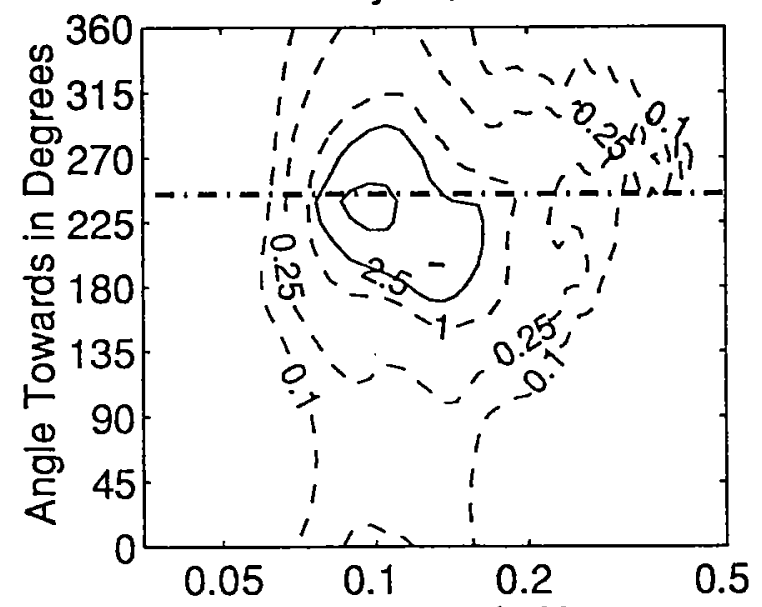

Frequency in $\mathrm{Hz}$

February 18, $199418 Z$

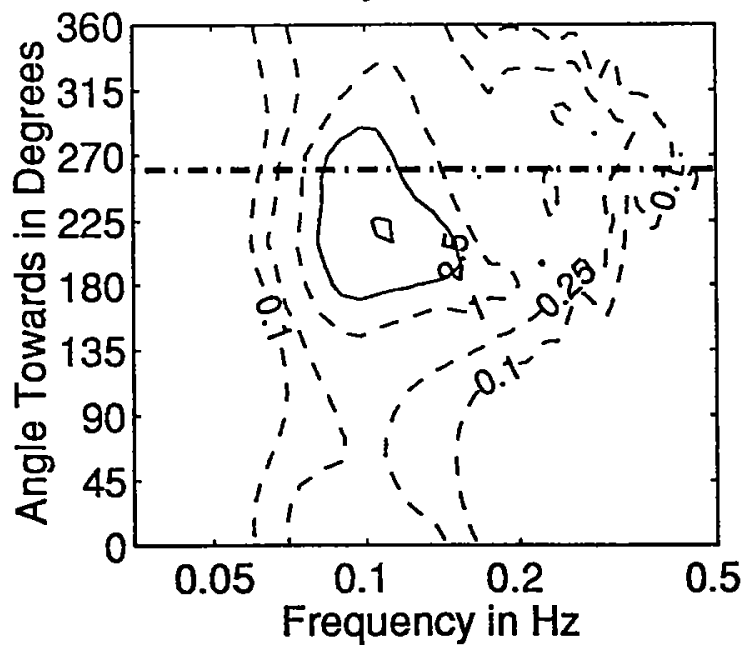

February 18, $199409 Z$

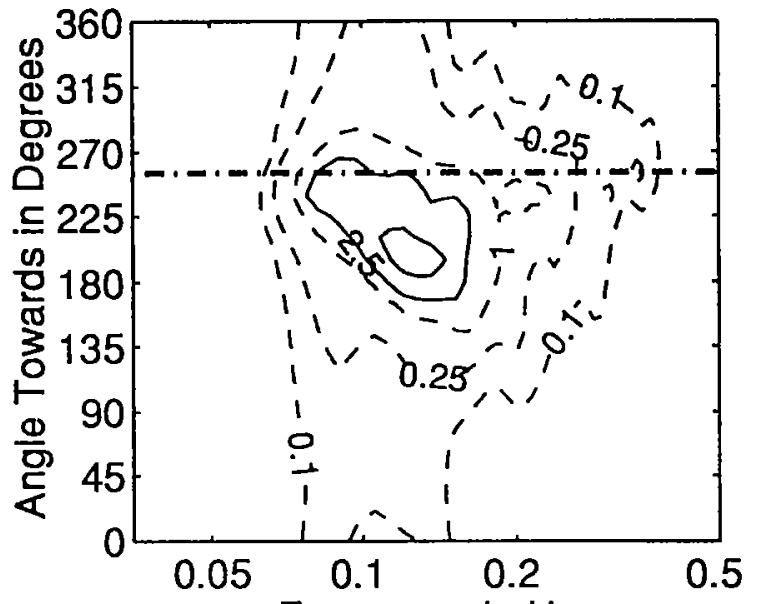

Frequency in $\mathrm{Hz}$

February 18, $199415 Z$

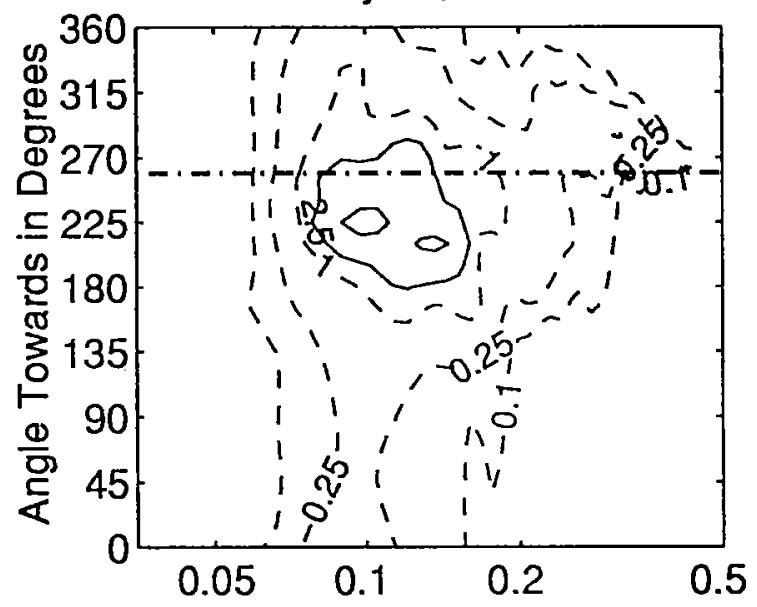

Frequency in $\mathrm{Hz}$

February 18, $199421 \mathrm{Z}$

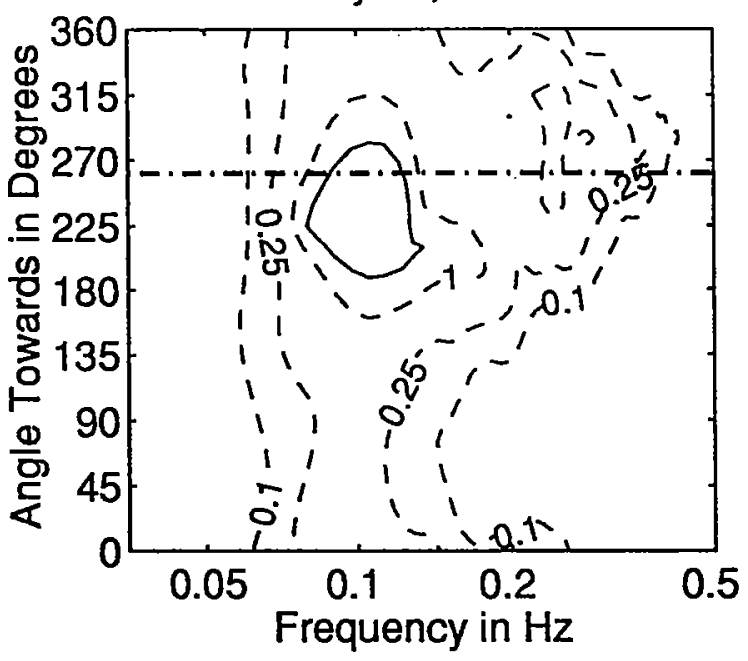

Figure 3.4.97: Directional wave spectra, computed using maximum entropy method. Contours of spectral density as a function of direction. Contours are 0.1 , $0.25,1$ (dashed), $2.5,10,25,100$, and 250 (solid). Wind direction is shown by thick dashed line. 
February 19, $199400 Z$

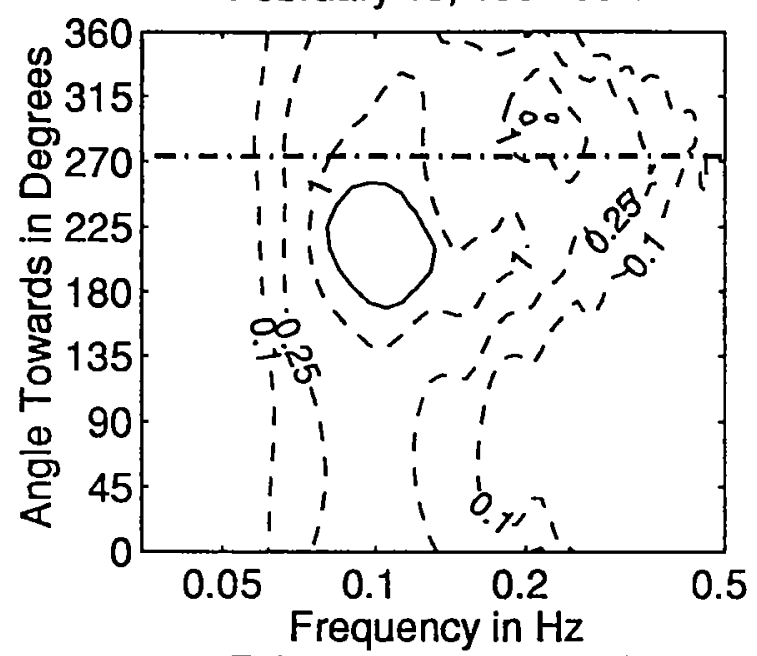

February 19, $199406 Z$

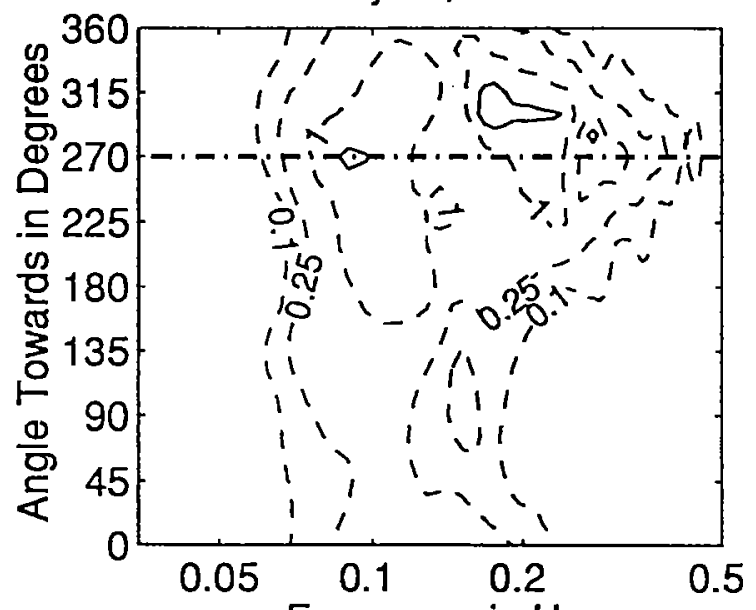

Frequency in $\mathrm{Hz}$

February 19, $199412 Z$

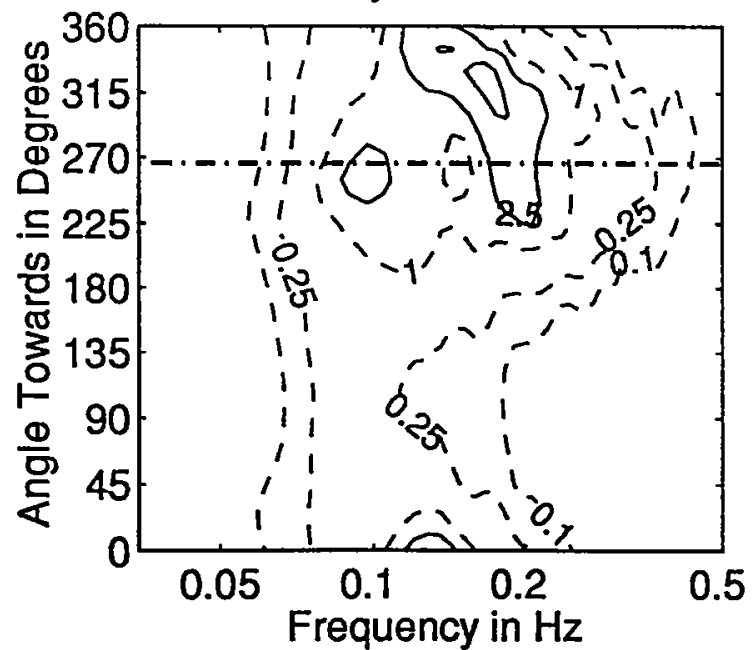

February 19, 1994032

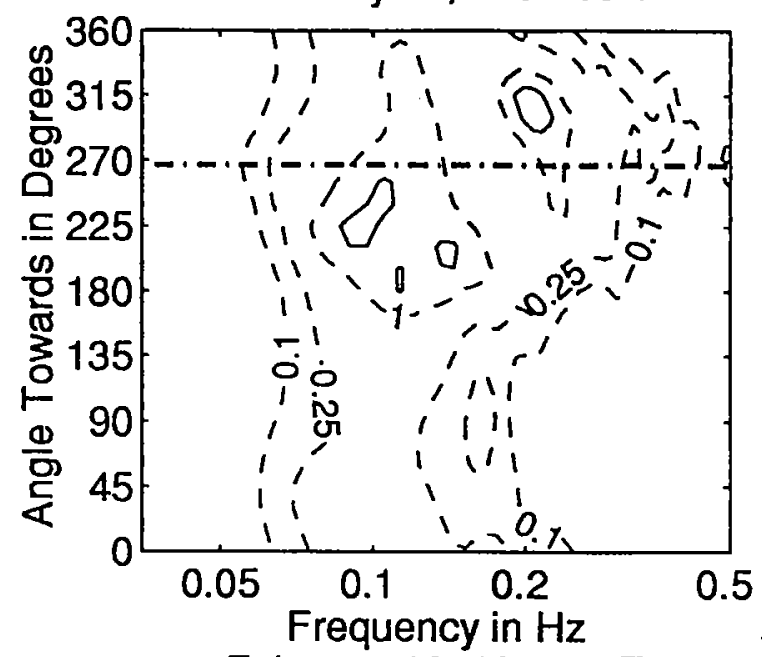

February 19, $199409 Z$

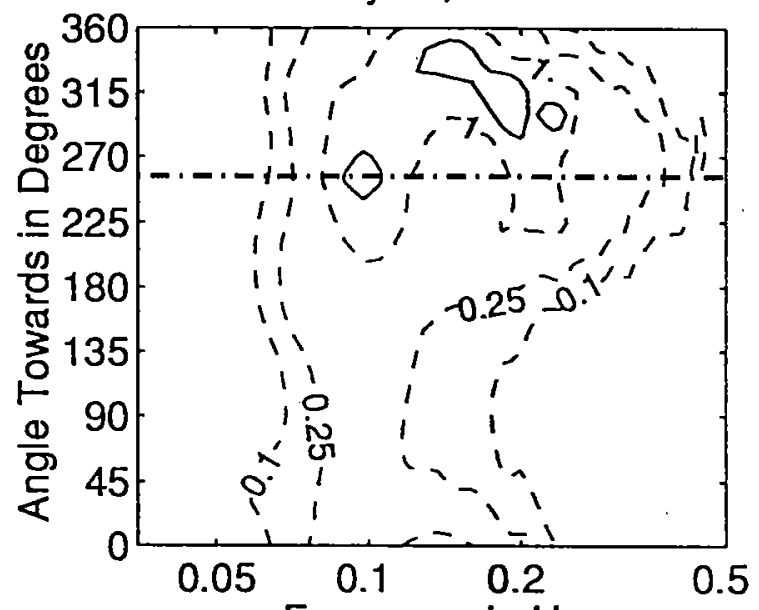

Frequency in $\mathrm{Hz}$

February 19, $199415 Z$

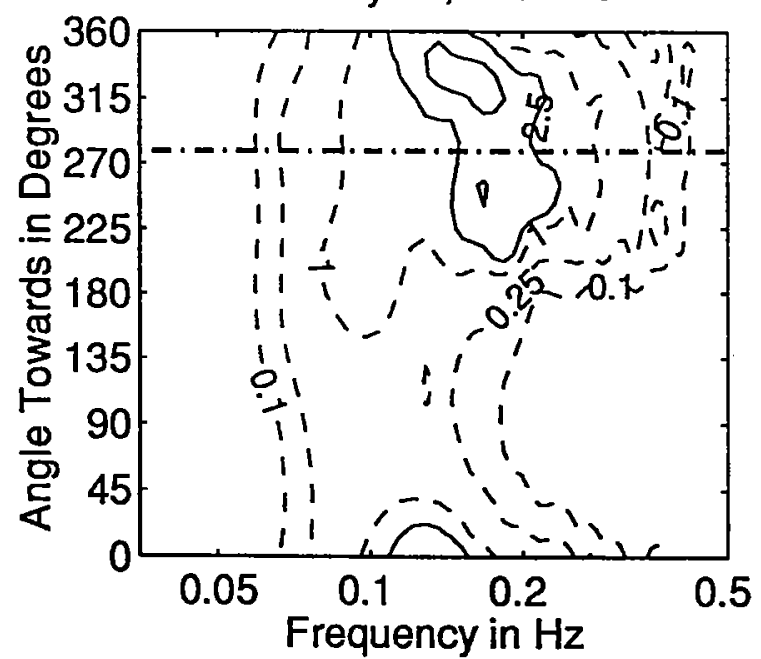

Figure 3.4.98: Directional wave spectra, computed using maximum entropy method. Contours of spectral density as a function of direction. Contours are 0.1 , $0.25,1$ (dashed), $2.5,10,25,100$, and 250 (solid). Wind direction is shown by thick dashed line. 
February 19, $199418 Z$

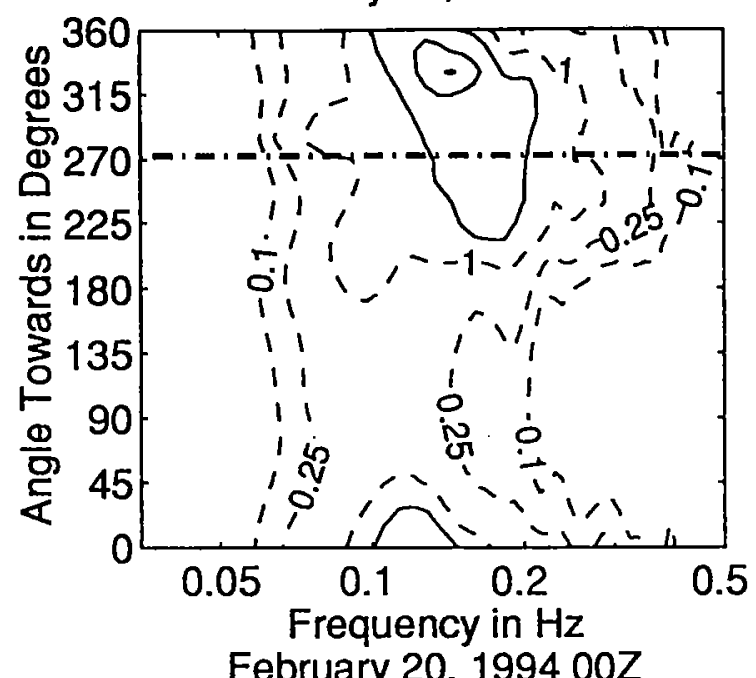

February 20, $199400 Z$

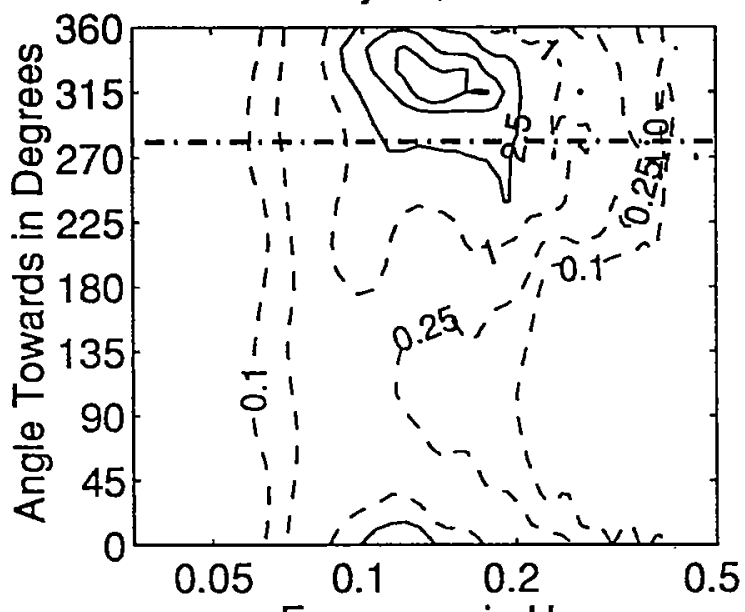

Frequency in $\mathrm{Hz}$

February 20, $199406 Z$

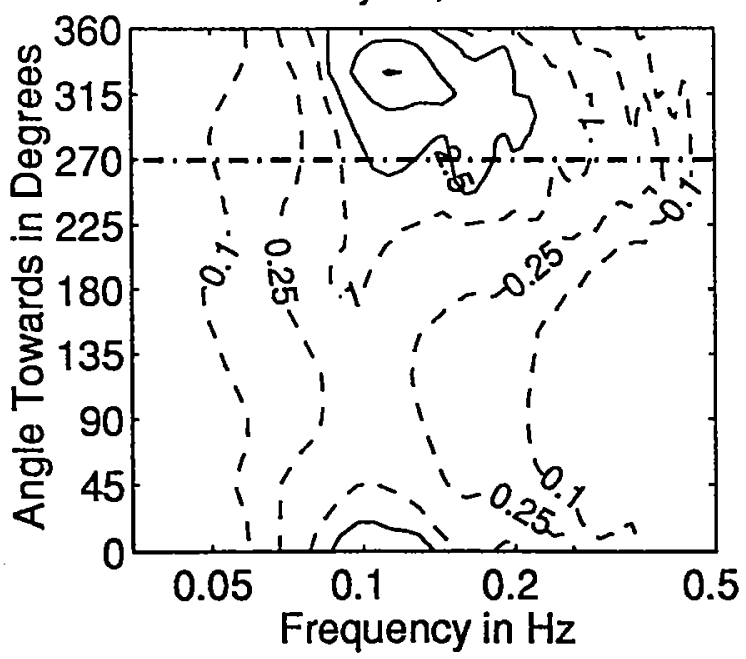

February 19, $199421 \mathrm{Z}$

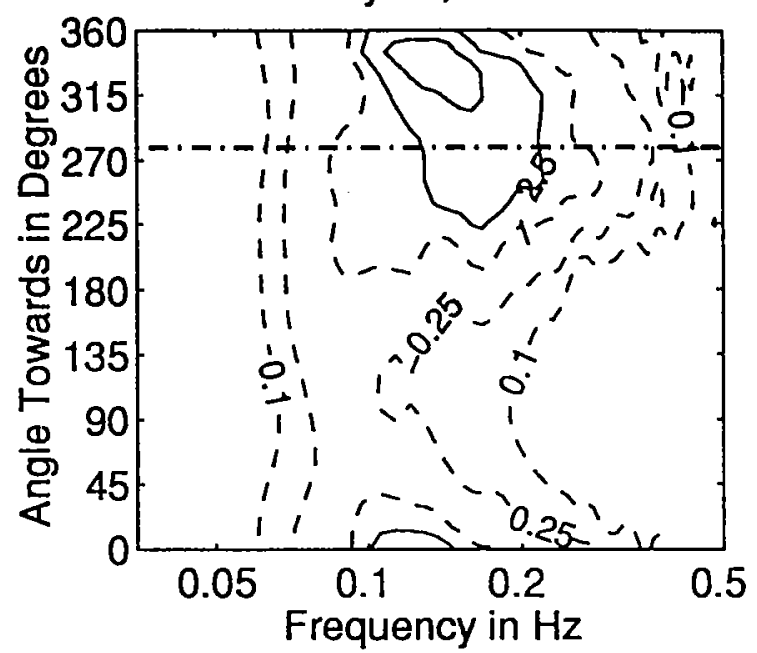

February 20, $199403 Z$

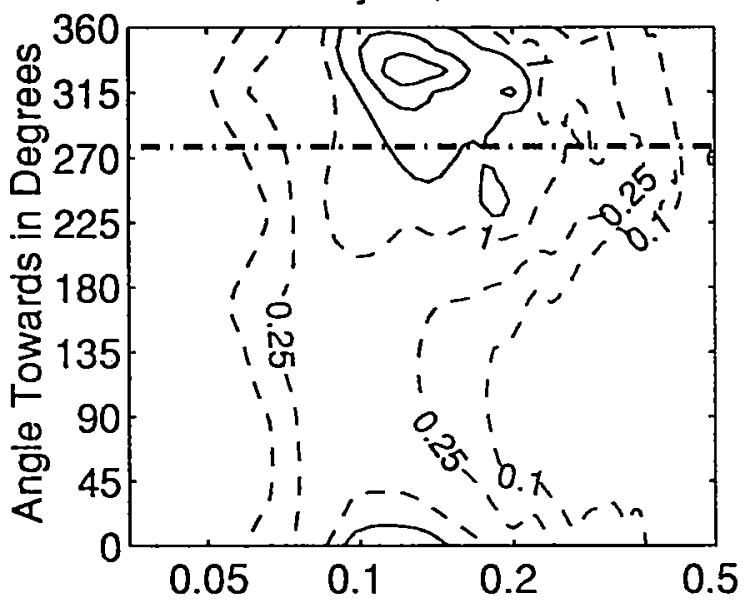

Frequency in $\mathrm{Hz}$

February 20, $199409 Z$

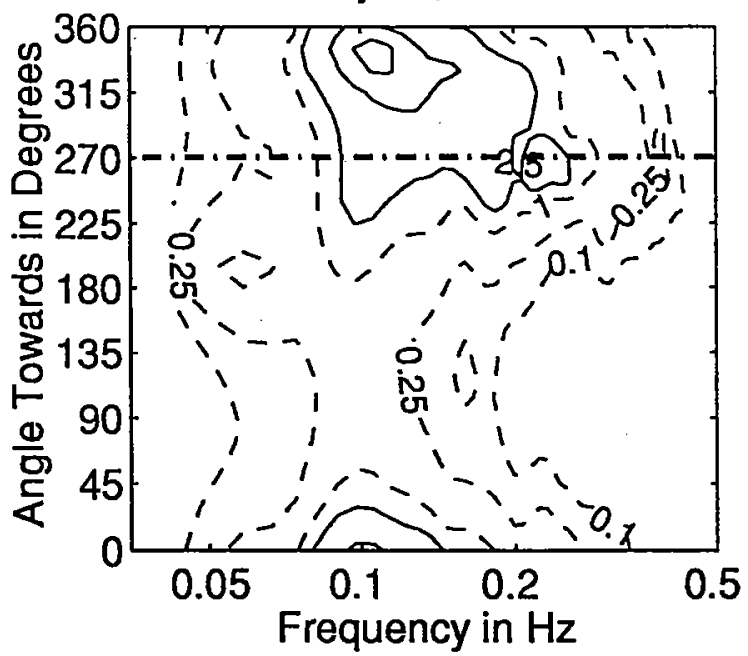

Figure 3.4.99: Directional wave spectra, computed using maximum entropy method. Contours of spectral density as a function of direction. Contours are 0.1 , $0.25,1$ (dashed), $2.5,10,25,100$, and 250 (solid). Wind direction is shown by thick dashed line. 
February 20, $199412 Z$

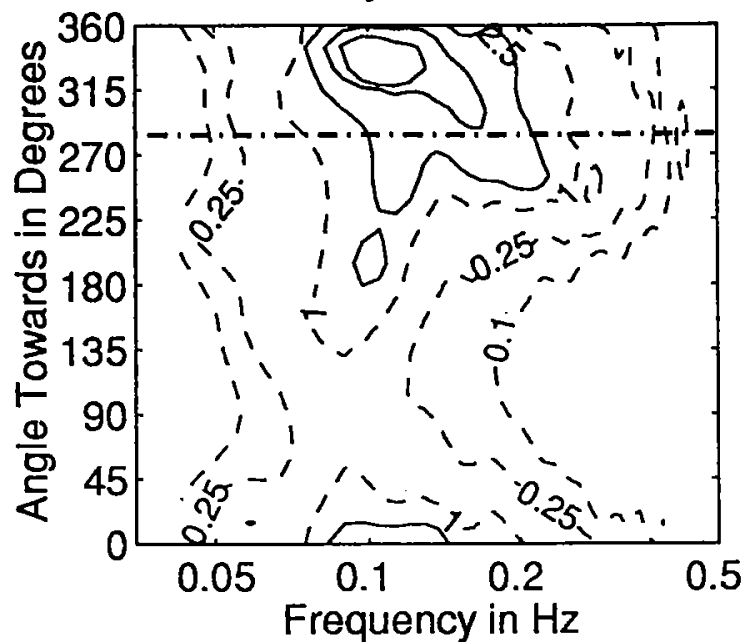

February 20, $199418 Z$

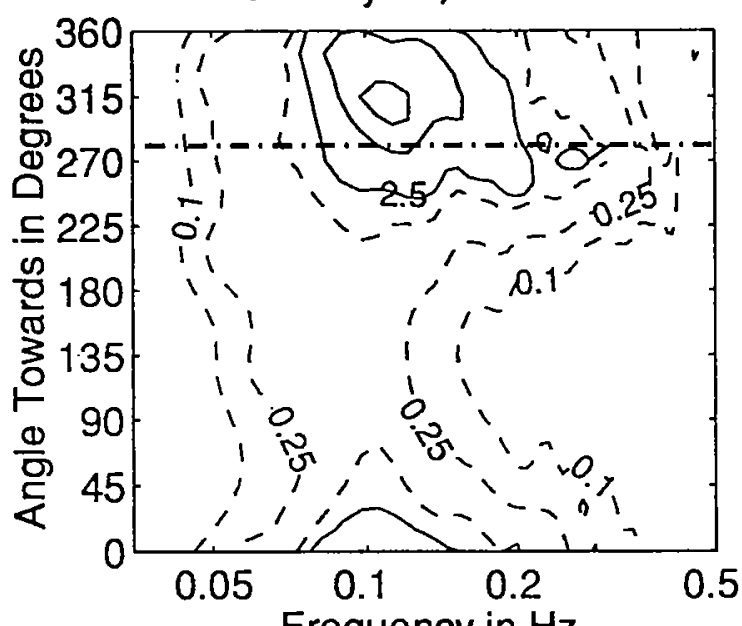

Frequency in $\mathrm{Hz}$

February 21, $199400 \mathrm{Z}$

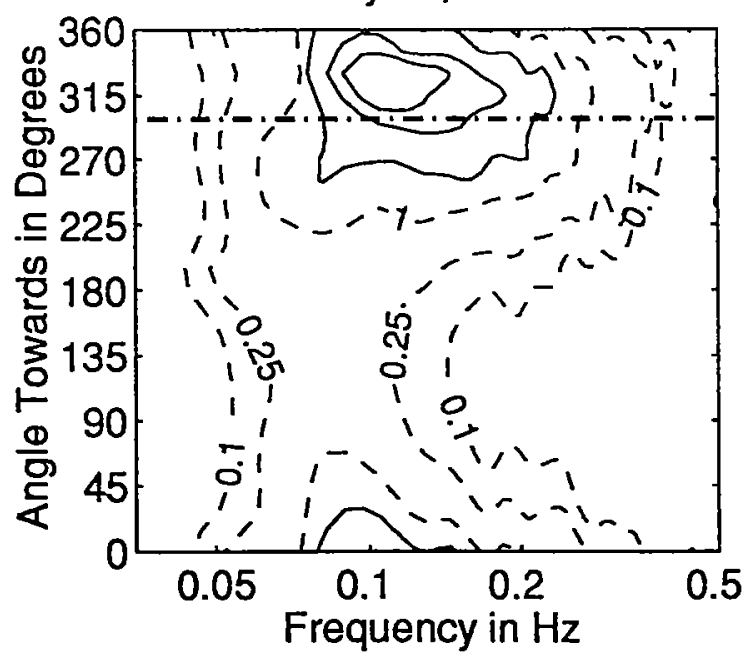

February 20, $199415 Z$

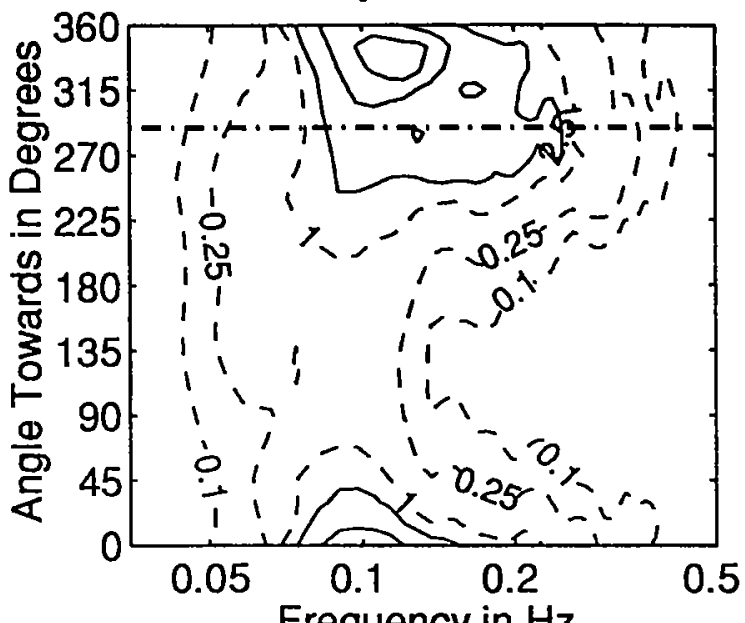

Frequency in $\mathrm{Hz}$

February 20, $199421 Z$

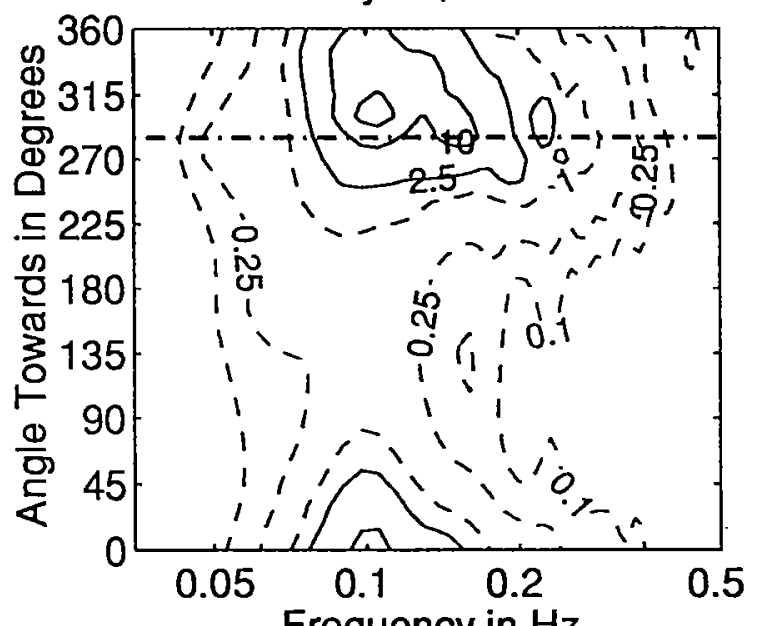

Frequency in $\mathrm{Hz}$

February 21, 1994032

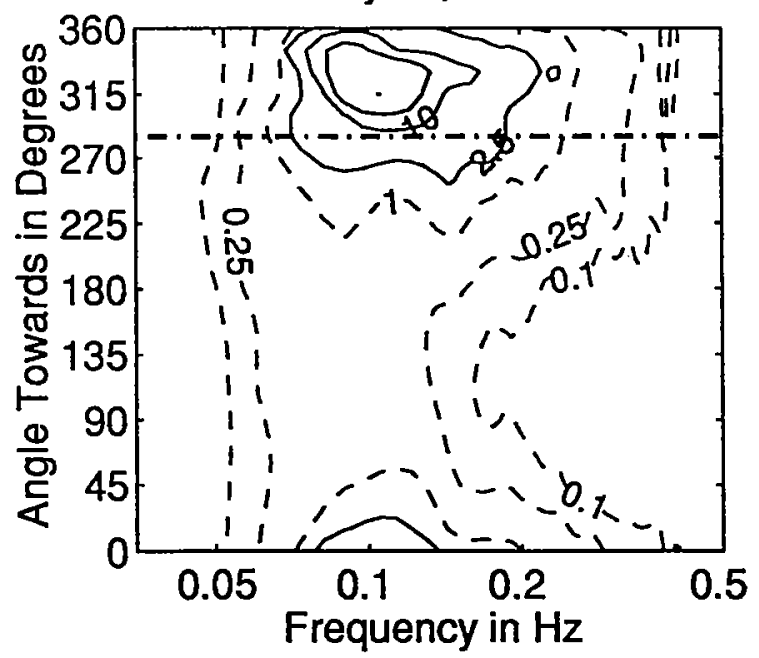

Figure 3.4.100: Directional wave spectra, computed using maximum entropy method. Contours of spectral density as a function of direction. Contours are 0.1 , $0.25,1$ (dashed), $2.5,10,25,100$, and 250 (solid). Wind direction is shown by thick dashed line. 
February 21, $199406 Z$

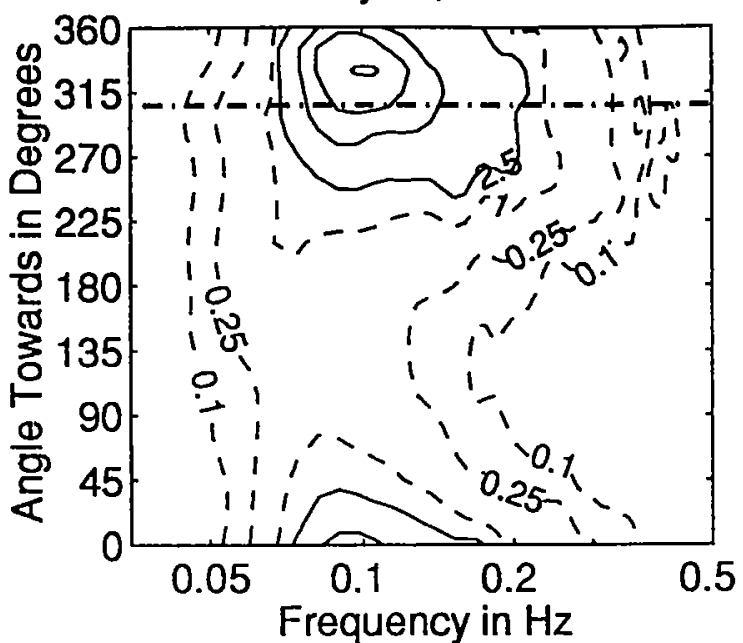

February 21, $199412 Z$

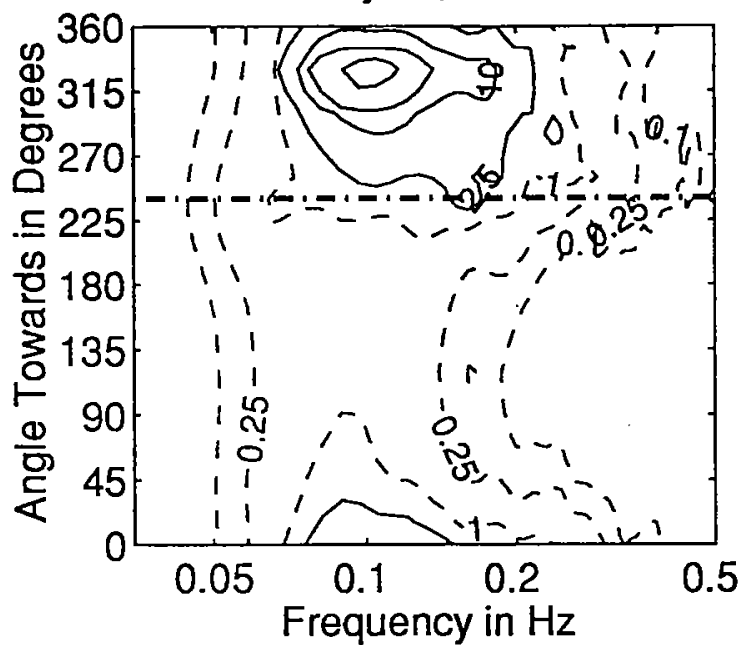

February 21, $199418 Z$

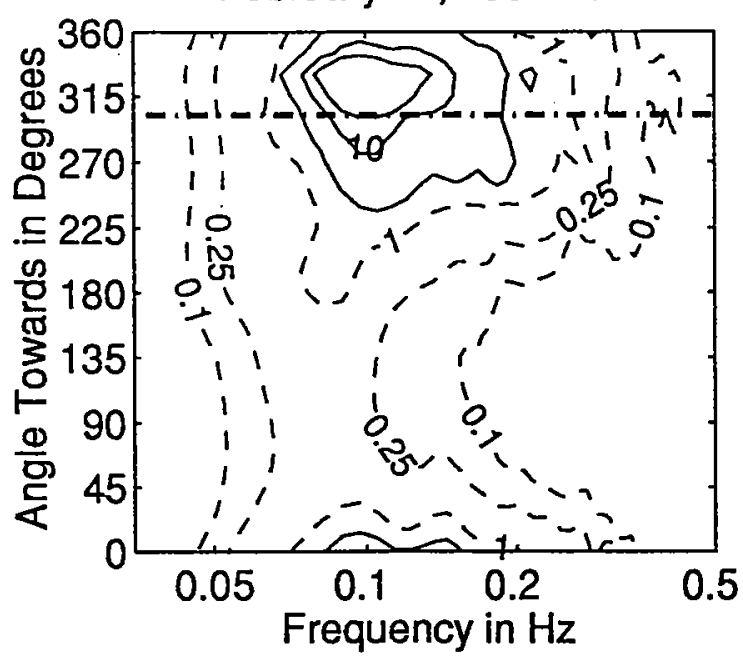

February 21, $199409 Z$

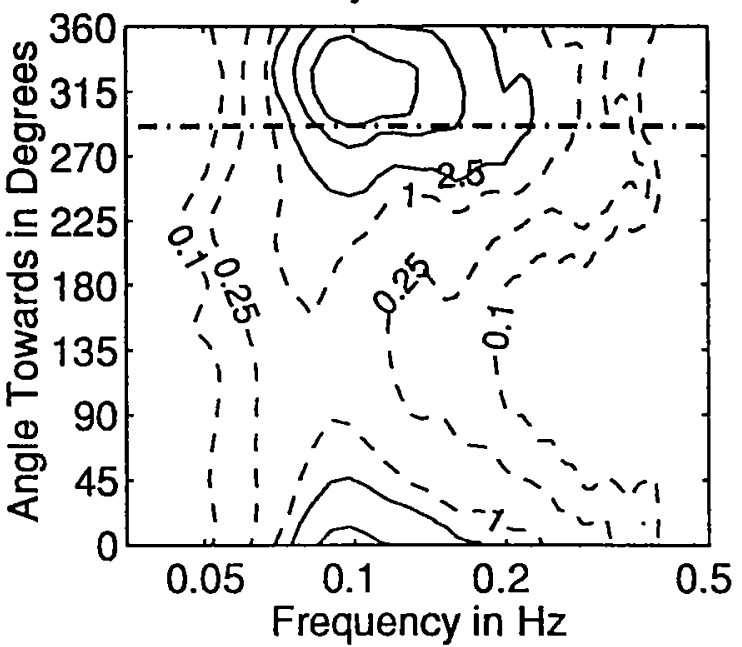

February 21, $199415 Z$

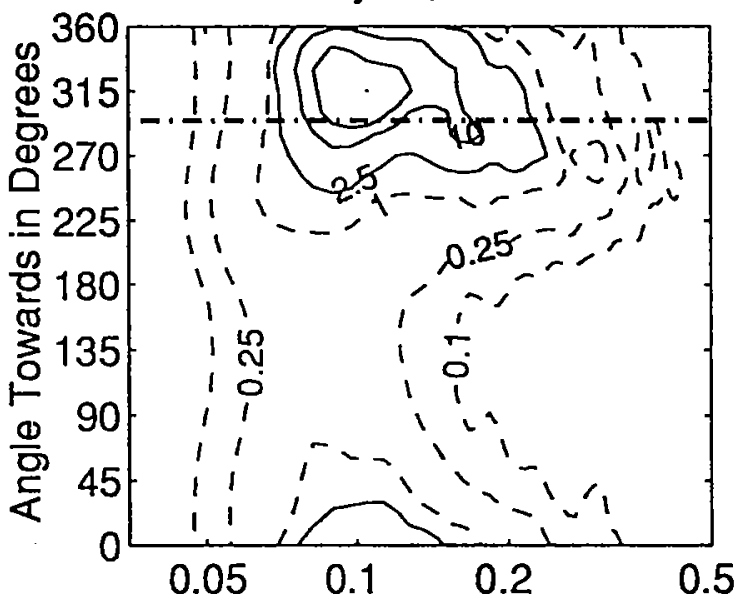

Frequency in $\mathrm{Hz}$

February 21, $199421 Z$

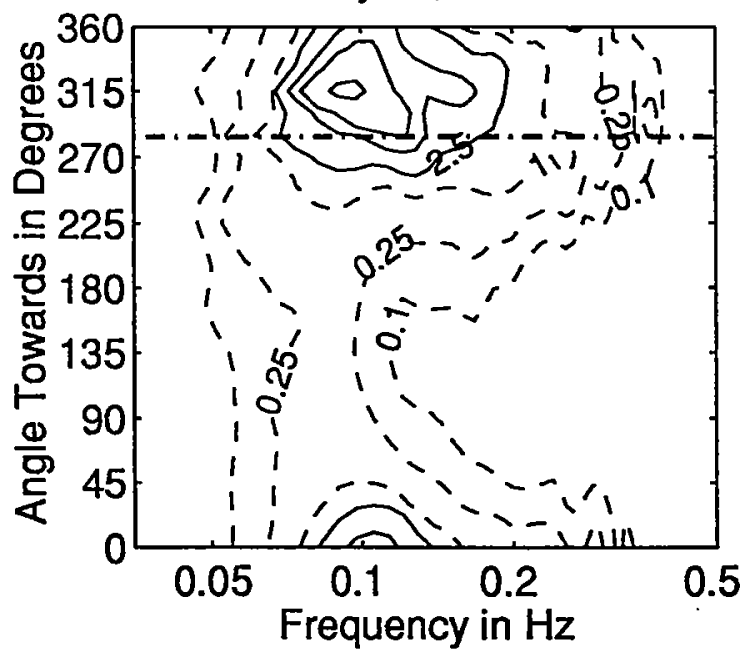

Figure 3.4.101: Directional wave spectra, computed using maximum entropy method. Contours of spectral density as a function of direction. Contours are 0.1, $0.25,1$ (dashed), $2.5,10,25,100$, and 250 (solid). Wind direction is shown by thick dashed line. 
February 22, $199400 Z$

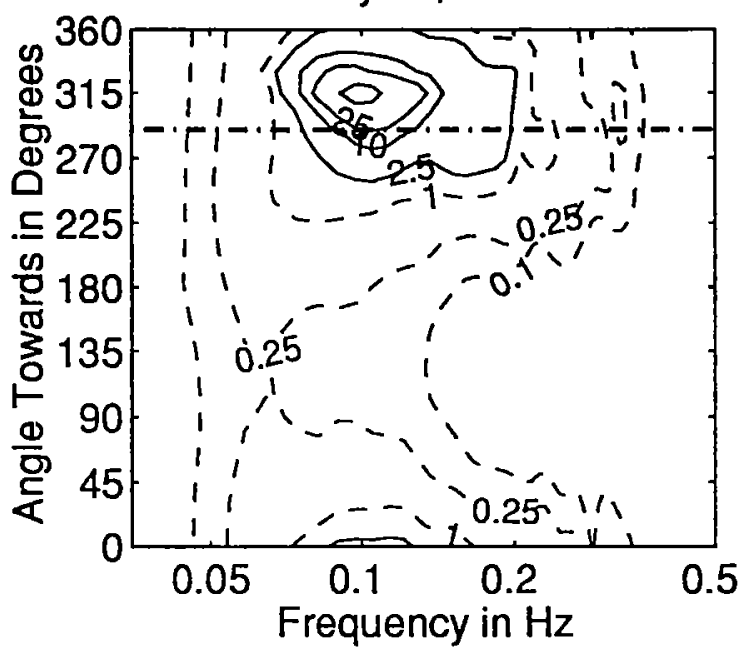

February 22, $199406 Z$

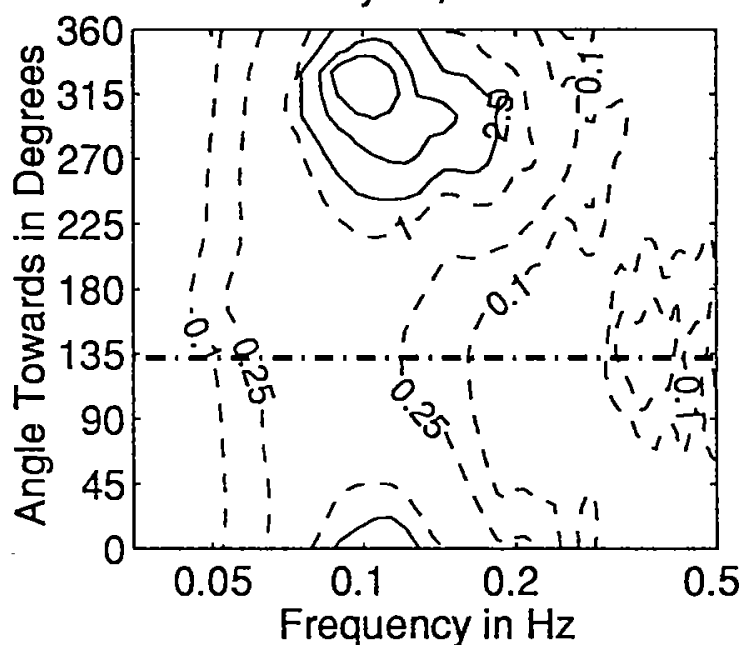

February 22, $199412 Z$

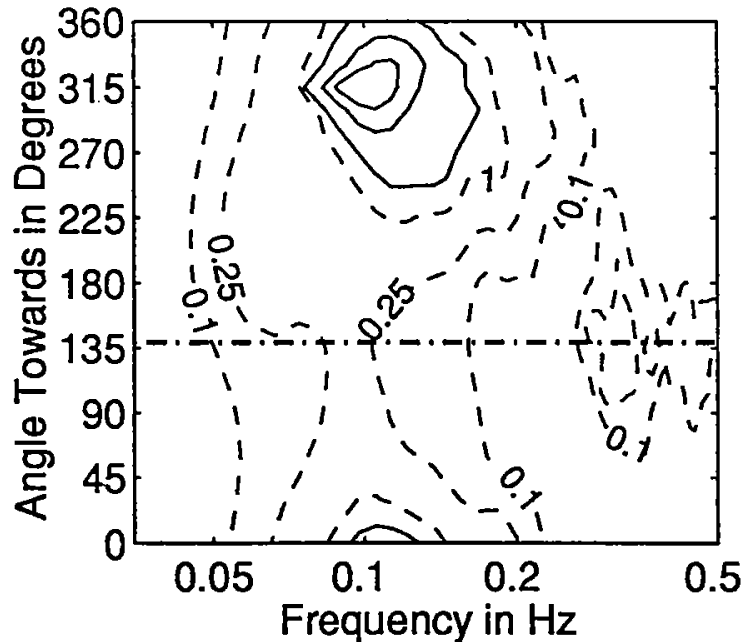

February 22, 1994032

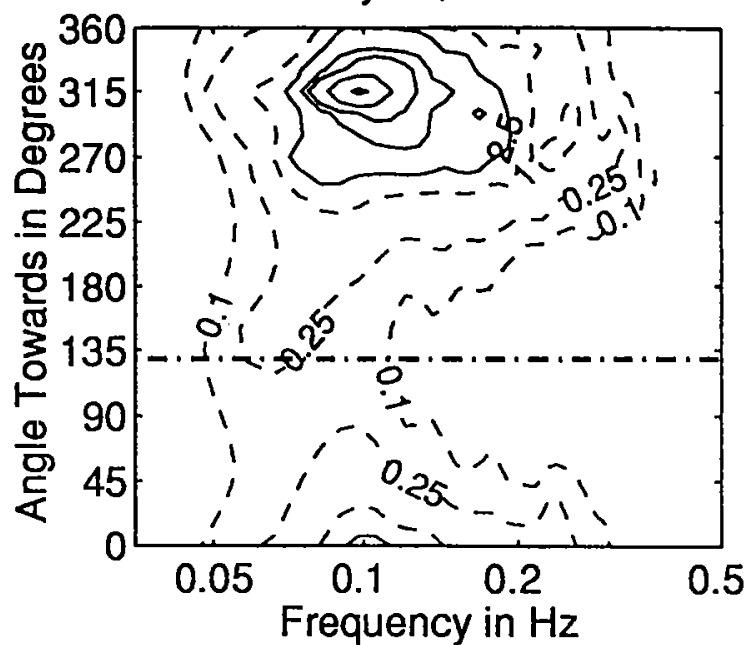

February 22, $199409 Z$

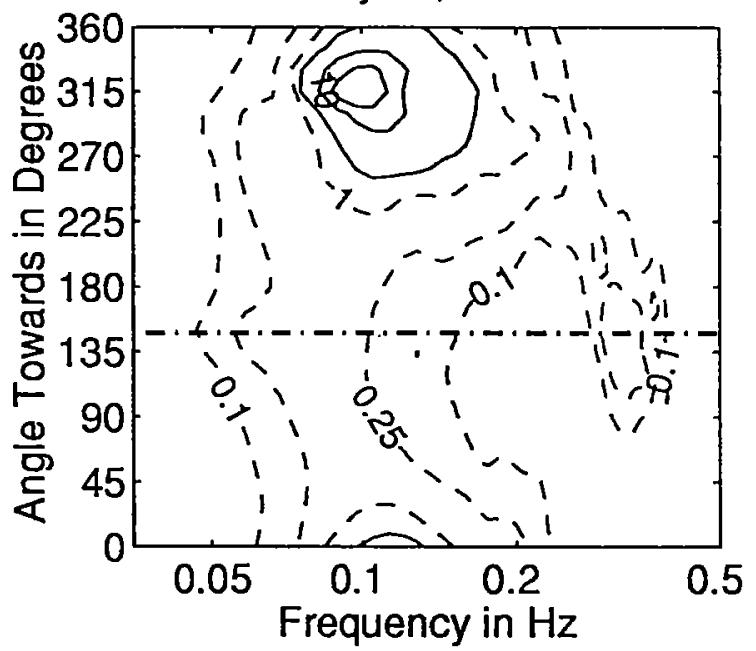

February 22, $199415 Z$

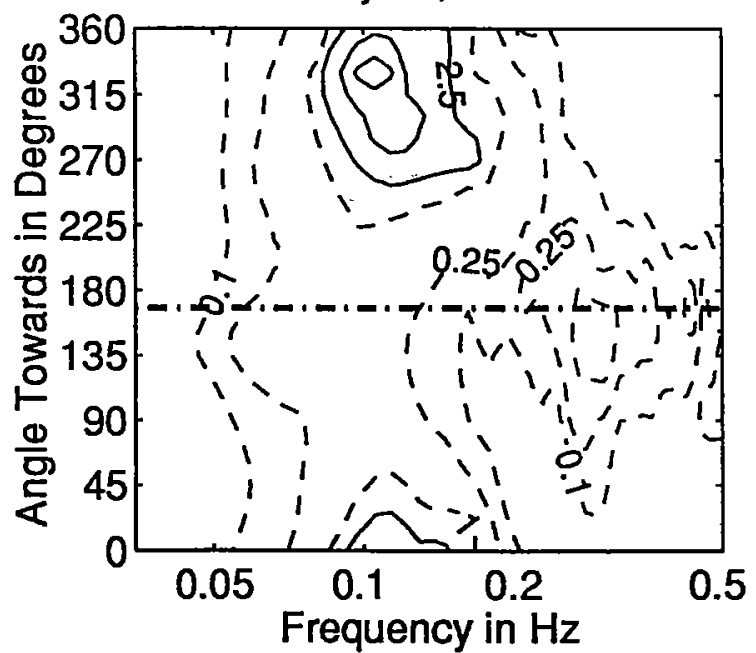

Figure 3.4.102: Directional wave spectra, computed using maximum entropy method. Contours of spectral density as a function of direction. Contours are 0.1, $0.25,1$ (dashed), $2.5,10,25,100$, and 250 (solid). Wind direction is shown by thick dashed line. 
February 22, $199418 Z$

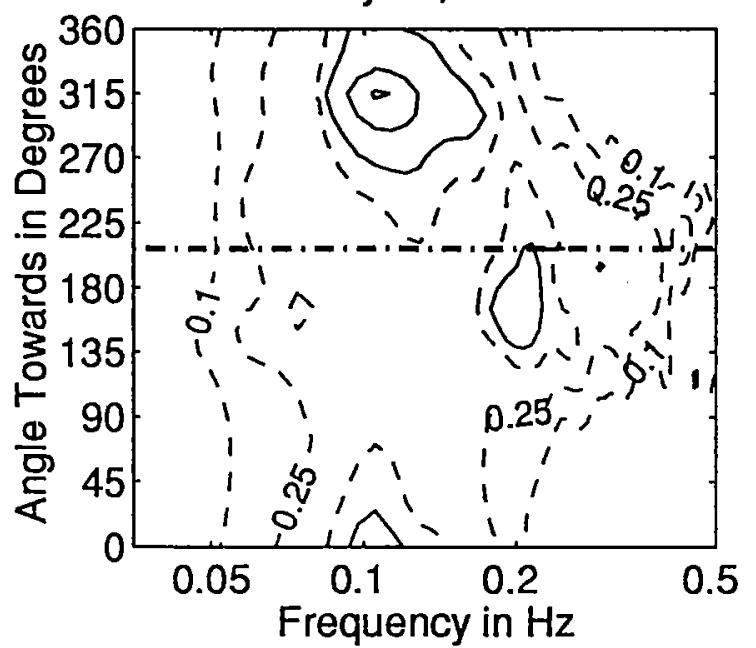

February 23, $199400 Z$

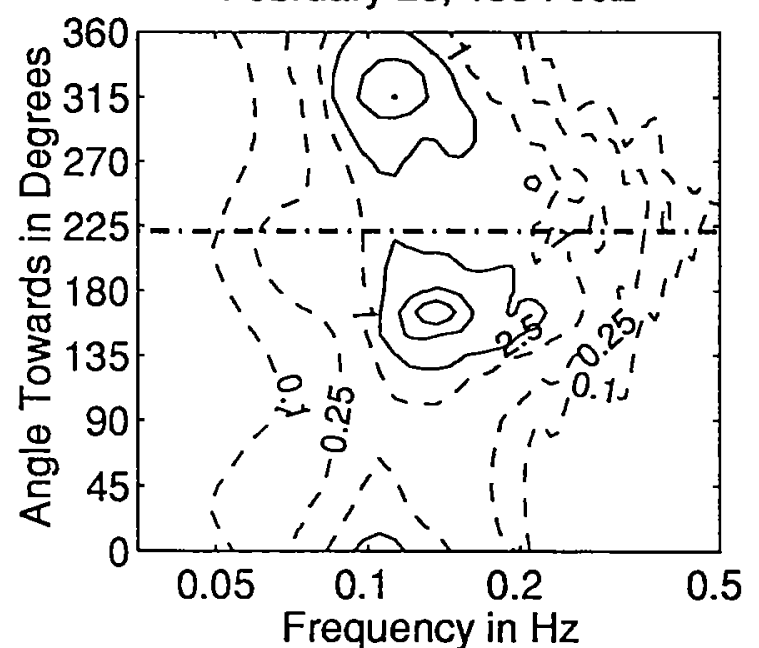

February 23, $199406 Z$

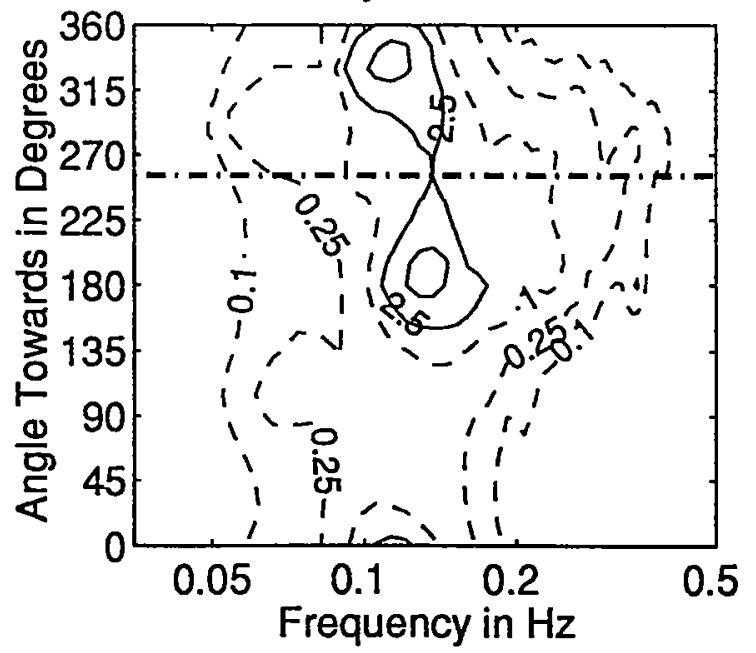

February 22, $199421 Z$

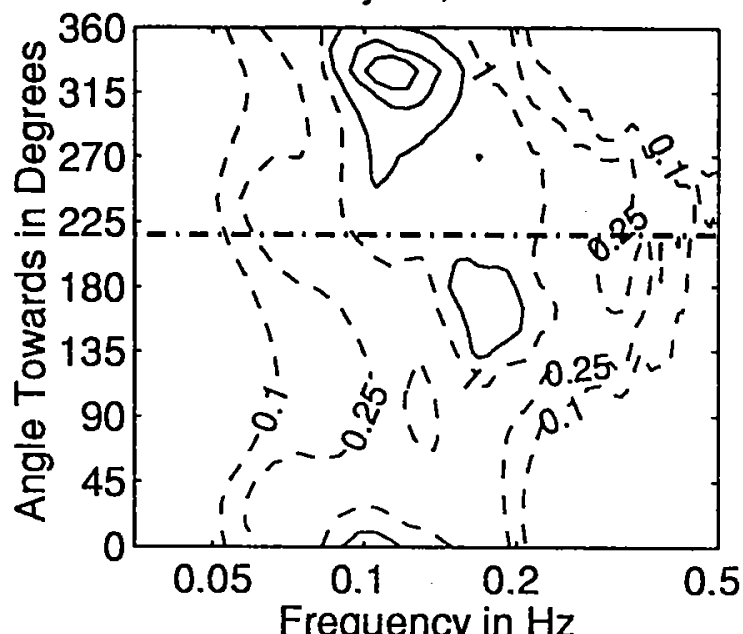

February 23, $199403 Z$

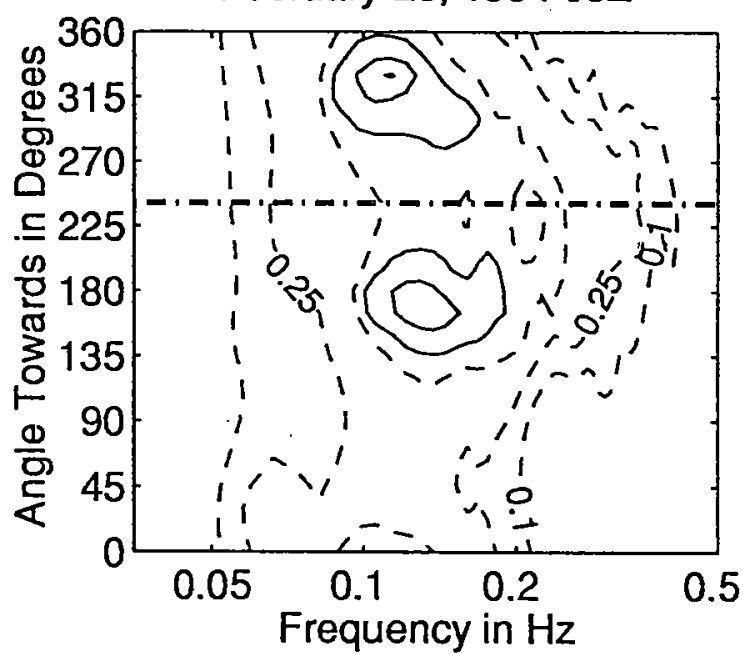

February 23, $199409 Z$

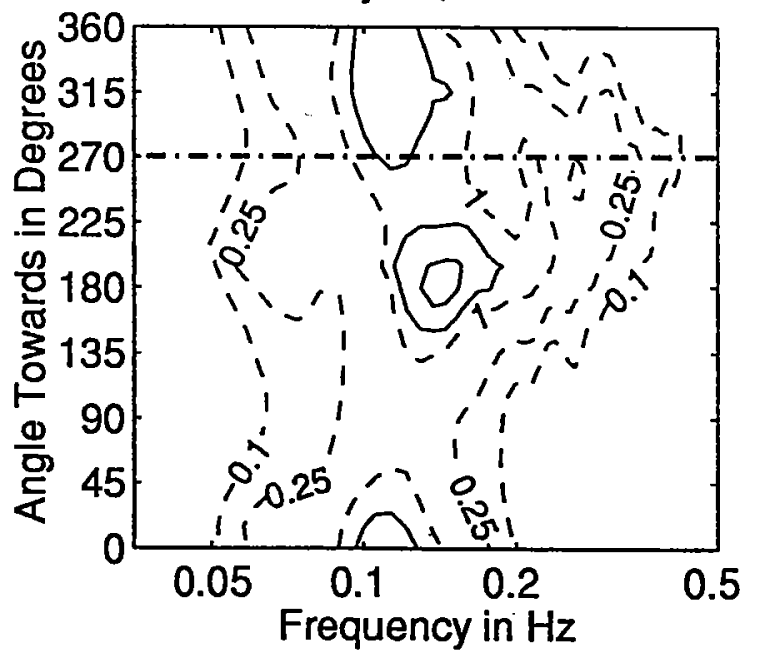

Figure 3.4.103: Directional wave spectra, computed using maximum entropy method. Contours of spectral density as a function of direction. Contours are 0.1, $0.25,1$ (dashed), $2.5,10,25,100$, and 250 (solid). Wind direction is shown by thick dashed line. 
February 23, $199412 Z$

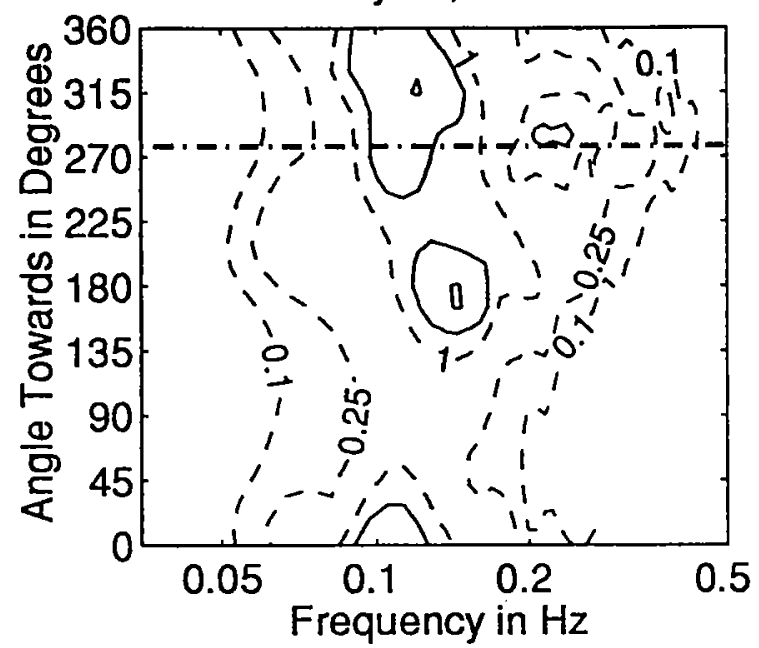

February 23, $199418 Z$

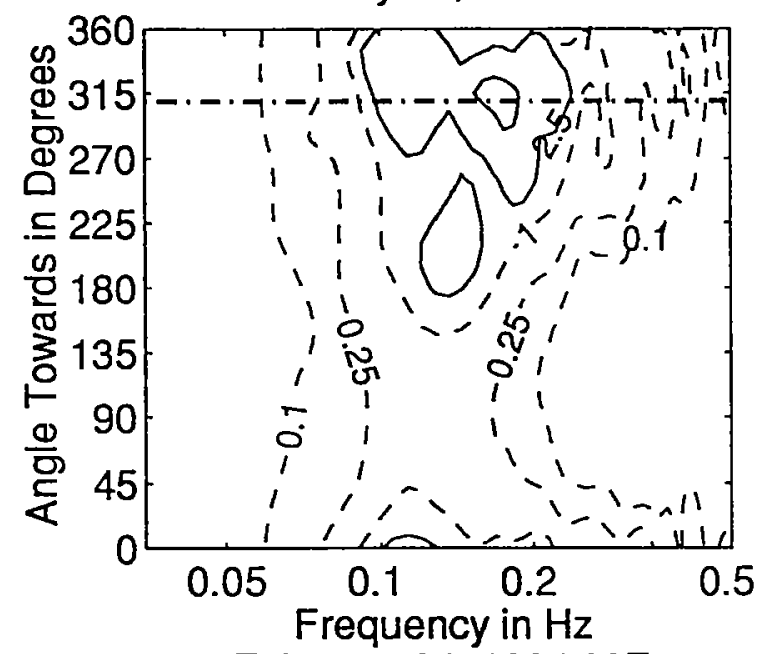

February 24, $199400 Z$

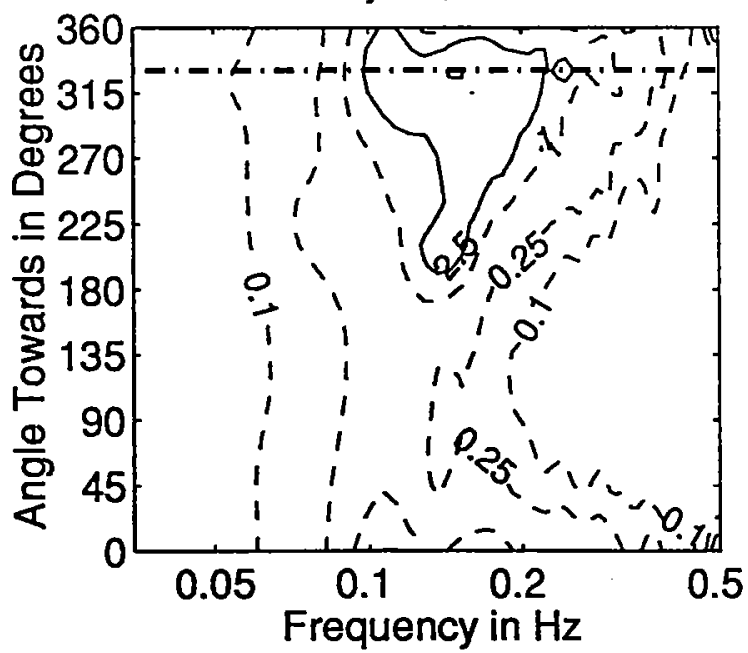

February 23, $199415 Z$

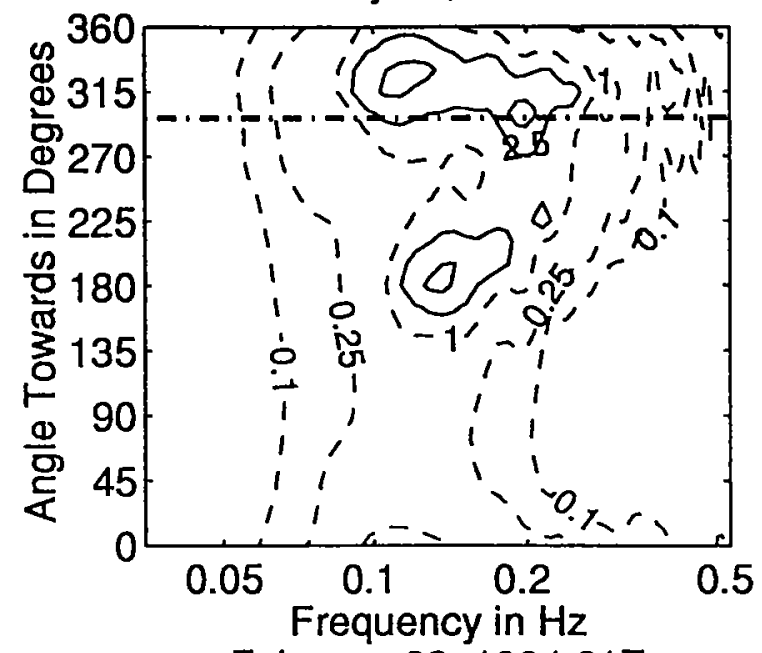

February 23, $199421 \mathrm{Z}$

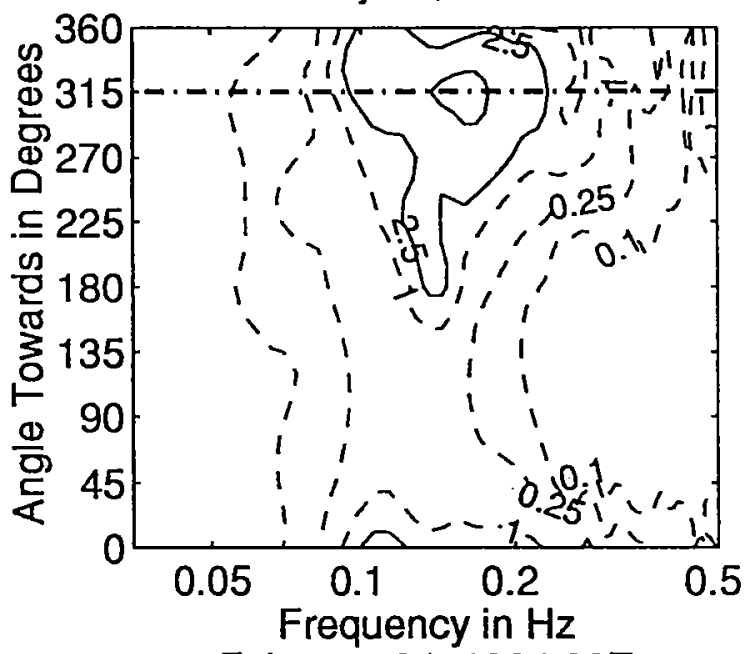

February 24, $199403 Z$

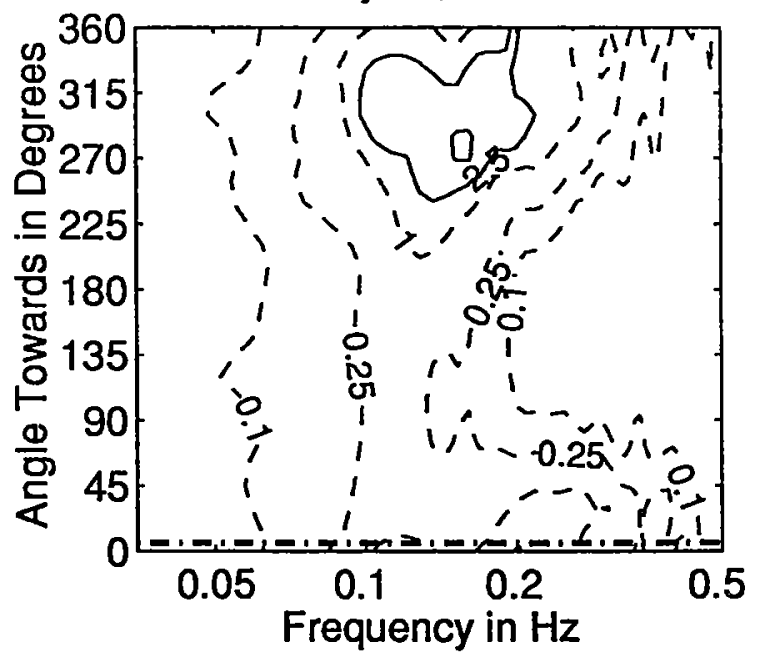

Figure 3.4.104: Directional wave spectra, computed using maximum entropy method. Contours of spectral density as a function of direction. Contours are 0.1, $0.25,1$ (dashed), $2.5,10,25,100$, and 250 (solid). Wind direction is shown by thick dashed line. 
February 24, $199406 Z$

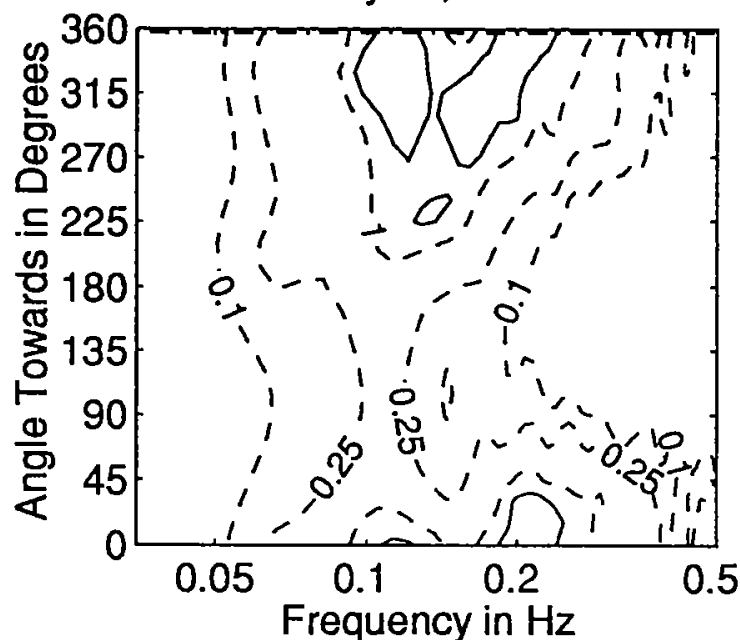

February 24, $199412 Z$

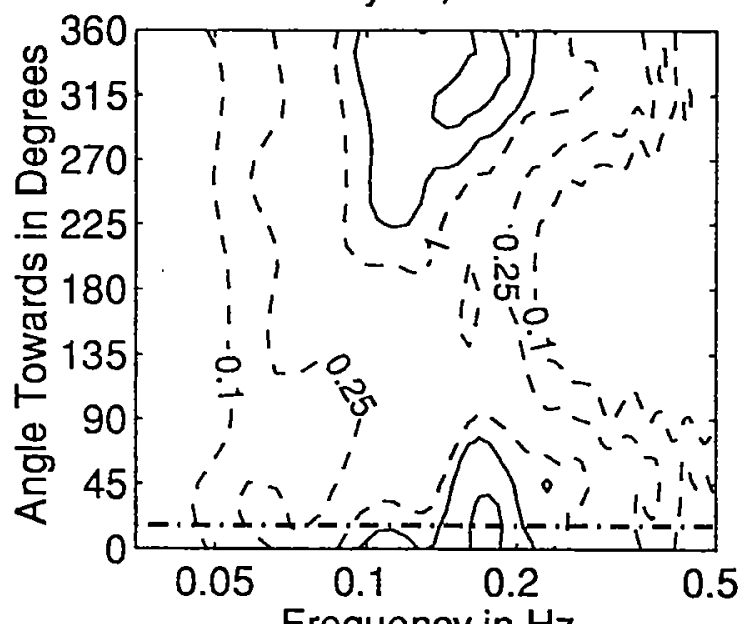

Frequency in $\mathrm{Hz}$

February 24, $199418 Z$

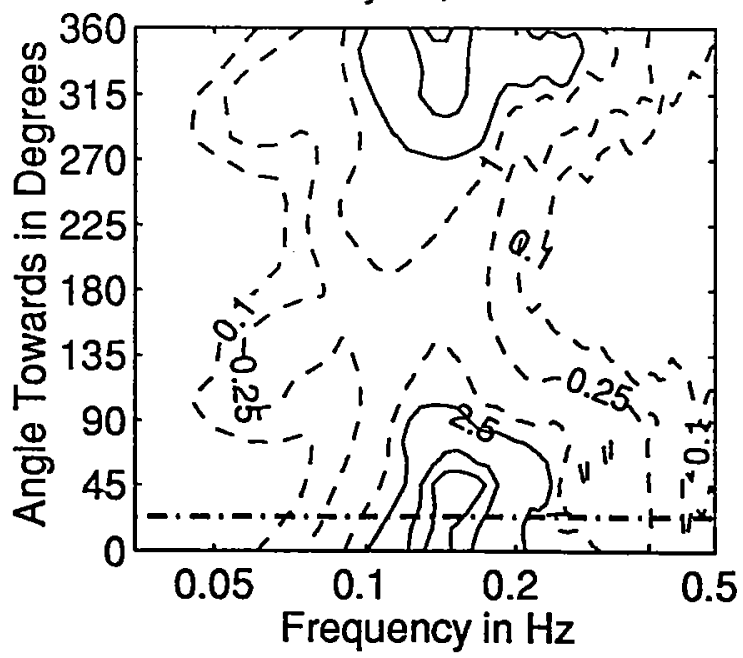

February 24, $199409 Z$

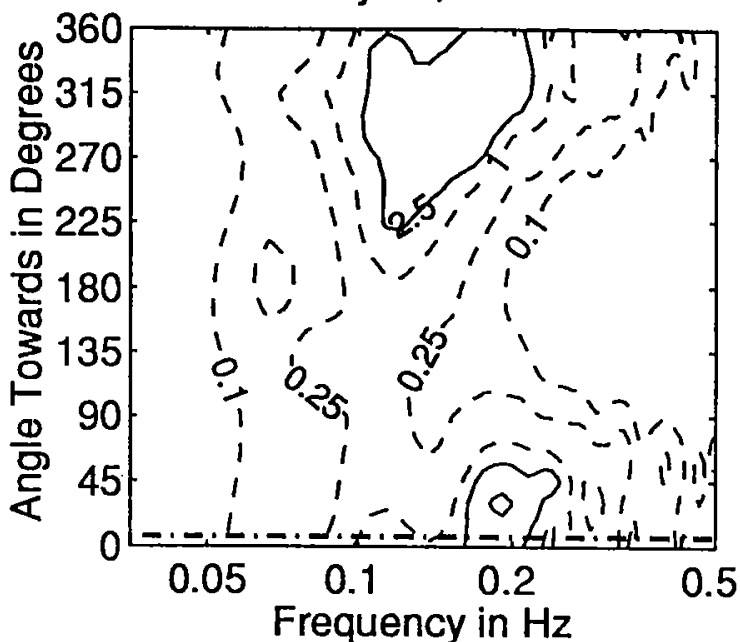

February 24, $199415 Z$

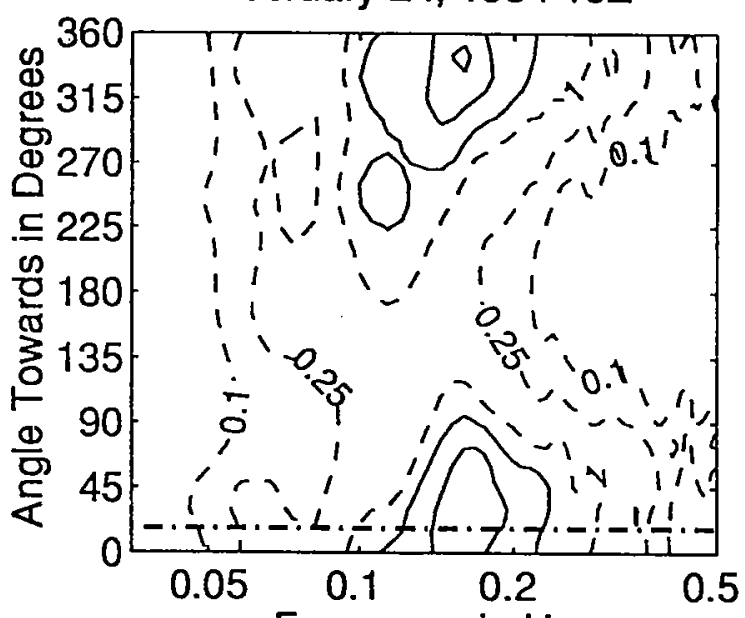

Frequency in $\mathrm{Hz}$

February 24, $199421 Z$

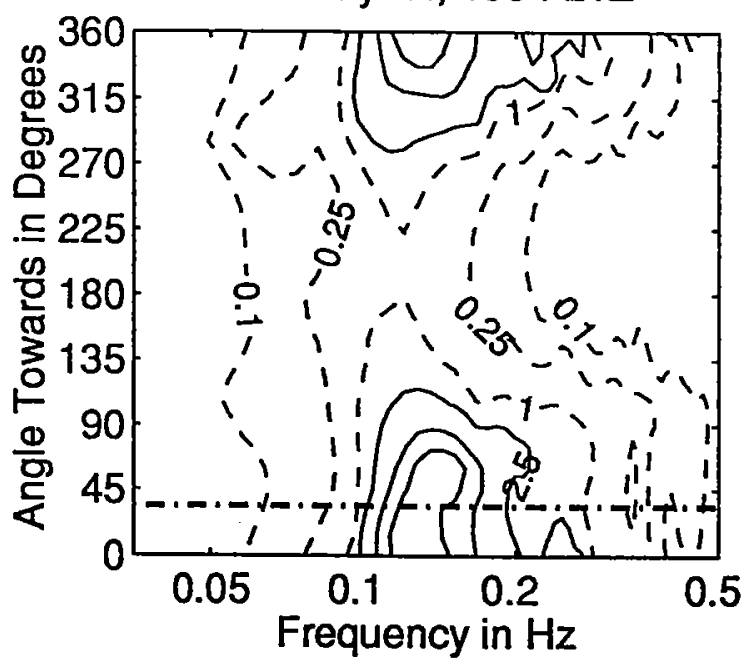

Figure 3.4.105: Directional wave spectra, computed using maximum entropy method. Contours of spectral density as a function of direction. Contours are 0.1, $0.25,1$ (dashed), $2.5,10,25,100$, and 250 (solid). Wind direction is shown by thick dashed line. 
February 28, $199400 Z$

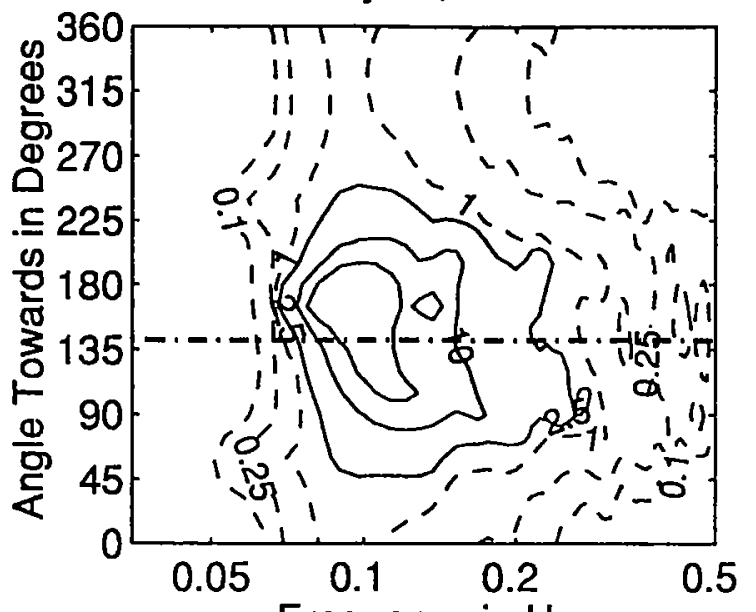

Frequency in $\mathrm{Hz}$

February 28, $199406 Z$

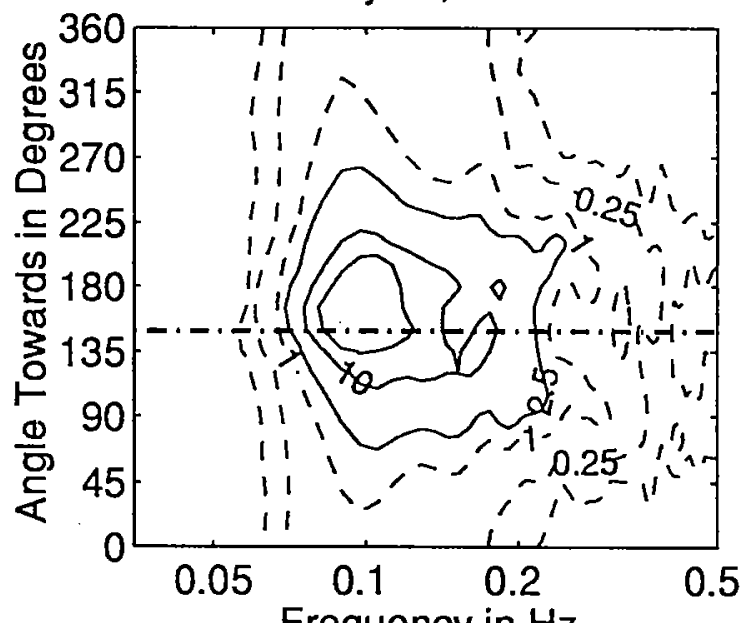

Frequency in $\mathrm{Hz}$

February 28, $199412 Z$

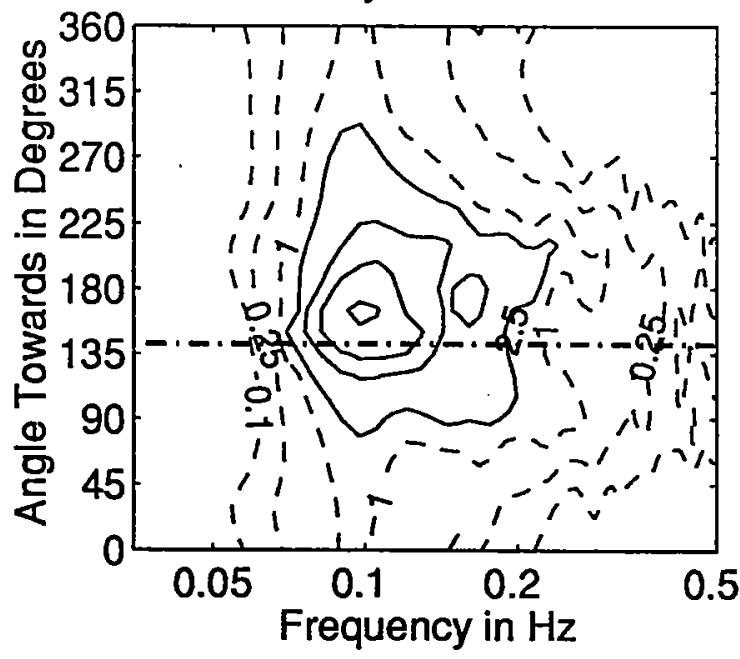

February 28, $199403 Z$

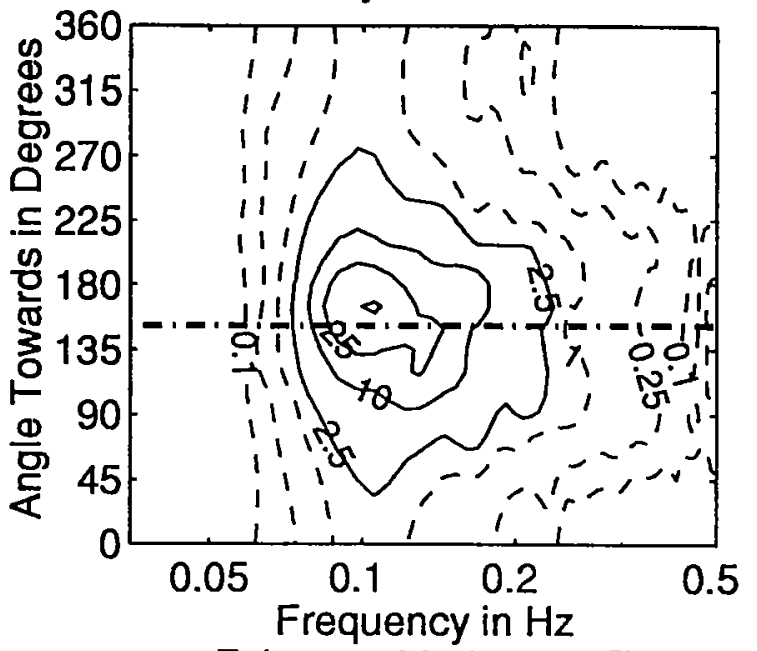

February 28, $199409 Z$

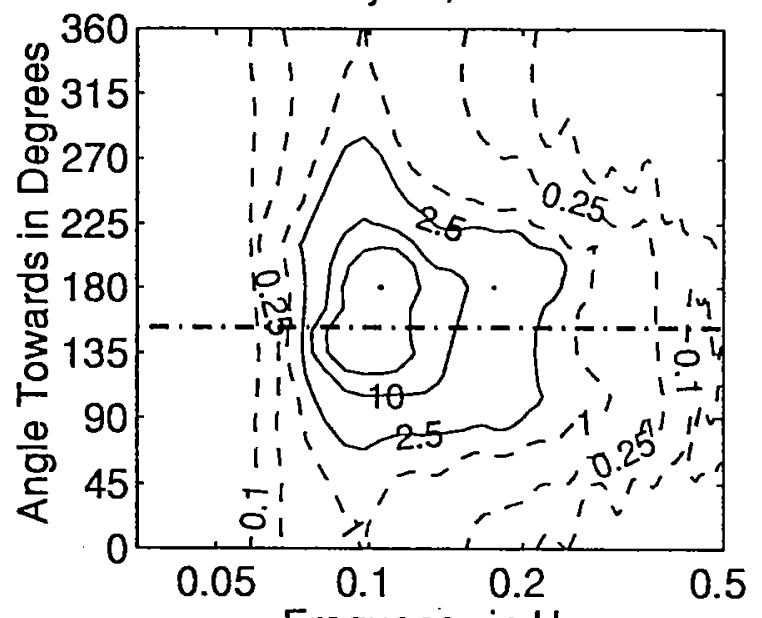

Frequency in $\mathrm{Hz}$

February 28, $199415 Z$

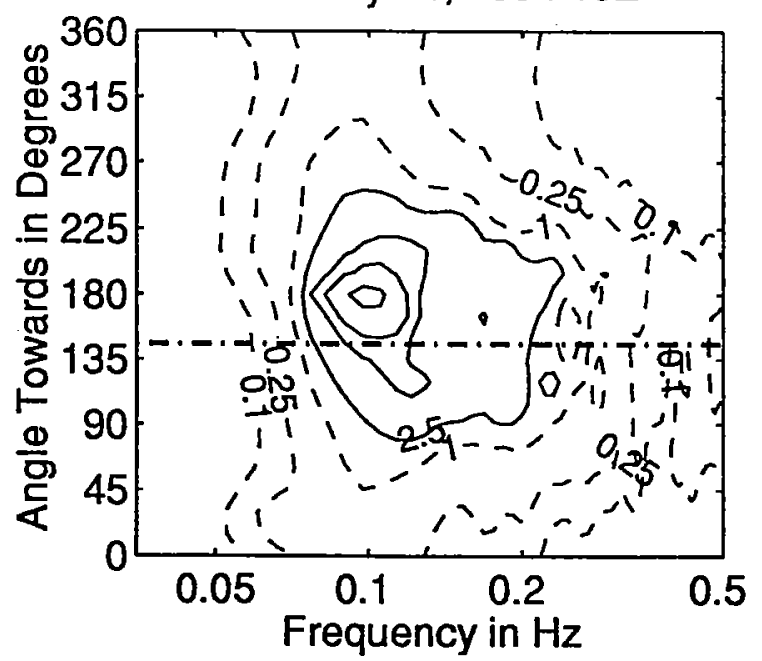

Figure 3.4.110: Directional wave spectra, computed using maximum entropy method. Contours of spectral density as a function of direction. Contours are 0.1 , $0.25,1$ (dashed), $2.5,10,25,100$, and 250 (solid). Wind direction is shown by thick dashed line. 
February 25, $199400 \mathrm{Z}$

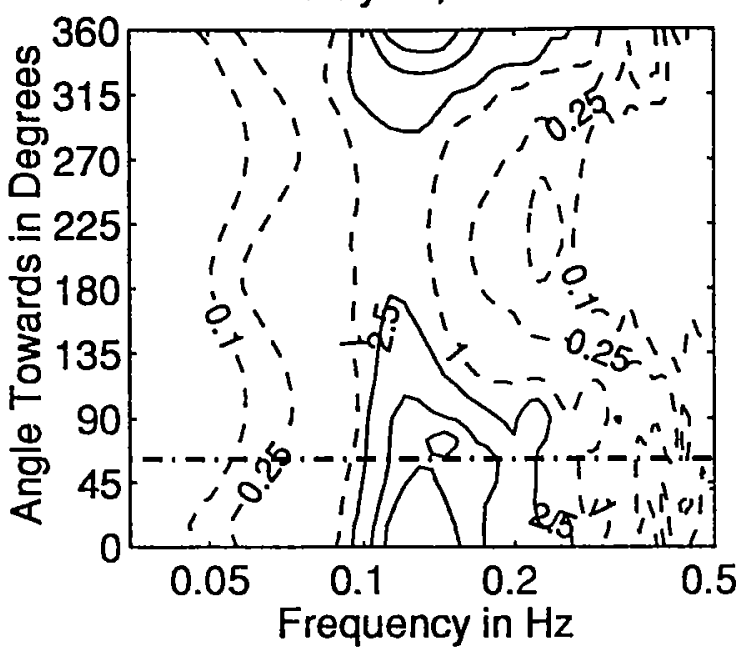

February 25, $199406 Z$

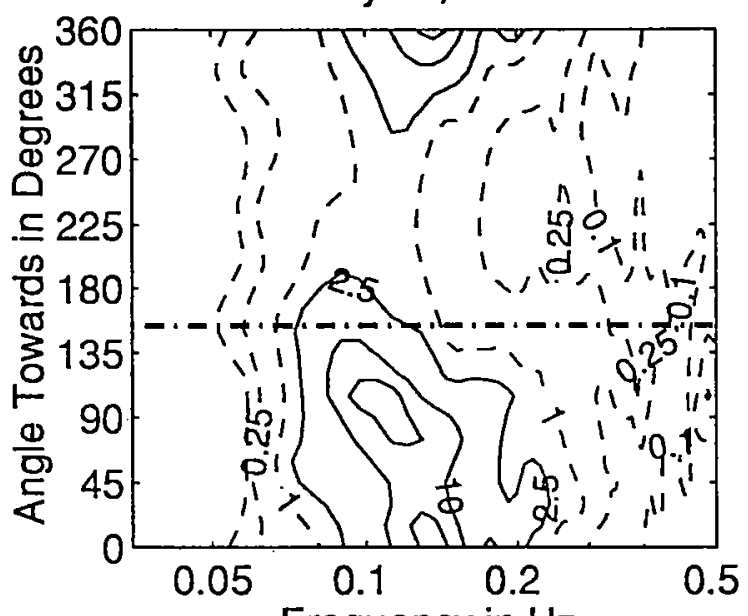

Frequency in $\mathrm{Hz}$

February 25, $199412 Z$

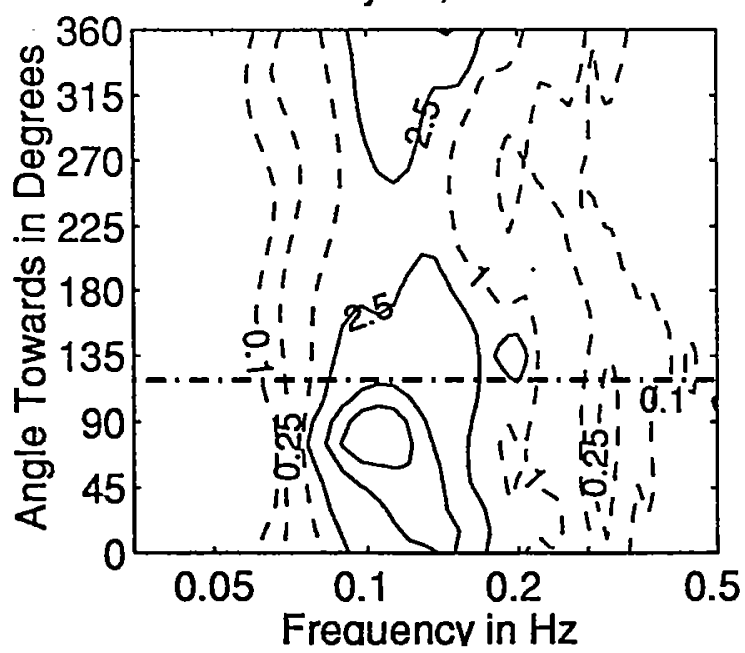

February 25, $199403 Z$

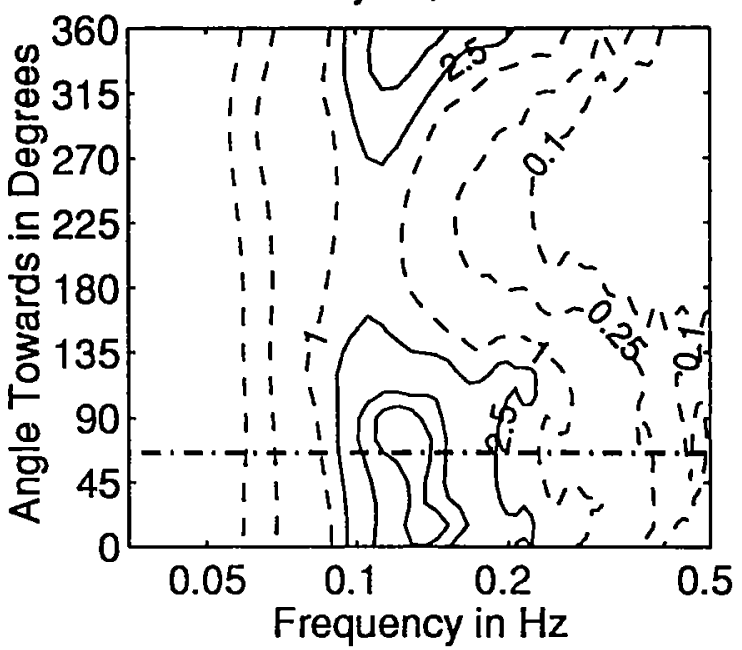

February 25, $199409 Z$

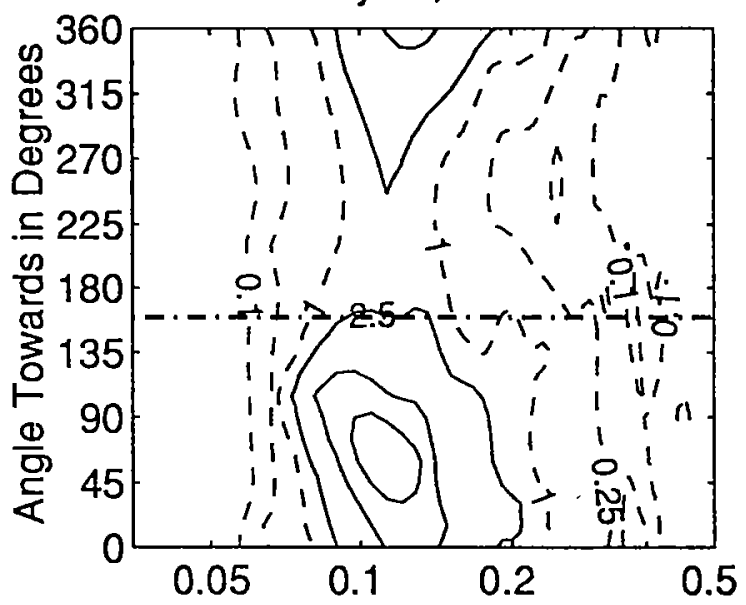

Frequency in $\mathrm{Hz}$

February 25, $199415 Z$

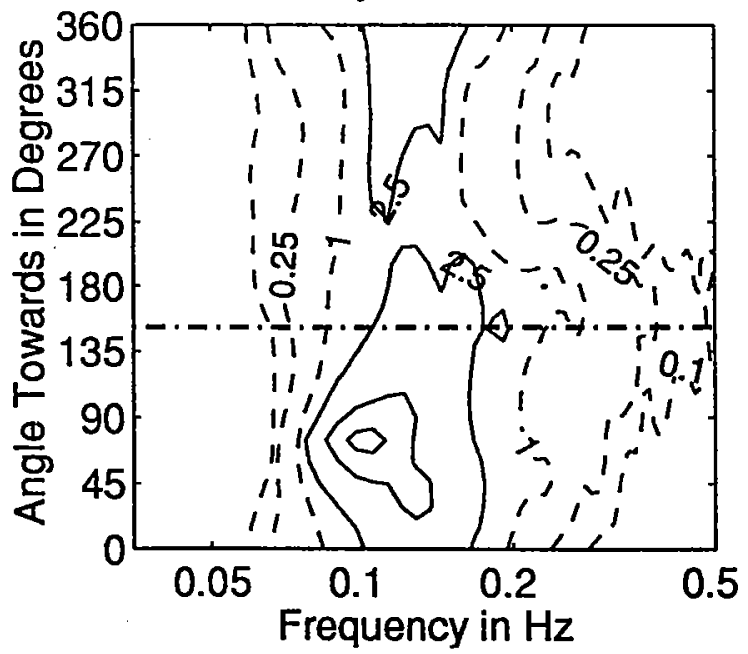

Figure 3.4.106: Directional wave spectra, computed using maximum entropy method. Contours of spectral density as a function of direction. Contours are 0.1, $0.25,1$ (dashed), $2.5,10,25,100$, and 250 (solid). Wind direction is shown by thick dashed line. 
February 25, $199418 Z$

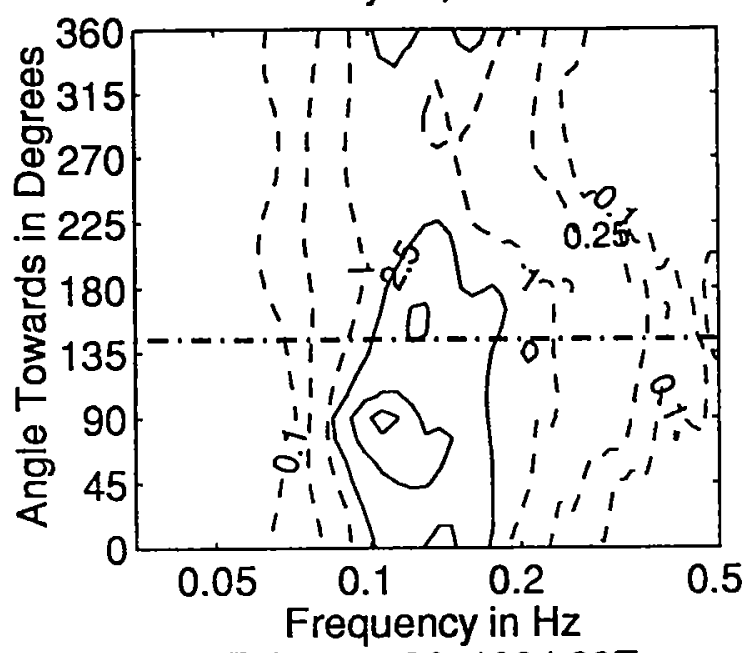

February 26, $199400 Z$

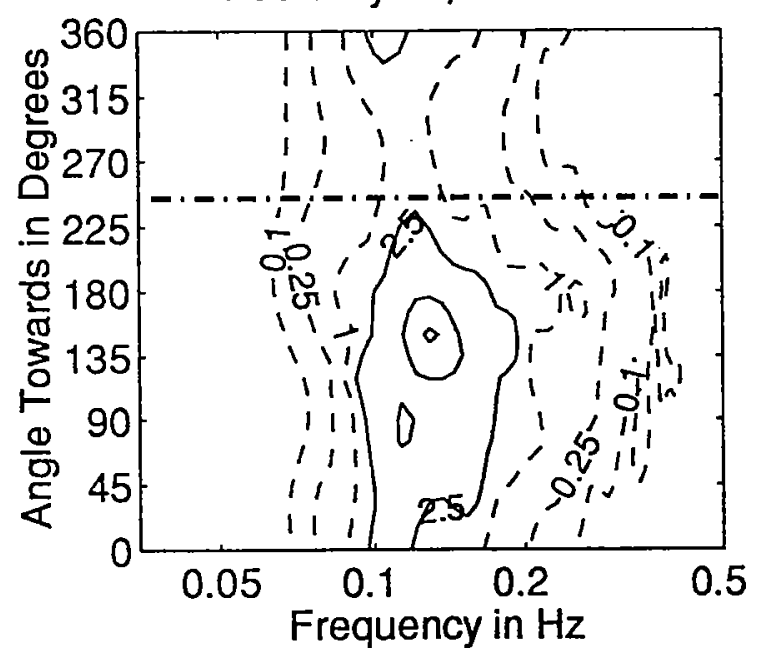

February 26, 1994 06Z

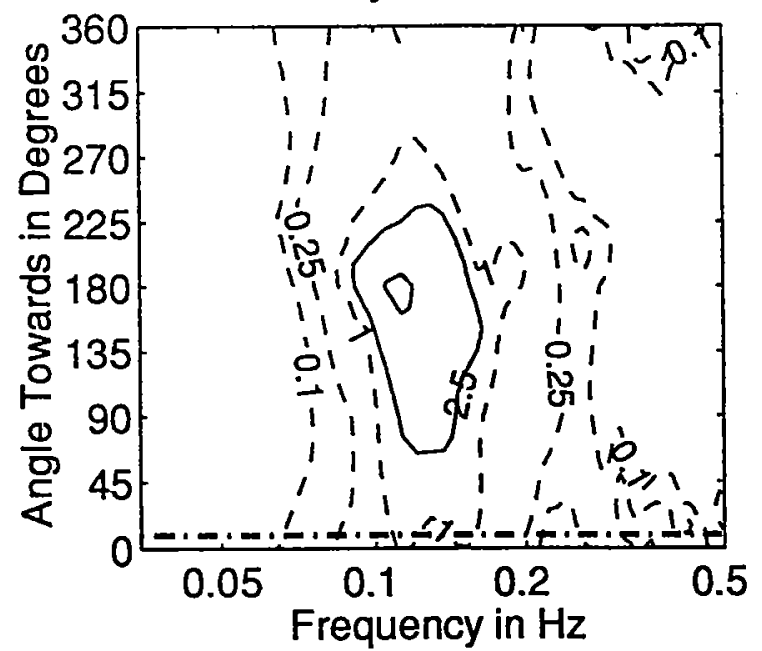

February 25, $199421 Z$

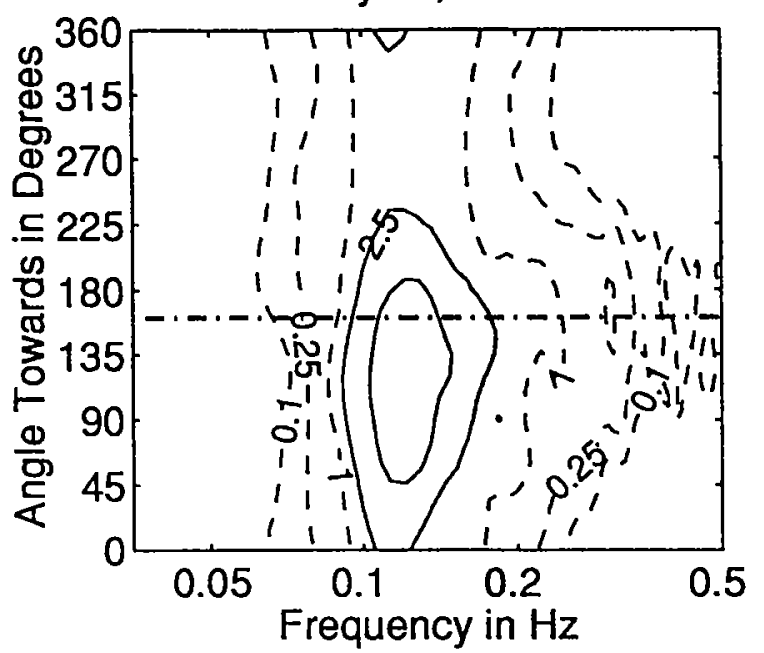

February 26, $199403 Z$

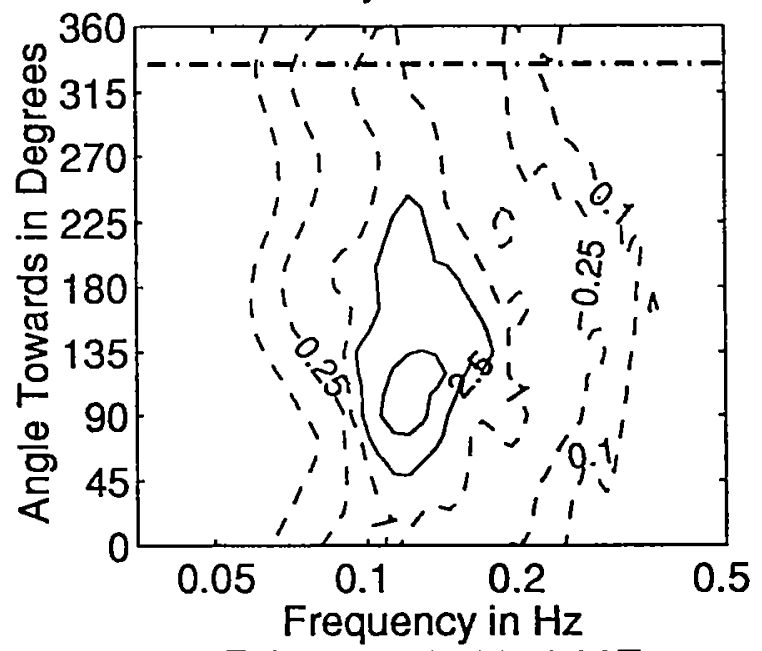

February 26, 1994 09Z

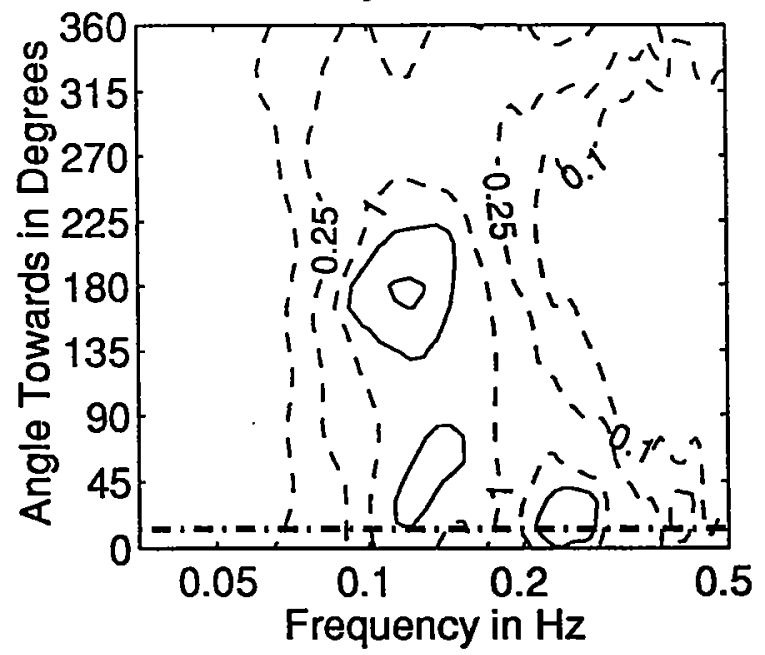

Figure 3.4.107: Directional wave spectra, computed using maximum entropy method. Contours of spectral density as a function of direction. Contours are 0.1 , $0.25,1$ (dashed), $2.5,10,25,100$, and 250 (solid). Wind direction is shown by thick dashed line. 
February 26, $199412 Z$

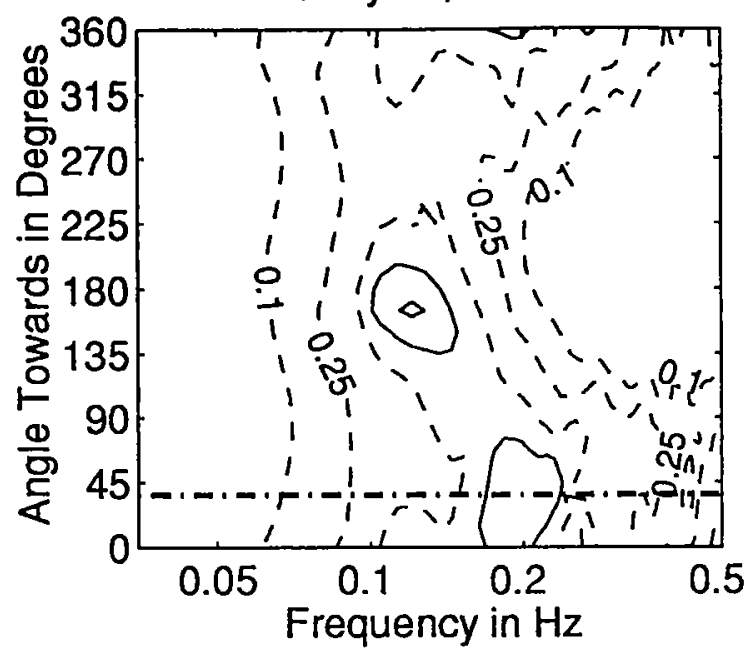

February 26, $199418 Z$

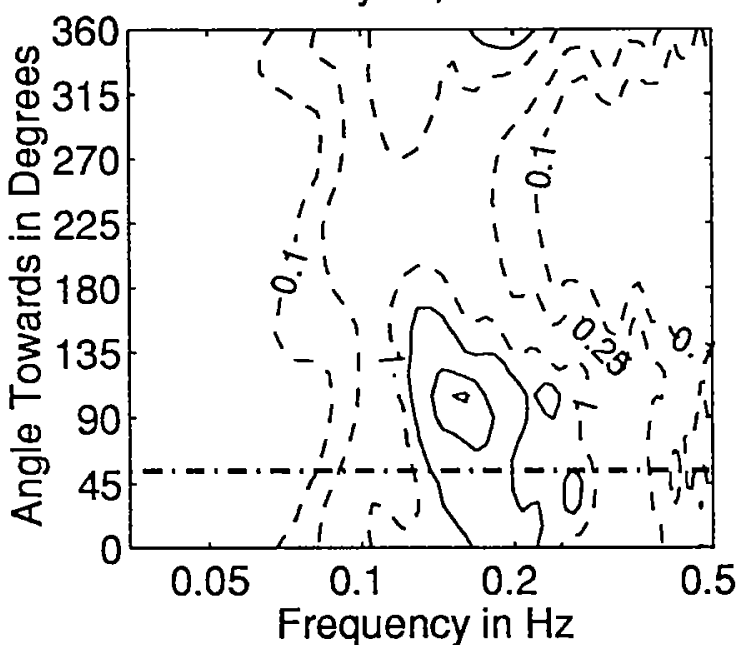

February 27, $199400 Z$

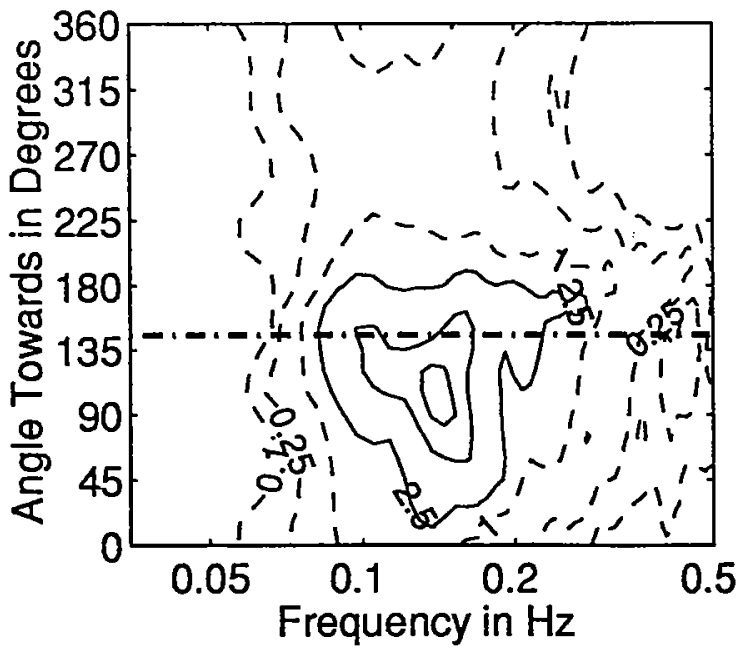

February 26, $199415 Z$

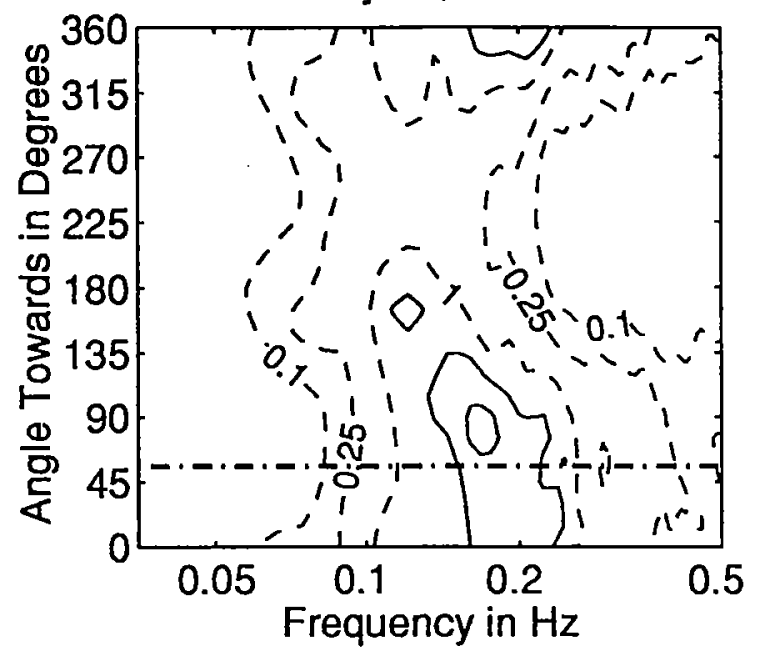

February 26, $199421 Z$

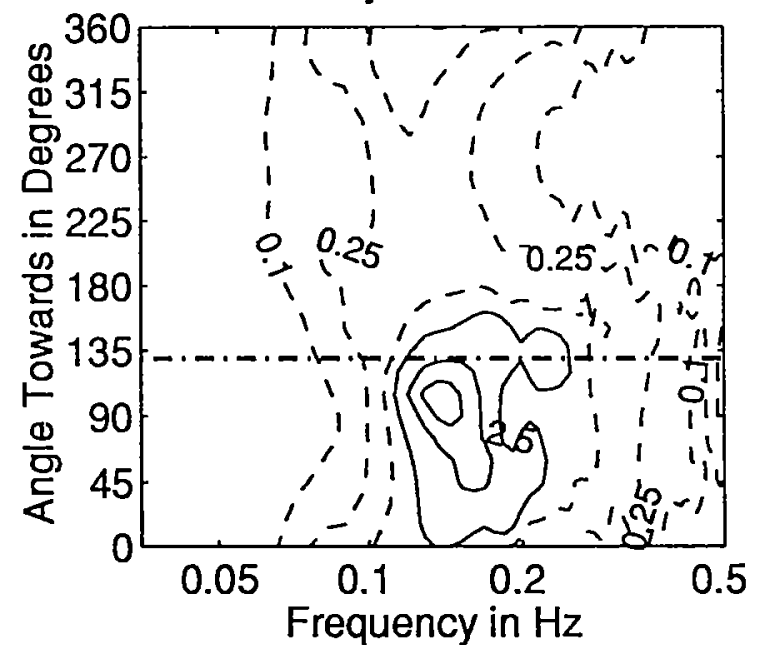

February 27, $199403 Z$

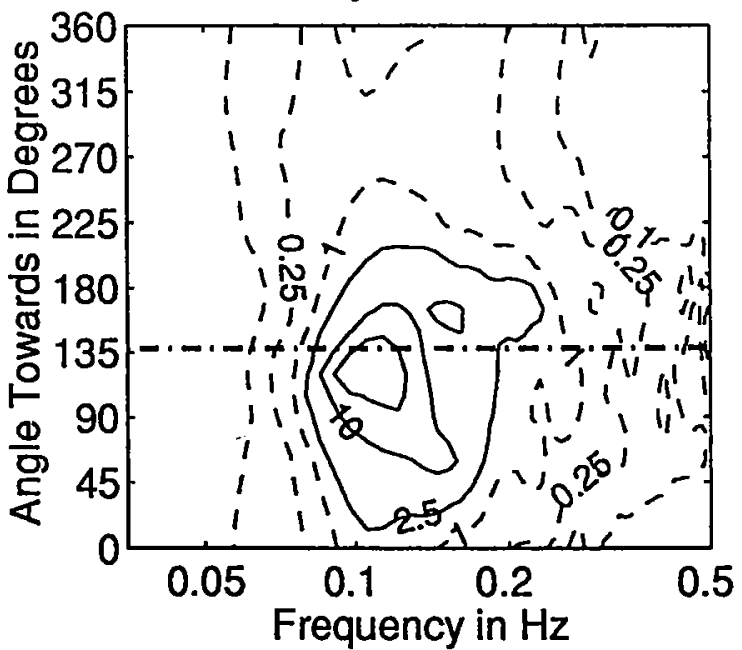

Figure 3.4.108: Directional wave spectra, computed using maximum entropy method. Contours of spectral density as a function of direction. Contours are 0.1, $0.25,1$ (dashed), $2.5,10,25,100$, and 250 (solid). Wind direction is shown by thick dashed line. 
February 27, $199406 Z$

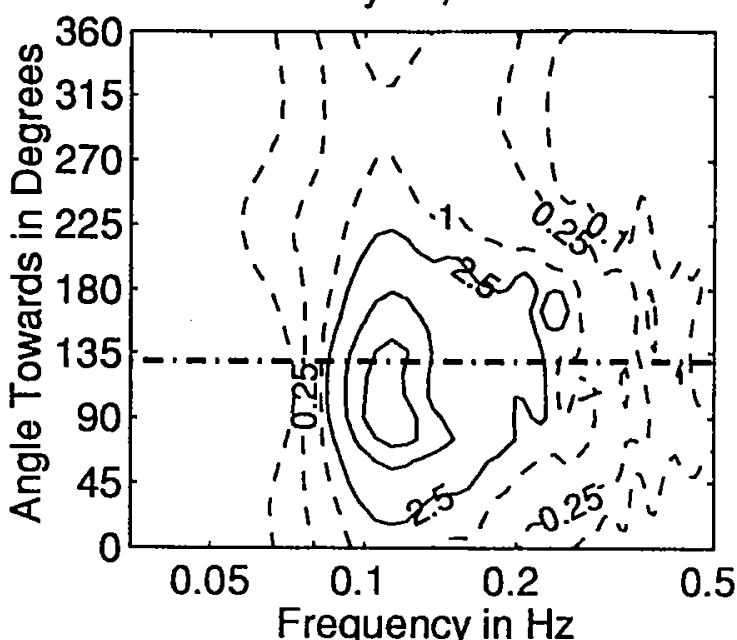

February 27, $199412 Z$

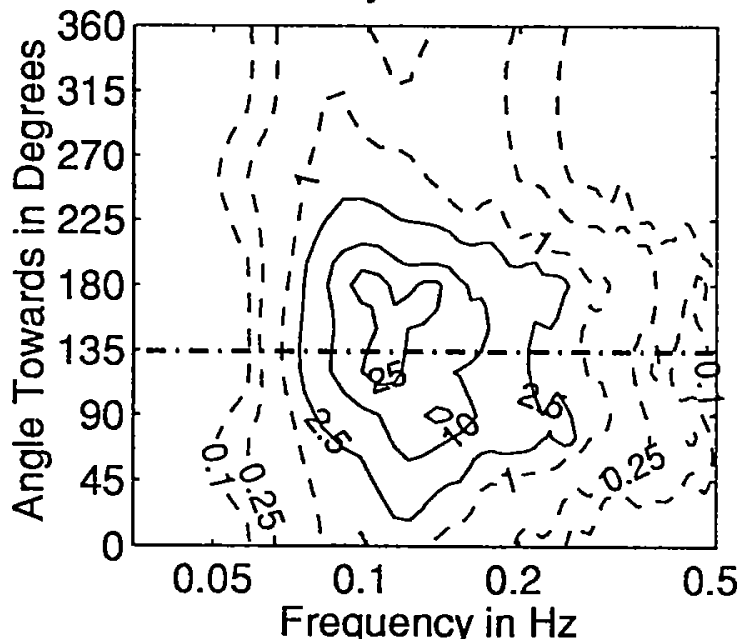

February 27, $199418 Z$

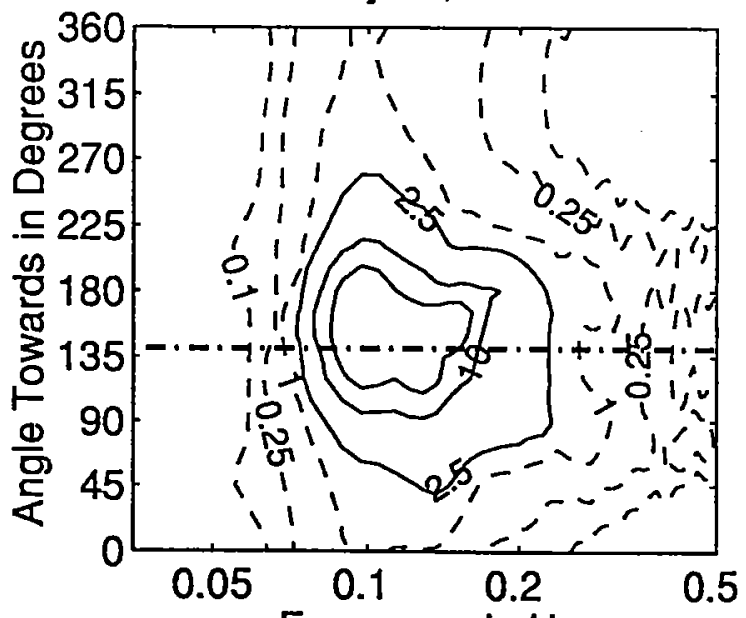

Frequency in $\mathrm{Hz}$
February 27, $199409 Z$

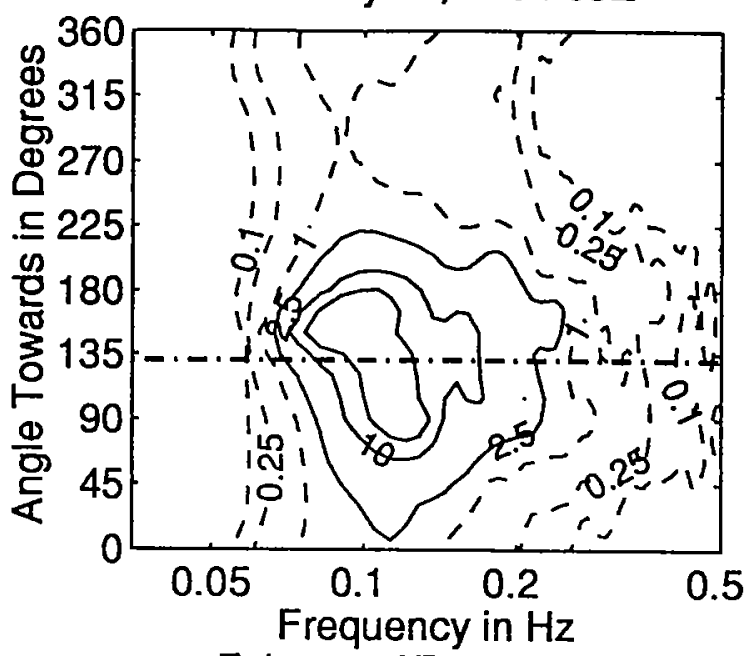

February 27, $199415 Z$

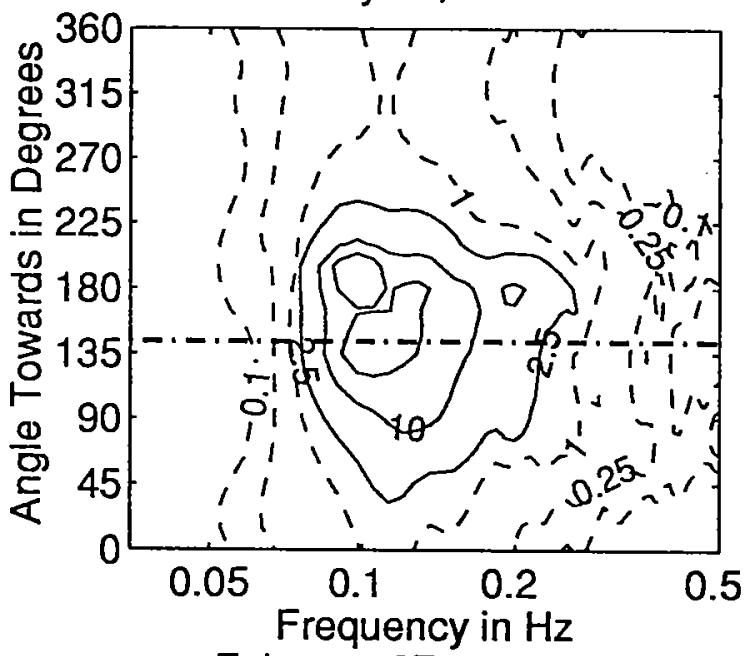

February 27, $199421 Z$

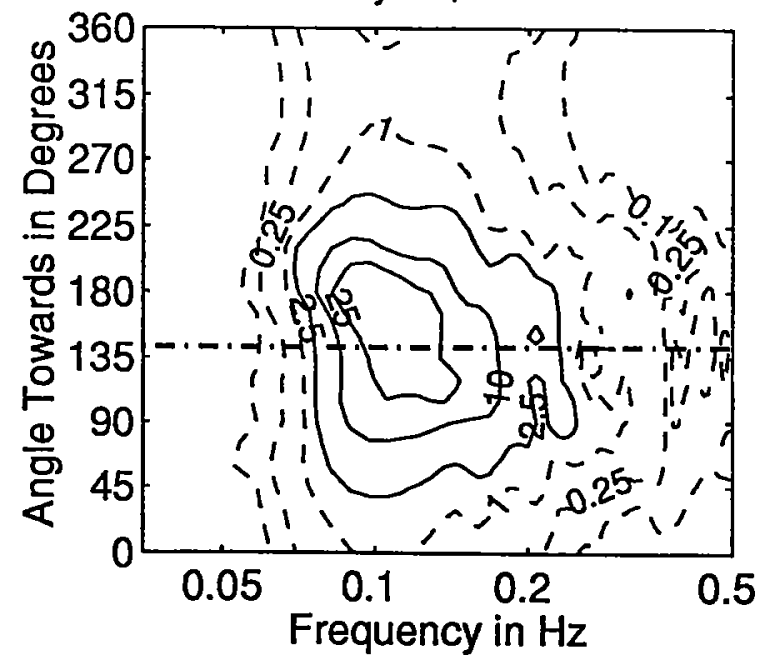

Figure 3.4.109: Directional wave spectra, computed using maximum entropy method. Contours of spectral density as a function of direction. Contours are 0.1 , $0.25,1$ (dashed), $2.5,10,25,100$, and 250 (solid). Wind direction is shown by
thick dashed line. 
February 28, $199418 Z$
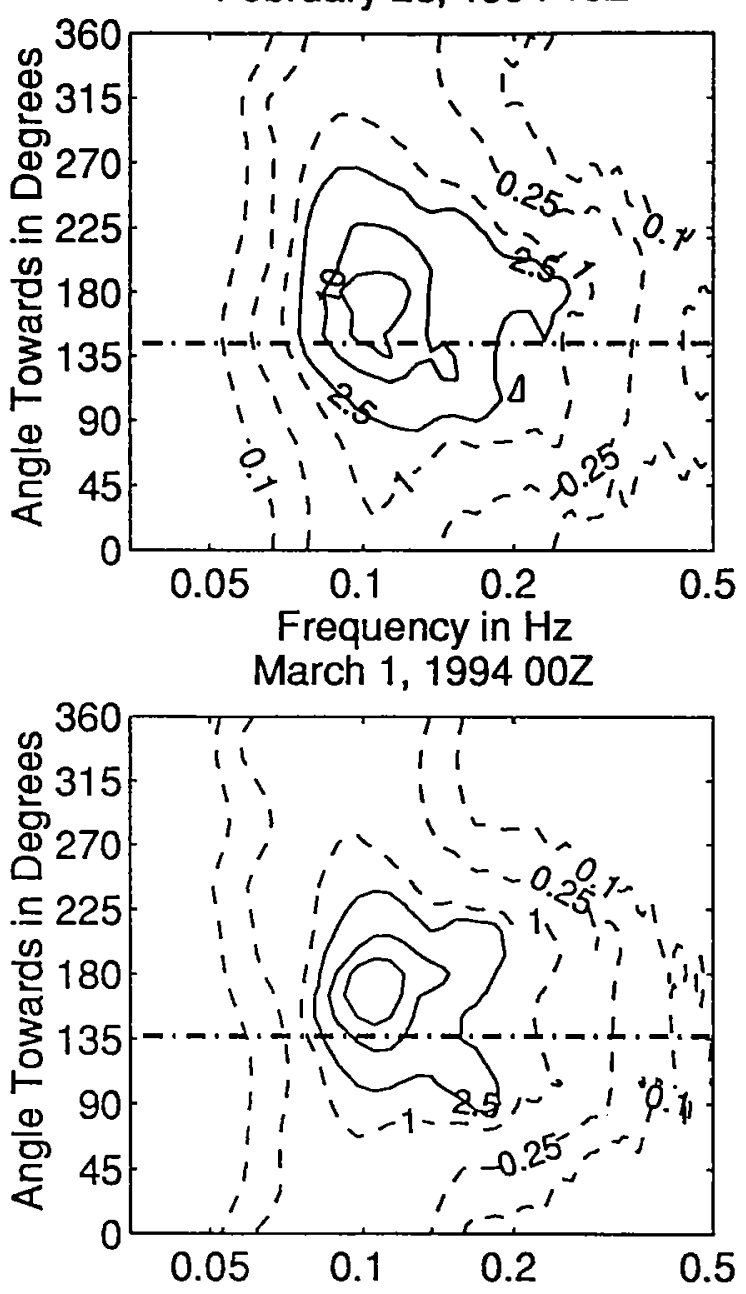

Frequency in $\mathrm{Hz}$

March 1, $199406 Z$

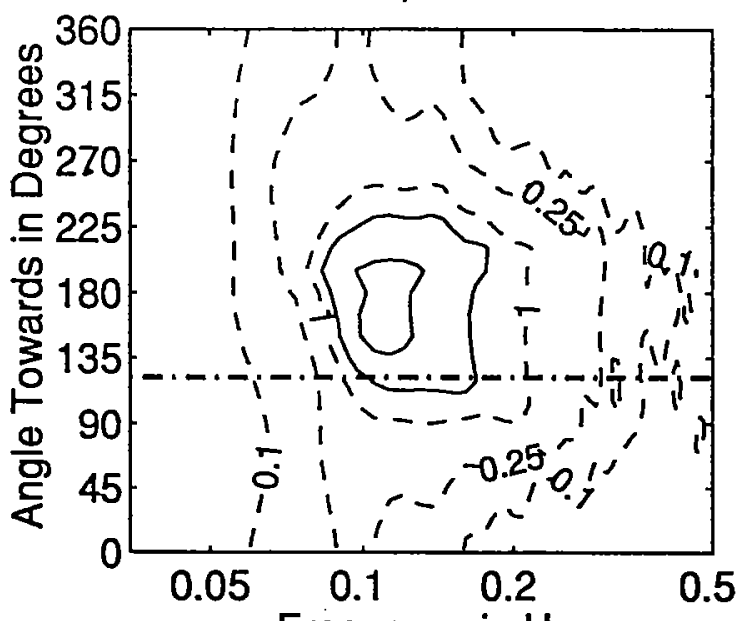

Frequency in $\mathrm{Hz}$
February 28, $199421 Z$
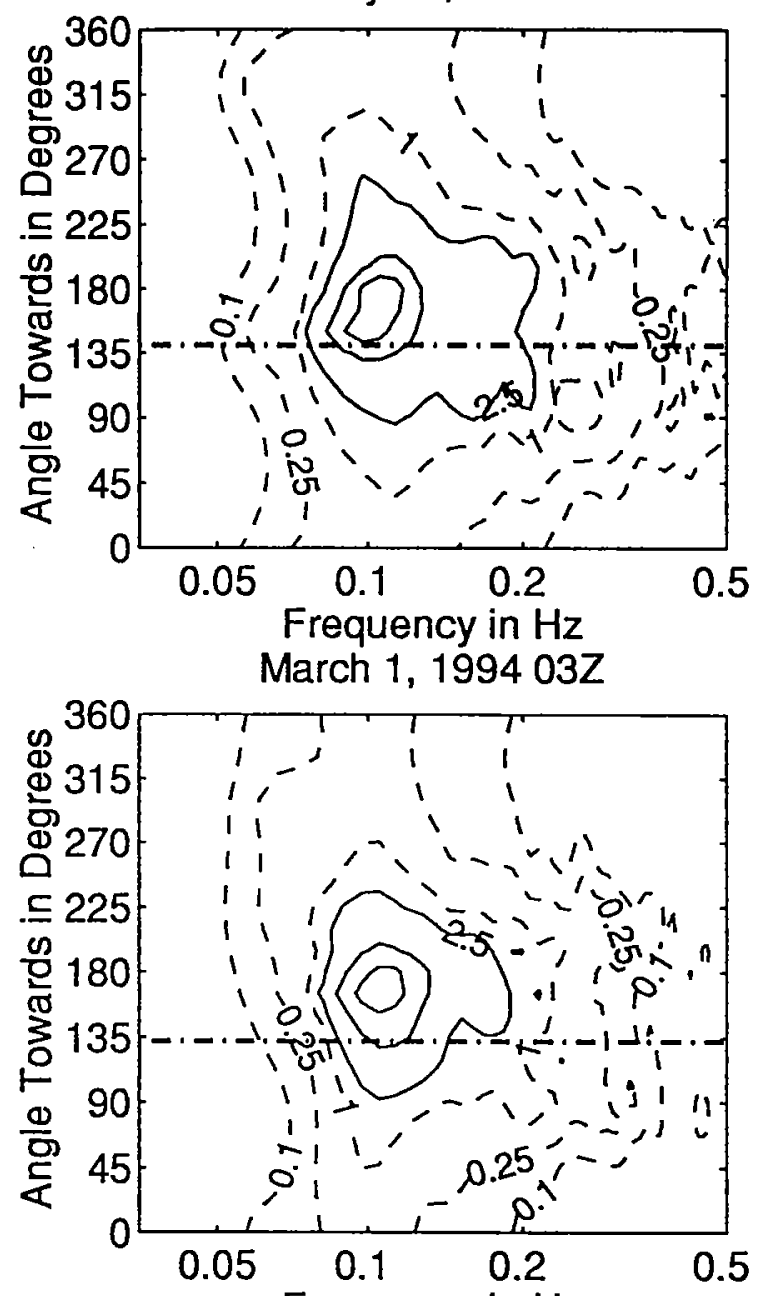

Frequency in $\mathrm{Hz}$

March 1, $199409 Z$

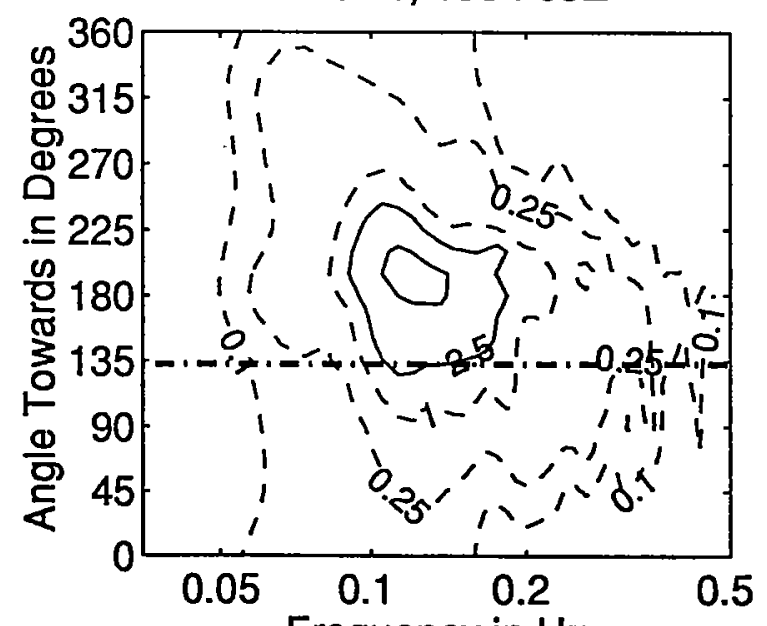

Erequency in $\mathrm{Hz}$

Figure 3.4.111: Directional wave spectra, computed using maximum entropy method. Contours of spectral density as a function of direction. Contours are 0.1, $0.25,1$ (dashed), $2.5,10,25,100$, and 250 (solid). Wind direction is shown by thick dashed line. 

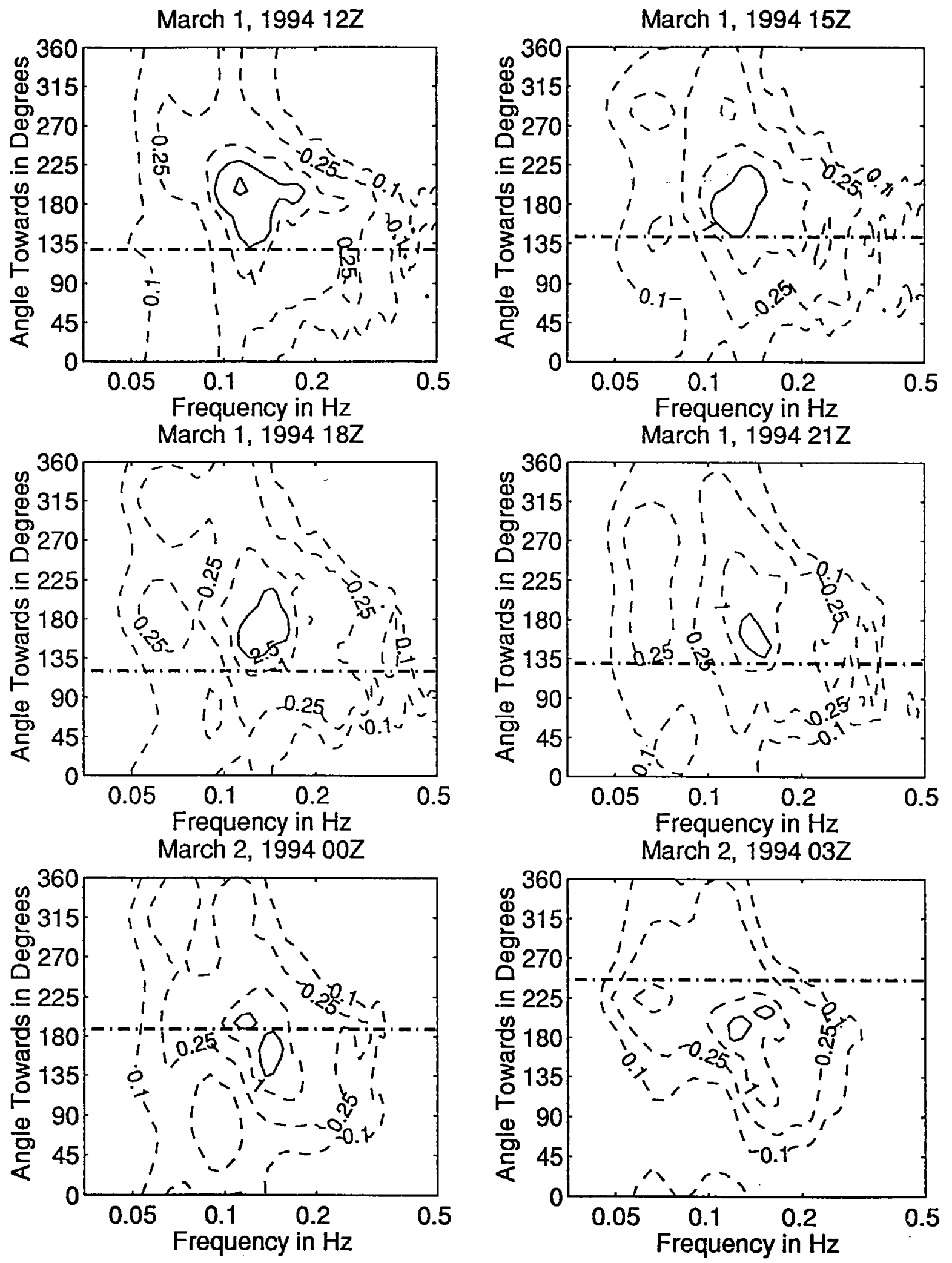

Figure 3.4.112: Directional wave spectra, computed using maximum entropy method. Contours of spectral density as a function of direction. Contours are 0.1 , $0.25,1$ (dashed), $2.5,10,25,100$, and 250 (solid). Wind direction is shown by thick dashed line. 
March 2, $199406 Z$

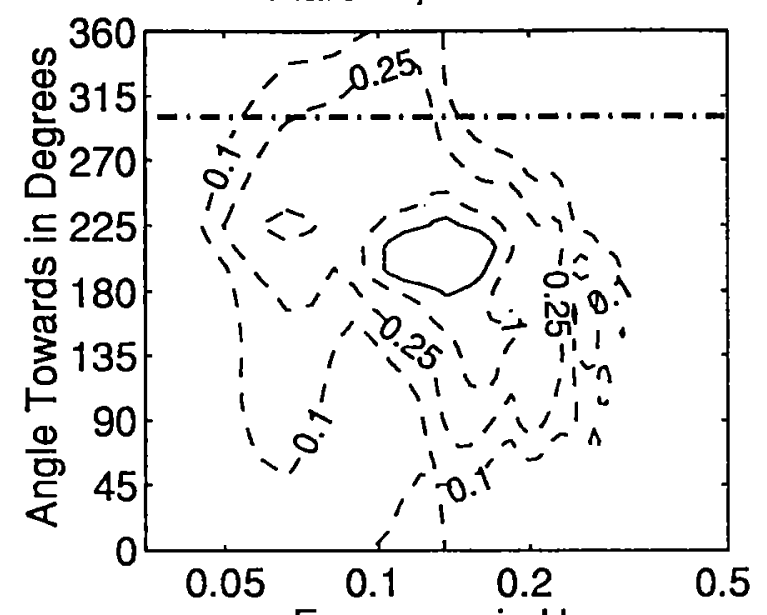

Frequency in $\mathrm{Hz}$

March 2, 1994127
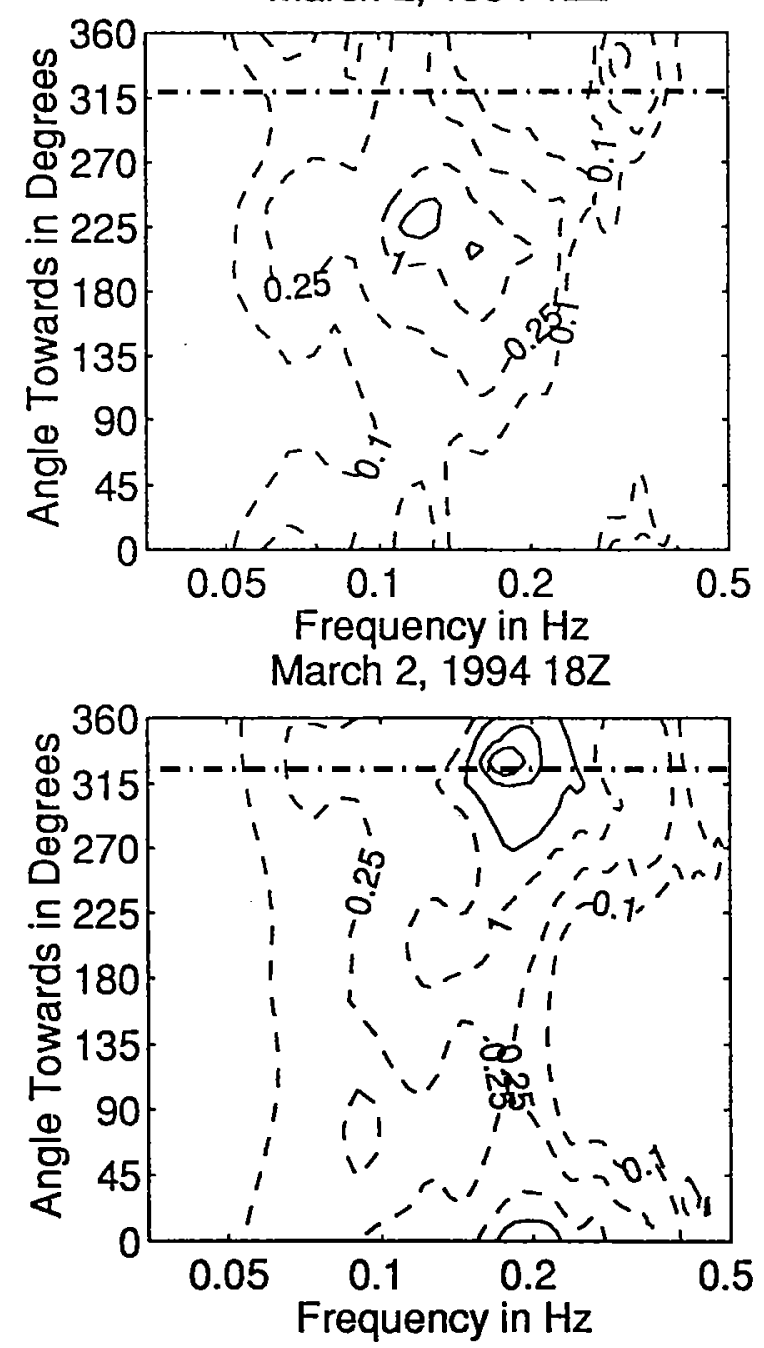

March 2, $199409 Z$

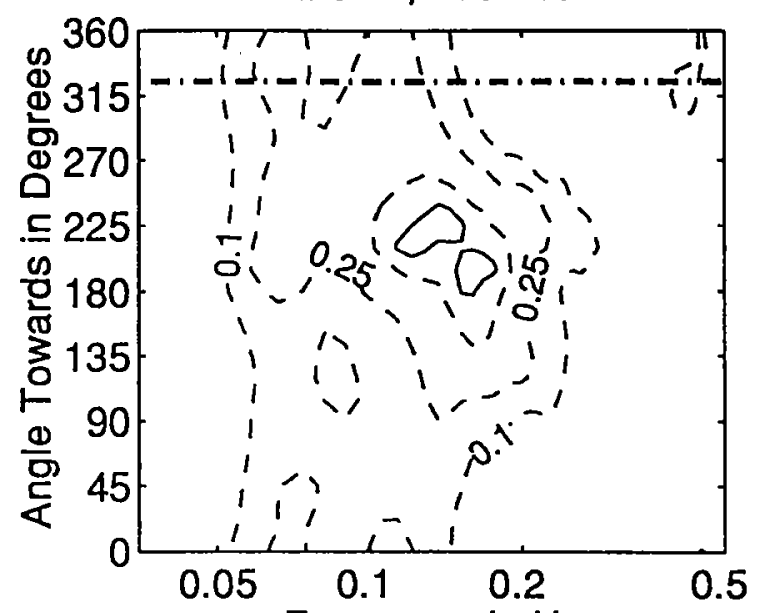

Frequency in $\mathrm{Hz}$

March 2, $199415 Z$
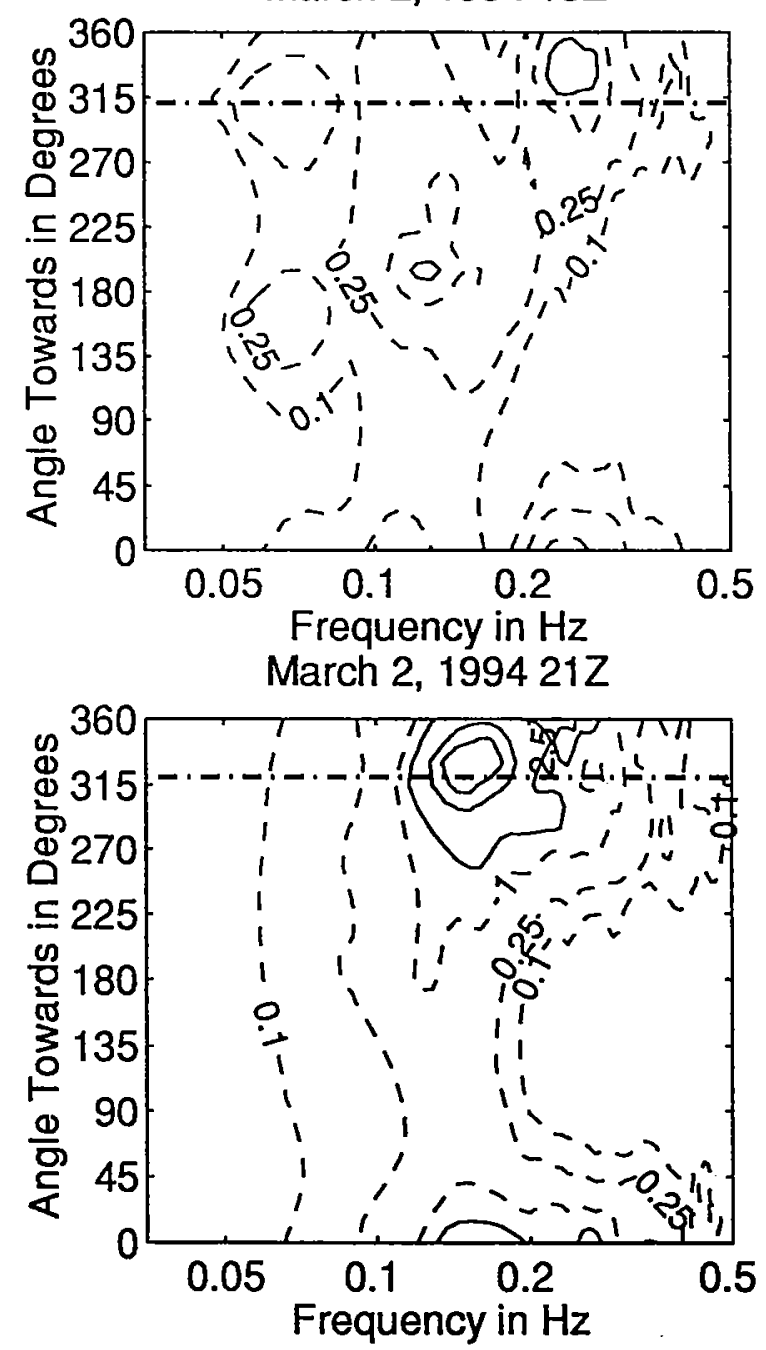

Figure 3.4.113: Directional wave spectra, computed using maximum entropy method. Contours of spectral density as a function of direction. Contours are 0.1, $0.25,1$ (dashed), $2.5,10,25,100$, and 250 (solid). Wind direction is shown by thick dashed line. 
March 3, $199400 Z$
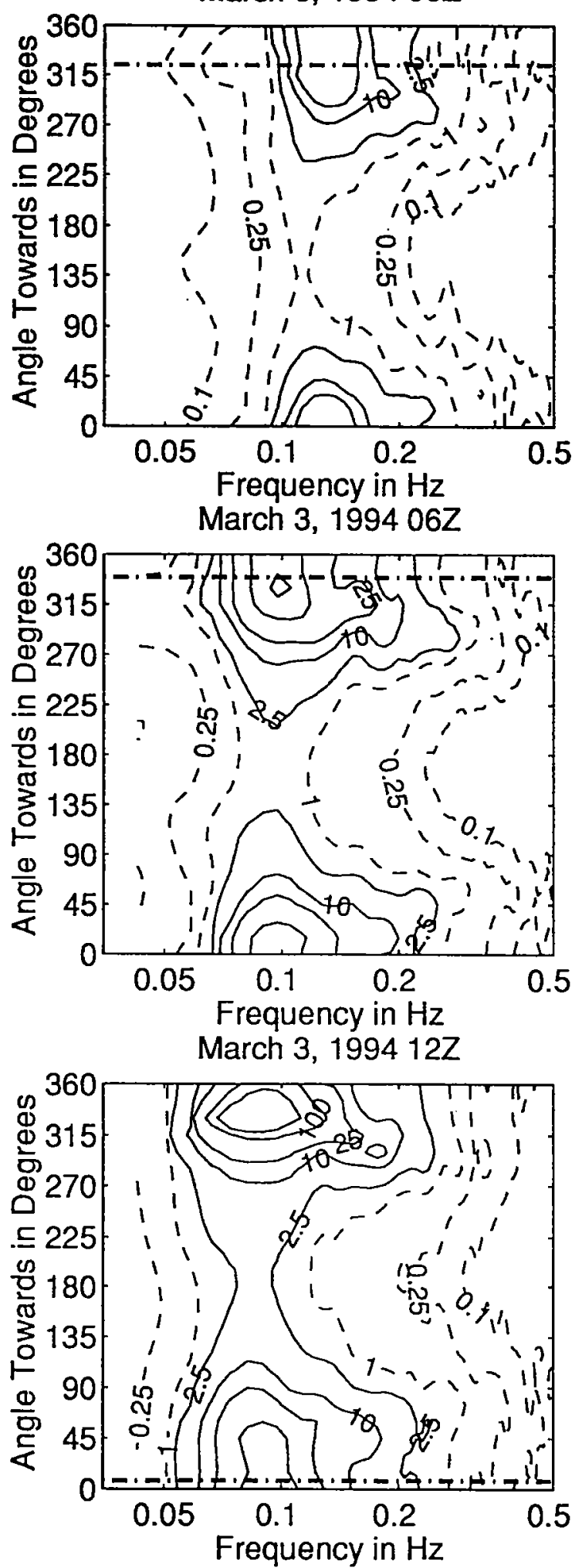

March 3, $199403 Z$

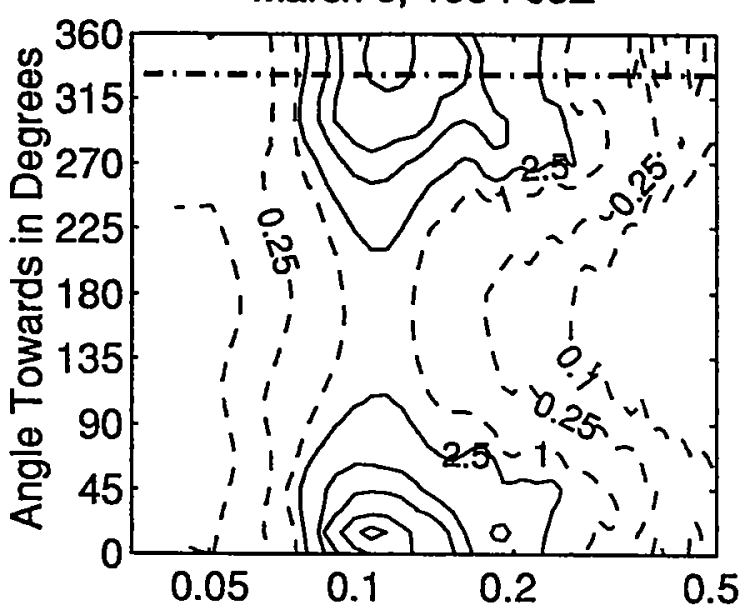

Frequency in $\mathrm{Hz}$

March 3, $199409 Z$

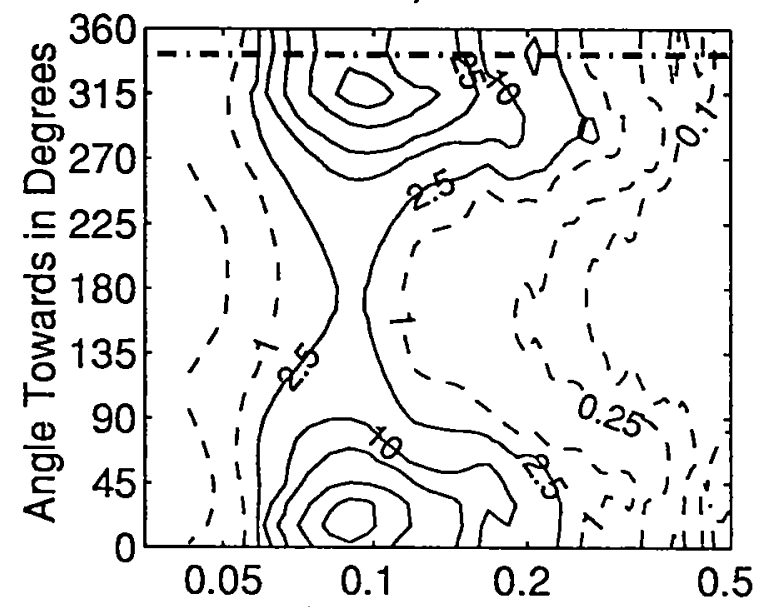

Frequency in $\mathrm{Hz}$

March 3, $199415 Z$

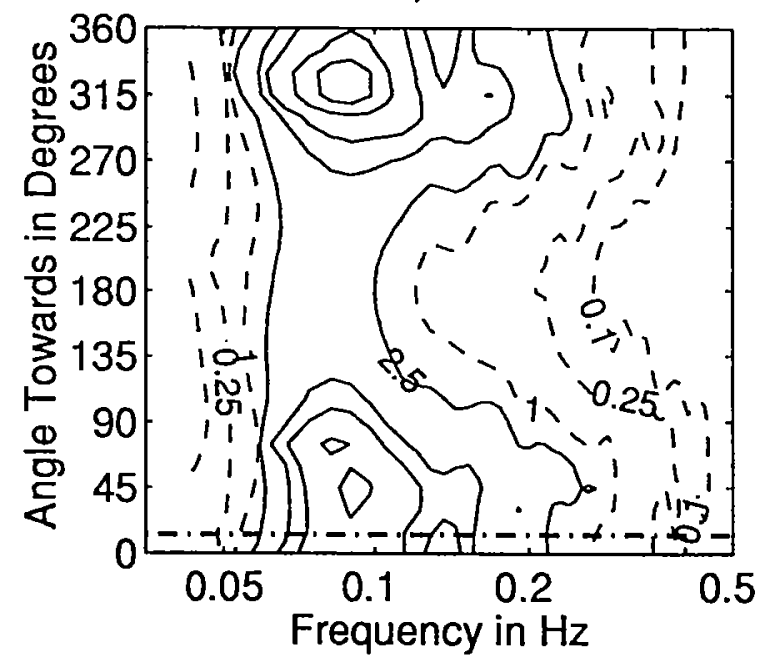

Figure 3.4.114: Directional wave spectra, computed using maximum entropy method. Contours of spectral density as a function of direction. Contours are 0.1 , $0.25,1$ (dashed), $2.5,10,25,100$, and 250 (solid). Wind direction is shown by thick dashed line. 
March 3, $199418 Z$

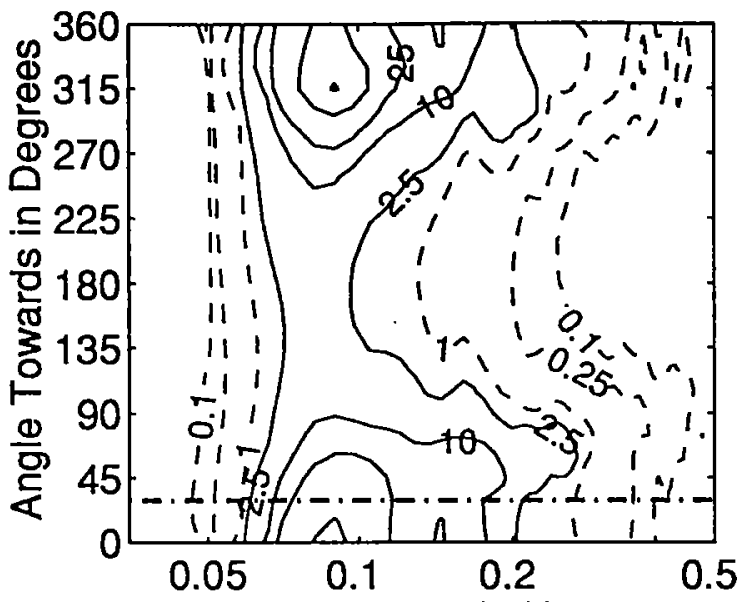

Frequency in $\mathrm{Hz}$

March 4, 1994 00Z
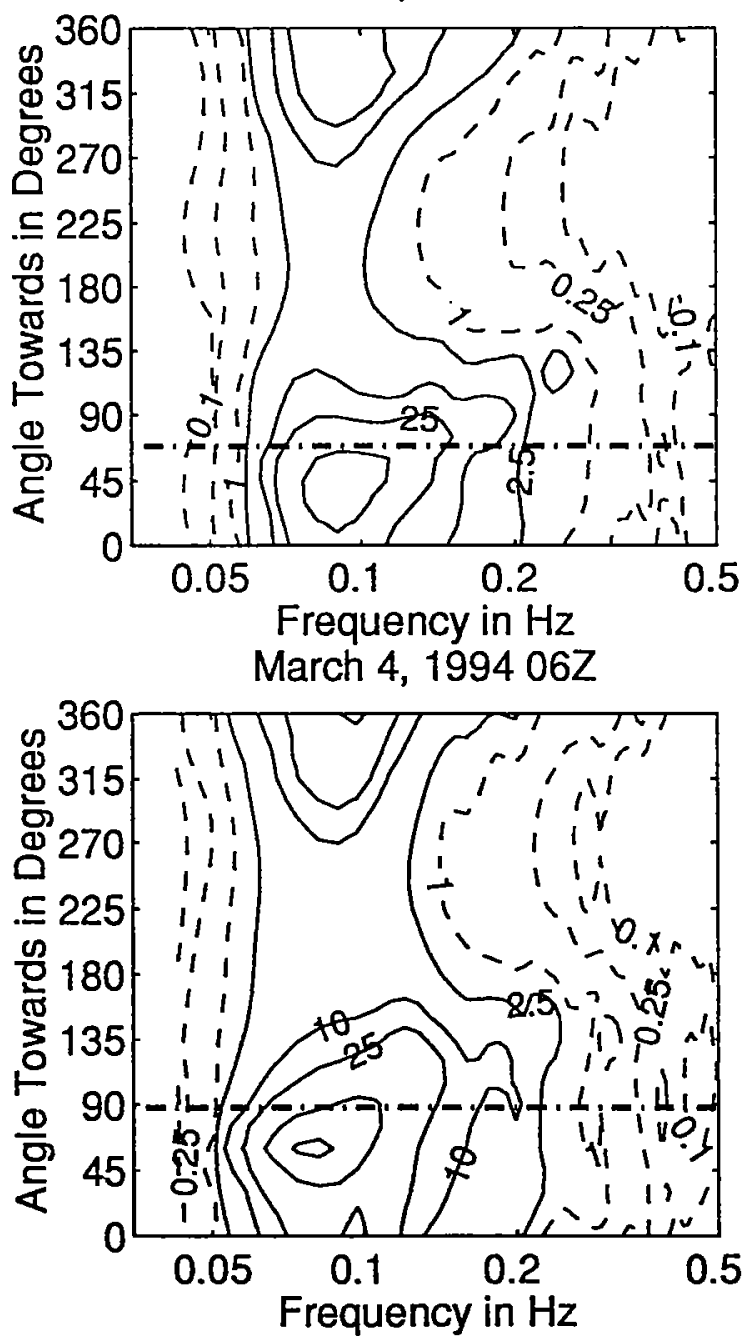

March 3, 199421 Z

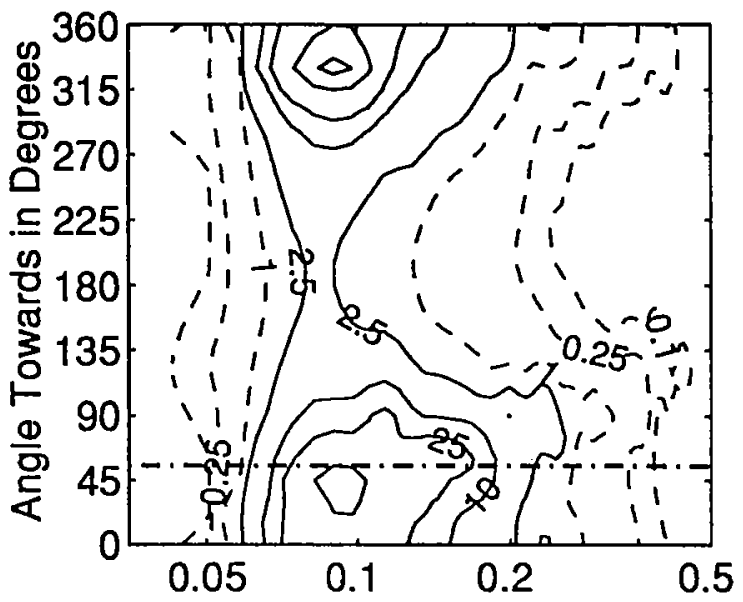

Frequency in $\mathrm{Hz}$

March 4, $199403 Z$
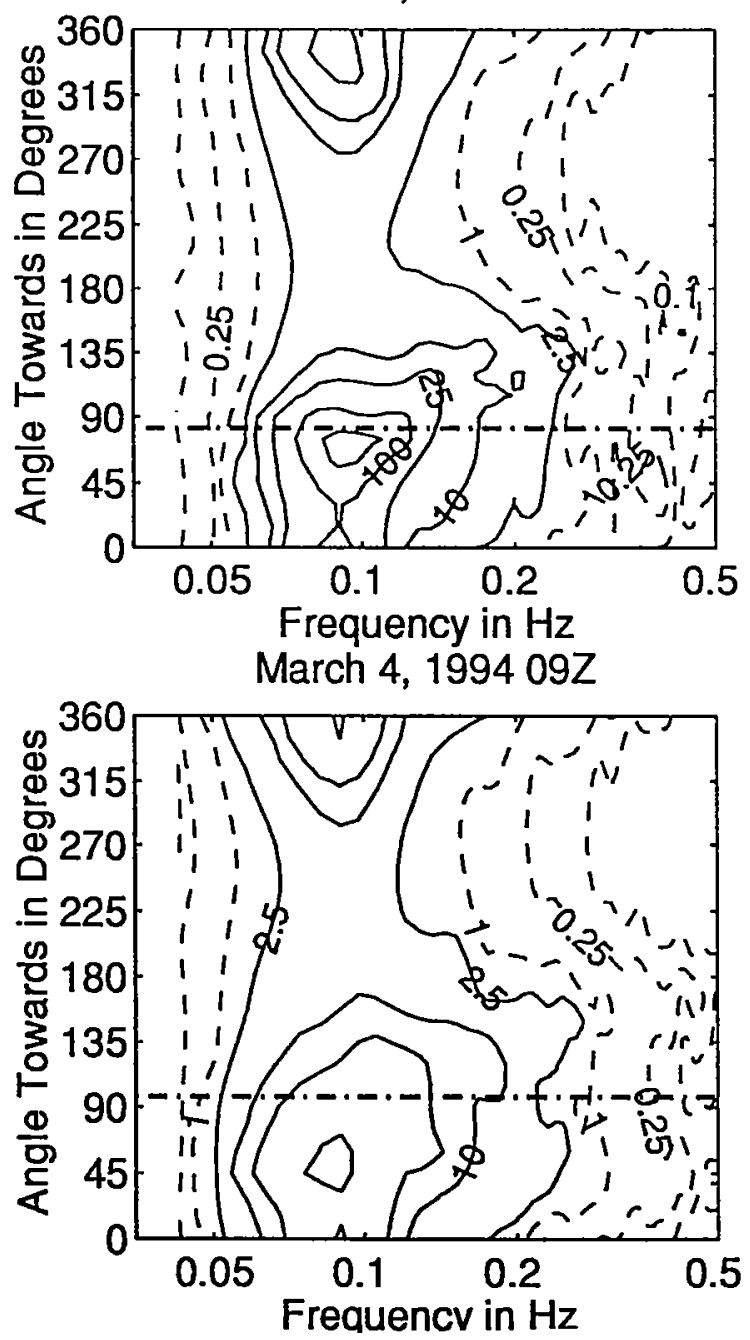

Figure 3.4.115: Directional wave spectra, computed using maximum entropy method. Contours of spectral density as a function of direction. Contours are 0.1 , $0.25,1$ (dashed), $2.5,10,25,100$, and 250 (solid). Wind direction is shown by thick dashed line. 
March 4, $199412 Z$

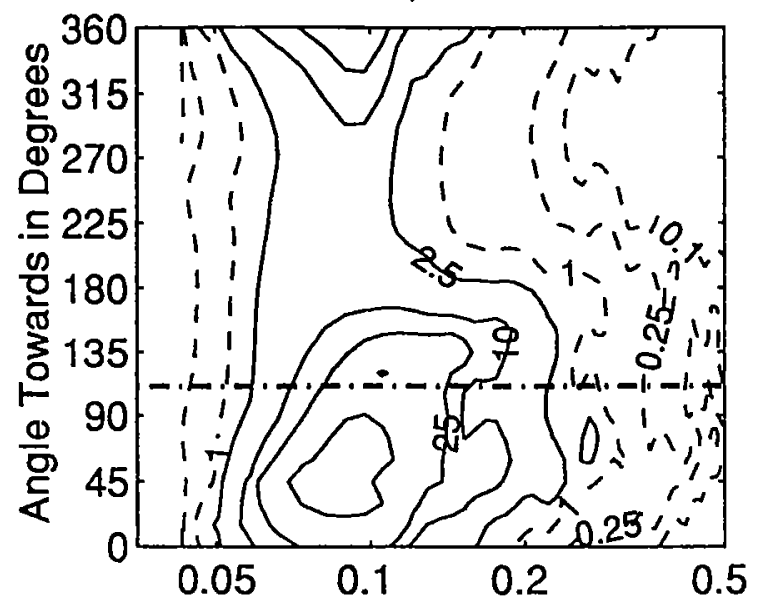

Frequency in $\mathrm{Hz}$

March 4, 1994 18Z

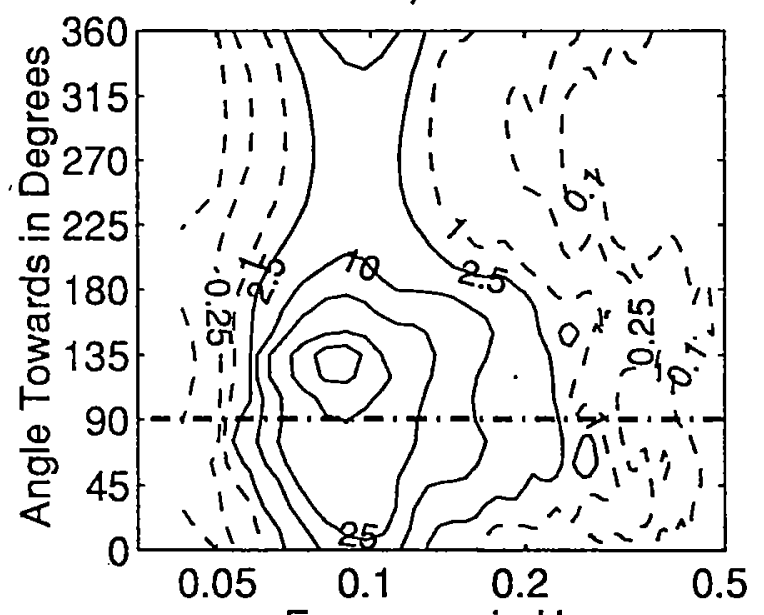

Frequency in $\mathrm{Hz}$

March 5, $199400 Z$

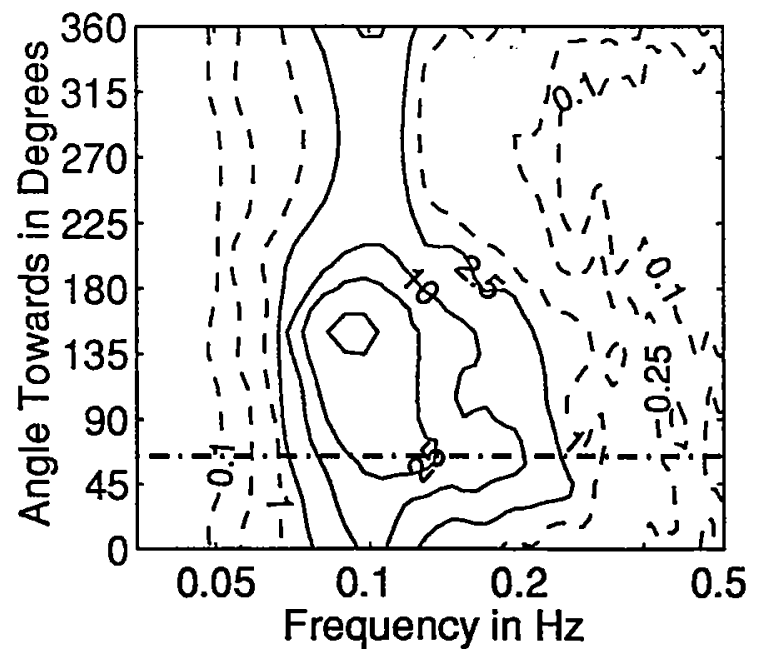

March 4, $199415 Z$

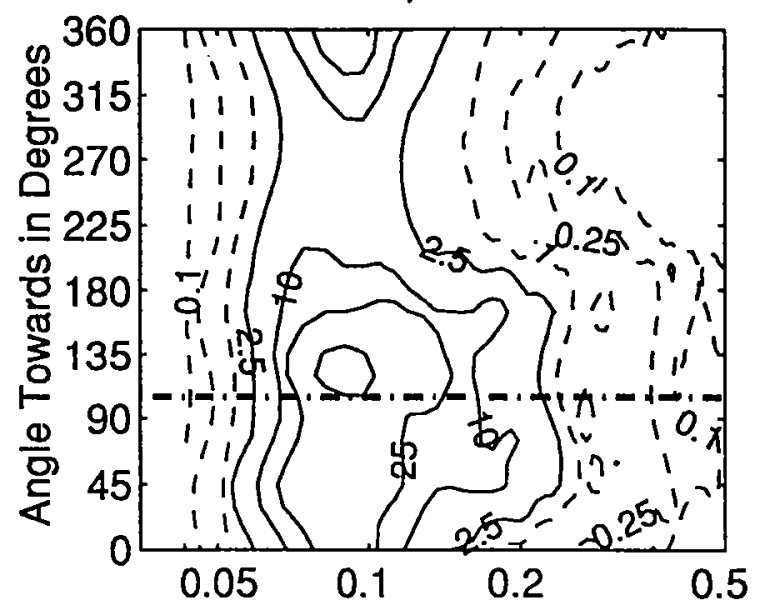

Frequency in $\mathrm{Hz}$

March 4, $199421 Z$

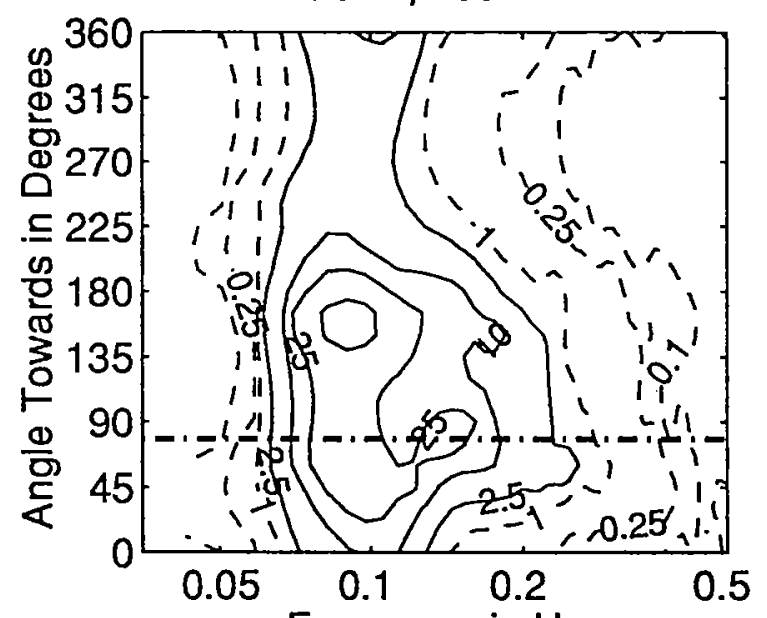

Frequency in $\mathrm{Hz}$

March 5, 1994032

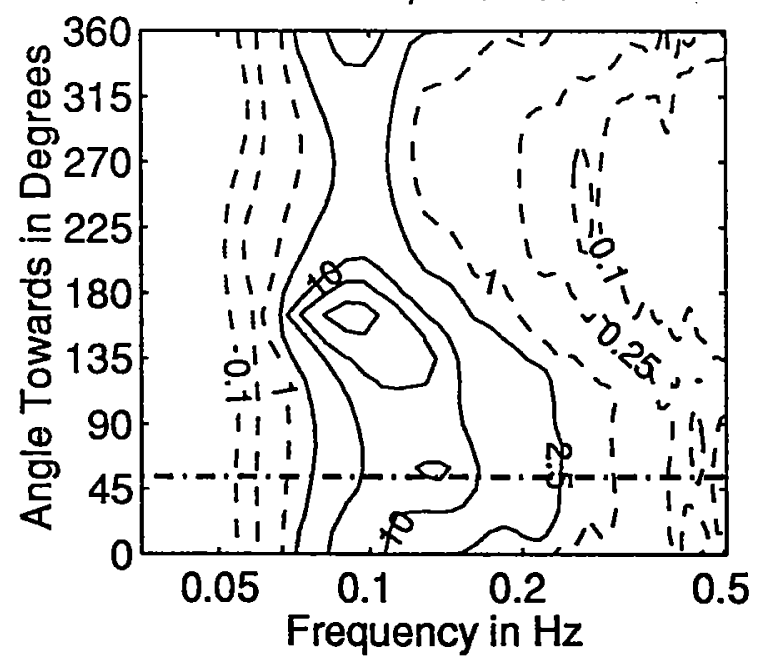

Figure 3.4.116: Directional wave spectra, computed using maximum entropy method. Contours of spectral density as a function of direction. Contours are $\mathbf{0 . 1}$, $0.25,1$ (dashed), $2.5,10,25,100$, and 250 (solid). Wind direction is shown by thick dashed line. 
March 5, $199406 Z$
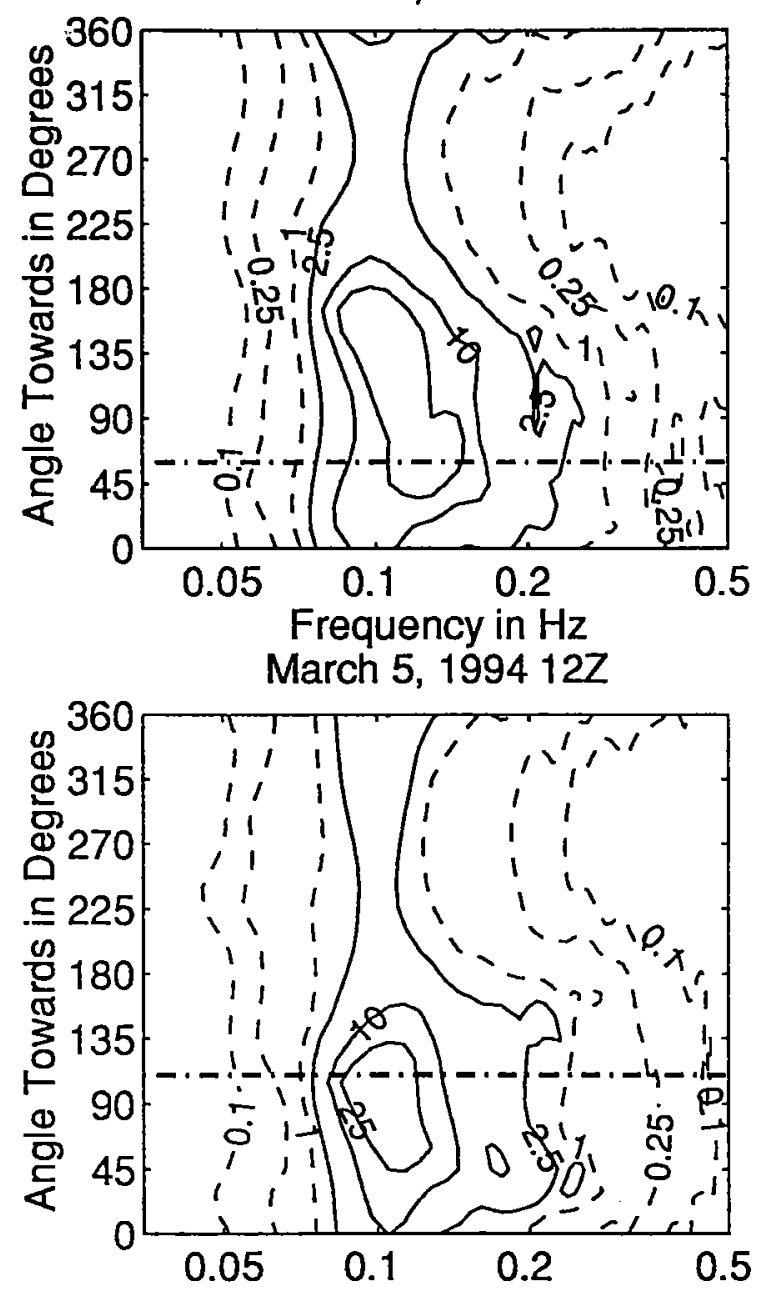

Frequency in $\mathrm{Hz}$

March 5, $199418 Z$

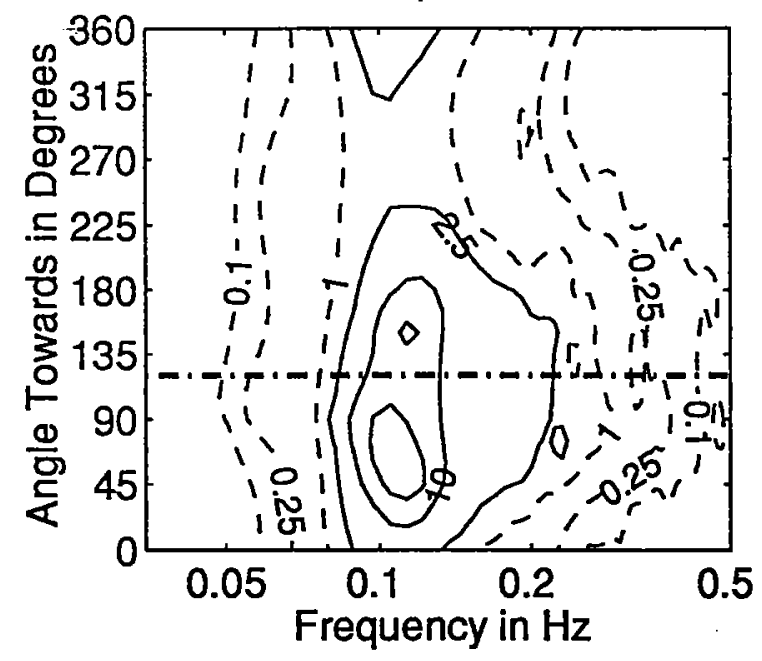

March 5, $199409 Z$
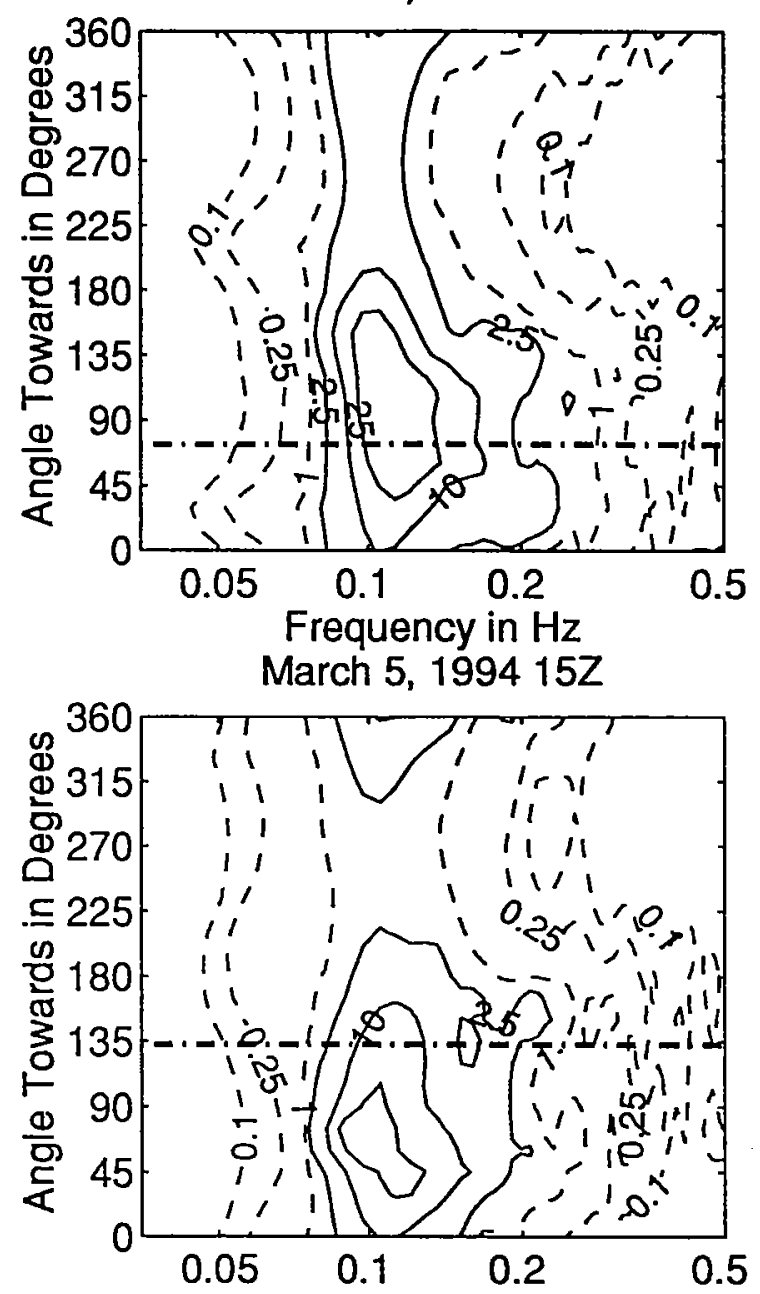

Frequency in $\mathrm{Hz}$

March 5, $199421 Z$

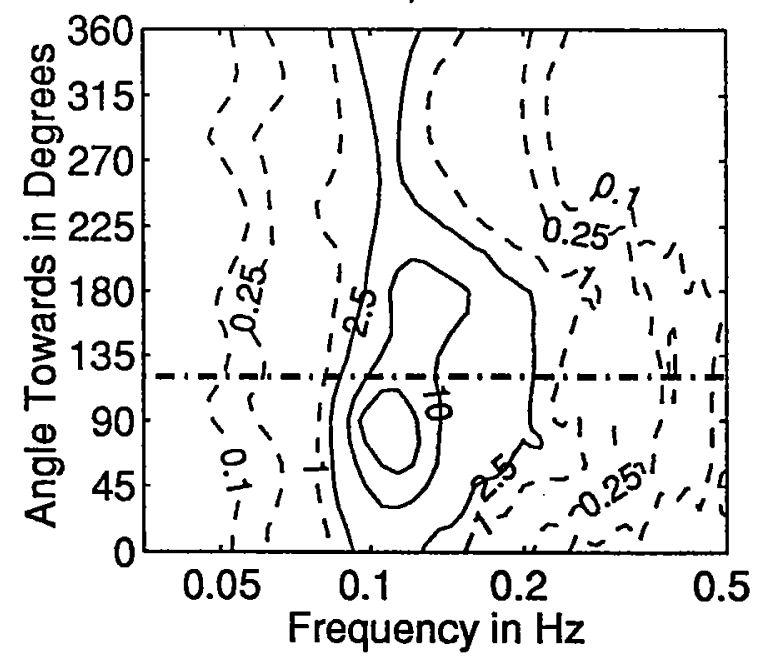

Figure 3.4.117: Directional wave spectra, computed using maximum entropy method. Contours of spectral density as a function of direction. Contours are 0.1, $0.25,1$ (dashed), $2.5,10,25,100$, and 250 (solid). Wind direction is shown by thick dashed line. 
March 6, $199400 Z$
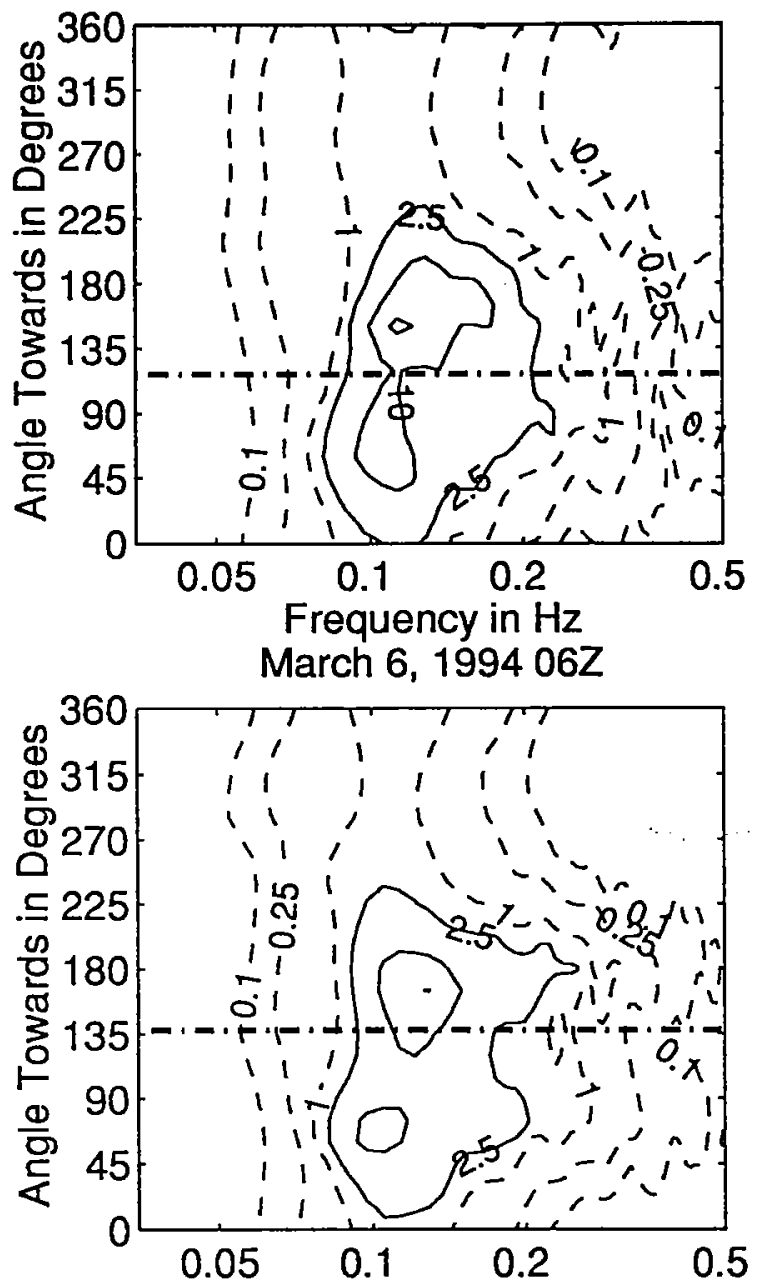

Frequency in $\mathrm{Hz}$

March 6, $199412 Z$

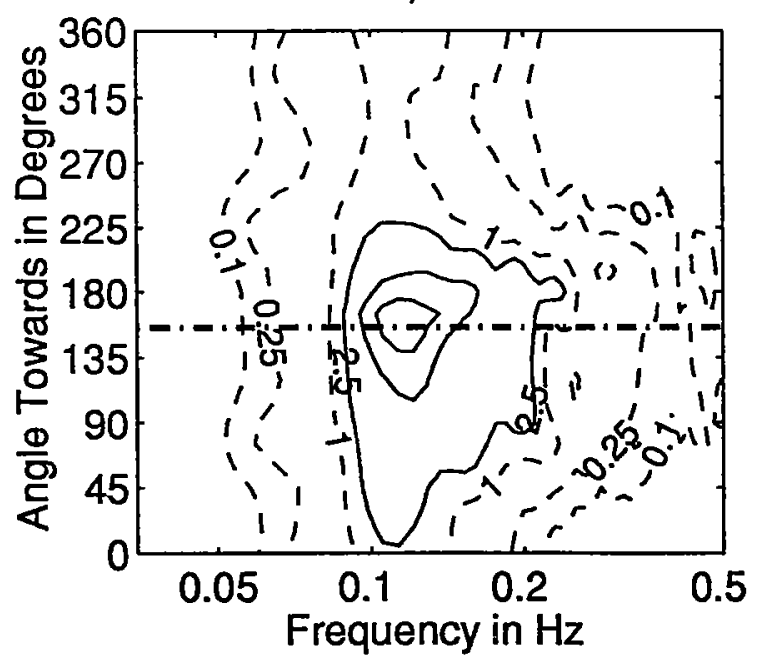

March 6, 1994032
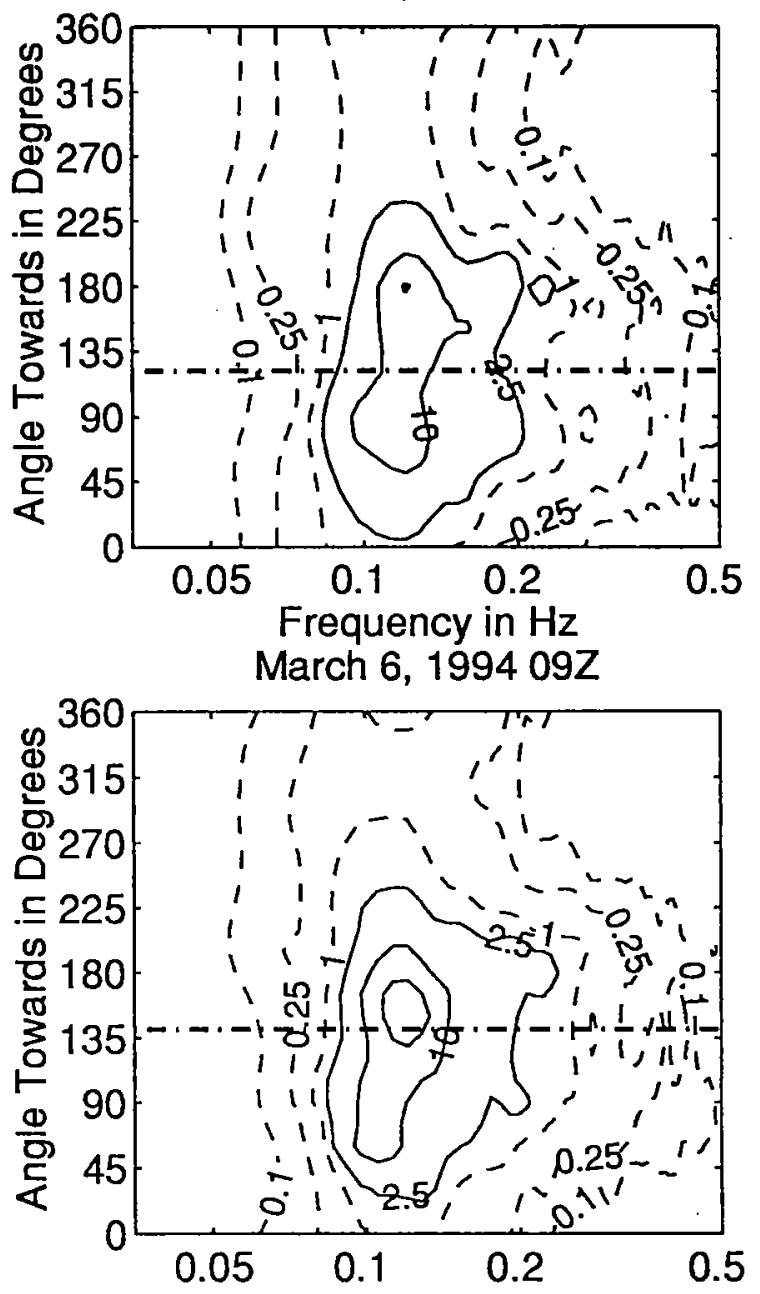

Frequency in $\mathrm{Hz}$

March 6, 1994 15Z

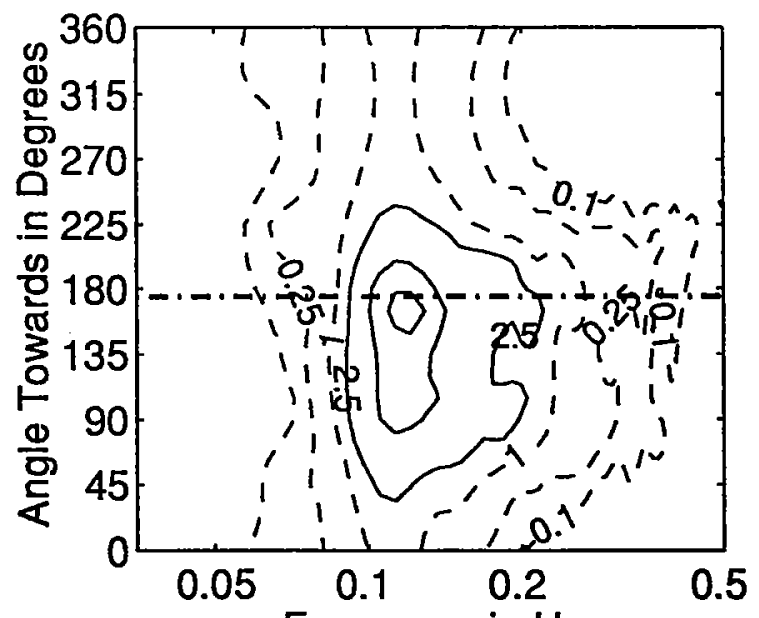

Frequency in $\mathrm{Hz}$

Figure 3.4.118: Directional wave spectra, computed using maximum entropy method. Contours of spectral density as a function of direction. Contours are 0.1 , $0.25,1$ (dashed), $2.5,10,25,100$, and 250 (solid). Wind direction is shown by thick dashed line. 
March 6, $199418 Z$

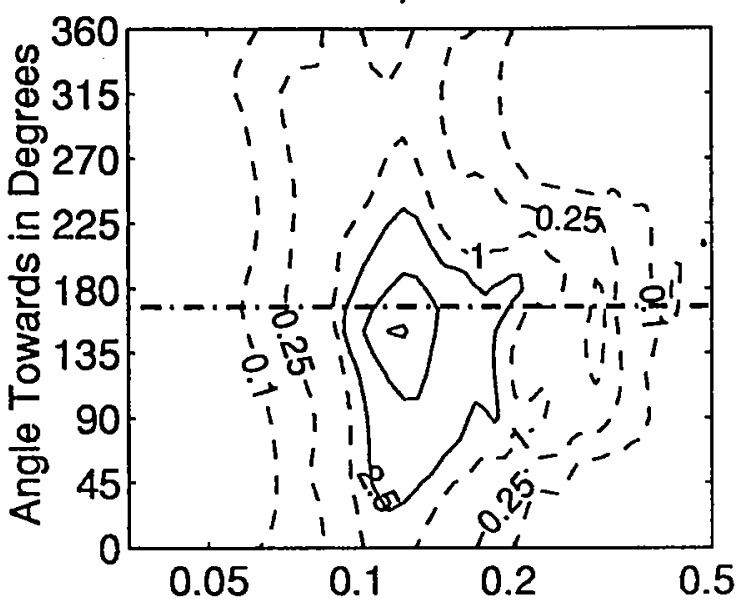

Frequency in $\mathrm{Hz}$

March 7, $199400 Z$
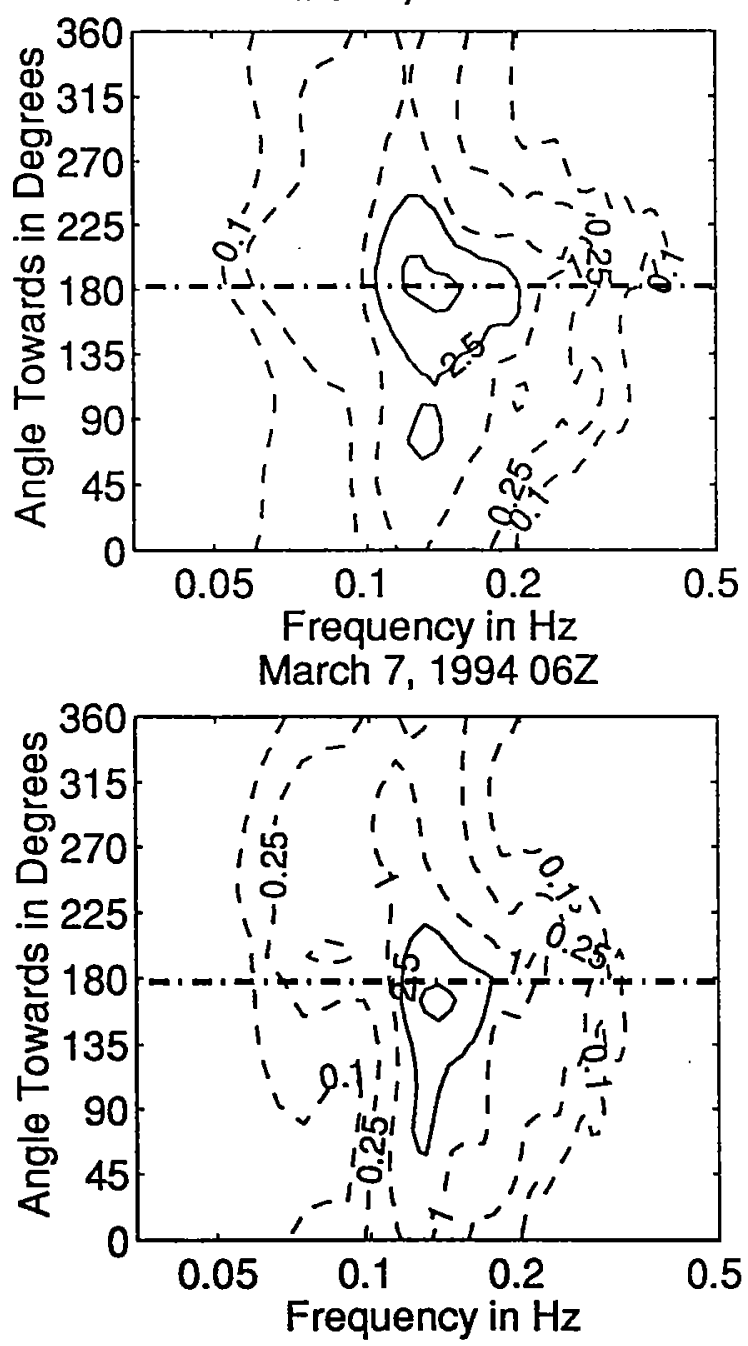

March 6, $199421 Z$

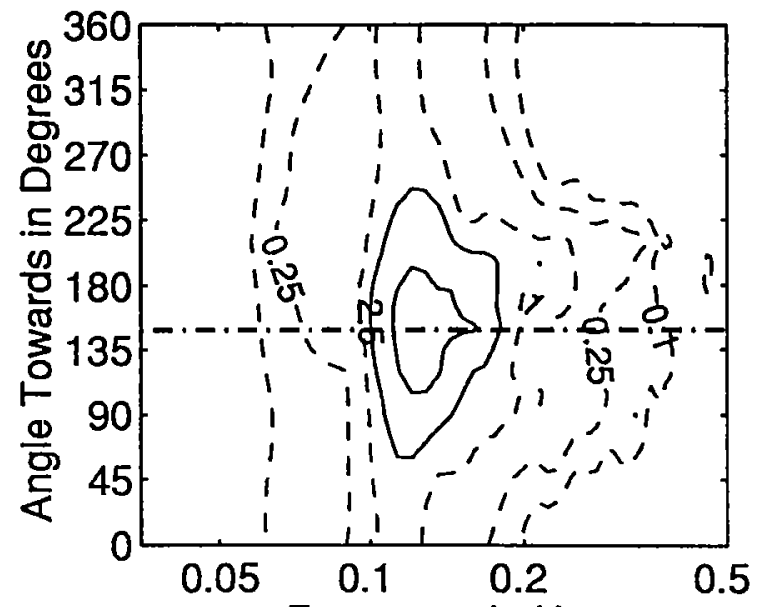

Frequency in $\mathrm{Hz}$

March 7, $199403 Z$
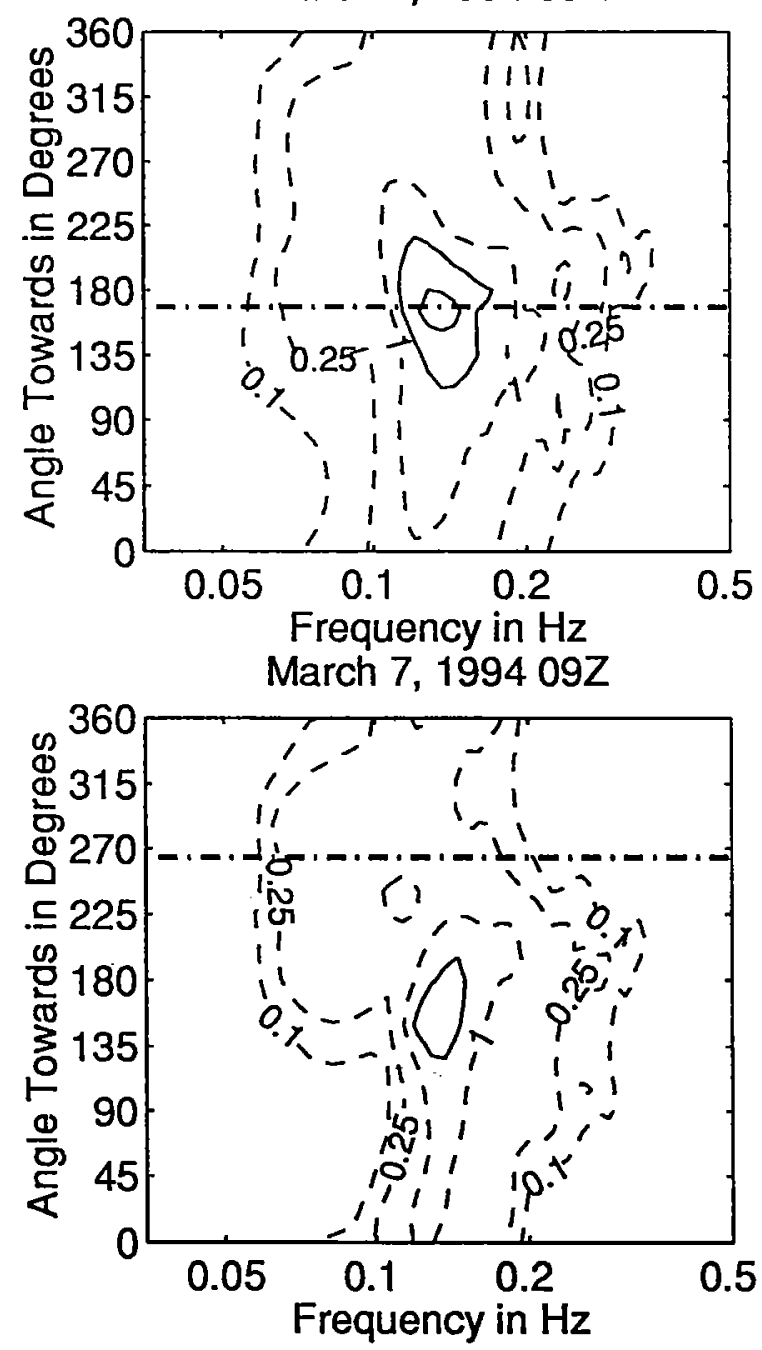

Figure 3.4.119: Directional wave spectra, computed using maximum entropy method. Contours of spectral density as a function of direction. Contours are 0.1, $0.25,1$ (dashed), 2.5, 10, 25, 100, and 250 (solid). Wind direction is shown by thick dashed line. 
March 7, $199412 Z$
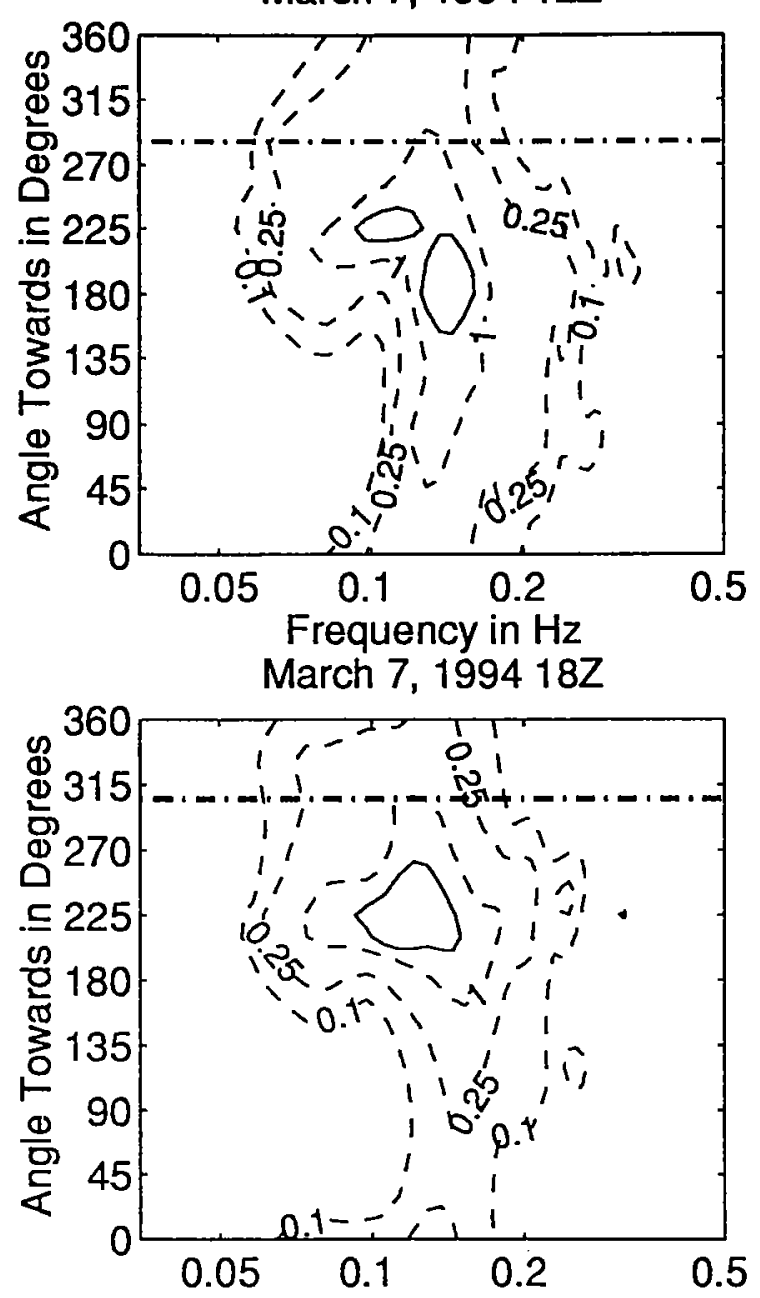

Frequency in $\mathrm{Hz}$

March 8, 1994 00Z

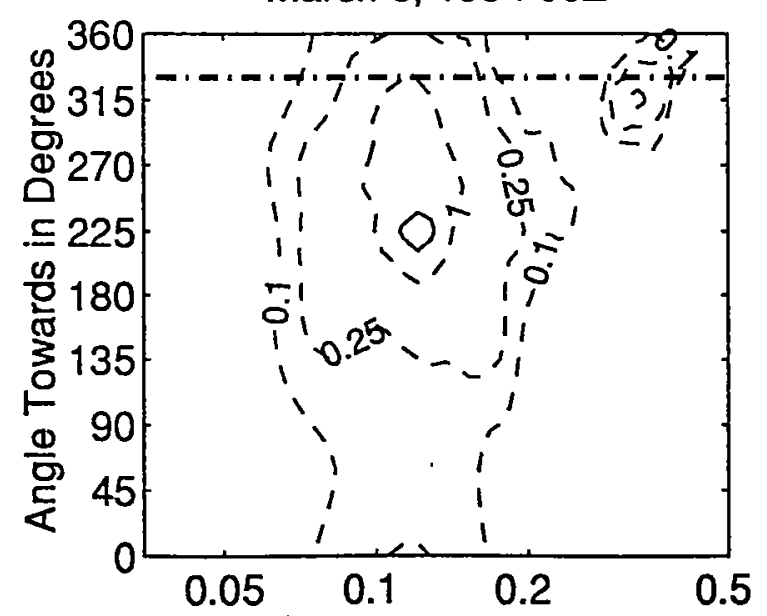

Frequency in $\mathrm{Hz}$
March 7, $199415 Z$
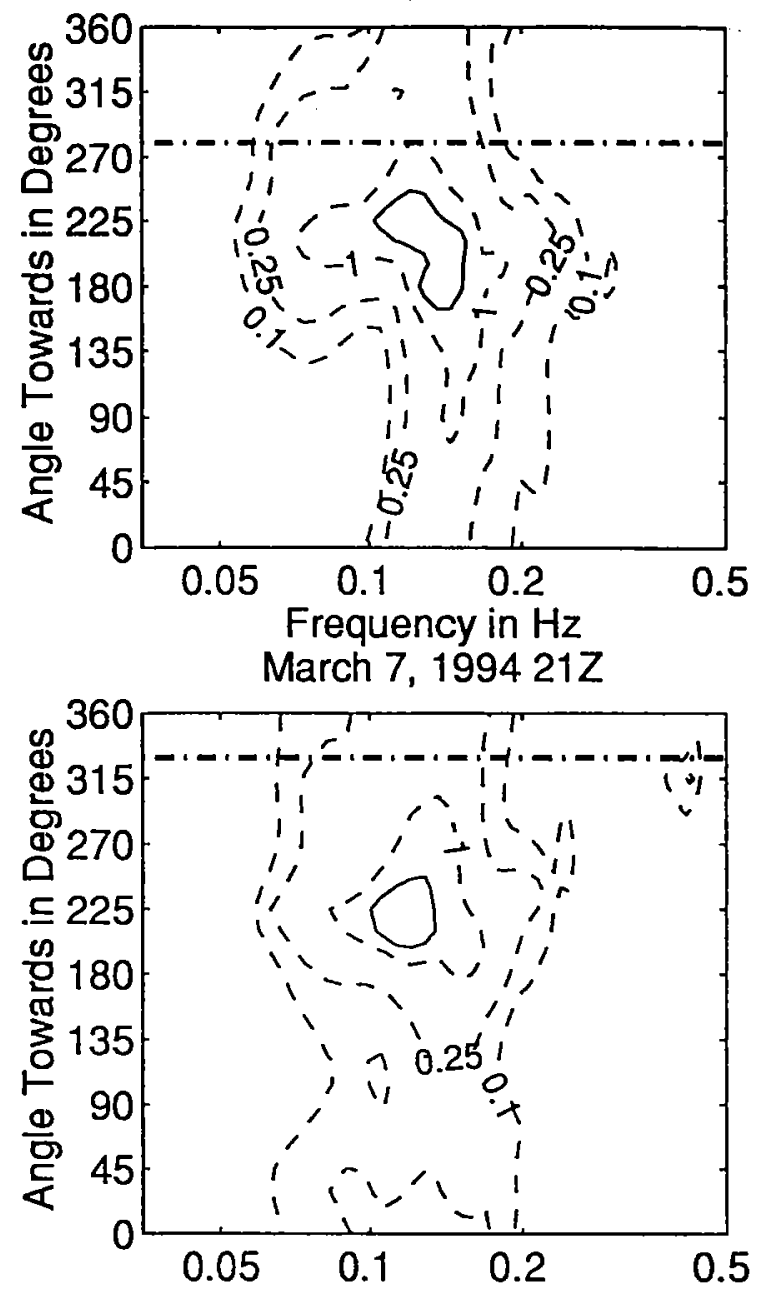

Frequency in $\mathrm{Hz}$

March 8, $199403 Z$

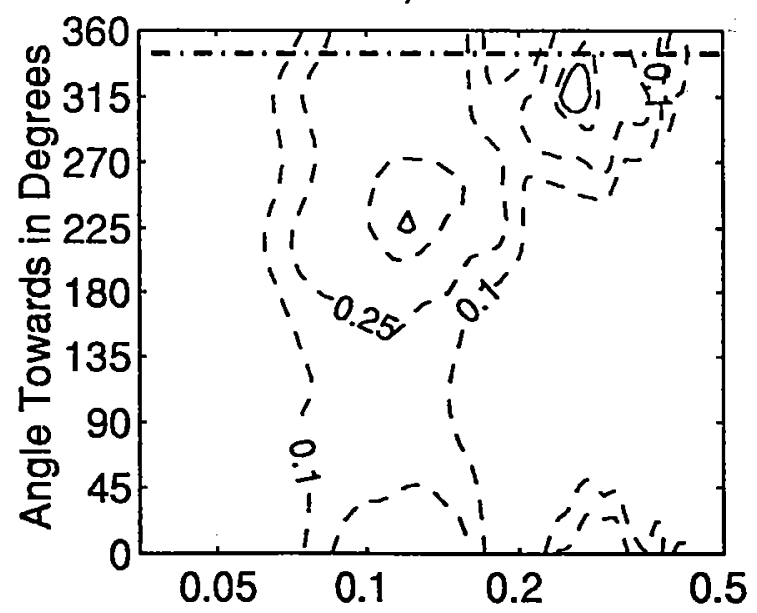

Frequency in $\mathrm{Hz}$

Figure 3.4.120: Directional wave spectra, computed using maximum entropy method. Contours of spectral density as a function of direction. Contours are 0.1, $0.25,1$ (dashed), $2.5,10,25,100$, and 250 (solid). Wind direction is shown by thick dashed line. 
March 8, 1994062

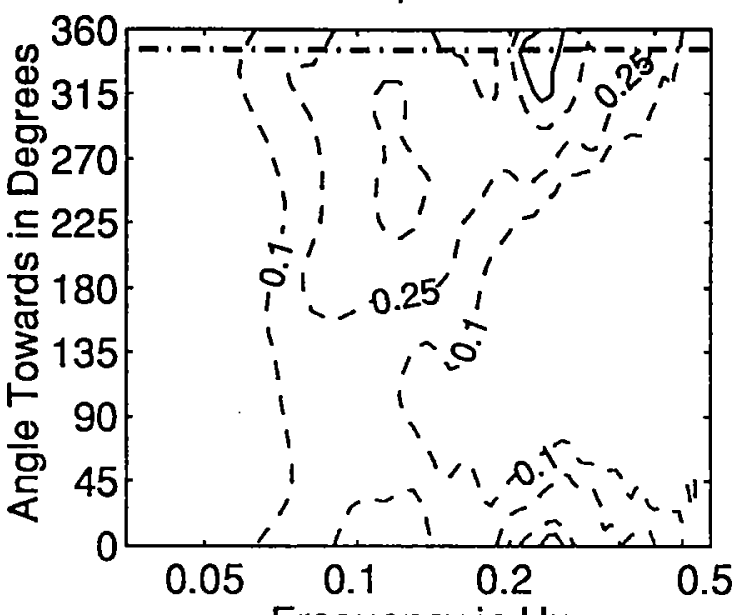

Frequency in $\mathrm{Hz}$

March 8, $199412 Z$
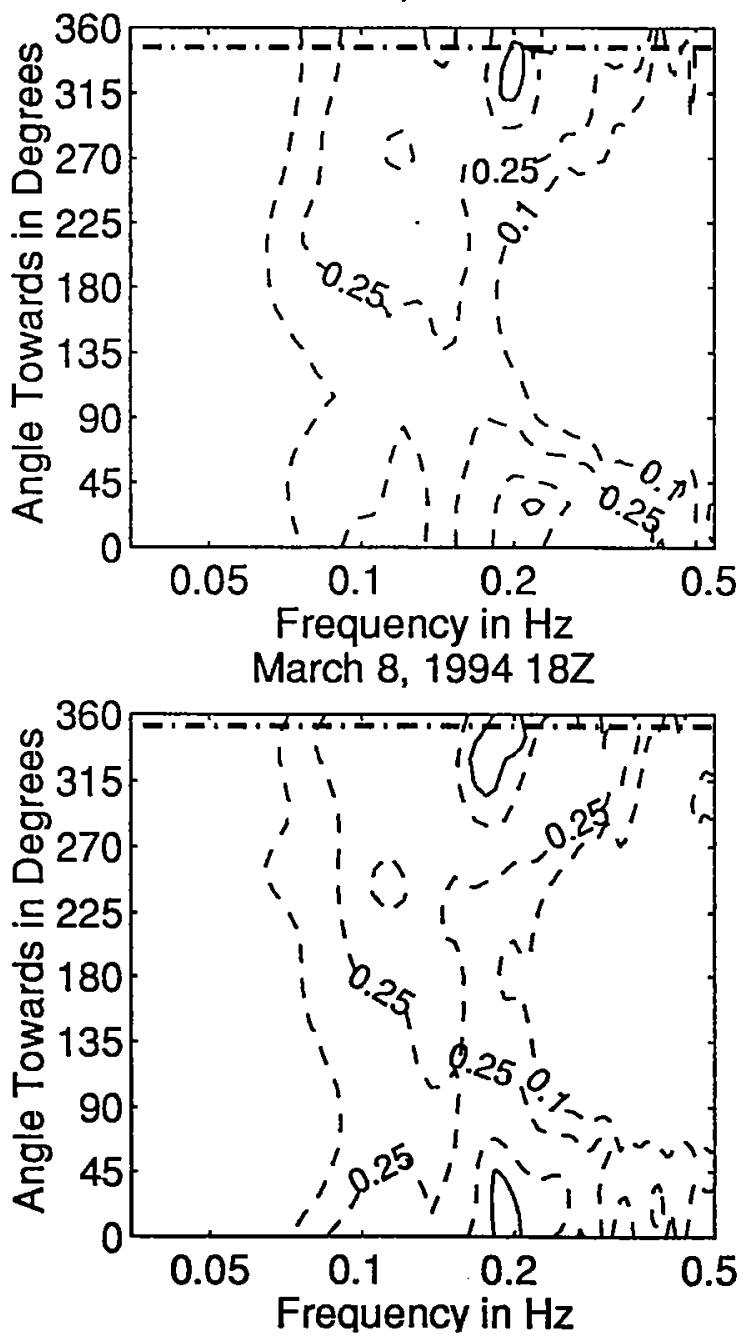

March 8, $199409 Z$

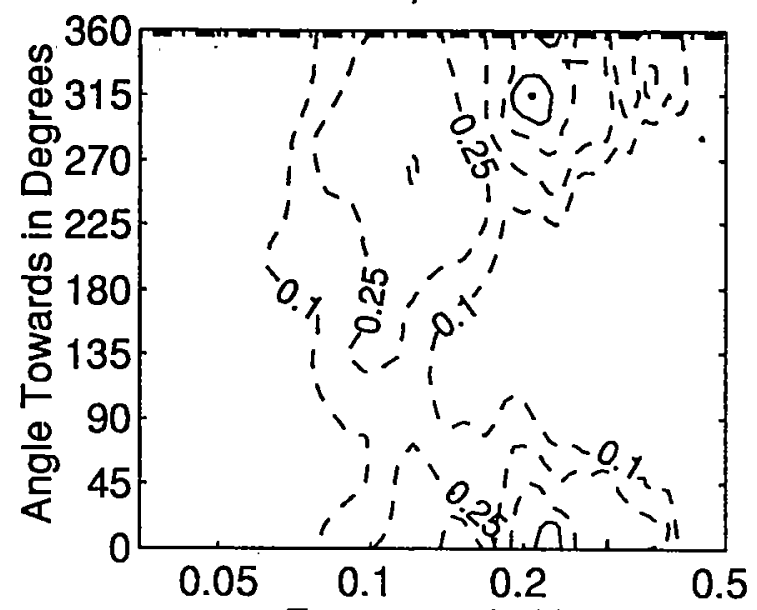

Frequency in $\mathrm{Hz}$

March 8, $199415 Z$

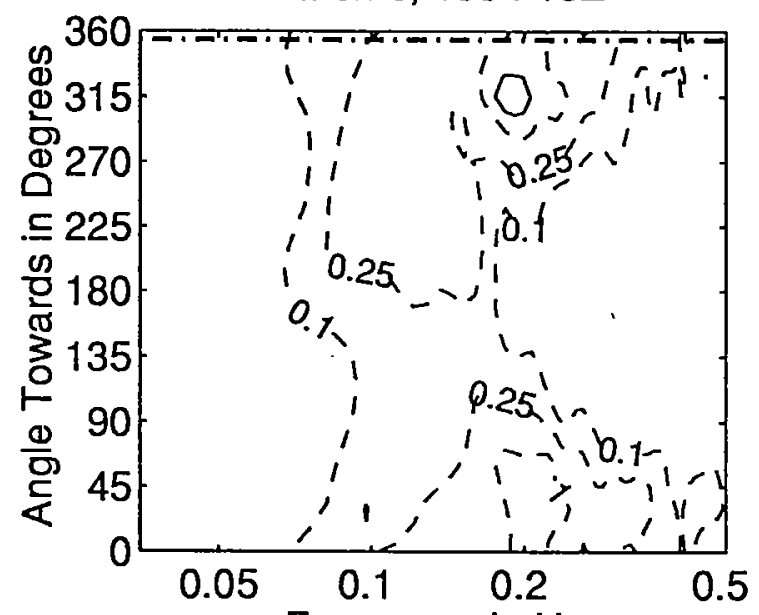

Frequency in $\mathrm{Hz}$

March 8, 199421 Z

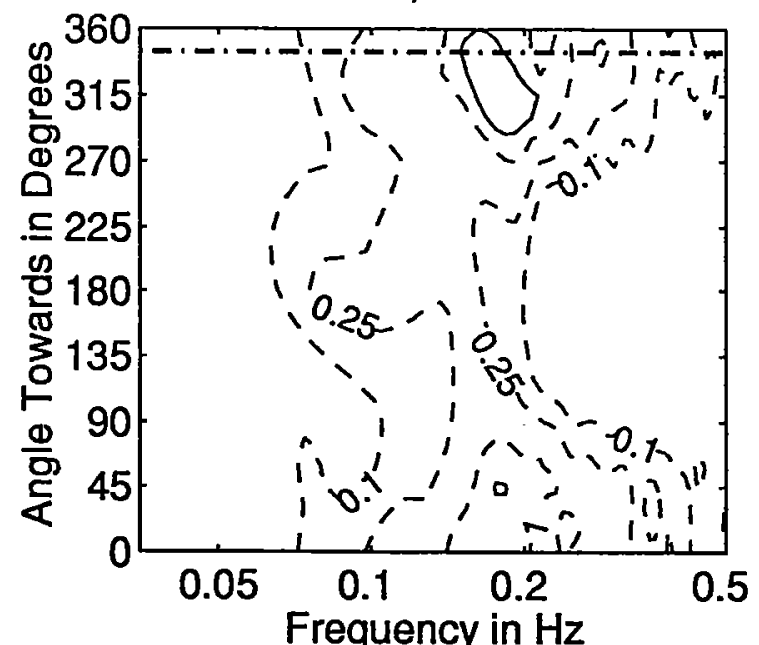

Figure 3.4.121: Directional wave spectra, computed using maximum entropy method. Contours of spectral density as a function of direction. Contours are 0.1, $0.25,1$ (dashed), $2.5,10,25,100$, and 250 (solid). Wind direction is shown by thick dashed line. 
March 9, $199400 Z$

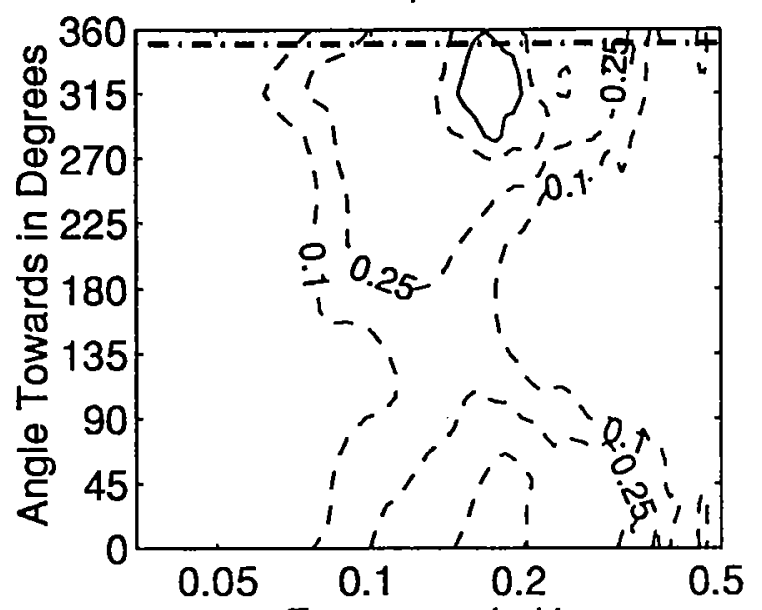

Frequency in $\mathrm{Hz}$

March 9, 1994 O6Z

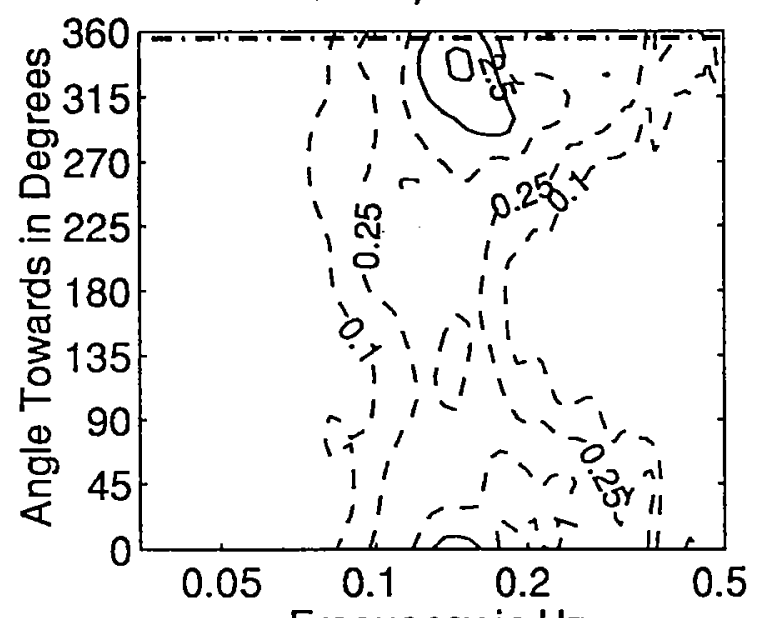

Frequency in $\mathrm{Hz}$

March 9, $199412 Z$

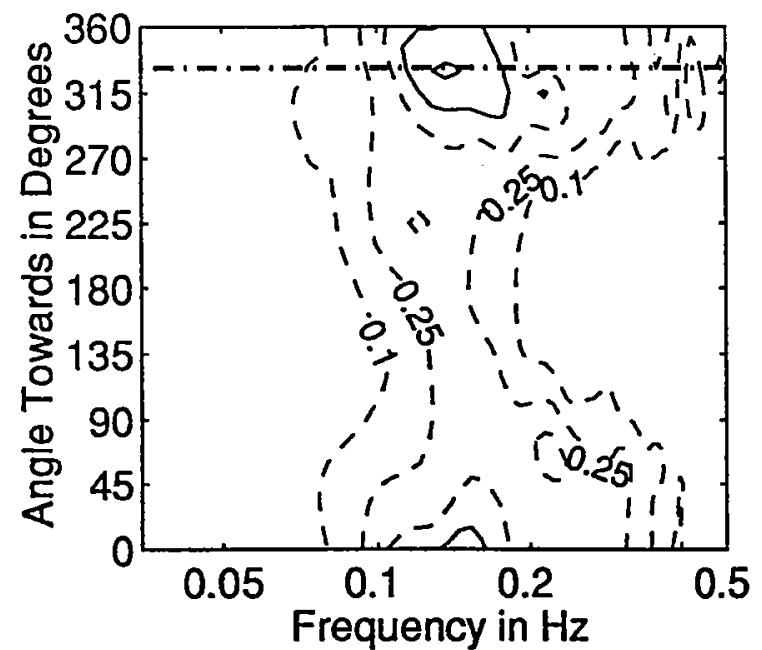

March 9, 1994032

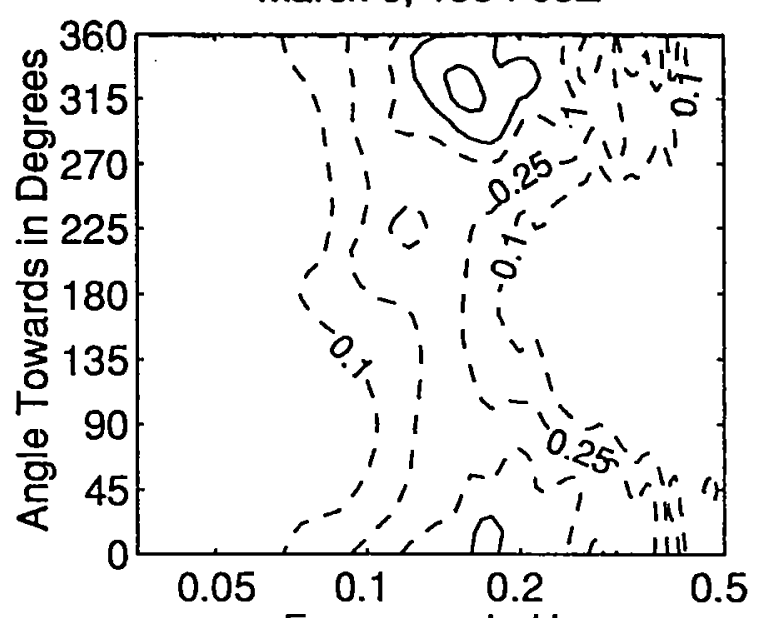

Frequency in $\mathrm{Hz}$

March 9, $199409 Z$

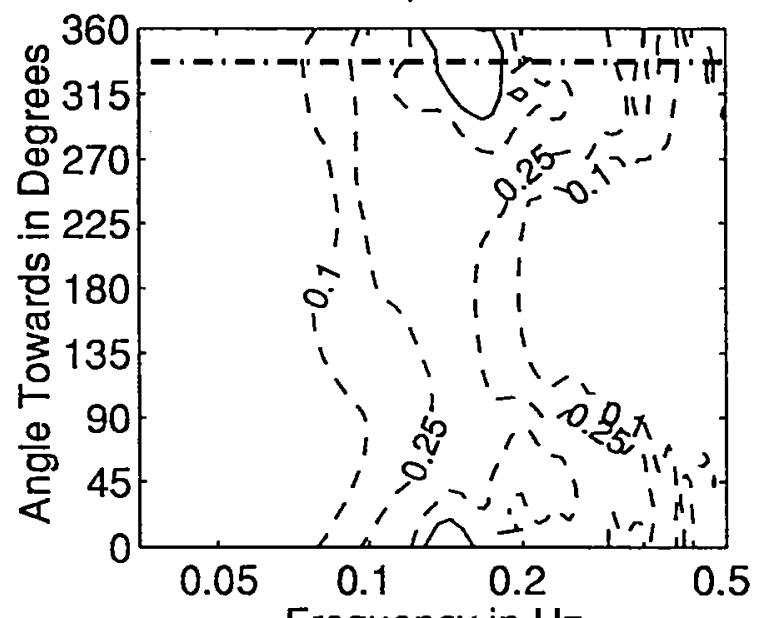

Frequency in $\mathrm{Hz}$

March 9, $199415 Z$

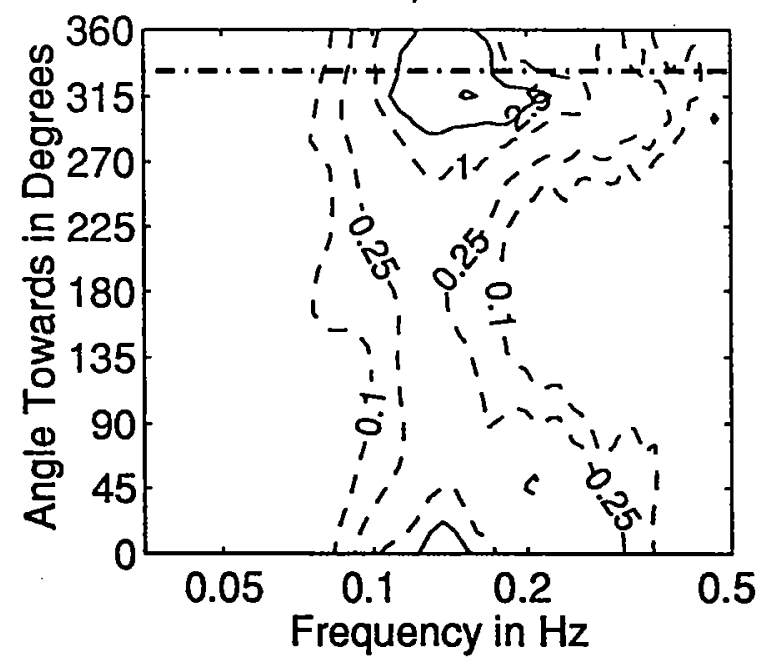

Figure 3.4.122: Directional wave spectra, computed using maximum entropy method. Contours of spectral density as a function of direction. Contours are 0.1, $0.25,1$ (dashed), $2.5,10,25,100$, and 250 (solid). Wind direction is shown by thick dashed line. 
March 9, $199418 Z$

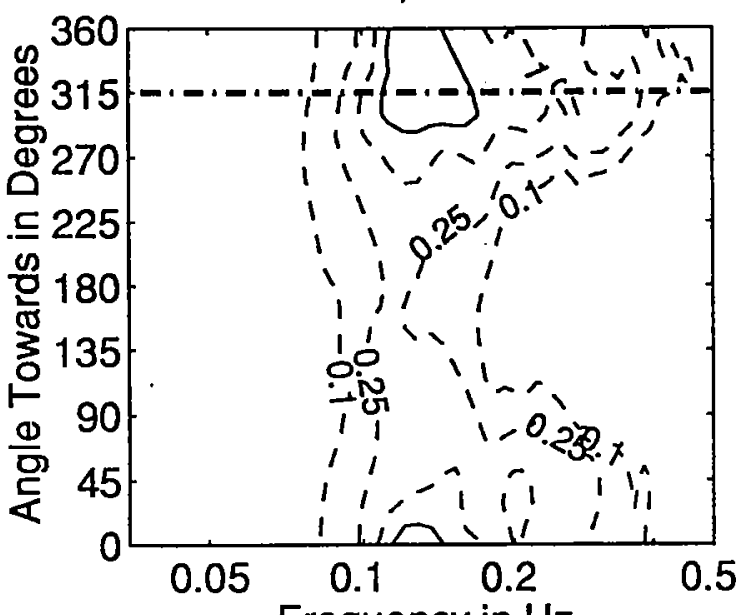

Frequency in $\mathrm{Hz}$

March 10, 1994 00Z
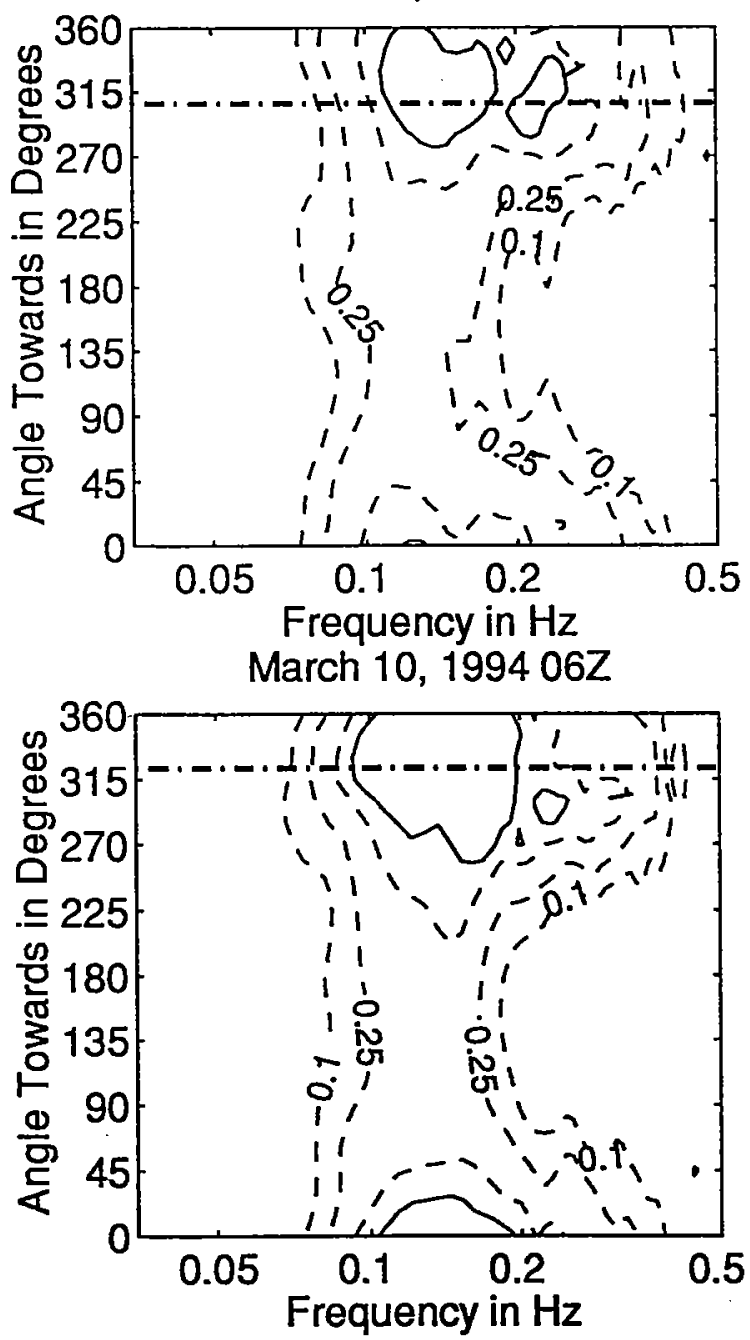

March 9, $199421 Z$

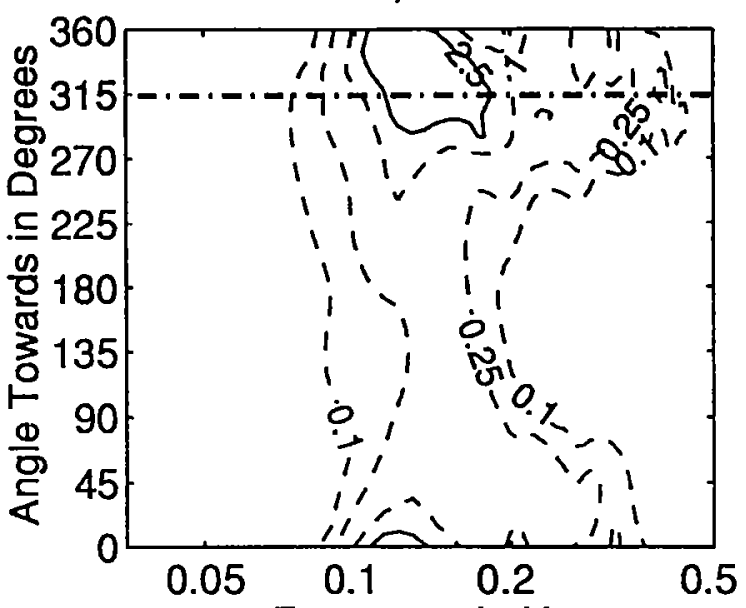

Frequency in $\mathrm{Hz}$ March 10, $199403 Z$
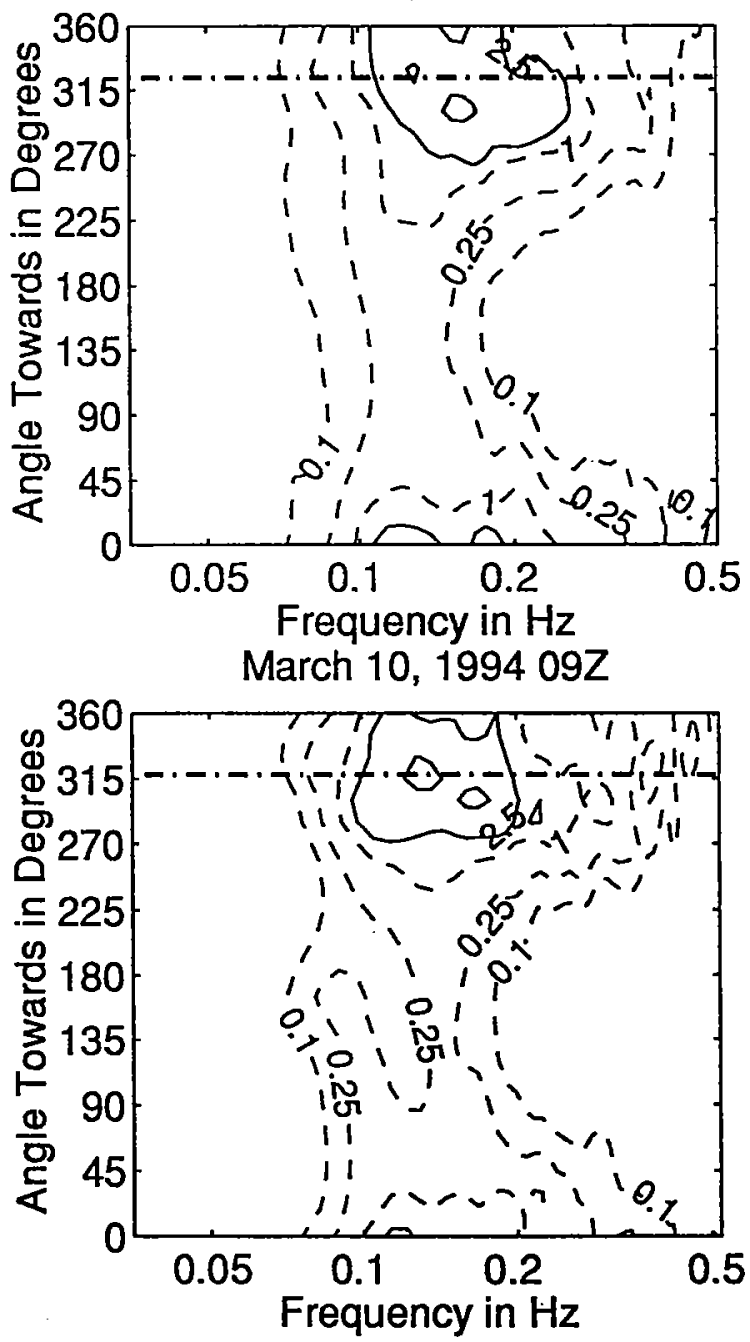

Figure 3.4.123: Directional wave spectra, computed using maximum entropy method. Contours of spectral density as a function of direction. Contours are 0.1, $0.25,1$ (dashed), $2.5,10,25,100$, and 250 (solid). Wind direction is shown by thick dashed line. 
March 10, $199412 Z$
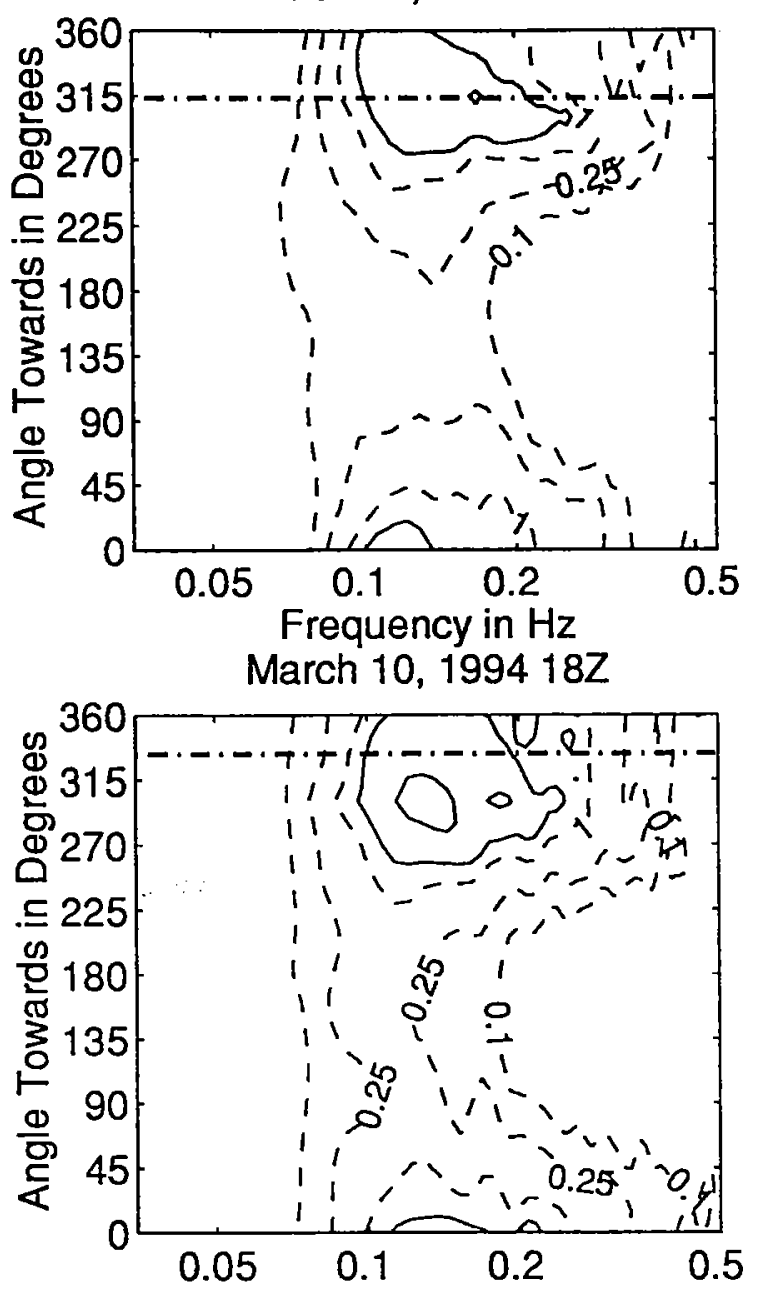

Frequency in $\mathrm{Hz}$

March 11, 1994 00Z

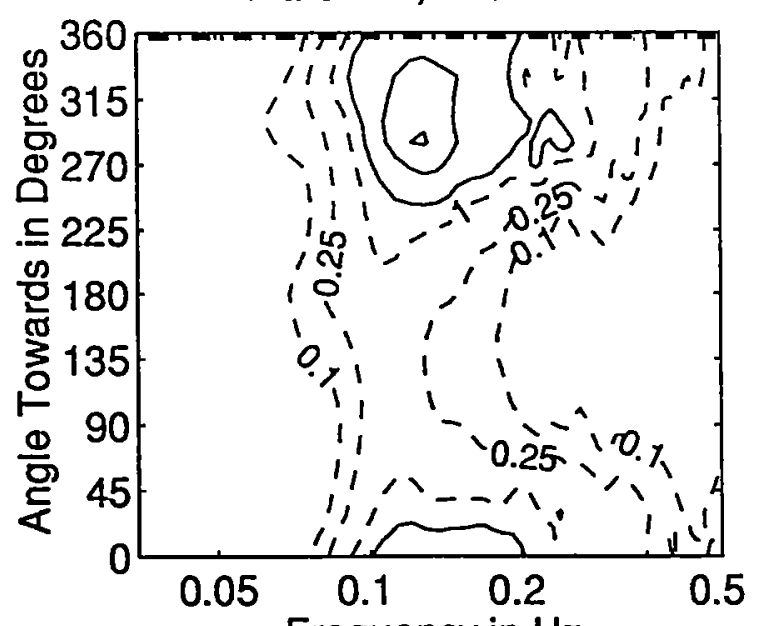

Frequency in $\mathrm{Hz}$
March 10, $199415 Z$
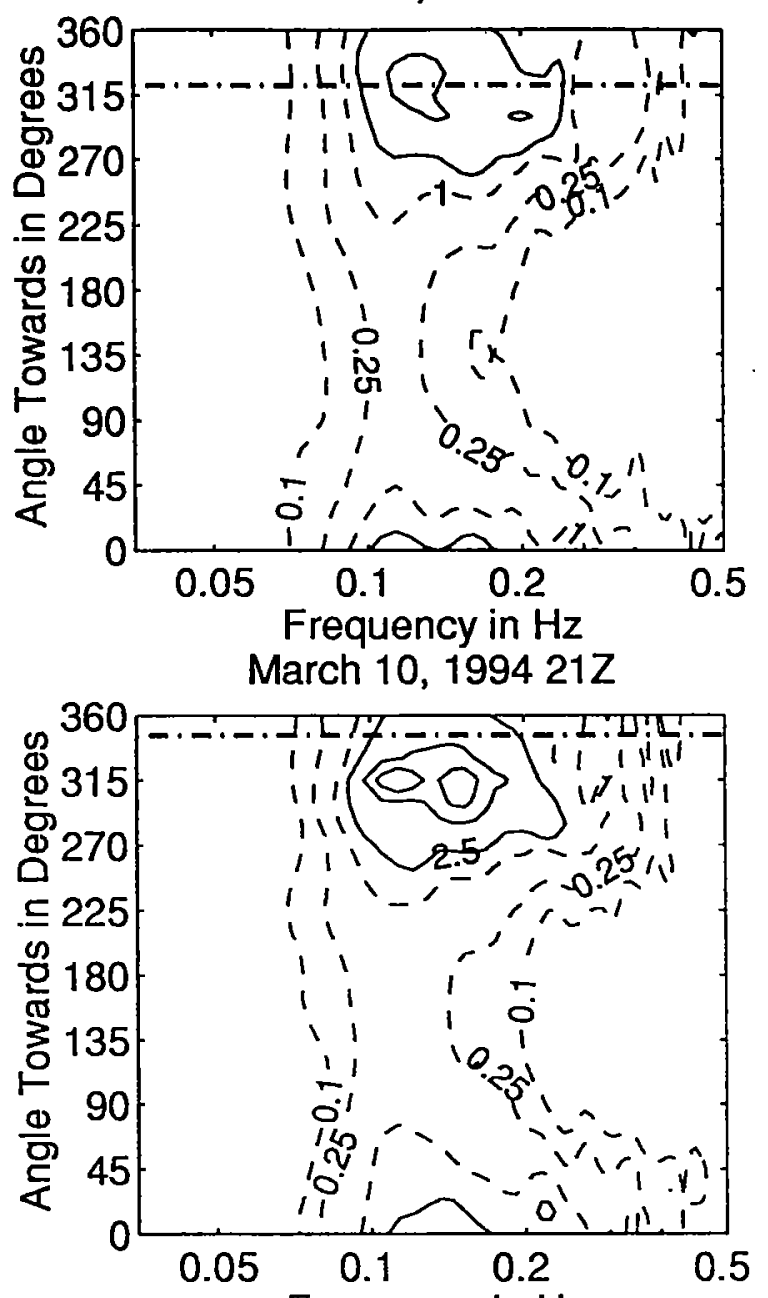

Frequency in $\mathrm{Hz}$

March 11, $199403 Z$

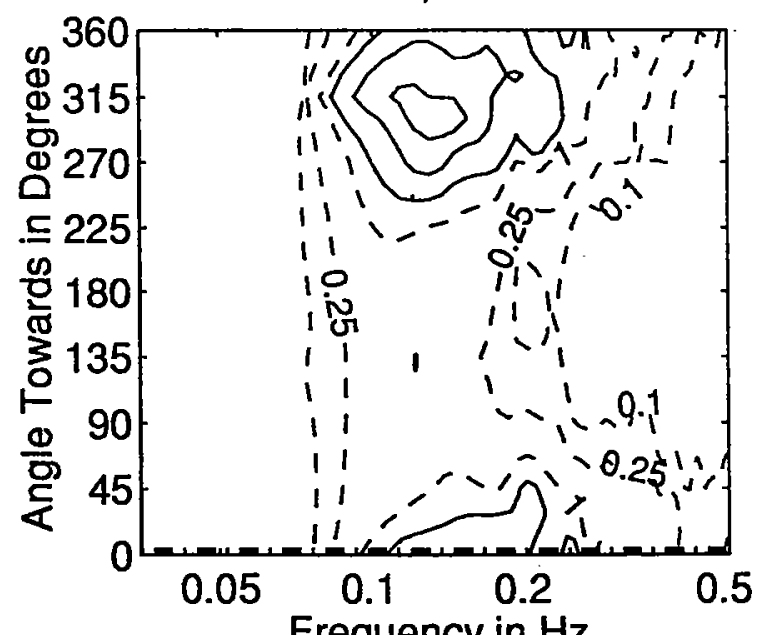

Frequency in $\mathrm{Hz}$

Figure 3.4.124: Directional wave spectra, computed using maximum entropy method. Contours of spectral density as a function of direction. Contours are 0.1 , $0.25,1$ (dashed), 2.5, 10, 25, 100, and 250 (solid). Wind direction is shown by thick dashed line. 
March 11, $199406 Z$

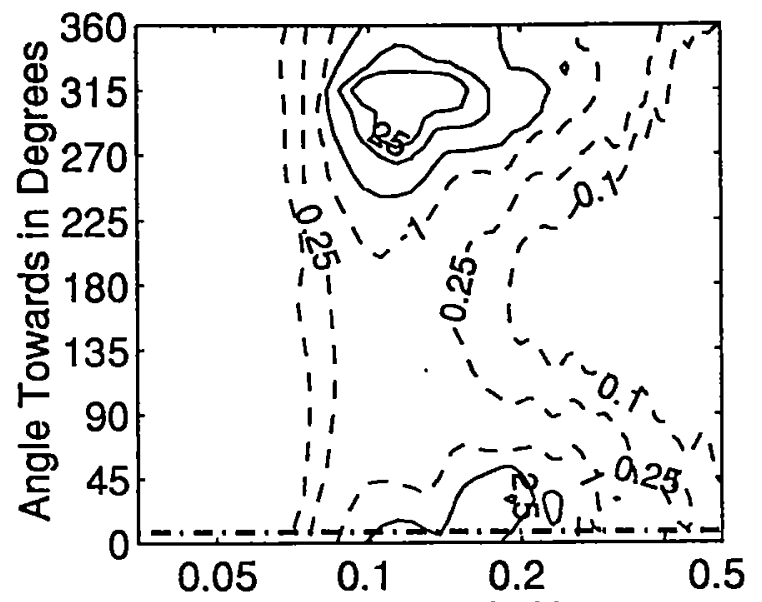

Frequency in $\mathrm{Hz}$

March 11, $199412 Z$

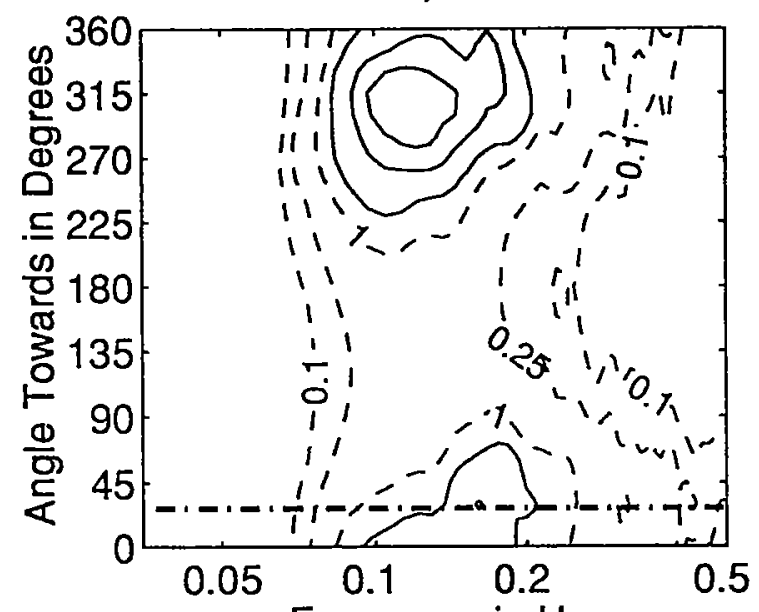

Frequency in $\mathrm{Hz}$

March 11, $199418 Z$

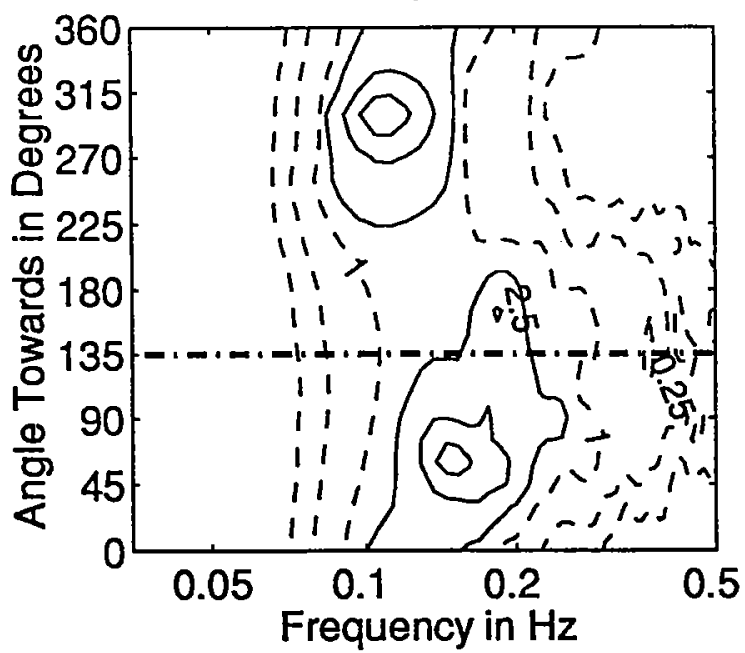

March 11, $199409 Z$

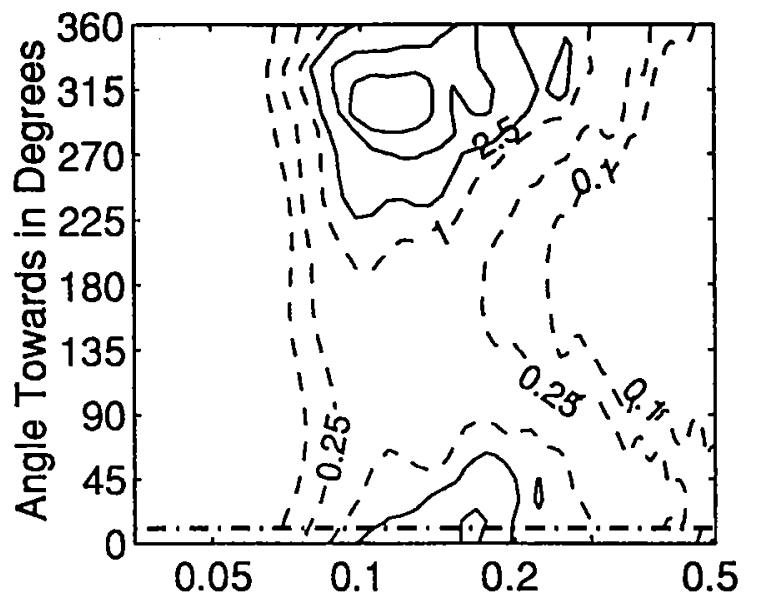

Frequency in $\mathrm{Hz}$

March 11, $199415 Z$
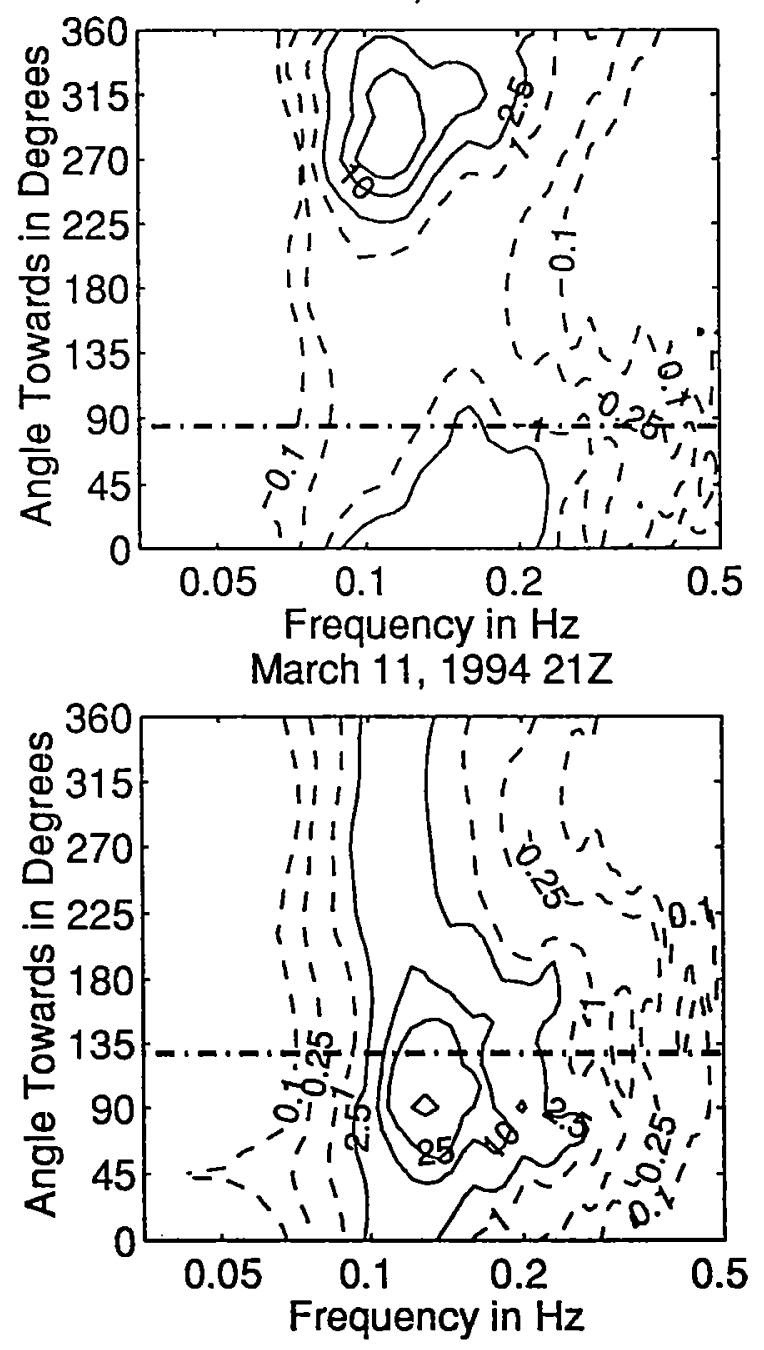

Figure 3.4.125: Directional wave spectra, computed using maximum entropy method. Contours of spectral density as a function of direction. Contours are 0.1 , $0.25,1$ (dashed), $2.5,10,25,100$, and 250 (solid). Wind direction is shown by thick dashed line. 
March 12, $199400 Z$
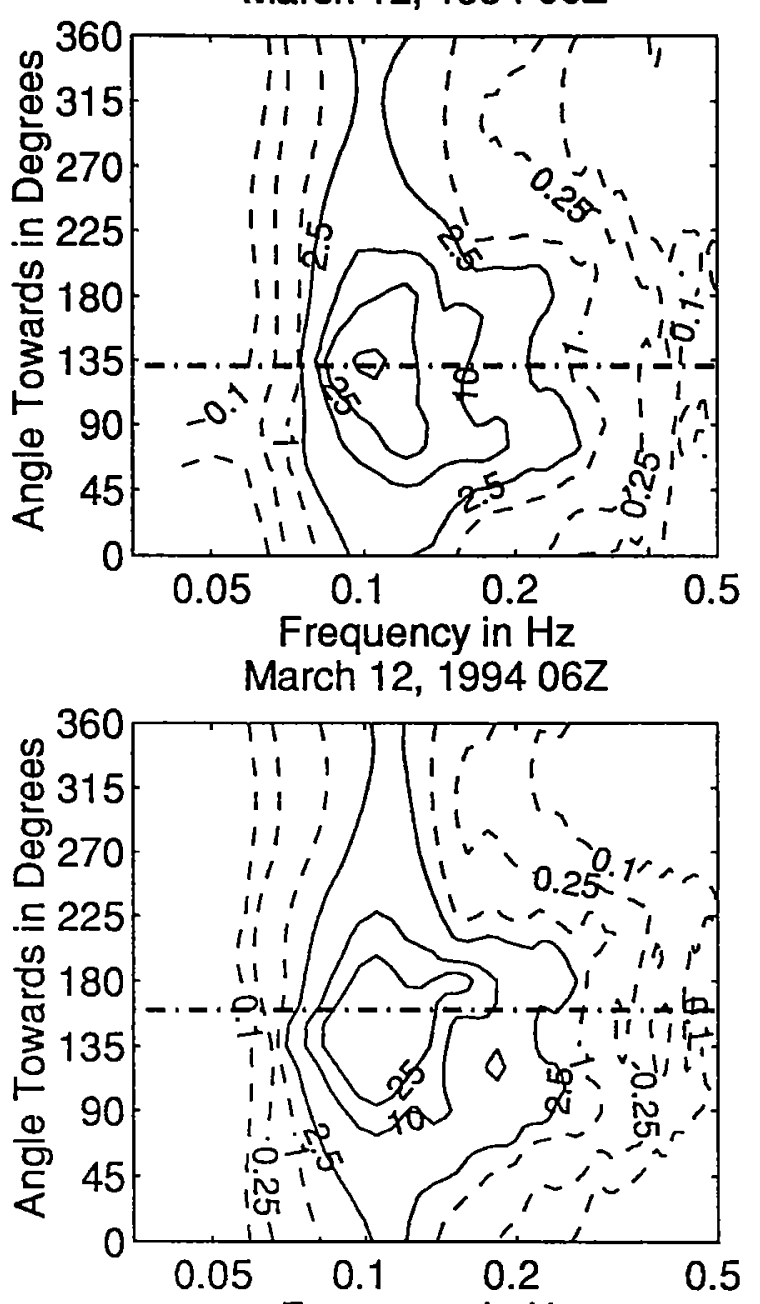

Frequency in $\mathrm{Hz}$

March 12, $199412 Z$

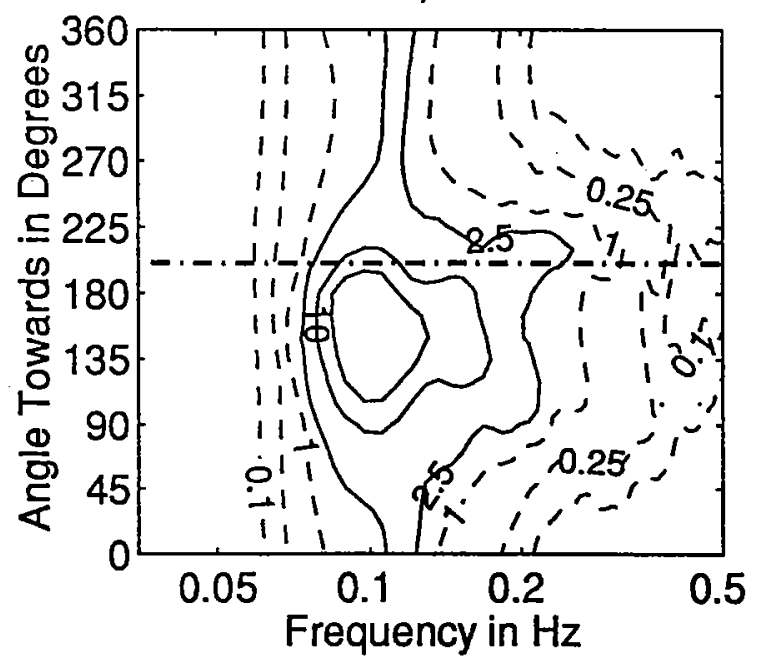

March 12, $199403 Z$
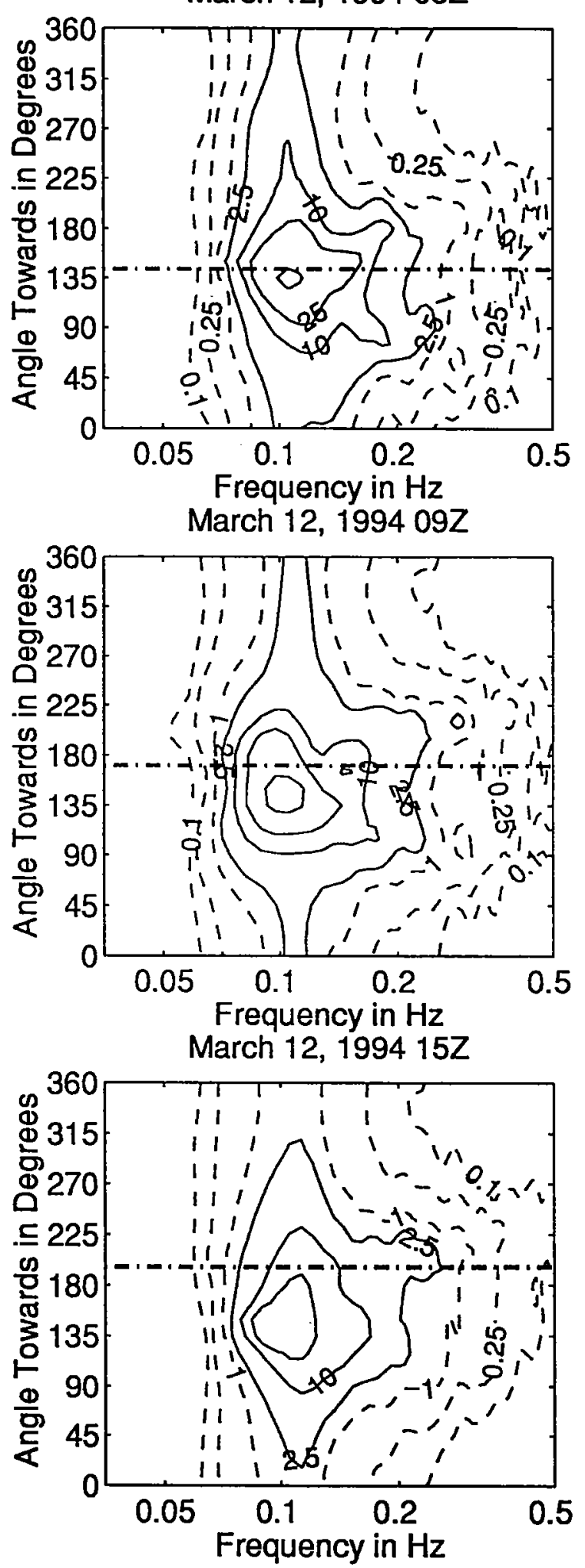

Figure 3.4.126: Directional wave spectra, computed using maximum entropy method. Contours of spectral density as a function of direction. Contours are 0.1, $0.25,1$ (dashed), $2.5,10,25,100$, and 250 (solid). Wind direction is shown by thick dashed line. 
March 12, $199418 Z$

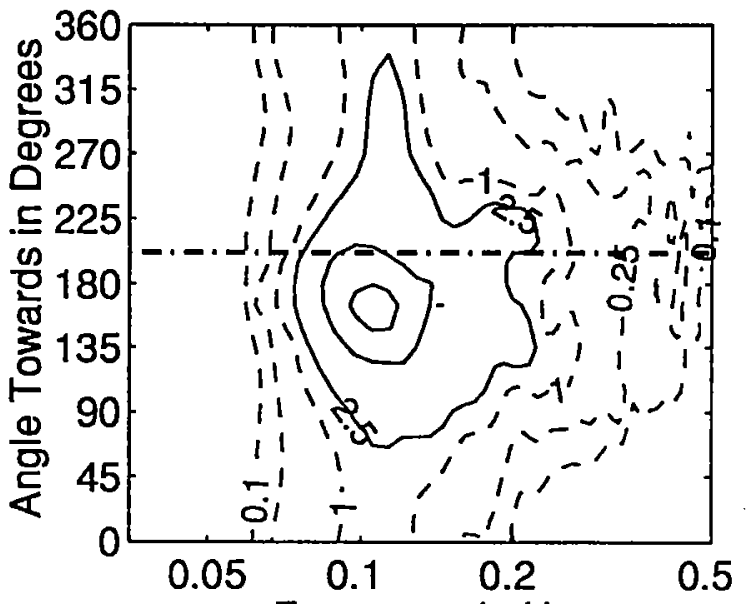

Frequency in $\mathrm{Hz}$

March 13, $199400 Z$

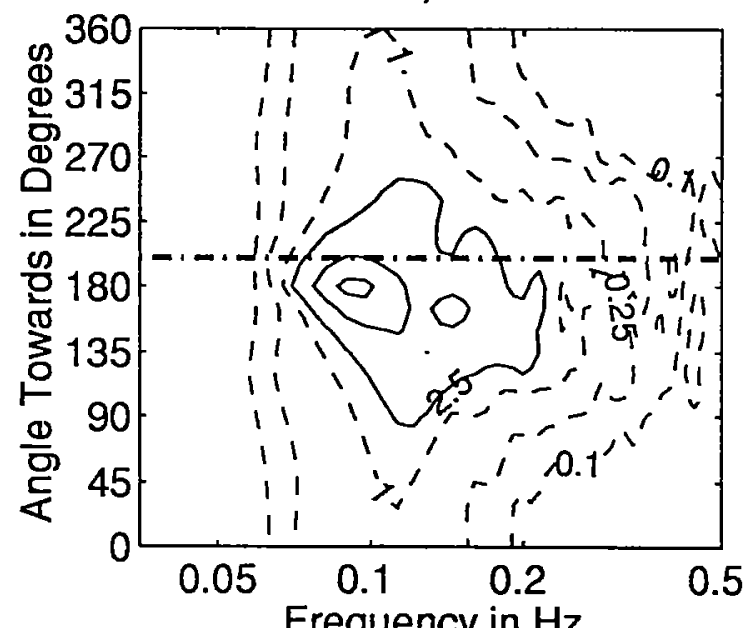

Frequency in $\mathrm{Hz}$

March 13, $199406 Z$

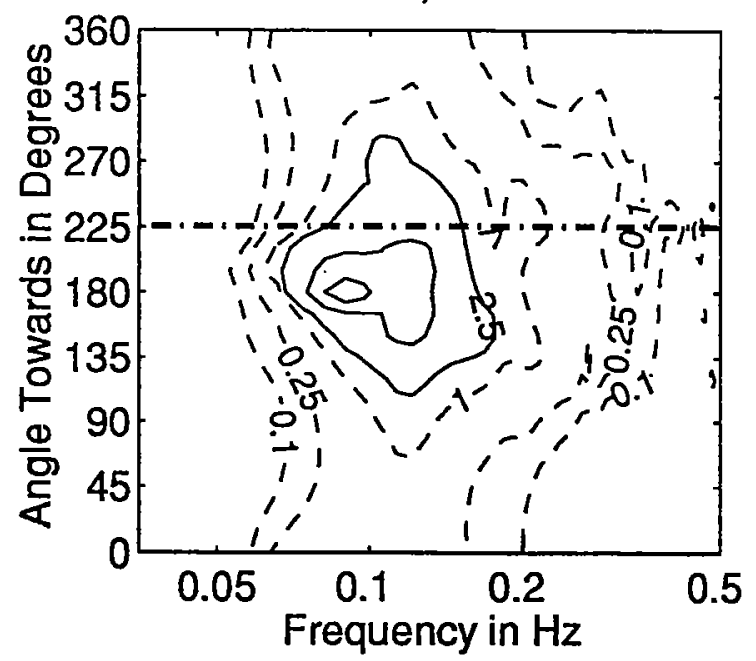

March 12, $199421 Z$

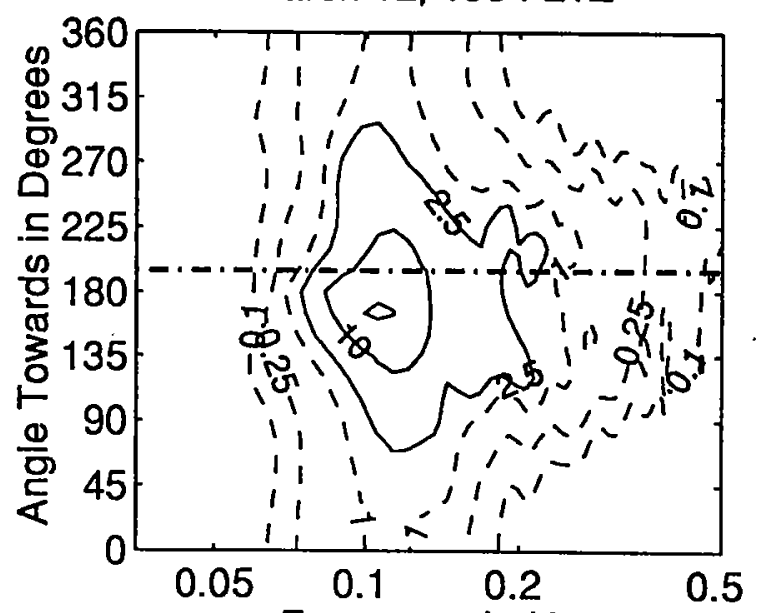

Frequency in $\mathrm{Hz}$

March 13, 1994032

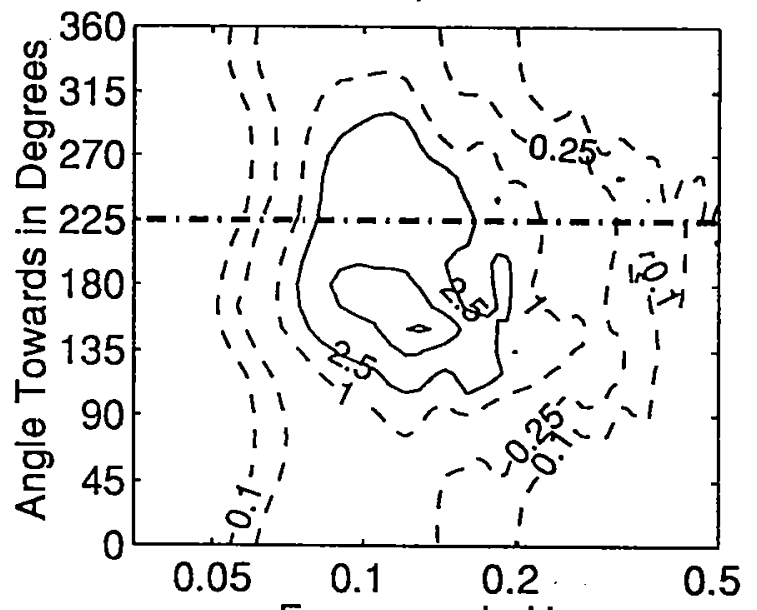

Frequency in $\mathrm{Hz}$

March 13, 1994 09Z

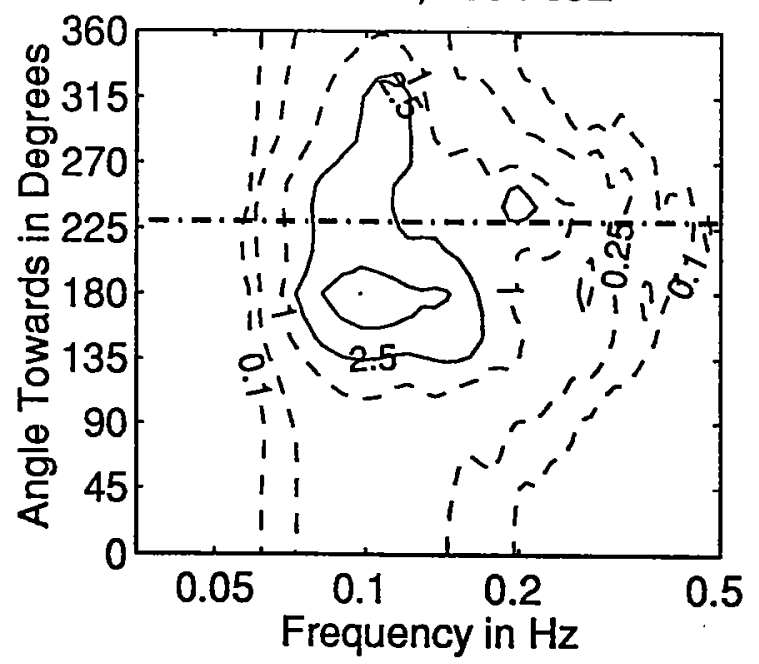

Figure 3.4.127: Directional wave spectra, computed using maximum entropy method. Contours of spectral density as a function of direction. Contours are 0.1, $0.25,1$ (dashed), $2.5,10,25,100$, and 250 (solid). Wind direction is shown by thick dashed line. 
March 13, 1994127

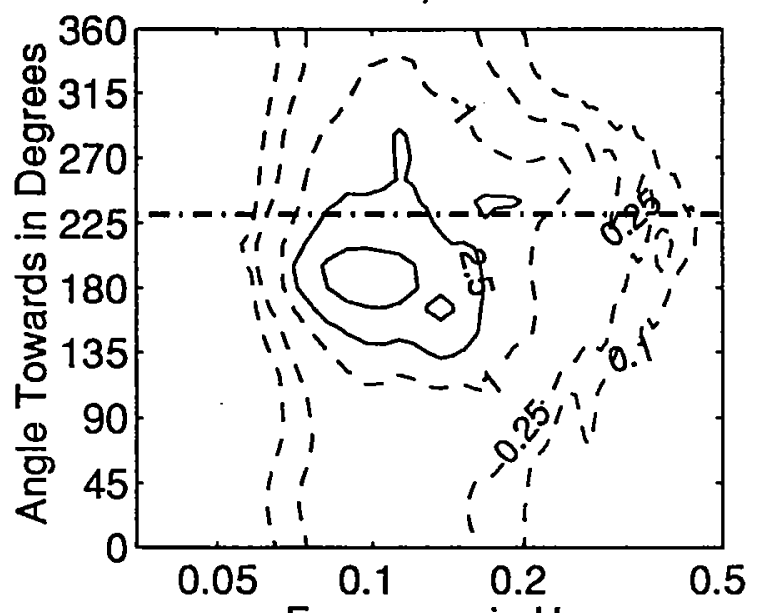

Frequency in $\mathrm{Hz}$

March 13, $199418 Z$

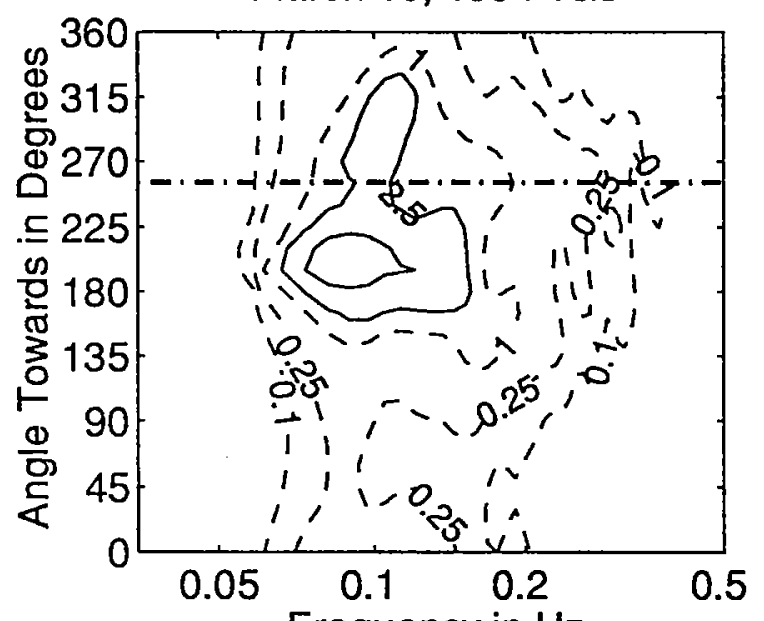

Frequency in $\mathrm{Hz}$

March 14, $199400 Z$

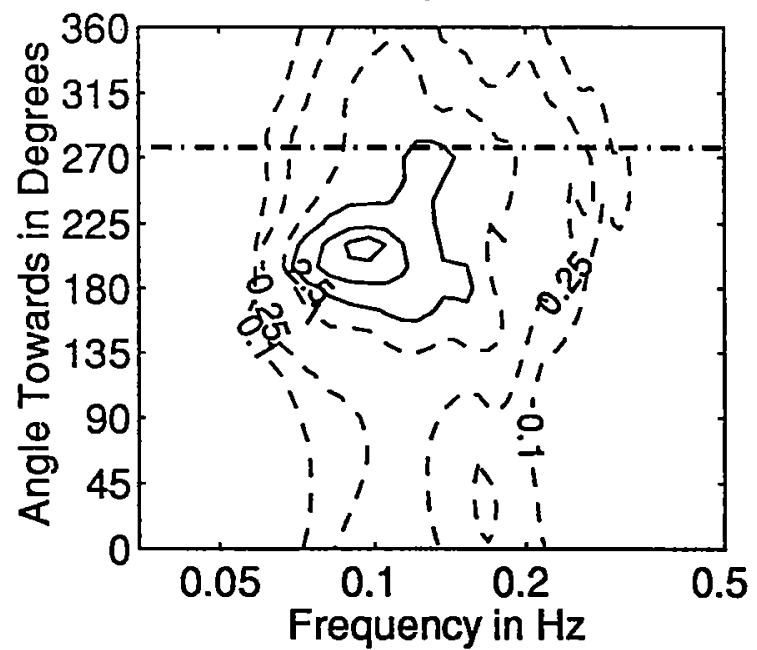

March 13, $199415 Z$

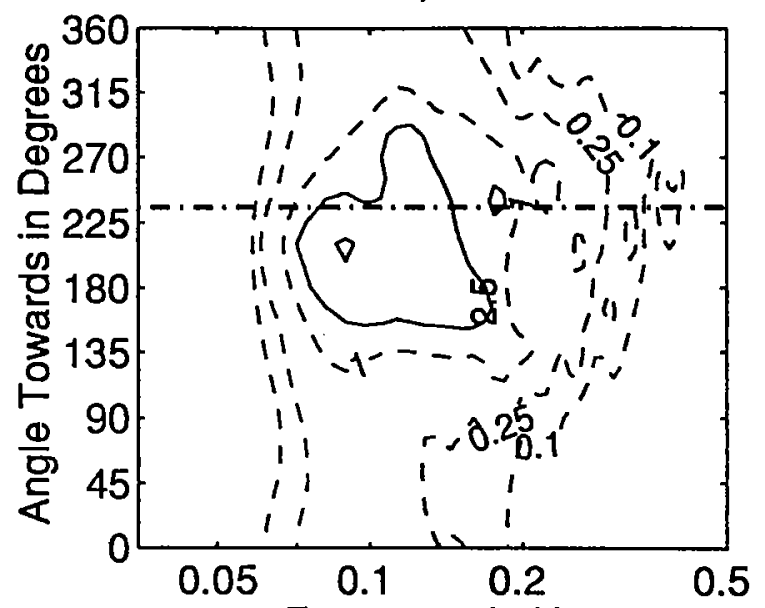

Frequency in $\mathrm{Hz}$

March 13, $199421 Z$

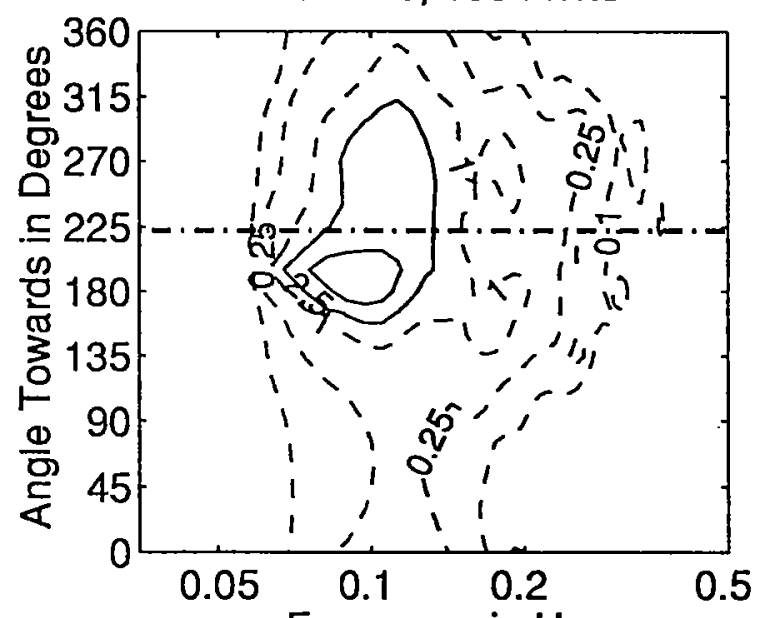

Frequency in $\mathrm{Hz}$

March 14, $199403 Z$

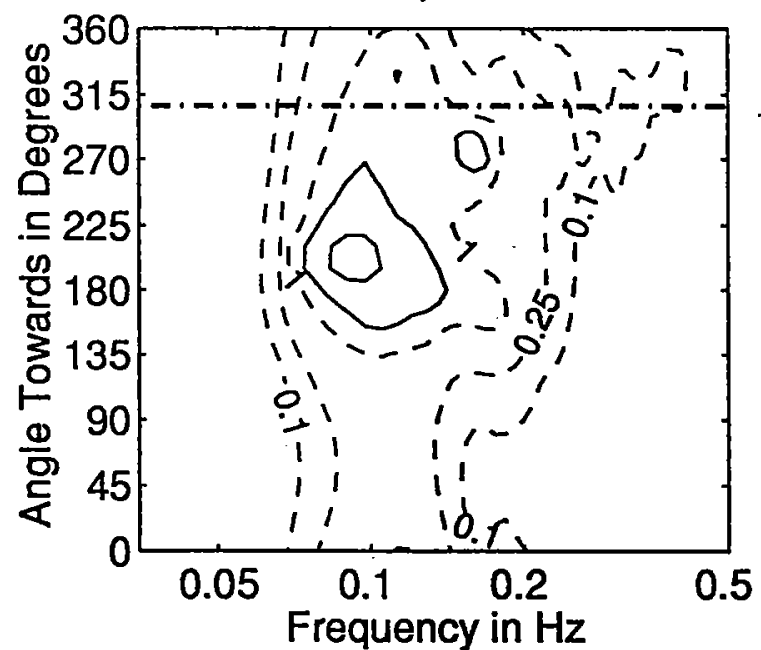

Figure 3.4.128: Directional wave spectra, computed using maximum entropy method. Contours of spectral density as a function of direction. Contours are 0.1, $0.25,1$ (dashed), $2.5,10,25,100$, and 250 (solid). Wind direction is shown by thick dashed line. 
March 14, $199406 Z$

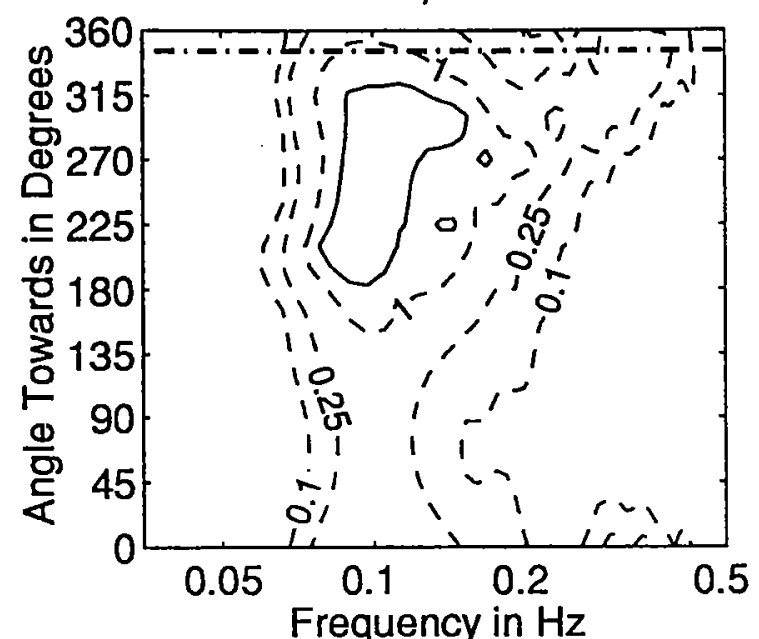

Frequency in $\mathrm{Hz}$

March 14, $199412 Z$

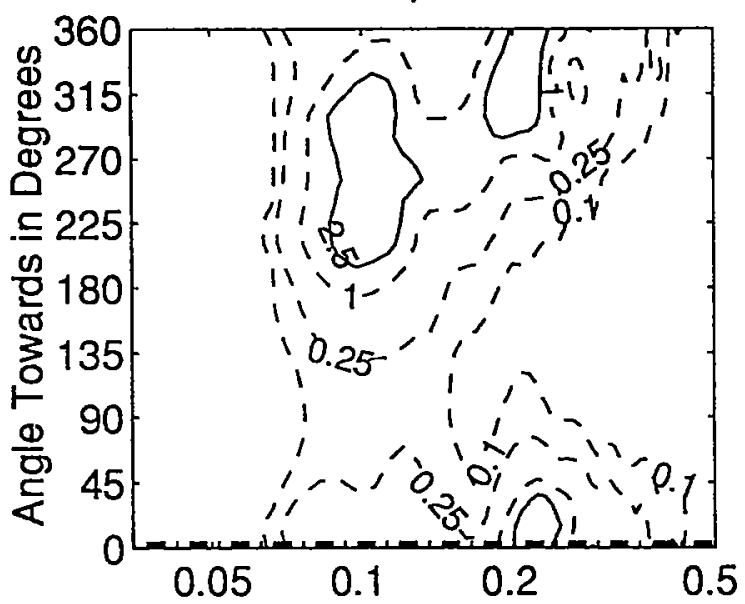

Frequency in $\mathrm{Hz}$

March 14, $199418 Z$

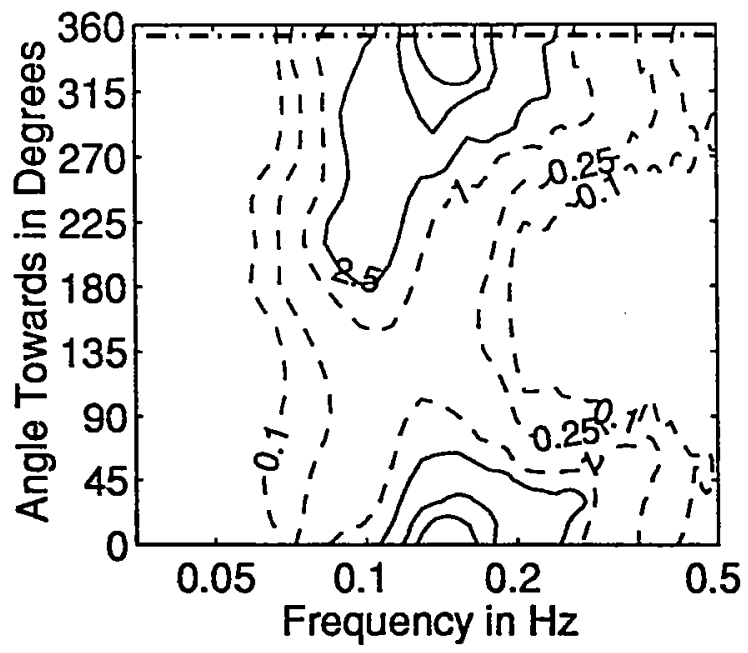

March 14, $199409 Z$
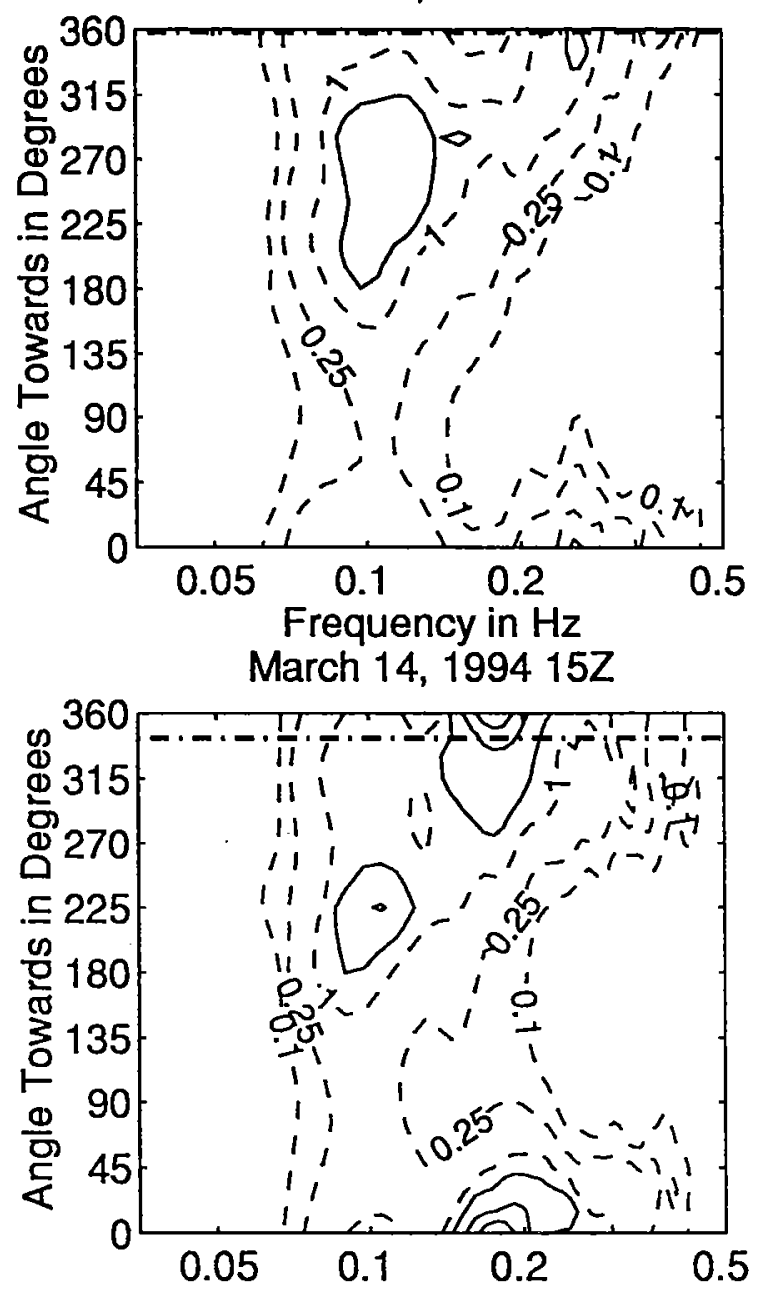

Frequency in $\mathrm{Hz}$ March 14, $199421 Z$

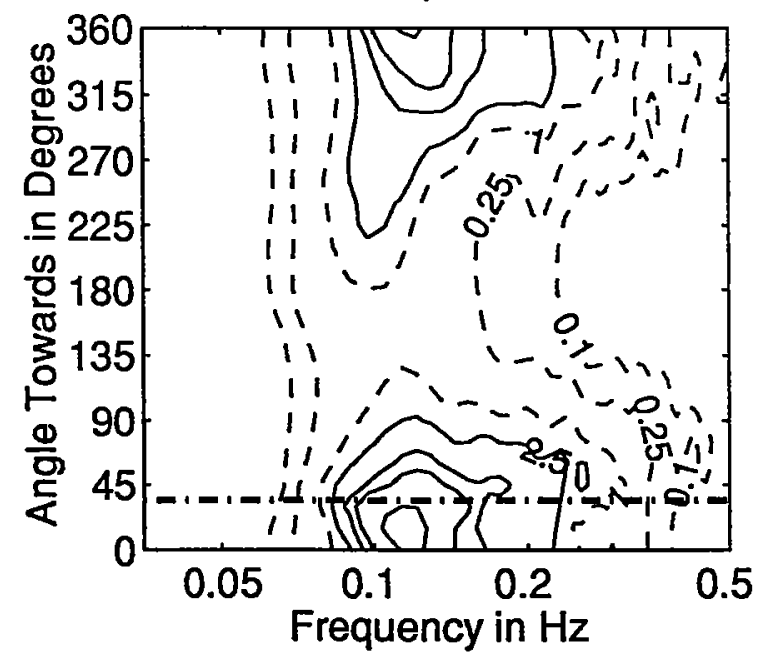

Figure 3.4.129: Directional wave spectra, computed using maximum entropy method. Contours of spectral density as a function of direction. Contours are 0.1, $0.25,1$ (dashed), $2.5,10,25,100$, and 250 (solid). Wind direction is shown by thick dashed line. 
March 15, $199400 Z$

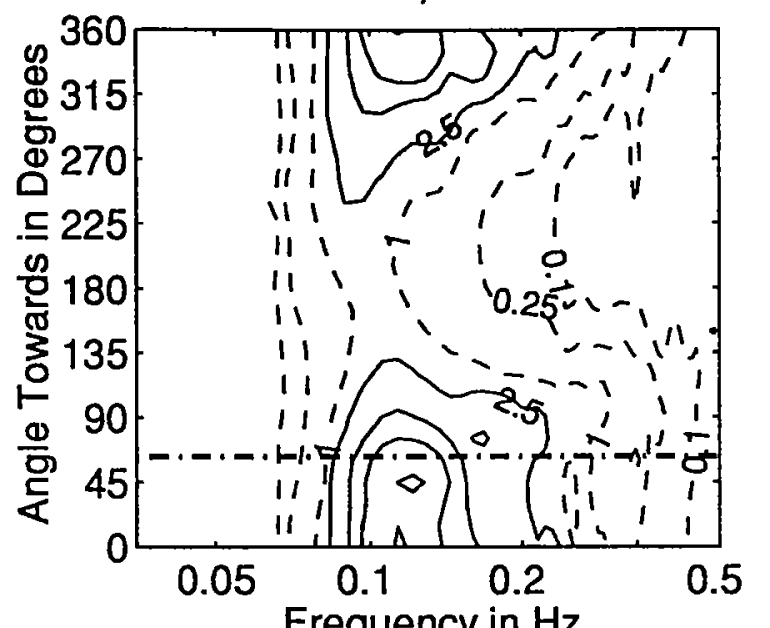

Frequency in $\mathrm{Hz}$

March 16, $199406 Z$

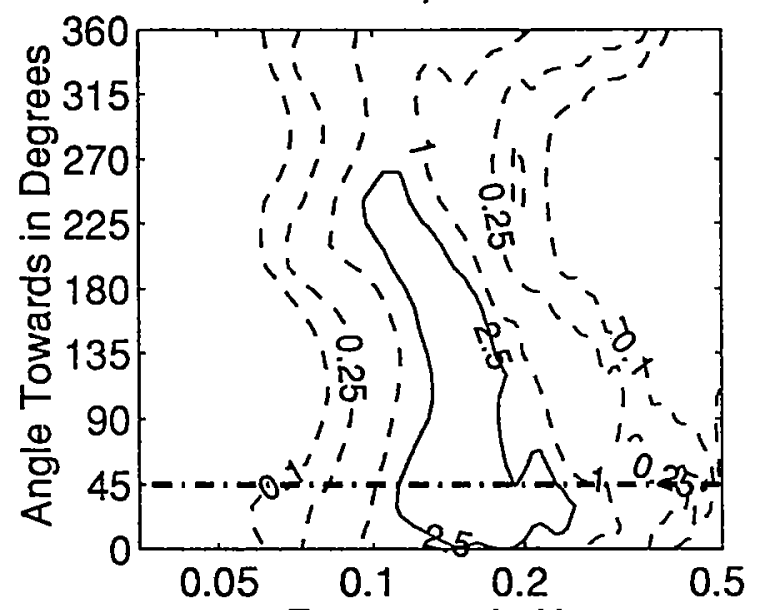

Frequency in $\mathrm{Hz}$

March 16, $199412 Z$

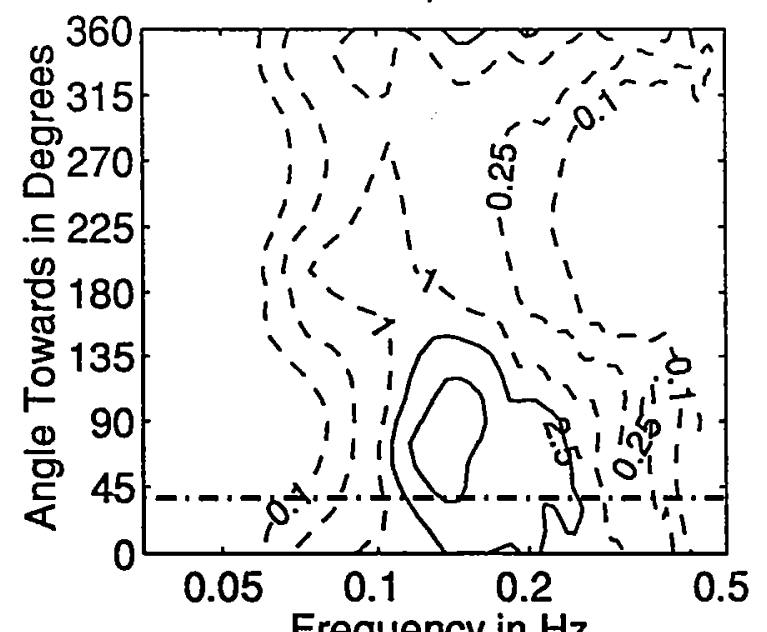

Frequency in $\mathrm{Hz}$

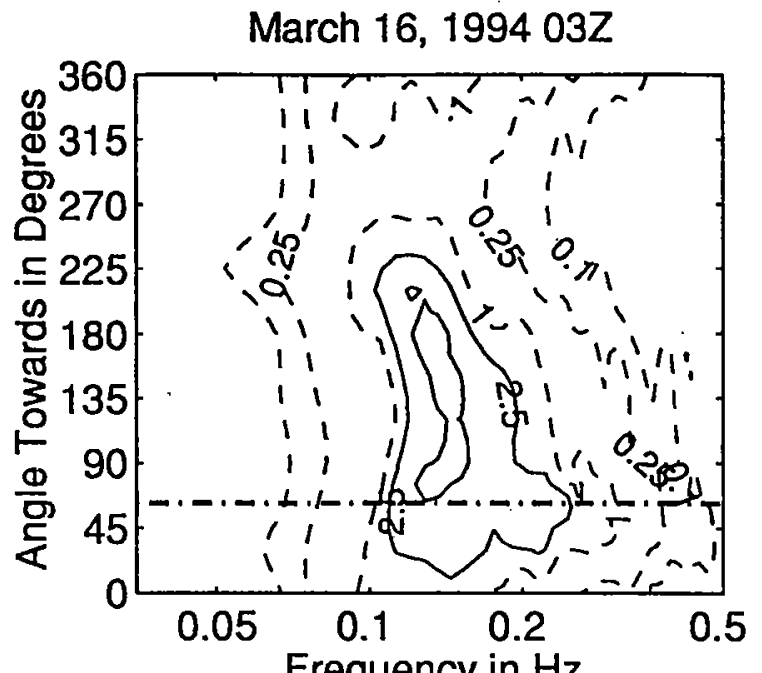

Frequency in $\mathrm{Hz}$

March 16, $199409 Z$

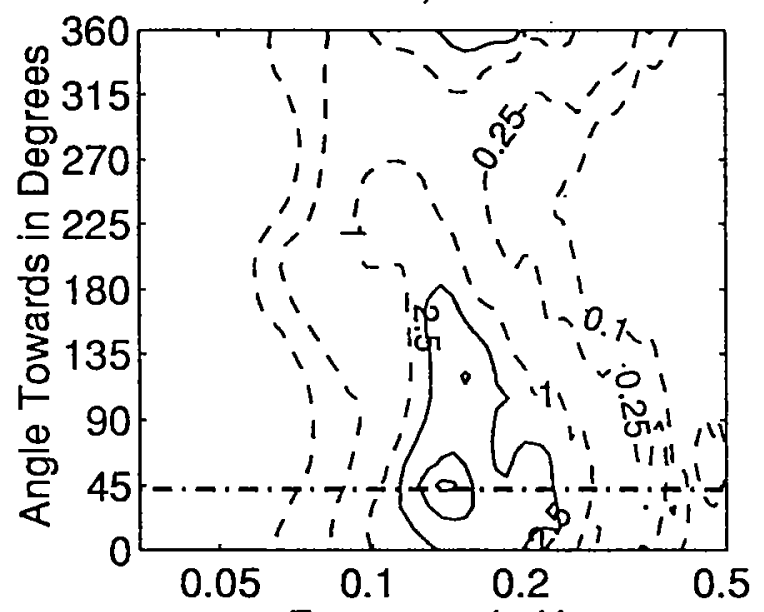

Frequency in $\mathrm{Hz}$

March 16, 1994 15Z

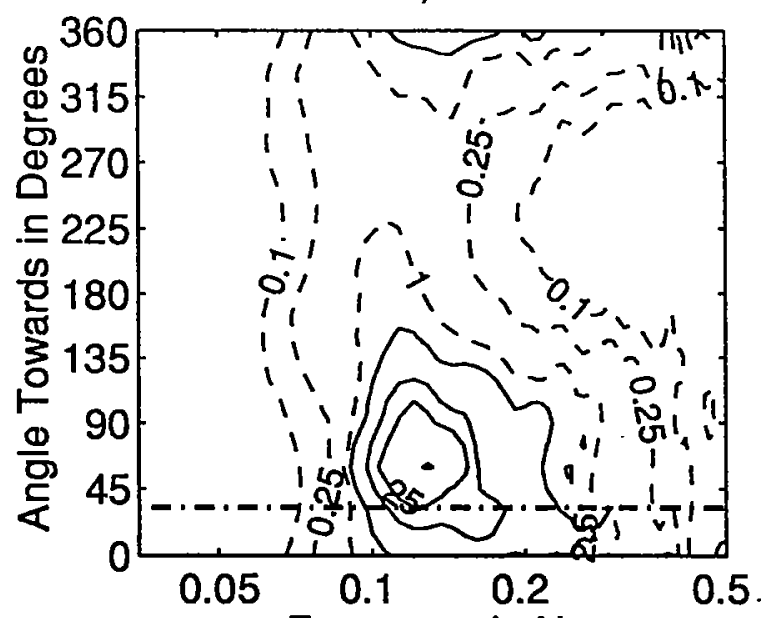

Frequency in $\mathrm{Hz}$

Figure 3.4.130: Directional wave spectra, computed using maximum entropy method. Contours of spectral density as a function of direction. Contours are 0.1, $0.25,1$ (dashed), $2.5,10,25,100$, and 250 (solid). Wind direction is shown by thick dashed line. 
March 16, $199418 Z$

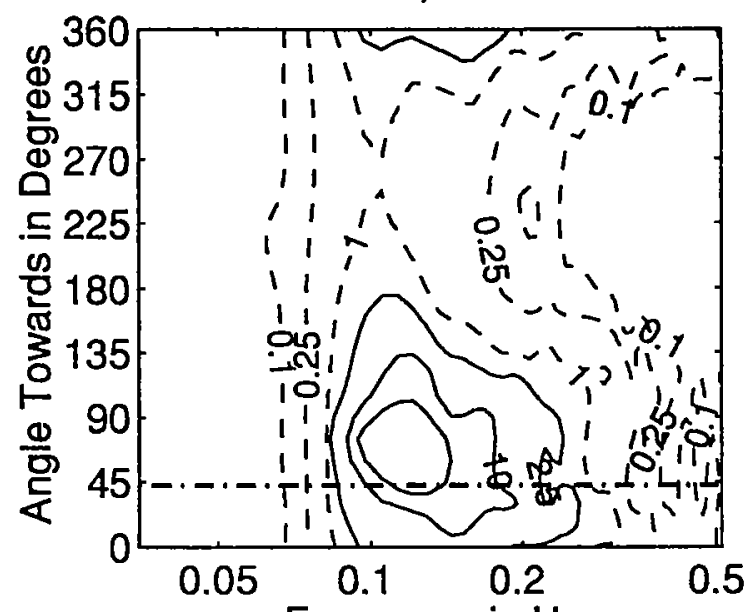

Frequency in $\mathrm{Hz}$

March 17, 1994 00Z

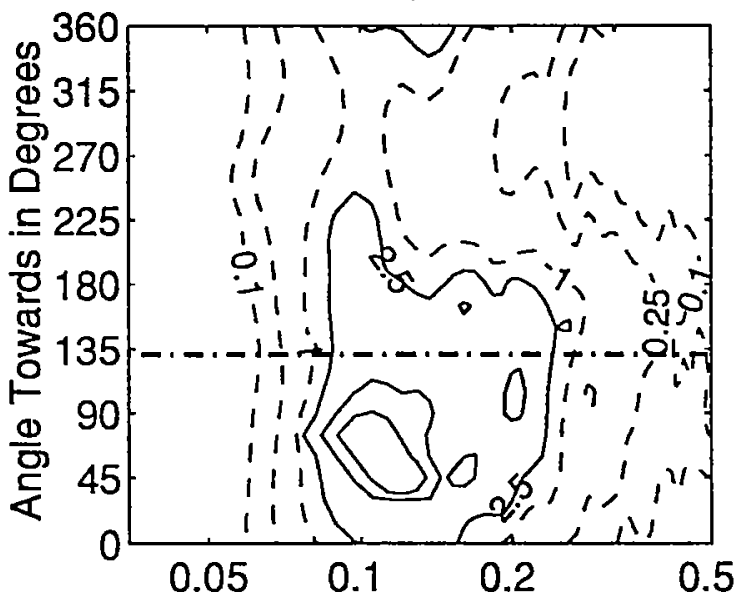

Frequency in $\mathrm{Hz}$

March 17, 1994 06Z

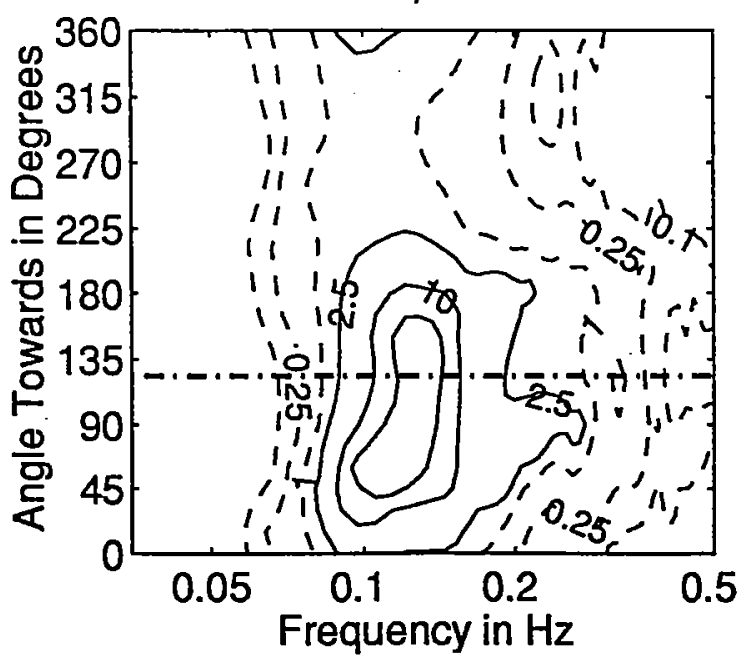

March 16, $199421 Z$

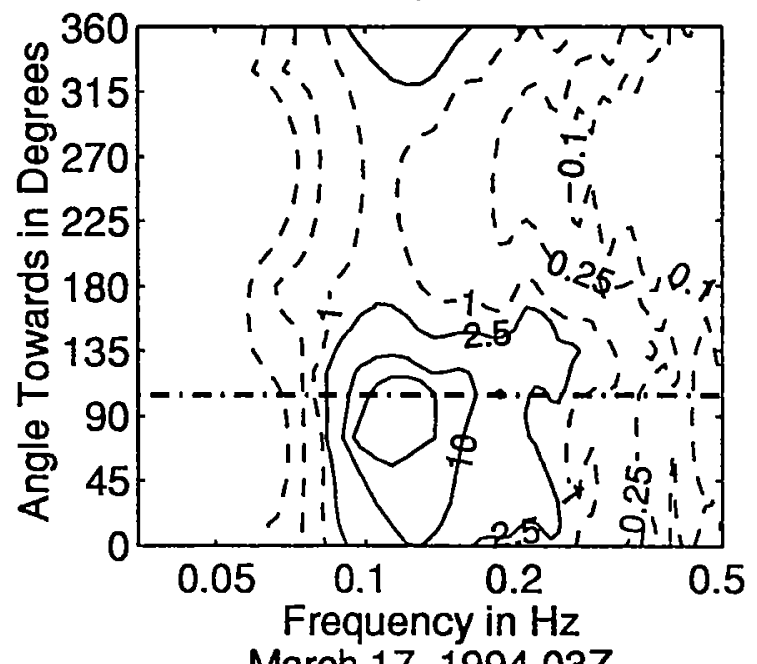

March 17, 1994 03Z

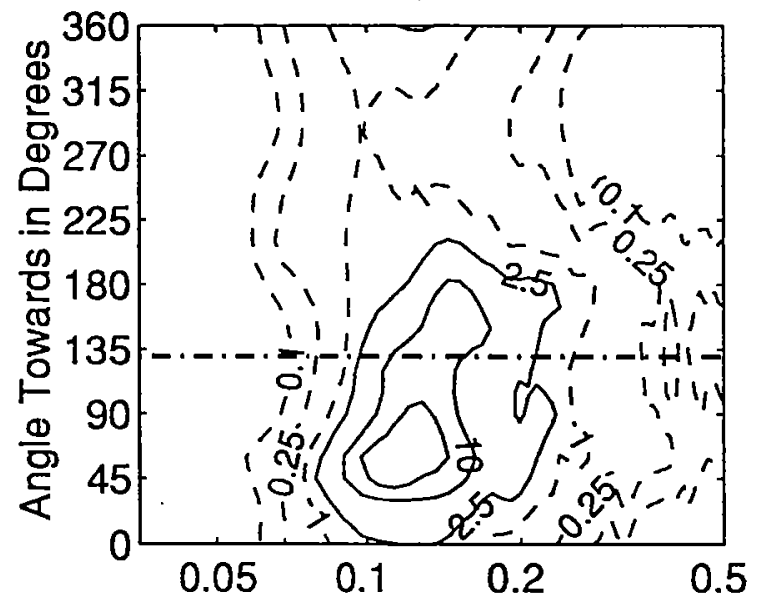

Frequency in $\mathrm{Hz}$

March 17, 1994 09Z

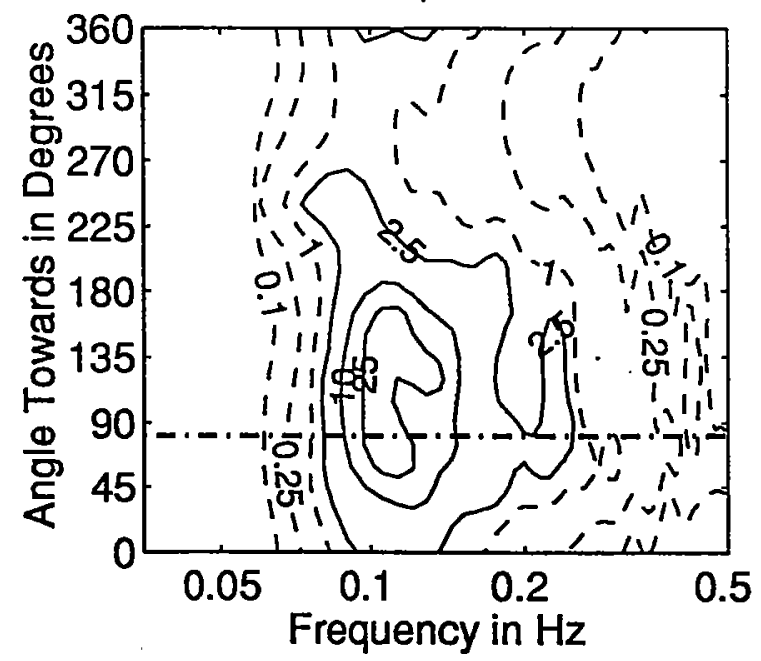

Figure 3.4.131: Directional wave spectra, computed using maximum entropy method. Contours of spectral density as a function of direction. Contours are 0.1, $0.25,1$ (dashed), $2.5,10,25,100$, and 250 (solid). Wind direction is shown by thick dashed line. 
March 17, 1994122

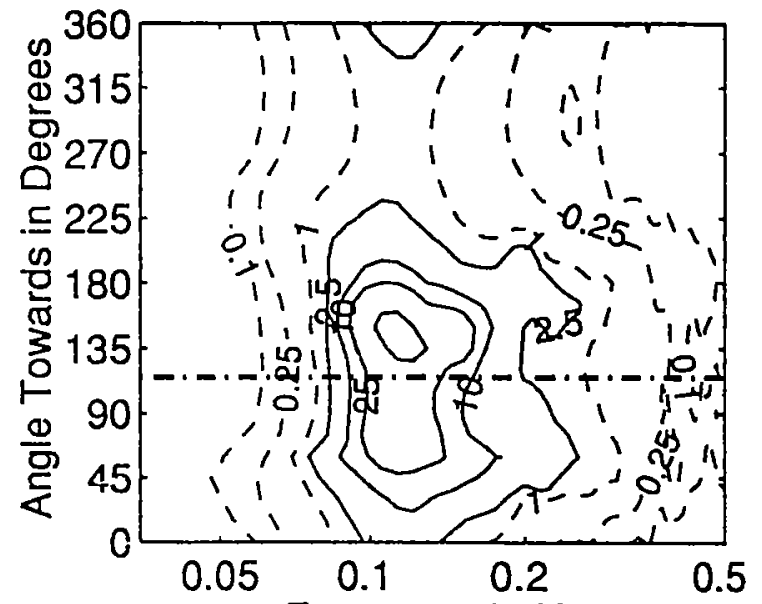

Frequency in $\mathrm{Hz}$

March 17, $199418 Z$

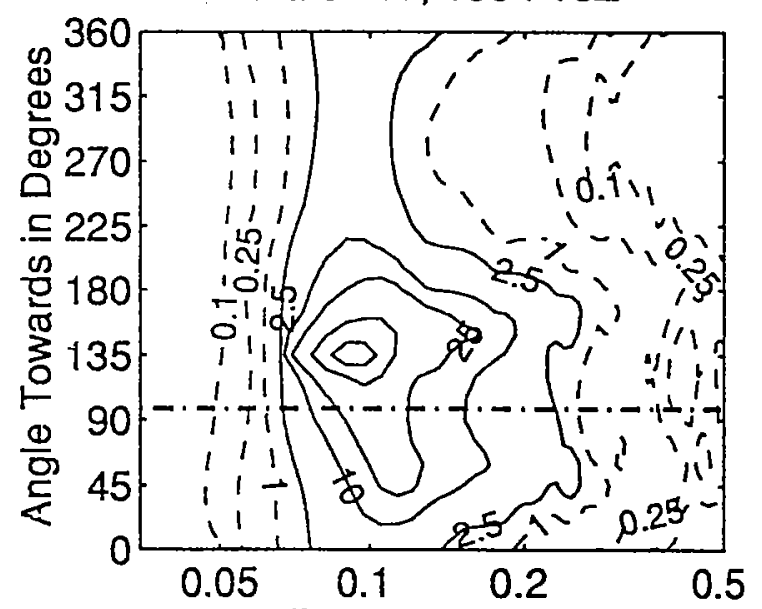

Frequency in $\mathrm{Hz}$

March 18, 1994 00Z

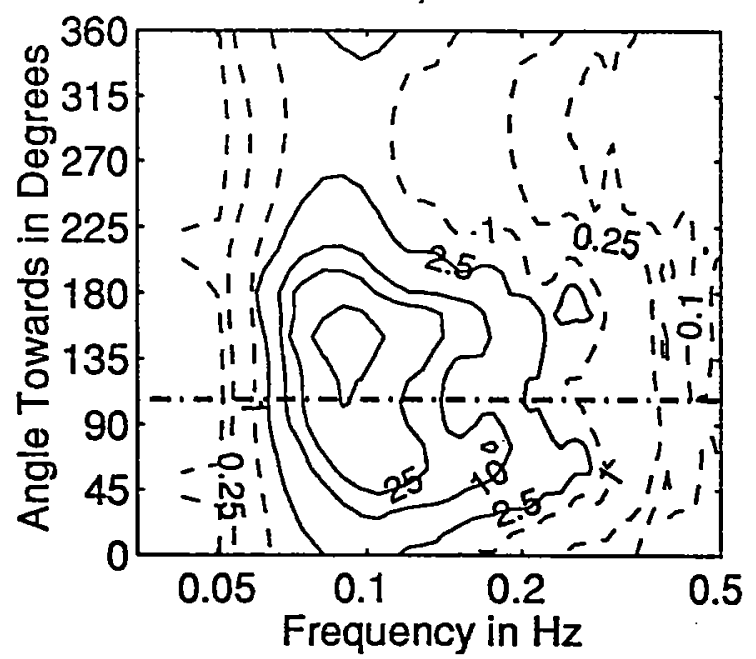

March 17, $199415 Z$

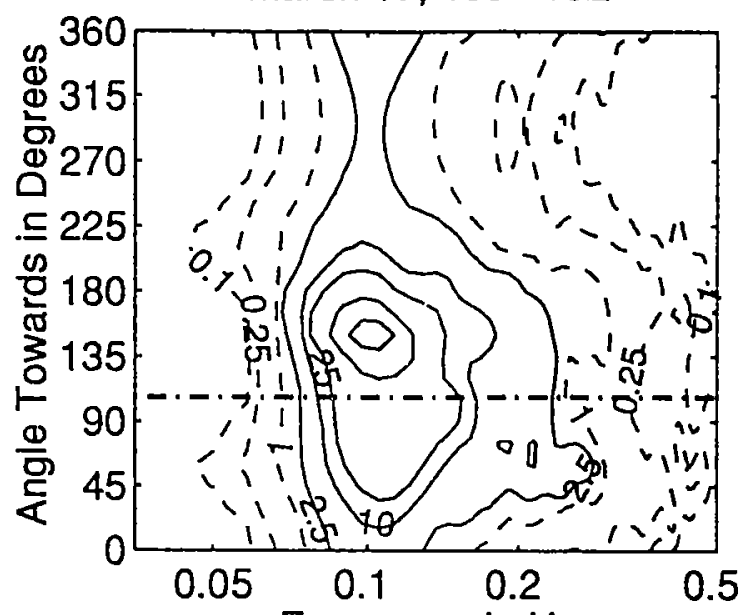

Frequency in $\mathrm{Hz}$

March 17, 1994212

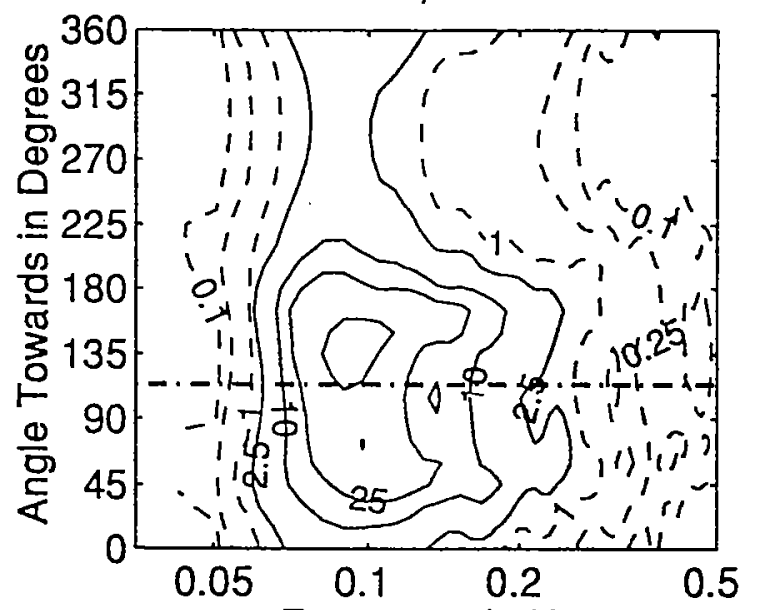

Frequency in $\mathrm{Hz}$

March 18, 1994032

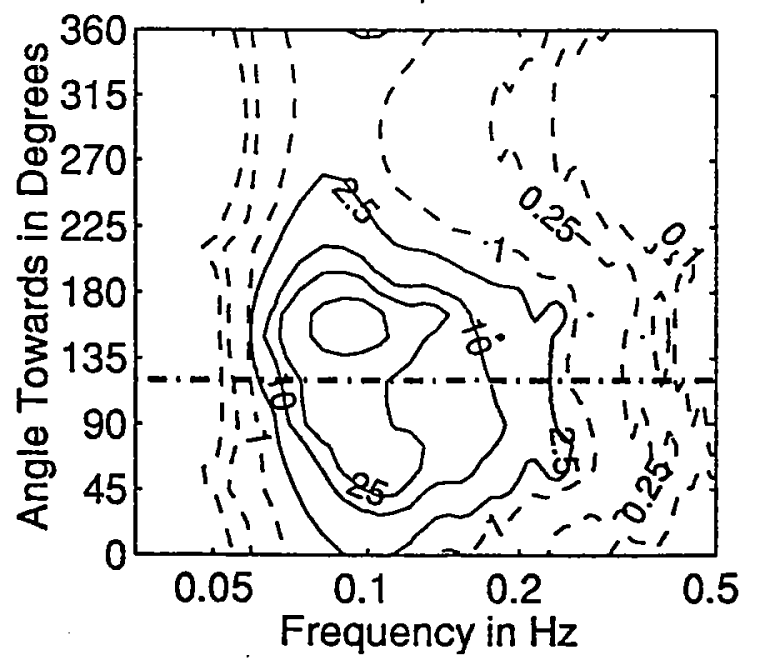

Figure 3.4.132: Directional wave spectra, computed using maximum entropy method. Contours of spectral density as a function of direction. Contours are 0.1, $0.25,1$ (dashed), 2.5, 10,25, 100, and 250 (solid). Wind direction is shown by thick dashed line. 
March 18, $199406 Z$

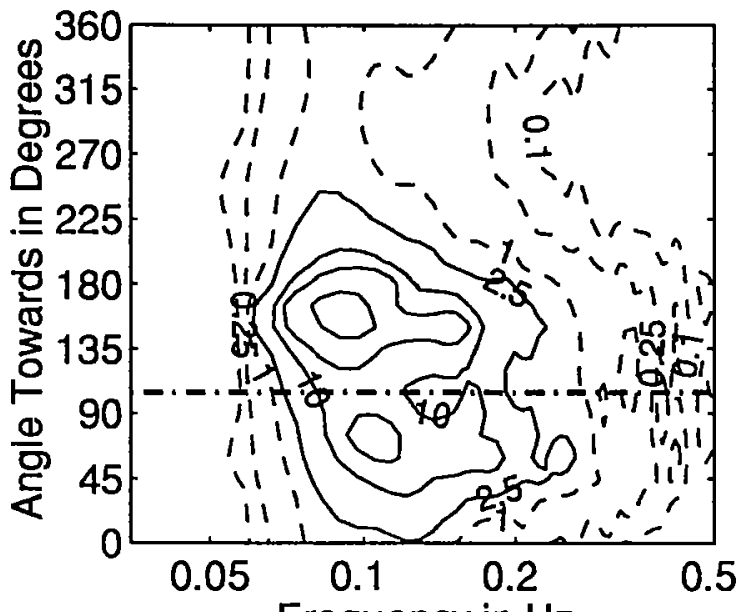

Frequency in $\mathrm{Hz}$

March 18, 1994127

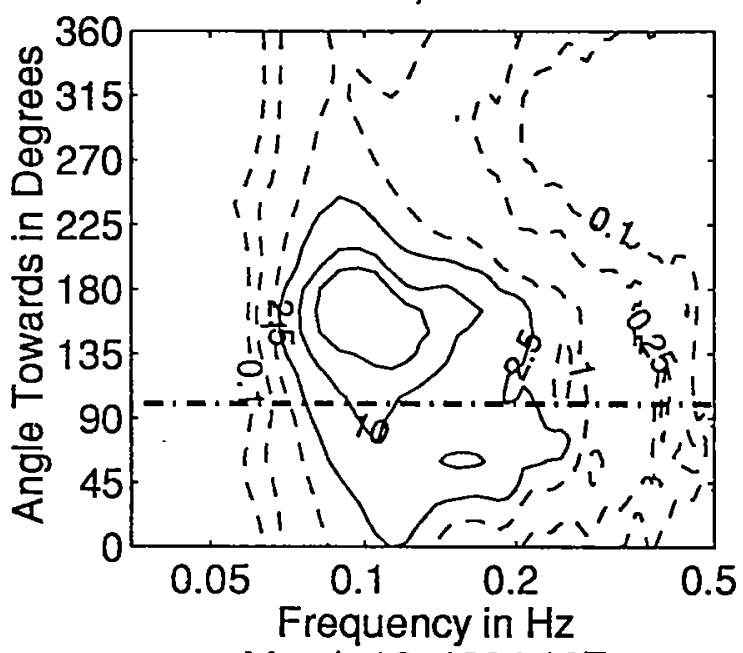

March 18, $199418 Z$

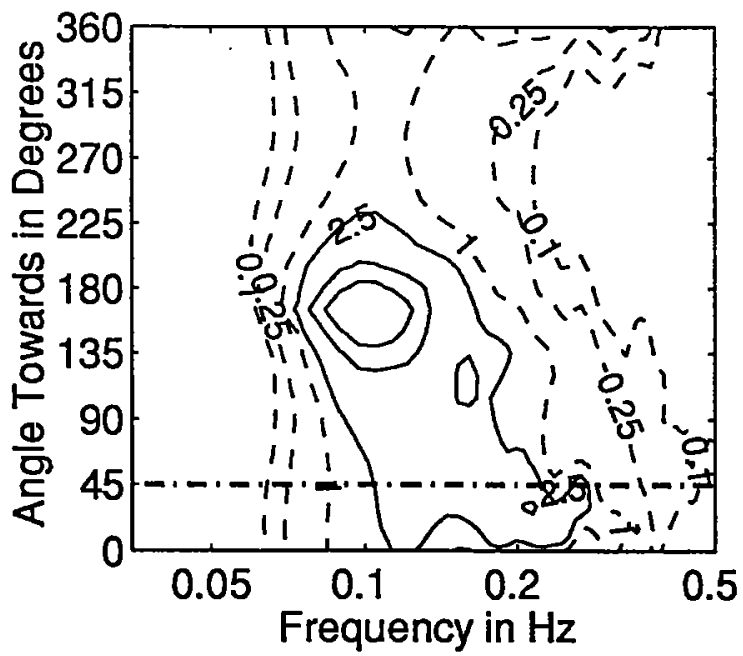

March 18, $199409 Z$

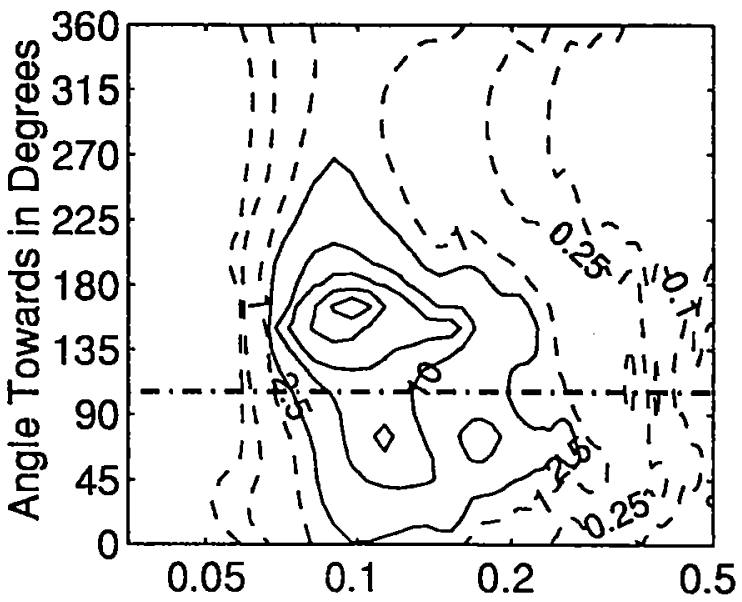

Frequency in $\mathrm{Hz}$

March 18, $199415 Z$

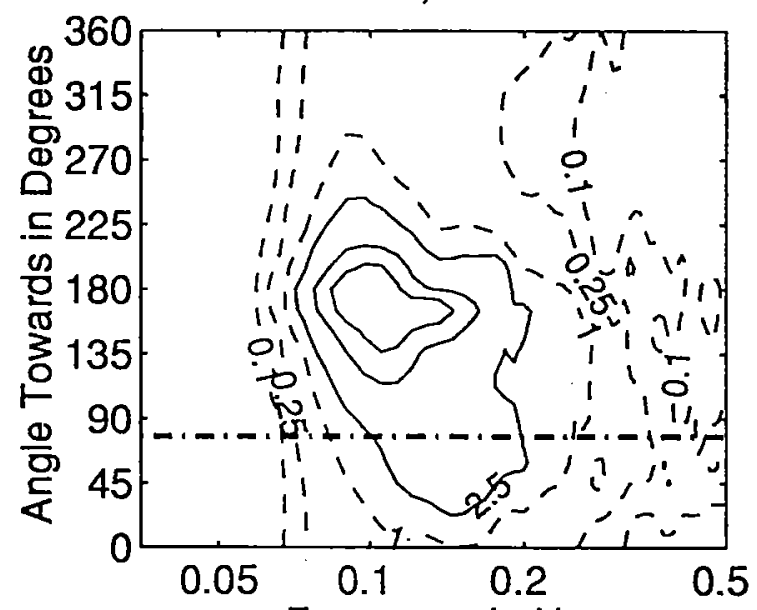

Frequency in $\mathrm{Hz}$

March 18, $199421 Z$

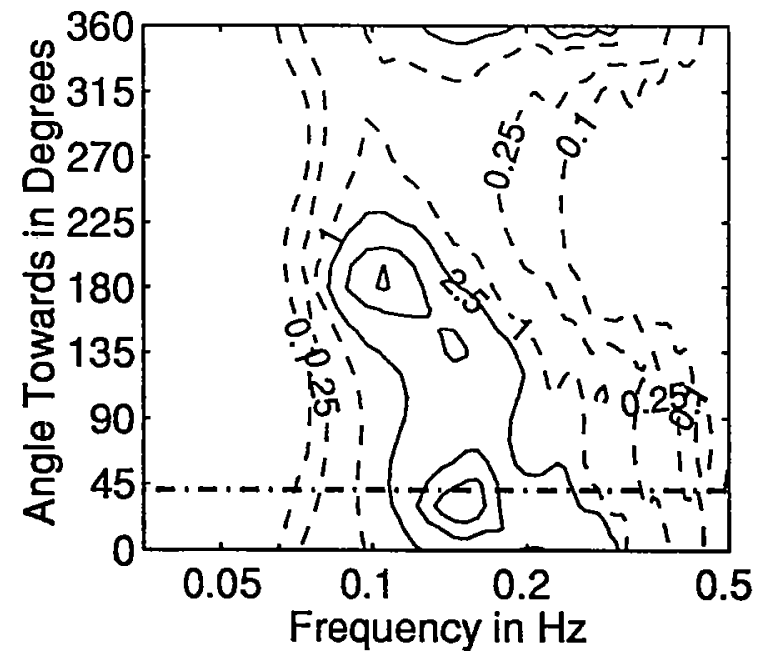

Figure 3.4.133: Directional wave spectra, computed using maximum entropy method. Contours of spectral density as a function of direction. Contours are 0.1, $0.25,1$ (dashed), 2.5, 10,25, 100, and 250 (solid). Wind direction is shown by thick dashed line. 
March 19, $199400 Z$

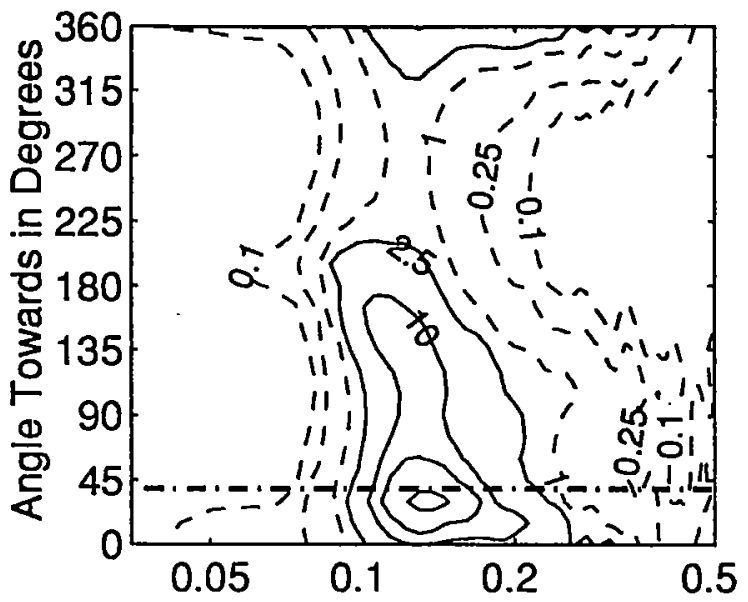

Frequency in $\mathrm{Hz}$

March 19, $199406 Z$

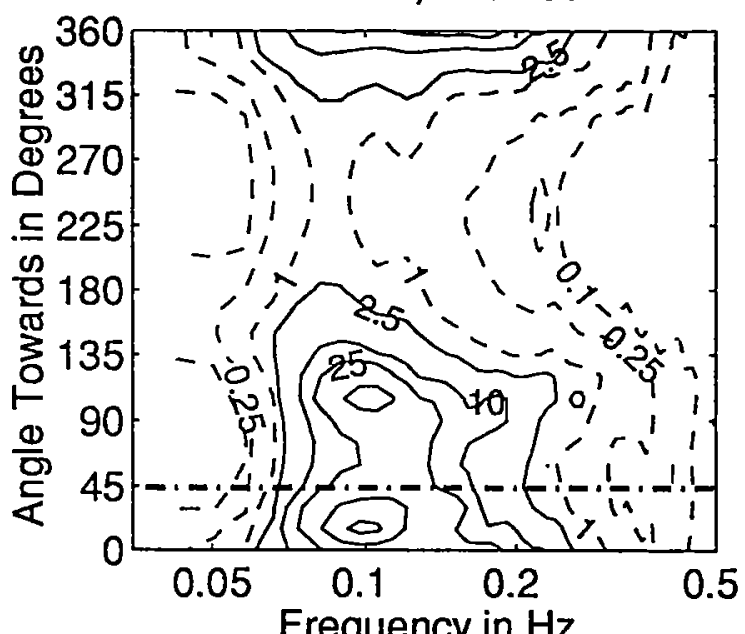

Frequency in $\mathrm{Hz}$

March 19, $199412 Z$

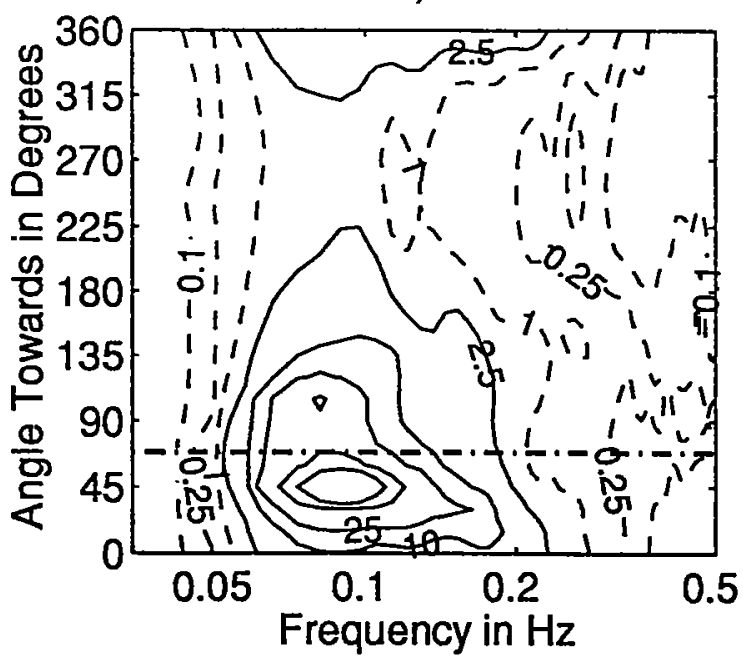

March 19, $199403 Z$

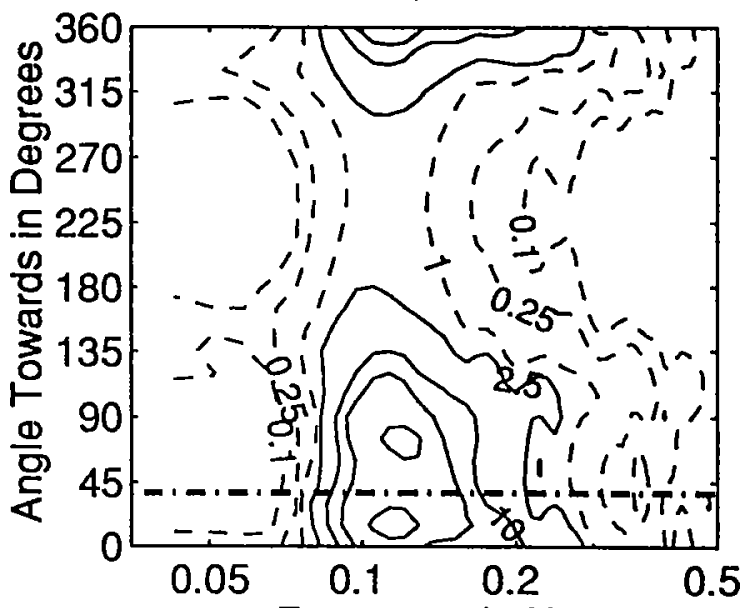

Frequency in $\mathrm{Hz}$

March 19, $199409 Z$

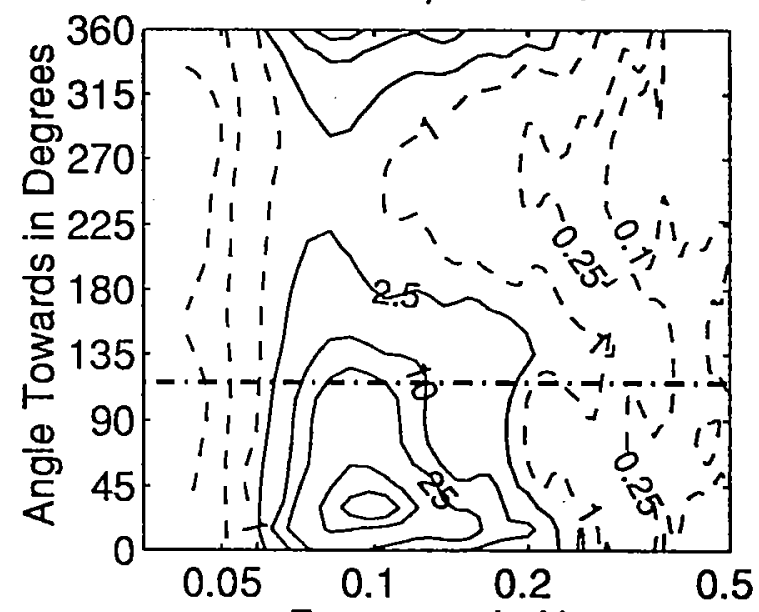

Frequency in $\mathrm{Hz}$

March 19, $199415 Z$

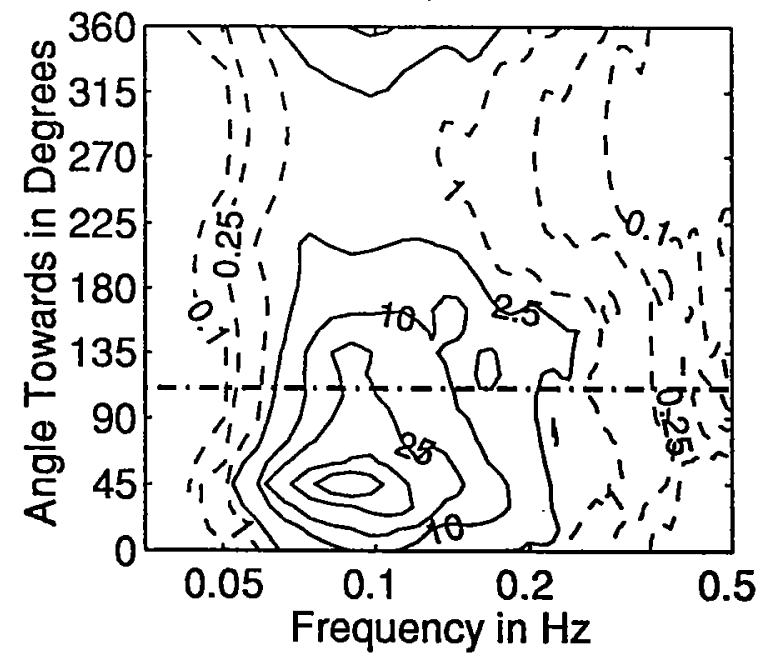

Figure 3.4.134: Directional wave spectra, computed using maximum entropy method. Contours of spectral density as a function of direction. Contours are 0.1, $0.25,1$ (dashed), $2.5,10,25,100$, and 250 (solid). Wind direction is shown by thick dashed line. 
March 19, $199418 Z$

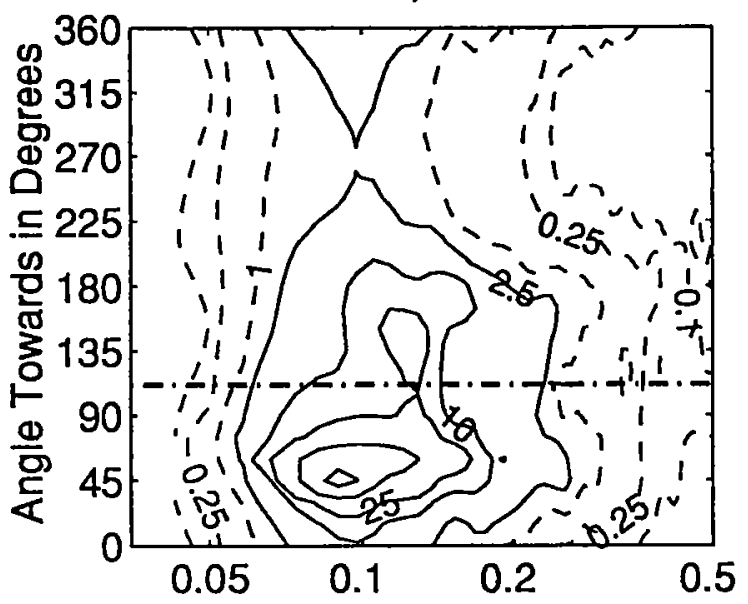

Frequency in $\mathrm{Hz}$

March 20, $199400 Z$
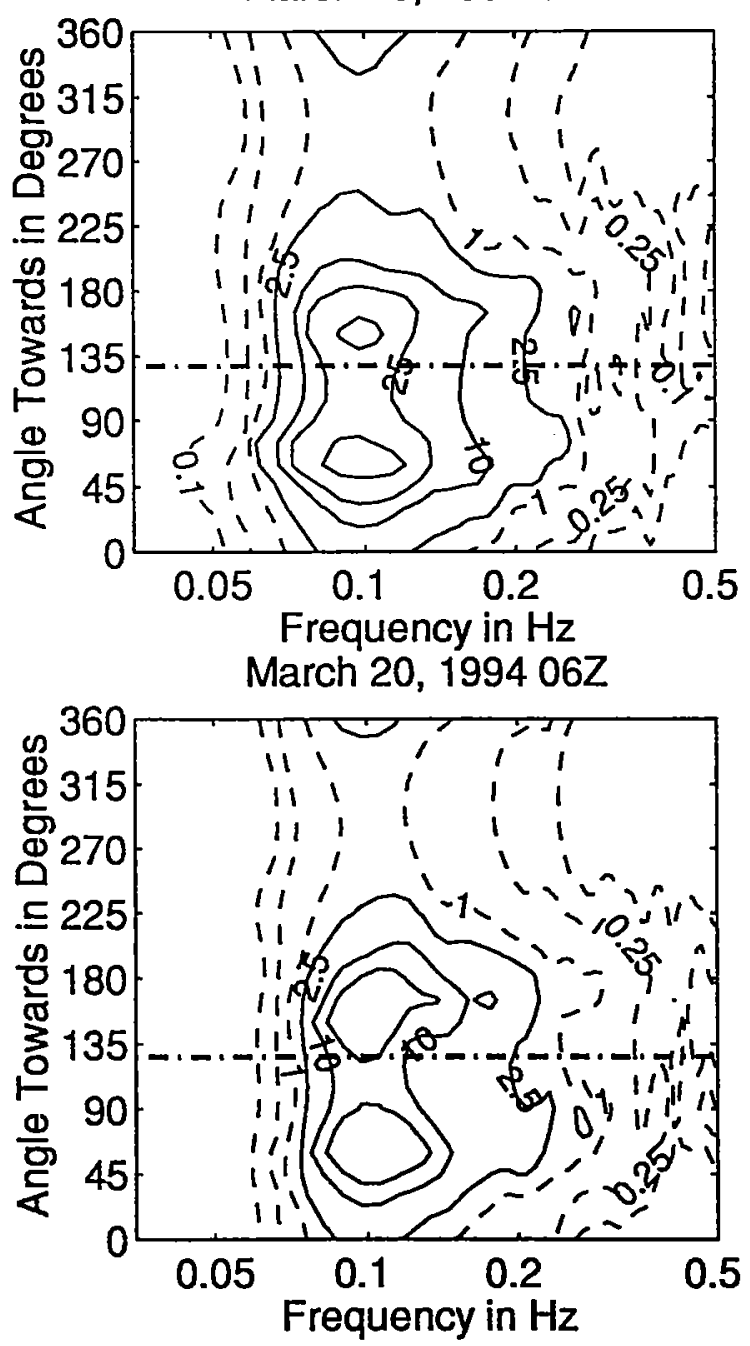

March 19, $199421 Z$

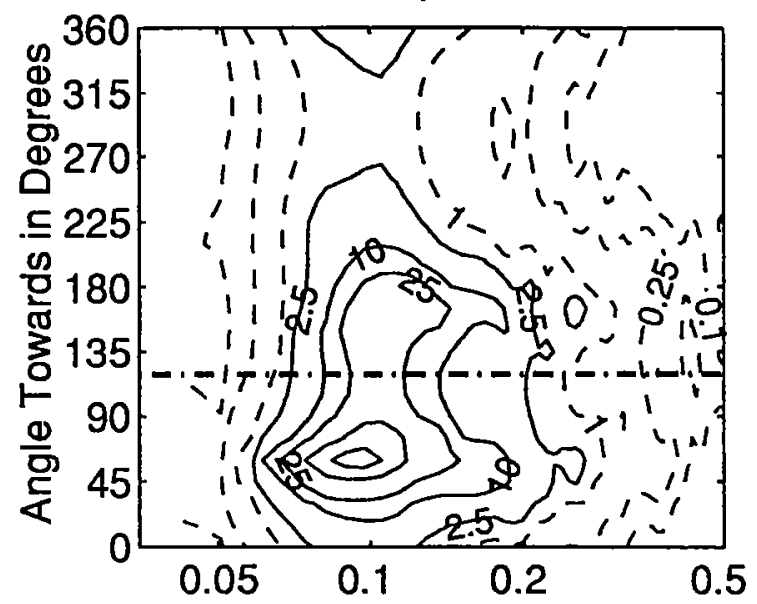

Frequency in $\mathrm{Hz}$

March 20, $199403 Z$
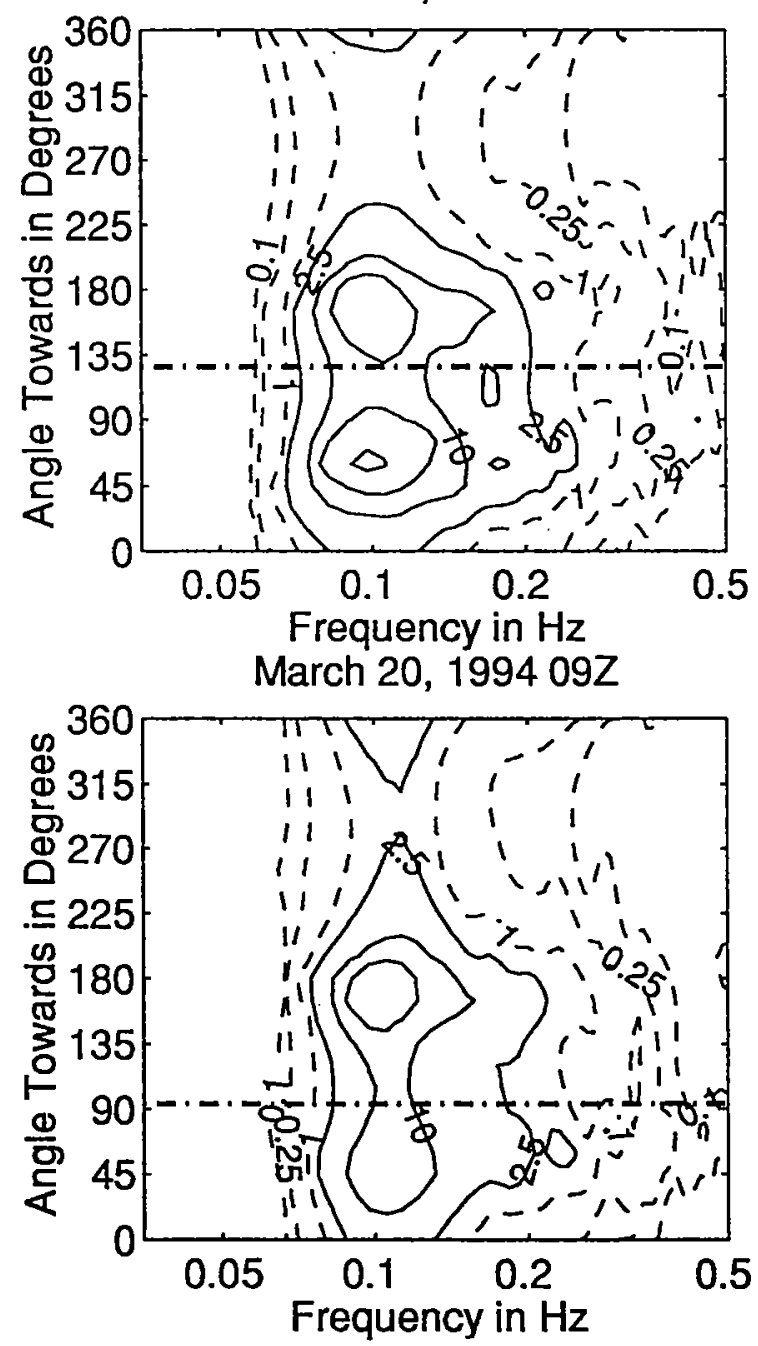

Figure 3.4.135: Directional wave spectra, computed using maximum entropy method. Contours of spectral density as a function of direction. Contours are 0.1 , $0.25,1$ (dashed), $2.5,10,25,100$, and 250 (solid). Wind direction is shown by thick dashed line. 
March 20, $199412 Z$
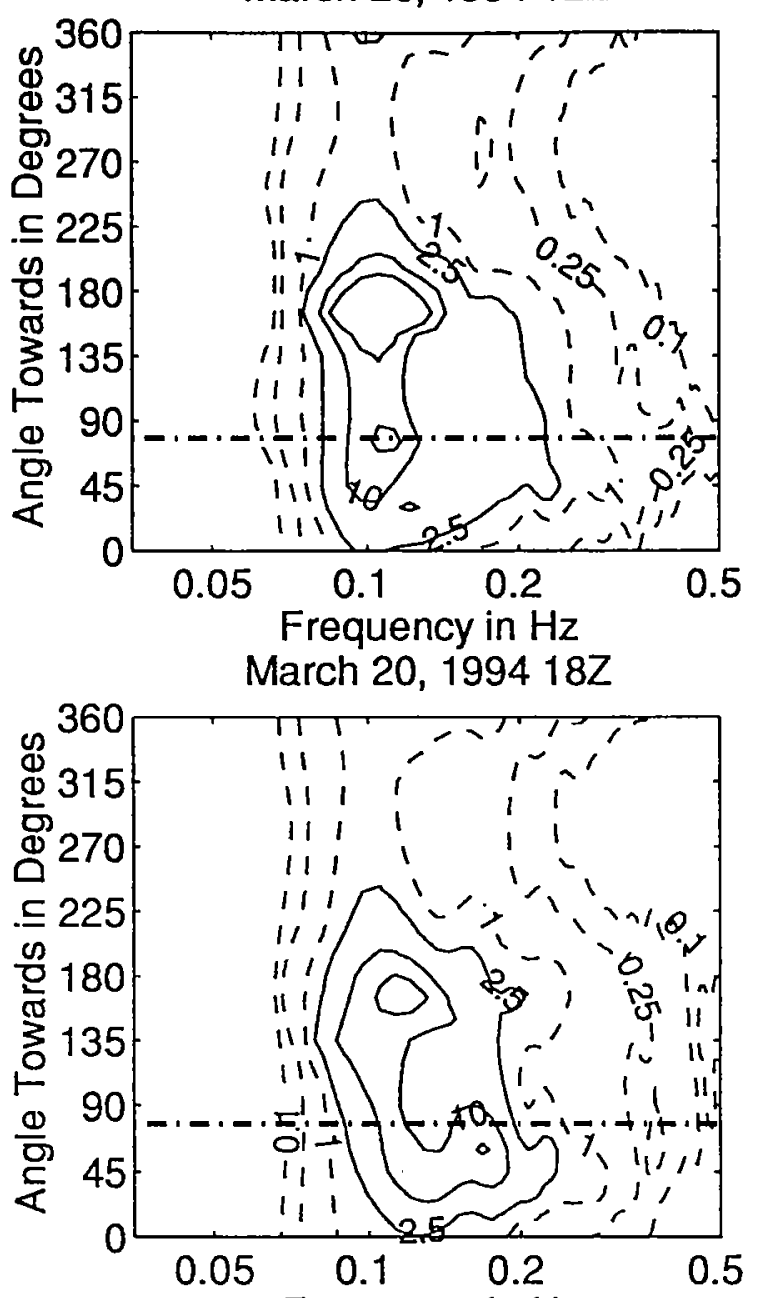

Frequency in $\mathrm{Hz}$

March 21, $199400 Z$

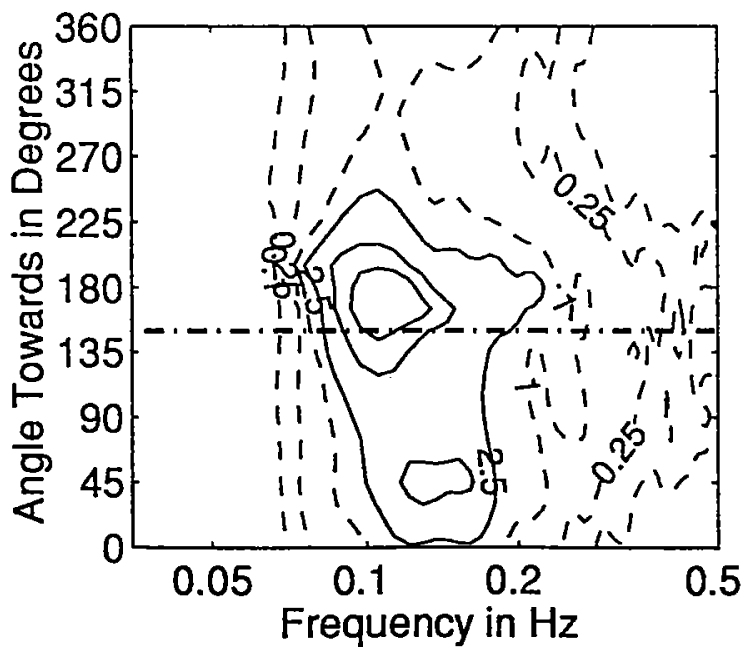

March 20, $199415 Z$
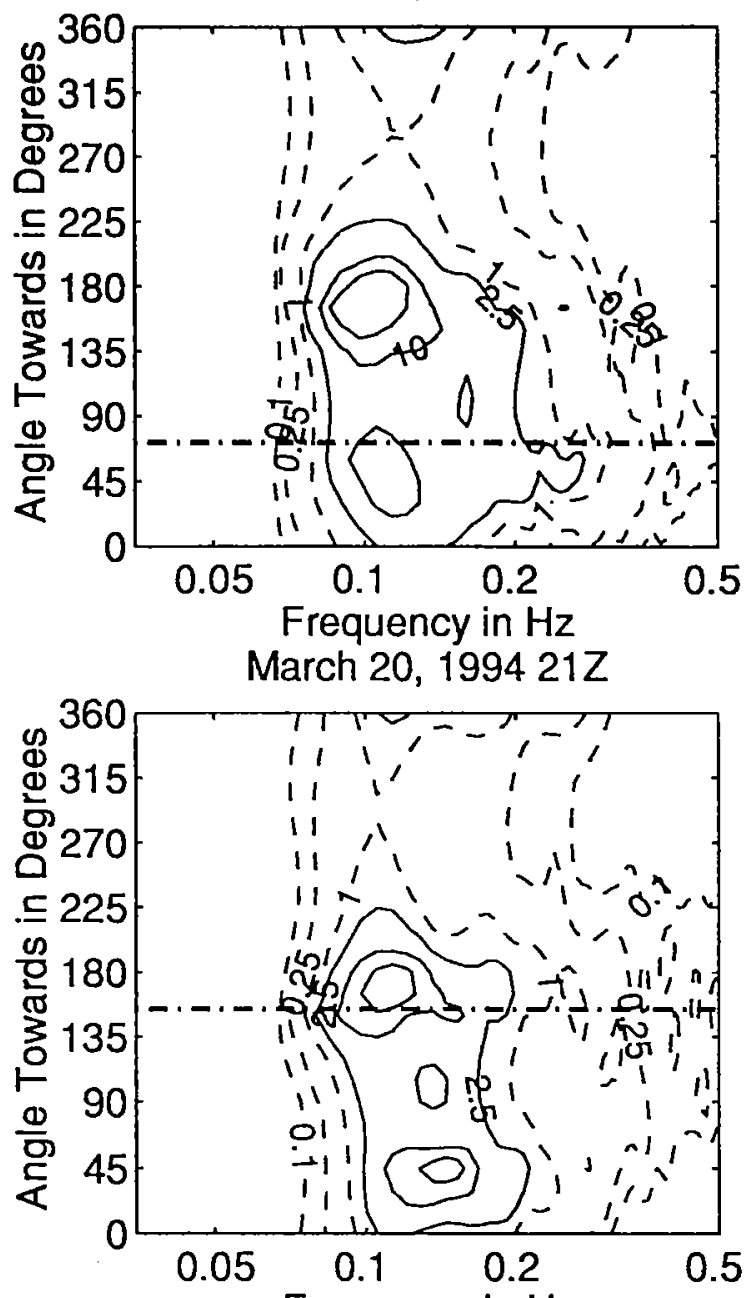

Frequency in $\mathrm{Hz}$

March 21, $199403 Z$

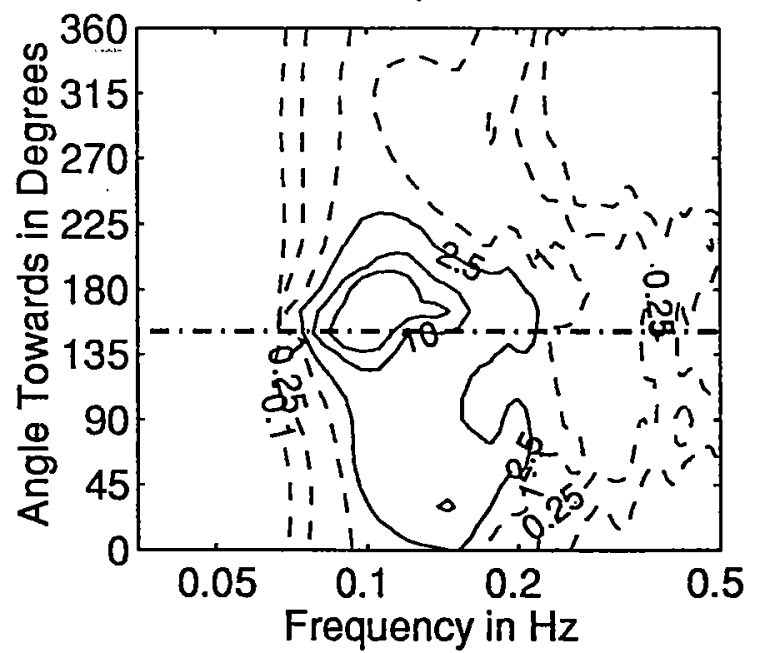

Figure 3.4.136: Directional wave spectra, computed using maximum entropy method. Contours of spectral density as a function of direction. Contours are 0.1 , $0.25,1$ (dashed), $2.5,10,25,100$, and 250 (solid). Wind direction is shown by thick dashed line. 

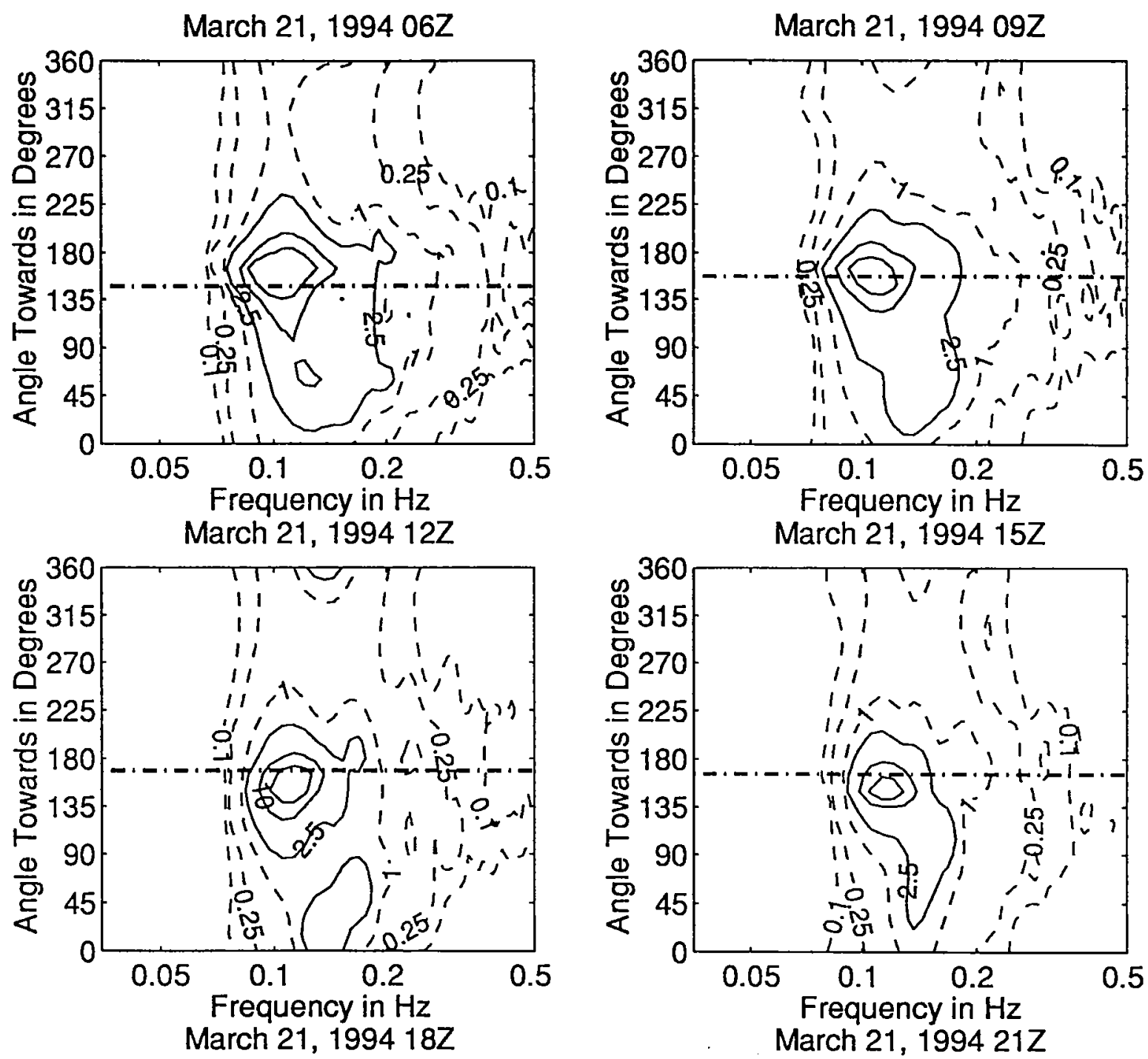

Frequency in $\mathrm{Hz}$

March 21, $199418 Z$
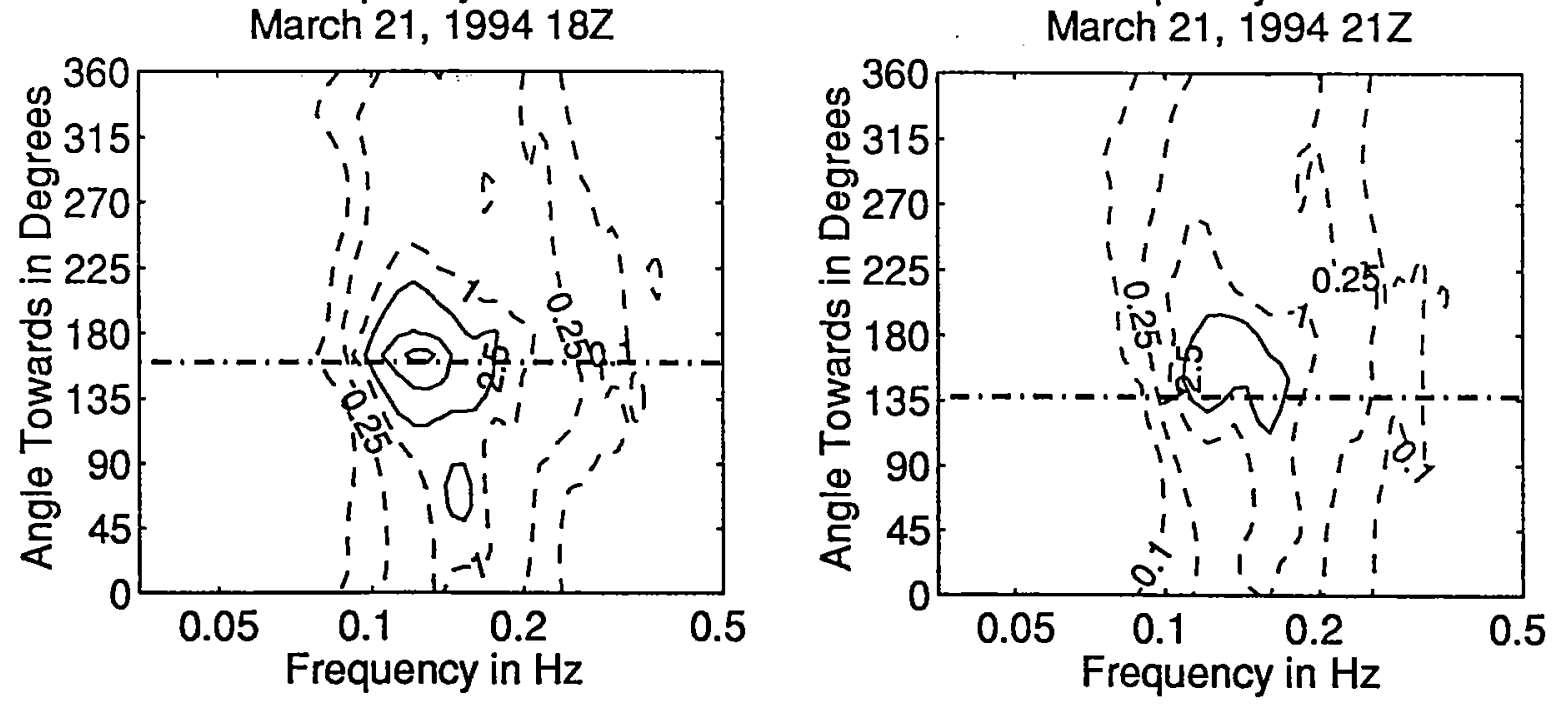

Figure 3.4.137: Directional wave spectra, computed using maximum entropy method. Contours of spectral density as a function of direction. Contours are 0.1 , $0.25,1$ (dashed), $2.5,10,25,100$, and 250 (solid). Wind direction is shown by thick dashed line. 
March 22, $199400 Z$

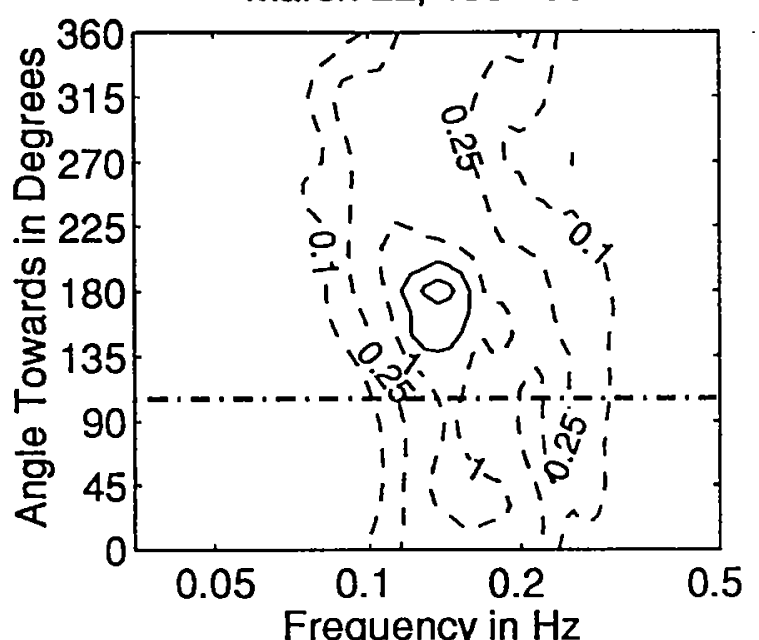

March 22, $199406 Z$

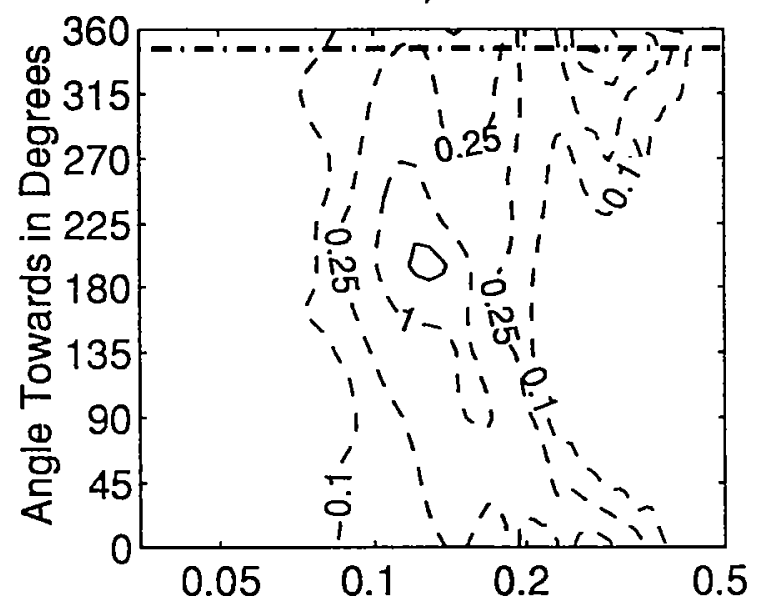

Frequency in $\mathrm{Hz}$

March 22, $199412 Z$

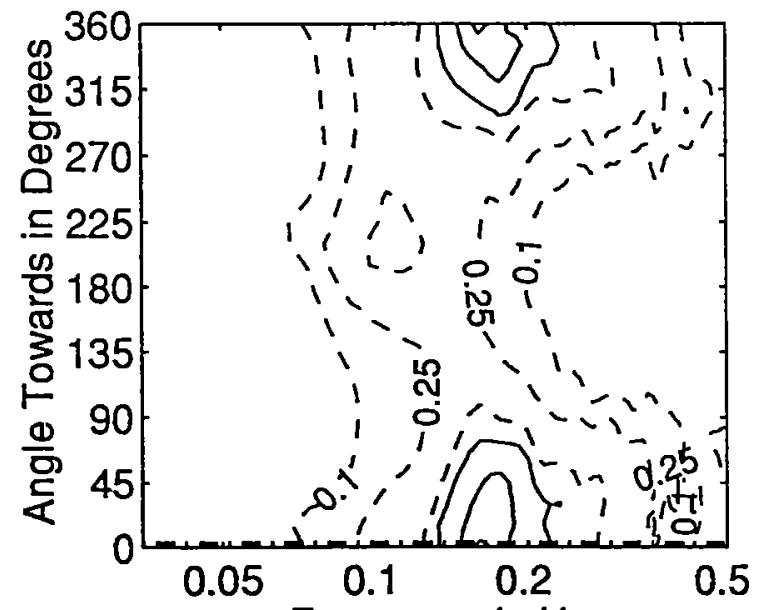

Frequency in $\mathrm{Hz}$
March 22, $199403 Z$

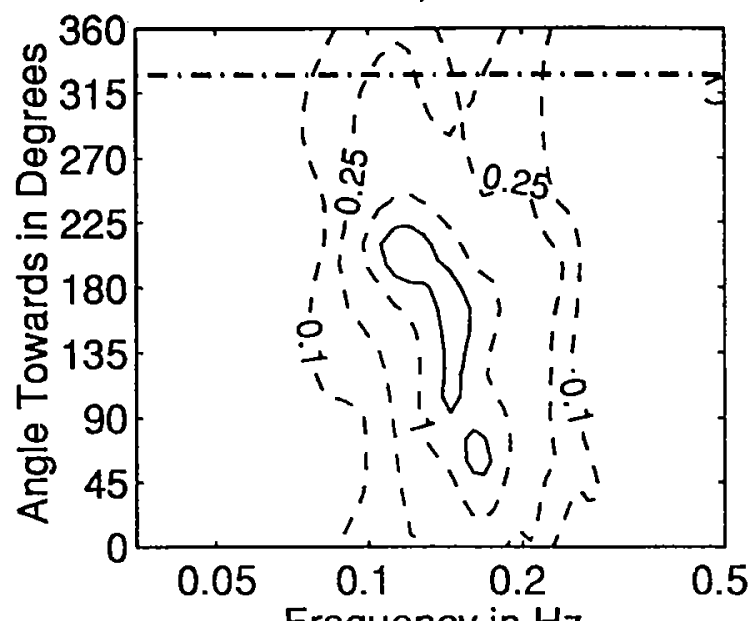

Frequency in $\mathrm{Hz}$

March 22, $199409 Z$

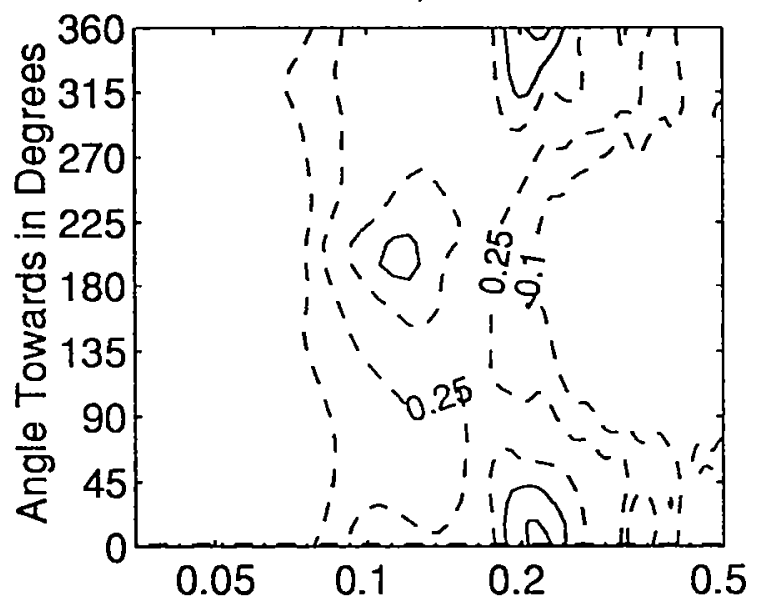

Frequency in $\mathrm{Hz}$

March 22, $199415 Z$

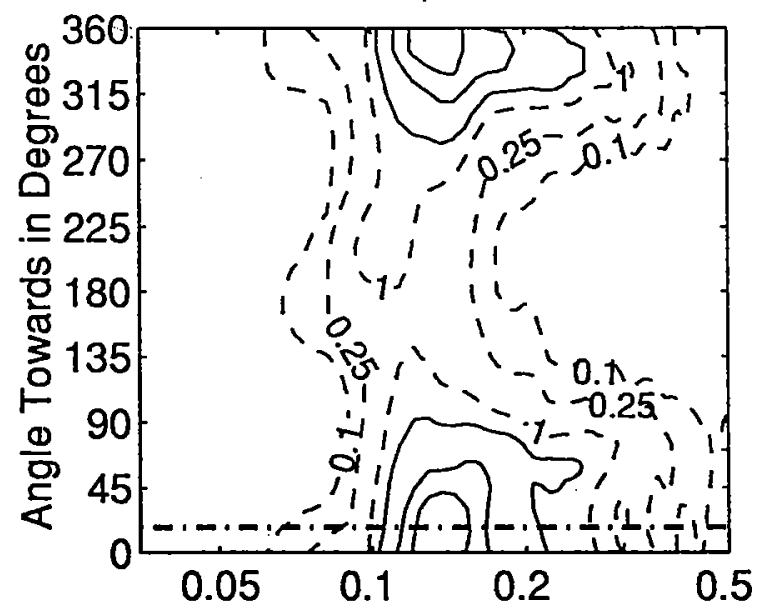

Frequency in $\mathrm{Hz}$

Figure 3.4.138: Directional wave spectra, computed using maximum entropy $0.25,1$ (dashedrs of spectral density as a function of direction. Contours are 0.1 , thick dashed line. 
March 22, $199418 Z$
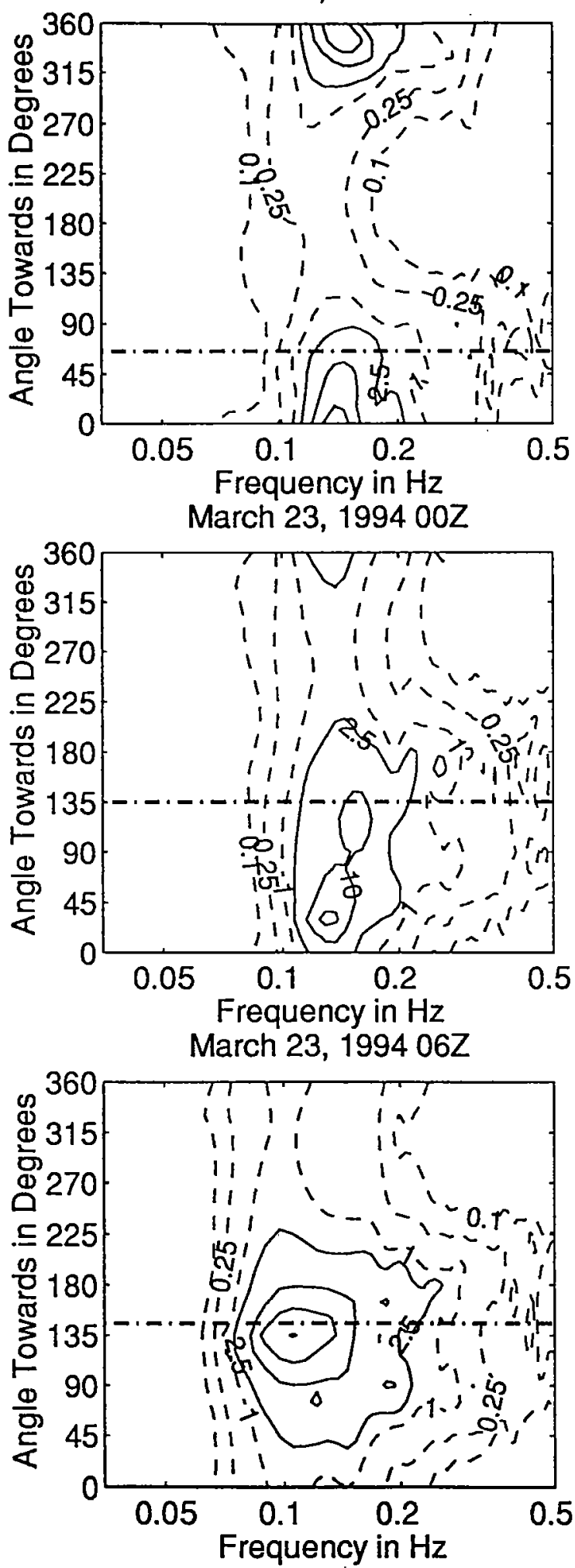

March 22, $199421 Z$
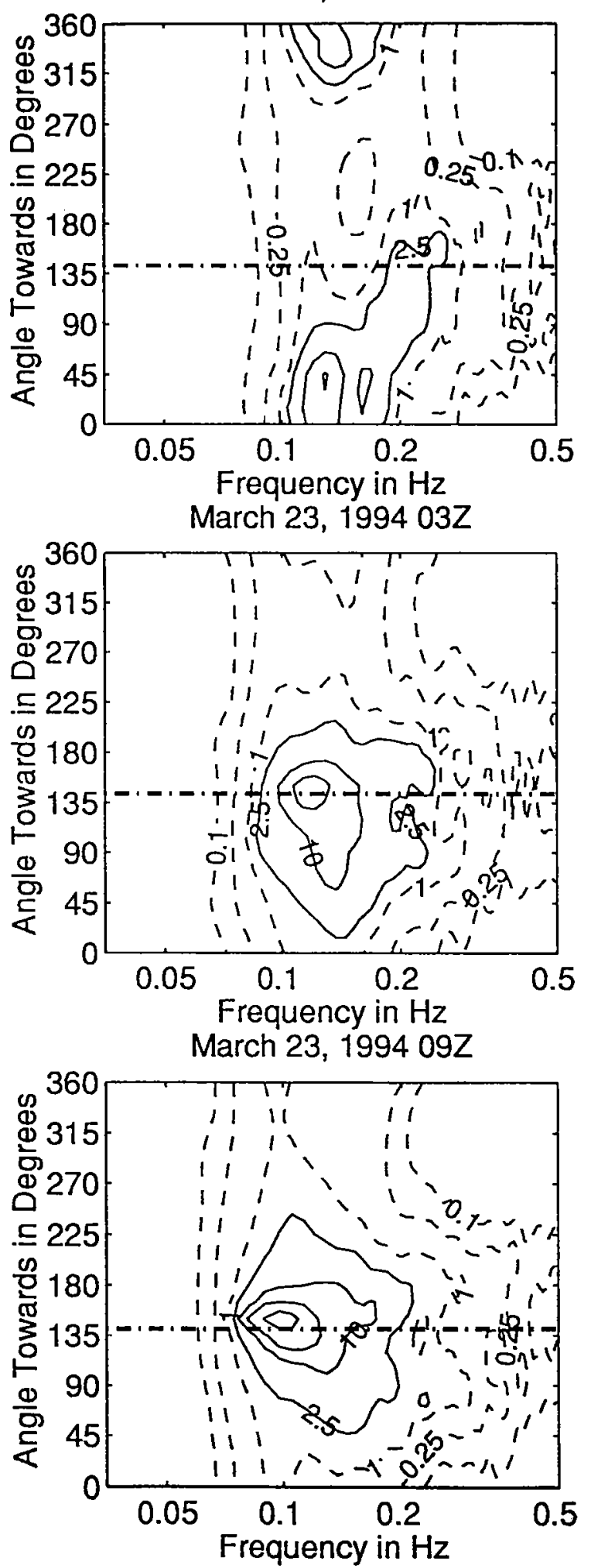

Figure 3.4.139: Directional wave spectra, computed using maximum entropy method. Contours of spectral density as a function of direction. Contours are 0.1, $0.25,1$ (dashed), 2.5, 10,25, 100, and 250 (solid). Wind direction is shown by thick dashed line. 


\section{Appendix 1: Cruise Participants}

\section{Deployment Cruise}

J. Bouthelette

WHOI

H. DeFerrari

(Chief Scientist)

Miami

T. Gidwitz

WHOI

A. Gnanadesikan

WHOI

S. Hill

IOS

R. Horn

SIO

J. Kemp

WHOI

W. Melville

SIO

M. Rebozo

Miami

W. Saunders

Miami

R. Shear

SIO

E. Terrill

SIO

G. Tupper

WHOI

N. Williams

Miami

B. Way

WHOI

\section{Recovery Cruise}

J. Bouthellette

WHOI
A. Gnanadesikan
S. Hill
J. Kemp
M. Rebozo
E. Terrill
B. Way

WHOI

IOS

(Chief Scientist)

WHOI

Miami

SIO

WHOI 


\section{Appendix 2: Cruise Chronology}

\section{Deployment Cruise}

\begin{tabular}{|c|c|c|}
\hline 8 Dec 93 & 1800 & Leave Dock aboard R/V Knorr. \\
\hline \multirow[t]{2}{*}{$9 \operatorname{Dec} 93$} & 1500 & Science meeting. \\
\hline & $1900-2200$ & Release Testing. \\
\hline \multirow[t]{7}{*}{$10 \operatorname{Dec} 93$} & 1100 & $\begin{array}{l}\text { Clearing deck for SIO Spar. } \\
\text { (WHOI Station No. 957) }\end{array}$ \\
\hline & 1305 & Surface Line in water \\
\hline & 1457 & Subsurface Line in water \\
\hline & 2041 & $\begin{array}{l}\text { Anchor Splash. } 3356.509 \text { N } 7006.426 \mathrm{~W} \\
\text { PDR Depth } 5375 \mathrm{~m} \text {. Steaming up to surface } \\
\text { float. }\end{array}$ \\
\hline & 2150 & Surface buoy in water. \\
\hline & 2249 & $\begin{array}{l}\text { Beginning anchor survey, transducer in water. } \\
\text { Wind increasing. }\end{array}$ \\
\hline & 2358 & $\begin{array}{l}\text { Finish anchor survey. Anchor at } 3356.62 \mathrm{~N} \\
7006.34 \mathrm{~W} \text {. }\end{array}$ \\
\hline
\end{tabular}

$11 \operatorname{Dec} 93$

Hove to. Estimate winds at 30 knots, seas $8-12 \mathrm{ft}$.

$12 \operatorname{Dec} 93$

Hove to. Estimate winds at 30-40 knots, seas $14 \mathrm{ft}$.

Barometric pressure survey within ship shows $1 \mathrm{mb}$ difference between main lab and bridge.

$13 \operatorname{Dec} 93 \quad 1150$

Preparing to launch Seatex (WHOI Moored Station 958).

Waves still high (15 ft) but wind has dropped.

1508 Buoy over side. Deploying mooring.

$2216 \quad$ Anchor splash. $3403.944 \mathrm{~N} 70$ 05.425W.

PDR Reading 5374m.

2259

Release on bottom. Beginning survey.

$14 \operatorname{Dec} 93 \quad 0009$

Finished survey. Anchor position 34 03.89N 70 05.10W.

1035

Checking out IMET package.

1130 Starting Echosounder. System comes up, indicates that it is entering keyboard mode, then fails to do so. 
1445

1727

2200

$15 \operatorname{Dec} 93 \quad 0002$

0613

0630

0800

1400

1505

$16 \operatorname{Dec} 93$

$17 \operatorname{Dec} 93$

$18 \operatorname{Dec} 93 \quad 1100$

2140

2350

$19 \operatorname{Dec} 930200$

0631

0713

0815

0935

Begin Discus deployment (WHOI Moored Station 959).

While changing spools, winch cycles unexpectedly causing us lose end over the side. Begin to recover mooring so as to reset.

Beginning redeployment of discus.

More problems with Lebus winch. Jumps at low speeds.

Anchor splash, discus mooring $3352.69 \mathrm{~N} 6944.97 \mathrm{~W}$. PDR Depth 5375m.

Beginning anchor survey.

Anchor survey complete $3352.7 \mathrm{~N} 6944.83 \mathrm{~W}$.

Miami Acoustics Mooring going over the side.

Because of 8 foot swells, predictions of increasing swell, and general fatigue, decide to abort Miami Acoustics mooring deployment

Hove to. Winds $\sim 35$ knots, gusting to 50 , seas $18-22 \mathrm{ft}$.

Hove to. Winds $\sim 30$ knots. Seas $18-24 \mathrm{ft}$. (Seatex sees a $39 \mathrm{ft}$ wave on this day).

Preparing to launch Miami Acoustics mooring (WHOI Moored Station 960).

ELSI A over side.

Source over side.

Anchor splash, Miami Acoustics mooring $3359.41 \mathrm{~N}$ 7000.13 W. PDR Depth 5372.

Preparing to deploy ELSI B mooring (WHOI Moored Station 961).

Miami Acoustics Mooring comes up on sonabuoy.

Anchor splash, ELSI B.

Anchor on bottom. Beginning anchor survey.

Anchor survey complete $3354.52 \mathrm{~N} 6956.20 \mathrm{~W}$.

Beginning anchor survey for Miami Acoustics Mooring.

Anchor survey complete. $3359.05 \mathrm{~N} 7000.25 \mathrm{~W}$. Leaving Site L for Jacksonville, FL.

In transit. 
$21 \operatorname{Dec} 93 \quad 1600$

Moorings at Sea

22 Jan 94

22 Feb 94

\section{Recovery Cruise}

$18 \operatorname{Mar} 94 \quad 1752$

$19 \operatorname{Mar} 94$

20 Mar 94

21 Mar $94 \quad 1030$

1148

1246

1300

1416

2100

$22 \mathrm{Mar} 94 \quad 0200$

1100

1234

1400

1900

1933

2242

2342

$23 \operatorname{Mar} 94 \quad 0300$
Arrive Jacksonville, FL.

Argos Telemetry lost from SIO Spar as a result of low battery power.

New beacon attached to SIO Spar by J. Cotter aboard $\mathrm{R} / \mathrm{V}$ Knorr en route to Barbados.

Leave Harbor Branch Oceanographic Inst. aboard R/V Edwin Link.

Transit

Transit

Passing SIO Spar. No floats on the surface.

Taking water samples for $\mathrm{O} 2$ concentration.

Fired ELSI Release on Miami mooring.

ELSI A aboard.

Fired release on Miami Acoustics mooring.

Mooring on deck. Unspooling winch.

Finished unspooling winch.

In sight of Discus. Decide that weather is a little rough (winds about 20 knots) and that we will proceed to ELSI.

ELSI upper release fired.

ELSI B aboard after multiple attempts.

ELSI upper portion recovered. Decide to stop until weather improves.

Decide to recover bottom of ELSI mooring.

Release fired.

Acoustic release aboard.

Start unspooling and stowing gear.

Finished unspooling. 
1100

1324

1357

1416

1723

$1800-1900$

2015

$24 \operatorname{Mar} 94 \quad 1143$

1215

1545

1729-1808

$1749-1815$

1802

1912

2213

2330

$25 \operatorname{Mar} 94 \quad 0345$

26 Mar 94

27 Mar 94
At discus, weather too rough to recover. Proceeding to Seatex.

Seatex release fired.

Cutting surface tether loose.

Seatex on board. Surface tether has lost most of its floats including polyform sphere. Only 11 of 45 floats remaining. Heavy fouling on buoy. Light damaged on recovery.

Recovering acoustic release.

Moving spheres and ELSI to 01 deck.

By discus, taking intensive observations.

Fired release on discus.

Discus aboard. Pins on Seacat 927 bent badly on recovery.

Stop to unspool line off winch.

Bagged VAWR SW sensor.

Cold bath spike on T-Pods, Seacats.

Resume spooling line onto winch.

Acoustic Release aboard. Streaming to SIO Spar.

Fired release on SIO Spar.

SIO Spar aboard. Recovering mooring.

Acoustic release aboard. Depart for Woods Hole.

Transit to Woods Hole

Arrive Woods Hole. 


\section{Appendix 3: ASREX Antifouling Paint Test}

\section{A.3.1: Introduction}

The Upper Ocean Processes Group for the past 4 years has used Ameron \#635 tributyltin paint for the prevention of bio-fouling on aluminum discus hulls and underwater instrument housing. This antifouling-paint has proven to work well in preventing fouling in very temperate waters for up to 6 months immersion. The active antifoulant ingredient, tributyltin, is a stateregulated hazardous material, making it undesirable as well as legally difficult to use for oceanographic applications. The purpose of this test was to find an alternative coating that is as effective and which can be used with less environmental impact.

The ASREX discus surface mooring paint test consisted of a comparison between 3 types of antifouling paint and 1 silicon-based coating applied to several mooring components in the upper 100 meters of the discus mooring. The 3 antifoulant paints tested were Ameron \#279 (black), \#536 (blue) and Interlux Tri-Lux II (red). The clear silicon polymer tested was KissCote.

\section{A.3.2: Test samples and coatings}

Ameron \#279 (black) is a chorinated polymeric antifouling paint suitable for steel. It is a cuprous oxide release ablative. The following mooring components were coated 9 mils dry film thickness.

1. All VMCM fans.

2. Discus bridle legs and discus bridle clamps (Figure A.3.1)

Ameron \#635 (blue) is a tributyltin release ablative antifouling suitable for aluminum. The following mooring components were painted with a 9 mils dry film thickness:

1. Approximately $50 \%$ underwater surface area of the discus hull bottom (Figure A.3.2)

2. Eight VMCM stings.

3. Upper 11" of the $5 \mathrm{~m}$ and $10 \mathrm{~m}$ VMCM instrument cases (Figure A.3.3)

Interlux Tri-Lux II is a copper thiocyantate copolymer antifoulant designed to be applied over aluminum. The following mooring components were coated up to 9 mils dry film thickness:

1. Approximately $50 \%$ of the underwater surface area of the discus hull bottom (Figure A.3.2).

2. The stainless steel VAWR SST flex tubing.

3. The bottom 11" of the $5 \mathrm{~m}$ and $10 \mathrm{~m}$ VMCM instrument cases (Figure A.3.3). 


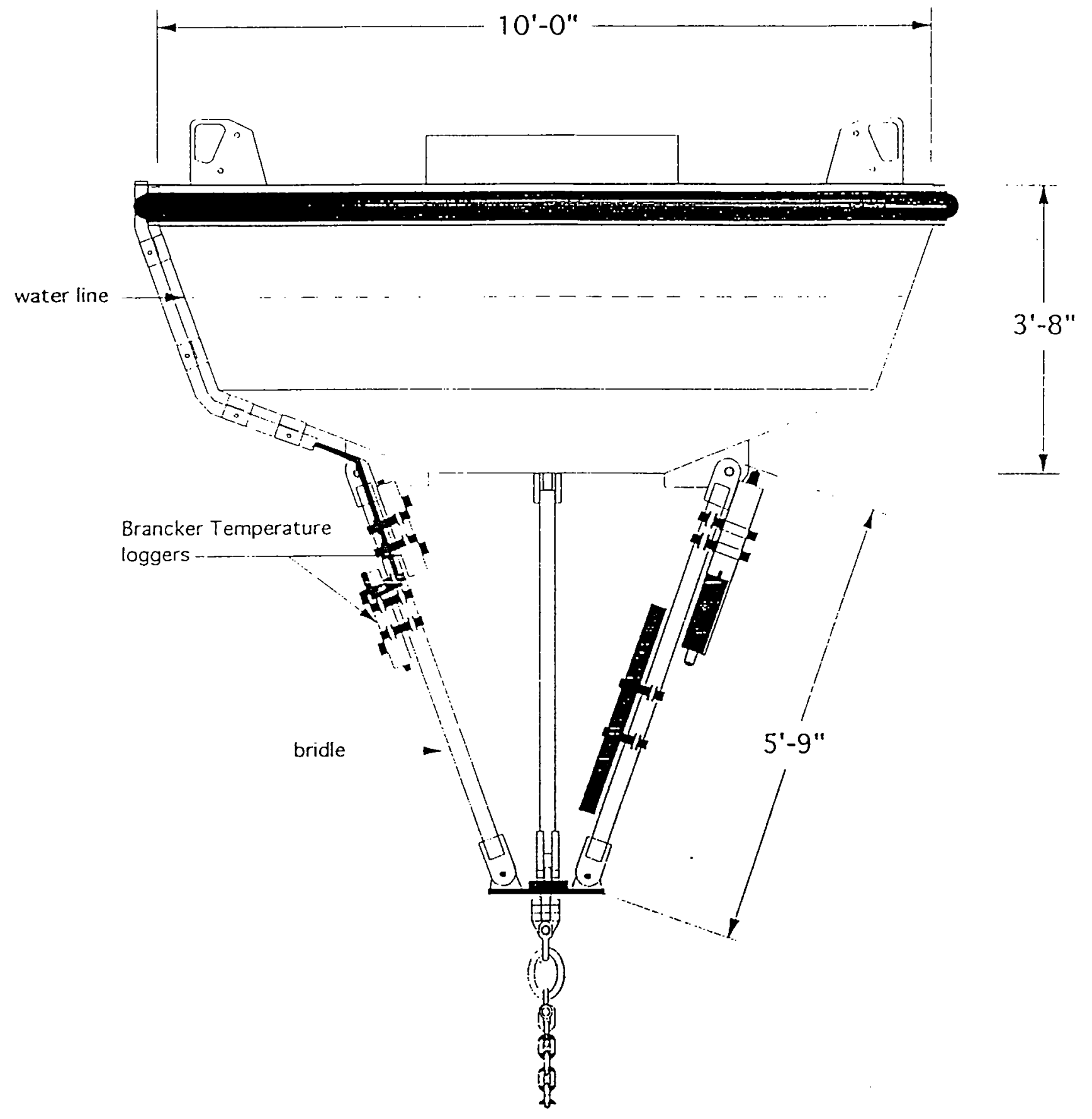

Figure A.3.1: Diagram of the discus hull and bridle profile. 


\section{ASREX ANTIFOULING PAINT TEST}

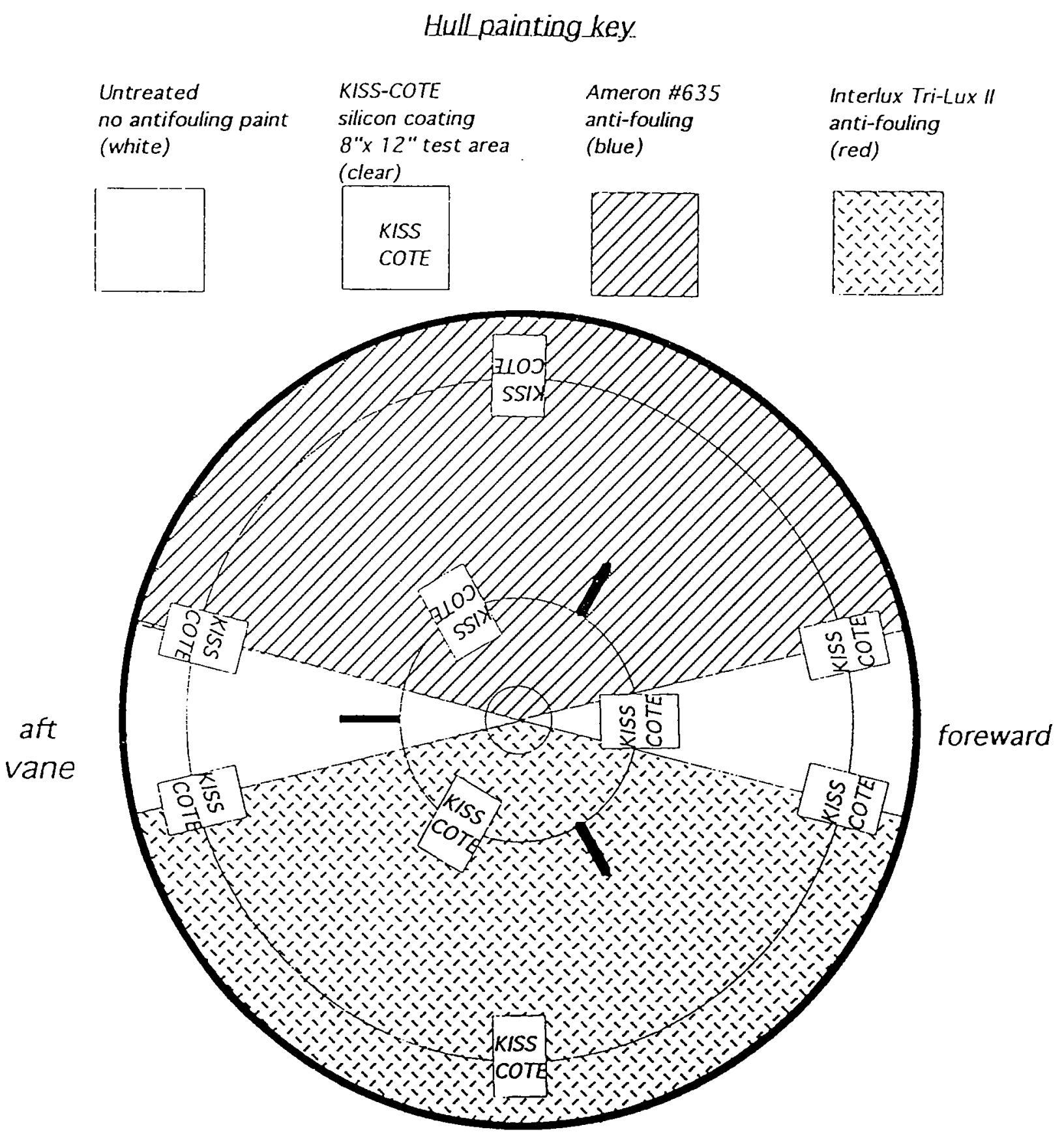

Figure A.3.2: ASREX antifouling paint test. Diagram of hull painting. 


\title{
ASREX ANITFOULING PAINT TEST
}

\author{
$5 m \& 10 m$ \\ VMCM
}

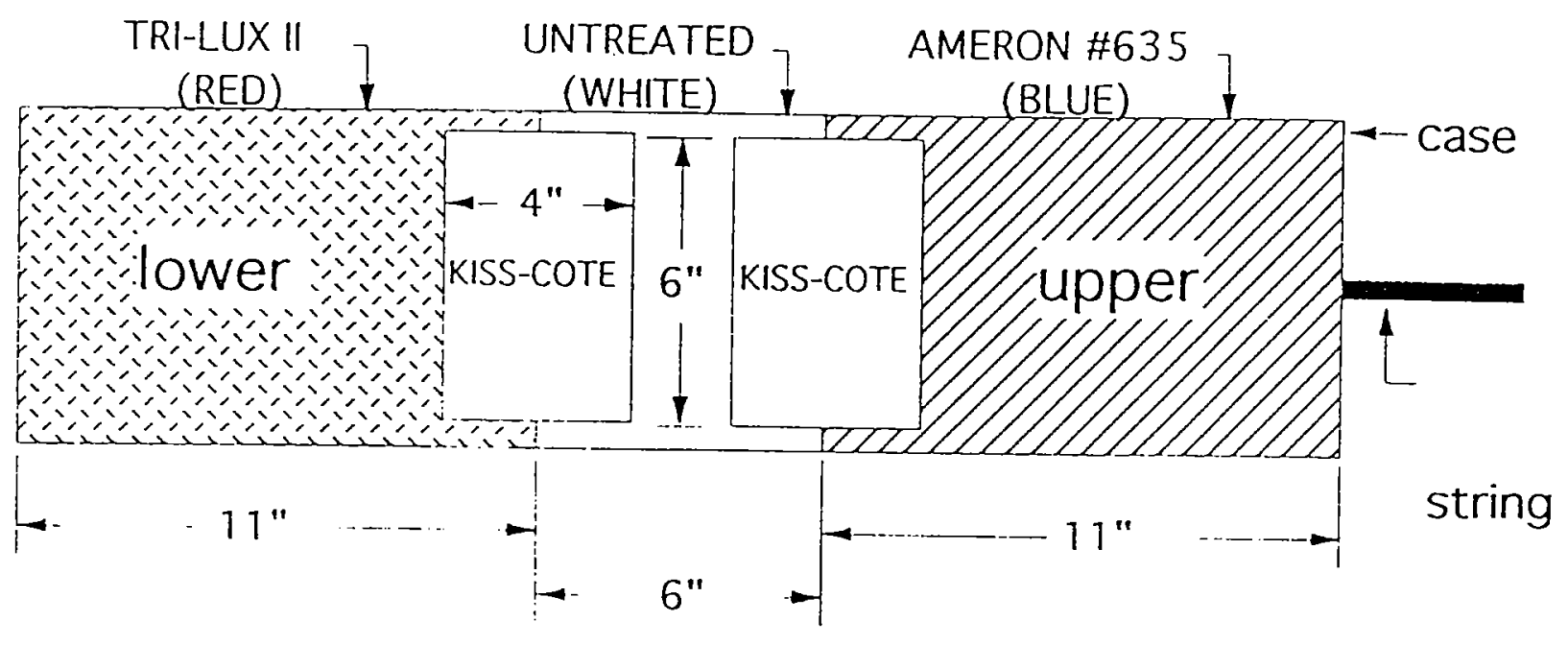

5- BRANCKER TEMP. LOGGER

$2 \times 1 \mathrm{~m}, 37 \mathrm{~m}, 75 \mathrm{~m}, 100 \mathrm{~m}$

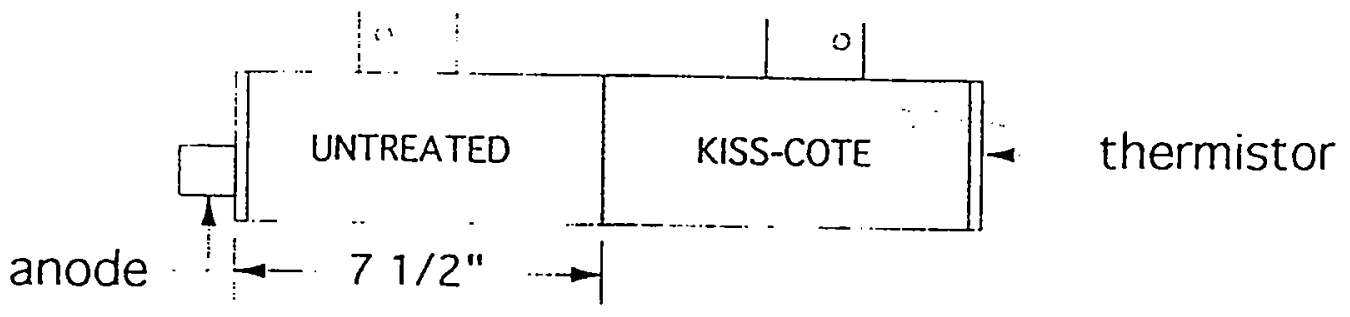

Figure A.3.3: ASREX antifouling paint test. Top: Diagram of how the VMCMs were painted. Bottom: Diagram of how the Brancker T-PODs were painted. 
Since the buoy tends to orient into the wind and current, the leading face of the hull tends to be exposed to more scrubbing action from the waves and currents. In order to ensure that the Ameron \#635 and Tri-Lux II paints had equal exposure, they were applied on either side of the wind vane axis as is shown in Figure A.3.2. A non-antifouled section, colored white, separated the two. There were 9 test areas measuring 12" by 8 " outlined in black on the buoy hull. These sections were coated with a silicon-based polymer, Kiss-Cote. This coating is intended to facilitate the removal of fouling and to extend the antifouling coating effective service life. The test areas were positioned to straddle sections coated with Ameron \#635, Trilux II and untreated control surfaces on the buoy hull. The $5 \mathrm{~m}$ and $10 \mathrm{~m}$ depth VMCM instrument cases were painted in a similar fashion to the discus hull. Eleven inches in from the top and bottom ends of each case were coated with Ameron \#635 and Tri-Lux II respectively. An untreated non-antifouled section, colored white, measuring 6 " and straddling the midpoint of the case acted as the control for this test. Two Kiss-Cote test patches measuring 6" $\times 4$ " were positioned to equally overlay the control and antifouling paints.

The two Brancker TPODs on the bridle, and those at $37.5,75$, and $100 \mathrm{~m}$ were coated from the thermistor endcap to the center of the instrument case with Kiss-Cote. The opposite ends of the Branckers were left untreated.

\section{A.3.3: Visual inspection upon recovery}

The discus hull's antifouling coating showed varying degrees of fouling. There were two types of fouling, green slime film and gooseneck barnacles, present on the hull. The Ameron \#635 had the fewest number of goosenecks, numbering 20 animals over its painted surface. The Tri-Lux II coating had large numbers of barnacles attached hard through the coating, the largest concentration of animals being located around the aft end of the discus bottom. The forward or upwind side of the hull had the least amount of fouling. The forward side of the hull saw a greater degree of wave action, causing the ablative paints to wear and self-polish. The gooseneck barnacles required hand-scraping for removal. The control area on the hull's bottom, which was not antifouled, had the greatest fouling, with large colonies of goosenecks. Present on both coatings was a thin film of slime which washed off easily. The Kiss-Cote patches failed in this test to produce any noticeable difference. The goosenecks which were attached to areas covered with Kiss-Cote, whether antifouled or not, proved to be no easier to remove than barnacles attached to the non-Kiss-Cote surface.

The Ameron \#279 which coated the steel bridle legs for the discus had little evidence of fouling. This coating showed a faster ablative wear rate than the Tri-Lux II and Ameron \#635. The 9 mils of coating used for this test would not have survived a 6 month deployment. 
The VMCM at $5 \mathrm{~m}$ depth showed a pattern of fouling similar to the discus hull with gooseneck barnacles attached to the Tri-Lux II and control areas, but no fouling on the Ameron \#635 coated surface. The VMCM at $10 \mathrm{~m}$ was clear upon recovery.

The VMCM instrument fans showed no evidence of biofouling. There were, however, areas along the glue joint where the blades and hub intersect where the paint had chipped off. It was concluded that this was due to blade flexure.

The two Brancker TPODs at $1 \mathrm{~m}$ depth had goosenecks slime, and grass growth fouling. The Kiss-Cote failed to make these instruments easier to clean. The TPODs at $37 \mathrm{~m}, 75 \mathrm{~m}$ and $100 \mathrm{~m}$ were recovered with little sign of fouling.

The coatings were painted onto the discus hull and instrument housings during the period 4-10 December 1993. The mooring was deployed on 14 December 1993 at $33^{\circ} 52 \mathrm{~N}, 69^{\circ} 44 \mathrm{~W}$. The mooring was recovered on 24 March 1994. The average current speed at a depth of $5 \mathrm{~m}$ was $28.65 \mathrm{~cm} / \mathrm{s}$. The average water temperature was $19.44^{\circ} \mathrm{C}$.

\section{A.3.4 Conclusion}

Biofouling to the discus hull and instrumentation was minimal below a depth of $10 \mathrm{~m}$. Ameron \#635 outperformed the Tri-Lux II in preventing the attachment of gooseneck barnacles. It was noted several days following recovery of the mooring that the Tri-Lux II surface hardness was not as ablative or soft as the Ameron \#635 coating. The Tri-Lux II may have developed an oxide film prior to immersion causing a weaker ablative toxic release.

The Ameron \#279 worked well. However, due to its high ablative release rate the coating would have failed if the test had been continued up to the standard 6 month deployment. Increasing the mil thickness to around 12 mils would improve the service life for this application.

The 18 Kiss-Cote test patches on the discus hull and sub-surface instrumentation failed to show any appreciable improvement in removal of biofouling. Through discussions with the formulators of Kiss-Cote following the recovery of this mooring, it was concluded that the prepainted surface on which the Kiss-Cote was applied were too high in profile. This profile allowed the biofouling a greater potential for establishing a physical bond. 


\section{Appendix 4: Matlab Code used for computing spectra}

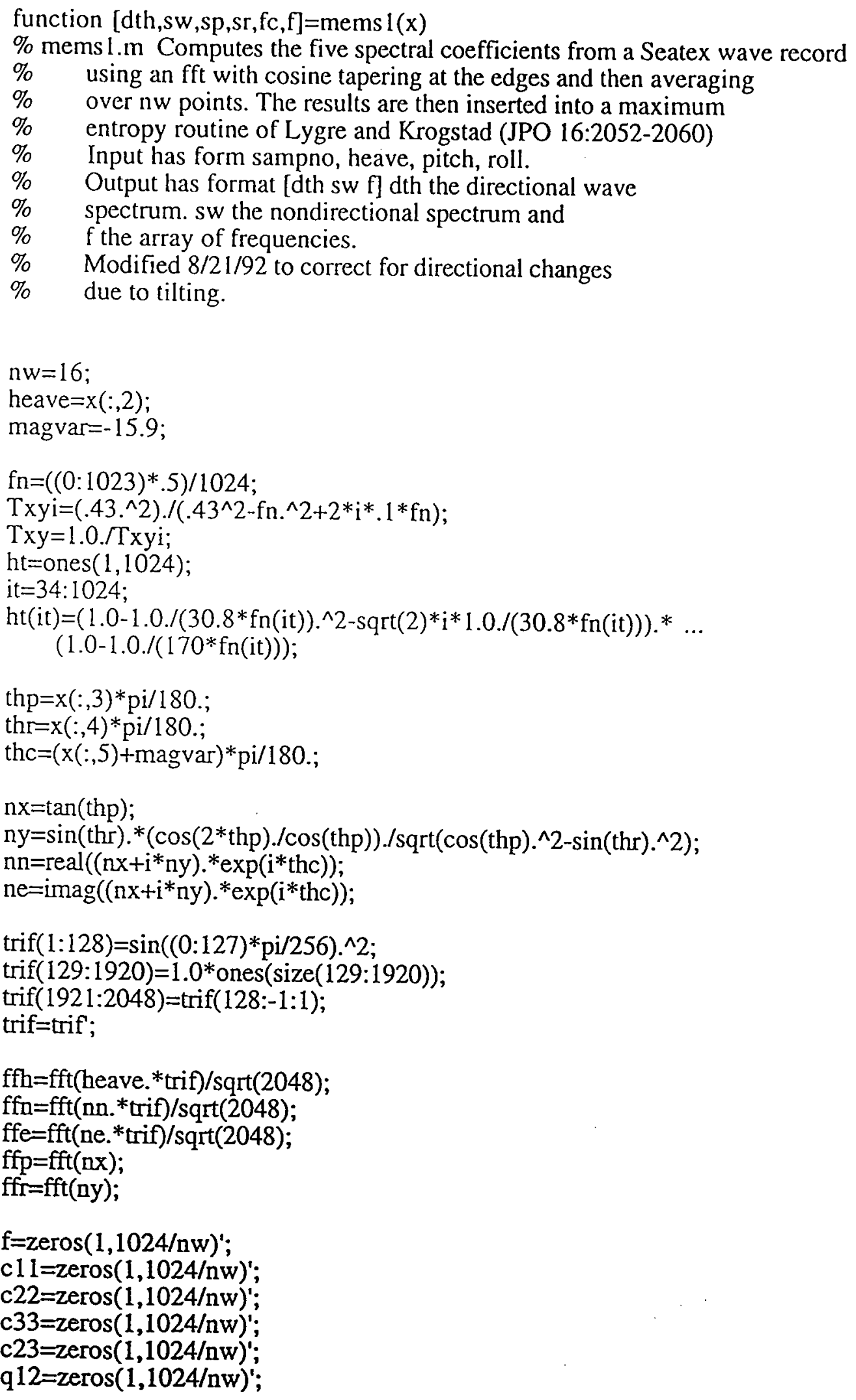




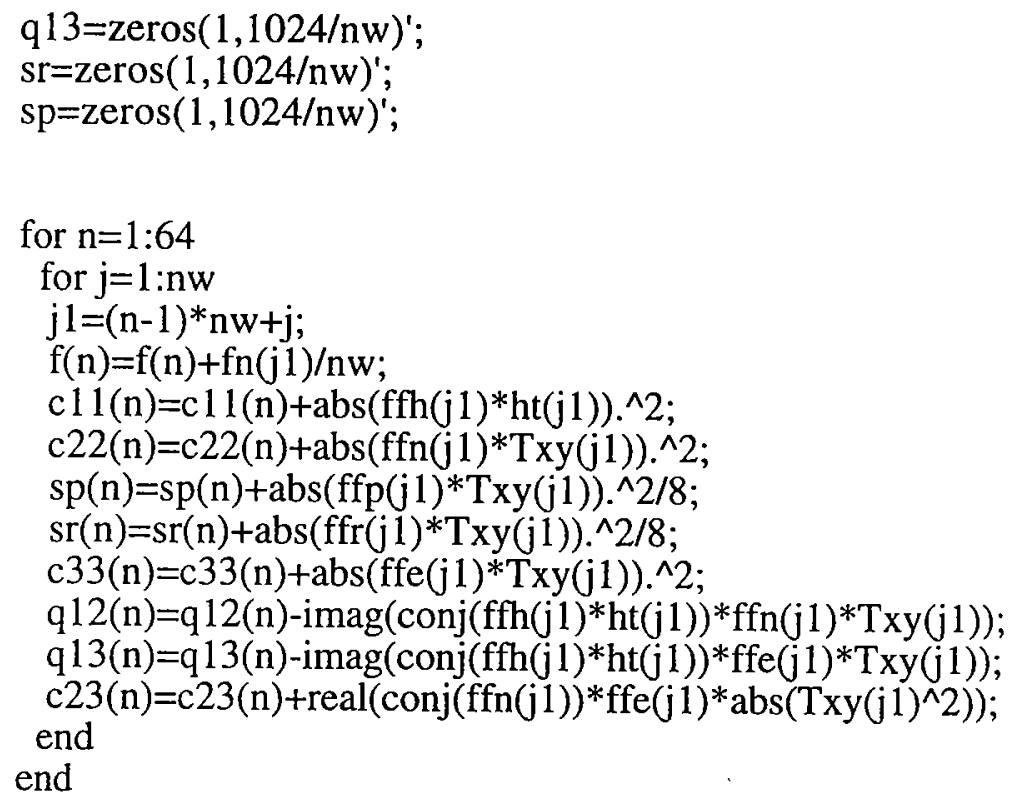

\%Convert to oceanographic coordinates

$\mathrm{cl}=-\mathrm{c} 1$

$\mathrm{fc}=[$ ones $(\operatorname{size}(\mathrm{c} 1)) \mathrm{c} 1 \mathrm{c} 2]$;

phil $=\left(\mathrm{c} 1-\mathrm{c} 2 .^{*} \operatorname{conj}(\mathrm{c} 1)\right) . /\left(1-\mathrm{abs}(\mathrm{c} 1) .^{\wedge} 2\right)$;

phi2 $=(\mathrm{c} 2-\mathrm{c} 1 . * \mathrm{c} 1) . /(1-\mathrm{abs}(\mathrm{c} 1) . \wedge 2)$;

for ith $=1: 25$

theta $=15 *(\mathrm{ith}-1) * \mathrm{pi} / 180$;

for $\mathrm{j}=1: 1024 / \mathrm{nw}$

$\operatorname{dth}(\mathrm{ith}, \mathrm{j})=\mathrm{c11}(\mathrm{j}) * \operatorname{abs}((1-\operatorname{phi1}(\mathrm{j}) * \operatorname{conj}(\mathrm{c} 1(\mathrm{j}))-\operatorname{phi} 2(\mathrm{j}) * \operatorname{conj}(\mathrm{c} 2(\mathrm{j}))) / \ldots$ $\left.\left(2 * \mathrm{pi}^{*}\left(1-\mathrm{phi} 1(\mathrm{j}) * \exp (-\mathrm{i} * \text { theta })-\mathrm{phi} 2(\mathrm{j}) * \exp \left(-2 * \mathrm{i}^{*} \text { theta }\right)\right)^{\wedge} 2\right)\right)$ $\operatorname{sw}(j)=c 11(j)$; end

end

$\%$ Smooth spectra in frequency space

$\mathrm{dth}=[(\mathrm{dth}(:, 1)+\mathrm{dth}(:, 2)) / 2(\mathrm{dth}(:, 1: 62)+2 * \mathrm{dth}(:, 2: 63)+\mathrm{dth}(:, 3: 64)) / 4(\mathrm{dth}(:, 63)+\mathrm{dth}(:, 64)) / 2]$; $\mathrm{dth}=[(\mathrm{dth}(:, 1)+\mathrm{dth}(:, 2)) / 2(\mathrm{dth}(:, 1: 62)+2 * \mathrm{dth}(:, 2: 63)+\mathrm{dth}(:, 3: 64)) / 4(\mathrm{dth}(:, 63)+\mathrm{dth}(:, 64)) / 2]$; return 


\section{DOCUMENT LIBRARY}

Distribution List for Technical Report Exchange - May 1995

University of California, San Diego

SIO Library $0175 \mathrm{C}$

9500 Gilman Drive

La Jolla, CA 92093-0175

Hancock Library of Biology \& Oceanography

Alan Hancock Laboratory

University of Southern California

University Park

Los Angeles, CA 90089-0371

Gifts \& Exchanges

Library

Bedford Institute of Oceanography

P.O. Box 1006

Dartmouth, NS, B2Y 4A2, CANADA

Commander

International Ice Patrol

1082 Shennecossett Road

Groton, CT 06340-6095

NOAA/EDIS Miami Library Center

4301 Rickenbacker Causeway

Miami, FL 33149

Research Library

U.S. Army Corps of Engineers

Waterways Experiment Station

3909 Halls Ferry Road

Vicksburg, MS 39180-6199

Institute of Geophysics

University of Hawaii

Library Room 252

2525 Correa Road

Honolulu, HI 96822

Marine Resources Information Center

Building E38-320

MIT

Cambridge, MA 02139

Library

Lamont-Doherty Geological Observatory

Columbia University

Palisades, NY z10964

Library

Serials Department

Oregon State University

Corvallis, OR 97331

Pell Marine Science Library

University of Rhode Island

Narragansett Bay Campus

Narragansett, RI 02882
Working Collection

Texas A\&M University

Dept. of Oceanography

College Station, TX 77843

Fisheries-Oceanography Library 151 Oceanography Teaching Bldg.

University of Washington

Seattle, WA 98195

Library

R.S.M.A.S.

University of Miami

4600 Rickenbacker Causeway

Miami, FL 33149

Maury Oceanographic Library

Naval Oceanographic Office

Building 1003 South

1002 Balch Blvd.

Stennis Space Center, MS, 39522-5001

Library

Institute of Ocean Sciences

P.O. Box 6000

Sidney, B.C. V8L 4B2

CANADA

National Oceanographic Library

Southampton Oceanography Centre

European Way

Southampton SO14 3ZH

UK

The Librarian

CSIRO Marine Laboratories

G.P.O. Box 1538

Hobart, Tasmania

AUSTRALIA 7001

Library

Proudman Oceanographic Laboratory

Bidston Observatory

Birkenhead

Merseyside L43 7 RA

UNITED KINGDOM

IFREMER

Centre de Brest

Service Documentation - Publications

BP 7029280 PLOUZANE

FRANCE 


\begin{tabular}{|c|c|c|}
\hline $\begin{array}{l}\text { REPORT DOCUMENTATION } \\
\text { PAGE }\end{array}$ & 1. REPORT NO. WHOI-96-10 & 3. Reclplent's Accession No. \\
\hline \multirow{2}{*}{\multicolumn{2}{|c|}{$\begin{array}{l}\text { 4. Title and Subtitle } \\
\text { Meteorological and Oceanographic Measurements during the ASREX III Field } \\
\text { Experiment: Cruise and Data Report }\end{array}$}} & $\begin{array}{l}\text { 5. Report Date } \\
\text { September } 1996\end{array}$ \\
\hline & & $\overline{6 .}$ \\
\hline \multicolumn{2}{|c|}{$\begin{array}{ll}\text { 7. Author(s) } & \text { Nancy R. Galbraith, Anand Gnanadesikan, William M. Ostrom, } \\
\text { Eugene A. Terray, Bryan S. Way, Neil J. Williams, Steven H. Hill, and Eric Terrill }\end{array}$} & $\begin{array}{l}\text { 8. Performing Organization Rept. No. } \\
\text { WHOI-96-10 }\end{array}$ \\
\hline \multirow{2}{*}{\multicolumn{2}{|c|}{$\begin{array}{l}\text { 9. Performing Organization Name and Address } \\
\text { Woods Hole Oceanographic Institution } \\
\text { Woods Hole, Massachusetts } 02543\end{array}$}} & 10. Project/Task/Work Unit No. \\
\hline & & $\begin{array}{l}\text { 11. Contract(C) or Grant(G) No. } \\
\text { (C) N00014-91-J-1891 } \\
\text { (G) }\end{array}$ \\
\hline \multirow{2}{*}{\multicolumn{2}{|c|}{$\begin{array}{l}\text { 12. Sponsoring Organization Name and Address } \\
\text { Office of Naval Research }\end{array}$}} & $\begin{array}{l}\text { 13. Type of Report \& Period Covered } \\
\text { Technical Report }\end{array}$ \\
\hline & & 14. \\
\hline
\end{tabular}

This report should be cited as: Woods Hole Oceanog. Inst. Tech. Rept., WHOI-96-10.

16. Abstract (Limit: 200 words)

The Third Acoustic Surface Reverberation Experiment (ASREX III) took place from December 1993 to March 1994 at Site $\mathrm{L}\left(34^{\circ} \mathrm{N}, 70^{\circ} \mathrm{W}\right)$ in the mid-Atlantic. As part of this experiment, two moorings were deployed to measure the environmental background. A meteorological and oceanographic mooring was deployed to characterize the surface wind stress, buoyancy flux, and the current and temperature structure over the top 500 meters. A Seatex Wavescan ${ }^{\mathrm{TM}}$ buoy was deployed to characterize the directional wave spectrum. This report presents results from these moorings. Wind speeds up to $25 \mathrm{~m} / \mathrm{s}$ were seen, with significant heat losses (up to $1050 \mathrm{~W} / \mathrm{m}^{2}$ ) when cold continental air moved out over the warm Atlantic. The wave heights ranged up to $8 \mathrm{~m}$, with significant wave heights of several meters persisting for relatively long periods. Wave height and period, nondirectional spectra, directional spectra and a typology of wave events are presented and related to surface forcing.

17. Document Analysis a. Descriptors

Meteorology: mid-Atlantic

Oceanography: mid-Atlantic

Moored Instrument Measurements •

b. Identifiers/Open-Ended Terms

c. COSATI Field/Group

18. Avallability Statement

Approved for public release; distribution unlimited.

\begin{tabular}{|l|l|}
$\begin{array}{c}\text { 19. Security Class (This Report) } \\
\text { UNCLASSIFIED }\end{array}$ & $\begin{array}{l}\text { 21. No. of Pages } \\
247\end{array}$ \\
\hline 20. Security Class (This Page) & 22. Price \\
\hline & $\begin{array}{l}\text { OPTIONAL FORM 272 (4-77) } \\
\text { (Formerly NTIS-35) }\end{array}$ \\
\hline
\end{tabular}

